\title{
Laboratory and Field Investigations of Small Crater Repair Technologies
}

Lucy P. Priddy, Jeb S. Tingle, Timothy J. McCaffrey,

September 2007

and Ray S. Rollings

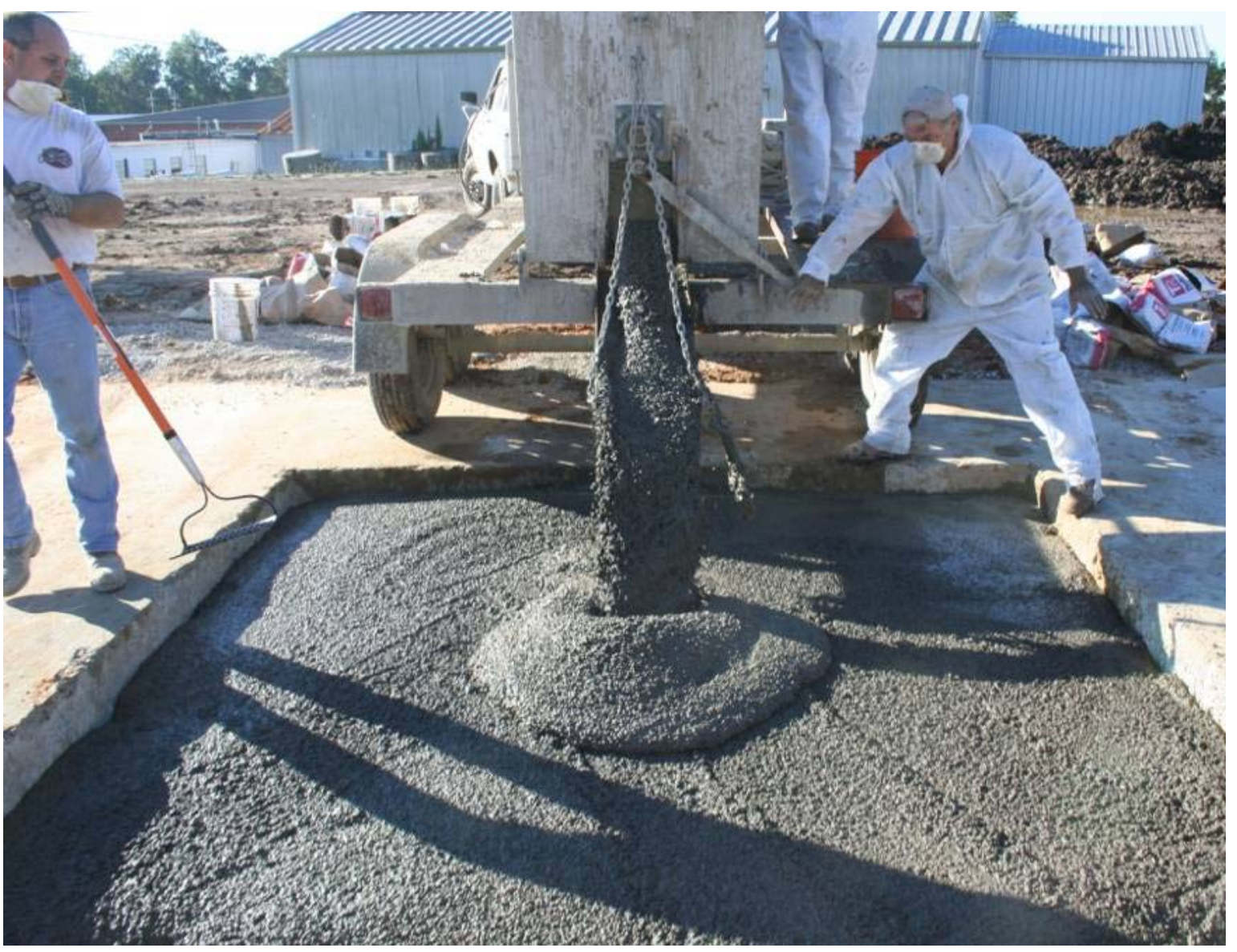




\section{Laboratory and Field Investigations of Small Crater Repair Technologies}

Lucy P. Priddy, Jeb S. Tingle, and Timothy J. McCaffrey

Geotechnical and Structures Laboratory

U.S. Army Engineer Research and Development Center

3909 Halls Ferry Road

Vicksburg, MS 39180-6199

Ray S. Rollings

Rollings Engineering

27 Park Square North

Beaufort, SC 29907

Final report

Approved for public release; distribution is unlimited.

Prepared for Headquarters, Air Combat Command

Langley Air Force Base, VA 23665 


\begin{abstract}
In support of the U.S. Air Force Air Combat Command, the U.S. Army Engineer Research and Development Center (ERDC) was tasked to develop and test innovative techniques, materials, and equipment for expedient and sustainment repairs of small bomb craters in airfield pavements. This airfield damage repair (ADR) investigation consisted of laboratory testing of selected crater fill and capping materials, as well as full-scale field testing of small crater repairs to evaluate field mixing methods, installation procedures, and repair performance. After $3 \mathrm{hr}$ of cure, each crater was trafficked under controlled traffic conditions to determine the ability of the repairs to support the gross load of an F-15E aircraft. Results of the traffic tests identified multiple repair materials that can be used for expedient and sustainment repairs of concrete airfield pavements. Both the laboratory and full-scale traffic tests were conducted at the ERDC in Vicksburg, MS, from February to November 2006. Experimental results were used to develop ADR criteria for rapidly repairing small craters.
\end{abstract}

DISCLAIMER: The contents of this report are not to be used for advertising, publication, or promotional purposes. Citation of trade names does not constitute an official endorsement or approval of the use of such commercial products. All product names and trademarks cited are the property of their respective owners. The findings of this report are not to be construed as an official Department of the Army position unless so designated by other authorized documents.

DESTROY THIS REPORT WHEN NO LONGER NEEDED. DO NOT RETURN IT TO THE ORIGINATOR. 


\section{Contents}

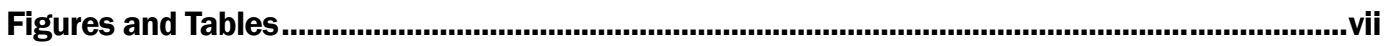

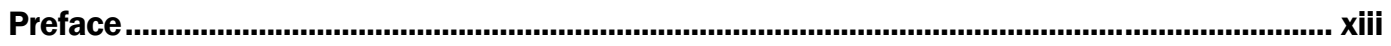

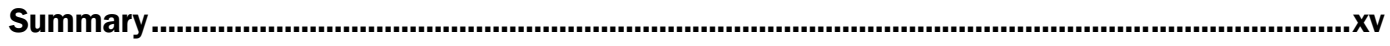

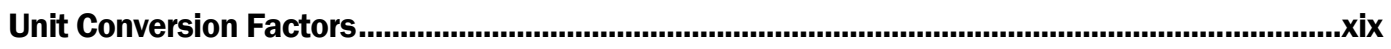

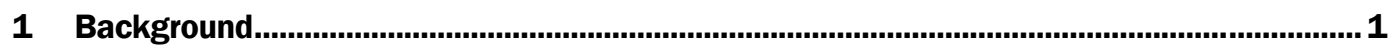

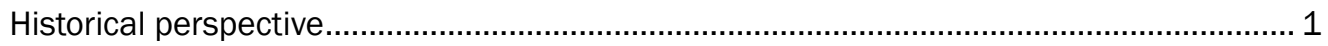

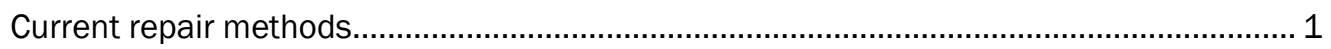

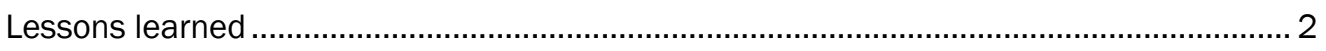

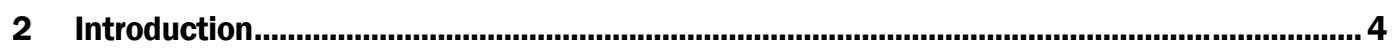

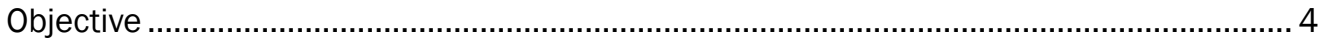

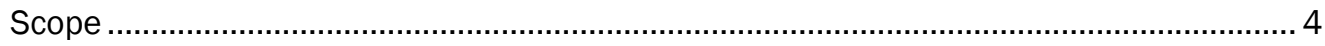

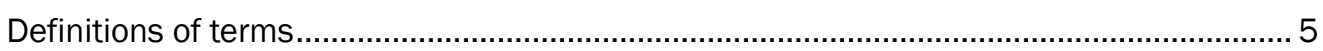

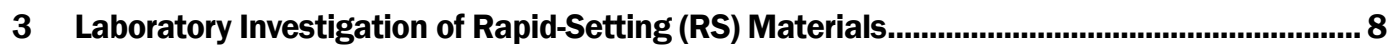

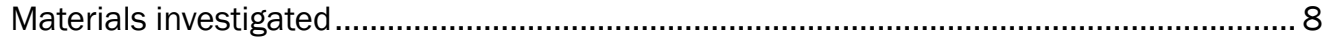

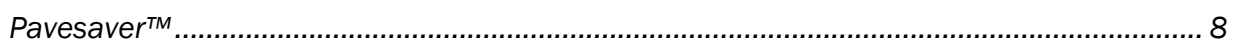

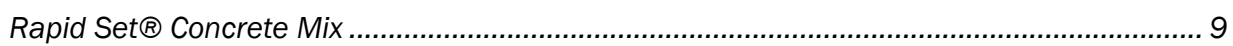

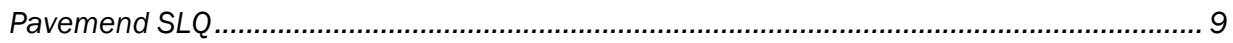

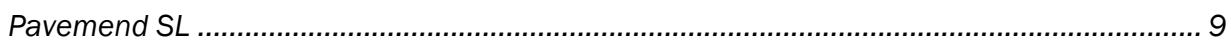

ThoRoc 10-60

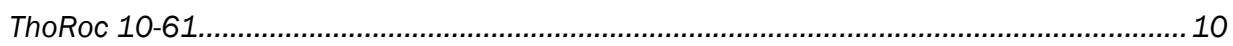

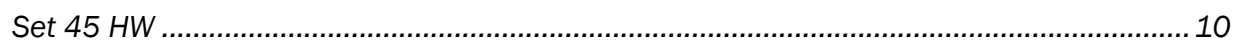

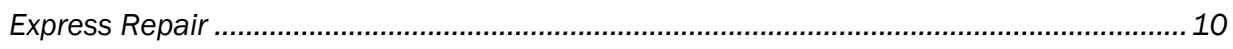

Ultimax Concrete ..................................................................................................... 10

ABC Cement Express Repair Mortar .................................................................................. 10

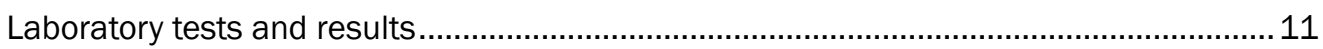

Unconfined compressive strength ...................................................................... 11

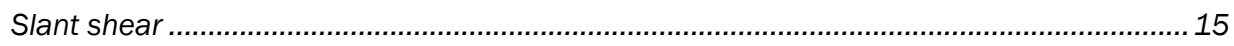

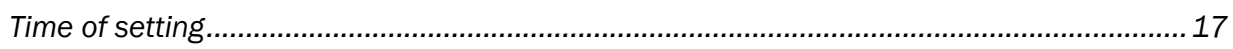

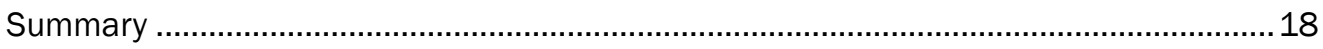

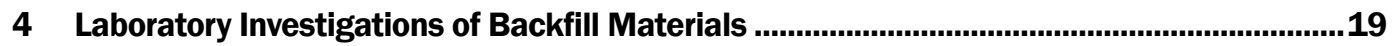

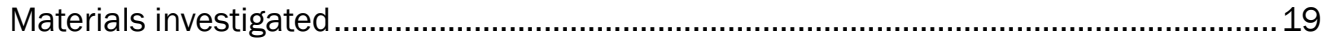

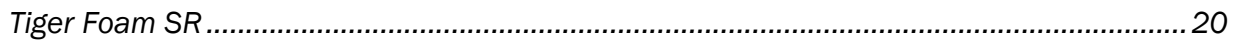

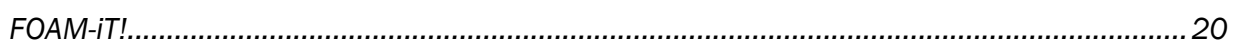

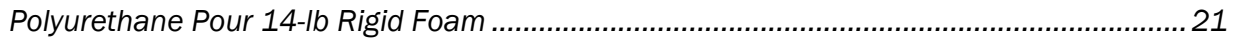

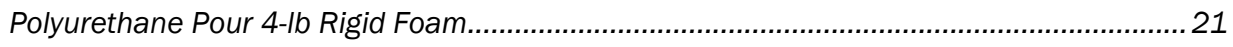

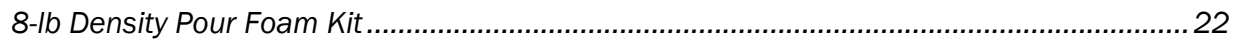




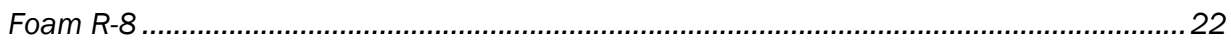

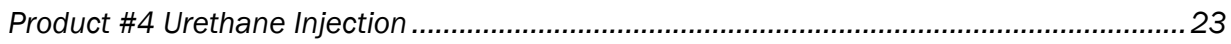

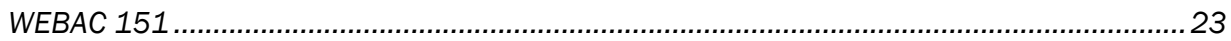

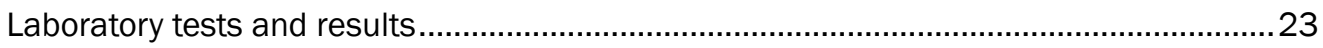

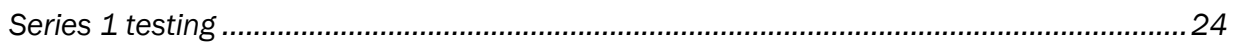

Detailed sample preparation by material ............................................................. 27

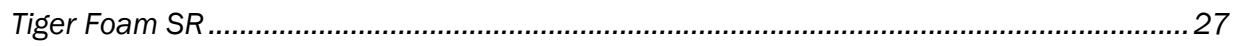

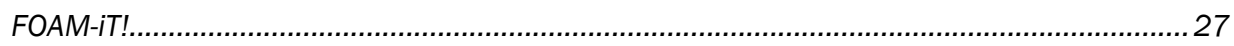

Polyurethane Pour 14-Ib Rigid Foam, Polyurethane Pour 4-Ib Rigid Foam, Foam

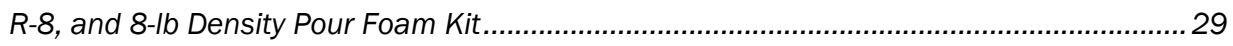

Product \#4 Urethane Injection and WEBAC 151 ............................................................... 29

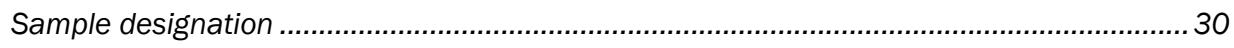

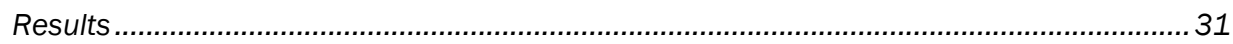

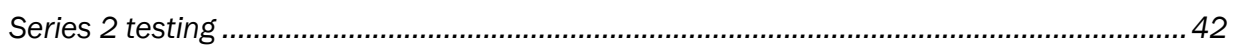

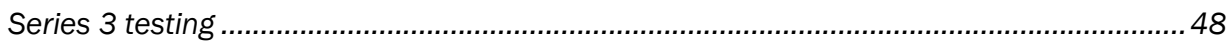

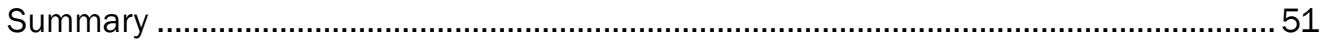

5 Test Section Construction ..........................................................................................53

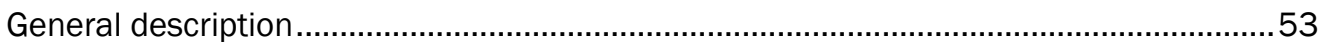

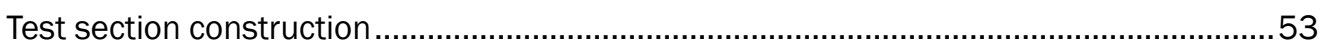

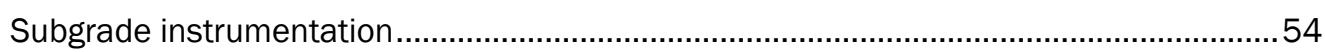

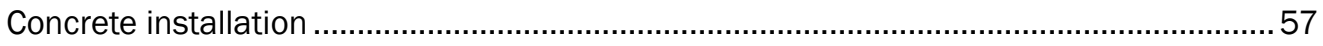

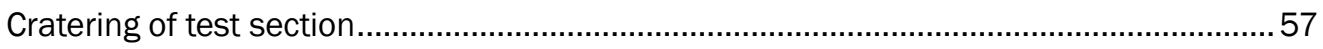

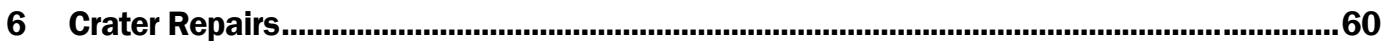

Description of crater repairs .........................................................................................60

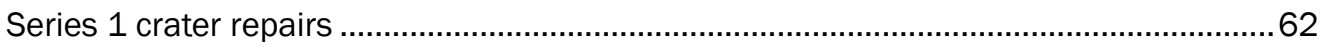

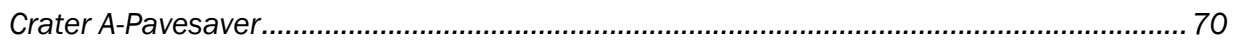

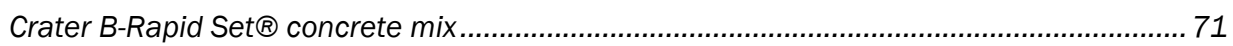

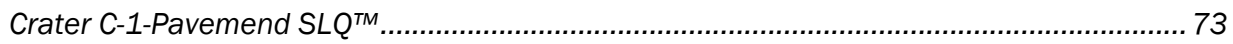

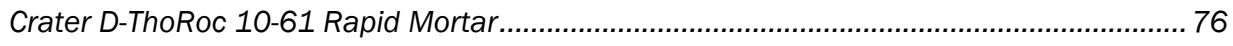

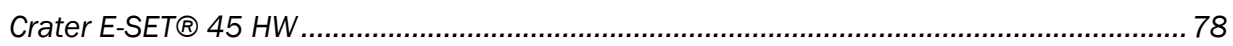

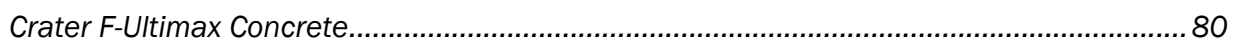

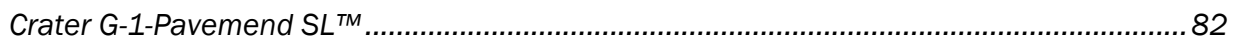

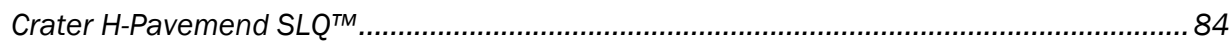

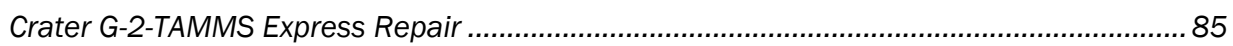

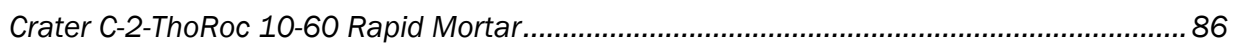

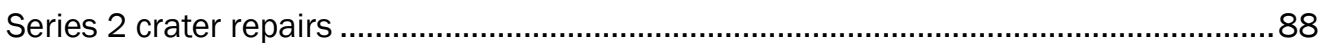

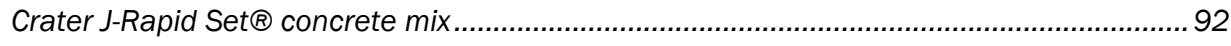

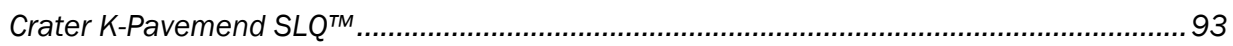

Crater L-ThoRoc 10-61 Rapid Mortar ............................................................................... 95

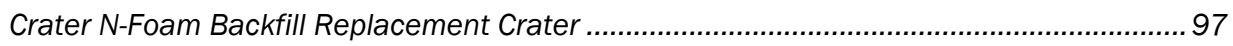

Crater O-Foam base repair ......................................................................................... 98

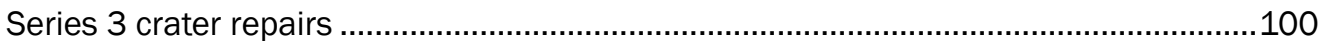

Crater P-Rapid Set ${ }^{\circledR}$ concrete mix ............................................................................... 103

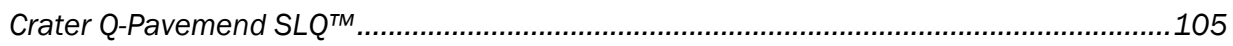

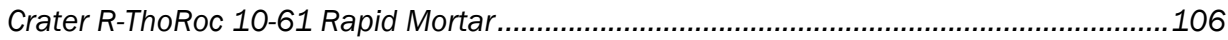




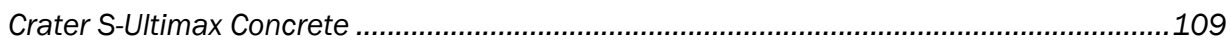

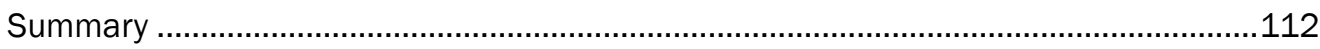

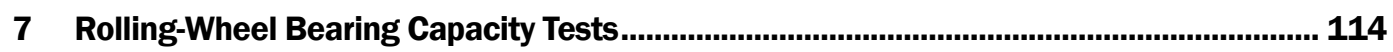

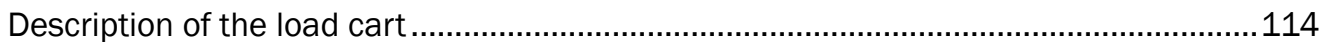

Application of traffic ............................................................................................. 114

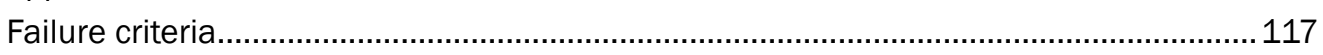

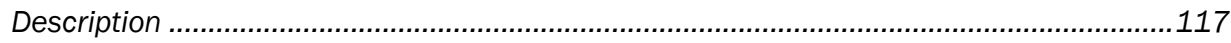

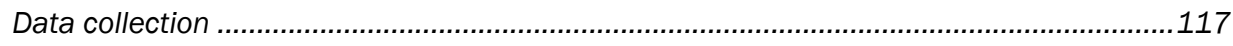

Behavior of crater repairs under traffic-Series 1.....................................................120

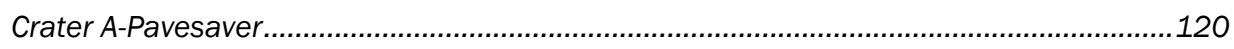

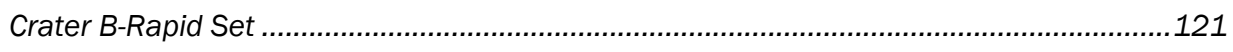

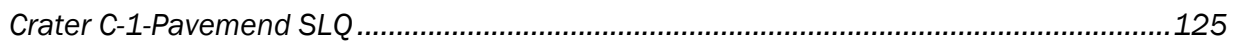

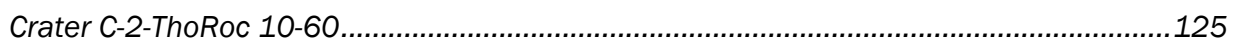

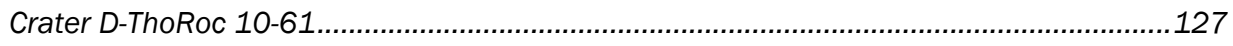

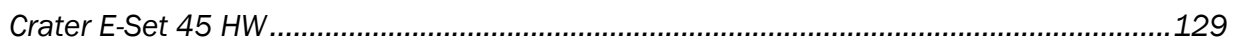

Crater F-Ultimax Concrete........................................................................................... 132

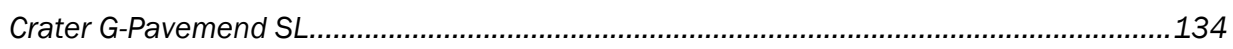

Crater G-2 Tamms Express Repair ............................................................................ 135

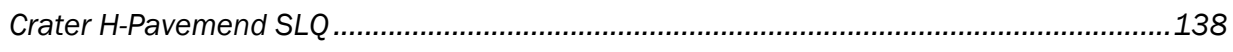

Behavior of crater repairs under traffic-Series 2 .................................................... 142

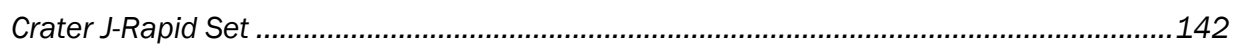

Crater K-Pavemend SLQ ......................................................................................... 145

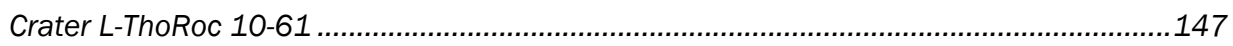

Behavior of crater repairs under traffic-Series 3 ........................................................149

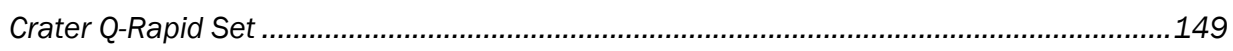

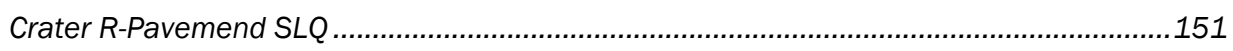

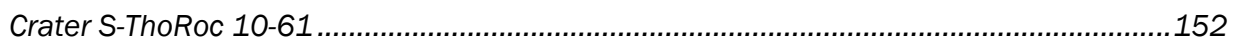

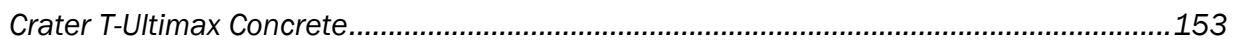

Permanent deformation ...................................................................................154

Heavy weight deflectometer data ............................................................................ 162

EPC data ................................................................................................................. 164

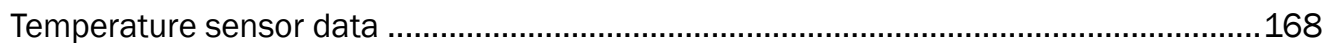

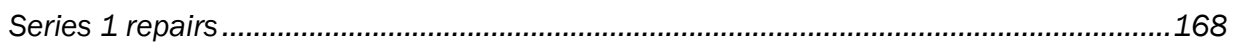

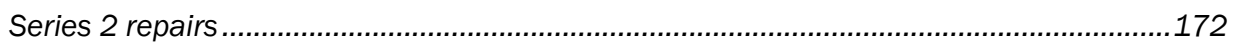

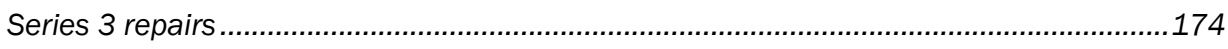

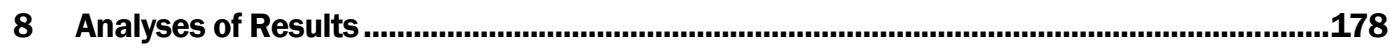

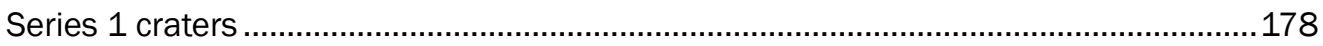

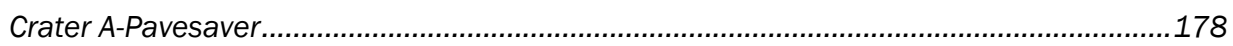

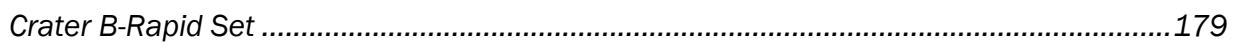

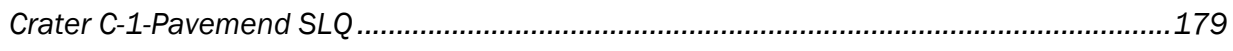

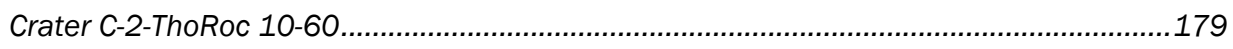

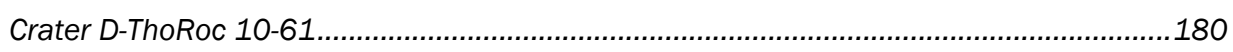

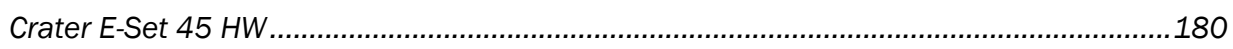

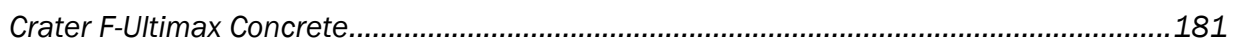




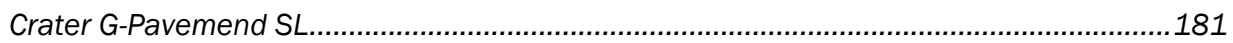

Crater G-2 Tamms Express Repair .............................................................................. 181

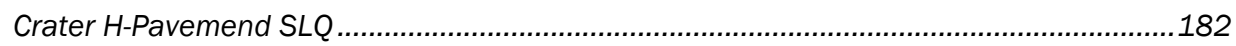

Series 2 craters ............................................................................................................ 182

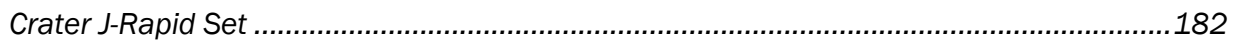

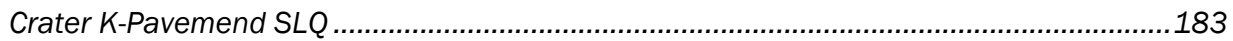

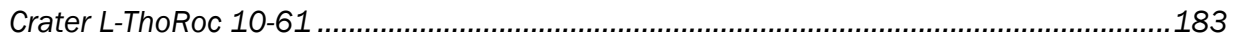

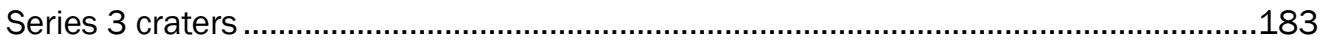

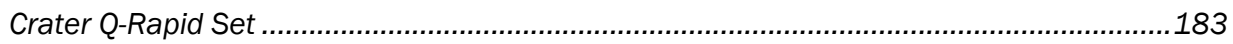

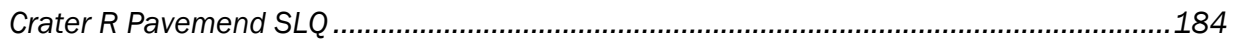

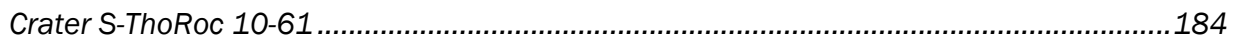

Crater T-Ultimax Concrete................................................................................................... 184

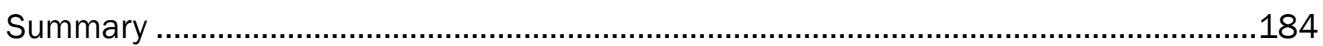

9 Conclusions and Recommendations ........................................................................... 186

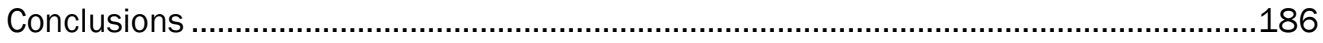

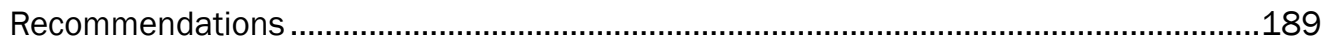

References................................................................................................................................................. 191

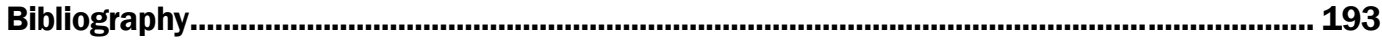

\section{Report Documentation Page}




\section{Figures and Tables}

\section{Figures}

Figure 1. Comparison of unconfined compressive strengths at ambient conditions....................... 14

Figure 2. Comparison of unconfined compressive strengths at elevated conditions. ....................... 14

Figure 3. Slant shear testing. ..................................................................................................... 16

Figure 4. Tiger Foam (a-left) and Foam-iT! 5 (b-right)................................................................ 21

Figure 5. IASCO (a), Pour Foam (b), and Foam R8 (c)................................................................. 22

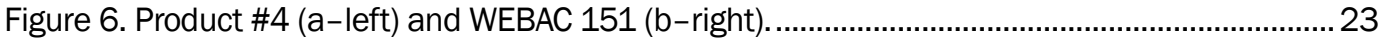

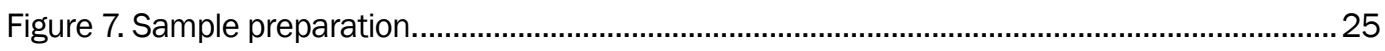

Figure 8. Foam-It 15 samples. ............................................................................................. 28

Figure 9. Aggregate distribution in fully and half-extended Foam-iT! 5 samples. ..............................28

Figure 10. Voids on surface of WEBAC sample..................................................................... 30

Figure 11. Product reactivity.......................................................................................................... 33

Figure 12. Machine used for compression and tension testing .................................................... 34

Figure 13. Data collection program.................................................................................................... 35

Figure 14. Foam-iT! 15 half-extended sample during and after loading...........................................35

Figure 15. Non-extended products stress-strain curve. .....................................................................38

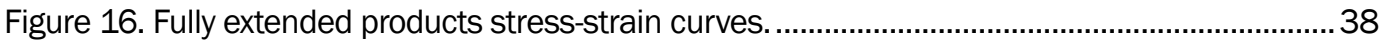

Figure 17. Half-extended products stress-strain curves. ................................................................ 39

Figure 18. Compressive strength change due to extension for the top products.............................39

Figure 19. Average product density compared to compressive strength. .........................................40

Figure 20. Tensile samples: (a) before, (b) during, and (c) after test. ............................................. 41

Figure 21. Tensile strength comparison.................................................................................... 42

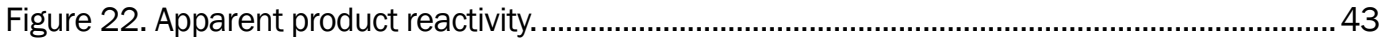

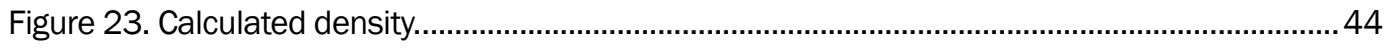

Figure 24. Calculated expansion ratio.................................................................................... 45

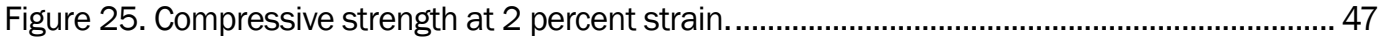

Figure 26. Compressive strength at 5 percent strain............................................................. 47

Figure 27. Compressive strength at 10 percent strain. ..................................................................... 48

Figure 28. Influence of aggregate size on product reactivity. .......................................................... 49

Figure 29. Small aggregate (0.125 in.) pushed from cylinder by expanding foam...........................50

Figure 30. Effects of aggregate size on compressive strength...................................................... 51

Figure 31. Subgrade testing locations. ........................................................................................ 55

Figure 32. Instrumentation locations................................................................................... 56

Figure 33. Test section construction layout............................................................................ 58

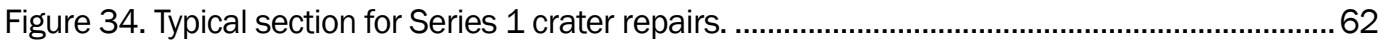

Figure 35. Typical section for Series 2 crater repairs. ...................................................................62 
Figure 36. Typical section for Series 2 foam-debris crater repair...................................................63

Figure 37. Typical section for Series 2 foam backfill crater repair. .................................................... 63

Figure 38. Typical Section for Series 3 crater repairs................................................................. 64

Figure 39. Earth pressure cell prior to installation....................................................................... 64

Figure 40. Instrumentation layout Series 1 craters. ................................................................... 65

Figure 41. Compaction of subgrade material...............................................................................6

Figure 42. Compaction of the crushed limestone base. ……...................................................... 67

Figure 43. Crater A. Mixing Pavesaver...................................................................................... 71

Figure 44. Crater A. Placing Pavesaver..................................................................................... 71

Figure 45. Crater B. Mixing and placing Rapid Set. .................................................................... 72

Figure 46. Crater B. Placing Rapid Set................................................................................... 73

Figure 47. Crater B. Rapid Set finishing................................................................................... 73

Figure 48. Crater C-1. Pavemend SLQ equipment and materials. ................................................. 75

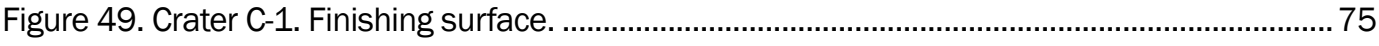

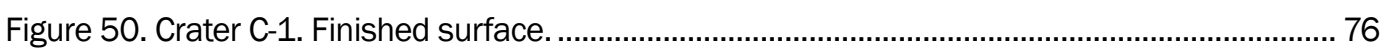

Figure 51. Crater D. Portable horizontal shaft mixer used for mixing. ............................................ 77

Figure 52. Crater D. Placing 10-61 in crater......................................................................... 77

Figure 53. Crater D. Broom-finishing 10-61 surface....................................................................... 78

Figure 54. Crater E. Placing Set 45 HW. .............................................................................. 79

Figure 55. Crater E. Application of 3/8-in. aggregate to surface..................................................... 79

Figure 56. Crater F. Finished surface. ................................................................................. 80

Figure 57. Crater F. Portable mortar mixer used for mixing Ultimax Concrete................................... 81

Figure 58. Crater F. Placing Ultimax Concrete material. ................................................................. 81

Figure 59. Crater F. Finishing Ultimax Concrete surface. ............................................................... 82

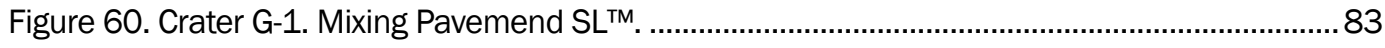

Figure 61. Crater G-1. Placement of Pavemend SL ${ }^{\mathrm{TM}}$.............................................................. 83

Figure 62. Crater G-1. Finishing crater surface. ....................................................................... 84

Figure 63. Crater H. Pavemend SLQTM repair placement............................................................. 85

Figure 64. Crater H. Pavemend SLQTM repair after finishing.......................................................... 85

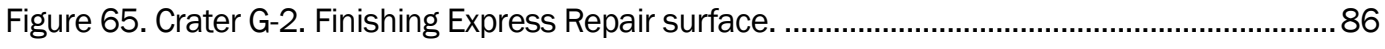

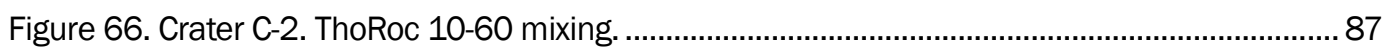

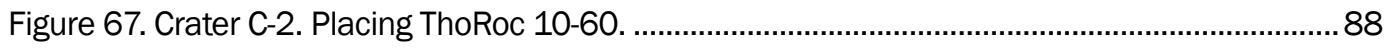

Figure 68. Crater C-2. Finishing ThoRoc 10-60..................................................................... 88

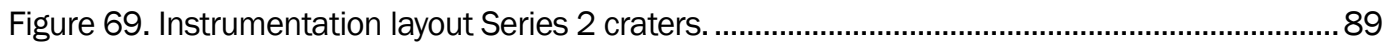

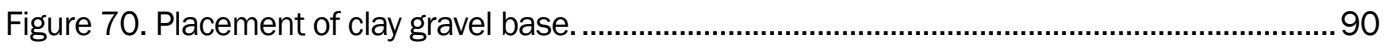

Figure 71. Crater J. Series 2 Rapid Set $₫$ placement....................................................................... 93

Figure 72. Crater J. Finished Rapid Set ${ }^{\circledR}$ surface.......................................................................93

Figure 73. Crater K. Mixing Pavemend SLQ ${ }^{\text {TM }}$ and crater placement. ............................................94

Figure 74. Crater K. Finishing Pavemend SLQ ${ }^{\text {TM }}$ surface ............................................................. 94

Figure 75. Crater L. Mixing and placement of ThoRoc 10-61.....................................................96 


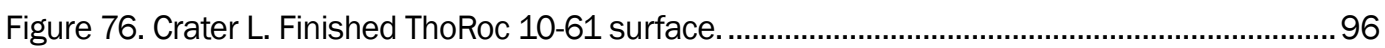

Figure 77. Crater N. Foam-iT! 5 application to debris. ………..................................................... 97

Figure 78. Crater N. Foam-iT! 5 application to debris after expansion. ...........................................98

Figure 79. Crater O. Foam-iT! 15 application as backfill. ................................................................99

Figure 80. Crater O. Foam-iT! 15 application as backfill after expansion......................................... 99

Figure 81. Instrumentation layout Series 3 craters. ………....................................................100

Figure 82. Skid steer with breaker attachment creating debris....................................................102

Figure 83. Concrete debris during placement in crater..............................................................102

Figure 84. Crater P. Placement of Rapid Set over concrete debris. ...............................................104

Figure 85. Crater P. Finishing Rapid Set repair with additional RS materials. ...............................104

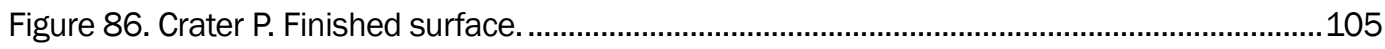

Figure 87. Crater Q. Placement of Pavemend SLQTM over debris. .................................................106

Figure 88. Crater Q. Surface of Pavemend SLQTM crater before finishing. .....................................106

Figure 89. Crater R. Rheofill placement.................................................................................. 107

Figure 90. Crater R: Using plate compactor to aid in RheoFill flow. .............................................108

Figure 91. Crater R. Placement of ThoRoc 10-61 cap...............................................................108

Figure 92. Crater R. Finished cap. .....................................................................................109

Figure 93. Crater S. Placing Aquacrete as flowable fill. ...........................................................110

Figure 94. Crater S. Addition of limestone to Aquacrete surface. ..............................................111

Figure 95. Crater S. Placing Ultimax Concrete cap. ………..............................................................111

Figure 96. Crater S. Finished Ultimax Concrete cap ................................................................112

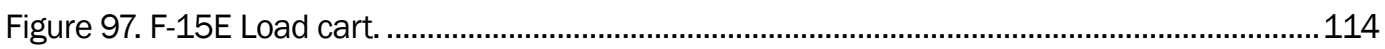

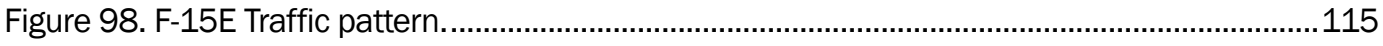

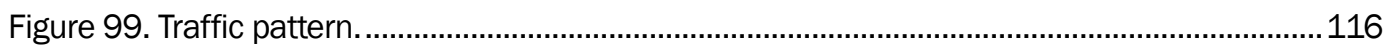

Figure 100. Locations of roughness measurements..............................................................119

Figure 101. Crater A: Debonding of repair to slab on the south and west edges. .........................120

Figure 102. Crater A: Cracking and debonding of repair on west edge..........................................121

Figure 103. Crater B: Spalling after 32 passes.............................................................................122

Figure 104. Crater B: Spalling and cracking- east and west edges after 224 passes. ...................123

Figure 105. Crater B: Spalling and cracking- south, east, and west edges after 320

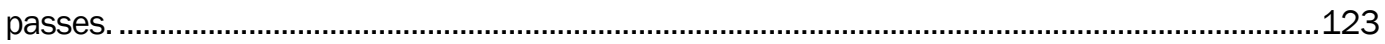

Figure 106. Crater B. Spalling and cracking along south edge after 480 passes..........................124

Figure 107. Crater B: Significant FOD and cracking along south edge after 688 passes...............124

Figure 108. Crater C-1: Significant cracking and settlement after 96 passes...............................125

Figure 109. Crater C-2. Under traffic...................................................................................126

Figure 110. Crater C-2. Spalling - northwest edge after 112 passes...........................................126

Figure 111. Crater D. Cracking and spalling of the south, east, and west edges after 320 passes. 128

Figure 112. Crater D. Cracking and spalling of the south, east, and west edges after 688 passes 
Figure 113. Crater D. Cracking and spalling - south, east, and west edges after 720 passes.

Figure 114. Crater E. Cracking along the south joint.............................................................130

Figure 115. Crater E. Cracking and spalling along the south, east, and west edges after

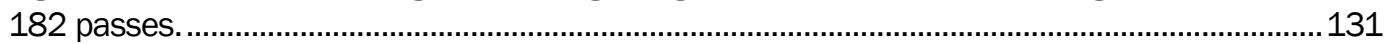

Figure 116. Crater E. Spalling along the south, east, and west edges after 688 passes...............131

Figure 117. Crater F. Cracking on northeast corner after 112 passes..........................................132

Figure 118. Crater F. Cracking along the east, south, and west edges after 384 passes...............133

Figure 119. Crater F. FOD and cracking along the southeast corner after 720 passes. ................133

Figure 120. Crater G-1. Cracking caused by HWD testing. ……...............................................134

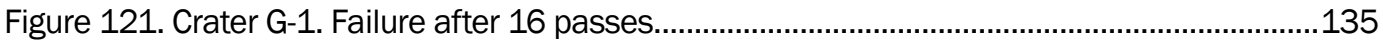

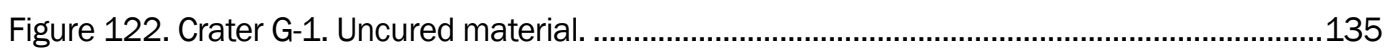

Figure 123. Crater G-2. Map cracking after 112 passes. ...........................................................137

Figure 124. Crater G-2. After 224 passes...........................................................................137

Figure 125. Crater G-2. After 688 passes. ........................................................................138

Figure 126. Crater H. After 112 passes.............................................................................139

Figure 127. Crater H. Cracks in center of crater after 320 passes. ..............................................140

Figure 128. Crater $\mathrm{H}$. Cracking along east and south edges after 920 passes. ..............................140

Figure 129. Crater H. Cracking after 1,344 passes. ..................................................................... 141

Figure 130. Crater H. High severity joint spall after 1,344 passes. .................................................. 141

Figure 131. Crater J. Trafficking. .............................................................................................. 143

Figure 132. Crater J. Spalling on the south edge after 336 passes. ...............................................143

Figure 133. Crater J. After 512 passes. ..................................................................................... 144

Figure 134. Crater J. Spalling on the south edge after 1,008 passes............................................144

Figure 135. Crater J. Spalling on trafficked edge after 2,000 passes...........................................145

Figure 136. Crater K. After 112 passes.................................................................................146

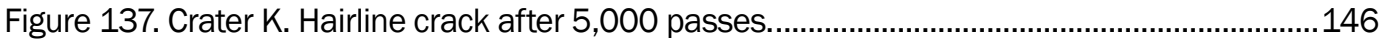

Figure 138. Crater L. Spalling and edge cracking on loaded edges after 336 passes...................148

Figure 139. Crater L. Spalling and edge cracking on loaded edges after 1,008 passes. ..............148

Figure 140. Crater L. Spalling and edge cracking on loaded edges after 2,000 passes. ..............149

Figure 141. Crater Q. Rapid Set shrinkage cracking pre-traffic. ..................................................150

Figure 142. Crater Q. Rapid Set cracking on the south edge after 2,000 passes. ........................150

Figure 143. Crater R. Pavemend SLQ repair after 5,000 passes. ............................................... 151

Figure 144. Crater S. ThoRoc 10-61 joint spall after 3,000 passes. ............................................152

Figure 145. Crater T. Ultimax repair crack after 3,000 passes. ......................................................153

Figure 146. Series 1 crater repair deflection with traffic. ...................................................................163

Figure 147. Series 2 crater repair deflection with traffic..............................................................163

Figure 148. Series 3 crater repair deflection with traffic. ............................................................164

Figure 149. Example of pressure distribution under Series 2 Crater J............................................165

Figure 150. Series 1 peak pressure at selected pass intervals. ........................................................166

Figure 151. Series 2 peak pressure at selected pass intervals. .....................................................167 
Figure 152. Series 3 peak pressure at selected pass intervals. ..................................................167

Figure 153. Rise in average temperature comparison for Series 1 craters..................................169

Figure 154. Rise in average temperature comparison selected Series 1 craters. ..........................169

Figure 155. Series 1. Rapid Set-temperature with depth. .........................................................170

Figure 156. Series 1. Pavemend SLQ-temperature with depth......................................................

Figure 157. Series 1: ThoRoc 10-61-temperature with depth. .................................................... 171

Figure 158. Series 1. Ultimax Concrete-temperature with depth.................................................... 171

Figure 159. Temperature rise comparison for Series 2 craters.....................................................172

Figure 160. Series 2. Rapid Set Concrete-temperature with depth............................................... 173

Figure 161. Series 2. Pavemend SLQ-temperature with depth.....................................................173

Figure 162. Series 2. Rapid Set Concrete-temperature with depth.............................................. 174

Figure 163. Temperature rise comparison for Series 3 craters.................................................... 175

Figure 164. Series 3. Rapid Set-temperature with depth. ........................................................... 176

Figure 165. Series 3. Pavemend SLQ-temperature with depth..................................................... 176

Figure 166. Series 3: ThoRoc 10-61-temperature with depth ..................................................... 177

\section{Tables}

Table 1. Rapid-setting materials investigated.................................................................................. 9

Table 2. Summary of laboratory testing for cementitious materials. ............................................... 11

Table 3. Summary of unconfined compressive testing. .................................................................... 12

Table 4. Results of slant shear investigation. .......................................................................... 15

Table 5. Initial and final set times............................................................................................ 17

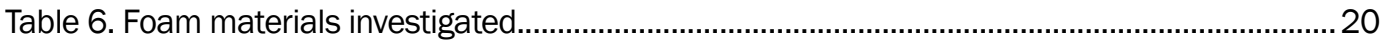

Table 7. Series 1 outline of tests for foam backfill materials. ............................................................. 24

Table 8. Comparison of published to measured density. .................................................................. 31

Table 9. Recommended product instructions and marketed properties.......................................... 31

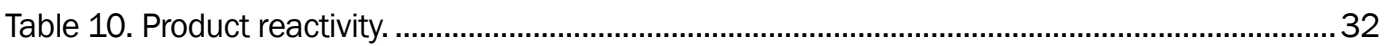

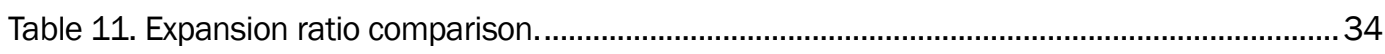

Table 12. Average compressive strength for non-, fully, and half-extended samples........................36

Table 13. Series 2 summary of tests for selected foam backfill materials. ...................................... 42

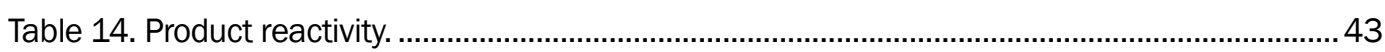

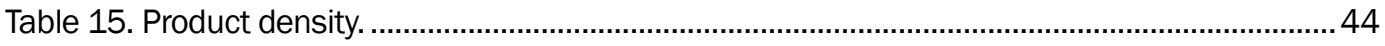

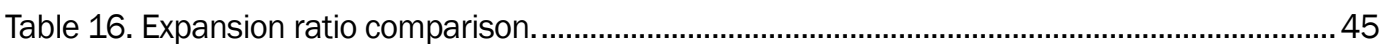

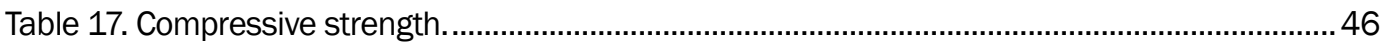

Table 18. Series 3 summary of tests for selected foam backfill materials. ...................................... 48

Table 19. Crater repair options. .................................................................................................... 61

Table 20. Series 1 backfill density and moisture content (continued). ............................................67

Table 21. Series 1 average DCP estimated CBR values............................................................... 70

Table 22. Series 2 construction density and moisture content....................................................... 91

Table 23. Series 2 average DCP estimated CBR values.................................................................92 
Table 24. Series 3 construction density and moisture content. ..................................................... 101

Table 25. Series 2 average DCP estimated CBR values............................................................. 101

Table 26. Frequency of testing - HWD, roughness, deterioration monitoring, and photos

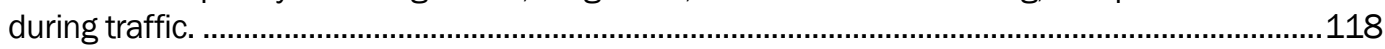

Table 27. Dynamic response data collection intervals. ………………………………….....118

Table 28. Change in elevation Series 1 craters at selected pass intervals (continued). ................154

Table 29. Change in elevation Series 2 craters at selected pass intervals...................................159

Table 30. Change in elevation Series 3 craters at selected pass intervals (continued). .................160

Table 31. Summary of maximum temperatures for each series of crater repairs.......................... 177

Table 32. Summary of crater repair failures.....................................................................................185

Table 33. Summary of recommended capping products...........................................................190

Table 34. Summary of recommended pavement repair thicknesses............................................190 


\section{Preface}

This report was developed for use by the U.S. Air Force, base civil engineers, major command pavement engineers, Red Horse units, and Prime BEEF (Base Engineer Emergency Force) units. Additional users include the Army, Navy, and Marine Corps units charged with an airfield damage repair (ADR) mission.

The project described in this report is part of the ADR Civil Engineer Modernization program currently sponsored by Headquarters, Air Combat Command, Langley AFB.

This publication was prepared by personnel of the U.S. Army Engineer Research and Development Center (ERDC), Geotechnical and Structures Laboratory (GSL), Vicksburg, MS. The findings and recommendations presented in this report are based upon a series of laboratory and field tests conducted at the ERDC in Vicksburg, MS, from February 2006 to November 2006. The principal investigator for this study was Lucy P. Priddy of the Airfields and Pavements Branch (APB), GSL. Lead technicians were Timothy McCaffrey and Patrick S. McCaffrey, APB. Program manager was J eb S. Tingle, APB. Numerous other ERDC personnel assisted in this study. Laboratory testing of cementitious materials was supported by the Concrete and Materials Branch (CMB), GSL. Additional technical assistance was provided by the ERDC Directorate of Public Works and the Instrumentation Systems Division of the ERDC Information Technology Laboratory.

The report was prepared by Priddy, Tingle, and T. J . McCaffrey, GSL, and Ray S. Rollings of Rollings Engineering, Beaufort, SC. Work was conducted under the supervision of Don R. Alexander, Chief, APB; Dr. Larry N. Lynch, Acting Chief, Engineering Systems and Materials Division; Dr. William P. Grogan, Deputy Director, GSL; and Dr. David W. Pittman, Director, GSL.

COL Richard B. J enkins was Commander and Executive Director of ERDC. Dr. J ames R. Houston was Director. 
Recommended changes for improving this publication in content and/ or format should be submitted on DA Form 2028 (Recommended Changes to Publications and Blank Forms) and forwarded to Headquarters, U.S. Army Corps of Engineers, Kingman Bldg, Rm. 321, 7701 Telegraph Road, Alexandria, VA 22315. 


\section{Summary}

In support of the U.S. Air Force Air Combat Command, the U.S. Army Engineer Research and Development Center (ERDC) was tasked to develop and test innovative techniques, materials, and equipment for expedient and sustainment repairs of small bomb craters in airfields. This airfield damage repair (ADR) investigation consisted of laboratory testing of selected crater fill and capping materials, and full-scale field testing of small crater repairs trafficked with an F-15E load cart to evaluate repair performance. Both the laboratory and full-scale traffic tests were conducted at the ERDC in Vicksburg, MS, from February to November 2006. Experimental results were used to develop criteria for rapidly repairing small craters in airfield pavements.

\section{Conclusions}

The following conclusions were derived from the Small Crater Repair project for bomb-damaged pavements:

a. Due to the extreme time restrictions for rapid runway repair, a minimum of 3,000 psi unconfined compressive strength (UCS) is required at $2 \mathrm{hr}$ of cure for rapid setting $(\mathrm{RS})$ materials for crater repairs. Materials must meet this minimum strength under temperature conditions similar to those expected during field placement.

b. A minimum of $800 \mathrm{psi}$ bond strength of RS materials to ordinary portland cement concrete (OPC) and 1,000 psi of RS materials to RS materials is required after 1 day of curing. These materials must be tested under temperature conditions similar to those expected during field placement.

c. Based upon the laboratory testing described in this report, high-density polyurethane foams result in higher UCS than lower density foams. UCSs between 300 and 1,000 psi are achievable with expandable polyurethane foams with densities between 8 and $15 \mathrm{lb} / \mathrm{ft}^{3}$. With $300 \mathrm{psi}$ UCS reasonably achievable at low strain levels ( 2 percent), these high-density polyurethane foams appear to possess adequate strength to serve as backfill in bomb craters by providing UCSs similar to well-compacted soil or aggregate without the need for aggregate extension.

d. High-density polyurethane foams ( 8 to $15 \mathrm{lb} / \mathrm{ft}^{3}$ ) provide a tack-free surface within $15 \mathrm{~min}$ when placed at temperatures between 32 and $110 \stackrel{\circ}{\circ}$. 
Higher temperatures result in shorter tack-free times. Thus, the rapid tack-free time indicates suitability of their use in rapid repair scenarios.

e. The optimal temperature for obtaining maximum compressive strength for foam is $70 \stackrel{\circ}{\circ}$. Higher and lower temperatures result in a reduction in strength and density. Higher temperatures result in a higher rate of reaction, reducing the set time (working time) of the material. At lower temperatures, lower rates of reaction take place, resulting in a decrease in compressive strength. Thus, foam should be placed slightly deeper in the crater repairs during elevated and lower temperatures because of the slight strength reduction.

f. The average expansion ratio of the high-density foams is inversely proportional to foam density and ranged from 4.1 to 9.8. This indicates that the foam material could be used to replace a minimum of four times its volume as backfill in a bomb crater, resulting in a savings of at least 75 percent material.

g. High-density foams can be strengthened by packing the foams with the addition of aggregate; however, extension of the foam with aggregate sizes less than $0.5 \mathrm{in}$. will result in the expulsion of material from the composite system and a reduction in the overall strength.

h. Laboratory investigations indicate that twice as much high-density foam will be needed in the field if extended with aggregates or debris.

i. Based upon the full-scale traffic tests described in this report, most of the RS materials evaluated demonstrated an ability to sustain aircraft traffic within $3 \mathrm{hr}$ of repair completion and are suitable for rapidly repairing small bomb craters provided minimum material specifications are met.

j. Excessive shrinkage cracking, initially a concern for the crater sizes and volumes of RS materials used, was not observed in any of the series of repairs. Although the RS materials did produce high temperatures (maximum measured temperature was $183^{\circ} \mathrm{F}$ ) during curing, this heat generation was not fast enough to cause thermal cracking.

$\mathrm{k}$. Use of large-diameter (1-ft) concrete debris increases the volume of concrete needed and time required to cap the repair due to flow of material through voids in concrete debris.

1. Materials such as Pavemend SLQ that are shipped in buckets take approximately 30 to 50 percent as long to place, with the difference increasing with increasing crater size. Average cap placement times for bagged materials ranged from $25 \mathrm{~min}$ to $96 \mathrm{~min}$ depending on crater size and cap thickness. For buckets of materials, the placement time ranged from $35 \mathrm{~min}$ to $174 \mathrm{~min}$. 
m. For expedient repairs, a 6-in. cementitious cap of RS materials meeting minimum material requirements is capable of withstanding greater than 100 passes of F-15E traffic when placed over 8 in. of well-graded, highquality base material having a CBR of 50 or greater and a compacted subgrade having a CBR of 4 or greater.

n. A 9-in. cementitious cap of Rapid Set, Ultimax Concrete, or ThoRoc 10-61 is capable of sustaining at least 2,000 passes of F-15E traffic when placed over 18 in. of low-quality base material having a CBR of 25 or greater and a compacted subgrade having a CBR of 4 or greater after $3 \mathrm{hr}$ of curing.

o. A 9-in. cementitious cap of Pavemend SLQ is capable of withstanding at least 5,000 passes of F-15E traffic when placed over 18 in. of low-quality base material having a CBR of 25 or greater and a compacted subgrade having a CBR of 4 or greater after $3 \mathrm{hr}$ of curing.

p. A crater repair consisting of Pavemend SLQ or Rapid Set extended with $2.5 \mathrm{ft}$ of high-quality concrete debris with a maximum diameter of $1 \mathrm{ft}$ and capped with $10 \mathrm{in}$. of the same RS material is capable of withstanding at least 5,000 passes of F-15E traffic after $3 \mathrm{hr}$ of curing.

q. A 10-in. cementitious cap of Ultimax Concrete is capable of withstanding at least 5,000 passes of F-15E traffic when placed over Aquacrete Concrete extended with $2.5 \mathrm{ft}$ of high-quality concrete debris after $3 \mathrm{hr}$ of curing.

r. A repair consisting of $10 \mathrm{in}$. of ThoRoc 10-61 over Rheocell extended with $2.5 \mathrm{ft}$ of high-quality concrete debris is not recommended for expedient operations due to long curing times, but will withstand greater than 5,000 passes of an F-15E load after approximately $24 \mathrm{hr}$ of curing.

s. The majority of the repairs failed due to FOD potential caused by highseverity joint spalls on the loaded repair edges.

\section{Recommendations}

Based on laboratory and field testing completed by ERDC personnel, the following recommendations are provided:

a. Mixing and dispensing devices need to be developed for placement of foam backfill to aid in cleanup and proper application of material.

b. Field testing is recommended to verify that field construction procedures can reasonably obtain engineering properties similar to the lab specimens and to verify that foam materials would generate sufficient strength to resist consolidation and prevent structural failure under traffic loads when placed at various depths beneath cementitious caps.

c. Additional testing needs to be conducted to improve the foam-aggregate composite. By reducing separation of aggregate, the stone-on-stone 
contact will increase and generate higher strength composite materials. Once this separation is reduced, it is predicted that lower strength foams could be used as a binding material for aggregate stabilization where high expansion ratios that these foams exhibit would reduce the amount of foam necessary to complete the repair.

d. Additives, such as a retarding agent for Pavemend SLQ, need to be explored to improve the surface appearance and roughness associated with Pavemend SLQ by extending the working time of the material.

e. Rapid Set, Pavemend SLQ, Ultimax Concrete, and ThoRoc 10-61 have desired properties for small crater capping materials under expedient conditions. These materials are recommended for capping small crater repairs.

f. Rapid Set is recommended as the user's choice for small crater repairs because of its ease of use, controllable set time, performance, and fast cure time.

g. Future exercises should be conducted to determine if the recommended repairs could be completed in the 4-hr time frame using manpower and equipment similar to that available during expedient and sustainment operations.

h. The required cap thickness as a function of backfill strength and expected aircraft loading should be explored through additional field testing and/ or the use of finite element models. Until this testing is complete, Table 34 in Chapter 9 of this report provides a matrix of layer thicknesses for standard pavement sections for typical design aircraft, traffic levels, conservative material properties, and relevant environmental conditions for expedient and sustainment repair missions. This matrix was developed based upon experimental testing and proven analytical techniques developed to simplify selection of pavement repair layer thicknesses.

i. Should the available backfill materials fail to meet the minimum strength requirements indicated in Table 34, an additional 1 in. of RS cap material is recommended to be added to the RS cap thickness noted in the table for every 10 percent CBR less than the minimum strength of 50 percent CBR. 


\section{Unit Conversion Factors}

\begin{tabular}{|l|c|l|}
\hline \multicolumn{1}{|c|}{ Multiply } & By & \multicolumn{1}{c|}{ To Obtain } \\
\hline cubic feet & 0.02831685 & cubic meters \\
\hline degrees Fahrenheit & (F-32)/1.8 & degrees Celsius \\
\hline feet & 0.3048 & meters \\
\hline gallons (U.S. liquid) & $3.785412 \mathrm{E}-03$ & cubic meters \\
\hline inches & 0.0254 & meters \\
\hline ounces (mass) & 0.02834952 & kilograms \\
\hline pounds (force) per square inch & 6.894757 & kilopascals \\
\hline pounds (mass) & 0.4535924 & kilograms \\
\hline square yards & 0.8361274 & square meters \\
\hline tons (2,000 pounds, mass) & 907.1847 & kilograms \\
\hline
\end{tabular}




\section{Background}

To evaluate possible approaches to the design of small crater repairs, it was necessary to become familiar with Airfield Damage Repair (ADR) procedures and past ADR work. A bibliography (following the References section) presents a list of ADR references used for the summary below.

\section{Historical perspective}

Landing mats emerged from WWII as the practical military engineering tool for expedient airfield construction and repair. Emerging threats of the Cold War led to intense U.S. Air Force (USAF) studies from 1960 through the end of the 20th century under several programs including the Bomb Damage Repair, Rapid Runway Repair, Have Bounce, and Base Recovery After Attack programs. Through these programs, a myriad of materials and repair systems were studied to deal with the problem of rapidly repairing spalls and both large and small craters from enemy attacks against an airfield. The materials investigated covered a range of fastsetting hydraulic cements, specialty chemical cements, polymeric materials, compacted aggregates, thermoplastic systems, matting systems, and bituminous materials. Repair concepts that have been studied have included flexible and rigid caps over debris backfill or specially placed or compacted backfill, structural systems to bridge craters, foamed crater backfills, and structural systems for backfill.

Procedures, equipment, and materials identified during this period were used to equip and train USAF repair teams. Repair materials included AM2 landing mat, folded fiberglass mat, polymer spall repair materials, and precast concrete slabs. Repair team proficiency was developed and maintained by local unit training, recurrent training at Field 4 at Eglin Air Force Base (AFB), and more recently Silver Flag training at several designated locations. Recurring unit Inspector General inspections and Operational Readiness Training are conducted to evaluate USAF civil engineer equipment and training for these tasks.

\section{Current repair methods}

Because of these research efforts and the transforming technologies of the past 35 years, the current expedient repair techniques for small and large 
craters were developed and employed by the Air Force, Army, Navy, and Marine Corps. Currently, the Air Force uses a crushed stone and sand-grid crater repair methods surfaced with a folded fiberglass mat (FFM) foreign object debris (FOD) cover. The Army employs either a sand-grid expedient repair method or a cement-stabilized backfill surfaced with a fiberglass reinforced panel (FRP) FOD cover, and the Navy and Marine Corps have identified AM2 mat repair as their only repair method. Sustainment repairs currently employed include stone and grout, concrete cap, rapid set cementitious cap, AM2 mat, and asphalt repair methods.

\section{Lessons learned}

The Cold War era repair methods were developed under the assumption that repairs would be conducted at fixed locations using prepositioned resources. These methods are not adequate in our current operations where military engineer teams have to rapidly open airfields, often in remote locations where minimal equipment and materials are available. In cases where equipment and material resources could not be airlifted to the site, military engineer teams heavily relied on in-situ materials and resources. As a result, runway repairs carried out in the Afghanistan and Iraq wars have not performed well and resulted in increased maintenance to maintain an operable surface. From this broad set of studies, experiences with crater repair exercises at training facilities and crater repairs in Afghanistan and Iraq, one may glean some common lessons in conducting crater repairs. These include:

a. Crater repair is performed under conditions of confusion, high stress, and intense pressure. Simplicity, reliability, robustness, and redundancy are key attributes for systems that will work in the field.

b. There is no substitute for training, experience, and leadership in the repair teams.

c. Structural landing mats such as AM2 or M-19 have proven repeatedly to be the most effective, all-weather, and troop constructible expedient airfield construction and repair system ever investigated. It is, however, an unbearable logistical burden for remote applications, and the Have Bounce program found its roughness associated with thicker mat systems and the inability of low-profile mat systems to adequately withstand heavy cargo aircraft unacceptable for crater repairs on the runway. In these situations, military units have been forced to use compacted soil, aggregate, stabilized materials, low-quality concrete, or unproven rapid-setting (RS) materials for crater repairs. 
d. There are many fast-setting, high early strength materials used to cap craters. The problem is in mixing, placing, and finishing the materials before they set up, and this remains the unresolved issue in such approaches. The use of these unproven products and techniques pose significant risk of aircraft damage known as FOD damage. This occurs when the repairs crumble, and the loosened material is projected at the aircraft or ingested into aircraft engines by moving tires, wind, or jet blast. These types of repairs require increased labor to maintain adequate takeoff and landing surfaces for aircraft operations.

e. As desired repair times are shortened, the materials with which to cap craters become more exotic, harder to use, more expensive, and generally have shortened shelf lives and may pose safety hazards.

f. Airfield pavements are crowned so self-leveling repair materials are seldom suitable.

g. All crater repair systems are compromises and trade-offs.

h. Target Repair Time: As one shortens the desired repair time from 24 to $4 \mathrm{hr}$ or less, problems escalate and chances of success in research and in the field decrease. These are exponential relations and not simple linear ones.

i. Equipment: Large specialized equipment does the job fastest and best but at the expense of decreased mobility and increasing the logistical burden.

j. Crater Backfill: One can either invest the resources in time, equipment, and materials to properly backfill the crater or one must plan for frequent maintenance and repair of the crater as the backfill settles and densifies in use.

k. Repair Problem: USAF engineer teams may potentially face a wide spectrum of repair problems ranging from spalls to very large craters. The repair of multiple small craters may be more difficult than the repair of a few large craters. Removal of upheaved concrete pavement is often one of the most difficult and onerous tasks that must be addressed. A repair team organization and equipment package that is optimized for one problem will likely do less well on a different type of repair problem. 


\section{Introduction}

Although RS materials and foam backfill are not new concepts for crater repair, improvements in proprietary products have increased their usage in the rapid repair of rigid pavements. During the hiatus between the last major crater repair studies in the 1990s and the present, material technology has continued to evolve. There have been further refinements in the composition of hydraulic and chemical cements, and there have been advances in admixtures and additives for these materials. New formulations for rigid, polyurethane foams and application equipment upgrades haveled to the use of foam for void filling beneath rigid pavements. Because of these advances, there are an increasingly large number of products for rapid repair to concrete pavements that are commercially available and that may be usable for military crater repairs. These commercial-off-the-shelf (COTS) products provide short set times, high early strength, and good durability and flexibility to withstand heavy loads, but many are the same technologies that have been tested in the past that have been repackaged and remarketed. The present investigation will evaluate what commercially available repair products may be exploited for advances in military small crater repair techniques. Experience gained from testing these products for small crater repairs will provide guidance for capping and backfill techniques that will expedite opening the runway to traffic and minimize the frequency of maintenance activities by engineering units.

\section{Objective}

The ultimate objective of this effort is to evaluate new materials for backfilling and capping small craters within a 4-hr time limit as defined by UFC 3-270-07 that are capable of sustaining significant aircraft traffic with minimum maintenance requirements. These expedient and/ or sustainment repair methods for small craters must sustain heavy cargo and fighter aircraft operations, minimize repair time, minimize logistical footprint, and be trafficked within $4 \mathrm{hr}$ of the start of the repair.

\section{Scope}

This project included the laboratory evaluation of backfill and capping materials for rapidly repairing small bomb craters and full-scale traffic tests to evaluate field mixing methods, installation procedures, and repair 
performance. These new technologies were also evaluated for the capability of reducing the logistical footprint, manpower, and cost within the objective time repair limit of $4 \mathrm{hr}$. The following tests were completed to accomplish the objectives of this effort:

a. Laboratory characterization of RS capping materials at early cure times.

b. Laboratory characterization of innovative foam backfill materials under varying temperature and aggregate extension conditions.

c. Full-scale simulated F-15E load cart testing on crater repairs to evaluate the ability of selected RS products over backfill materials to sustain the aircraft traffic.

\section{Definitions of terms}

For clarity, terms used in this report are defined as follows:

a. Airfield Damage Repair (ADR): Activities of engineer personnel in response to the attack of an airbase to provide adequate launch and recovery surfaces for the mission aircraft. Although ADR criteria were based on repairing airfields in friendly territory, recent military operations require repairing airbases occupied previously by hostile forces damaged during forcible entry or purposely sabotaged by departing forces. ADR encompasses other areas besides the repair of bomb damage including damage assessment, identification of candidate minimum operating strips, and the safing and disposal of explosive ordnance.

b. Expedient Repair: Repairs conducted to create an initial operationally capable launch and recovery surface known as the minimum operation strip (MOS) based on projected mission aircraft requirements. These repairs are conducted in the most expeditious manner possible. When sufficient equipment and materials are available, individual crater repairs should be completed within $4 \mathrm{hr}$. Expedient repairs in this investigation must provide an accessible and functional MOS that will sustain 100 passes of an F-15E aircraft with a gross weight of 35,235 lb.

c. Sustainment Repairs: Repair efforts to upgrade expedient repairs for increased aircraft traffic. These repairs are conducted as soon as the operational tempo permits and are expected to support the operation of 5,000 passes of an F-15E aircraft with a gross weight of 35,235 lb without requiring additional maintenance. For these repairs, quality control is more important than construction time to minimize maintenance and maintain operational tempo; however, for this investigation, an individual sustainment repair was also expected to be completed within $4 \mathrm{hr}$. 
d. Spall: Breakdown of a repair or slab edge that does not extend vertically through the slab but intersects either a joint or edge at an angle. Spalls develop from localized overloading of the concrete that may originate in traffic loads, restraint of the concrete as it undergoes volume change, or durability problems. Severity levels are determined by length and FOD potential.

e. Crater: Damage that penetrates through the pavement surface into the underlying base and subgrade soil uplifting the surrounding pavement and ejecting soil, rock, and pavement debris around the impact area.

f. Large Crater: Crater with an apparent diameter equal to or greater than $15 \mathrm{ft}$.

g. Small Crater: Crater with an apparent diameter less than $15 \mathrm{ft}$.

h. Rapid-Setting (RS) Material: A cementitious material similar to portland cement concrete (PCC) but with high early compressive strengths and very fast set times. These materials typically contain finely ground ordinary portland cement (OPC) or modern hydrating materials such as magnesium phosphate or alumina.

i. Pass: One traverse of a load wheel across a given length of runway, taxiway, or test section surface.

j. Coverage: One application of the load wheel over every single point in the central portion of the traffic lane. For a normally distributed traffic pattern, the test section pass to coverage ratio is determined by dividing the total number of passes in one pattern of traffic by the number of times the load wheel passes over the peak traffic lane. For a single-wheel aircraft gear, the number of coverages is simply the number of times the wheel travels down the center traffic lane in a five lane distribution. For this test, the pass to coverage ratio for the single-wheel F-15E load cart was 4.0. Thus, four passes of the load cart resulted in one coverage of the traffic lane.

k. Pattern: The completion of one simulated normal distribution of traffic in a test lane by the test load cart.

1. Subgrade: An area of soil processed under controlled conditions to provide a desired bearing capacity upon which additional pavement layers are placed.

m. Test section: A concrete surfaced pavement specifically constructed to simulate a typical runway pavement under controlled conditions.

n. Traffic lane: The portion of the test section that is subjected to the moving load of the load cart.

o. Load cart: A specially constructed vehicle used in engineering tests for simulating aircraft taxiing operations. 
p. Test wheel: The wheel on the load cart that supports the main load. In this test, the wheels are actual aircraft wheels mounted on the load cart.

q. Elastic deformation: Temporary vertical bending of the crater cap under the static load from the test wheel.

r. Plastic/ permanent deformation: The permanent change in elevation of the cap resulting from load applications.

s. California bearing ratio (CBR): A soil strength index based upon its shearing resistance. The $\mathrm{CBR}$ value is calculated by dividing the unit load required to force a piston into the soil by the unit load required to force the same piston the same depth into a standard sample of crushed stone and multiplying by 100 percent. 


\section{Laboratory Investigation of Rapid-Setting (RS) Materials}

There are a number of COTS products available that have been used to repair pavement surfaces. Several of these RS products have been used successfully on airfields to repair pavement spalls and other small repairs (less than $1 \mathrm{ft}^{3}$ ). The challenge of this project was to apply these materials for larger volume repairs without inducing excessive shrinkage cracking. Laboratory testing was conducted on numerous products to select the most promising materials for field evaluation.

\section{Materials investigated}

This investigation examined RS cementitious materials that were identified as potential capping products for crater repair. The materials identified met the following requirements:
a. Have a color similar to PCC
b. Can be mixed and placed like concrete with portable equipment
c. Do not pose significant health risks to users
d. Have accelerated hardening characteristics
e. Yield a permanent patch in concrete that can withstand traffic within short time frames of repair

Materials investigated in this study are listed in Table 1 and are briefly described in the following section.

\section{Pavesaver $^{\mathrm{TM}}$}

Pavesaver, manufactured by D.S. Brown Company, is a two-part polymeric patching material typically used for repairing spalls and cracks in concrete pavement. When extended with sand and aggregate, this material can be used for thicker pavement repairs. This was the only RS polymer product evaluated in this experiment. 
Table 1. Rapid-setting materials investigated.

\begin{tabular}{|c|c|c|}
\hline Material & Vendor & Material Type \\
\hline Pavesaver & D.S. Brown Co. & Polymeric \\
\hline Rapid Set Concrete Mix & CTS Cement & Proprietary Cement \\
\hline Pavemend SLQ & CeraTech, Inc. & Magnesium Phosphate \\
\hline Pavemend SL & CeraTech, Inc. & Magnesium Phosphate \\
\hline ThoRoc 10-60 & BASF Building Solutions & High-Alumina Cement \\
\hline ThoRoc 10-61 & BASF Building Solutions & High-Alumina Cement \\
\hline Set 45 HW & BASF Building Solutions & Magnesium Phosphate \\
\hline Express Repair & Tamms & Portland Cement \\
\hline Ultimax Concrete & Ultimax Corp. & Alumina Phosphate \\
\hline ABC Cement Express Repair Mortar & ABC $®$ Cement & Proprietary Cement \\
\hline
\end{tabular}

\section{Rapid Set ${ }^{\circledR}$ Concrete Mix}

Rapid Set Concrete Mix, manufactured by CTS Cement, is a rapid-setting cementitious product that consists of a dry blend of Rapid Set ${ }^{\circledR}$ hydraulic cement and sand. The material is mixed with water for repairing highways, airfield pavements, parking decks, and steps.

\section{Pavemend SLQ}

Pavemend SLQ, manufactured by CeraTech, Inc., is a rapid-setting, magnesium phosphate-based cementitious material. In recent laboratory and small-scale field tests conducted by the U.S. Army Engineer Research and Development Center (ERDC), other Pavemend materials exhibited desirable qualities suitable for rapid repairs, including ease-of-mixing and placement, self-leveling ability, and acceptable rapid strength gain (Mann 2006). Pavemend SLQ can be used for repairing spalls in concrete pavements, and, when extended with aggregate, the material can be used for full-depth concrete pavement repairs.

\section{Pavemend SL}

Pavemend SL, manufactured by CeraTech, Inc., is a rapid-setting, magnesium phosphate-based cementitious material. Pavemend SL is recommended by the manufacturer when more working time is needed for placing the material. This product is intended for horizontal repairs for concrete pavements including spalls and full-depth repairs. 


\section{ThoRoc 10-60}

ThoRoc 10-60, manufactured by BASF Building Solutions (formerly Degussa), is a rapid-setting cementitious material consisting of a proprietary blend of high-alumina cement, portland cement, and fly ash. This product is intended for horizontal repair for concrete. As with other products, this material can be extended with aggregate for thicker pavement repairs.

\section{ThoRoc 10-61}

ThoRoc 10-61, also manufactured by BASF Building Solutions, is a rapidsetting cementitious material of similar chemical composition to the 10-60 material but formulated for warmer environments. It is intended for horizontal repair of concrete.

\section{Set 45 HW}

Set $45 \mathrm{HW}$, also manufactured by BASF Building Solutions, is a rapidsetting, one-component, magnesium phosphate-based patching product formulated for horizontal concrete repair in warmer environments ranging from 85 to $100^{\circ} \mathrm{F}$. When extended with aggregate, this material can be used for thicker pavement repairs.

\section{Express Repair}

Express Repair, manufactured by Tamms, is a rapid-setting, portland cement-based repair material. When extended with aggregate, this material can be used for horizontal repair of concrete or as a patching material for thin layers.

\section{Ultimax Concrete}

Ultimax Concrete, manufactured by Ultimax Corporation, is a rapidsetting aluminum phosphate-based repair material similar to Rapid Set. The product can be used for thin or thick pavements without the need of extension.

\section{ABC Cement Express Repair Mortar}

ABC Cement Express Repair Mortar, manufactured by ABC Cement, is another rapid-setting cementitious material consisting of a proprietary 
blend of portland cement and other hydrating cements and aggregate that has been tested for spall repair purposes. A new formulation was sent to ERDC for property investigation. The material is intended for horizontal repair of concrete pavements.

\section{Laboratory tests and results}

The various laboratory tests and specific test conditions for this investigation are presented in the following text. Properties of interest, test methods, test ages, number of replicate specimens, and test-temperature conditions are listed in Table 2.

Table 2. Summary of laboratory testing for cementitious materials.

\begin{tabular}{|c|c|c|c|c|}
\hline Property & Test Method & Test Ages & No. Replicates & Test Temperatures \\
\hline $\begin{array}{c}\text { Unconfined } \\
\text { Compressive } \\
\text { Strength }\end{array}$ & ASTM C 39 & $2,6 \mathrm{~h}-1,28 \mathrm{~d}$ & 3 & $73^{\circ} \mathrm{F}, 90^{\circ} \mathrm{F}$ \\
\hline Slant Shear & ASTM C 882 & $24 \mathrm{~h}, 28 \mathrm{~d}$ & $2^{\mathrm{a}}$ & $73^{\circ} \mathrm{F}$ \\
\hline $\begin{array}{c}\text { Time of } \\
\text { Setting }\end{array}$ & ASTM C 403 & N/A & 2 & $73^{\circ} \mathrm{F}, 90^{\circ} \mathrm{F}$ \\
\hline
\end{tabular}

a Two series of testing conducted to investigate material-to-mortar bond and material-to-material bond.

All materials were mixed with portable concrete mixing equipment per manufacturer mixing instructions. When manufacturer instructions required extension of the RS materials with aggregate, materials meeting manufacturer specifications with a maximum size not exceeding $0.75 \mathrm{in}$. were used to prepare the compressive strength samples. No extension was used to produce slant shear samples or time of set in accordance with ASTM C 882 and ASTM C 403. The equipment used for mixing included rotary drum mixers, high-speed drills with paddle attachments, and horizontal shaft mortar mixers. The appropriate equipment was used to mix each material per manufacturer instructions. The test methods used and results are briefly described below.

\section{Unconfined compressive strength}

Unconfined compressive strength (UCS) is a commonly used property for routine evaluation of materials and quality assurance activities. It is also important to ensure that the repair materials will not crush easily under aircraft wheel loads or by pavement movements (AFCESA 2006). Therefore, UCS testing was included in the laboratory investigation and was conducted in accordance with ASTM C 39 procedures. Each sample 
was cast in 6-in. by 12-in. cylinders. The materials were allowed to air cure for short durations as would be experienced in the field and were tested in unconfined compression at 2, 6, and $24 \mathrm{hr}$. Additional cylinders were cast and tested in compression to compare early strengths to 28-day strengths. The materials were cast and tested at ambient and elevated temperatures of 73 and $90^{\circ} \mathrm{F}$. The materials were cured at these temperatures to evaluate the effect of elevated temperatures on material strength. Capping was accomplished with unbonded neoprene pad caps (ASTM C 1231). A minimum of three replicates were tested for each material at each test age and temperature.

Results of testing are reported as the maximum unconfined compressive stress (lb/in. $\left.{ }^{2}\right)$, which is the maximum force divided by the cross-sectional area of the specimens. A summary of the average UCS for three replicates for each material is presented in Table 3.

Table 3. Summary of unconfined compressive testing.

\begin{tabular}{|c|c|c|c|c|c|}
\hline \multirow{2}{*}{ Material } & \multirow{2}{*}{ Temperature } & \multicolumn{4}{|c|}{ Average UCS, psi } \\
\hline & & $2 \mathrm{hr}$ & $6 \mathrm{hr}$ & $24 \mathrm{hr}$ & 28 day \\
\hline \multirow{2}{*}{ Pavesaver } & Ambient $\left(73^{\circ} \mathrm{F}\right)$ & 1,190 & 1,767 & 3,087 & 4,120 \\
\hline & Elevated $\left(90^{\circ} \mathrm{F}\right)$ & 457 & 1,463 & 1,633 & 2,170 \\
\hline \multirow{2}{*}{$\begin{array}{l}\text { Rapid Set Concrete } \\
\text { Mix }\end{array}$} & Ambient $\left(73^{\circ} \mathrm{F}\right)$ & 3,777 & 7,903 & 8,513 & 9,160 \\
\hline & Elevated $\left(90^{\circ} \mathrm{F}\right)$ & 4,070 & 4,567 & 5,890 & 7,640 \\
\hline \multirow{2}{*}{ Pavemend SLQ } & Ambient $\left(73^{\circ} \mathrm{F}\right)$ & 2,630 & 2,980 & 3,590 & 5,140 \\
\hline & Elevated $\left(90^{\circ} \mathrm{F}\right)$ & 1,360 & 1,050 & 1,990 & $-\mathrm{-a}^{\mathrm{a}}$ \\
\hline \multirow{2}{*}{ ThoRoc 10-61 } & Ambient $\left(73^{\circ} \mathrm{F}\right)$ & 3,887 & 4,093 & 5,070 & 8,233 \\
\hline & Elevated $\left(90^{\circ} \mathrm{F}\right)$ & 3,610 & 4,277 & 5,083 & 8,217 \\
\hline \multirow{2}{*}{ Set $45 \mathrm{HW}$} & Ambient $\left(73^{\circ} \mathrm{F}\right)$ & 2,820 & 3,993 & 4,427 & 6,317 \\
\hline & Elevated $\left(90^{\circ} \mathrm{F}\right)$ & 3,227 & 3,340 & 3,823 & 4,233 \\
\hline \multirow{2}{*}{ Ultimax Concrete } & Ambient $\left(73^{\circ} \mathrm{F}\right)$ & --- b & 3,713 & 7,875 & 9,030 \\
\hline & Elevated $\left(90^{\circ} \mathrm{F}\right)$ & $-\mathrm{-a}^{-a}$ & $---a^{a}$ & --- a & $-\mathrm{-a}^{\mathrm{a}}$ \\
\hline \multirow{2}{*}{ Pavemend SL } & Ambient $\left(73^{\circ} \mathrm{F}\right)$ & 3,093 & 3,940 & 3,877 & 4,257 \\
\hline & Elevated $\left(90^{\circ} \mathrm{F}\right)$ & 120 & 2,613 & 3,867 & 4,413 \\
\hline \multirow{2}{*}{ ThoRoc 10-60 } & Ambient $\left(73^{\circ} \mathrm{F}\right)$ & 3,100 & 4,017 & 4,360 & 6,893 \\
\hline & Elevated $\left(90^{\circ} \mathrm{F}\right)$ & 2,627 & 2,690 & 3,697 & 5,680 \\
\hline \multirow{2}{*}{ Express Repair } & Ambient $\left(73^{\circ} \mathrm{F}\right)$ & 3,250 & 3,557 & 4,023 & 10,633 \\
\hline & Elevated $\left(90^{\circ} \mathrm{F}\right)$ & 2,963 & 3,540 & 3,813 & 9,783 \\
\hline \multirow{2}{*}{$\begin{array}{l}\text { ABC Cement Express } \\
\text { Repair Mortar }\end{array}$} & Ambient $\left(73^{\circ} \mathrm{F}\right)$ & 1,770 & 3,670 & 4,917 & 9,230 \\
\hline & Elevated $\left(90^{\circ} \mathrm{F}\right)$ & 1,860 & 3,373 & 4,700 & 10,000 \\
\hline
\end{tabular}

a Test results not complete.

b Too weak to test. 
Recent Air Force protocol for evaluating rigid repair materials recommended a minimum UCS for RS materials of 3,000 psi after $3 \mathrm{hr}$ of cure for selecting cementitious materials that merit field inspection (AFCESA 2006). This protocol was based on 6 years of laboratory and field experiments in the 1990s conducted by Vaysburd et al. (1999) in which laboratory results were compared to field performance to establish allowable limits on laboratory test results. Based on the results of the current laboratory testing, the majority of the materials met this requirement at ambient temperatures after only $2 \mathrm{hr}$ of cure, as can be seen in Table 3. Figures 1 and 2 show that UCS increased with increasing age for both ambient and elevated conditions. This was expected as cementitious materials gain strength as they cure. However, as can be seen in Table 3 there was a reduction in strength for most materials when the temperature was elevated. This was especially evident in the Pavemend SL and Pavesaver materials which showed significant reductions in strength at $2 \mathrm{hr}$ at elevated temperature conditions from 3,093 to $120 \mathrm{psi}$ (2 percent of 28-day strength) and 1190 to 457 psi, (21 percent of 28-day strength), respectively. Elevated compressive testing was not completed on these materials prior to field testing due to time constraints. Had these results been available prior to field testing, these materials may not have been recommended for crater placement. Field testing was conducted with average daily high temperatures in excess of the laboratory elevated temperatures. Early failures occurred during the field placement of these materials and are detailed in Chapter 7 of this report. If the temperatures during field testing had mimicked ambient laboratory testing temperatures, the material should have gained 72 percent of its 28-day strength after $2 \mathrm{hr}$ of cure, and the problems of using this material at elevated conditions may have gone undetected.

With the exception of ABC Cement, all materials were recommended for the first series of field experimentation. Because of the low early strengths achieved for both ambient and elevated temperatures, ABC Cement withdrew from the remainder of the laboratory testing and field testing. 


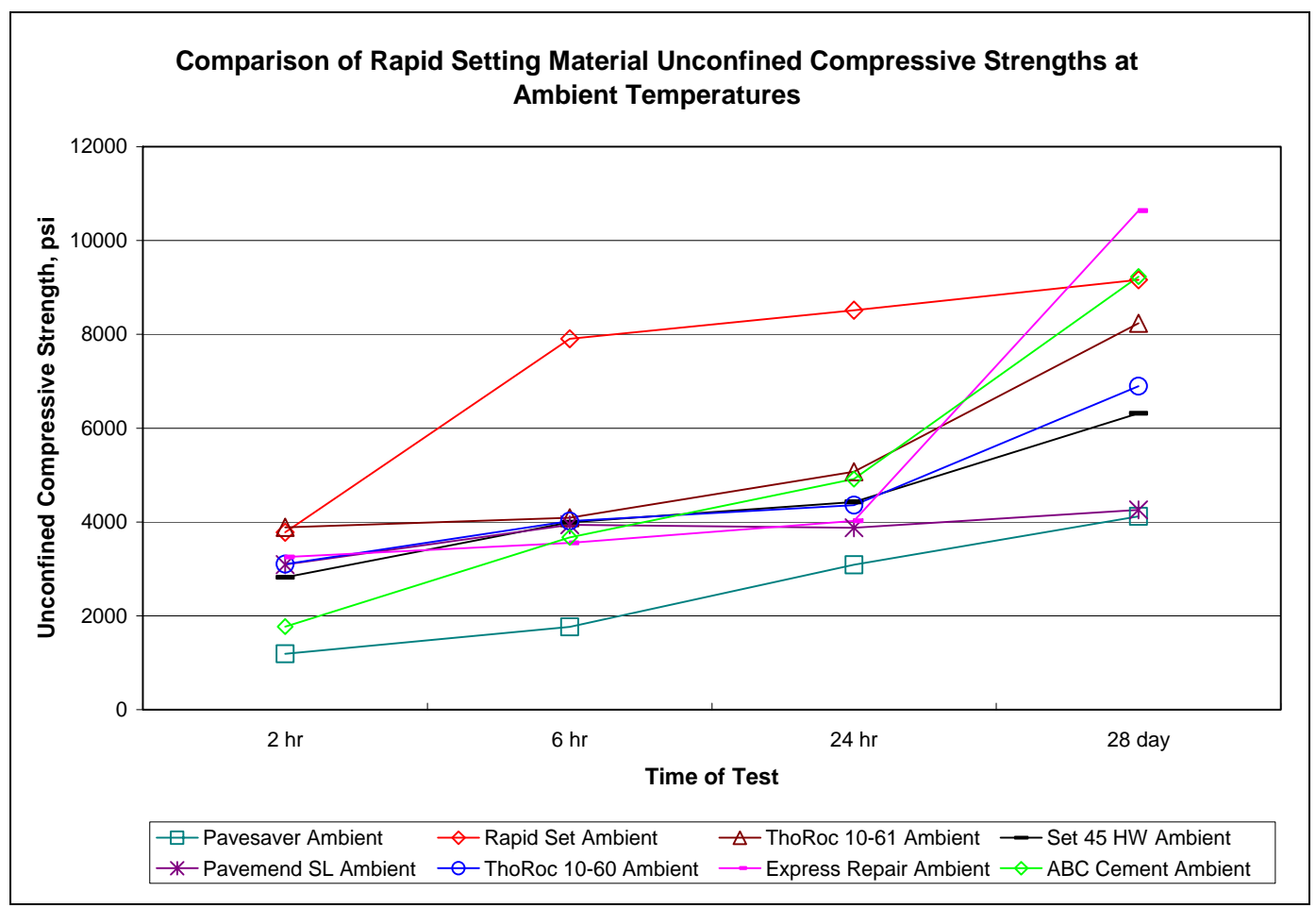

Figure 1. Comparison of unconfined compressive strengths at ambient conditions.

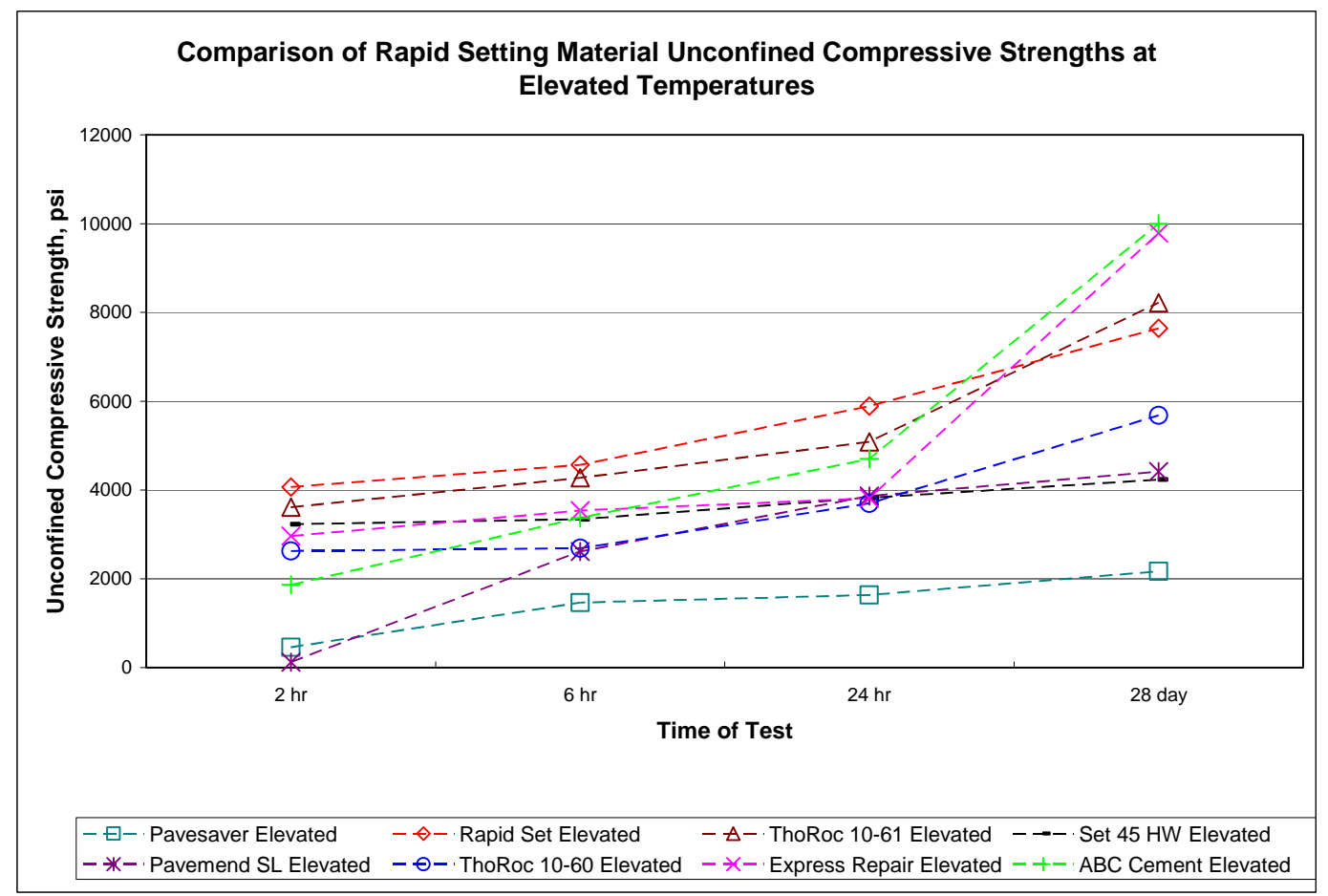

Figure 2. Comparison of unconfined compressive strengths at elevated conditions. 


\section{Slant shear}

Slant shear testing was conducted to determine the bond strength of the various materials. Bond strength is an important measurement to ensure that the repair material will have a strong bond to the parent material onto which the repair was applied. Testing of material bond to itself is also important when the repair will involve multiple small lifts. Bond strength testing was accomplished in accordance with ASTM C 882 procedures. This procedure involved the use of 3-in. by 6-in. cylinder molds. A bond line is produced at approximately $30 \mathrm{deg}$ from vertical by first making wedge-shaped dummy sections of either OPC mortar or the repair material itself. After curing, these wedge-shaped sections are slid into the bottom of the cylinder molds. The repair material is then placed on top of the dummy section. After curing for 1 day, the composite cylinder, produced with repair material bonded either to OPC mortar or to itself, is tested in unconfined compression. Results are reported as the maximum bond stress (pounds (force) per square inch), which is calculated as maximum force divided by the area of the elliptical bonding surface. Additionally, samples were produced to test the bond strength after 28 days of cure. Materials were allowed to air cure and were capped in the same manner as the compressive samples with a minimum of two replicates. The average bond strength for each material to OPC mortar and material to material is reported in Table 4. A typical specimen is shown in Figure 3.

Table 4. Results of slant shear investigation.

\begin{tabular}{|c|c|c|c|c|}
\hline \multirow{3}{*}{ Material } & \multicolumn{4}{|c|}{ Bond Strength, psi } \\
\hline & \multicolumn{2}{|c|}{ RS Material/OPC Mortar } & \multicolumn{2}{|c|}{ RS Material/RS Material } \\
\hline & 1 day & 28 day & 1 day & 28 day \\
\hline Pavesaver & 520 & 230 & 690 & 480 \\
\hline Rapid Set Concrete Mix & 1,510 & 1,600 & 1,340 & 2,330 \\
\hline Pavemend SLQ & \multicolumn{4}{|c|}{ Not Tested } \\
\hline Pavemend SL & 1,360 & 1,130 & 1,880 & 1,780 \\
\hline ThoRoc 10-60 & 1,170 & 2,160 & 1,850 & 2,900 \\
\hline ThoRoc 10-61 & 1,230 & 1,480 & 1,600 & 2,100 \\
\hline Set $45 \mathrm{HW}$ & 1,240 & 2,190 & 1,480 & 2,190 \\
\hline Express Repair & 720 & 1,470 & 960 & 1,340 \\
\hline Ultimax Concrete & 1,050 & 1,140 & 3,260 & 3,440 \\
\hline $\begin{array}{c}\text { ABC Cement Express Repair } \\
\text { Mortar }\end{array}$ & \multicolumn{4}{|c|}{ Not Tested } \\
\hline
\end{tabular}




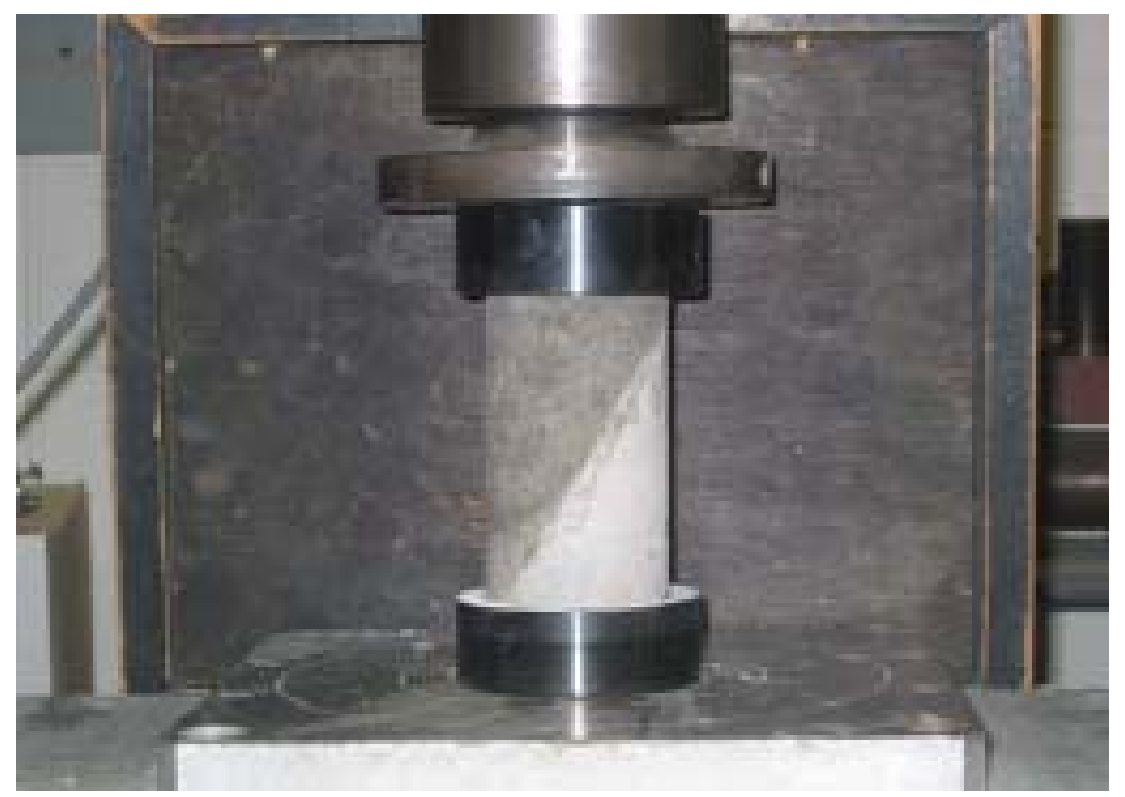

Figure 3. Slant shear testing.

Air Force protocol established for testing RS materials for rigid repairs requires a bond strength greater than or equal to 500 psi for repair bonding to OPC mortar and 1,000 psi for repair material bonding to repair material after 1 day of cure (AFCESA 2006). As with UCS testing minimums, these minimum bond strengths were established based on the work of Vaysburd et al. (1999). Based on these requirements, for material to mortar, all of the materials tested met minimum requirements for 1 day of cure. After 28 days, Pavesaver showed a weaker bond and did not meet this requirement. The remaining materials showed some increase in bond strength after 28 days of cure with the exception of Pavemend SL that showed some loss in bond strength for both bonding conditions after 28 days. For the material to material samples, Pavesaver and Express Repair did not meet the 1,000 psi requirement. Pavesaver had higher bond strength to itself, but after 28 days, its bond showed a decrease in strength. Pavemend SL also showed a similar decrease in bond strength after 28 days to itself. The remaining materials tended to have a better bond to themselves after 1 day and 28 days than to the OPC mortar blanks.

As with the compressive testing, slant shear testing was not complete at the time of field testing. Had these results been available prior to field testing, some of these products may not have been recommended. Results of the laboratory tests will be further discussed with the results of the field tests. 


\section{Time of setting}

Time of setting is a critical property for rapid repair concepts. Setting times that are too short or too long can be a disadvantage. Time of set is defined as the point in time at which penetration resistance reaches specified values. Therefore, this property was measured for each batch of material mixed. ASTM C 403 identifies initial and final time of set as the penetration resistance of $500 \mathrm{psi}$ for initial time of set indicating that the material cannot be vibrated and 4000 psi for the final time of set indicating that the material can carry some measurable load. Many factors can influence the time of set including the cementitious material chemistry, fineness, cement content, water to cementitious material ratio, and ambient temperature. Two replicates for each batch of material mixed were produced in accordance with the standard and tested accordingly. The average results are presented in Table 5.

Table 5. Initial and final set times.

\begin{tabular}{|c|c|c|c|}
\hline Material & Temperature & Initial Set, min & Final Set, $\min$ \\
\hline \multirow{2}{*}{ Pavesaver } & Ambient $\left(73^{\circ} \mathrm{F}\right)$ & 95 & 140 \\
\hline & Elevated $\left(90^{\circ} \mathrm{F}\right)$ & 55 & 105 \\
\hline \multirow{2}{*}{ Rapid Set Concrete Mix } & Ambient $\left(73^{\circ} \mathrm{F}\right)$ & 95 & 100 \\
\hline & Elevated $\left(90^{\circ} \mathrm{F}\right)$ & No data & No data \\
\hline \multirow{2}{*}{ Pavemend SLQ } & Ambient $\left(73^{\circ} \mathrm{F}\right)$ & 6 & 7.5 \\
\hline & Elevated $\left(90^{\circ} \mathrm{F}\right)$ & 3.5 & 5.5 \\
\hline \multirow{2}{*}{ Pavemend SL } & Ambient $\left(73^{\circ} \mathrm{F}\right)$ & 11 & 17 \\
\hline & Elevated $\left(90^{\circ} \mathrm{F}\right)$ & 17 & 36 \\
\hline \multirow{2}{*}{ ThoRoc 10-60 } & Ambient $\left(73^{\circ} \mathrm{F}\right)$ & No data & No data \\
\hline & Elevated $\left(90^{\circ} \mathrm{F}\right)$ & 20 & 25 \\
\hline \multirow{2}{*}{ ThoRoc 10-61 } & Ambient $\left(73^{\circ} \mathrm{F}\right)$ & 193 & 200 \\
\hline & Elevated $\left(90^{\circ} \mathrm{F}\right)$ & No data & 86 \\
\hline \multirow{2}{*}{ Set $45 \mathrm{HW}$} & Ambient $\left(73^{\circ} \mathrm{F}\right)$ & 76 & 81 \\
\hline & Elevated $\left(90^{\circ} \mathrm{F}\right)$ & 25 & 35 \\
\hline \multirow{2}{*}{ Express Repair } & Ambient $\left(73^{\circ} \mathrm{F}\right)$ & 55 & 57 \\
\hline & Elevated $\left(90^{\circ} \mathrm{F}\right)$ & 23 & 25 \\
\hline \multirow{2}{*}{ Ultimax Concrete } & Ambient $\left(73^{\circ} \mathrm{F}\right)$ & 130 & 290 \\
\hline & Elevated $\left(90^{\circ} \mathrm{F}\right)$ & No data & No data \\
\hline \multirow{2}{*}{$\begin{array}{l}\text { ABC Cement Express } \\
\text { Repair Mortar }\end{array}$} & Ambient $\left(73^{\circ} \mathrm{F}\right)$ & 43 & 60 \\
\hline & Elevated $\left(90^{\circ} \mathrm{F}\right)$ & 20 & 35 \\
\hline
\end{tabular}

Because of the factors influencing time of set, it was expected that the times would vary by material as each possessed different cementitious 
materials. At elevated temperatures, the materials tended to set more rapidly. None of the materials tested took longer than 300 min to set with Ultimax Concrete requiring the most time to reach final set. It is recommended to select a material that achieves final set prior to trafficking. For the field testing in this investigation, $3 \mathrm{hr}$ was the allotted cure time at elevated temperatures to simulate rapid repair requirements. All materials reached initial set within this time.

\section{Summary}

Based on laboratory investigations of the RS materials, ABC Cement was not selected for field testing. Due to time constraints, some materials were field tested before laboratory testing was completed. Details of these repairs and results are included in the following chapters. Based on the USAF laboratory protocols, the following materials would not have been recommended for field testing: Pavemend SL based on low UCS at $2 \mathrm{hr}$ at elevated conditions, Pavesaver based on low UCS at $2 \mathrm{hr}$ at elevated conditions and low bond strength for RS material to RS material bond requirements at 1 day of cure, and Express Repair based on low bond strength for RS material to RS material bond requirements at 1 day of cure. 


\section{Laboratory Investigations of Backfill Materials}

Due to the locality of airfields needing repair, there may be little or no quality material available to provide backfill for crater repairs. Either the material has been ejected from the crater and is unsuitable or is nonexistent. If this debris is present, it can be used once it is cleared of ordnance, but debris can settle under traffic loads as voids gradually collapse or unsuitable fill consolidates. Innovative materials are needed to replace missing debris or material or to stabilize unsuitable backfill material for crater repair. Shipment of aggregate can take time or simply be unattainable in an expedient or sustainment operation where equipment and manpower transport takes precedence. A product that can easily be shipped in a small container that can expand many times its volume when placed would be ideal for this type of backfill replacement. Several COTS products are available that will rapidly expand when individual components are mixed. Although these products have not been used for pavement repair purposes, past research identified rigid, polyurethane foams as a potential crater backfill alternative. ${ }^{1}$ Recently developed COTS products have relatively high early strength and rapid set times. Laboratory testing was conducted on numerous products to determine if the foam materials could be used for backfill replacement or debris stabilization and to select the most promising materials for field placement.

\section{Materials investigated}

This investigation examined rapidly expanding rigid, polyurethane foams identified as potential backfill products for crater repair. The materials identified met the following requirements:
a. Expand many times the packaged volume
b. Provide compressive strengths similar to well-compacted soil or aggregate
c. Be easily mixed and placed with portable equipment
d. Have accelerated set times

\footnotetext{
1 P. B. Rand and B. G. Hance, 1995. “Foams for barrier crossing-initial properties," Memorandum, Sandia National Laboratories, Albuquerque, NM.
} 
e. Yield a temporary repair that can easily be capped and withstand traffic within short time frames of repair.

The goal of this portion of the investigation was to recommend foam products for field testing. Characteristics and limitations of these foams are detailed in the following sections. Detailed descriptions of three series of laboratory tests, product information, test outlines, and sample preparation are described. Table 6 presents a summary of the materials identified as potential backfill materials, and brief descriptions of these materials are included below.

Table 6. Foam materials investigated.

\begin{tabular}{|c|c|c|}
\hline Material & Manufacturer & Product Type \\
\hline Tiger Foam SR & Fomo Foam Products & Slow-Rise Polyurethane Foam \\
\hline Foam-iT! 5 & Smooth-On & Rigid, High-Density Polyurethane Foam \\
\hline Foam-iT! 10 & Smooth-On & Rigid, High-Density Polyurethane Foam \\
\hline Foam-iT! 15 & Smooth-On & Rigid, High-Density Polyurethane Foam \\
\hline Polyurethane Pour 14-Ib Rigid Foam & IASC0 & Rigid, High-Density Polyurethane Foam \\
\hline Polyurethane Pour 4-Ib Rigid Foam & IASC0 & Rigid, High-Density Polyurethane Foam \\
\hline 8-Ib Density Pour Foam Kit & Fiberglass Supply & Rigid, High-Density Polyurethane Foam \\
\hline Foam R-8 & Architectural Polymers & Rigid, High-Density Polyurethane Foam \\
\hline Product \#4 Urethane Injection & Epoxy Systems & Injection Foam/Grout \\
\hline WEBAC 151 & WEBAC Corporation & Polyurethane Soil Stabilization Grout \\
\hline
\end{tabular}

\section{Tiger Foam SR}

Tiger Foam SR, manufactured by Fomo Foam Products, is a slow-rise polyurethane foam consisting of two components. The foam will cure to a semi-rigid, closed-cell foam upon the chemical reaction of component A (polymeric isocyanate) with component B (a polyol blend containing certain additives). Each component is separately held in 5-gal tanks. A nozzle attachment with hosing connects to each tank, and the foam is mixed and sprayed through the nozzle attachment. This foam product is formulated to slowly rise and fill large enclosed spaces and deep cavities with typical applications for pontoon boats and insulating walls and floors (Figure 4a) (www.fomofoam.com).

\section{FOAM-iT!}

FOAM-iT!, manufactured by Smooth-On, is a series of polyurethane pour foams each consisting of two components. The foam will cure to a rigid, 
closed-cell foam upon the chemical reaction of component A (polymeric isocyanate) with component $\mathrm{B}$ (a polyol blend containing certain additives). Products selected include FOAM-iT! in 5, 10 and $15 \mathrm{lb} / \mathrm{ft}^{3}$ densities. Equal parts by volume of components A and B are mixed by hand or electric drill with paddle attachment, and this mixture will expand many times original volume depending on product density to develop a uniform cell structure. FOAM-iT! products have been used as backfill material for hollow castings to add structural strength and as an encapsulation material. The two components are shipped in 1-gal plastic containers or in 55-gal drums for larger applications (Figure 4b) (www.smoothon.com).

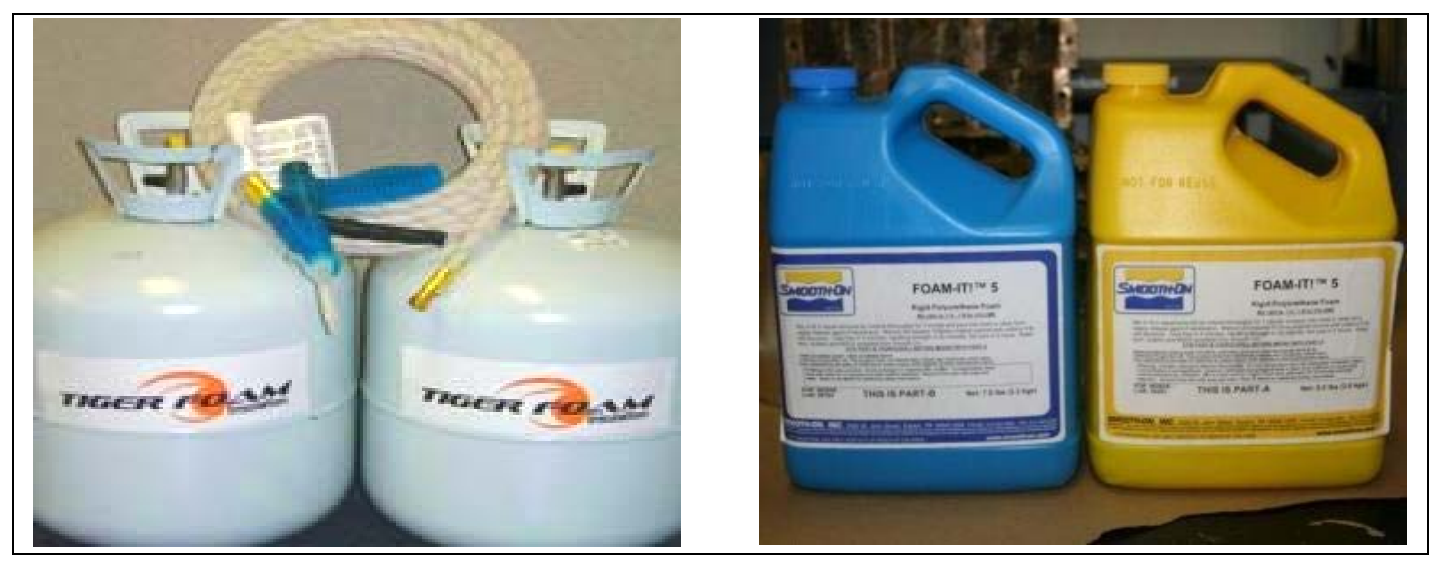

Figure 4. Tiger Foam (a-left) and Foam-iT! 5 (b-right).

\section{Polyurethane Pour 14-lb Rigid Foam}

Polyurethane Pour 14-lb Rigid Foam, manufactured by Industrial Arts and Supply Company (IASCO) (Figure 5a), is a high-density polyurethane foam consisting of two components. The foam will cure to a rigid, closedcell foam upon the chemical reaction equal parts by weight of component A (polymeric isocyanate) with component B (a polyol blend containing certain additives) when mixed by hand or electric drill and paddle attachment. This mixture expands many times its original volume and is marketed as a simulated wood for architectural and artistic applications. It is shipped in a 5-gal kit or in 55-gal drum kits for larger applications (www.iasco-tesco.com).

\section{Polyurethane Pour 4-Ib Rigid Foam}

Polyurethane Pour 4-lb Rigid Foam, manufactured by IASCO, is a highdensity polyurethane foam consisting of two components. The foam will 
cure to a rigid, closed-cell foam upon the chemical reaction equal parts by weight of component A (polymeric isocyanate) with component B (a polyol blend containing certain additives) when mixed by hand or electric drill and paddle attachment. This mixture expands many times its original volume and is marketed for architectural and artistic applications. It is shipped in a 5-gal kit or in 55-gal drum kits for larger applications (www.iasco-tesco.com).

\section{8-Ib Density Pour Foam Kit}

The 8-lb Density Pour Foam Kit, manufactured by Fiberglass Supply Company, is a high-density polyurethane foam consisting of two components. This foam system can be poured or frothed. The foam will cure to a rigid, closed-cell foam upon the chemical reaction equal parts by weight of component A (polymeric isocyanate) with component B (a polyol blend containing certain additives) when mixed by hand or electric drill and paddle attachment. It is shipped in a 5-gal kit (Figure 5b) and is typically used to facilitate irregular shapes, as an insulator, to fill voids, and to maintain buoyancy (www.fiberglasssupply.com).

\section{Foam R-8}

Foam R-8, manufactured by Architectural Polymers, is a polyurethane foam that is demoldable in short time spans. The foam will cure to a rigid, closed-cell foam upon the chemical reaction equal parts by volume of component A (polymeric isocyanate) with component B (a polyol blend containing certain additives) when mixed by hand or electric drill and paddle attachment. This product is shipped in a 5-gal kit (Figure 5c). It has been used for architectural mold casting (www.architecturalpolymers.com).

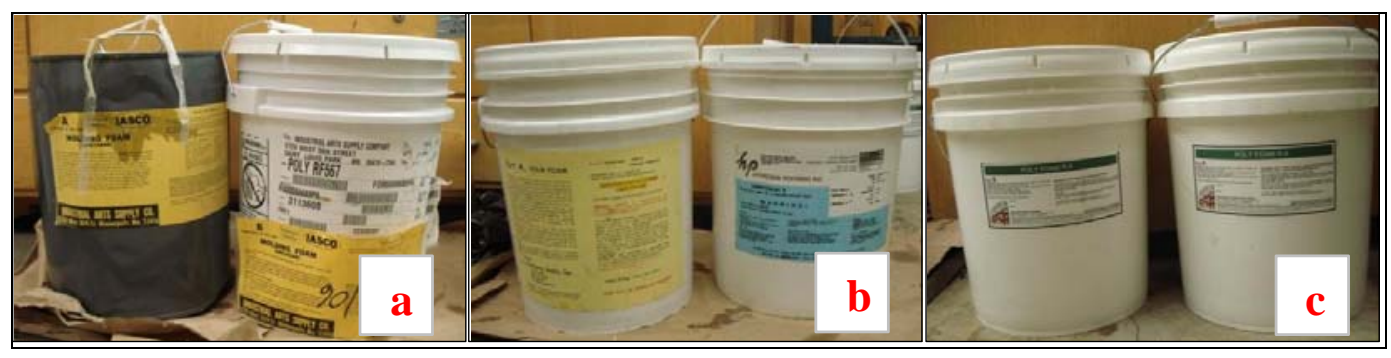

Figure 5. IASCO (a), Pour Foam (b), and Foam R8 (c). 


\section{Product \#4 Urethane Injection}

Product \#4 (Figure 6a), manufactured by Epoxy Systems, is a closed-cell, one-component, MDI-(methylene-diphenyl-isocynate) based hydrophilic urethane injection that can be used with pea gravel to form a flexible pavement. Water must be present for this product to react. Studies by Epoxy Systems produced $2 \mathrm{ft}^{3}$ of material with 1 gal of product. The product expands many times its original volume when exposed to water (www.epoxysystems.com).

\section{WEBAC 151}

WEBAC 151 (Figure 6b), manufactured by WEBAC Corporation, is a water-activated one component, closed-cell polyurethane soil stabilization grout used to fill large cracks or spaces in concrete structures. WEBAC 151 is a hydrophobic grout based on an MDI closed cell polyurethane. A tributylamine-based accelerator (WEBAC 15X) is needed to increase reaction speed and expansion. It is shipped in a 1-gal kit (www.webac.com).

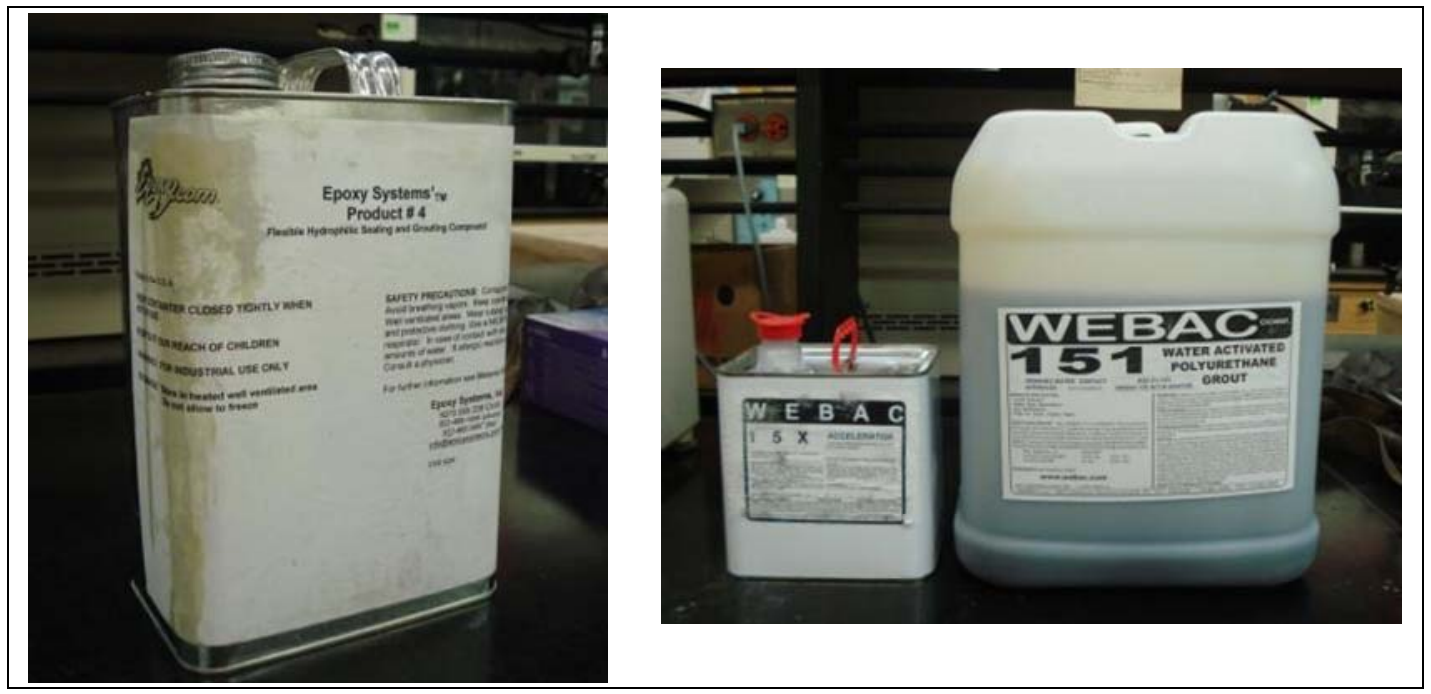

Figure 6. Product \#4 (a-left) and WEBAC 151 (b-right).

\section{Laboratory tests and results}

Laboratory tests were conducted on potential foam backfill materials. These tests consisted of three series. Series 1 evaluated the compressive and tensile strength of 10 one- and two-component rigid, polyurethane foam products as well as compressive strength testing on foam extended with aggregate. Series 2 investigated the effect of the environment on the foam reactivity, strength, and density under freezing, ambient, and 
elevated temperatures. The final series of tests, Series 3, investigated the impact of aggregate size in foam extension on strength and reactivity. These three series are further discussed in the following sections.

\section{Series 1 testing}

Table 7 lists properties of interest and test methods included in the project, along with the number of minimum required replicate specimens and test temperature conditions.

Table 7. Series 1 outline of tests for foam backfill materials.

\begin{tabular}{|c|c|c|c|}
\hline Property & Test Method & Replicates & Temperature \\
\hline Compressive Strength & ASTM D 1621-04a & $5^{\mathrm{a}}$ & $73^{\circ} \mathrm{F}$ \\
\hline Tensile Strength & ASTM D 1623-03 & $3^{\mathrm{b}}$ & $73^{\circ} \mathrm{F}$ \\
\hline Density & ASTM D 3574-05 & $3^{\mathrm{c}}$ & $73^{\circ} \mathrm{F}$ \\
\hline Rise Time & N/A & $3^{\mathrm{c}}$ & $73^{\circ} \mathrm{F}$ \\
\hline Set Time & N/A & $3^{\mathrm{c}}$ & $73^{\circ} \mathrm{F}$ \\
\hline Expansion Ratio & N/A & $3^{\mathrm{c}}$ & $73^{\circ} \mathrm{F}$ \\
\hline
\end{tabular}

a Testing included fully extended, half-extended, and non-extended product samples.

b Tensile tests only performed on non-extended materials.

c Testing included non-extended and fully extended product samples.

Compressive strength

As with testing of cementitious materials, compressive strength is a commonly used property for routine verification of materials and quality assurance activities. Compressive strength testing was included in the laboratory investigation to verify that the foam backfill materials would generate sufficient strength to resist consolidation or structural failure under heavy aircraft loads. Compressive strength testing was conducted in accordance with ASTM D 1621-04a procedures. A minimum of five replicates of each product were necessary to meet the standard. Sample preparation for compressive strength testing is described below.

Each compressive strength sample was cast in 4- by 8-in. plastic cylinders typically used in molding concrete cylinders. The cylinders were first prepared by applying a release agent to the walls, bottoms, and rims. In preparing each product, foam components were measured and mixed by hand in glass cylinders with a wooden tongue depressor. They were then poured into metal quart-sized paint cans and mixed for the recommended time per product instructions (Figure 7). The mixed products were 
immediately poured into the plastic cylinders and allowed to react and rise to the cylinder height. The samples were allowed to cure 10 to $15 \mathrm{~min}$ before the tops of the specimens were cut to create a parallel top and bottom for each specimen prior to demolding.
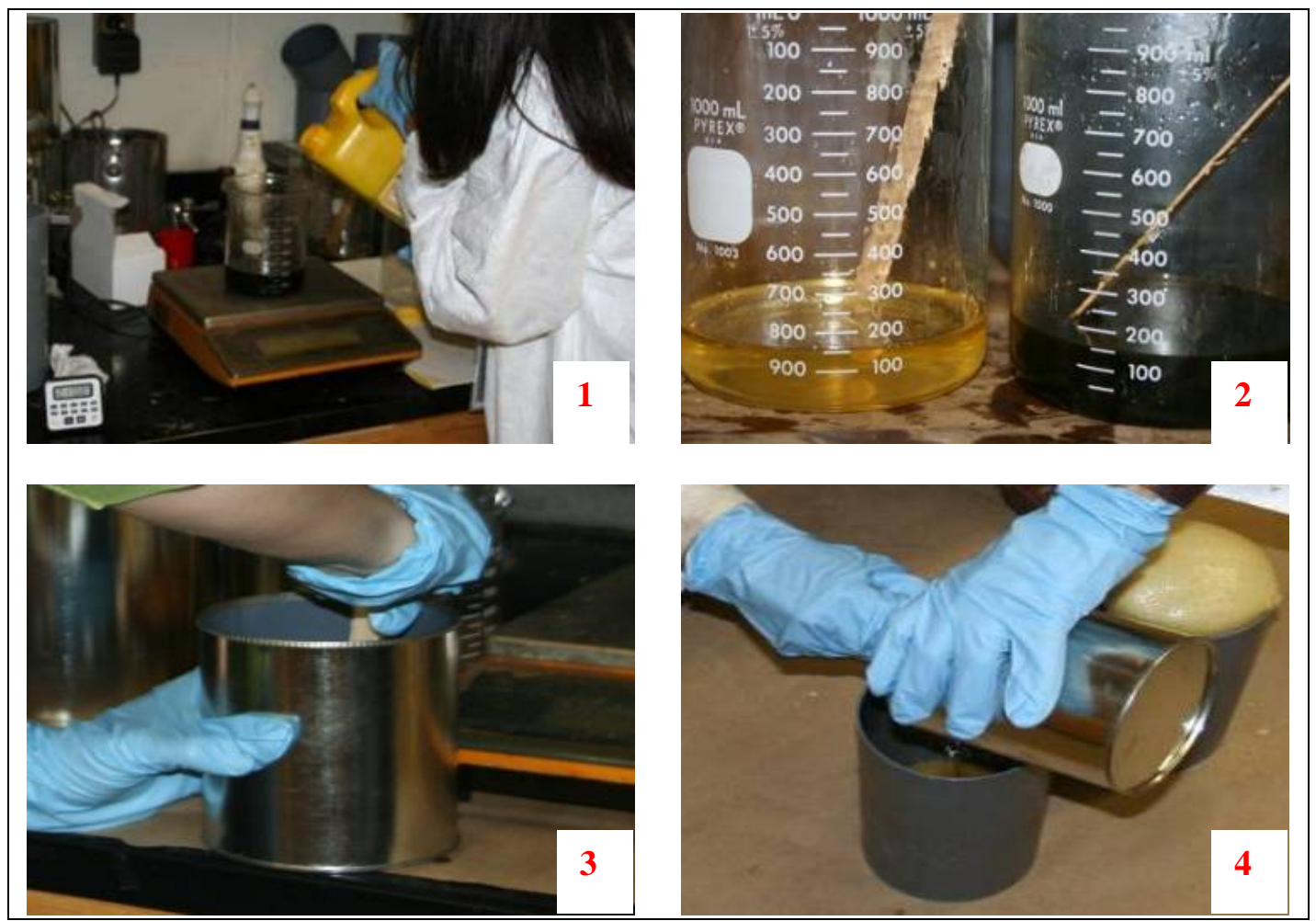

Figure 7. Sample preparation.

Extended samples were also prepared to determine if the foam products could be used to stabilize aggregate and concrete debris to prevent settlement of backfill under aircraft loadings and prevent the need for compaction of materials. For these extended samples, $1125 \mathrm{~g}$ of 0.75 - to 1.5-in. crushed limestone was added to the bottom of each plastic cylinder to simulate uniform sized concrete debris. Each sample was weighed to ensure sample consistency. The aggregate height in the cylinders was approximately $4 \mathrm{in}$. The extended samples required the same amount of materials to foam as the non-extended samples to expand to the full height of the cylinders.

\section{Reactivity}

Reactivity of the foams was evaluated using a stopwatch to measure rise time and tack free time (set time) during sample preparation of the compressive samples with and without aggregate extension. The rise time was 
considered the time from initial product mixing until the foam stopped rising. Tack free time was the time it took from mixing until the surface no longer stuck to a gloved finger. Only the tack free time of the surface was determined in order to allow samples to fully cure before demolding. A minimum of three replicates were required to determine these properties.

\section{Density}

Densities were obtained in these tests by determining the density of the foam in the plastic cylinder following ASTM D 3574-05 specifications. Density was determined using the compressive strength samples. Each predetermined quantity of mixed components for each product was measured and recorded before pouring into the cylinders. After the foam set, any foam dome was cut off level with the top of the container to create parallel tops and bottoms for each specimen. The foam was then removed from the container and weighed. Density was calculated using this weight and the calculated container volume. A minimum of three replicates were required to meet specification requirements.

\section{Expansion ratio}

Expansion ratio was calculated as a ratio of expanded volume to unexpanded volume. Compressive strength samples were also used to determine this property. The unexpanded volume was measured by adding the volume of each component before mixing. The products were then mixed and poured into the cylinders and allowed to rise and overfill the containers. When set, any foam dome created was cut off and the volumes of the cylinder and the removed dome were calculated, added, and recorded. From this, the ratio of the expanded volume to the unexpanded volume was calculated to determine the expansion ratio. A minimum of three replicates were required to determine this property.

Tensile strength

Tensile strength samples were machined with a special cutter specified by ASTM D 1621-04a on a lathe from samples prepared in the cylinders in the same manner as the non-extended compressive strength samples. This cutter was designed only for foam machining. Because of this, no tensile samples could be made with aggregate extension. A minimum of three replicates were required to meet testing requirements. 


\section{Detailed sample preparation by material}

Each material was mixed per manufacturer instructions. Detailed mixing and sample preparation for these materials is described in this section.

\section{Tiger Foam SR}

Tiger Foam SR samples were prepared first. This product differed from the other products in that the mixing takes place when the components meet in a spray gun attachment. Equal parts of components A and B are mixed in the spray gun attachment, and the dispensed product foams and expands rapidly as it exits the gun. Because of this mixing process, the volume of unexpanded material could not be measured. Therefore, expansion ratio could not be determined for this product. Attempts at using this product to penetrate the voids in the aggregate by spraying it on the surface were unsuccessful. In order to create extended compressive strength samples, aggregate was added in three layers during product application. This process provided full extension of the aggregate in the cylinders. Much care was given to prevent any aggregate loss from these samples. Rise time and tack free time were recorded for each sample. When the samples were demoldable, any overfill was cut off level with the top of the cylinder, and the sample was removed from the container and weighed so that the density could be calculated. For this product, only foam overfilled the containers, so no aggregate was lost. Three samples were reserved to make tensile samples (non-extended as explained previously), and the remaining samples were split with a rotary tile saw into 4-in.-tall specimens to meet height-to-diameter specifications set by ASTM D 1623-03 for compressive strength testing.

\section{FOAM-iT!}

Foam-it! 5, 10, and 15 samples took longer to react than the Tiger Foam SR. Each component was measured and weighed separately prior to mixing. The components were stirred separately before combining, and all samples were prepared individually to ensure that equal volumes of mixed components were used for each sample. Figure 8 shows the 4 -in. samples prior to compressive strength testing.

For the extended samples, the aggregate was weighed and placed in the bottom of the cylinders. Then the mixed product was poured evenly over the aggregate surface. These products filled all cavities and caused the 
aggregate to rise approximately 2 in. Only foam overfilled the containers; no aggregate was lost. Samples were then used to calculate the density, measure rise time and tack free time, and tensile and compressive strength samples were prepared for testing. Because the aggregate rose 2 in., the top 4 in. of the extended samples could be tested as half-extended samples and the bottom half as fully extended samples. Figure 9 shows the aggregate distribution through the fully and half-extended Foam-iT! 5 samples. It should be noted that the addition of foam caused separation of the aggregates within the sample resulting in little stone-on-stone contact.

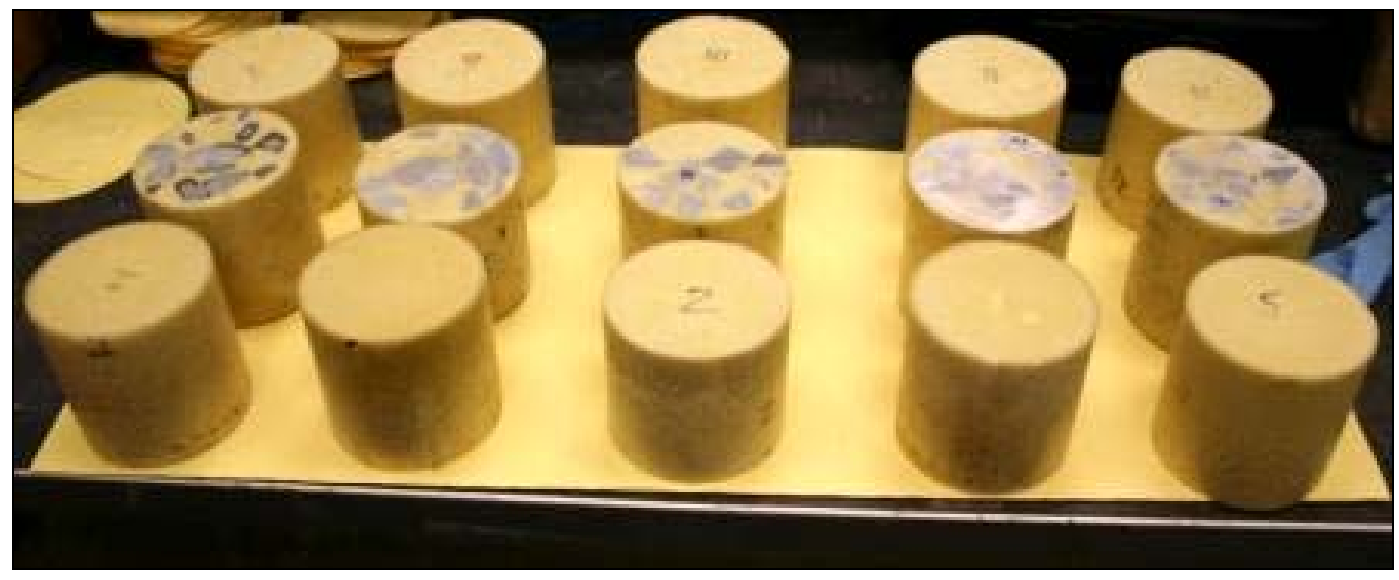

Figure 8. Foam-It 15 samples.

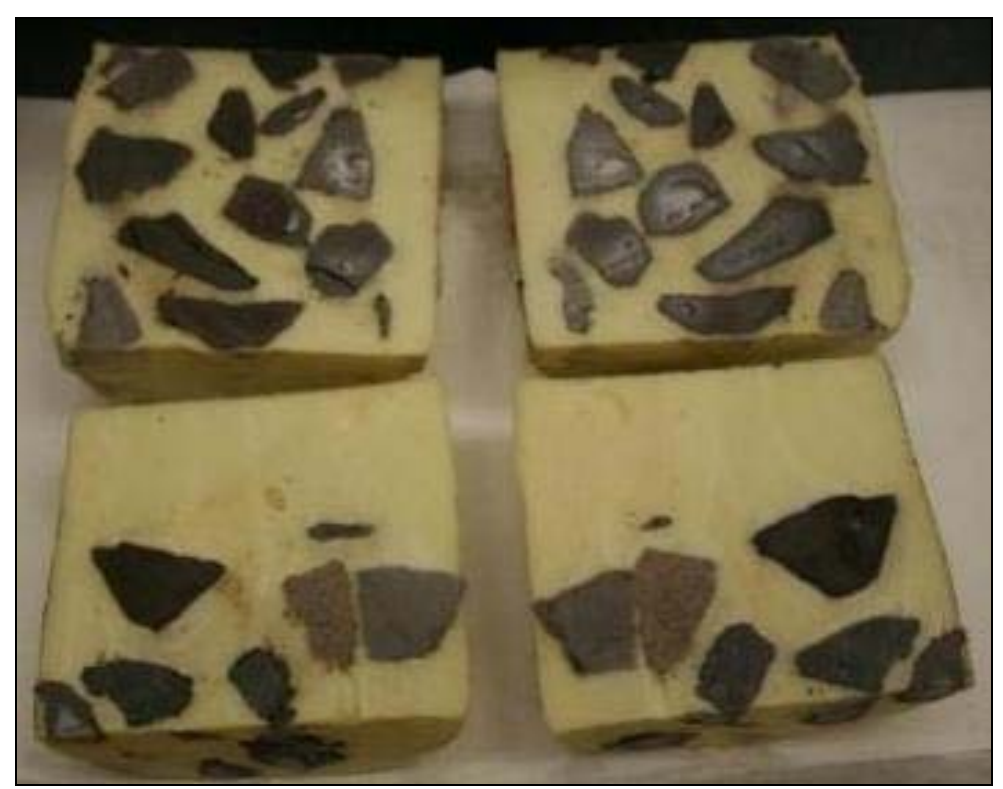

Figure 9. Aggregate distribution in fully and half-extended Foam-iT! 5 samples. 


\section{Polyurethane Pour 14-lb Rigid Foam, Polyurethane Pour 4-lb Rigid Foam, Foam R-8, and 8-Ib Density Pour Foam Kit}

These products were prepared in the order they are listed in the heading above. All of these products consisted of two components, so the same procedure as described for the Foam-iT! products was used.

\section{Product \#4 Urethane Injection and WEBAC 151}

The procedures used for the previous products could not be used for either Product \#4 or WEBAC 151 because both of these products require water to initiate the foam reaction. Product \#4 consisted of one component, which was weighed and measured. The material was mixed by hand prior to pouring into the concrete cylinders. For the non-extended samples, approximately $10 \mathrm{ml}$ of water was poured on top of these samples to initiate the foam reaction. The process was slow compared to the reactions for the previously tested products. For the extended samples, the preweighed aggregate was dipped in a pan of water, drained, and placed into the cylinders. The product was immediately mixed and poured on top of the wet aggregate. As with the non-extended samples, the reaction was slow. Product \#4 started to react 3 min after pouring, and $2 \mathrm{hr}$ later, there was still unreacted product in the bottom of the cylinders. Because of this, the calculated expansion ratio was not accurate. Monitoring was stopped after $2 \mathrm{hr}$ when it was still sticky to touch, and it took more than 1 day to set. In addition, Product \#4 cylinders had a fully extended bottom half and an uneven foam surface that did not rise to the top of the container despite doubling or tripling the product amount and water. The top of these samples was very flexible. Nonetheless, density, rise time and tack free time, expansion ratio, and compressive tests were calculated. No tensile strength samples could be made due to the flexible nature of the samples.

A similar procedure was followed for the WEBAC 151 product. This product consisted of the polyurethane product and an accelerator. WEBAC 151 was weighed and measured and accelerator was added following a 10:1 ratio of product to accelerator. This material was mixed by hand prior to pouring into the plastic cylinders. Several attempts to create nonextended samples were unsuccessful due to many days and large amounts of water required for the product to fully react; therefore, only extended samples were produced. Non-extended samples were friable and brittle, crumbling easily when handled. Because of this crumbling, no tensile samples could be made. For the extended samples, the preweighed 
aggregate was dipped in a pan of water, drained, and immediately placed back into the cylinders. The product was mixed and poured over the aggregate surface. Rise and tack free time and expansion ratio tests were performed. The top $4 \mathrm{in}$. of these cylinders were full of voids and did not create a suitable sample, and because of that, neither volume nor density could be calculated (Figure 10). The bottom 4 in. of these cylinders was used for fully extended samples. When these samples were tested in compression, the aggregate poured out of a small hole that formed in the side of the sample. This aggregate was still wet and had little or no foam adhered to the aggregate surfaces.

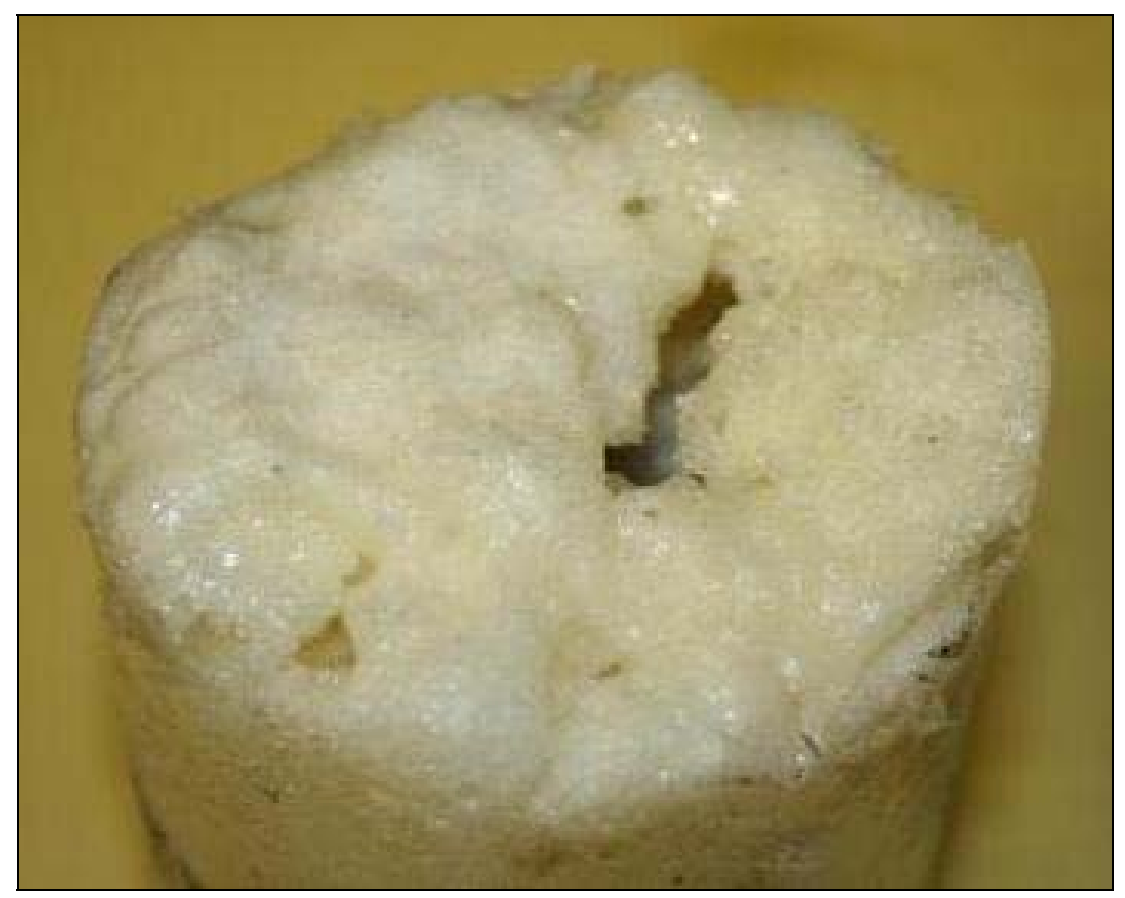

Figure 10 . Voids on surface of WEBAC sample.

\section{Sample designation}

Samples were named according to product name and type of test. To reduce the number of samples necessary, density, expansion ratio, rise time, and tack free time were calculated using the compressive and tensile strength samples prior to cutting or machining. A sample naming example is included below:

Tiger Foam-Slow Rise Compressive strength samples- TF-SRC.

Tiger Foam-Slow Rise Compressive strength samples with Extension- TFSRCE. 


\section{Results}

Table 8 presents the published material density compared to the calculated density of each sample determined from laboratory testing. These calculated densities were similar to those published in information provided by the manufacturers, with the exception of Pour Foam 8 (PF-8) that had a calculated density of approximately $11 \mathrm{lb} / \mathrm{ft}^{3}$. This difference had an effect in the compressive strength of the samples, which will be discussed later in this section.

Table 8. Comparison of published to measured density.

\begin{tabular}{|c|c|c|}
\hline Sample & Published Density $\left(\mathrm{lb} / \mathrm{ft}^{3}\right)$ & Measured Density $\left(\mathrm{lb} / \mathrm{ft}^{3}\right)$ \\
\hline TF-SR & 2 & 1.9 \\
\hline FI-5 & 5 & 6.1 \\
\hline Fl-10 & 10 & 10.5 \\
\hline FI-15 & 15 & 15.2 \\
\hline IASCO-14 & 14 & 14.0 \\
\hline IASCO-4 & 4 & 4.4 \\
\hline PF-8 & 8 & 11.1 \\
\hline PoF-R8 & 8 & 7.2 \\
\hline
\end{tabular}

Table 9. Recommended product instructions and marketed properties.

\begin{tabular}{|c|c|c|c|c|c|c|c|}
\hline Product & $\begin{array}{l}\text { Mix } \\
\text { Time } \\
\text { (s) }\end{array}$ & Mix Ratio & $\begin{array}{l}\text { Creme } \\
\text { Time } \\
(\mathbf{s})^{c}\end{array}$ & $\begin{array}{l}\text { Rise } \\
\text { Time } \\
\text { (min) }\end{array}$ & $\begin{array}{l}\text { Tack } \\
\text { Free } \\
\text { (min) }\end{array}$ & $\begin{array}{c}\text { Storage } \\
\text { Temperature } \\
\left({ }^{\circ} \mathrm{F}\right)\end{array}$ & $\begin{array}{l}\text { Demold } \\
\text { Time (hr) }\end{array}$ \\
\hline TF-SR & $\mathrm{N} / \mathrm{A}$ & $\mathrm{N} / \mathrm{A}$ & N/A & N/A & 1.5 & $75-85$ & $30-45$ \\
\hline $\mathrm{Fl}-5$ & 60 & 1A:1B by volumea & 90 & $-\mathrm{b}$ & 5 & 91 (max) & 2 \\
\hline $\mathrm{Fl}-10$ & 60 & 1A:1B by volume & 90 & $-\mathrm{b}$ & 5 & 91 (max) & $4-5$ \\
\hline $\mathrm{Fl}-15$ & 60 & 1A:1B by volume & 90 & $-\mathrm{b}$ & 4 & 91 (max) & 2 \\
\hline IASC0-14 & 30 & $1 \mathrm{~A}: 1 \mathrm{~B}$ by vol. or weight & $60-90$ & $2-3$ & $15-20$ & - $\mathrm{b}$ & $10-12 \min$ \\
\hline IASCO-4 & 30 & $1 \mathrm{~A}: 1 \mathrm{~B}$ by vol. or weight & $60-91$ & $2 .-3$ & $15-20$ & $-\mathrm{b}$ & $10-12 \min$ \\
\hline PF-8 & 30 & 1A:1B by weight & $20-50$ & $2-4$ & $2-4$ & $60-90$ & $-\mathrm{b}$ \\
\hline PoF-R8 & 30 & $1 \mathrm{~A}: 1 \mathrm{~B}$ by vol. or weight & 45 & $2-3$ & 3 & $-\ldots$ & $10-15 \min$ \\
\hline P-4 & 30 & presence of water & $\mathrm{N} / \mathrm{A}$ & $\mathrm{N} / \mathrm{A}$ & $\mathrm{N} / \mathrm{A}$ & $-\mathrm{b}$ & $\mathrm{N} / \mathrm{A}$ \\
\hline W-151 & 30 & 10-50A:1B+water & 70 & $\mathrm{~N} / \mathrm{A}$ & $\mathrm{N} / \mathrm{A}$ & $58-85$ & $\mathrm{~N} / \mathrm{A}$ \\
\hline
\end{tabular}

a Note: "A" and "B" refer to each component required to prepare the foam. For WEBAC, " $A$ " is the 151, and " $\mathrm{B}$ " the accelerator.

b Data unavailable.

${ }^{c}$ Creme Time refers to pot life of the material. 
Each product presented different instructions for recommended mix time, ratios, storage, and demolding times. Additionally, some manufacturers marketed their products based on expected product reactivity. This information is presented in Table 9. Measured reactivity of each product is presented in Table 10.

Table 10. Product reactivity.

\begin{tabular}{|c|c|c|}
\hline Sample & Rise Time (s) & Tack Free Time (s) \\
\hline TF-SR C & 91 & 164 \\
\hline TF-SR CE & 93 & 347 \\
\hline FI-5 C & 292 & 460 \\
\hline FI-5 CE & 415 & 306 \\
\hline Fl-10 C & 306 & 464 \\
\hline FI-10 CE & 464 & 177 \\
\hline Fl-15 C & 172 & 252 \\
\hline FI-15 CE & 234 & 191 \\
\hline IASCO-14 C & 191 & 219 \\
\hline IASCO-14 CE & 220 & 413 \\
\hline IASCO-4 C & 366 & 663 \\
\hline IASCO-4 CE & 659 & 163 \\
\hline PF-8 C & 156 & 226 \\
\hline PF-8 CE & 226 & 158 \\
\hline PoF-R8 C & 157 & 198 \\
\hline PoF-R8 CE & 198 & 1324 \\
\hline P-4 CE & 2484 & $10,800(3 \mathrm{hr})$ \\
\hline W-151 CE & 707 & 132 \\
\hline & & \\
\hline & & \\
\hline & & \\
\hline
\end{tabular}

Figure 11 shows the product reactivity. The addition of aggregate increases the rise time and tack-free time for all materials. As the foam reaction begins, tiny bubbles are formed. The aggregate extension either breaks the surface tension of the foam causing individual foam bubbles to collapse or prevents the foam cells from expanding their maximum diameter due to the aggregate creating a surcharge weight. Even though there is less volume to fill (with the addition of the aggregate to the container), more foam would be required to generate enough foam reaction and expansion to work its way to the surface. This may explain the need for twice as much material in producing the extended samples as non-extended. This is termed "packing" the foam, which results in a denser, stronger foam system. By comparing the reactivity of all products tested, it can be 
concluded that the products with the fastest reactivity were Foam-iT!-15 (FI-15), Foam R-8 (PoF-R8), Pour Foam 8 (PF-8), and IASCO-14. It is also noted that the higher density foams have faster reactions.

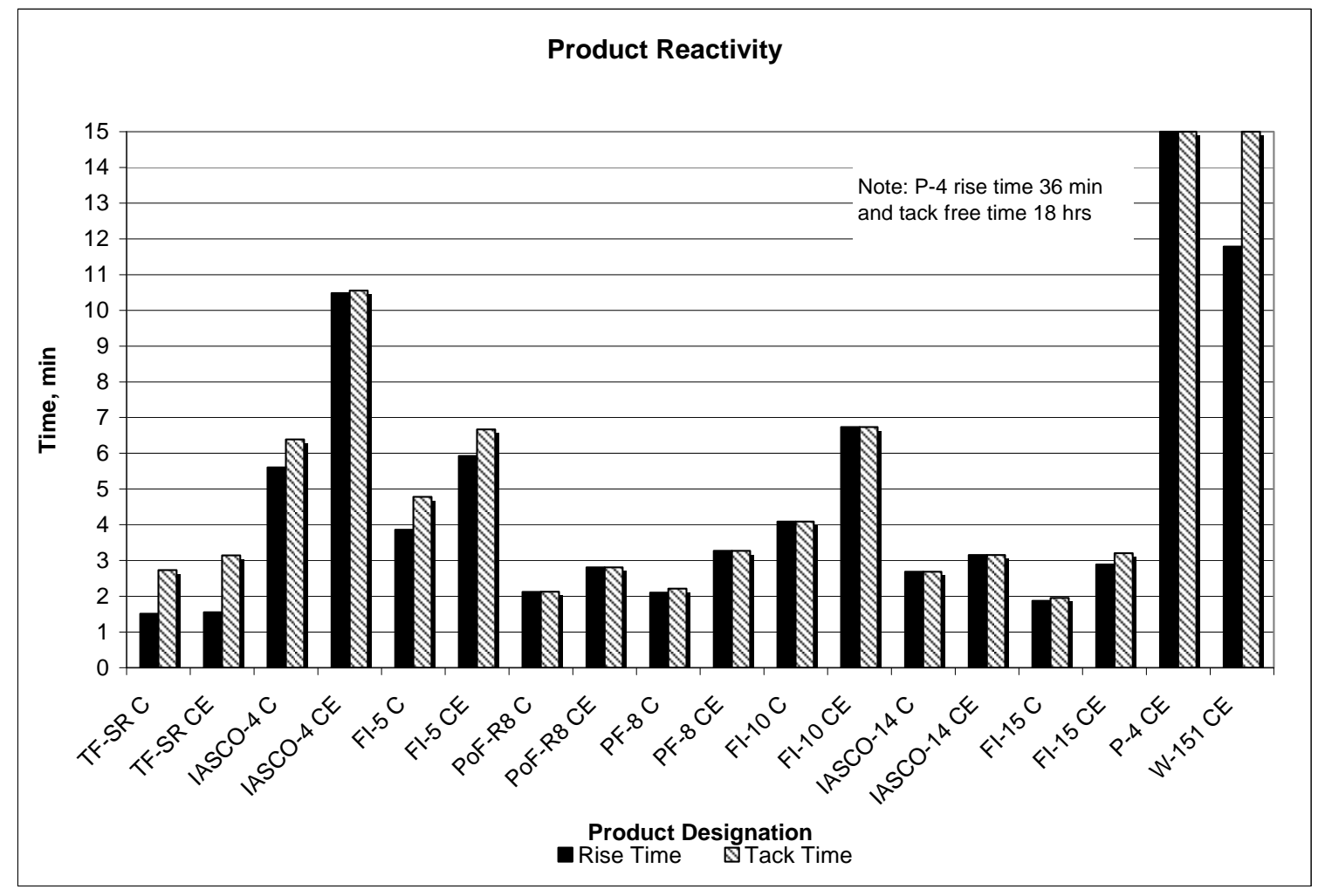

Figure 11. Product reactivity.

Expansion ratio was calculated, and a comparison of the measured to expected expansion ratios for the products is presented in Table 11. The measured expansion did not differ significantly from the published values. Because Tiger Foam is mixed at the dispensing gun, expansion ratio could not be determined experimentally because it was too costly to use one kit to determine this number. However, visually, the product appears to expand 10 times the applied volume.

The compressive strength tests, as well as the tension tests, were performed using an Instron testing machine (Figure 12). Before starting the tests, all the parameters were configured following the ASTMD 162104a procedure by using the system's data collecting software (Figure 13). 
Table 11. Expansion ratio comparison.

\begin{tabular}{|c|c|c|}
\hline Sample Designation & Published Exp. Ratio & Exp. Ratio \\
\hline TF-SRC & 10 & N/A \\
\hline FI-5C & 10 & 8.4 \\
\hline Fl-10 C & $4-6$ & 6.5 \\
\hline FI-15C & $4-6$ & 4.3 \\
\hline IASCO-14 C & -- & 4.1 \\
\hline IASCO-4 C & --- & 14.5 \\
\hline PF-8 C & --- & 5.5 \\
\hline PoF-R8 C & -- & 7.8 \\
\hline P-4 C & 7 & 6.2 \\
\hline W-151 CE & N/A & 8.3 \\
\hline
\end{tabular}

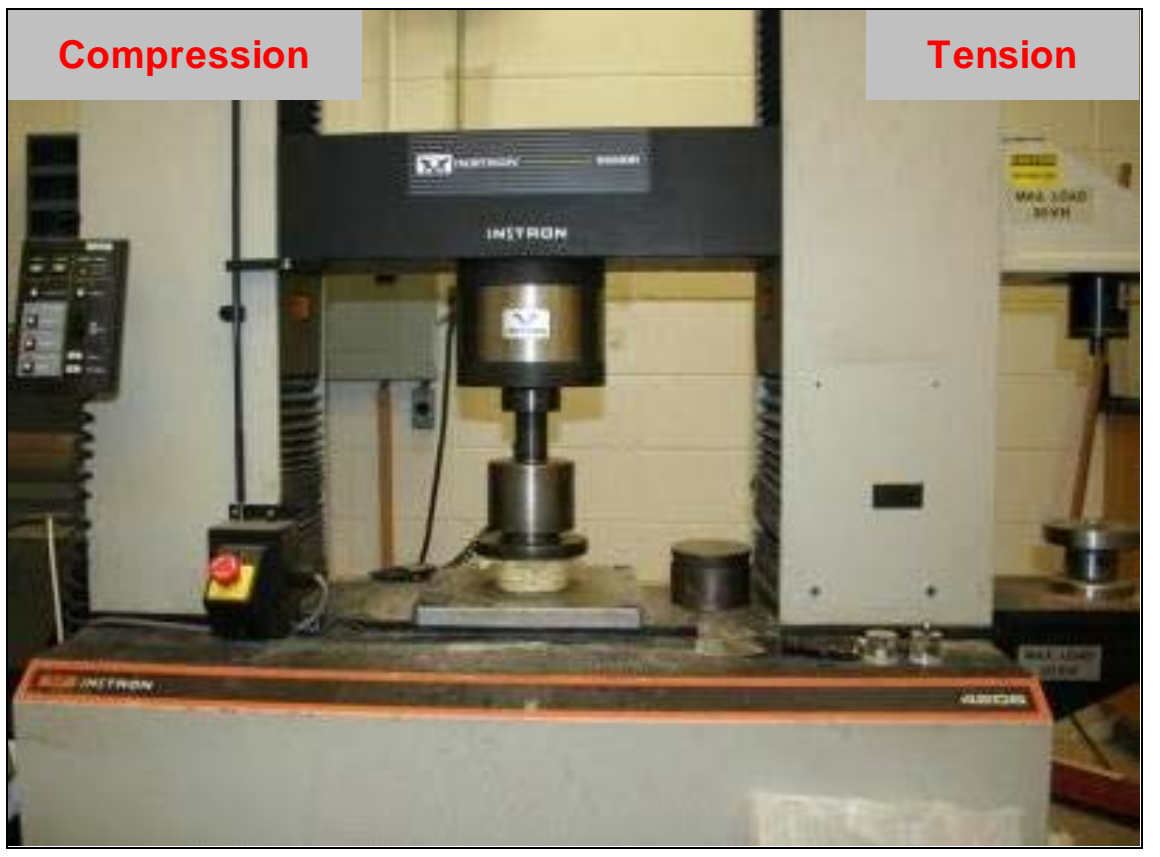

Figure 12. Machine used for compression and tension testing. 


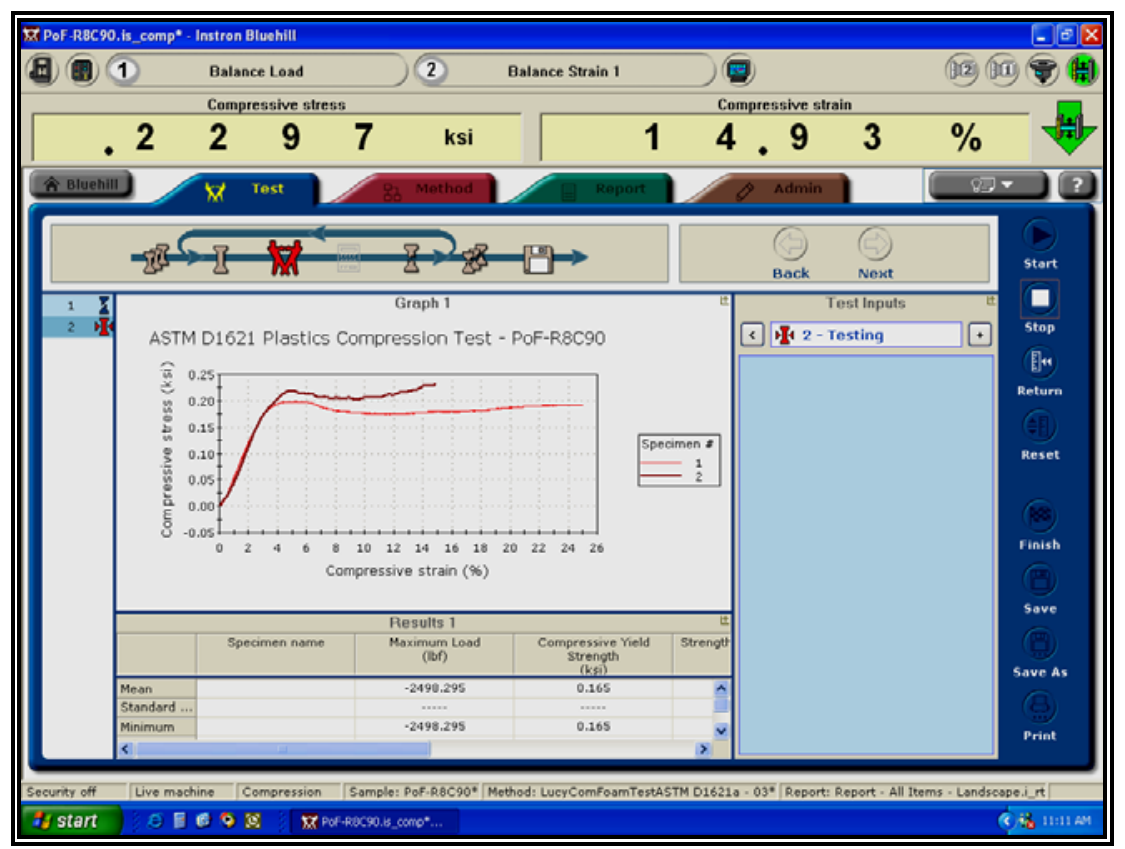

Figure 13. Data collection program.

Figure 14 presents a sample undergoing compressive strength testing. When the load was removed, most foams rebounded to near the pretest height. Table 12 summarizes the average compressive strength at 2 percent strain of all samples including non-, fully, and half-extended samples. The compressive strength at 2 percent strain was determined because this is the expected amount of strain the foams would receive under a pavement in the field.

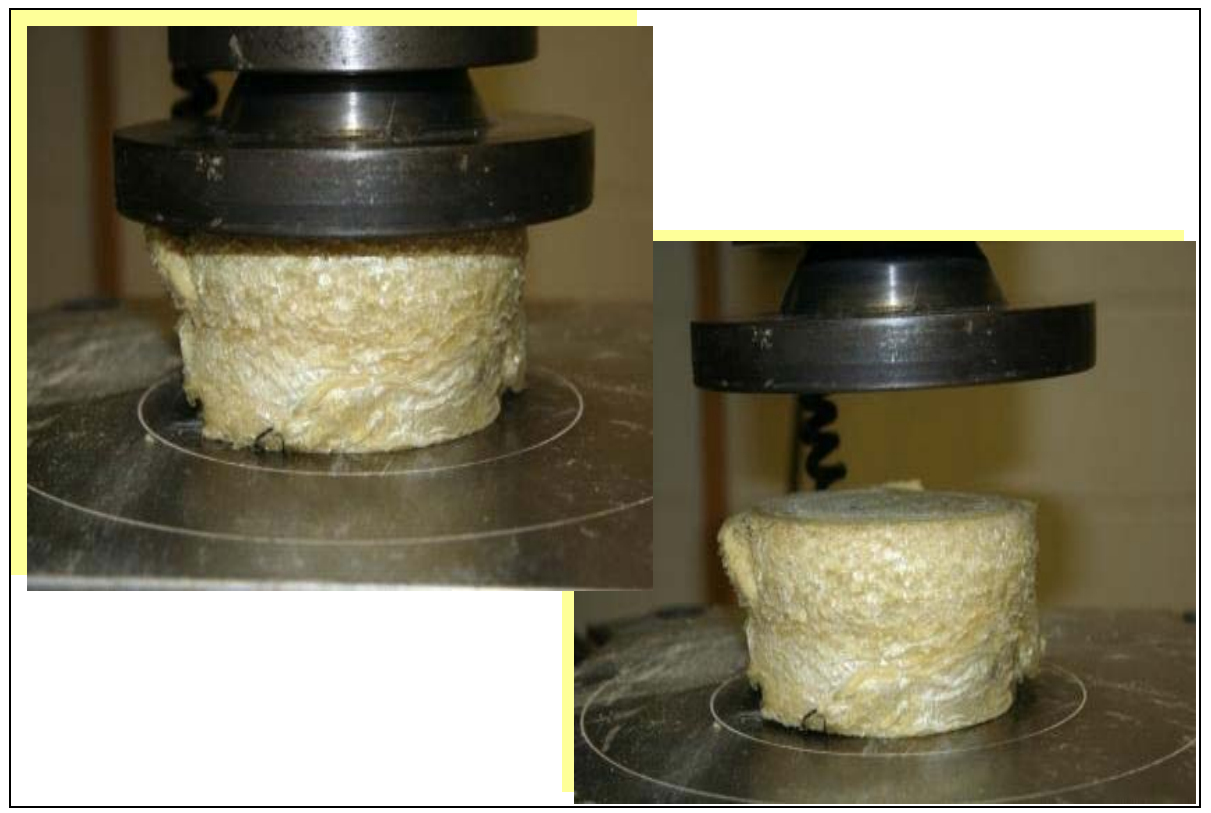

Figure 14. Foam-iT! 15 half-extended sample during and after loading. 
Table 12. Average compressive strength for non-, fully, and half-extended samples.

\begin{tabular}{|c|c|}
\hline Samples & Compressive Strength at $2 \%$ Strain (psi) \\
\hline TF-SR C & 8 \\
\hline TF-SR CE & 10 \\
\hline IASCO-4 C & 30 \\
\hline IASCO-4 CE & 49 \\
\hline IASCO-4 CHE & 54 \\
\hline $\mathrm{Fl}-5 \mathrm{C}$ & 77 \\
\hline $\mathrm{Fl}-5 \mathrm{CE}$ & 48 \\
\hline Fl-5 CHE & 59 \\
\hline PoF-R8 C & 123 \\
\hline PoF-R8 CE & 150 \\
\hline PoF-R8 CHE & 148 \\
\hline PF-8 C & 313 \\
\hline PF-8 CE & 346 \\
\hline PF-8 CHE & 342 \\
\hline $\mathrm{Fl}-10 \mathrm{C}$ & 282 \\
\hline $\mathrm{FI}-10 \mathrm{CE}$ & 299 \\
\hline Fl-10 CHE & 255 \\
\hline IASCO-14 C & 334 \\
\hline IASCO-14 CE & 446 \\
\hline IASCO-14 CHE & 386 \\
\hline $\mathrm{Fl}-15 \mathrm{C}$ & 470 \\
\hline $\mathrm{Fl}-15 \mathrm{CE}$ & 593 \\
\hline $\mathrm{FI}-15 \mathrm{CHE}$ & 582 \\
\hline P-4 CE & 8 \\
\hline W-151 CE & 22 \\
\hline
\end{tabular}

Figures 15, 16, and 17 present the material behavior with varying levels of aggregate extension. In Figure 15, the maximum compressive stress reached was approximately 700 psi. At this stress level, for the 4-in. (diameter) cylinders, a maximum load of $8,800 \mathrm{lb}$ was applied. In Figure 16, the compressive strength increased due to the compressive load being resisted by the aggregate in the fully extended samples.

Unlike the non-extended samples, the strength continued to rise at 10 percent strain. As described previously, the foam products were added to act as a binder material for aggregate to prevent the need for compaction while still allowing flexibility to provide good aggregate contact under load. However, the foam caused separation within the composite. This situation caused the aggregate contact to be minimal until 
heavier loadings were applied. The half-extended samples showed an increase in strength from the addition of the aggregate, but had similar curves to the non-extended samples. At 10 percent strain, the fully extended samples began to fail under compressive load due to shearing of the foam by the aggregate present at the surface of the samples. This accounts for the rise in compressive strength at this level where the nonextended and half-extended samples compressive strengths leveled out at 5 percent strain.

Figure 18 presents the compressive strength change due to extension of the products with the highest measured compressive strengths identified from the previous figures. The compressive strength at 2 percent strain was determined because this is the expected amount of maximum strain the foams would receive under loading in the field. For cement-stabilized base course materials, previous research measuring the unconfined compressive strength resulted in values ranging from 300 psi to 1,000 psi (Ahlberg and Barenberg 1965). Results from compressive testing of the foam materials should be within this range to be considered applicable for base stabilization or base replacement. From this figure, it can be seen that at low strain levels, the compressive strengths of the extended specimens were higher than the non-extended specimens. Despite an increase, at low strain levels, as the samples compressed under load, the stone-on-stone contact was not enough to result in a great increase in the compressive strength for any of the materials. The resulting increase is more likely to have come from the packing of the foam materials explained previously. This indicates that these higher strength foams would be better suited as backfill replacement as opposed to debris stabilizers. With compressive strengths greater than $300 \mathrm{psi}$, such as those obtained with FI-15, IASCO-14, and PF-8, these foams could potentially be used as backfill replacement materials. Lower strength foam materials might be suitable for aggregate stabilization if stone-on-stone contact could be improved to provide adequate strength. Even with extension, these materials were not expected to provide adequate resistance to deformation under load as base course materials. 


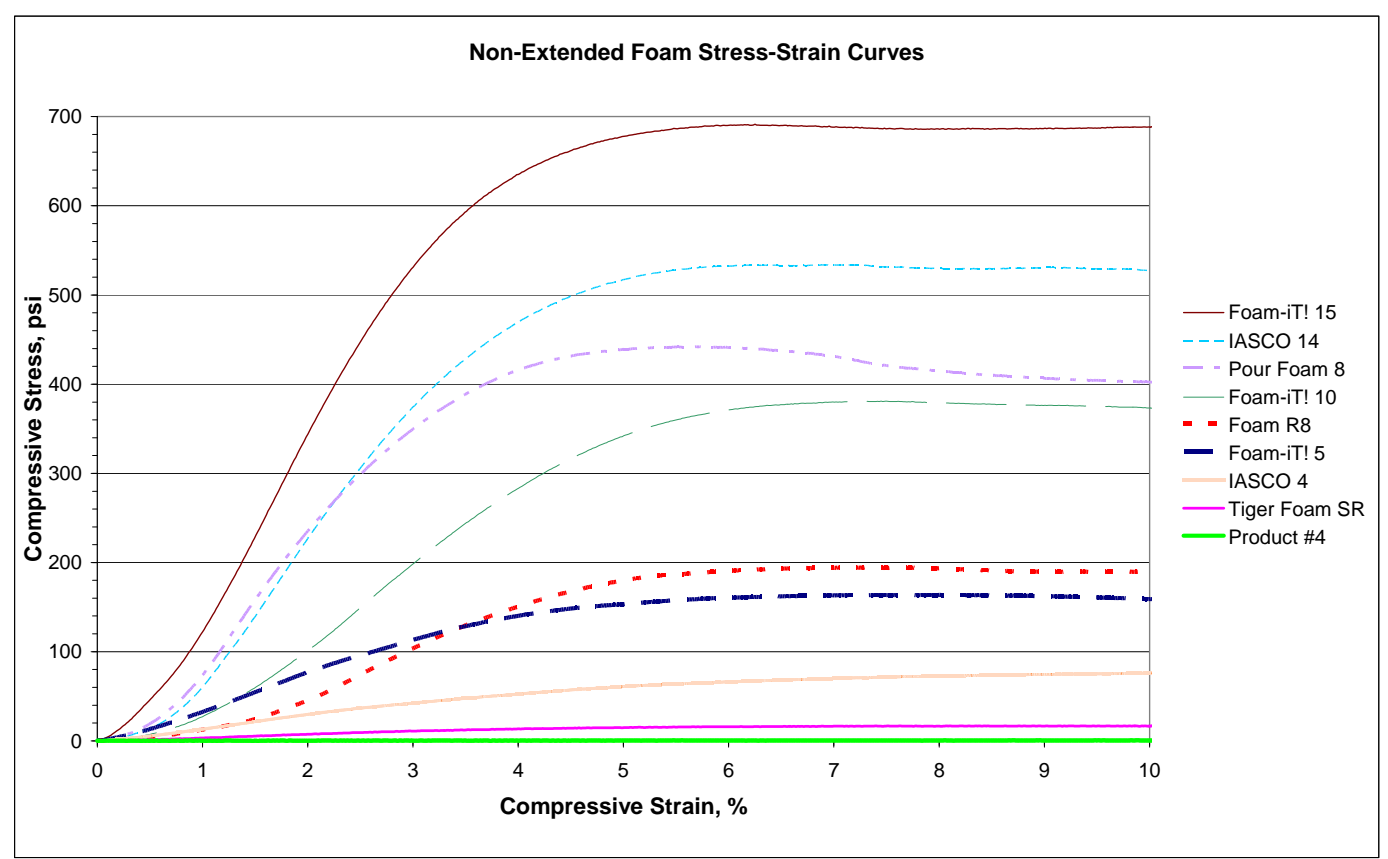

Figure 15. Non-extended products stress-strain curve.

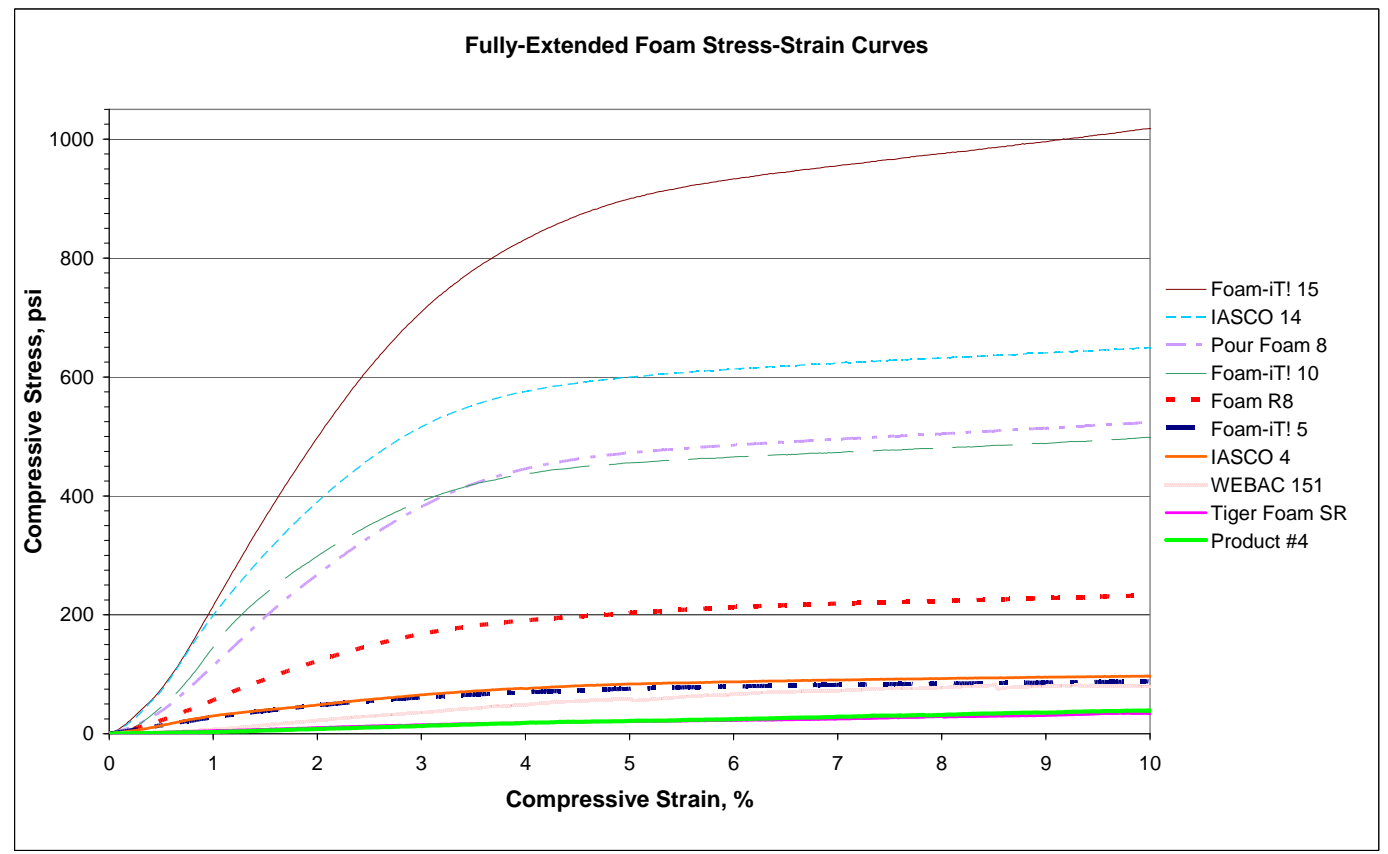

Figure 16. Fully extended products stress-strain curves. 


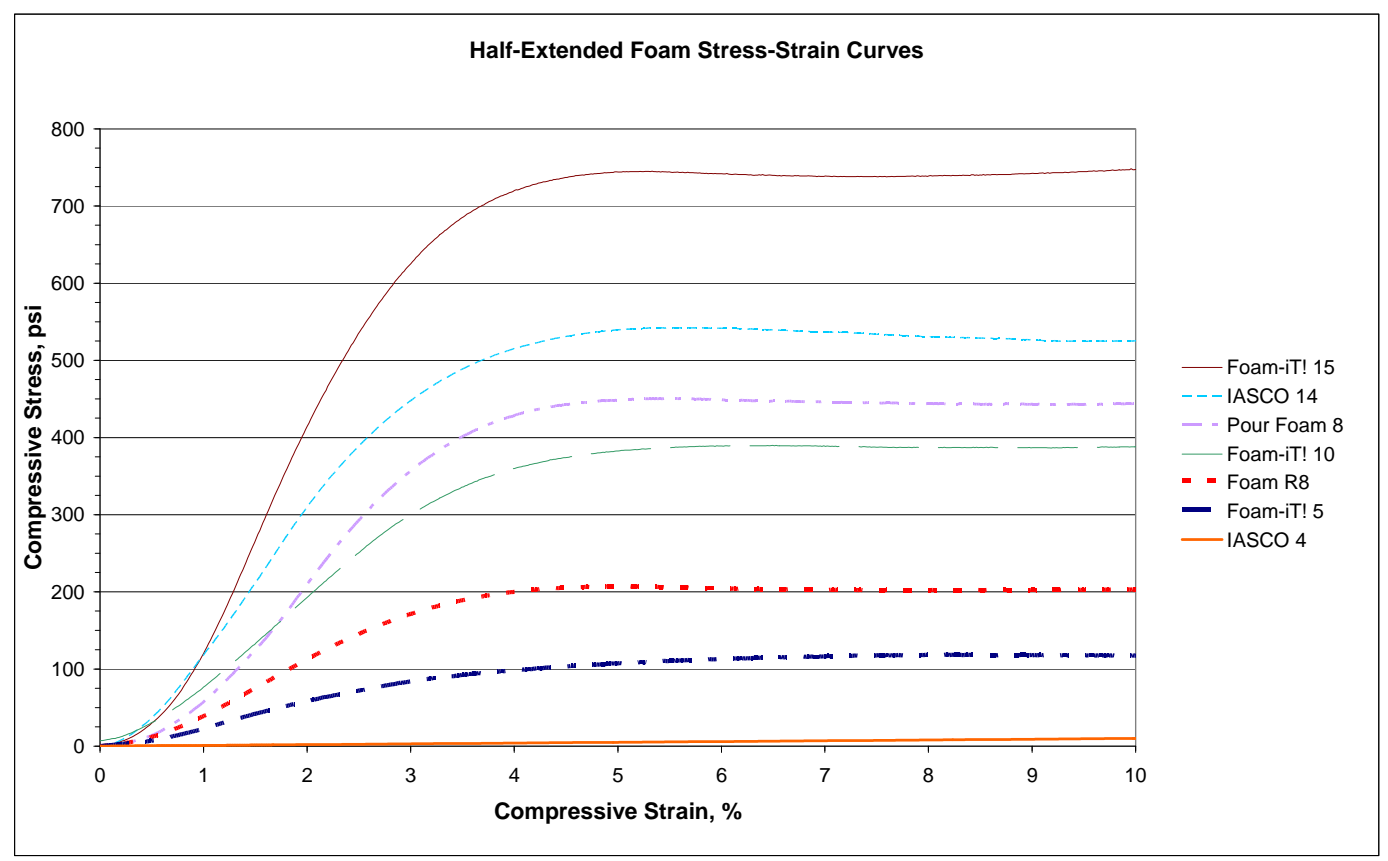

Figure 17. Half-extended products stress-strain curves.

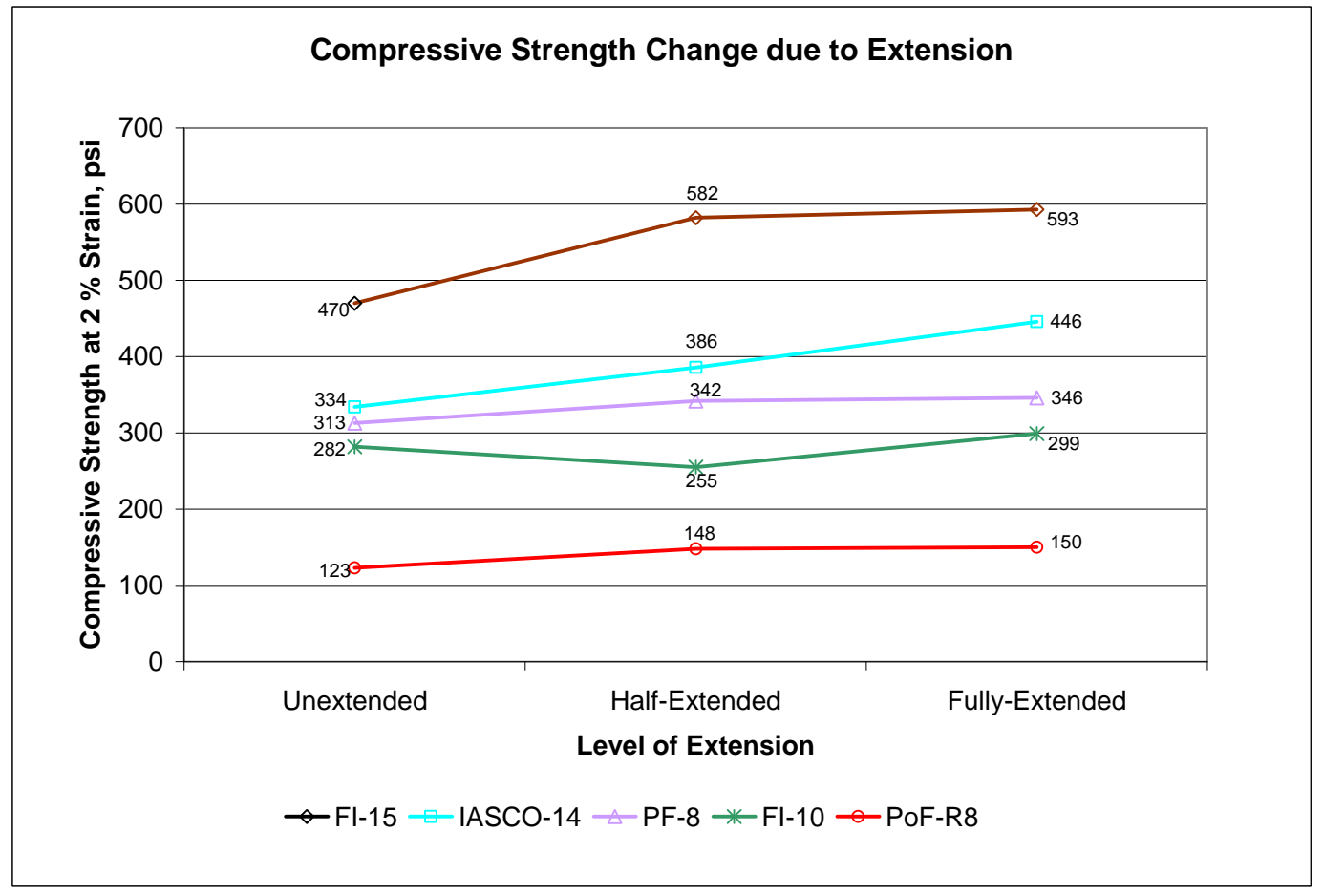

Figure 18. Compressive strength change due to extension for the top products.

Figure 19 presents a comparison of measured densities of all tested materials and the average compressive strengths. WEBAC 151 and Product \#4 were not included because it was not possible to determine the density due to large voids within the samples. From this figure, it can be 
seen that as density increased, compressive strength also increased. It can be concluded that unconfined compressive strengths between 300 and 1,000 psi were achievable with most foams with densities between 8 and $15 \mathrm{lb} / \mathrm{ft}^{3}$. The higher density foams appear to possess adequate strength to serve as backfill in bomb craters with a minimum of 300 psi compressive strength achievable at 2 percent strain. The measured density of Pour Foam 8 (PF-8) was $11 \mathrm{lb} / \mathrm{ft}^{3}$, which was different than the $8 \mathrm{lb} / \mathrm{ft}^{3}$ published by the manufacturer. For this reason, the product had a higher compressive strength than Foam-iT! 10 whose calculated density matched the published density of $10 \mathrm{lb} / \mathrm{ft}^{3}$. Unlike Pour Foam 8, Foam R-8 did not possess higher densities than those published, and will not be considered for field testing.

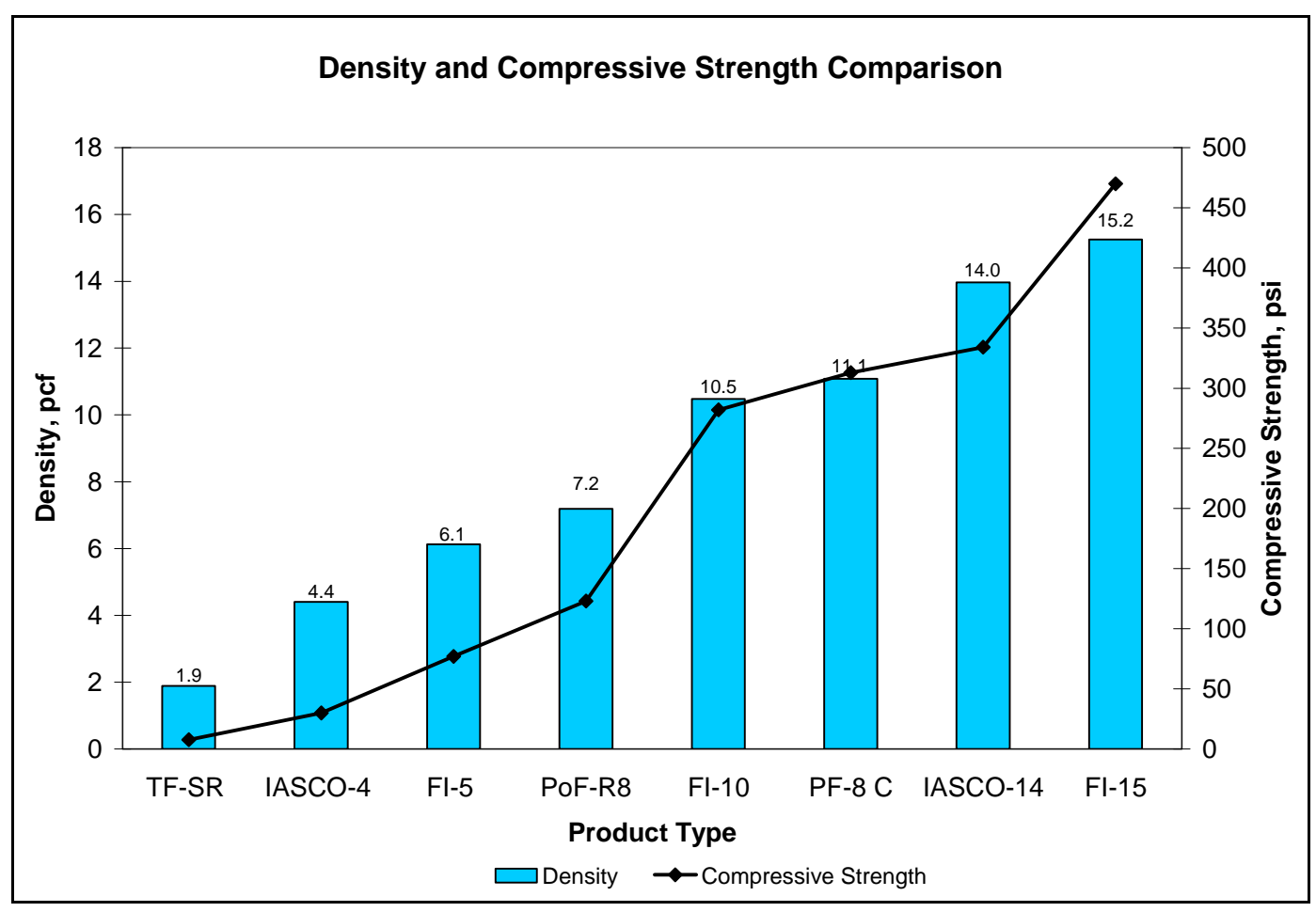

Figure 19. Average product density compared to compressive strength.

\section{Tension tests}

As mentioned previously, no tensile samples were machined with aggregate extension. The tensile samples took two weeks to machine due to the special equipment setup. Before starting the tests, all the parameters for the testing apparatus were configured following the ASTM D 1623-03 test standard. Figure 20 shows the tensile strength samples before, during, and after testing. 
During this test, the samples were sliding in the grips. This caused some of the tests to take longer to complete. In addition, some of the samples failed close to the grip, but still inside the gage length. Because of this slipping and the resulting failures, tensile test results are included in this report only to make strength comparisons, not to report accurate tensile strengths. In order to achieve better results in the future, the grips will be improved to prevent the end grips from opening during testing, allowing the samples to slide.

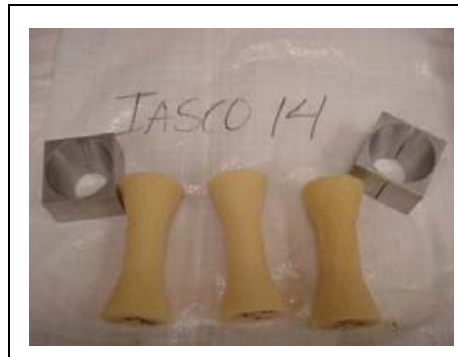

(a) Before

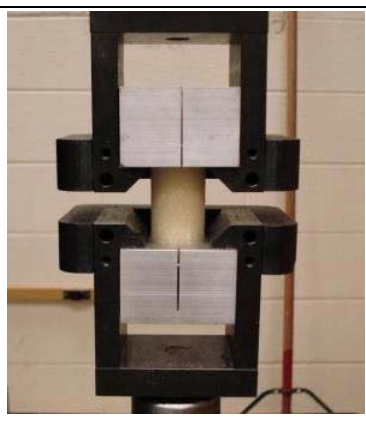

(b) During

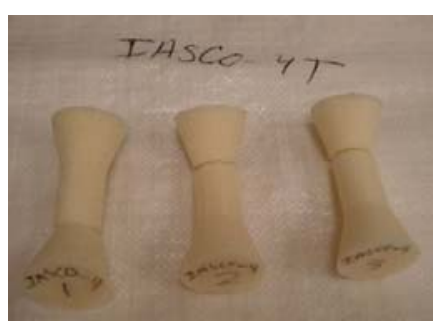

(c) After

Figure 20. Tensile samples: (a) before, (b) during, and (c) after test.

Figure 21 shows the tensile stress-strain curve for eight of the ten foam products. Samples from WEBAC 151 and Product \#4 could not be prepared because their components required wet aggregate to react. This figure shows that after 1 percent strain, the samples started sliding in the grips causing the waves in the stress-strain curves. Furthermore, this figure and the density data indicate that higher density samples provide higher tensile strengths. 


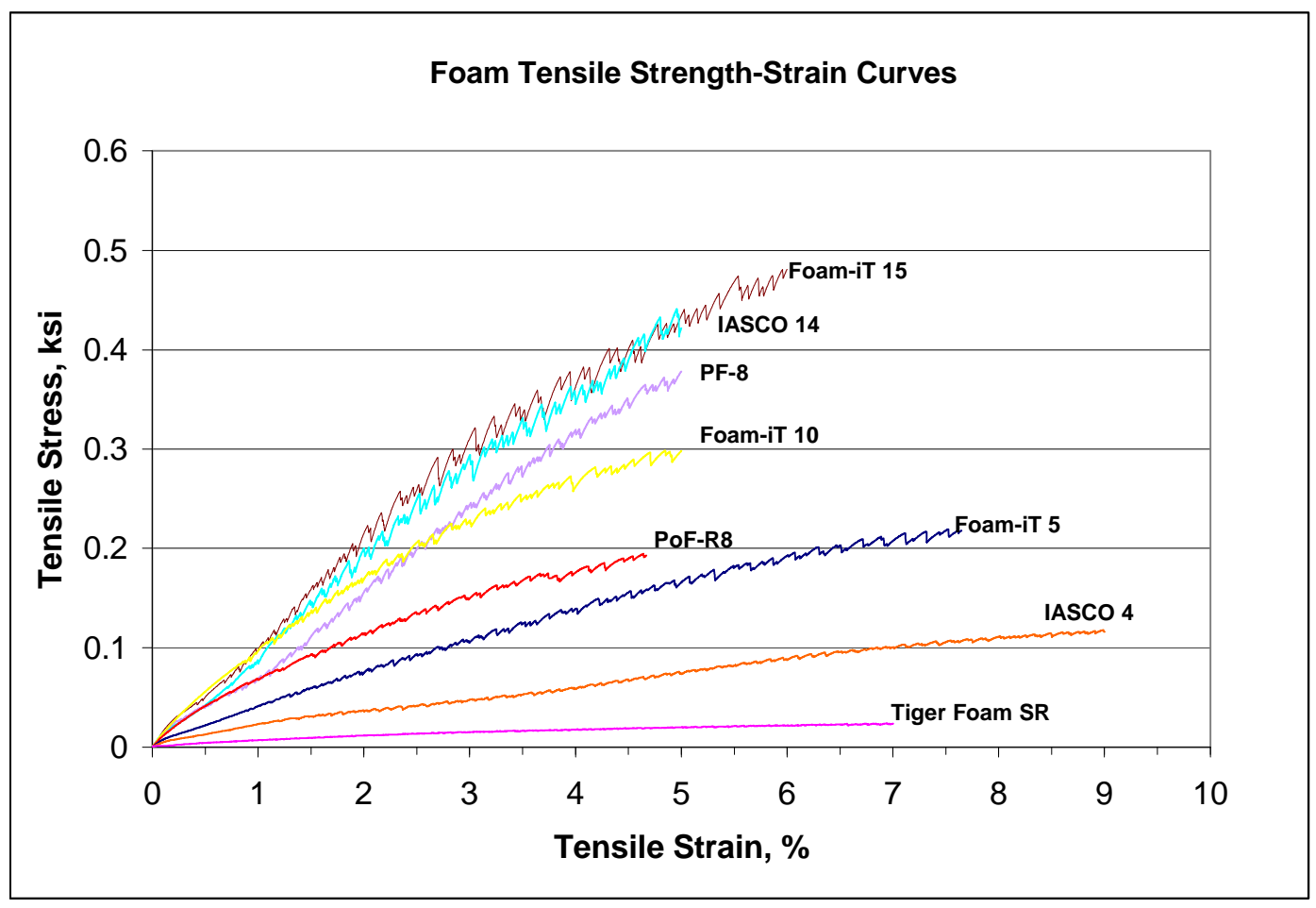

Figure 21. Tensile strength comparison.

\section{Series 2 testing}

Series 2 testing was conducted to determine the effect of the environment on the foam strength, density, expansion ratio, and reactivity. The top products from Series 1(Foam-iT! 15, IASCO-14, Pour Foam-8, Foam-iT! 10, and Foam-R8) were tested at different temperatures. No aggregate extension was used in the preparation of these samples. The materials selected had the highest compressive strengths and densities with and without aggregate extension of all the products tested with quick cure times. Properties of interest and test methods included in this series, along with number of minimum required replicate specimens and testtemperature conditions, are listed in Table 13. The properties investigated in this series follow the sample preparation and test methods described in Series 1 testing.

Table 13. Series 2 summary of tests for selected foam backfill materials.

\begin{tabular}{|c|c|c|c|}
\hline Property & Test Method & Replicates & Temperatures \\
\hline Compressive Strength & ASTM D 1621-04a & 5 & \multirow{2}{*}{$32^{\circ} \mathrm{F}, 50^{\circ} \mathrm{F}}$, \\
\hline Density & ASTM D 3574-05 & 3 & \multirow{2}{*}{$70^{\circ} \mathrm{F}, 90^{\circ} \mathrm{F}, \& 110^{\circ} \mathrm{F}$} \\
\hline Rise Time & N/A & 3 & \\
\hline Set Time & N/A & 3 & \\
\hline Expansion Ratio & N/A & 3 & \\
\hline
\end{tabular}


Table 14 and Figure 22 show a comparison of the reactivity of each product under different temperatures. Data for $70 \stackrel{\circ}{F}$ correspond to the data obtained in Series 1 for the top products. This table also presents the calculated product reactivity compared to those published by the manufacturer. Figure 22 shows that the higher the temperature, the less time needed for the product to become tack free. The higher density foams (8-15 lb/ $\left.\mathrm{ft}^{3}\right)$ were tack free in under $15 \mathrm{~min}$ with shorter tack free times corresponding to higher temperatures. Thus, the rapid tack free time indicates suitability for use in rapid repair scenarios.

Table 14. Product reactivity.

\begin{tabular}{|c|c|c|c|c|c|c|}
\hline \multirow{2}{*}{ Product } & $\begin{array}{c}\text { Published Reactivity }(\mathrm{min}) \\
\text { (Tack Free Time) }\end{array}$ & \multicolumn{5}{|c|}{ Measured Reactivity (min) (Tack Free Time) } \\
\cline { 3 - 7 } & 3 & $32^{\circ} \mathrm{F}$ & $50^{\circ} \mathrm{F}$ & $70^{\circ} \mathrm{F}$ & $90^{\circ} \mathrm{F}$ & $110^{\circ} \mathrm{F}$ \\
\hline PoF-R8 & $2-4$ & 5.5 & 4.9 & 2.6 & 2.6 & 1.4 \\
\hline PF-8 C & 5 & 11.4 & 9.4 & 2.7 & 2.9 & 1.6 \\
\hline FI-10 & $15-20$ & 10.3 & 8.7 & 5.1 & 3.2 & 1.5 \\
\hline IASCO-14 & 4 & 15.3 & 8.7 & 3.2 & 3.3 & 1.8 \\
\hline FI-15 & 10.6 & 6.4 & 2.9 & 2.2 & 1.9 \\
\hline
\end{tabular}

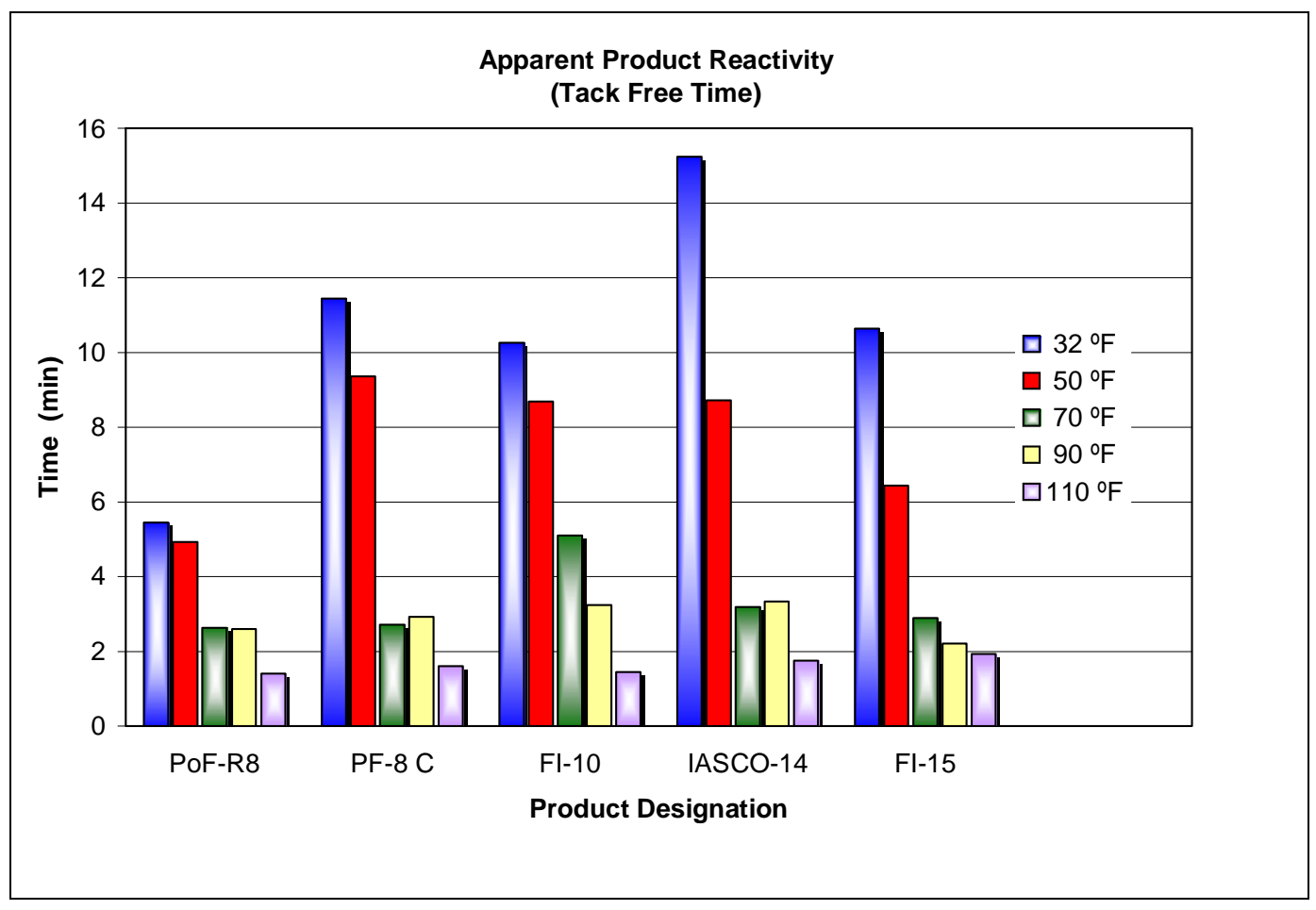

Figure 22. Apparent product reactivity. 
Table 15 shows the calculated densities at different temperatures, and Figure 23 presents a graph illustrating that there is some decrease in density at higher temperatures. A slight decrease in density will result in a slight decrease in compressive strength. As a result, the foam should be placed slightly deeper in a crater repair during elevated temperatures due to this reduction in strength.

Table 15. Product density.

\begin{tabular}{|c|c|r|r|r|r|r|}
\hline \multirow{2}{*}{ Product } & \multirow{2}{*}{$\begin{array}{c}\text { Published Density } \\
\left(\mathrm{lb} / \mathrm{ft}^{3}\right)\end{array}$} & \multicolumn{5}{|c|}{ Calculated Density $\left(\mathrm{lb} / \mathrm{ft}^{3}\right)$} \\
\cline { 4 - 7 } & 8 & $32^{\circ} \mathrm{F}$ & $50^{\circ} \mathrm{F}$ & $70^{\circ} \mathrm{F}$ & $90^{\circ} \mathrm{F}$ & $110^{\circ} \mathrm{F}$ \\
\hline PoF-R8 & 8 & 13.43 & 11.2 & 11.08 & 10.42 & 9.36 \\
\hline PF-8 C & 10 & 10.53 & 10.2 & 10.48 & 9.57 & 9.07 \\
\hline Fl-10 & 14 & 14.82 & 12.7 & 13.96 & 13.48 & 10.23 \\
\hline IASCO-14 & 15 & 14.81 & 16.0 & 13.78 & 15.30 & 13.40 \\
\hline Fl-15 & & & & & & \\
\hline
\end{tabular}

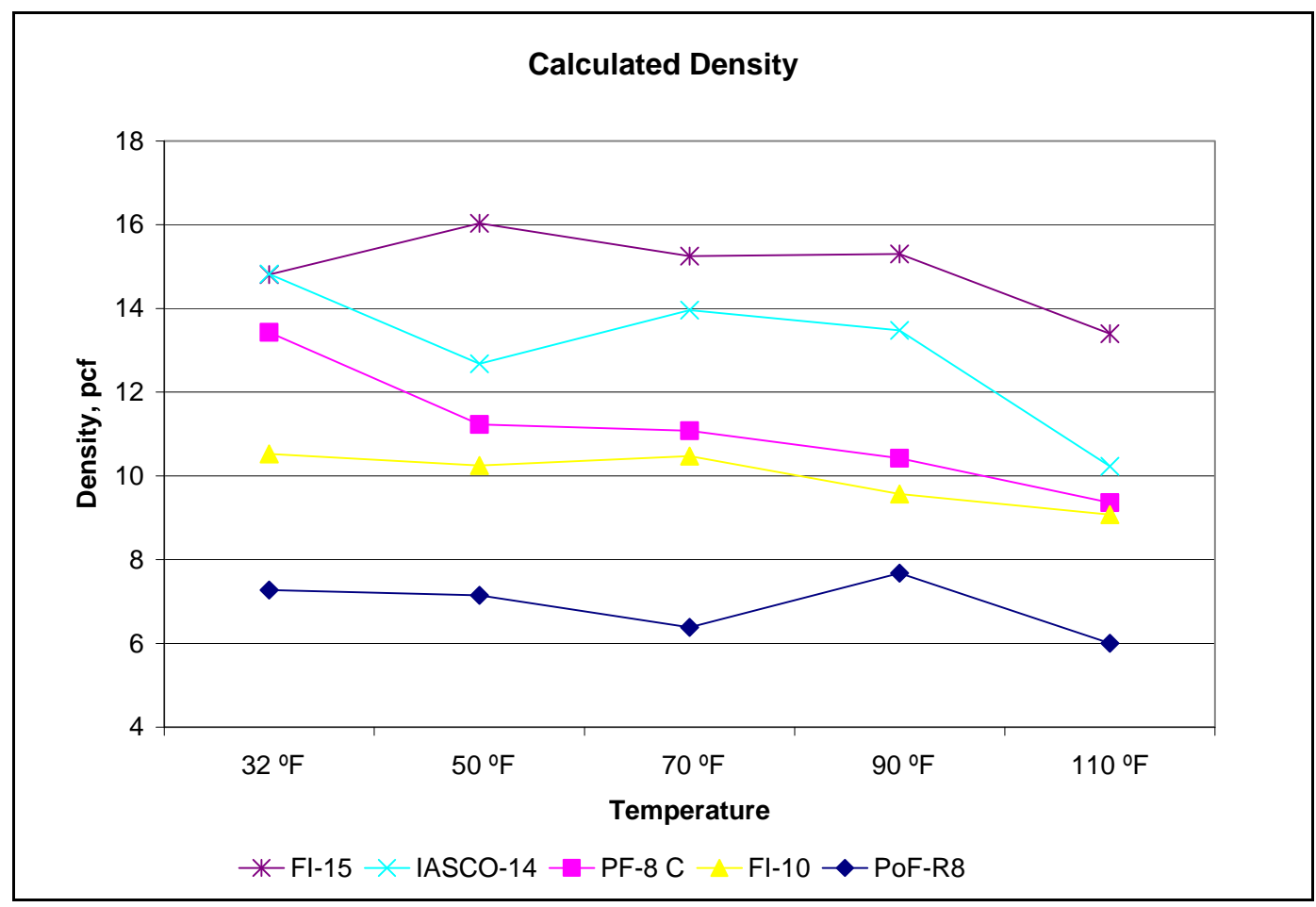

Figure 23. Calculated density.

As mentioned previously, the density tended to decrease when the temperature increased. This occurred because the expansion ratio was higher at higher temperatures. An increase in volume caused the density to be lower due to an increase in voids that were created due to the expansion 
at a high temperature. This behavior can be observed in Table 16 and Figure 24. It can also be noted from this table that the average expansion ratio of the higher density foams was inversely proportional to foam density and ranged from 4.1-9.8 indicating that the foam material could be used to replace up to four times its volume as backfill in a bomb crater, resulting in a savings of at least 75 percent material.

Table 16. Expansion ratio comparison.

\begin{tabular}{|c|c|c|c|c|c|c|}
\hline & & \multicolumn{5}{|c|}{ Calculated Exp. Ratio } \\
\cline { 3 - 7 } Product & Published Exp. Ratio & $\mathbf{3 2}^{\circ} \mathrm{F}$ & $\mathbf{5 0 ^ { \circ }} \mathrm{F}$ & $\mathbf{7 0 ^ { \circ }} \mathrm{F}$ & $90^{\circ} \mathrm{F}$ & $110^{\circ} \mathrm{F}$ \\
\hline PoF-R8 & -- & 7.3 & 9.8 & 7.9 & 8.7 & 8.8 \\
\hline PF-8 C & -- & 4.6 & 5.8 & 5.5 & 6.3 & 6.4 \\
\hline FI-10 & 6 & 5.5 & 6.4 & 6.5 & 6.6 & 6.5 \\
\hline IASCO-14 & -- & 3.8 & 4.8 & 4.1 & 5.1 & 5.8 \\
\hline FI-15 & 4 & 4.5 & 4.3 & 4.6 & 4.2 & 4.7 \\
\hline
\end{tabular}

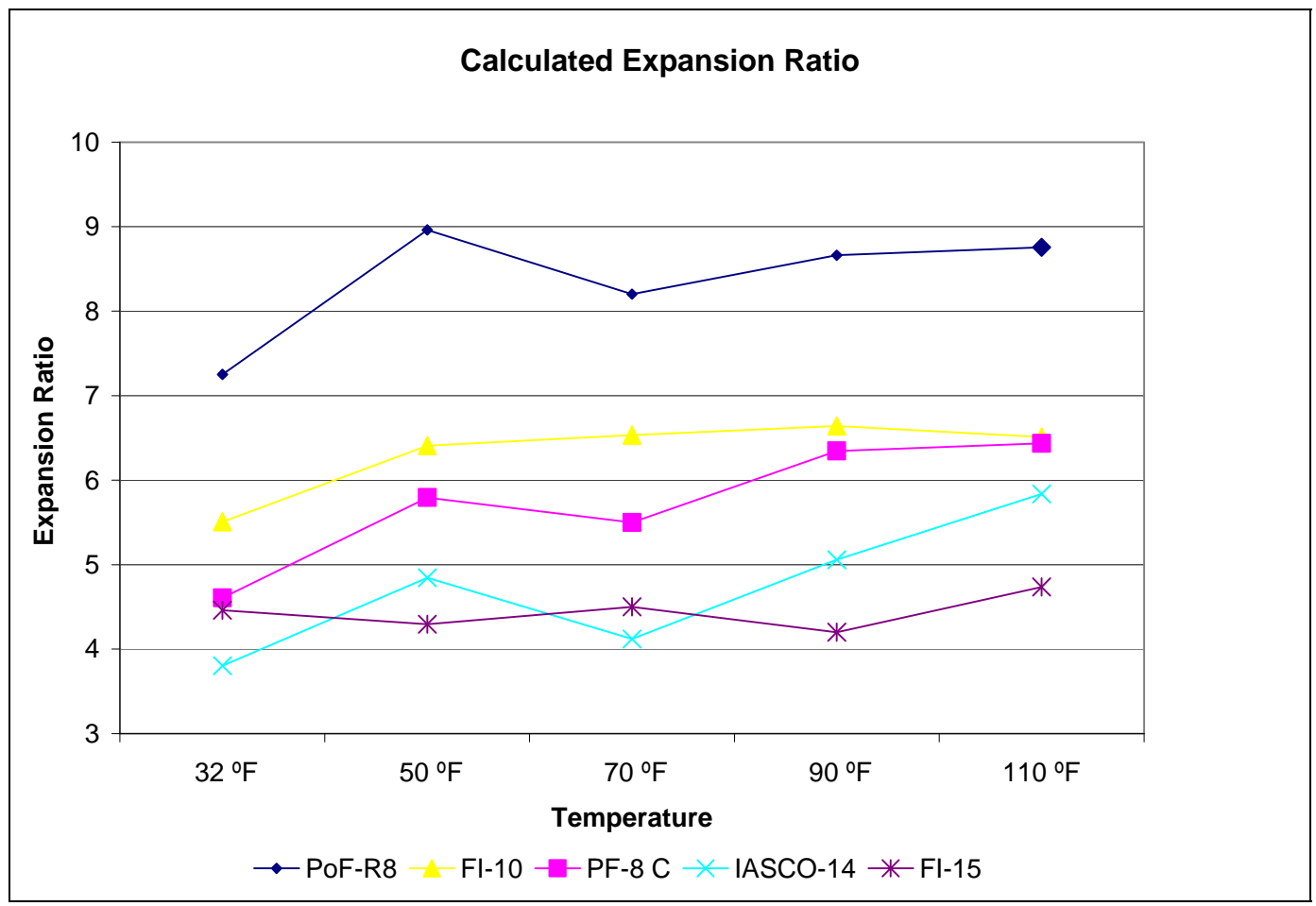

Figure 24. Calculated expansion ratio.

The compressive strength at 2, 5, and 10 percent strain is summarized in Table 17. These strain levels were selected based on the strain that would be experienced by the foam in a pavement structure ( 2 percent), the ultimate strength ( 5 percent), and in the strain level at which the software reports stress (10 percent). The compressive strength had different 
behaviors at these percent strains. At 2 percent strain (Figure 25), the compressive strength tended to decrease at lower and at higher temperatures. In addition, the compressive strength decreased more at higher temperatures than at lower ones. At 5 percent strain (Figure 26), similar behavior was observed, but at 10 percent strain (Figure 27), compressive strength tended to decrease at higher temperatures. At higher temperatures, higher rates of reaction occur, causing gases to expand more. This can cause the material to set rapidly without allowing gases to escape, leading to weaker material because of increased air voids. At lower temperatures, lower rates of reaction take place causing gases generated in the reaction to occupy less volume. This caused the decrease in compressive strengths measured for these samples. At 10 percent strain, the values recorded were in the strain-softening region of the load-strain curve. Decreasing of these values would be expected. Based on these observations, the optimum temperature is $70 \stackrel{\circ}{\mathrm{F}}$.

The test results show that high compressive strengths could be obtained over a wide variety of temperatures and strain levels for FI-15, FI-10, IASCO-14, and PF-8.

Table 17. Compressive strength.

\begin{tabular}{|c|c|c|c|c|c|c|c|c|c|c|c|c|c|c|c|}
\hline \multirow{4}{*}{ Product } & \multicolumn{15}{|c|}{ Compressive Strength (psi) } \\
\hline & \multicolumn{3}{|c|}{$32^{\circ} \mathrm{F}$} & \multicolumn{3}{|c|}{$50^{\circ} \mathrm{F}$} & \multicolumn{3}{|c|}{$70^{\circ} \mathrm{F}$} & \multicolumn{3}{|c|}{$90^{\circ} \mathrm{F}$} & \multicolumn{3}{|c|}{$110^{\circ} \mathrm{F}$} \\
\hline & \multicolumn{3}{|c|}{ \% Strain } & \multicolumn{3}{|c|}{ \% Strain } & \multicolumn{3}{|c|}{ \% Strain } & \multicolumn{3}{|c|}{$\%$ Strain } & \multicolumn{3}{|c|}{ \% Strain } \\
\hline & 2 & 5 & 10 & 2 & 5 & 10 & 2 & 5 & 10 & 2 & 5 & 10 & 2 & 5 & 10 \\
\hline PoF-R8 & 100 & 184 & 224 & 86 & 153 & 184 & 62 & 193 & 190 & 127 & 206 & 188 & 44 & 98 & 108 \\
\hline $\mathrm{Fl}-10$ & 99 & 229 & 314 & 193 & 323 & 360 & 183 & 371 & 369 & 199 & 311 & 306 & 106 & 203 & 220 \\
\hline PF-8 C & 224 & 379 & 425 & 181 & 305 & 362 & 313 & 442 & 400 & 199 & 331 & 306 & 127 & 227 & 233 \\
\hline IASCO-14 & 268 & 397 & 450 & 244 & 444 & 481 & 324 & 530 & 525 & 324 & 513 & 476 & 157 & 300 & 301 \\
\hline $\mathrm{Fl}-15$ & 271 & 568 & 660 & 381 & 700 & 783 & 427 & 687 & 691 & 374 & 640 & 591 & 212 & 425 & 457 \\
\hline
\end{tabular}




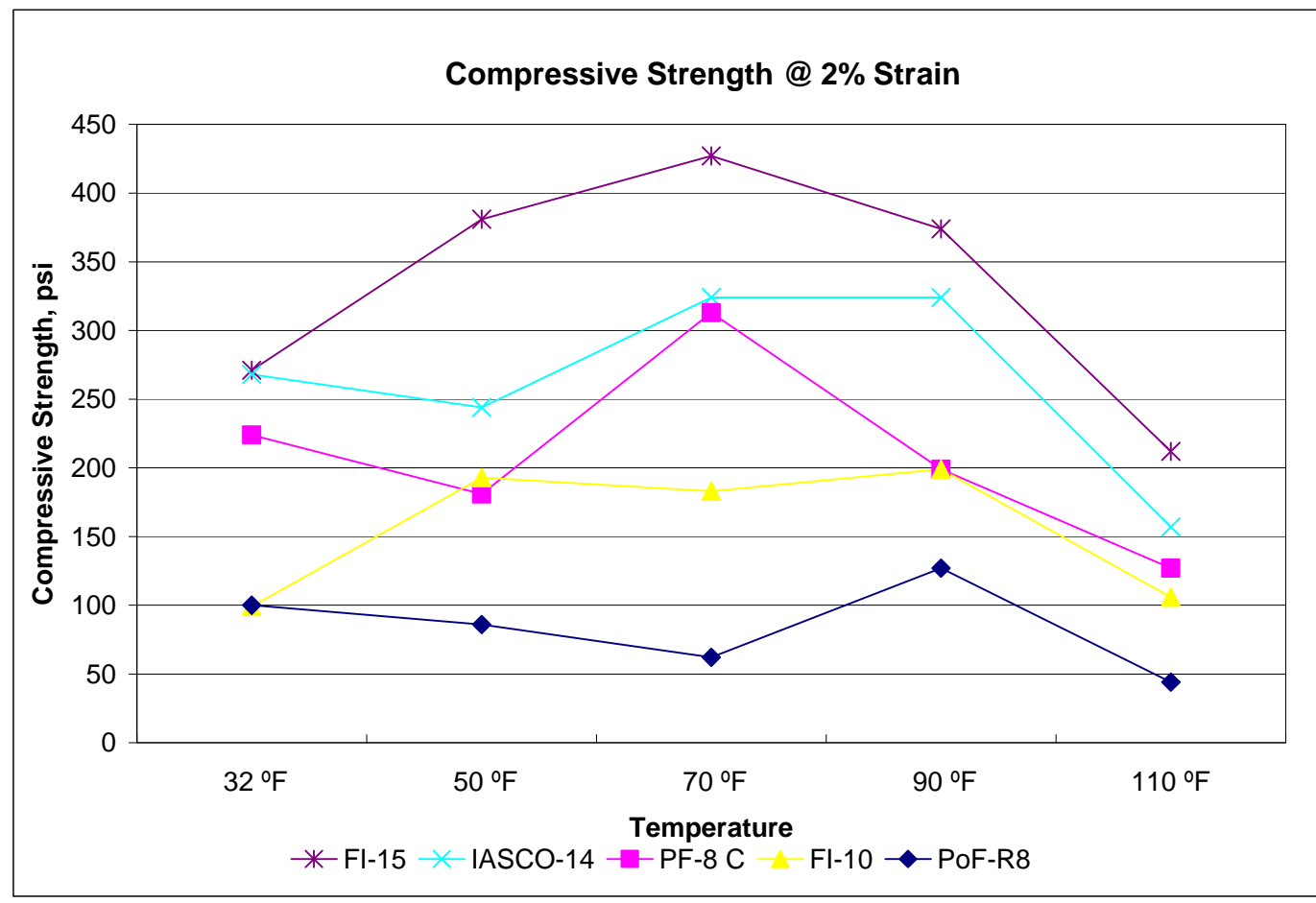

Figure 25. Compressive strength at 2 percent strain.

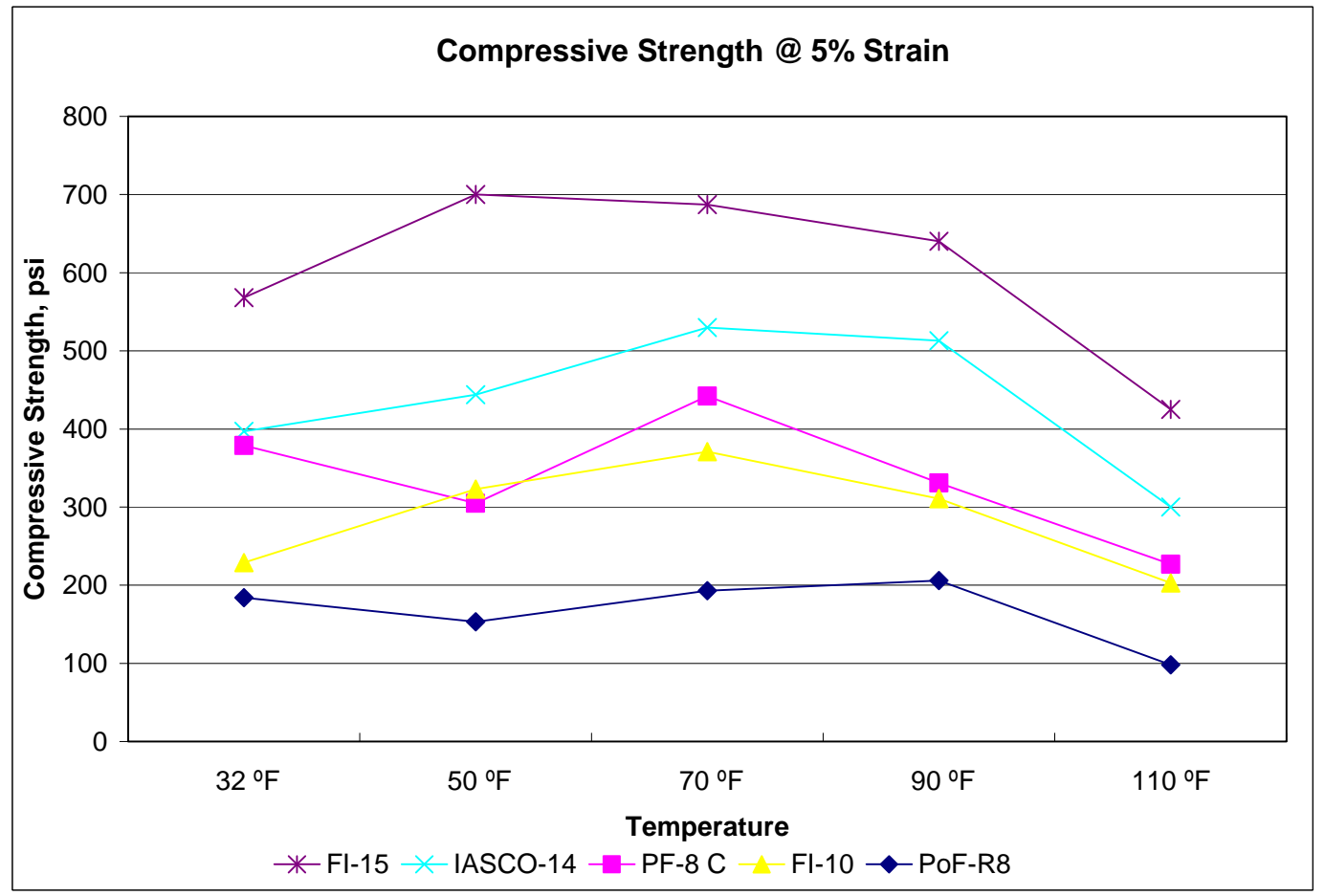

Figure 26. Compressive strength at 5 percent strain. 


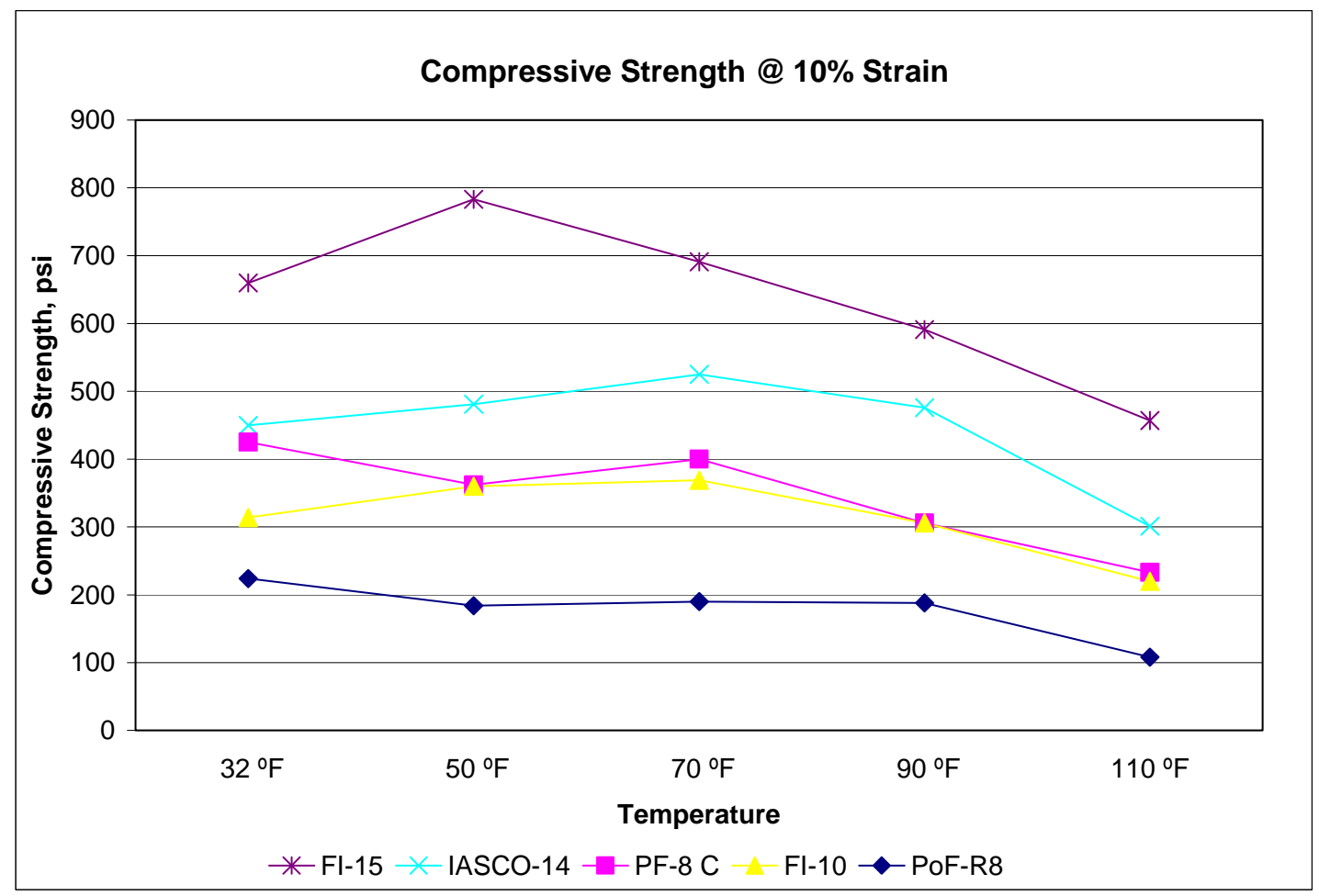

Figure 27. Compressive strength at 10 percent strain.

\section{Series 3 testing}

Additional extension tests were performed to determine the effect of aggregate size on the compressive strength, expansion ratio, and product reactivity (tack free time) of the top performing products selected from Series 2 . The sizes used for these tests were 0.5 to $0.75 \mathrm{in}$., 0.25 to $0.5 \mathrm{in}$., and 0.125 to $0.25 \mathrm{in}$. of limestone aggregate to simulate a wide variety of debris sizes. The samples were prepared in the same manner as detailed in Series 1 testing. For extension, enough aggregate was used to fill each cylinder. The same weight of this aggregate was measured and used to prepare the cylinders of the samples for each type of aggregate.

Table 18. Series 3 summary of tests for selected foam backfill materials.

\begin{tabular}{|c|c|c|c|}
\hline Property & Test Method & Replicates $^{a}$ & Temperature $^{-1}$ \\
\hline Compressive Strength & ASTM D 1621-04 & 5 & $73^{\circ} \mathrm{F}$ \\
\hline Density & ASTM D 3574-05 & 3 & $73^{\circ} \mathrm{F}$ \\
\hline Rise Time & N/A & 3 & $73^{\circ} \mathrm{F}$ \\
\hline Set Time & N/A & 3 & $73^{\circ} \mathrm{F}$ \\
\hline Expansion Ratio & N/A & 3 & $73^{\circ} \mathrm{F}$ \\
\hline
\end{tabular}

a Testing included fully extended and quarter-extended product samples. 
Figure 28 shows that using a smaller aggregate size will increase the tack free time of the products when extended the full height.

There was no way possible to prepare half-extended samples for FoamiT! 15 (FI-15) with 0.25-in. and 0.125-in. aggregate because of the difficulty in preparing samples. This difficulty was due to the reduced space between the aggregate grains and the light weight of the small grains. The reduced space made it difficult to penetrate completely through the aggregate, and when the foam penetrated, the grains were expelled from the container as it expanded. This can be observed in Figure 29.

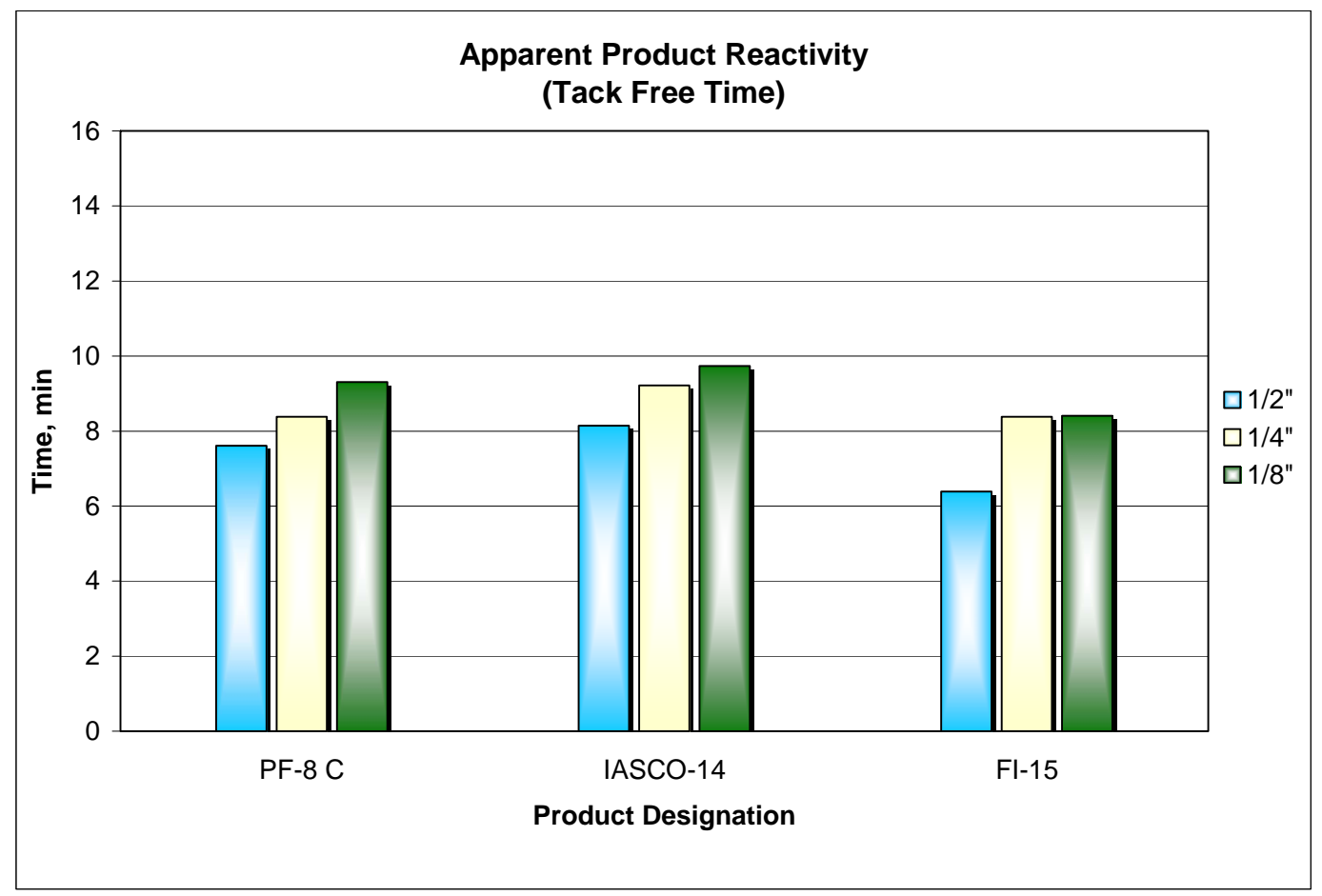

Figure 28. Influence of aggregate size on product reactivity. 


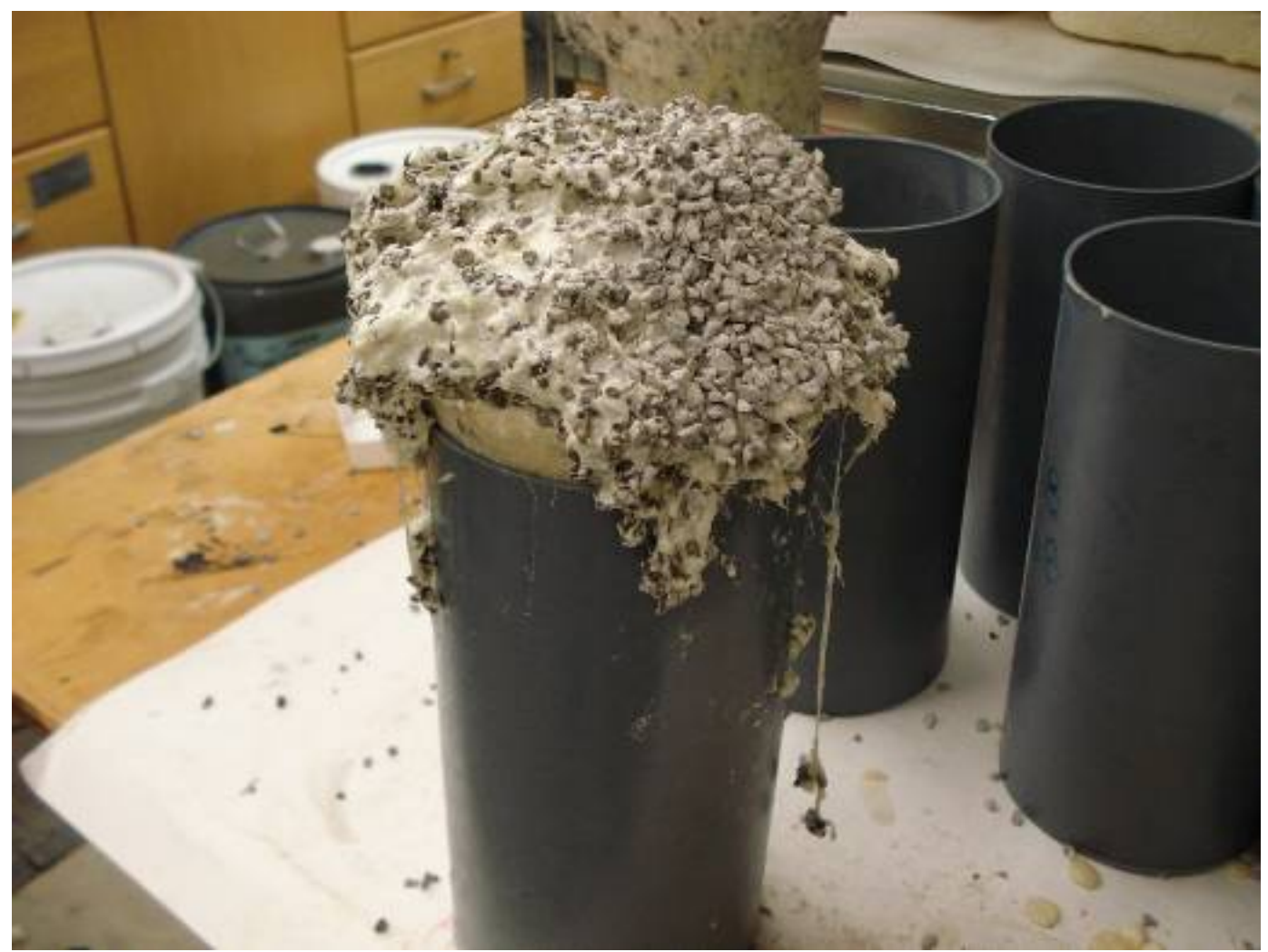

Figure 29. Small aggregate (0.125 in.) pushed from cylinder by expanding foam.

The compressive strength comparison at 2 percent strain for each fully extended aggregate size is presented in Figure 30. This compares the samples from Series 3 with the non-extended and fully extended samples from Series 1. The 1-in. aggregate extension results represent the samples from Series 1. As can be seen from the graph, the decrease in aggregate size causes a decrease in the compressive strength. This is very apparent in the samples with 0.125 -in. aggregate. This is due to the inability of the products to penetrate the small aggregate. Under compression, pockets of aggregate would be released resulting in a sudden decrease in strength for the IASCO and Pour Foam products. However, this was not the case with the Foam-iT! product. Either the samples had a better suspension or the material pushed more aggregate from the sample during preparation. Small particles will not produce as strong of a suspension as the larger aggregate. From this, the minimum aggregate recommended for extension would be $0.5 \mathrm{in}$. Otherwise, penetration is difficult with little increase in compressive strength as compared with a non-extended sample. 


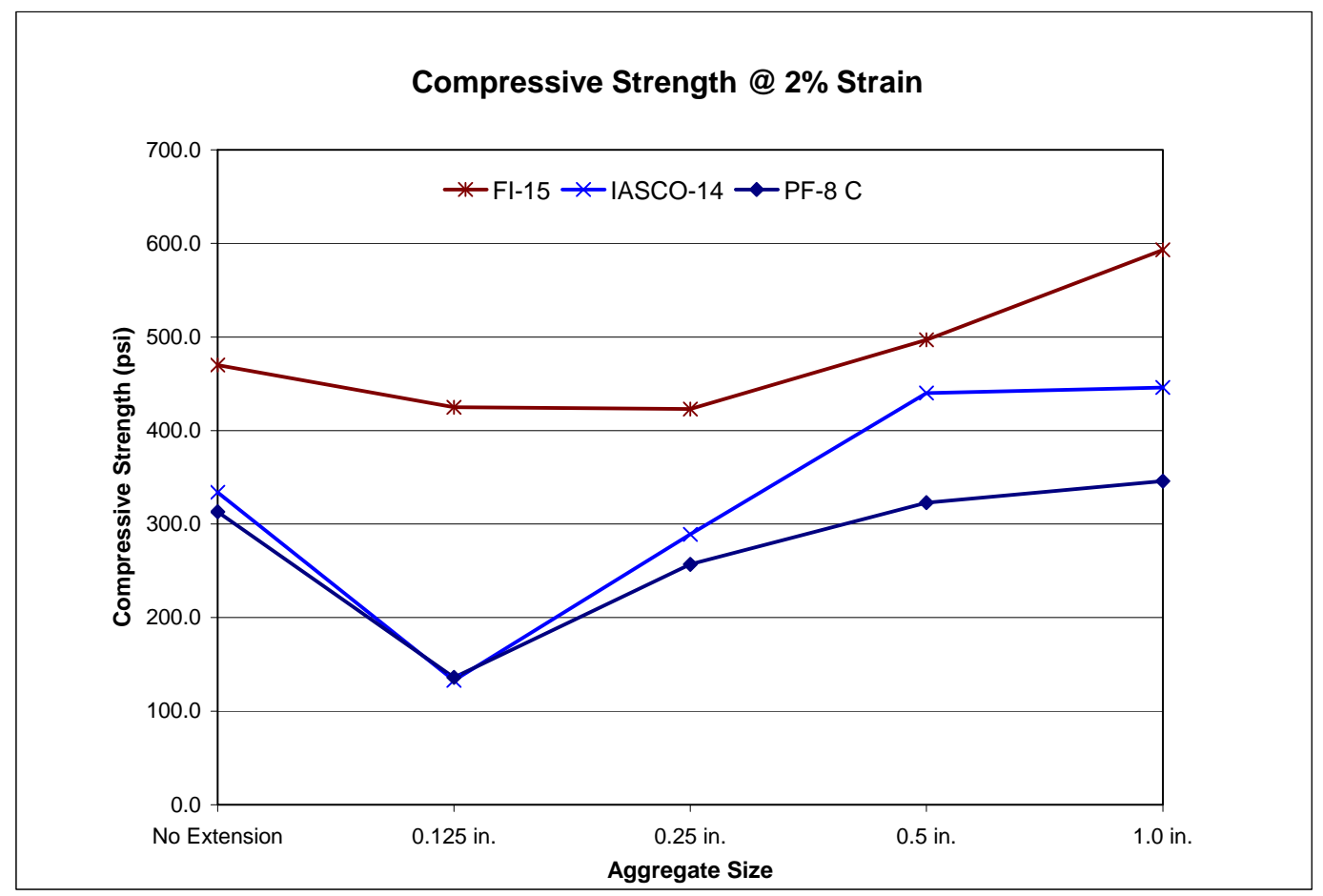

Figure 30. Effects of aggregate size on compressive strength.

\section{Summary}

Based on observations from laboratory investigations, the top performing foam products were identified and recommended for field testing. Foam-iT! 15, IASCO 14, and Pour Foam 8 all exhibited the highest compressive strengths and performed well under different temperature conditions. Although these products could be extended easily, the strength gained by extension is not significant enough to recommend using them in that manner. Twice as much material was needed to extend samples in the laboratory; it is expected that this would be the same in the field. Therefore, it is recommended that these products be considered for field testing as backfill replacement materials. The lower density foams such as Pour Foam- 5 would be recommended for debris stabilization where added strength from the foam is not the goal, but with high expansion ratios that would reduce the amount of foam necessary to complete the repair. Modification in the foam-aggregate composite must be made to generate sufficient strength for base materials. Extension with foam is most difficult when the aggregate sizes were less than $0.5 \mathrm{in}$. Therefore, if foam is to be used for debris stabilization, it is recommended that fine aggregate be kept at a minimum in backfilling the crater. Otherwise, the foam will lift these materials out of the craters or not penetrate to the bottom of the hole. Finally, because these materials are not typically used in the pavements 
community, it is important to work with the manufacturers to provide larger volume containers of these materials for field testing. 


\section{Test Section Construction}

All crater repairs and trafficking were conducted by ERDC on a full-scale test section constructed at ERDC in Vicksburg, MS. The following paragraphs describe the construction of the full-scale test section.

\section{General description}

The full-scale concrete test section consisted of a 60 -ft-wide by 140 -ft-long section of 5,000-psi airfield mix concrete divided into three lanes of slabs each 20 -ft-wide and 20 -ft-long. The concrete was placed directly over a compacted subgrade of low-plasticity clay (CL) constructed to provide a modulus of subgrade reaction, $\mathrm{k}$, of not less than of $100 \mathrm{psi} / \mathrm{in}$. The 14-in.thick concrete was placed on top of the prepared subgrade and allowed to cure prior to cratering and repair of cratered areas. Each crater was trafficked until 5,000 passes or repair failure occurred. Details regarding the test section construction are included in the following text.

\section{Test section construction}

The full-scale concrete test section was constructed adjacent to a soil processing area, which required removal of older pavement prior to construction. Coring of the soil processing area and investigation with radar revealed 5 to $7 \mathrm{in}$. of asphalt concrete (AC) over 2 to $9 \mathrm{in}$. of sandy clay over a silty clay subgrade. A rotary mixer was used to pulverize the existing AC surface. The surface was excavated with a front-end loader and removed from the site with dump trucks. The subgrade was wet with approximately $800 \mathrm{gal}$ of water and mixed with a rotary mixer several times. The loosened material was then piled and mixed using a front-end loader and then smoothed in place. Bags of existing subgrade material were sent to the soils lab, and this material was subjected to a suite of laboratory tests including a grain-size analysis (hydrometer), Atterberg Limit testing, and modified-proctor compaction testing. These data were used to determine the target moisture content and dry density required to obtain the target soil strength.

Soil testing revealed the subgrade material was sandy low-plasticity clay with a Unified Soil Classification (ASTM D 2487) of CL. This soil had the following percentages of gravel, sand, and fines, 0.4, 13.9, and 85.8 percent, 
respectively. The soil's liquid limit and plasticity index (ASTM D 4318) were 37 and 16 percent, respectively. The color of this soil was a light brown to a dark brown depending on moisture content. With modified Proctor compaction (ASTM D 1557), this soil had an optimum moisture content and a laboratory maximum dry density of approximately 11.4 percent and $121.0 \mathrm{lb} / \mathrm{ft}^{3}$, respectively.

Following the soil classification, the material was leveled with a small bulldozer and then compacted with a vibratory roller compactor. Each compacted lift was subjected to nuclear moisture and density tests to verify that target values had been met. Additionally, plate load tests were conducted to ensure that adequate strength had been obtained. Locations of tests are presented in Figure 31. Plate load tests revealed an average modulus of subgrade reaction for the compacted subgrade to be $215 \mathrm{psi} / \mathrm{in}$. Average dry density, wet density, and moisture content of the subgrade prior to concrete placement was $117.81 \mathrm{lb} / \mathrm{ft}^{3}, 128.53 \mathrm{lb} / \mathrm{ft}^{3}$, and 9.12 percent, respectively.

In addition, falling weight deflectometer (FWD) testing and dynamic cone penetrometer (DCP) testing were also conducted prior to concrete placement. FWD results reported an average backcalculated modulus for the entire subgrade as 7,910 psi. The average DCP correlated strength resulted in a 9 percent $C B R$ value.

\section{Subgrade instrumentation}

The subgrade instrumentation conduit was installed prior to concrete placement to create routing and protection for instrumentation wires placed during crater repair. A trench was dug along the north side of the test section $2 \mathrm{ft}$ wide by $140 \mathrm{ft}$ long and $2 \mathrm{ft}$ deep to install the main trunk line for the routing of wires to the instrumentation pod. Thick-walled pipe was cut and assembled for placement. Additional smaller instrumentation pipes were installed at intervals of $5 \mathrm{ft}$ along the north side of the section for the first series of craters as shown in Figure 32. This figure also presents the location of the additional main trunk lines and the sizes and locations of the three series of proposed craters. After the pipe was installed, approximately 6 in. of backfill material was placed on top of the pipe and compacted with a 6-in. pneumatic compactor. Once this was complete, the trenches were backfilled and compacted with a jumping-jack style plate compactor. Parachute cord was routed through the main trunk lines to aid in installing instrumentation wires. 


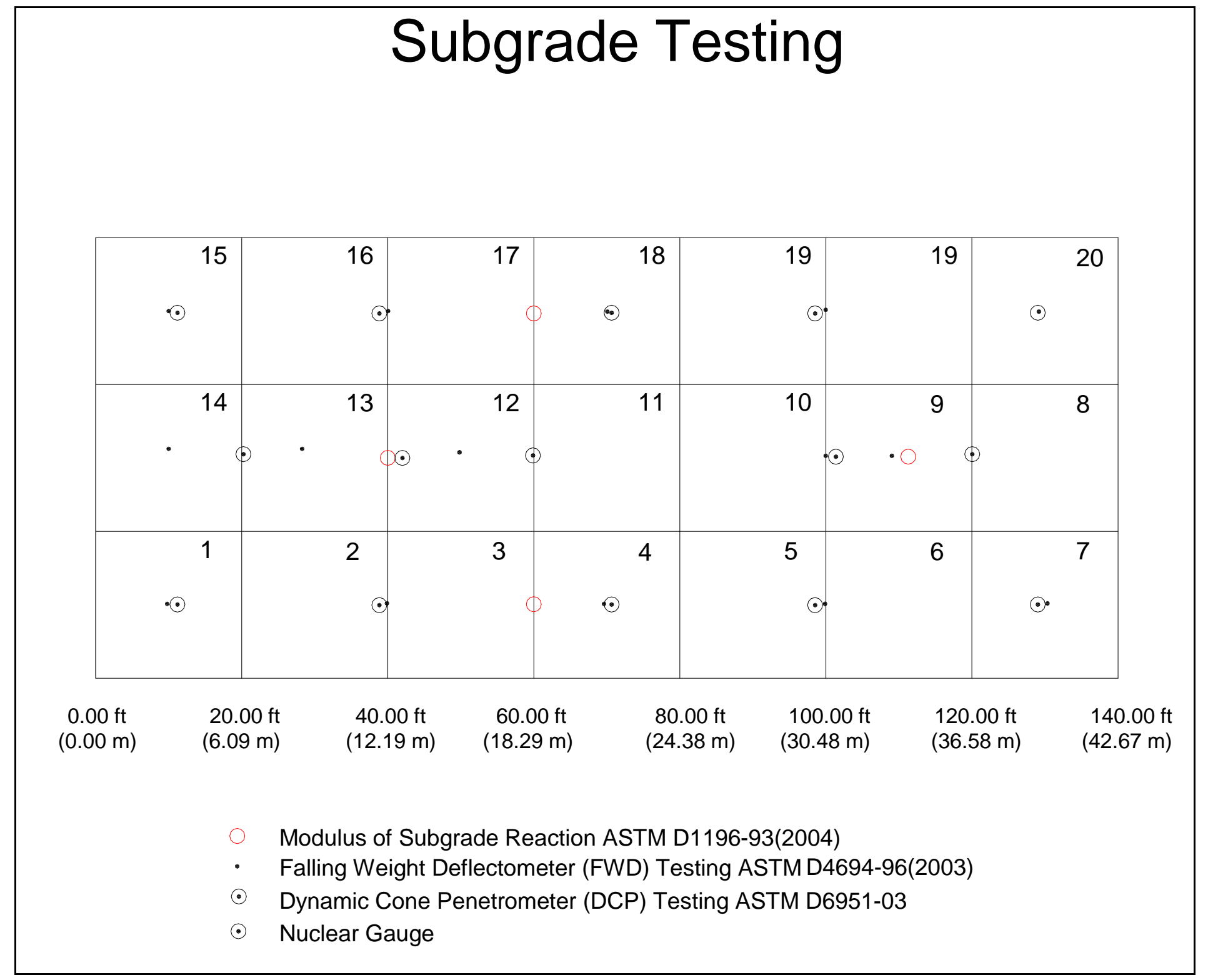

Figure 31. Subgrade testing locations. 


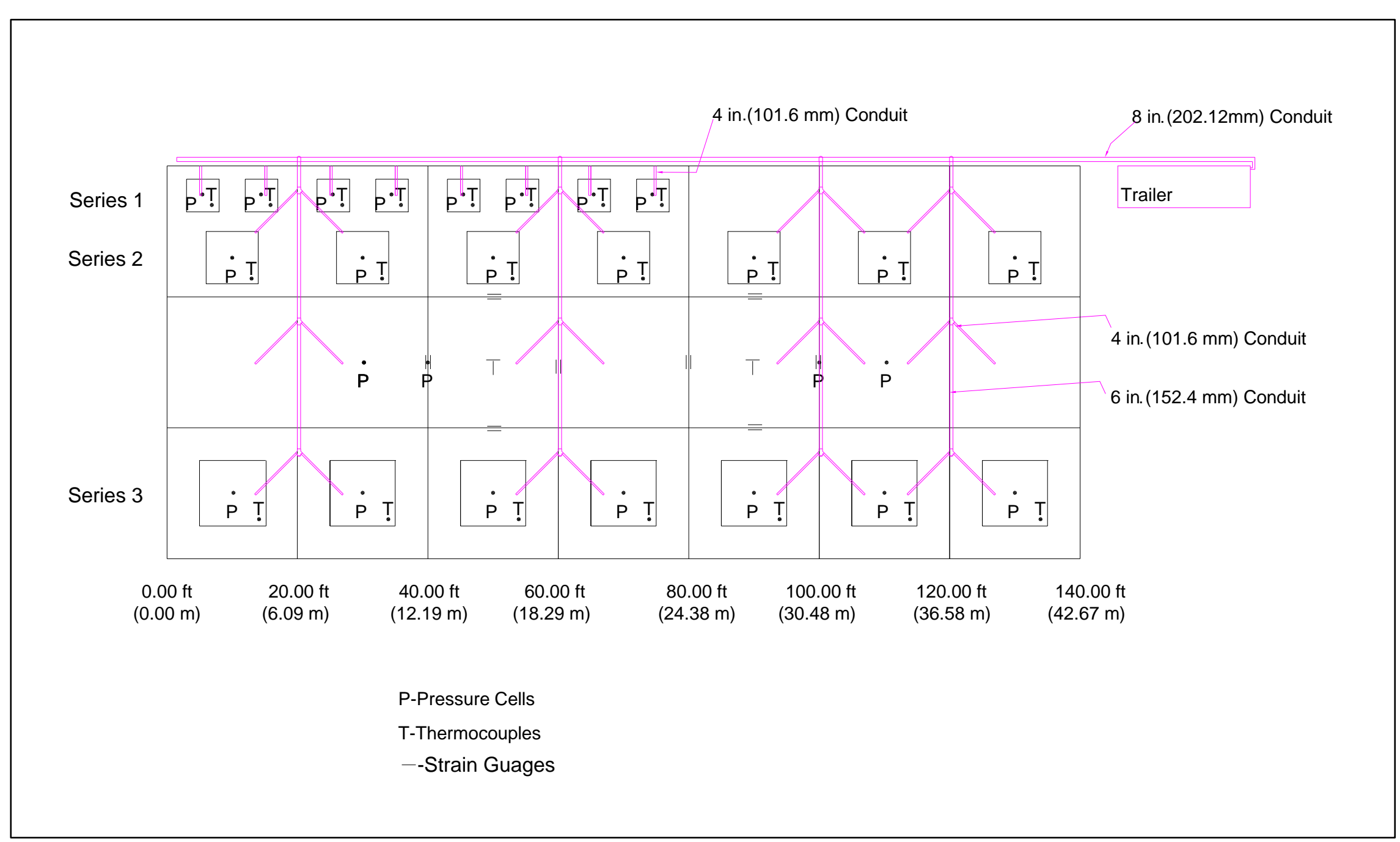

Figure 32. Instrumentation locations. 


\section{Concrete installation}

Fourteen inches of 5,000-psi (28-day compressive strength) airfield concrete mix with a minimum 28-day flexural strength of 550 psi was designed for the F-15E aircraft for 50,000 passes using PavementTransportation Computer Assisted Structural Engineering Program (PCASE) design software (www.pcase.com). The concrete was placed on the surface of the prepared test section subgrade by an experienced labor crew in three 140 - by 20 -ft lanes. A concrete cutting crew sawed joints at 20 -ft intervals to produce twenty-one 20 -ft by 20 -ft slabs. These slabs were cut to a minimum depth of $5 \mathrm{in}$. and allowed to crack to the bottom of the slab. Once a lane was completed, the formwork was removed and new formwork was installed for the next lane of placement. This layout, including proposed crater placement, is presented in Figure 33. Beams and cylinders were cast onsite during each lane placement and were tested for flexural and compressive strength to ensure the concrete met specifications (ASTM C 39-05 and ASTM C 78-94). Results of concrete 28-day compressive and flexural strength testing produced a compressive strength of 5,319- and 590-psi flexural strength. These values met the specifications of 5,000-psi compressive strength and 550-psi flexural strength.

\section{Cratering of test section}

Once the concrete slab construction was complete, 5-ft by 5-ft sections of the pavement were removed to produce Series 1 crater locations. To prevent overcutting, 6-in. cores were removed at the corners of each crater. A concrete cutting contractor sawcut each crater a minimum of 14 in. in the center of each side without over cutting using a concrete saw with a series of blade sizes. Following cutting, the pavement was broken using a breaker attachment and a backhoe. Broken pieces were removed by hand, shovel, and mini-excavator. The exposed craters were excavated to a depth of $2 \mathrm{ft}$ with the mini-excavator and shovel.

Additional cratering was conducted in the same manner for Series 2 and 3 craters. For Series 2, seven 8-ft-wide by 8-ft-long craters were sawcut to a minimum depth of 14 in. For Series 3, eight 10-ft-wide by 10-ft-long craters were sawcut. As with Series 1, 6-in. cores were removed at each crater corner to prevent overcutting. A backhoe with a breaker attachment was used to break material inside saw cuts of Series 2 . Series 3 saw cuts and 


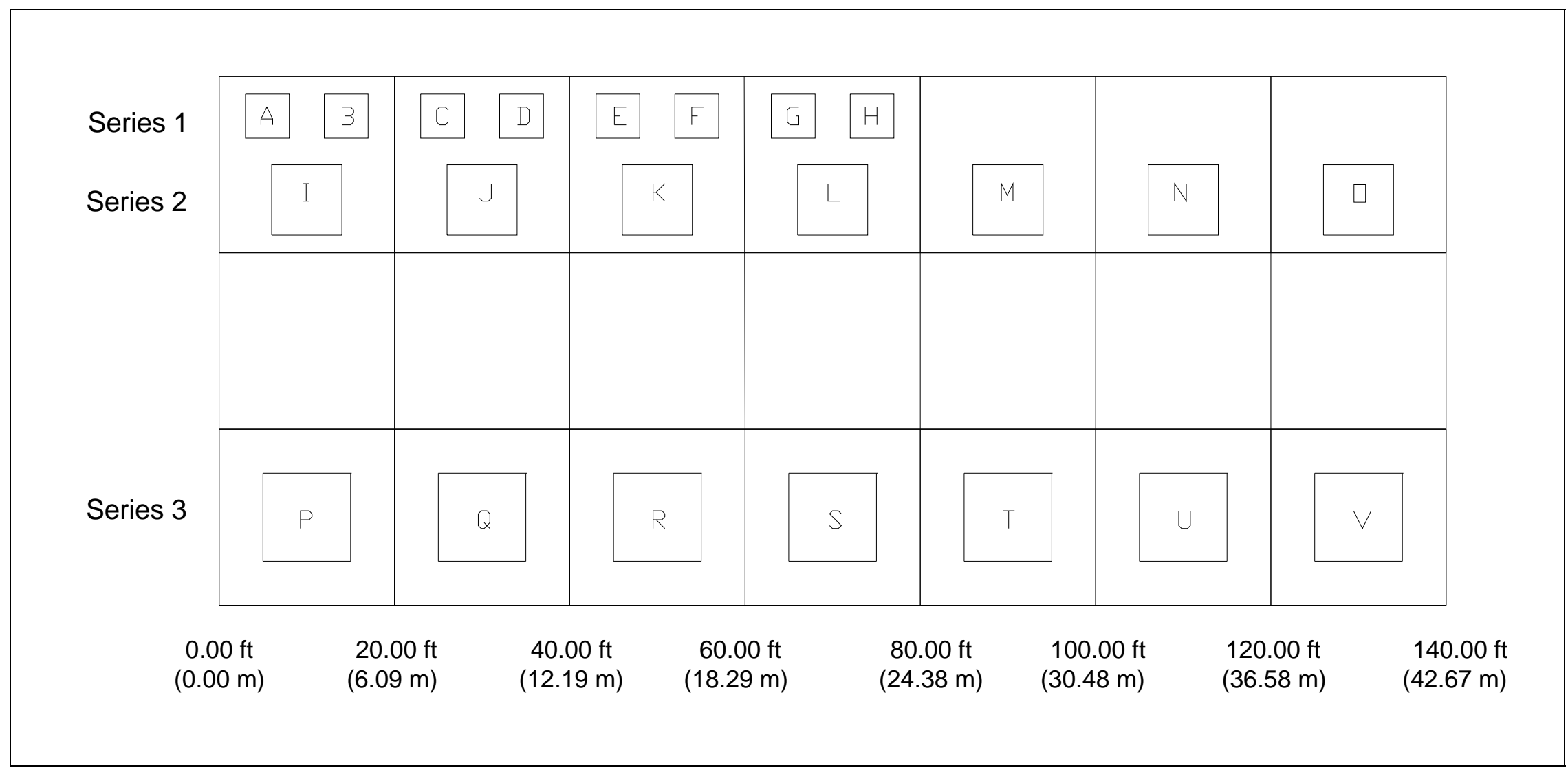

Figure 33. Test section construction layout. 
core holes were filled with joint sealant to prevent moisture from getting to the subgrade until the final series of testing began. Series 2 debris was removed, and the craters were excavated to a depth of $3 \mathrm{ft}$ with a backhoe.

Series 3 craters were excavated just prior to testing. As with Series 1 and 2 , the concrete was broken using a backhoe with a breaker attachment. The subgrade material was removed with a backhoe, and each crater was excavated to a depth of $3.5 \mathrm{ft}$. All concrete debris from Series 1 through 3 was sorted for use as backfill material for a maximum diameter of $1 \mathrm{ft}$; this material was stockpiled for Series 3 repairs. 


\section{Crater Repairs}

\section{Description of crater repairs}

As noted, the crater repairs were divided into three series based upon crater size. Each series of repairs was trafficked with 112 passes of an F-15E load cart on the third point at exactly $5 \mathrm{hr}$ after the repair had begun or within $3 \mathrm{hr}$ after cap placement was complete. Crater dimensions and profiles for each series are presented in Table 19 and in Figures 34- 38.

Series 1 was conducted to compare various RS materials identified through literature and laboratory tests under field test conditions. The goal of this series was to identify RS materials capable of supporting aircraft traffic with minimum preparation and curing requirements. Vendor participation was encouraged during the placement of each product. Each material was mixed and placed using manufacturer mixing guidelines with minimal labor, equipment, and working time.

Series 2 consisted of larger 8-ft by 8-ft craters with different types of backfill capped with the four RS products selected from the Series 1 testing. The first crater was used to investigate debris sorting and equipment requirements for this sorting as well as placement in a crater. The next three repairs were capped with the top performing RS product from Series 1 over compacted aggregate backfill. The last two craters were reserved for investigations of foam backfill. Two foams identified in the backfill laboratory investigation were mixed and placed in the field. One foam was a high density, rigid polyurethane that was identified as a potential base replacement material. This material was placed over compacted aggregate backfill. The other foam was a lower density, rigid polyurethane that was poured over preplaced debris to investigate the performance of foam as a stabilizer. Together, the repairs investigated the material performance of RS capping materials over compacted aggregate backfill and the applicability of using these type materials over foam backfill. 
Table 19. Crater repair options.

\begin{tabular}{|c|c|c|c|c|}
\hline Crater & Repair Description & $\begin{array}{l}\text { Size }(\mathrm{LxWxD}) \\
(\mathrm{ft})\end{array}$ & Volume $\left(\mathrm{yd}^{3}\right)$ & $\begin{array}{l}\text { Target } \\
\text { Passes }\end{array}$ \\
\hline \multicolumn{5}{|c|}{ Series 1} \\
\hline$A$ & RS-1 (Pavesaver) & $5 \times 5 \times 1.5$ & 1.4 & $100-5000$ \\
\hline B & RS-2 (Rapid Set) & $5 \times 5 \times 1.5$ & 1.4 & $100-5000$ \\
\hline C-1 & RS-3 (Pavemend SLQ) & $5 \times 5 \times 1.5$ & 1.4 & $100-5000$ \\
\hline $\mathrm{C}-2$ & RS-9 (ThoRoc 10-60) & $5 \times 5 \times 1.5$ & 1.4 & $100-5000$ \\
\hline $\mathrm{D}$ & RS-4 (ThoRoc 10-61) & $5 \times 5 \times 1.5$ & 1.4 & $100-5000$ \\
\hline $\mathrm{E}$ & RS-5 (Set 45) & $5 \times 5 \times 1.5$ & 1.4 & $100-5000$ \\
\hline $\mathrm{F}$ & RS-6 (Ultimax Concrete) & $5 \times 5 \times 1.5$ & 1.4 & $100-5000$ \\
\hline G-1 & RS-7 (Pavemend SL) & $5 \times 5 \times 1.5$ & 1.4 & $100-5000$ \\
\hline G-2 & RS-8 (Tamms Express Repair) & $5 \times 5 \times 1.5$ & 1.4 & $100-5000$ \\
\hline $\mathrm{H}$ & RS-3 (Pavemend SLQ) & $5 \times 5 \times 1.5$ & 1.4 & $100-5000$ \\
\hline \multicolumn{5}{|c|}{ Series 2} \\
\hline I & Debris Placement Trial & $8 \times 8 \times 3$ & 7.0 & $\mathrm{~N} / \mathrm{A}$ \\
\hline$J$ & $\begin{array}{c}\text { RS- } 2 \text { (Rapid Set) over Clay } \\
\text { Gravel Backfill }\end{array}$ & $8 \times 8 \times 3$ & 7.0 & $100-5000$ \\
\hline K & $\begin{array}{c}\text { RS-3 (Pavemend SLQ) over Clay } \\
\text { Gravel Backfill }\end{array}$ & $8 \times 8 \times 3$ & 7.0 & $100-5000$ \\
\hline L & $\begin{array}{c}\text { RS-4 (ThoRoc 10-61) over Clay } \\
\text { Gravel Backfill }\end{array}$ & $8 \times 8 \times 3$ & 7.0 & $100-5000$ \\
\hline M & $\begin{array}{l}\text { Reserved for RS-6 (not } \\
\text { conducted) }\end{array}$ & $8 \times 8 \times 3$ & 7.0 & $100-5000$ \\
\hline $\mathrm{N}$ & $\begin{array}{l}\text { RS-3 (Pavemend SLQ) over } \\
\text { Foam-iT! } 5\end{array}$ & $8 \times 8 \times 3$ & 7.0 & $100-5000$ \\
\hline 0 & $\begin{array}{l}\text { RS-3 (Pavemend SLQ) over } \\
\text { Foam-iT! } 15\end{array}$ & $8 \times 8 \times 3$ & 7.0 & $100-5000$ \\
\hline \multicolumn{5}{|c|}{ Series 3} \\
\hline $\mathrm{Q}$ & RS-2 (Rapid Set) over Debris & $10 \times 10 \times 3.5$ & 13.0 & 5000 \\
\hline $\mathrm{R}$ & $\begin{array}{l}\text { RS-3 (Pavemend SLQ) over } \\
\text { Debris }\end{array}$ & $10 \times 10 \times 3.5$ & 13.0 & 5000 \\
\hline S & $\begin{array}{c}\text { RS-4 (ThoRoc 10-61) over } \\
\text { Debris Stabilized with Flowable } \\
\text { Fill }\end{array}$ & $10 \times 10 \times 3.5$ & 13.0 & 5000 \\
\hline $\mathrm{T}$ & $\begin{array}{l}\text { RS-6 (Ultimax) over Debris } \\
\text { Stabilized with Aquacrete Fill }\end{array}$ & $10 \times 10 \times 3.5$ & 13.0 & 5000 \\
\hline
\end{tabular}

Series 3 was conducted to evaluate the top performing RS materials from Series 2 over preplaced concrete debris in a larger volume repair. Series 3 craters were designed to validate that RS materials and expedient repair procedures could meet the 5,000-pass sustainment repair criteria. The 
remaining craters were not excavated and were reserved for future crater repair investigations.

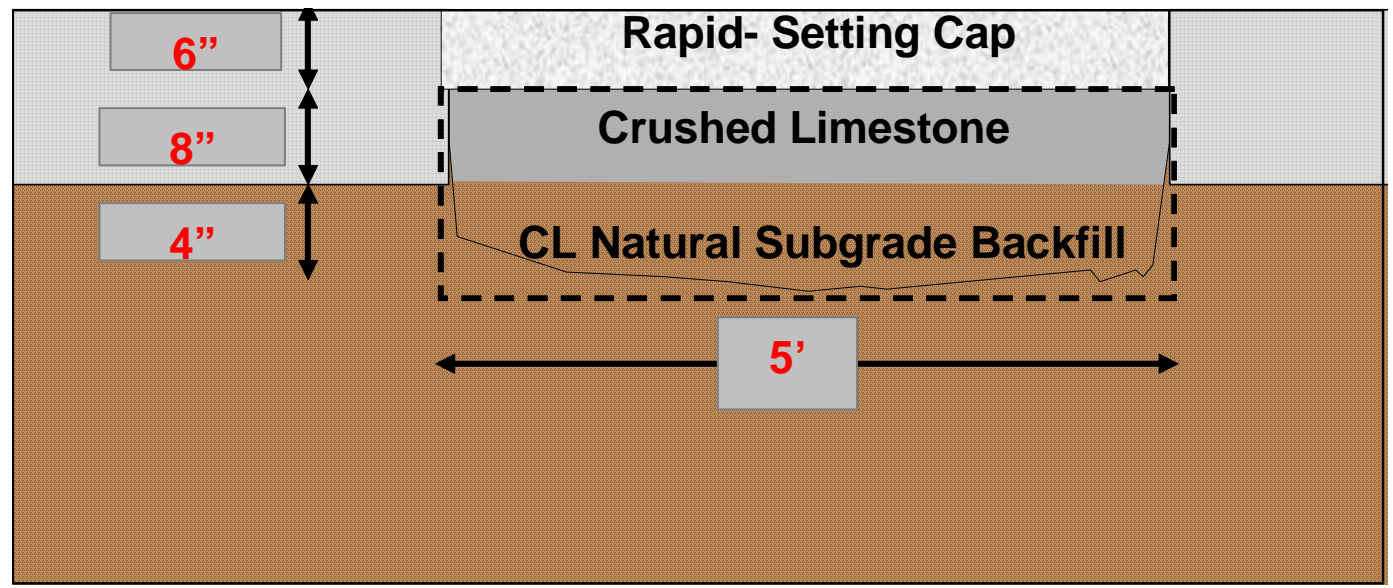

Figure 34. Typical section for Series 1 crater repairs.

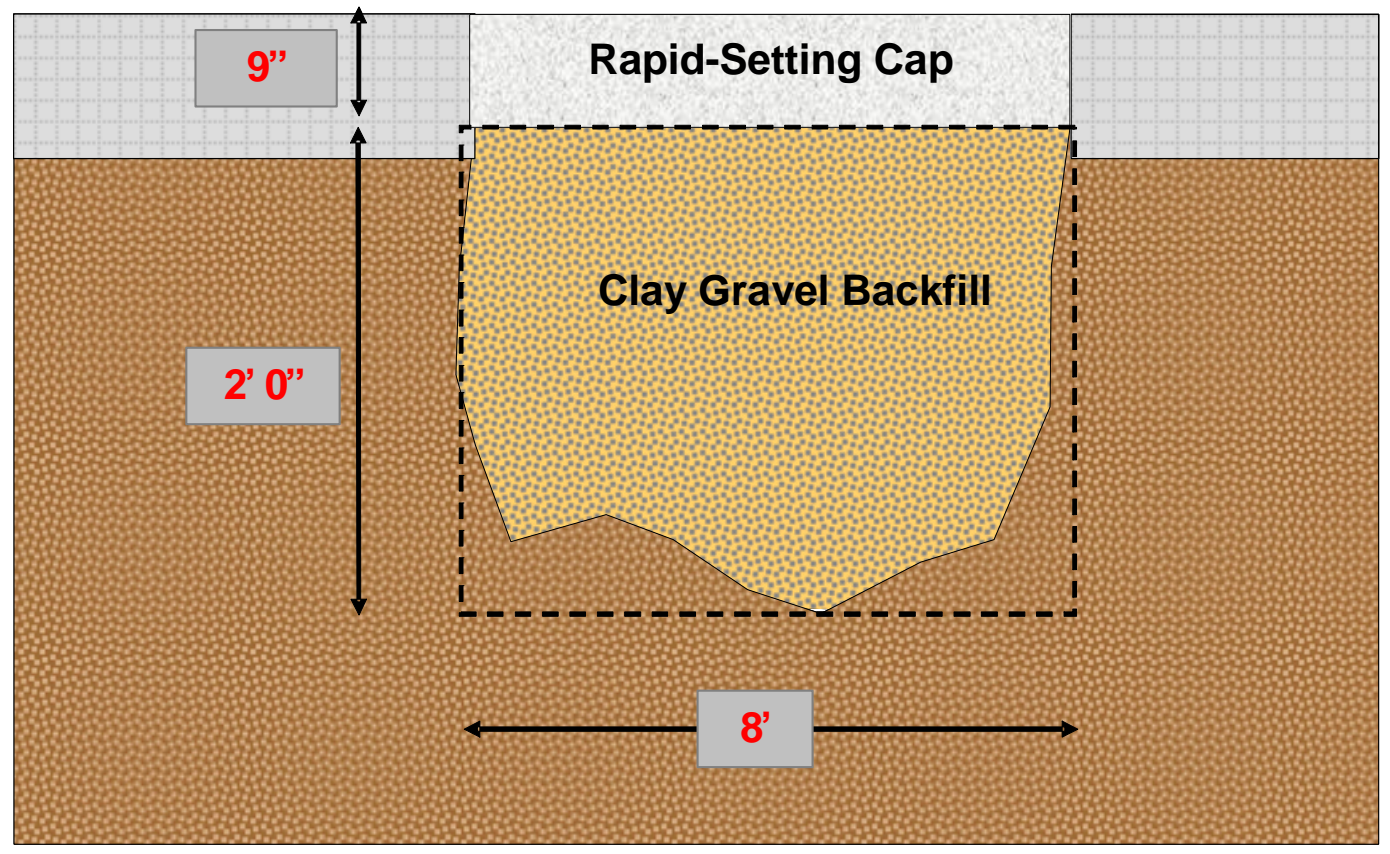

Figure 35. Typical section for Series 2 crater repairs.

\section{Series 1 crater repairs}

Series 1 crater repairs began J uly 17, 2006. A team from ERDC repaired Craters A- H in this series. Each repair had a total volume of $1.4 \mathrm{yd}^{3}$ including a cap volume of $12.5 \mathrm{ft}^{3}$. A total of 10 repairs were completed, including one repeat repair due to a subgrade failure. Prior to each crater repair, 14 to $18 \mathrm{in}$. of the subgrade was removed with a mini-excavator from each crater to locate the instrumentation conduit in the center of 
each crater. Once located, the instrumentation wires were pulled through the conduit in each crater and routed through a main trunk line adjacent to the north side of the section to the instrumentation pod. Three temperature thermocouples and one pressure cell were attached to these wires and placed in each crater prior to cap placement. One pressure cell (shown in Figure Error! Not a valid link.) was placed at the center of the crater and three thermocouples were placed near the edge of the repair, as shown in Figure 40.

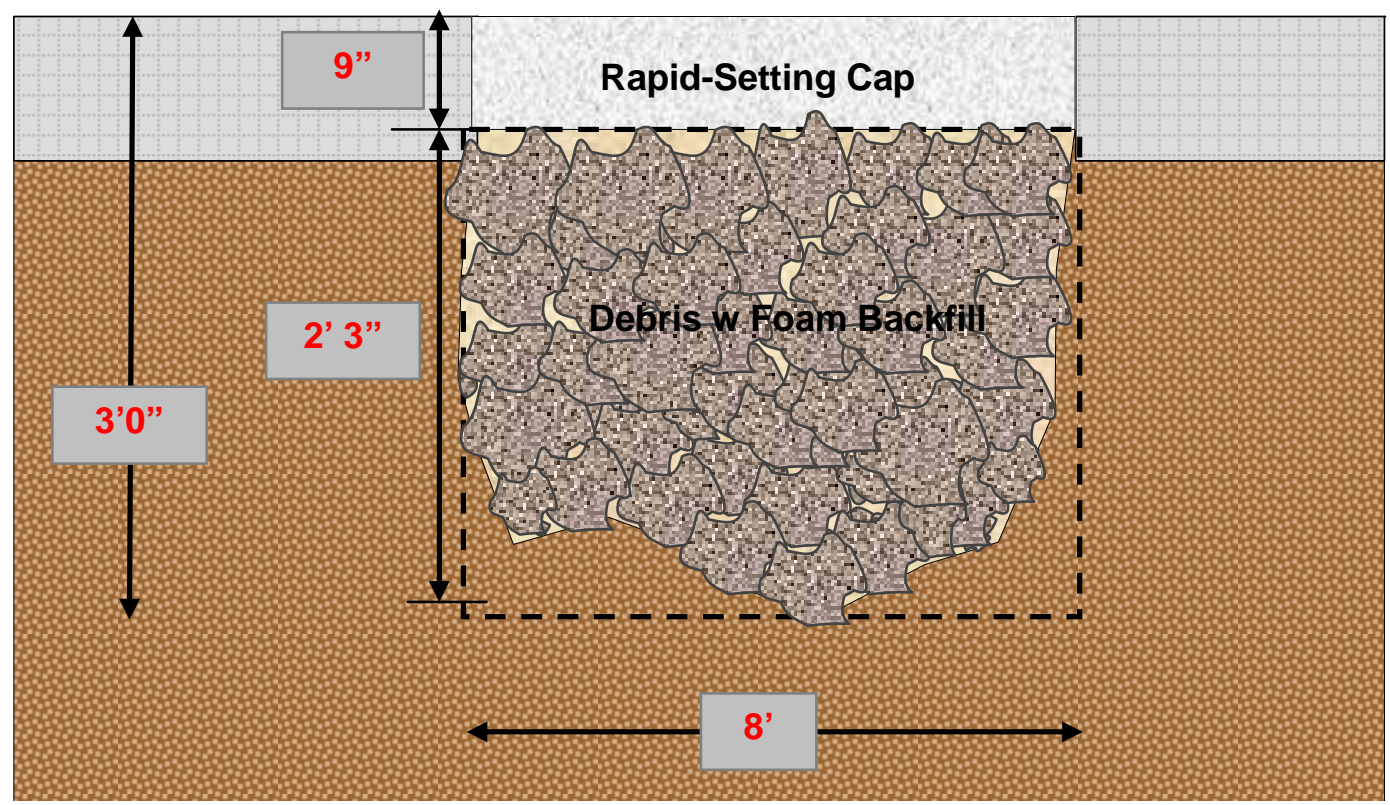

Figure 36. Typical section for Series 2 foam-debris crater repair.

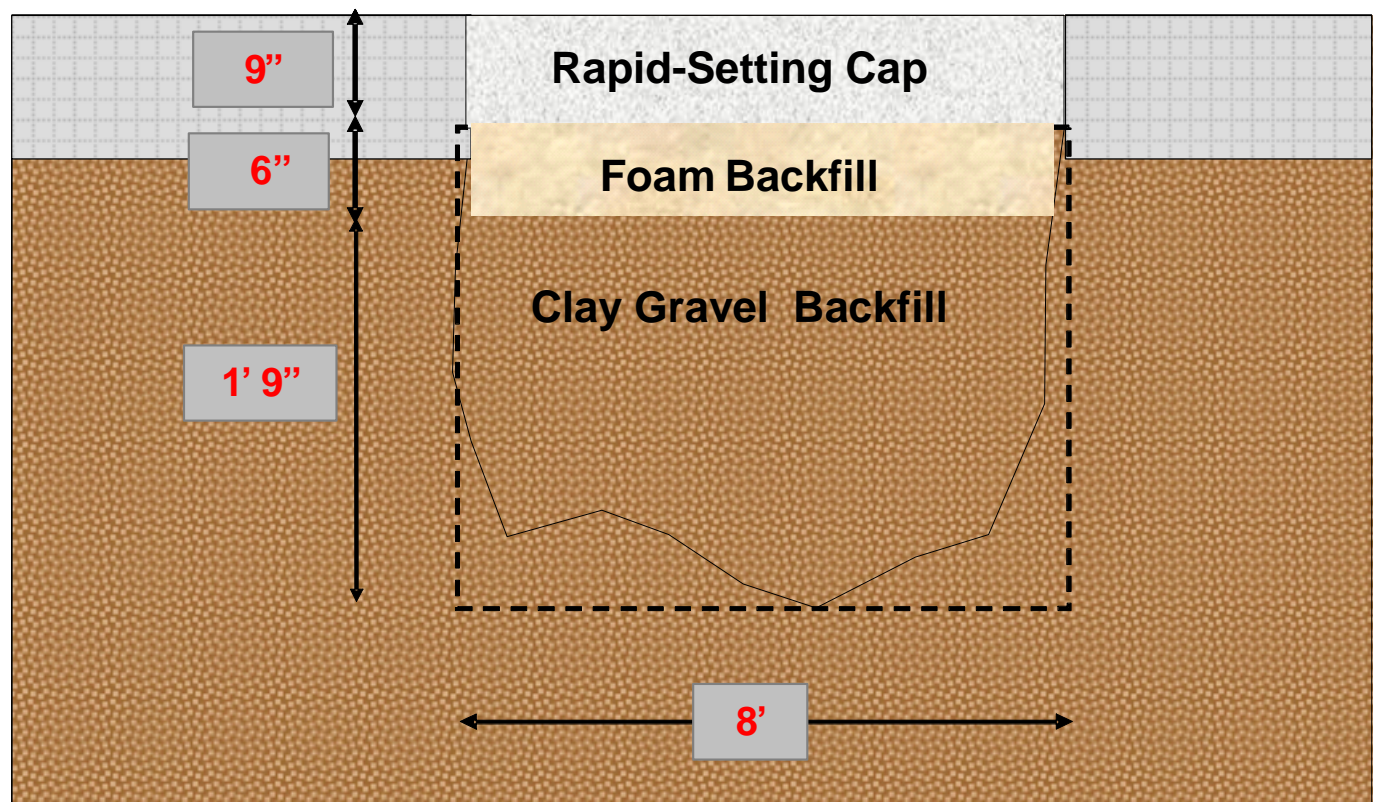

Figure 37. Typical section for Series 2 foam backfill crater repair. 


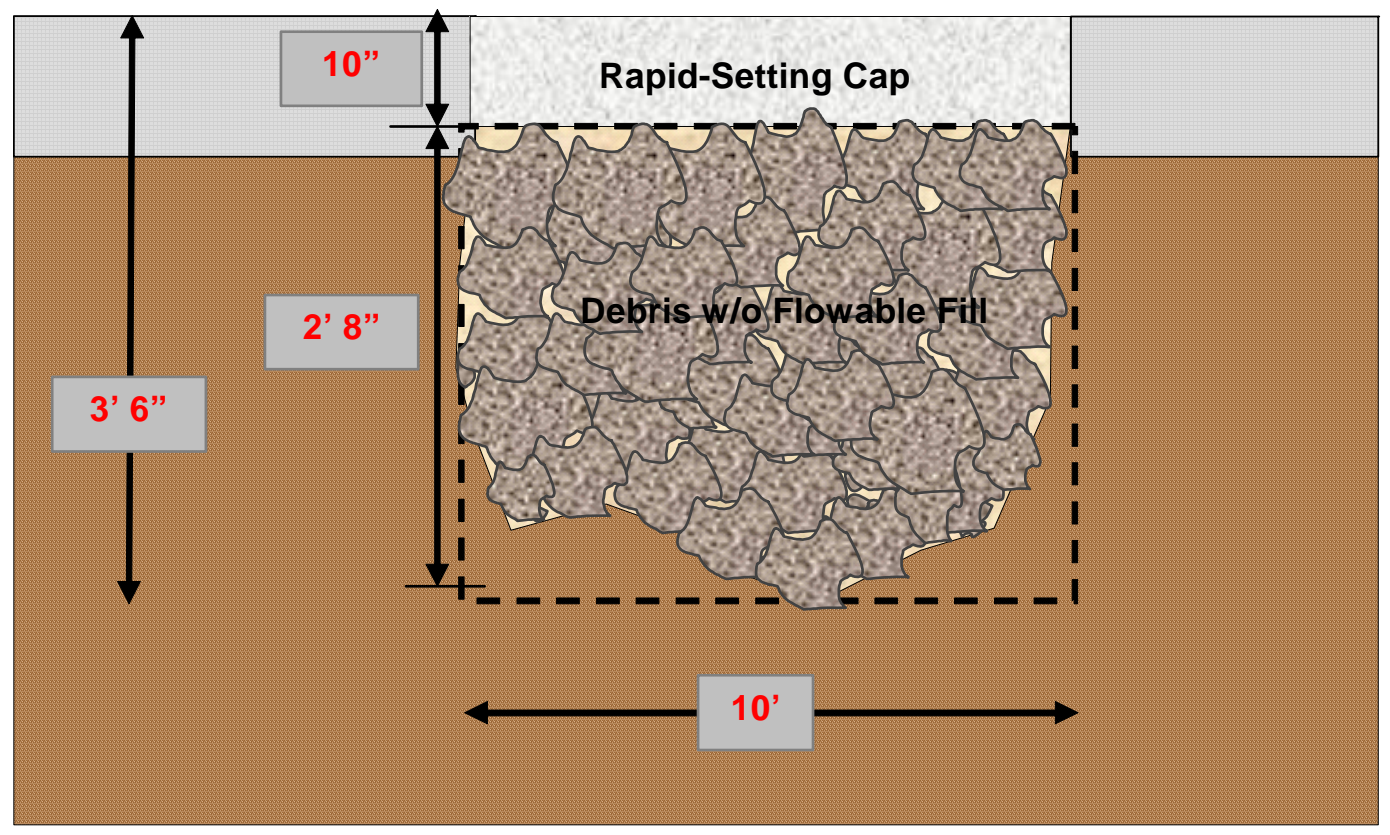

Figure 38. Typical Section for Series 3 crater repairs.

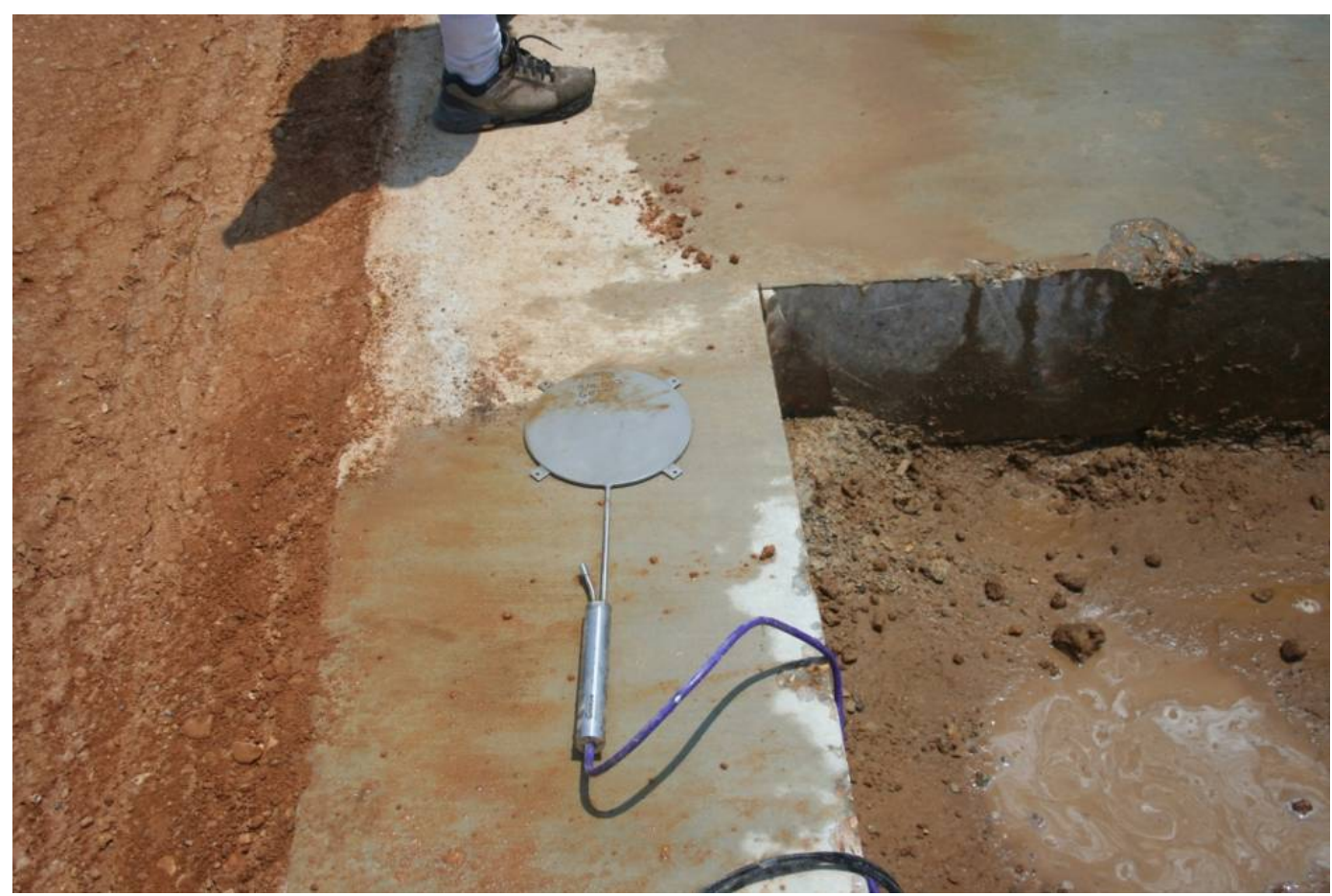

Figure 39. Earth pressure cell prior to installation.

The subgrade material was replaced and compacted in 6-in. lifts with a small tamping compactor to 14 in. below the pavement surface. The surface was then surveyed to ensure adequate thickness, and moisture and density measurements were performed with a Troxler 3440 nuclear gauge to ensure proper compaction. 


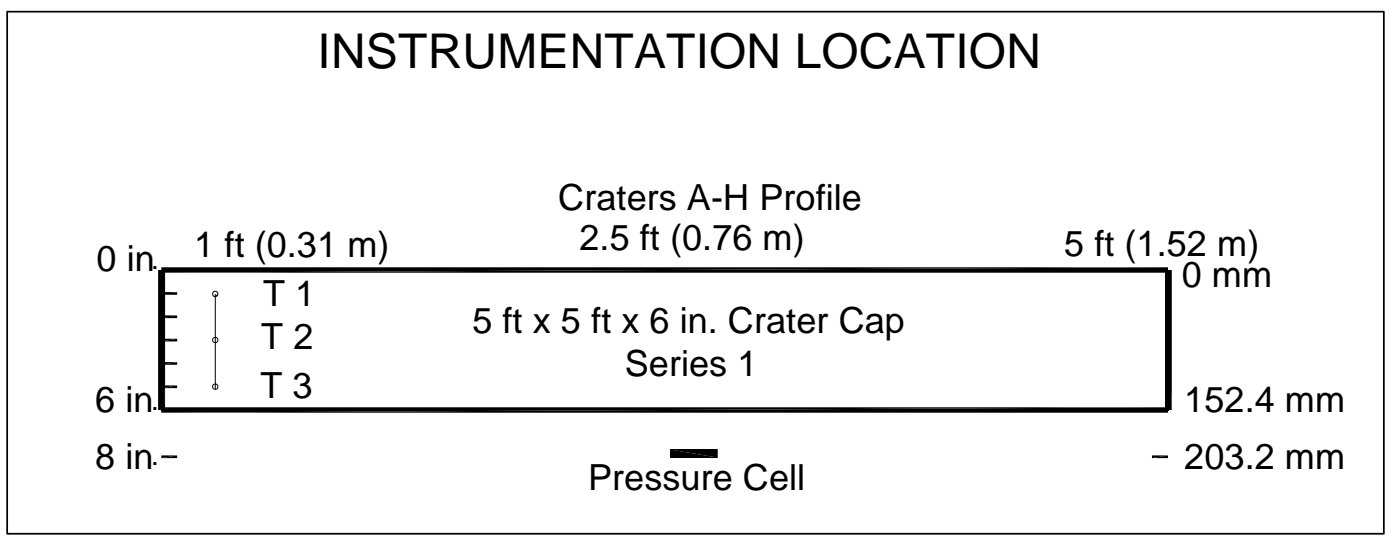

Figure 40. Instrumentation layout Series 1 craters.

A crushed limestone base was then placed and compacted in 6-in. lifts with a 136-lb plate compactor with a 12- by 10-in. plate area (Figure 41) and a small vibratory plate compactor (Figure 42). The crushed limestone was classified by the Unified Soil Classification system (ASTM D 2487) as a poorly graded gravel. This material had the following percentages of gravel, sand, and fines: 67.4, 30.7, and 1.8 percent, respectively. The color of the aggregate was gray. The crushed limestone produced a modified Proctor compaction (ASTM D 1557) optimum moisture content and a laboratory maximum dry density of approximately 1.9 percent and $120.6 \mathrm{lb} / \mathrm{ft}^{3}$, respectively. The pressure cells were installed $8 \mathrm{in}$. below the surface of the existing pavement with a 1-in. layer of sand over and under the earth pressure cell and over the wires for the three temperature sensors to protect them from the repair activities. Readings were performed under static and dynamic loading conditions. A temperature history of the rapid repair materials were monitored near the surface, at the center, and at the bottom of each cap layer. Additional crushed limestone was placed and compacted over this until a depth of 6 in. below the pavement surface remained for the rapid set cap.

Prior to placing the cap, DCP tests were performed to determine the strength of the underlying layers. Moisture and density measurements were performed with a nuclear gauge to ensure proper compaction. Three DCP tests and nuclear gauge tests were conducted in each crater. The density and moisture tests were conducted on both the base and subgrade. DCP tests were conducted after the base was in place. These tests were located $1 \mathrm{ft}$ from the southwest, southeast, and northeast corners of each crater. The tests were conducted along these edges as opposed to the center of the crater because compaction near the edges was more difficult to achieve for such a small area of repair. Because the craters would be 
trafficked along the south edge, proper compaction in this area was needed. It was assumed that if these areas met density and moisture specifications from modified proctor testing, then the center areas would exceed these values. Following these tests, the base surface was surveyed to make certain proper cap thickness would be achieved. Density, moisture, and DCP data are presented in Tables 20 and 21.

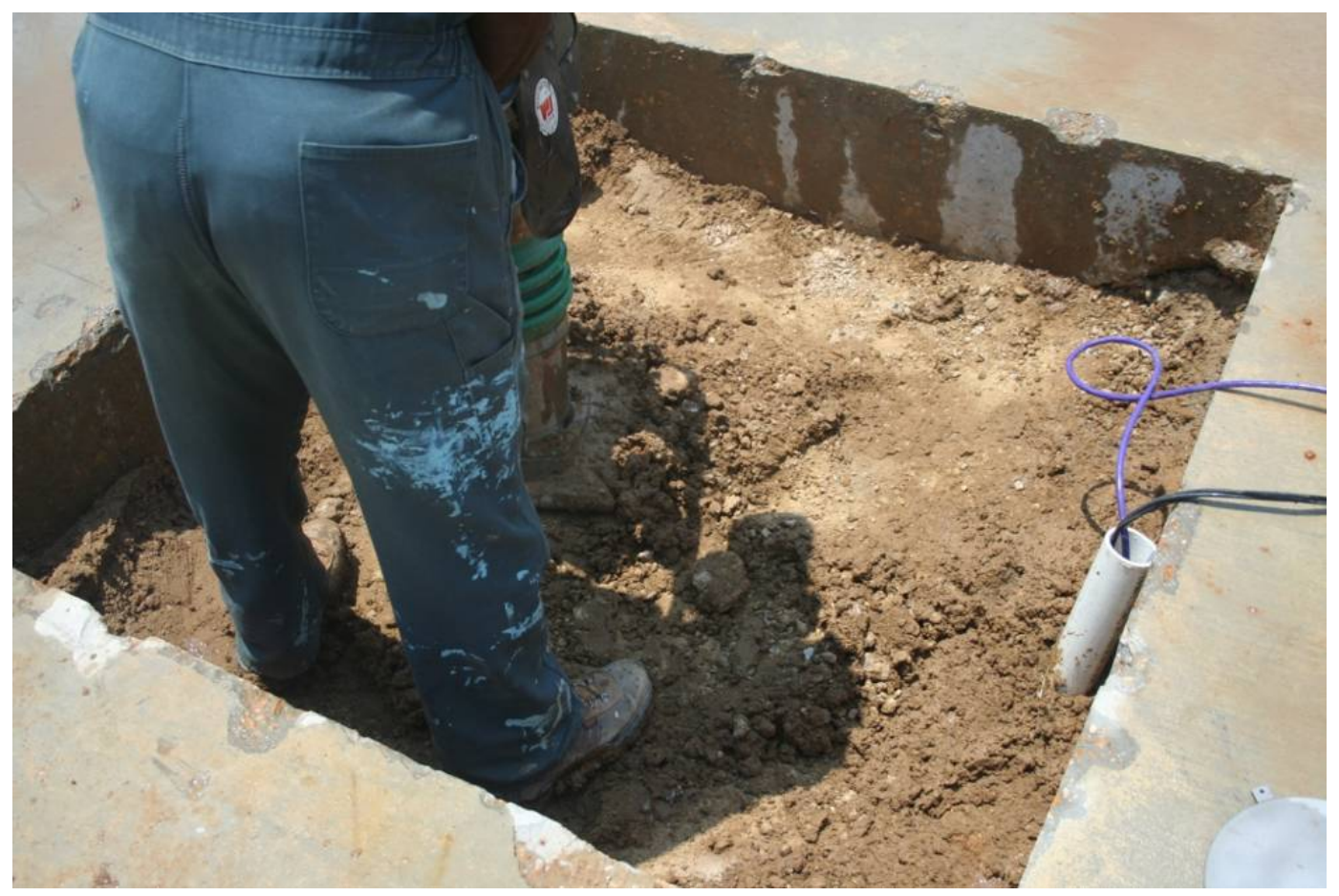

Figure 41. Compaction of subgrade material. 


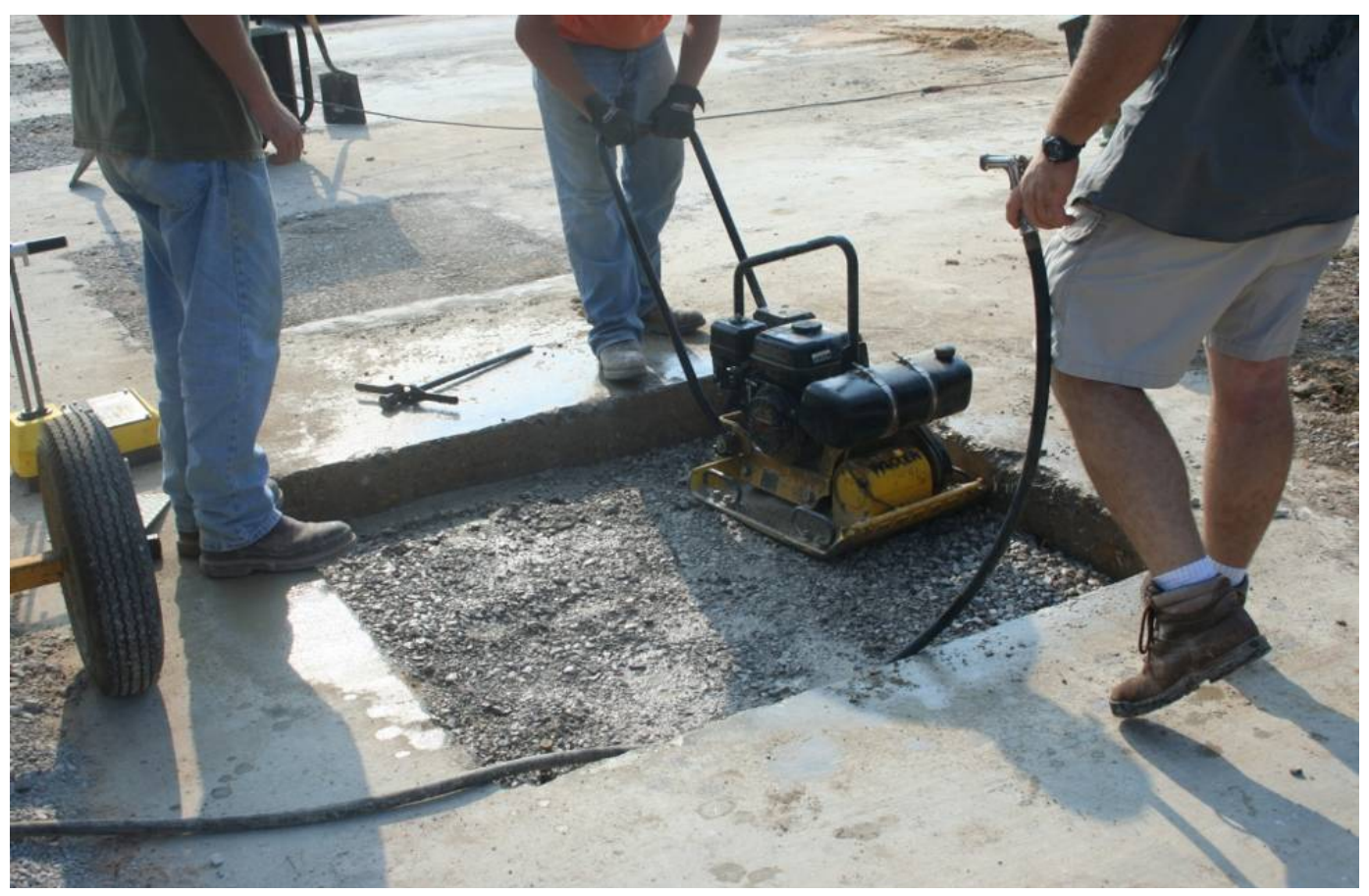

Figure 42. Compaction of the crushed limestone base.

Table 20. Series 1 backfill density and moisture content (continued).

\begin{tabular}{|c|c|c|c|c|c|c|}
\hline \multirow[b]{2}{*}{ Feature } & \multirow[b]{2}{*}{ Location } & \multirow[b]{2}{*}{$\begin{array}{l}\text { Depth, } \\
\text { in. }\end{array}$} & \multirow[b]{2}{*}{ Material } & \multicolumn{3}{|c|}{ Nuclear Gauge Measurements } \\
\hline & & & & $\begin{array}{l}\text { Wet } \\
\text { Density } \\
\left(\mathrm{lb} / \mathrm{ft}^{3}\right)\end{array}$ & $\begin{array}{c}\text { Dry } \\
\text { Density } \\
\left(\mathrm{lb} / \mathrm{ft}^{3}\right)\end{array}$ & $\begin{array}{c}\text { Moisture } \\
\text { Content } \\
\text { (\%) }\end{array}$ \\
\hline \multirow{8}{*}{ Crater A } & Southwest & 14 & Sandy Clay & 122.6 & 110.7 & 10.7 \\
\hline & Southeast & 14 & Sandy Clay & 121.6 & 109.6 & 11.0 \\
\hline & Northeast & 14 & Sandy Clay & $--^{-a}$ & $--^{-a}$ & $--^{-a}$ \\
\hline & \multicolumn{3}{|c|}{ Average } & 122.1 & 110.2 & 10.9 \\
\hline & Southwest & 6 & Limestone & 127.9 & 124.4 & 2.8 \\
\hline & Southeast & 6 & Limestone & 118.5 & 115.3 & 2.8 \\
\hline & Northeast & 6 & Limestone & $--a$ & $--a$ & $--a$ \\
\hline & \multicolumn{3}{|c|}{ Average } & 123.2 & 119.9 & 2.8 \\
\hline \multirow{8}{*}{ Crater B } & Southwest & 14 & Sandy Clay & 126.2 & 112.9 & 11.8 \\
\hline & Southeast & 14 & Sandy Clay & 126.4 & 110.3 & 14.5 \\
\hline & Northeast & 14 & Sandy Clay & $--^{a}$ & $--^{a}$ & $--^{-a}$ \\
\hline & \multicolumn{3}{|c|}{ Average } & 126.3 & 111.6 & 13.2 \\
\hline & Southwest & 6 & Limestone & 126.2 & 122.0 & 3.5 \\
\hline & Southeast & 6 & Limestone & 121.6 & 117.2 & 3.8 \\
\hline & Northeast & 6 & Limestone & $--^{a}$ & $--^{a}$ & $--a$ \\
\hline & \multicolumn{3}{|r|}{ Average } & 123.9 & 119.6 & 3.7 \\
\hline
\end{tabular}

a Data not collected at this location. 
Table 20. (Continued).

\begin{tabular}{|c|c|c|c|c|c|c|}
\hline \multirow[b]{2}{*}{ Feature } & \multirow[b]{2}{*}{ Location } & \multirow[b]{2}{*}{$\begin{array}{l}\text { Depth, } \\
\text { in. }\end{array}$} & \multirow[b]{2}{*}{ Material } & \multicolumn{3}{|c|}{ Nuclear Gauge Measurements } \\
\hline & & & & $\begin{array}{l}\text { Wet } \\
\text { Density } \\
\left(\mathrm{lb} / \mathrm{ft}^{3}\right)\end{array}$ & $\begin{array}{c}\text { Dry } \\
\text { Density } \\
\left(\mathrm{lb} / \mathrm{ft}^{3}\right)\end{array}$ & $\begin{array}{c}\text { Moisture } \\
\text { Content } \\
\text { (\%) }\end{array}$ \\
\hline \multirow{8}{*}{ Crater C-1 } & Southwest & 14 & Sandy Clay & 123.3 & 109.6 & 12.5 \\
\hline & Southeast & 14 & Sandy Clay & 117.6 & 102.7 & 14.5 \\
\hline & Northeast & 14 & Sandy Clay & $--a$ & $--a$ & $-{ }^{-a}$ \\
\hline & \multicolumn{3}{|r|}{ Average } & 120.5 & 106.2 & 13.5 \\
\hline & Southwest & 6 & Limestone & 140.8 & 128.3 & 9.8 \\
\hline & Southeast & 6 & Limestone & 140.3 & 126.3 & 11.1 \\
\hline & Northeast & 6 & Limestone & 143.0 & 131.3 & 8.9 \\
\hline & & & Average & 141.4 & 128.6 & 9.9 \\
\hline \multirow{8}{*}{ Crater C-2 } & Southwest & 14 & Sandy Clay & 136.7 & 119.2 & 14.6 \\
\hline & Southeast & 14 & Sandy Clay & 137.5 & 118.8 & 15.8 \\
\hline & Northeast & 14 & Sandy Clay & 134.4 & 115.9 & 15.9 \\
\hline & \multicolumn{3}{|r|}{ Average } & 136.2 & 118.0 & 15.4 \\
\hline & Southwest & 6 & Limestone & 147.5 & 141.2 & 4.5 \\
\hline & Southeast & 6 & Limestone & 141.5 & 134.8 & 5.0 \\
\hline & Northeast & 6 & Limestone & 147.4 & 140.3 & 5.1 \\
\hline & \multicolumn{3}{|r|}{ Average } & 145.5 & 138.8 & 4.9 \\
\hline \multirow{8}{*}{ Crater D } & Southwest & 14 & Sandy Clay & 127.8 & 114.7 & 11.4 \\
\hline & Southeast & 14 & Sandy Clay & 135.7 & 122.0 & 11.2 \\
\hline & Northeast & 14 & Sandy Clay & 107.7 & 123.7 & 14.9 \\
\hline & \multicolumn{3}{|r|}{ Average } & 123.7 & 120.1 & 12.5 \\
\hline & Southwest & 6 & Limestone & 123.0 & 119.0 & 3.4 \\
\hline & Southeast & 6 & Limestone & 139.5 & 135.4 & 3.0 \\
\hline & Northeast & 6 & Limestone & 133.6 & 130.6 & 2.2 \\
\hline & \multicolumn{3}{|r|}{ Average } & 132.0 & 128.3 & 2.9 \\
\hline \multirow{8}{*}{ Crater E } & Southwest & 14 & Sandy Clay & 117.3 & 101.2 & 16.0 \\
\hline & Southeast & 14 & Sandy Clay & 134.5 & 120.0 & 12.0 \\
\hline & Northeast & 14 & Sandy Clay & 128.3 & 116.2 & 10.4 \\
\hline & \multicolumn{3}{|r|}{ Average } & 126.7 & 112.5 & 12.8 \\
\hline & Southwest & 6 & Limestone & 128.1 & 125.4 & 2.2 \\
\hline & Southeast & 6 & Limestone & 127.9 & 124.6 & 2.7 \\
\hline & Northeast & 6 & Limestone & 121.0 & 117.2 & 3.2 \\
\hline & \multicolumn{3}{|r|}{ Average } & 125.7 & 122.4 & 2.7 \\
\hline
\end{tabular}

a Data not collected at this location. 
Table 20. (Concluded).

\begin{tabular}{|c|c|c|c|c|c|c|}
\hline \multirow[b]{2}{*}{ Feature } & \multirow[b]{2}{*}{ Location } & \multirow[b]{2}{*}{$\begin{array}{l}\text { Depth, } \\
\text { in. }\end{array}$} & \multirow[b]{2}{*}{ Material } & \multicolumn{3}{|c|}{ Nuclear Gauge Measurements } \\
\hline & & & & $\begin{array}{c}\text { Wet } \\
\text { Density } \\
\left(\mathrm{lb} / \mathrm{ft}^{3}\right)\end{array}$ & $\begin{array}{c}\text { Dry } \\
\text { Density } \\
\left(\mathrm{lb} / \mathrm{ft}^{3}\right)\end{array}$ & $\begin{array}{c}\text { Moisture } \\
\text { Content } \\
\text { (\%) }\end{array}$ \\
\hline \multirow{8}{*}{ Crater F } & Southwest & 14 & Sandy Clay & 114.7 & 101.1 & 13.5 \\
\hline & Southeast & 14 & Sandy Clay & 118.5 & 101.8 & 16.4 \\
\hline & Northeast & 14 & Sandy Clay & 112.5 & 97.2 & 15.7 \\
\hline & \multicolumn{3}{|r|}{ Average } & 115.2 & 100.0 & 15.2 \\
\hline & Southwest & 6 & Limestone & 139.8 & 135.1 & 3.4 \\
\hline & Southeast & 6 & Limestone & 142.7 & 138.3 & 3.2 \\
\hline & Northeast & 6 & Limestone & 150.0 & 143.1 & 4.8 \\
\hline & \multicolumn{3}{|r|}{ Average } & 144.2 & 138.8 & 3.8 \\
\hline \multirow{8}{*}{ Crater G-1 } & Southwest & 14 & Sandy Clay & 126.1 & 108.3 & 16.4 \\
\hline & Southeast & 14 & Sandy Clay & 125.8 & 109.4 & 15.0 \\
\hline & Northeast & 14 & Sandy Clay & 127.8 & 110.6 & 15.5 \\
\hline & \multicolumn{3}{|r|}{ Average } & 126.6 & 109.4 & 15.6 \\
\hline & Southwest & 6 & Limestone & 145.0 & 139.0 & 4.3 \\
\hline & Southeast & 6 & Limestone & 143.1 & 137.5 & 4.1 \\
\hline & Northeast & 6 & Limestone & 140.5 & 135.0 & 4.0 \\
\hline & \multicolumn{3}{|r|}{ Average } & 142.9 & 137.2 & 4.1 \\
\hline \multirow{8}{*}{ Crater G-2 } & Southwest & 14 & Sandy Clay & 125.0 & 106.0 & 17.9 \\
\hline & Southeast & 14 & Sandy Clay & 119.8 & 104.1 & 15.1 \\
\hline & Northeast & 14 & Sandy Clay & $-\mathrm{a}^{-a}$ & $--a$ & $-\mathrm{-a}^{-a}$ \\
\hline & \multicolumn{3}{|r|}{ Average } & 122.4 & 105.1 & 16.5 \\
\hline & Southwest & 6 & Limestone & 155.0 & 148.2 & 4.6 \\
\hline & Southeast & 6 & Limestone & 150.9 & 143.5 & 5.1 \\
\hline & Northeast & 6 & Limestone & 149.2 & 140.4 & 6.3 \\
\hline & \multicolumn{3}{|r|}{ Average } & 151.7 & 144.0 & 5.3 \\
\hline \multirow{8}{*}{ Crater H } & Southwest & 14 & Sandy Clay & 126.2 & 110.8 & 13.9 \\
\hline & Southeast & 14 & Sandy Clay & 124.8 & 109.7 & 13.8 \\
\hline & Northeast & 14 & Sandy Clay & 124.3 & 110.7 & 12.3 \\
\hline & \multicolumn{3}{|r|}{ Average } & 125.1 & 110.4 & 13.3 \\
\hline & Southwest & 6 & Limestone & 145.7 & 139.3 & 4.6 \\
\hline & Southeast & 6 & Limestone & 154.1 & 147.4 & 4.5 \\
\hline & Northeast & 6 & Limestone & 146.7 & 139.8 & 4.9 \\
\hline & \multicolumn{3}{|r|}{ Average } & 148.8 & 142.2 & 4.7 \\
\hline
\end{tabular}

a Data not collected at this location. 
Table 21. Series 1 average DCP estimated CBR values.

\begin{tabular}{|c|c|c|}
\hline \multirow{2}{*}{ Crater } & \multicolumn{2}{|c|}{ CBR, \% } \\
\cline { 2 - 3 } & Base & Subgrade \\
\hline A & 21 & 13 \\
\hline B & 25 & 11 \\
\hline C-1 & 16 & 12 \\
\hline C-2 & 34 & 11 \\
\hline D & 20 & 12 \\
\hline E & 21 & 12 \\
\hline F & 41 & 10 \\
\hline G-1 & 40 & 8 \\
\hline G-2 & 56 & 10 \\
\hline H & 42 & 10 \\
\hline
\end{tabular}

Once the crater subgrade and base were prepared, a 6-in. cap repair was conducted by a six-man team from ERDC. Special care was taken when mixing these products. Components in some of the products posed health risks to skin and eyes, so coveralls, goggles, masks, and gloves were provided for crew members.

\section{Crater A-Pavesaver}

Pavesaver is a two-part polymeric patching material for concrete pavement cracks and spalls. Prior to mixing, the crew was briefed by the vendor on proper mixing and placement of the repair material. Material was mixed in twenty-four 5-gal plastic buckets with heavy-duty drills and grout mixing blades. Each bucket was filled with 2,000 $\mathrm{ml}$ of component A; 2,300 ml of component B; two 75-lb bags of pre-weighed aggregate blend; and $100 \mathrm{ml}$ of vendor-provided accelerator. Components $\mathrm{A}$ and $\mathrm{B}$ and accelerator were mixed for approximately $30 \mathrm{sec}$. The aggregate blend was then added and mixing was continued until a uniform color was obtained (Figure 43). The mixed buckets were poured into the crater as soon as they were properly mixed (Figure 44). This continued until 24 buckets were mixed and placed. A total of $42 \mathrm{~min}$ was required to mix and place the cap. The mix was self-leveling and did not require special equipment to finish. 


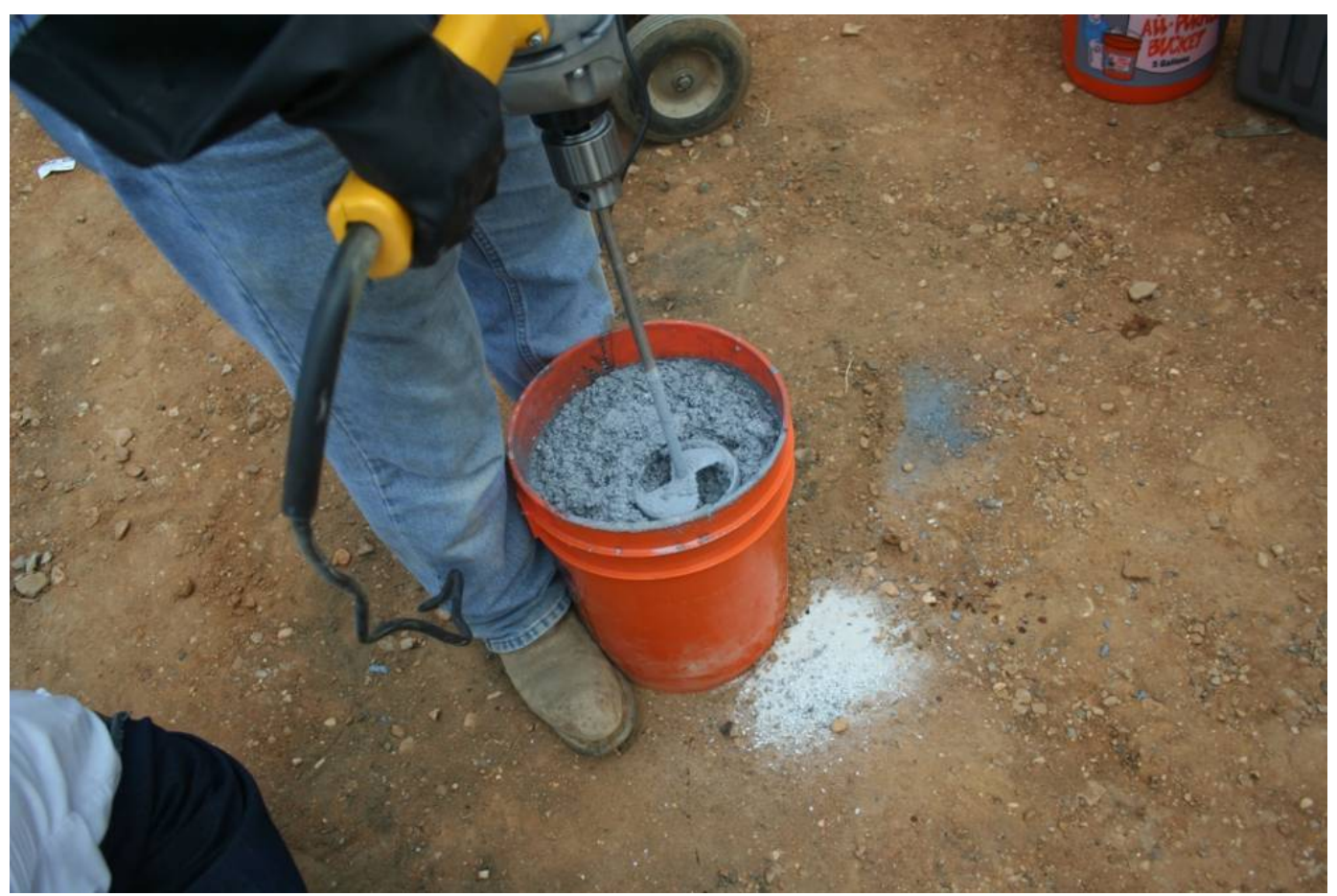

Figure 43. Crater A. Mixing Pavesaver.

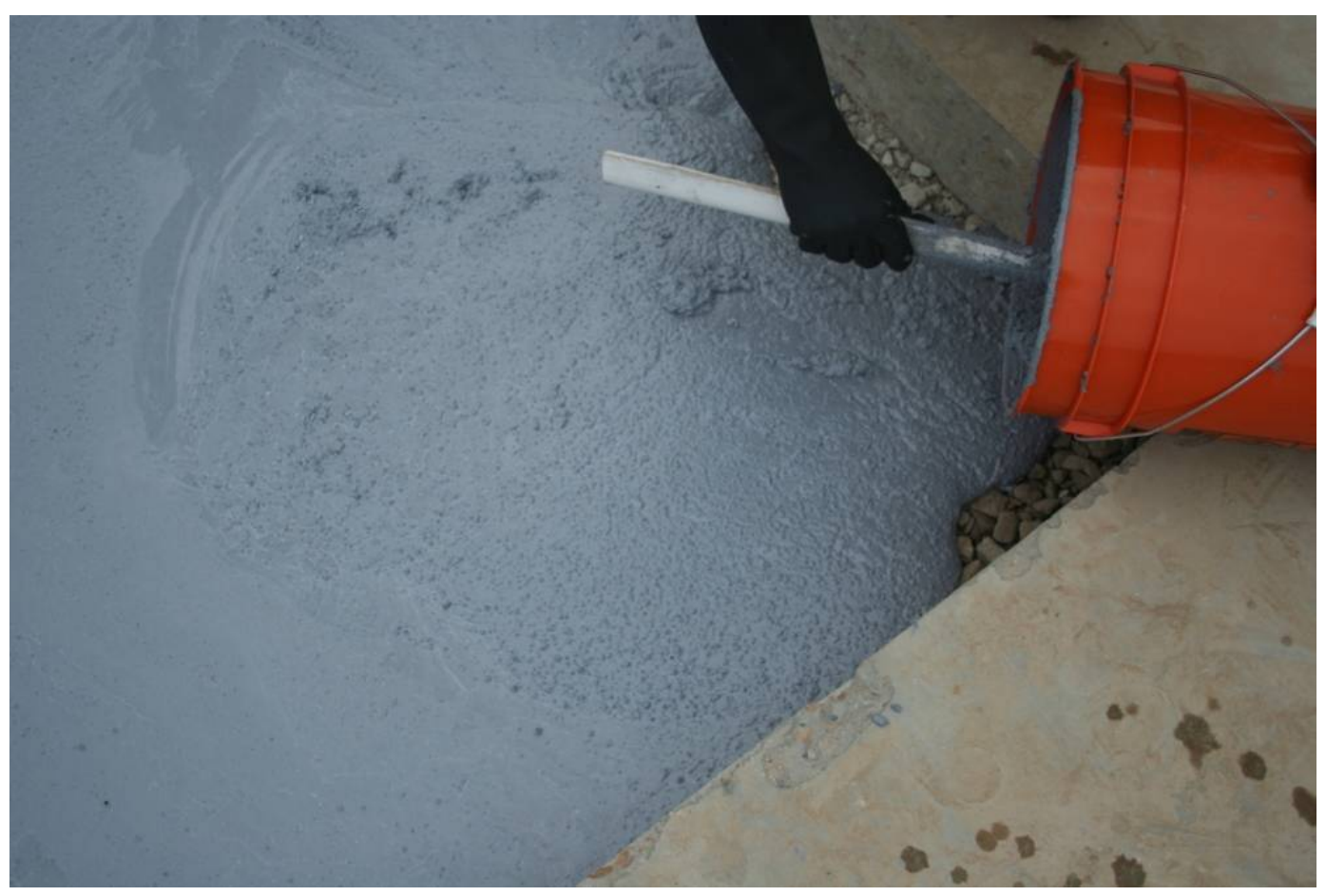

Figure 44. Crater A. Placing Pavesaver.

\section{Crater B-Rapid Set ${ }^{\circledR}$ concrete mix}

Rapid Set ${ }^{\circledR}$ is a very fast setting cementitious material that is used for rapid concrete pavement repair. As with Crater $\mathrm{A}$, the vendor 
representative briefed the six-person crew on proper mixing and placing of this material. The material was mixed in a $9 \mathrm{ft}^{3}$ portable drum mixer, transferred into a wheelbarrow, and placed. Each batch started by adding $5 \mathrm{gal}$ of water to the running mixer followed by five 60-lb bags of concrete mix and 15 packets of retarder. The retarder was Rapid Set FLOW CONTROL citric acid plasticizing admixture to extend the working time. The batches were mixed for 1.5 min until lump-free and uniform in consistency. Each batch was installed in full-depth sections, and placement progressed horizontally from the north side of the crater to the south with the aid of rakes and shovels. Six batches were required for the repair, and only 30 min was required to mix and place all of the repair material. The cap was struck level, hand troweled, and finished with a bull float. Figures 45, 46, and 47 present the mixing, placing, and finishing of the crater, respectively. Once placed, the cap was kept damp for $1 \mathrm{hr}$ by covering it with a piece of burlap.

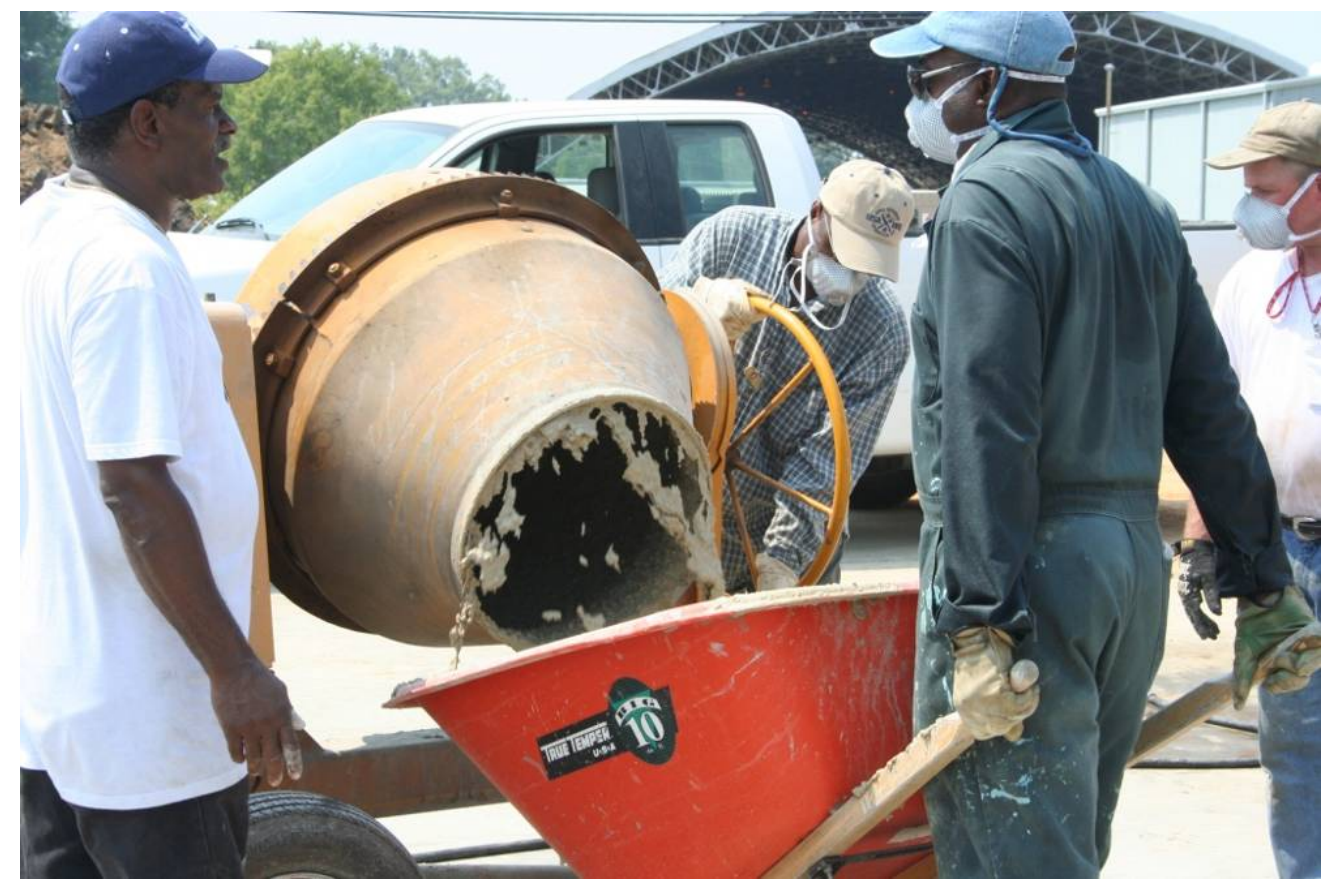

Figure 45. Crater B. Mixing and placing Rapid Set. 


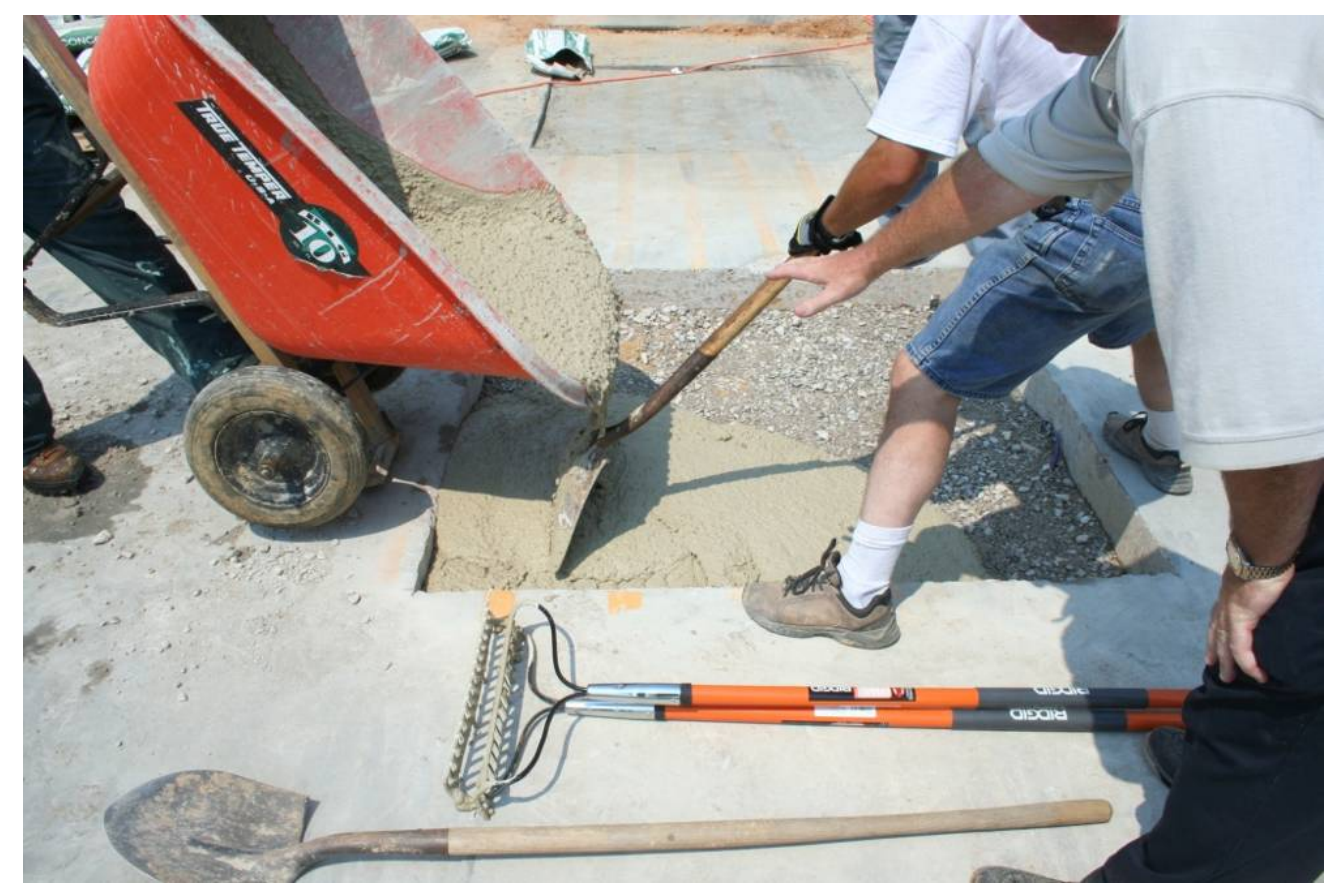

Figure 46. Crater B. Placing Rapid Set.

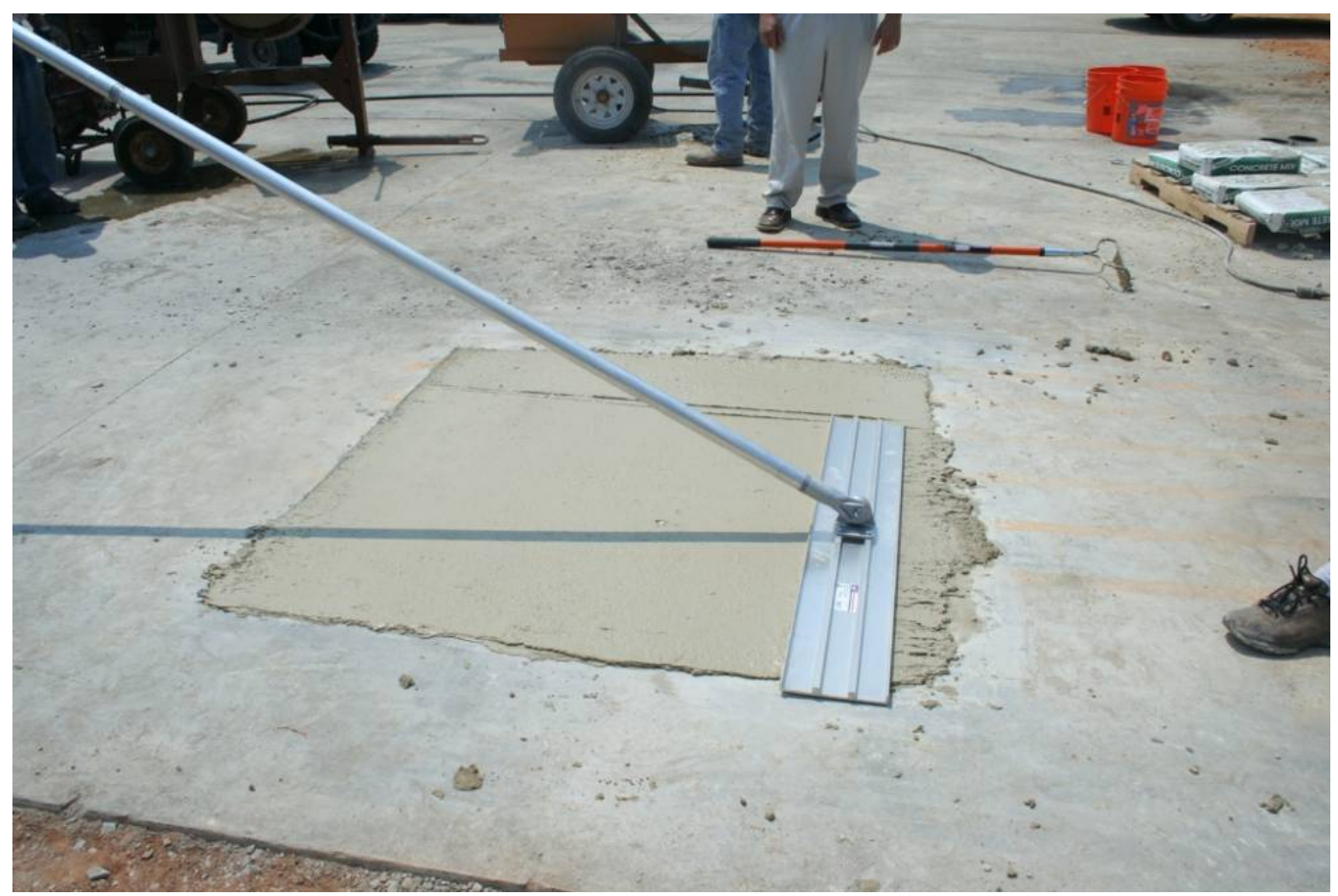

Figure 47. Crater B. Rapid Set finishing.

\section{Crater C-1-Pavemend SLQ ${ }^{\mathrm{TM}}$}

Pavemend $\mathrm{SLQ}^{\mathrm{TM}}$ is a rapid repair mortar that is used for rapid concrete pavement repair. Nearly $5 \mathrm{in}$. of rain fell prior to the repair of Crater C, so on the day of placement, the crater was filled with $4 \mathrm{in}$. of water. The crater 
was pumped free of standing water with a sump pump. DCP tests revealed a weakened subgrade. Fans were set up to dry the material in the crater. The vendor wished to continue with the scheduled repair despite the wet conditions. A survey of the base surface indicated that it had settled due to the excess water. Approximately $1 \mathrm{in}$. of crushed limestone base material was placed on the surface to increase the base thickness to the appropriate level and was hand tamped to compact. Moisture, density, and additional DCP tests were conducted.

As with the other craters, the vendor representative briefed the six-person crew on proper mixing and placing of this material. Gallon buckets each containing $22.5 \mathrm{lb}$ of 3/ 8-in. maximum aggregate size crushed limestone, drills, mixer blade attachments, and 5-gal buckets of material were shipped to the site. The material was then mixed in the 5-gal buckets it was shipped in. Two crews were set up to mix simultaneously. The materials and equipment are presented in Figure 48. Each bucket of dry material was first mixed with a high-speed drill with a mixer blade to loosen. A minimum of $300 \mathrm{rpm}$ was required. One gallon of water was then added and mixed for $90 \mathrm{sec}$. One bucket of aggregate was added and mixed for $15 \mathrm{sec}$. The buckets were immediately poured into the crater working around the perimeter of the crater until the entire bottom was covered. Once the crater bottom was covered, material was poured in layers in the same manner until the crater was filled completely. Approximately $5 \mathrm{~min}$ was required to open the buckets. Additionally, a total of 17 min was required to mix 26 buckets of repair material, place, and finish with hand trowels and a straightedge. Figure 49 shows finishing of the crater. Within minutes of pouring one bucket into the crater, the material was set (Figure 50). 


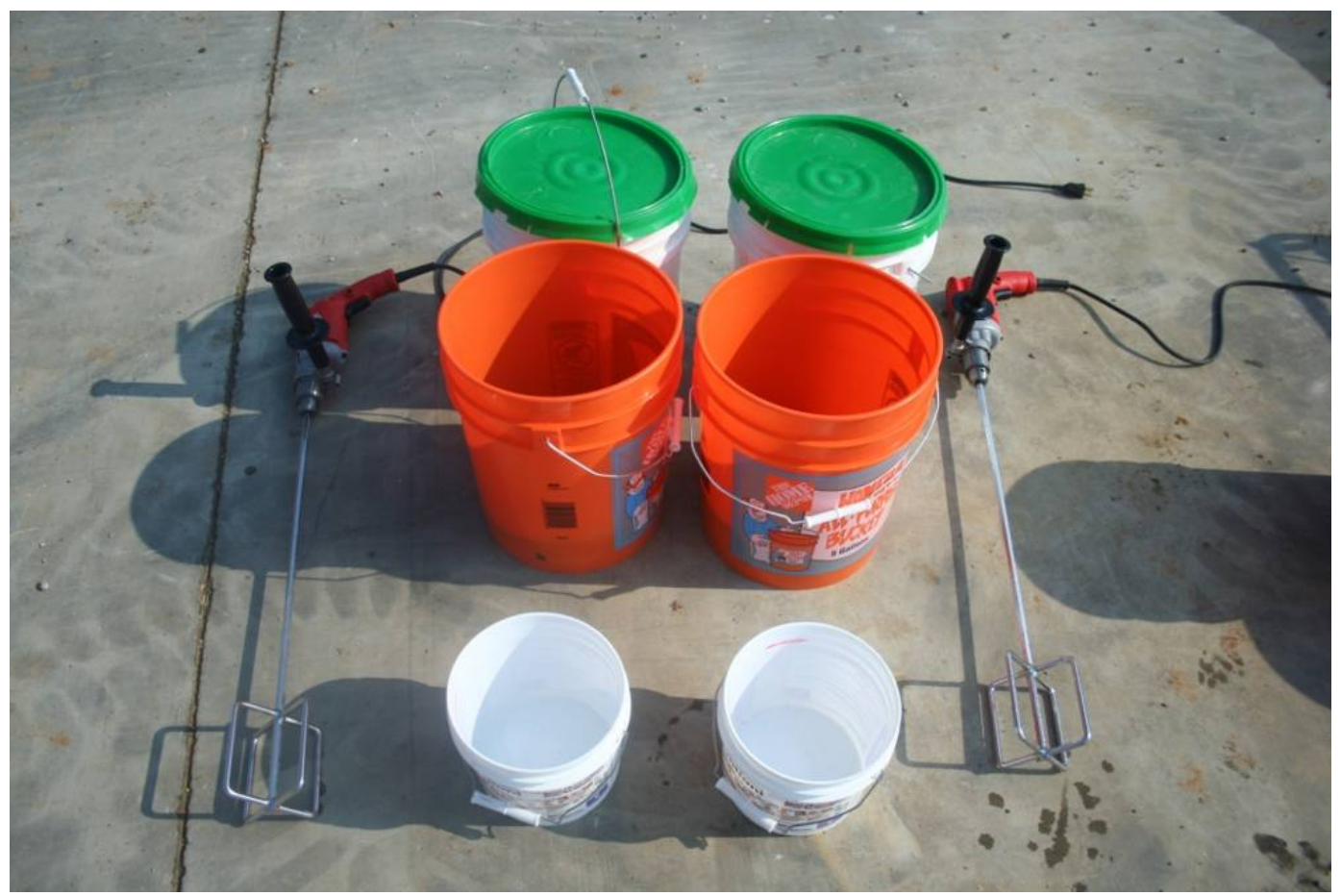

Figure 48. Crater C-1. Pavemend SLQ equipment and materials.

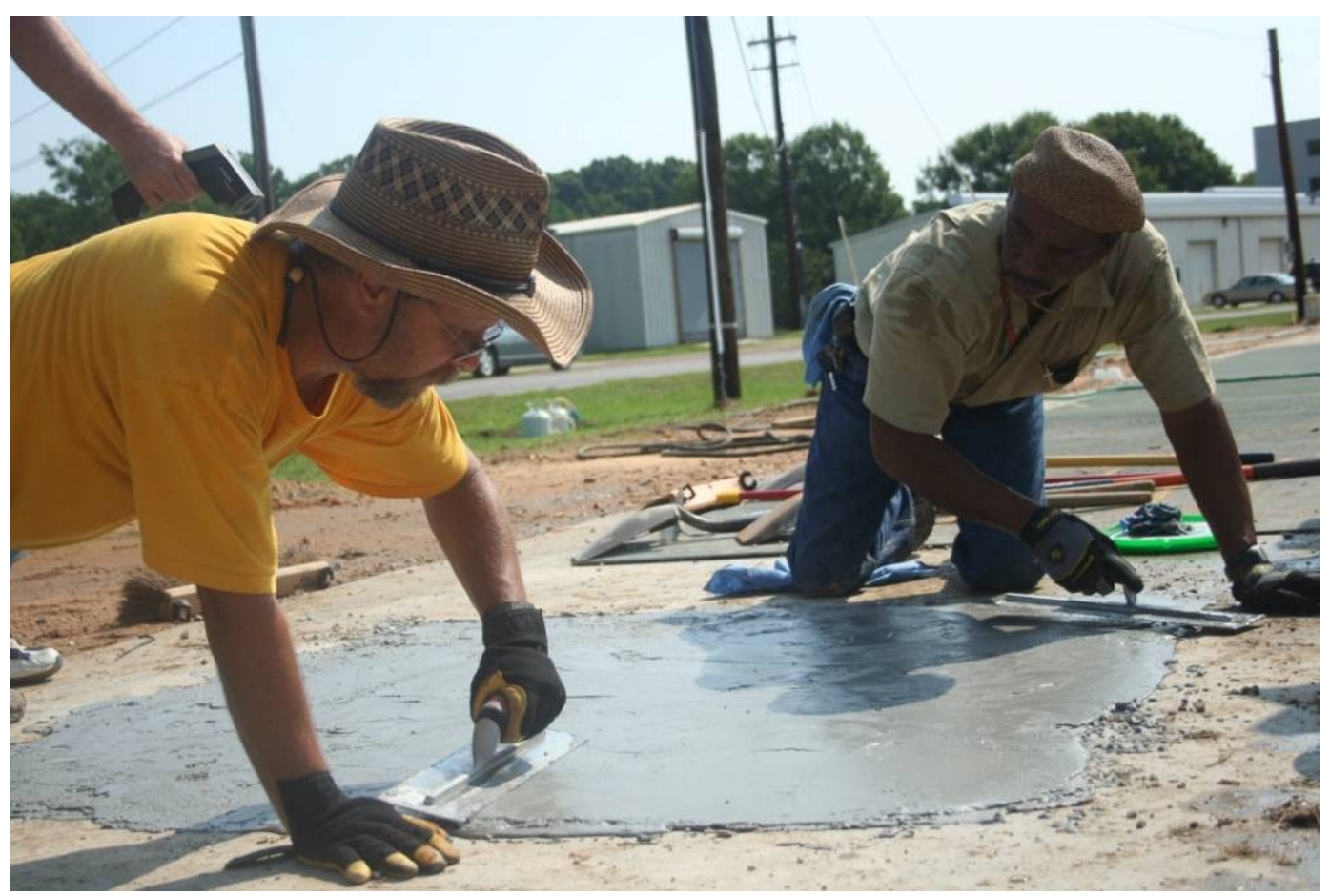

Figure 49. Crater C-1. Finishing surface. 


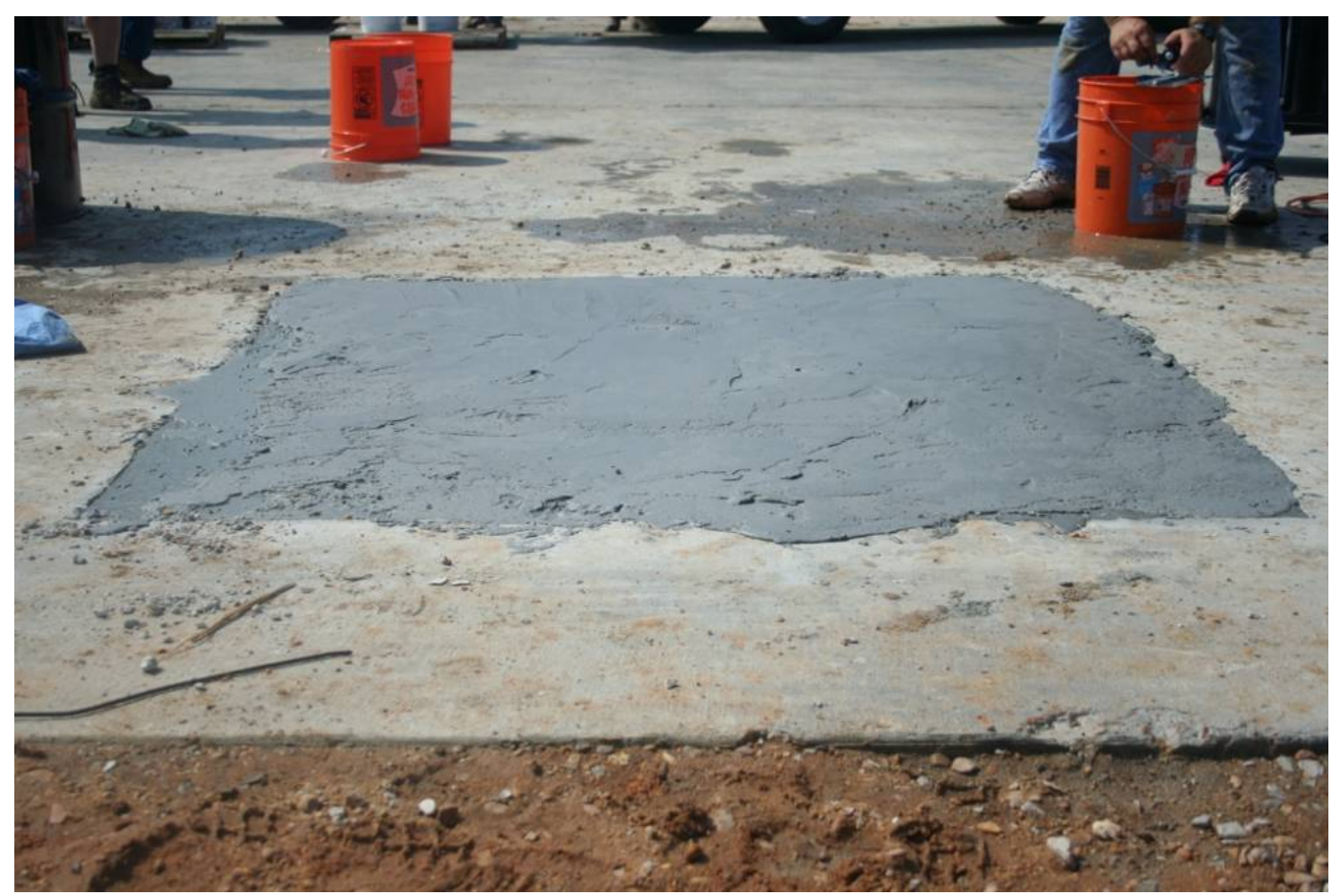

Figure 50. Crater C-1. Finished surface.

\section{Crater D-ThoRoc 10-61 Rapid Mortar}

ThoRoc 10-61 Rapid Mortar is a high alumina and portland cement-based rapid repair mortar that is used for rapid concrete pavement repair. As with the other craters, the vendor representative briefed the six-person crew on proper mixing and placing of this material.

Two portable horizontal shaft mortar mixers (Figure 51) were supplied by the vendor. Unfortunately, the other materials shipped by the vendor did not arrive in time, so 3/ 8-in. aggregate from a local stockpile and materials left over from laboratory tests were used. Two crews were set up to mix simultaneously with a mixer set up at the corners of the crater. Seventeen empty 5-gal buckets were filled with $50 \mathrm{lb}$ each of the aggregate. Once all materials were readied, mixing and placing began. To mix one batch, $2 \mathrm{gal}$ of water was poured into a mixer followed by three buckets of aggregate and three 50-lb bags of material. This was then allowed to mix for $3 \mathrm{~min}$. Additional water was needed during mixing as indicated by gears on the mixer's grinding. An extra $0.5 \mathrm{gal}$ of water was added to each batch. When mixing was complete, the mixers were emptied directly into the crater. Figure 52 shows using shovels to prevent material from setting in thin layers. Seventeen bags of material and buckets of aggregate were required to repair the crater. A total of 16 min was required to mix, place, and finish 
the material. The material was leveled with a straightedge and finished with a bull float and broom. Figure 53 shows the application of a broom finish to Crater D. Water was sprayed on the surface and plastic was laid over the crater for $1 \mathrm{hr}$.

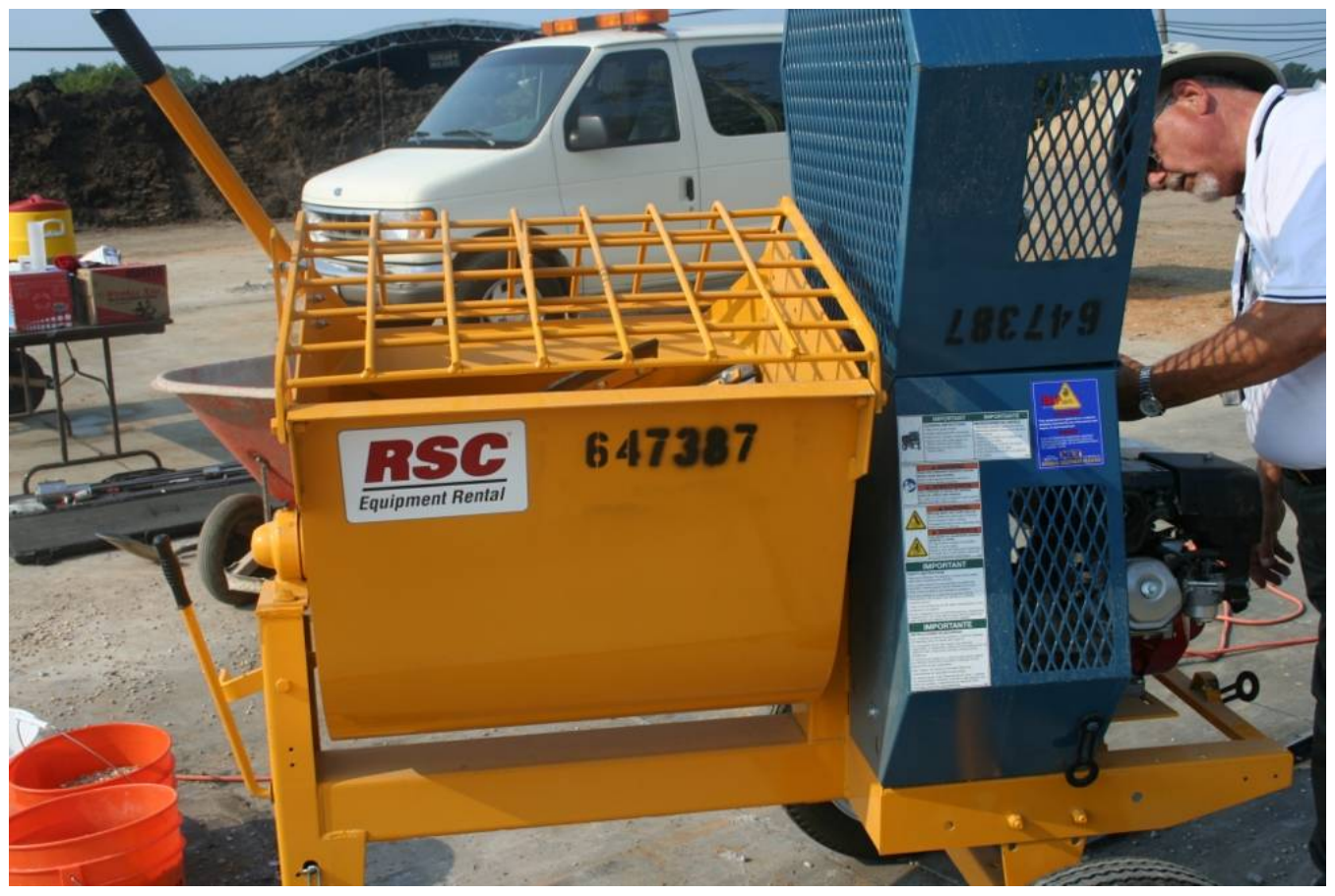

Figure 51. Crater D. Portable horizontal shaft mixer used for mixing.

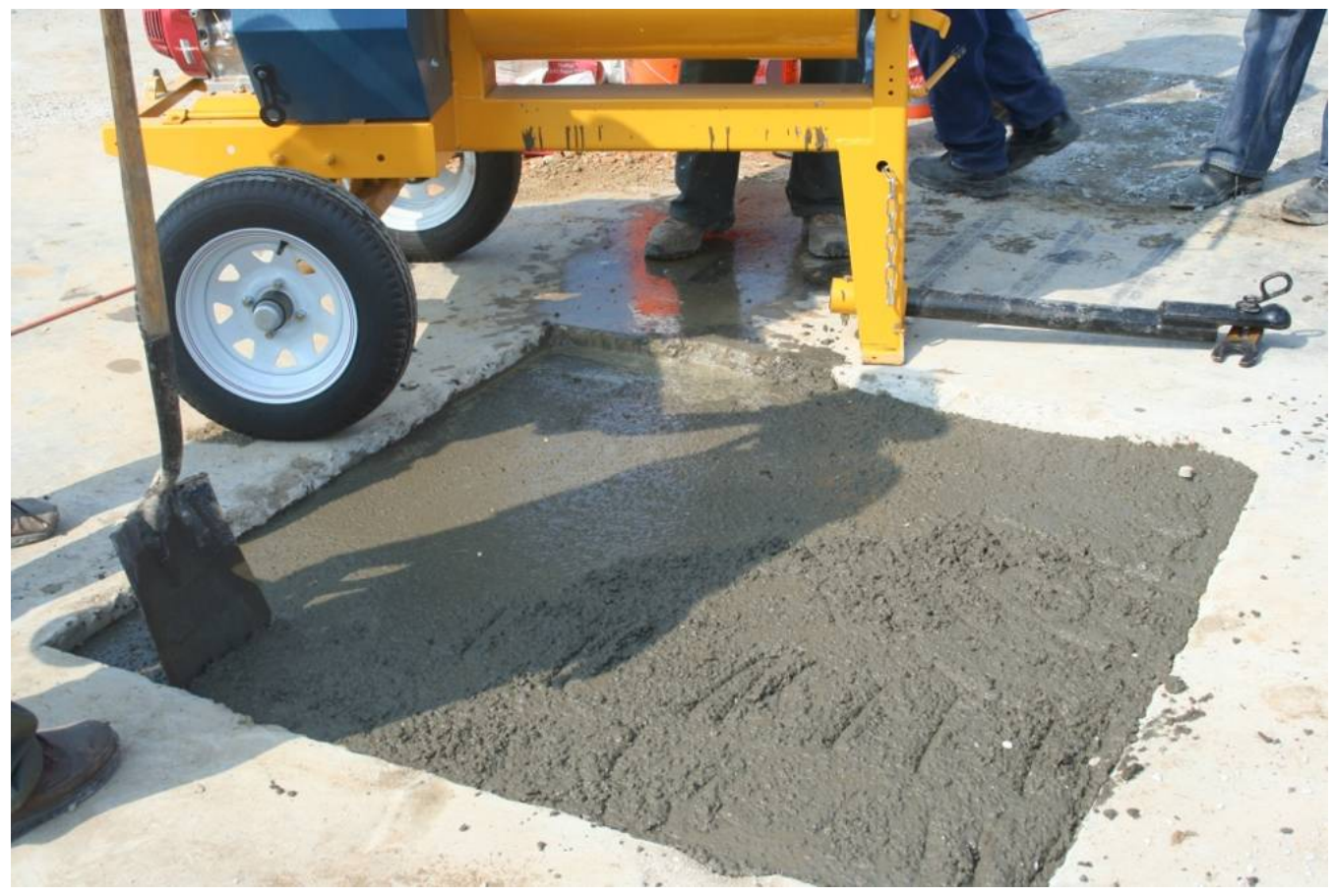

Figure 52. Crater D. Placing 10-61 in crater. 


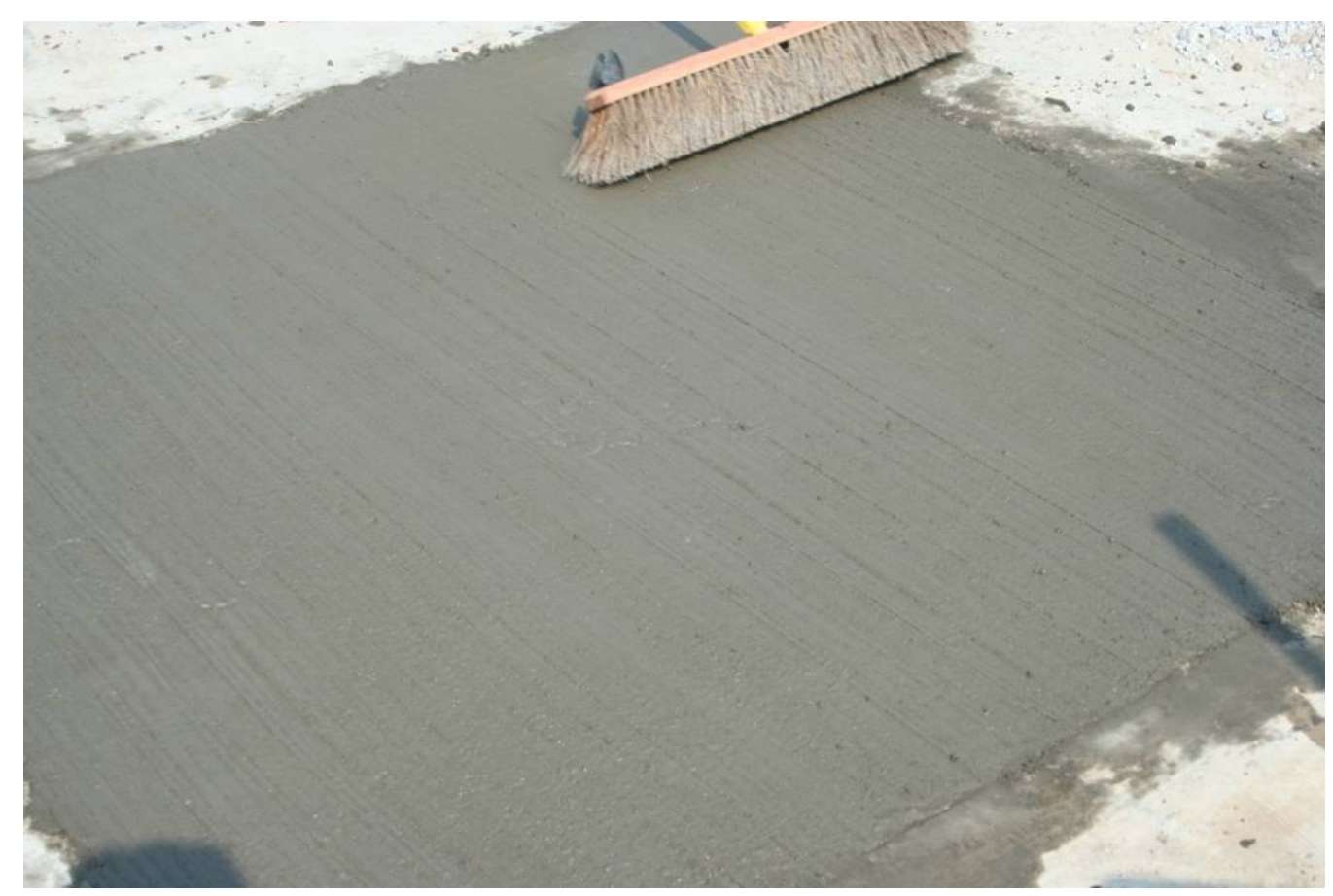

Figure 53. Crater D. Broom-finishing 10-61 surface.

\section{Crater E-SET ${ }^{\circledR} 45$ HW}

SET ${ }^{\circledR} 45 \mathrm{HW}$ is a magnesium phosphate-based cement that is used for rapid concrete pavement repair. This repair followed the ThoRoc 10-61 repair. The same vendor representative for ThoRoc 10-61 briefed the sixperson crew on proper mixing and placing of this material. The materials shipped by the vendor did not arrive in time, so the 50 -lb bags of SET $45 \mathrm{HW}$ and 60 -lb bags of 0.5-in. rounded aggregate previously supplied by the vendor for laboratory tests were used. The two portable horizontal shaft mortar mixers supplied by the vendor were also used. Two crews were set up to mix simultaneously with a mixer set up at the corners of the crater.

Once all materials were readied, mixing and placing began. To mix one batch, 1.5 gal of water were poured into a mixer, followed by 1.5 bags of aggregate and three 50 -lb bags of material. The batch was allowed to mix for 2 to $3 \mathrm{~min}$. Additional water was needed during mixing as indicated by gears on the mixers grinding. An extra 0.5 gal of water was added to each batch. When mixing was complete, the mixers were emptied directly into the crater. Figure 54 shows the placement of the first two batches of mix. Approximately 20 bags of material and 10 bags of aggregate were required to repair the crater. Bags of aggregate and material available did not fill the crater completely. An additional $50 \mathrm{lb}$ of 3/ 8-in. aggregate left over 
from Crater D was sprinkled on top of the repair and worked into the placed material by shovel and hand trowel (Figure 55). A total of $31 \mathrm{~min}$ was required to mix, place, and finish the material. The material was leveled with a straightedge and finished with a bull float. Figure 56 shows the finished crater marked for traffic and cross sections.

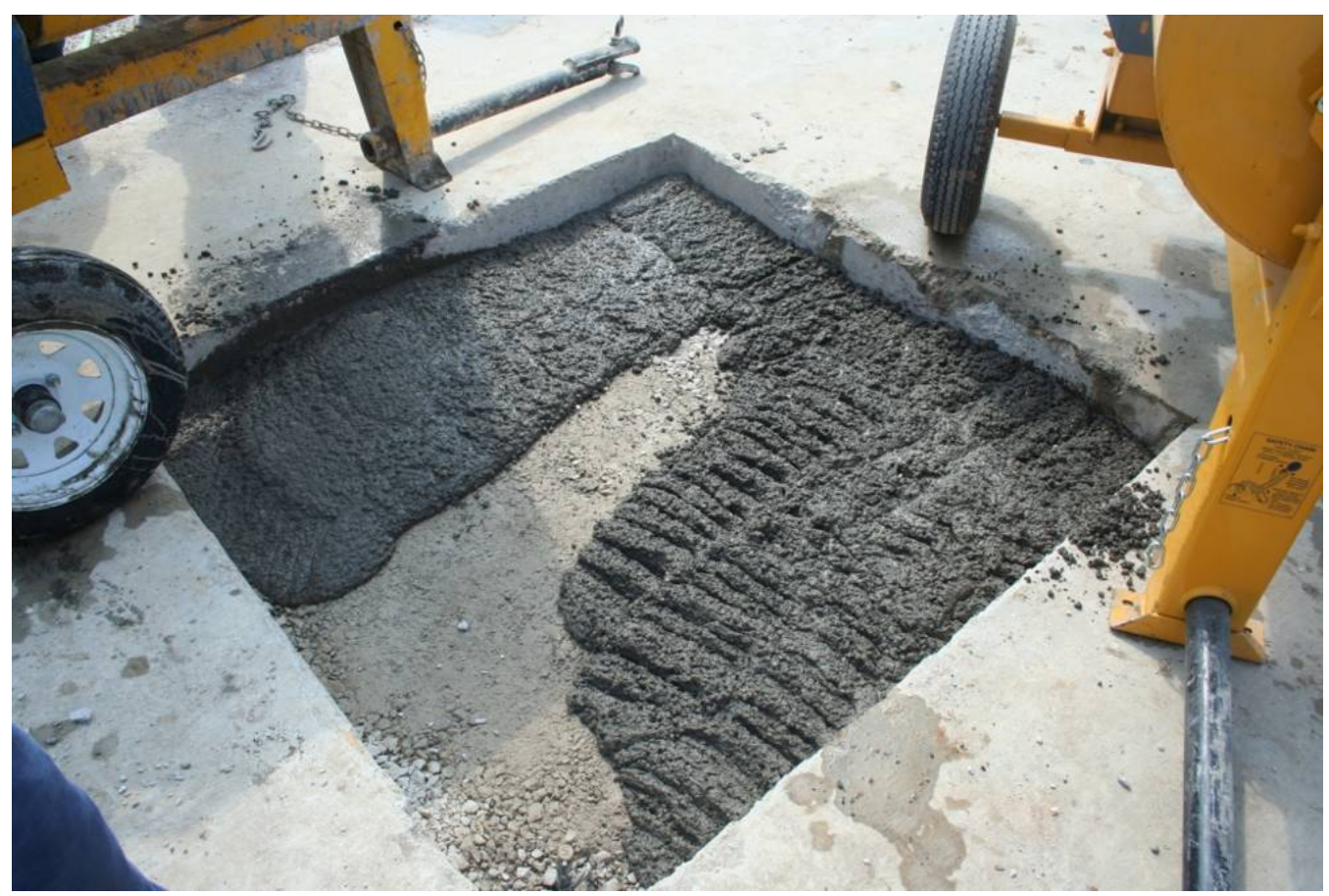

Figure 54. Crater E. Placing Set 45 HW.

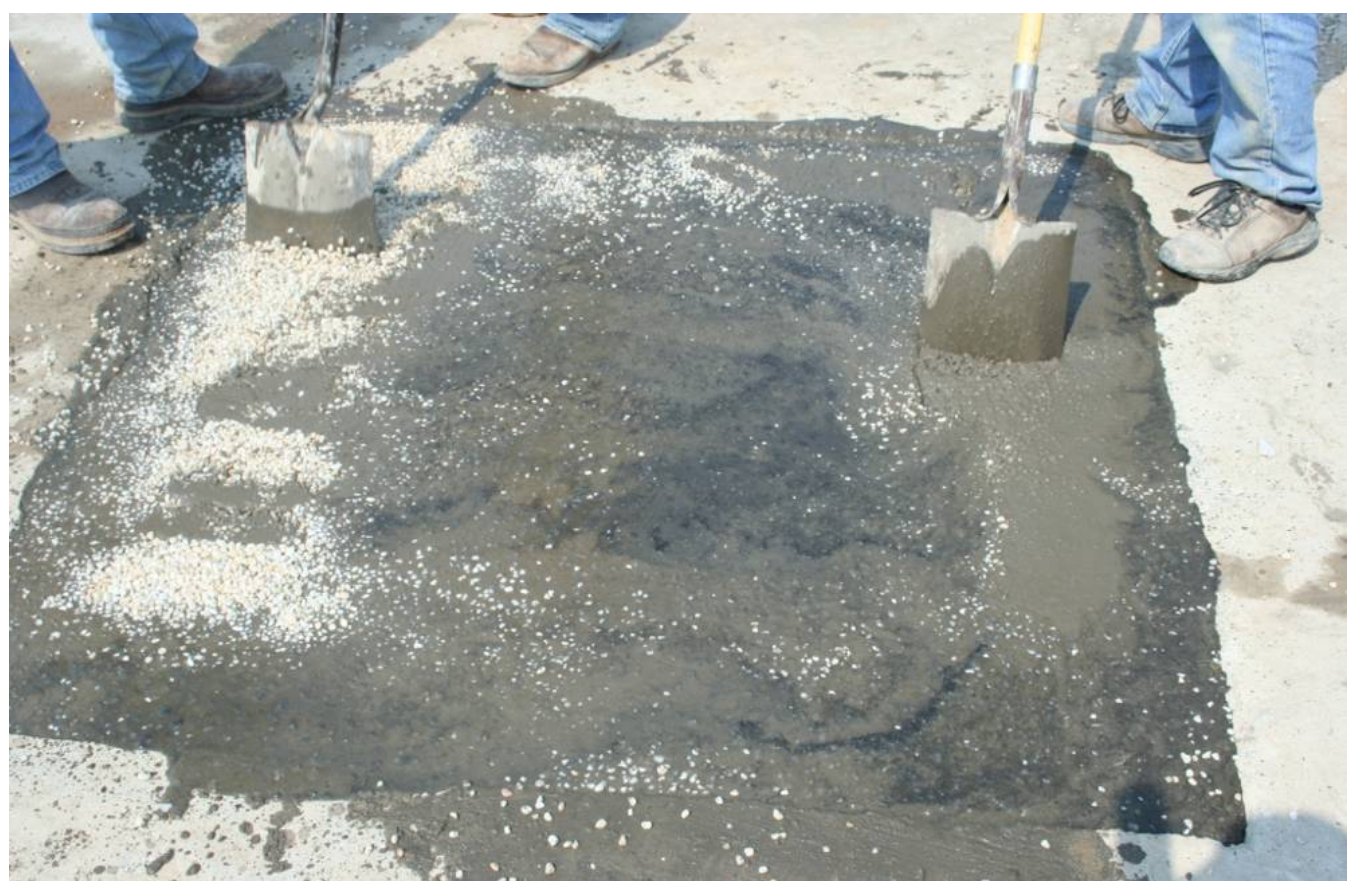

Figure 55. Crater E. Application of 3/8-in. aggregate to surface. 


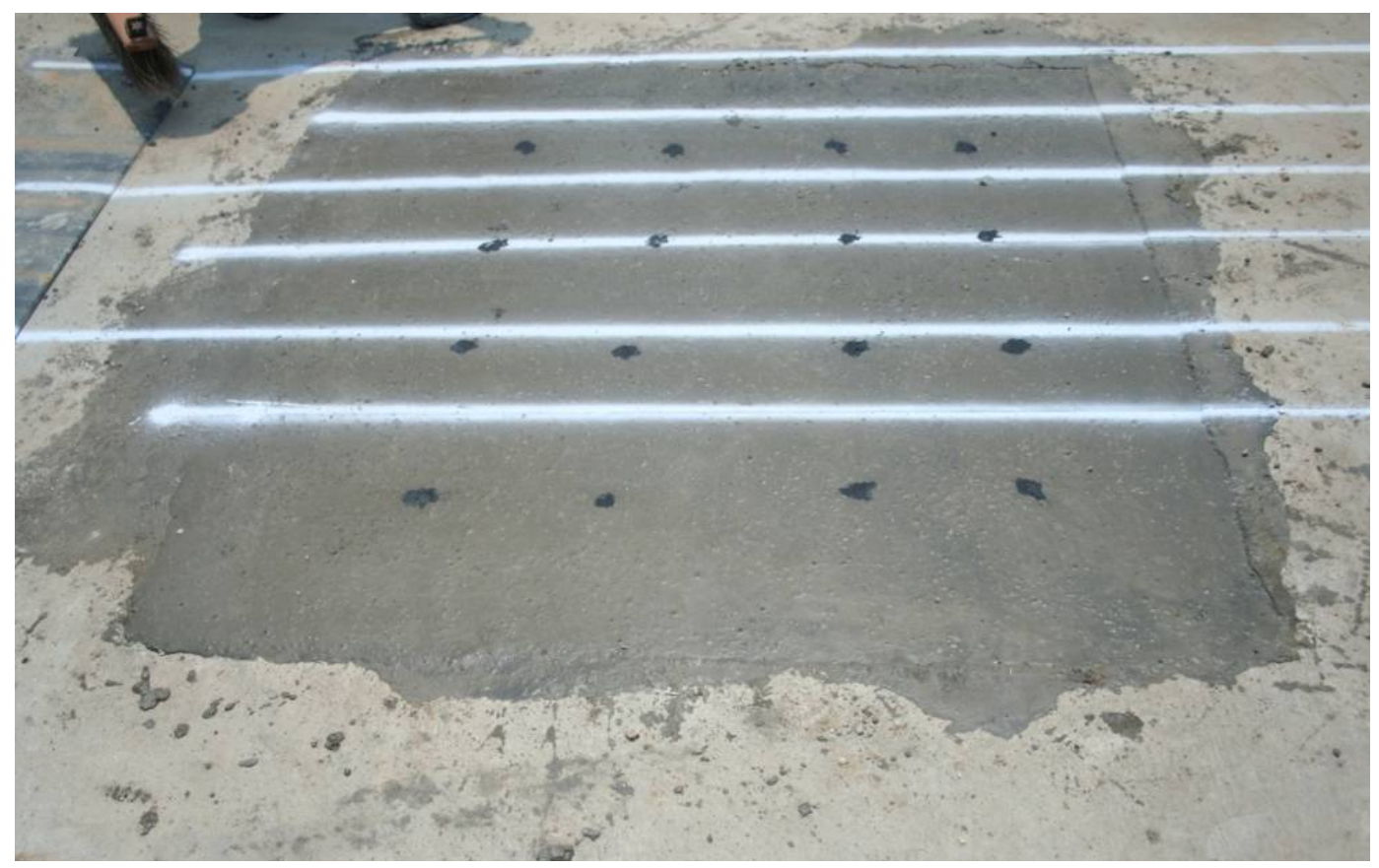

Figure 56. Crater F. Finished surface.

\section{Crater F-Ultimax Concrete}

Ultimax Concrete is a very fast setting aluminum phosphate-based cement material that is used for rapid concrete pavement repair. As with the other craters, the vendor representative briefed the six-person crew on proper mixing and placing of this material. The material was mixed in a $9 \mathrm{ft}^{3}$ portable drum mixer and emptied directly into the southeast corner of the crater (Figure 57). The first batch started by adding $3.5 \mathrm{gal}$ of water to the running mixer followed by five 50 -lb bags of concrete mix. An additional $0.75 \mathrm{gal}$ of water was added, and the mixture was allowed to mix for $3 \mathrm{~min}$ or until lump-free and uniform in consistency. The second and third batches consisted of $5 \mathrm{gal}$ of water followed by seven bags of concrete mix and an extra $0.5 \mathrm{gal}$ of water. Batch 4 was increased to 6 gal of water, eight bags of mix, and an extra 0.5 gal of water. Batch 5 consisted of 3.5 gal of water, five bags of mix, and no extra water. Each batch was spread across the crater in layers (Figure 58). Flat shovels were used to blend layers and prevent layering. A total of five batches were required for the repair. A total of 23 min was required to mix and place the repair material. The cap was struck level, hand troweled, and finished with a bull float (Figure 59). 


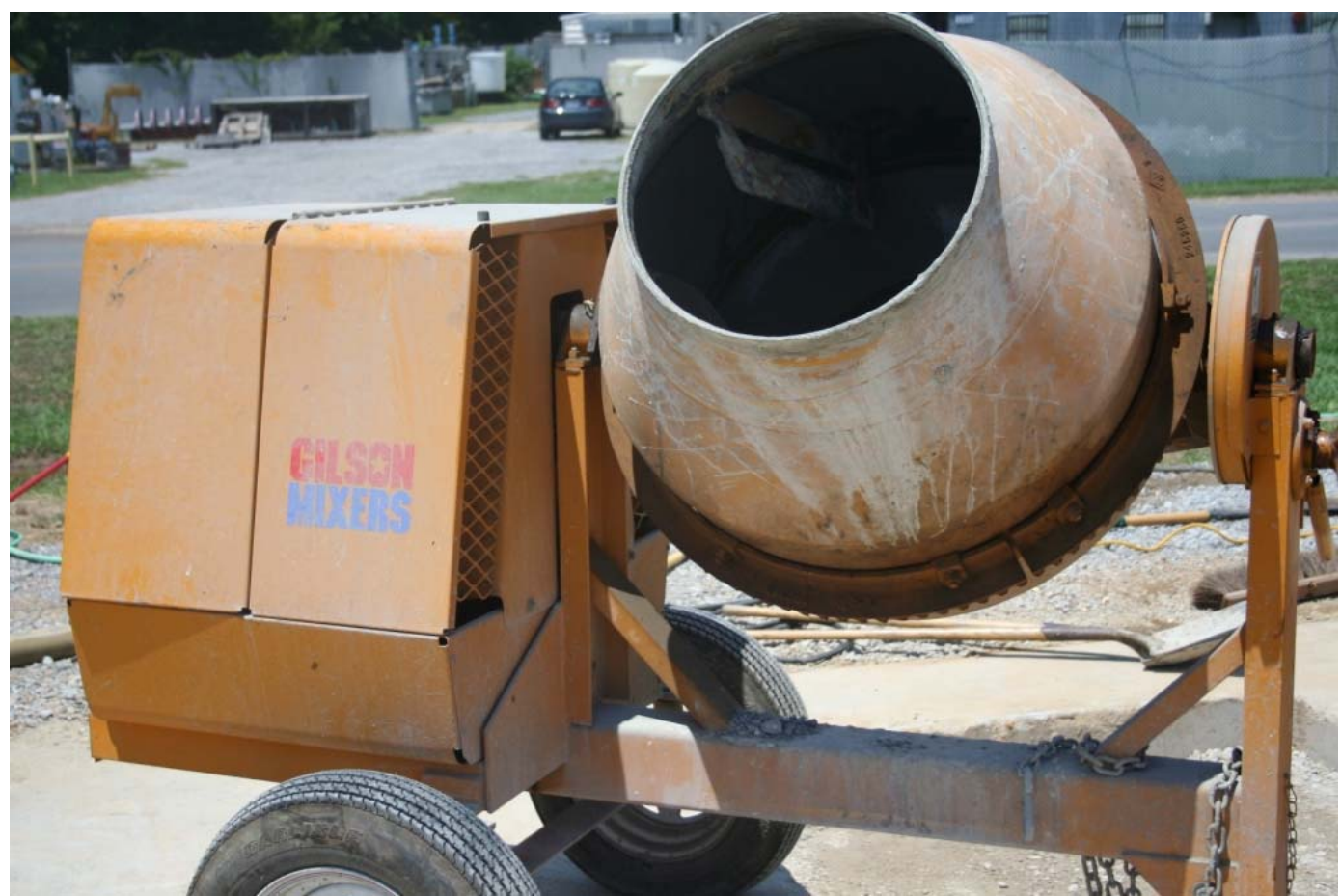

Figure 57. Crater F. Portable mortar mixer used for mixing Ultimax Concrete.

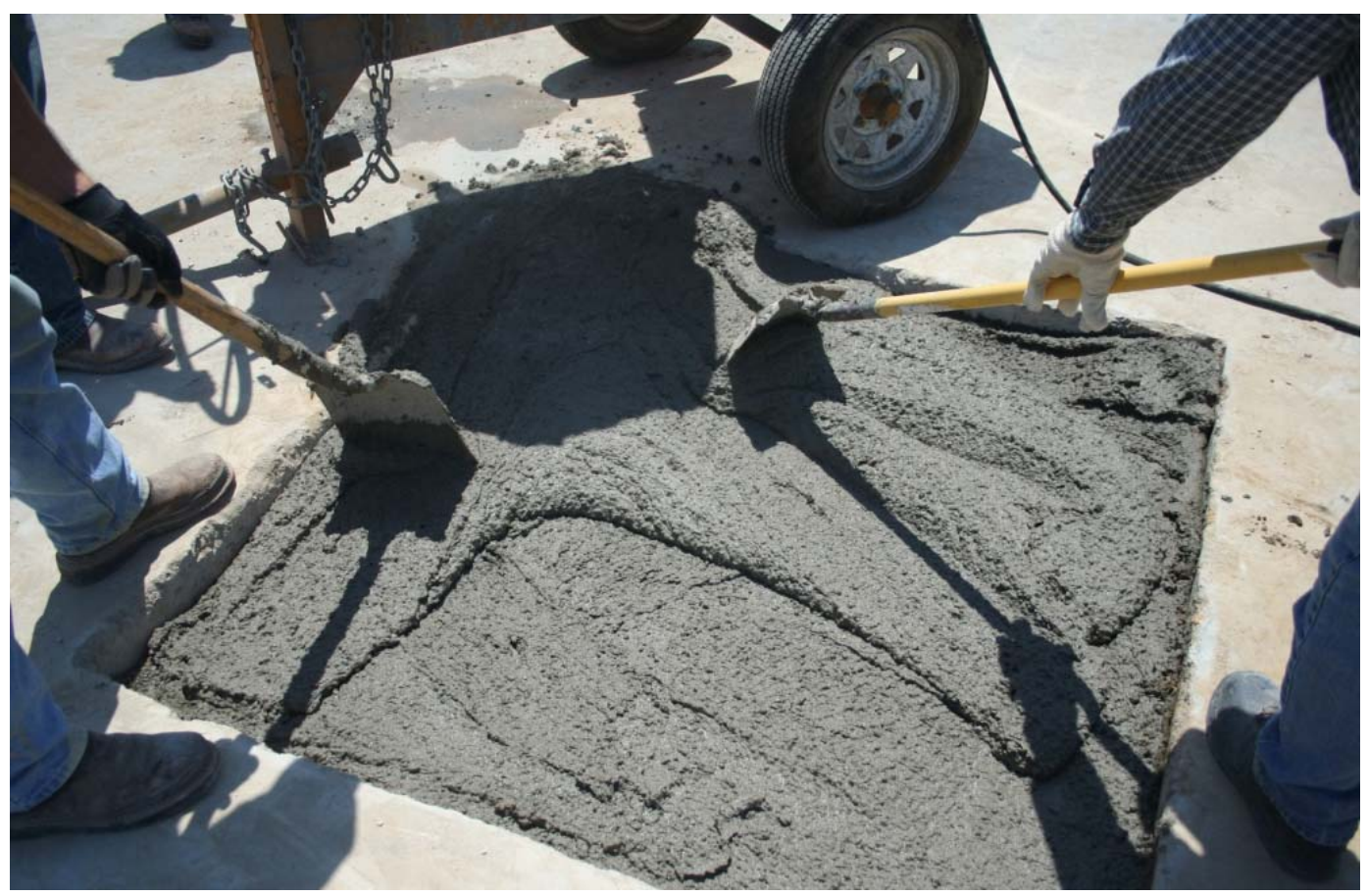

Figure 58. Crater F. Placing Ultimax Concrete material. 


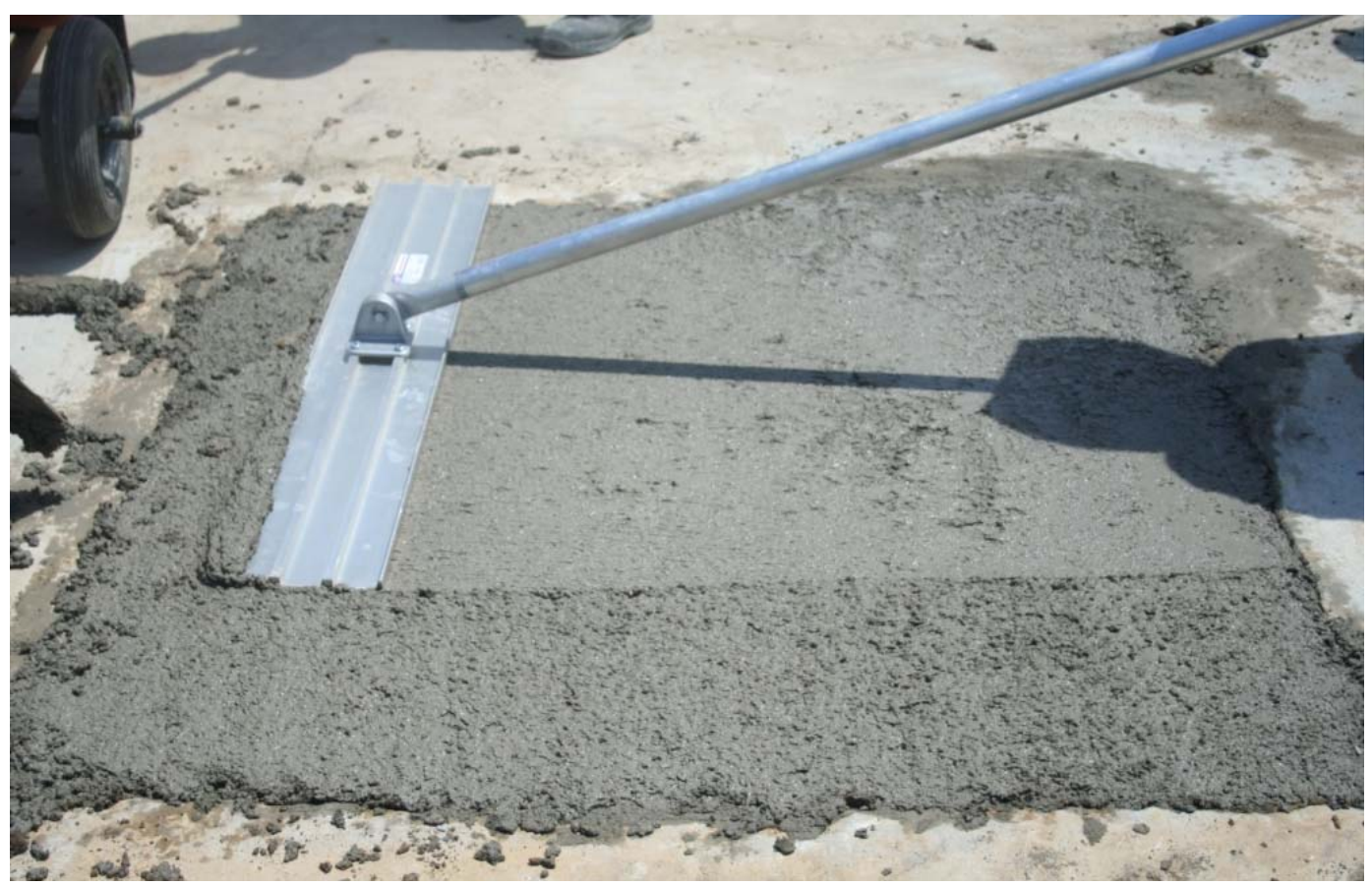

Figure 59. Crater F. Finishing Ultimax Concrete surface.

\section{Crater G-1-Pavemend SLTM}

Pavemend $\mathrm{SL}^{\mathrm{TM}}$ is another magnesium phosphate-based cementitious material that is used for rapid concrete pavement repair. Vendor representation arrived on site J uly 25, 2006. As with the previous Pavemend repair, the vendor representative briefed the six-person crew on proper mixing and placing of this material. The same mixing and placement procedures used for Crater $\mathrm{C}$ were followed with the exception that the water and powder were mixed for $2.5 \mathrm{~min}$ prior to aggregate addition. An additional $15 \mathrm{sec}$ of mixing followed the aggregate addition. Figure 60 presents mixing the material. The buckets were immediately poured into the crater working around the perimeter of the crater until the entire bottom was covered. The procedure was repeated until the entire crater was filled. Figure 61 presents this placement. Approximately $5 \mathrm{~min}$ was required to open the buckets. A total of $39 \mathrm{~min}$ was required to mix and place 25 buckets (not including the time to open the buckets). The surface finish was provided by striking the surface off level with a straightedge, hand troweling (Figure 62), and finishing with a broom. 


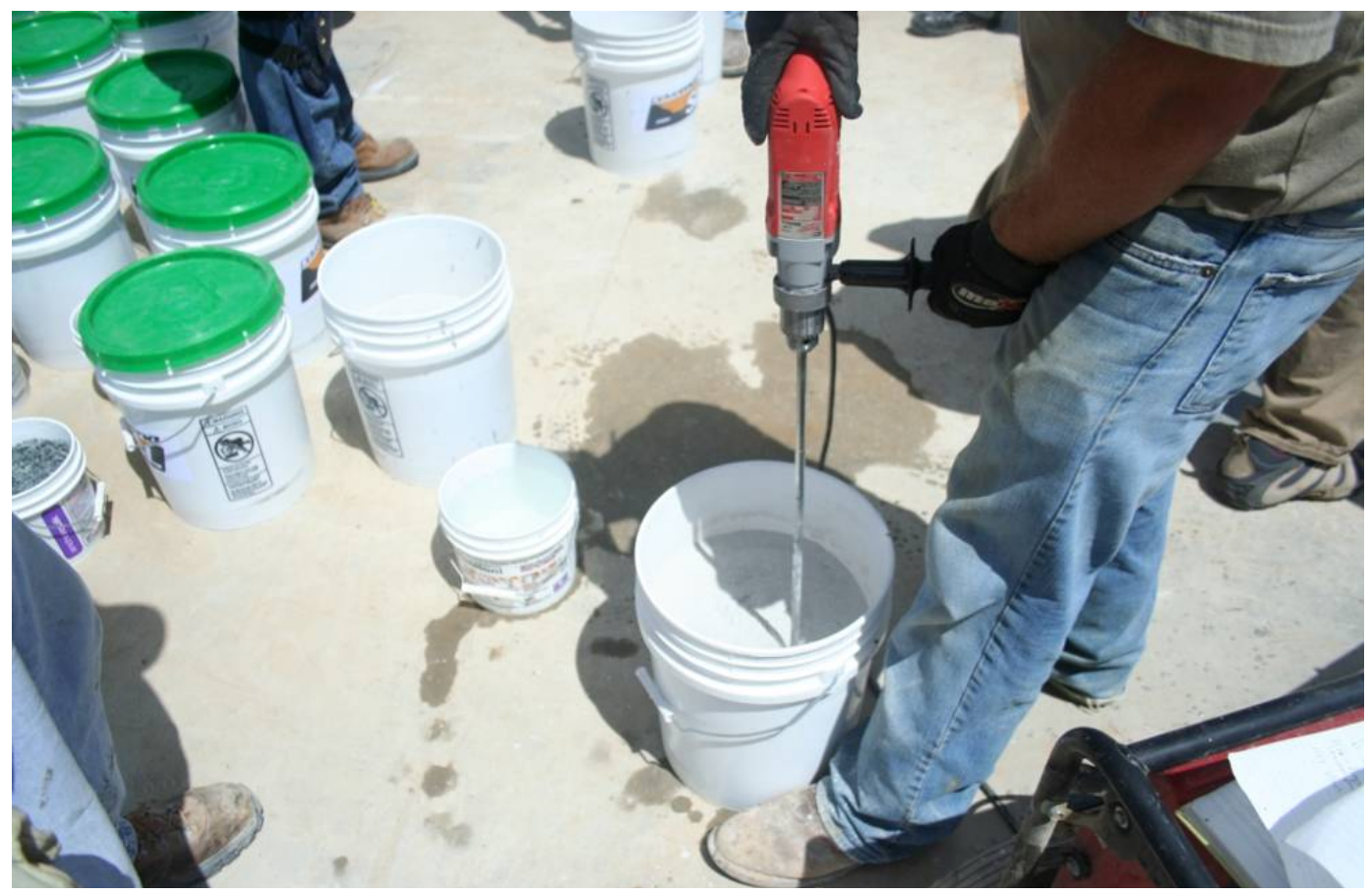

Figure 60. Crater G-1. Mixing Pavemend SL ${ }^{\mathrm{TM}}$.

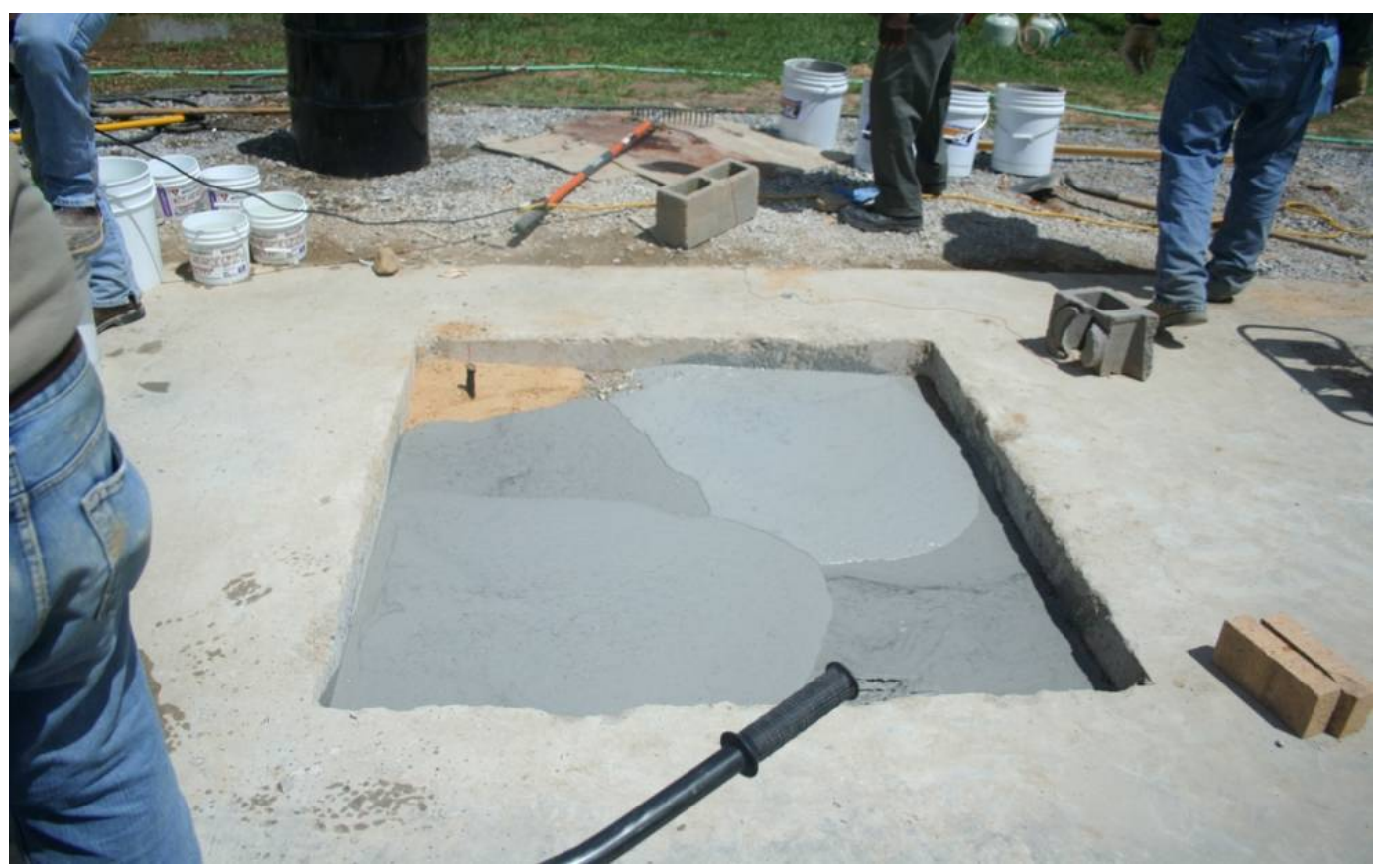

Figure 61. Crater G-1. Placement of Pavemend SLTM. 


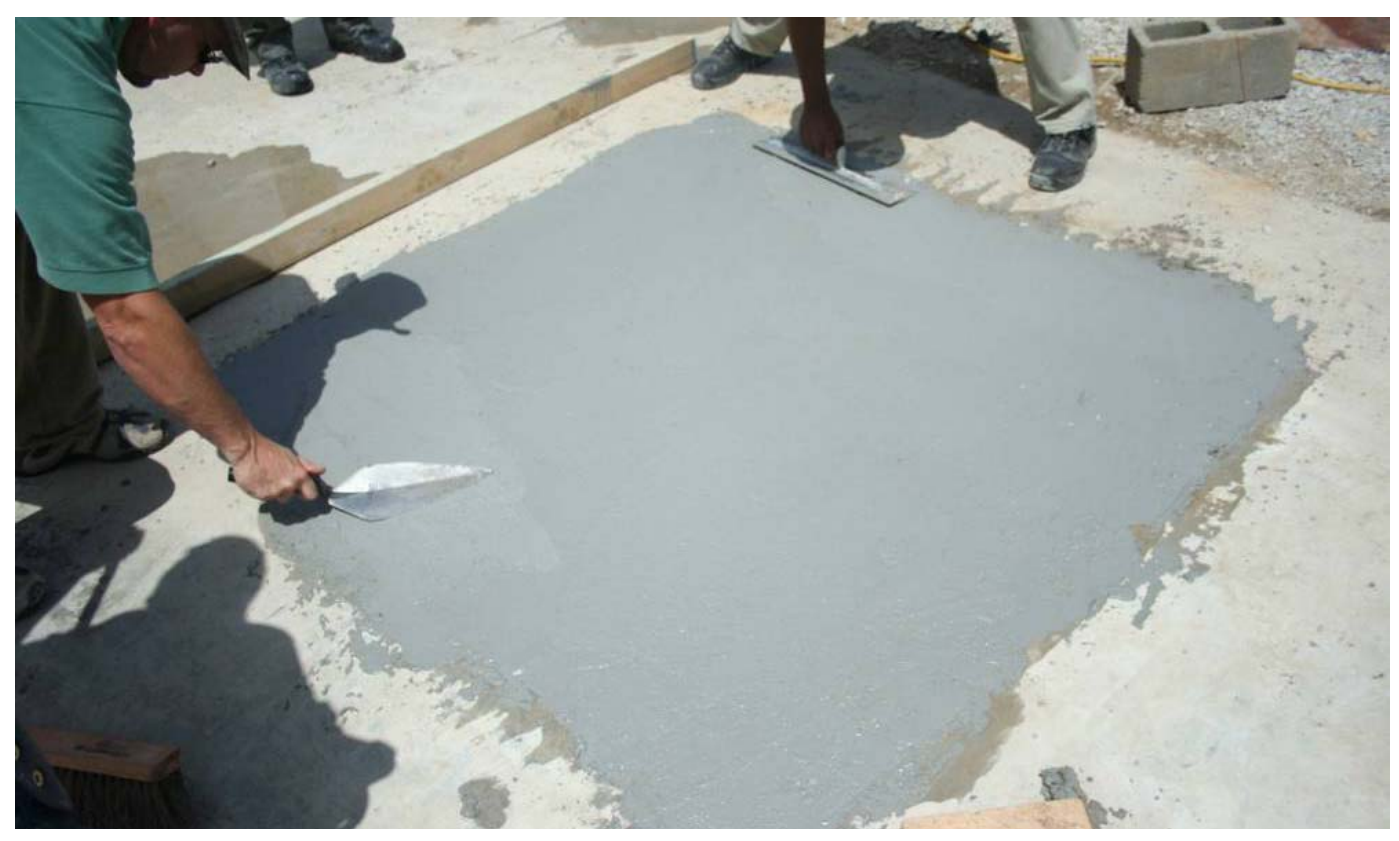

Figure 62. Crater G-1. Finishing crater surface.

\section{Crater H-Pavemend SLQTM}

After a subgrade failure occurred during the repair of Crater C, Pavemend $\mathrm{SLQ}^{\mathrm{TM}}$ was mixed and placed again in Crater $\mathrm{H}$. The same mixing and placement procedure as described for Crater $\mathrm{C}$ was followed.

Approximately 5 min was required to open the buckets. A total of 24 min was required to mix 30 buckets of repair material, place, and finish with hand trowels and a straightedge (not including the time to open the buckets). Figures 63 and 64 present the placement and finished surface of the repair. 


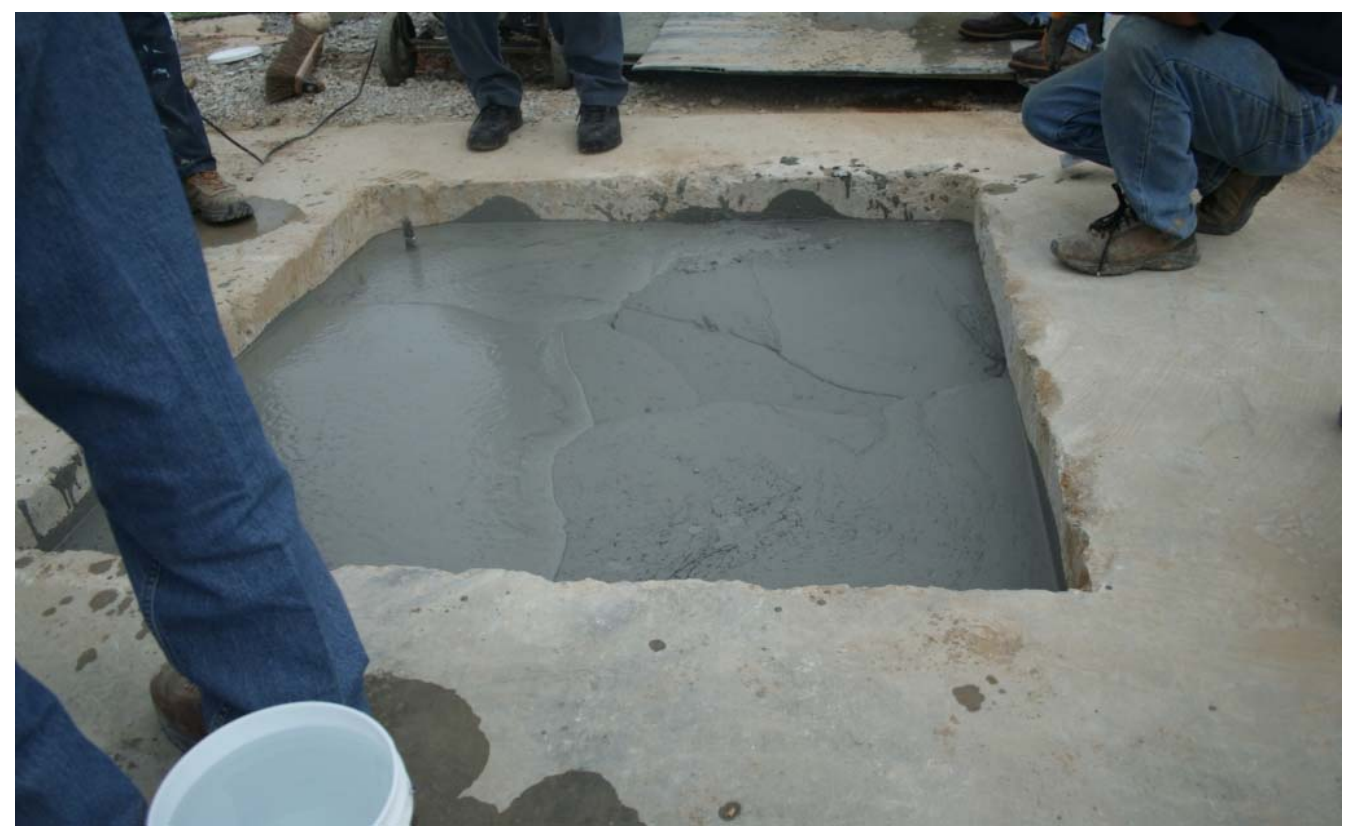

Figure 63. Crater H. Pavemend SLQTM repair placement.

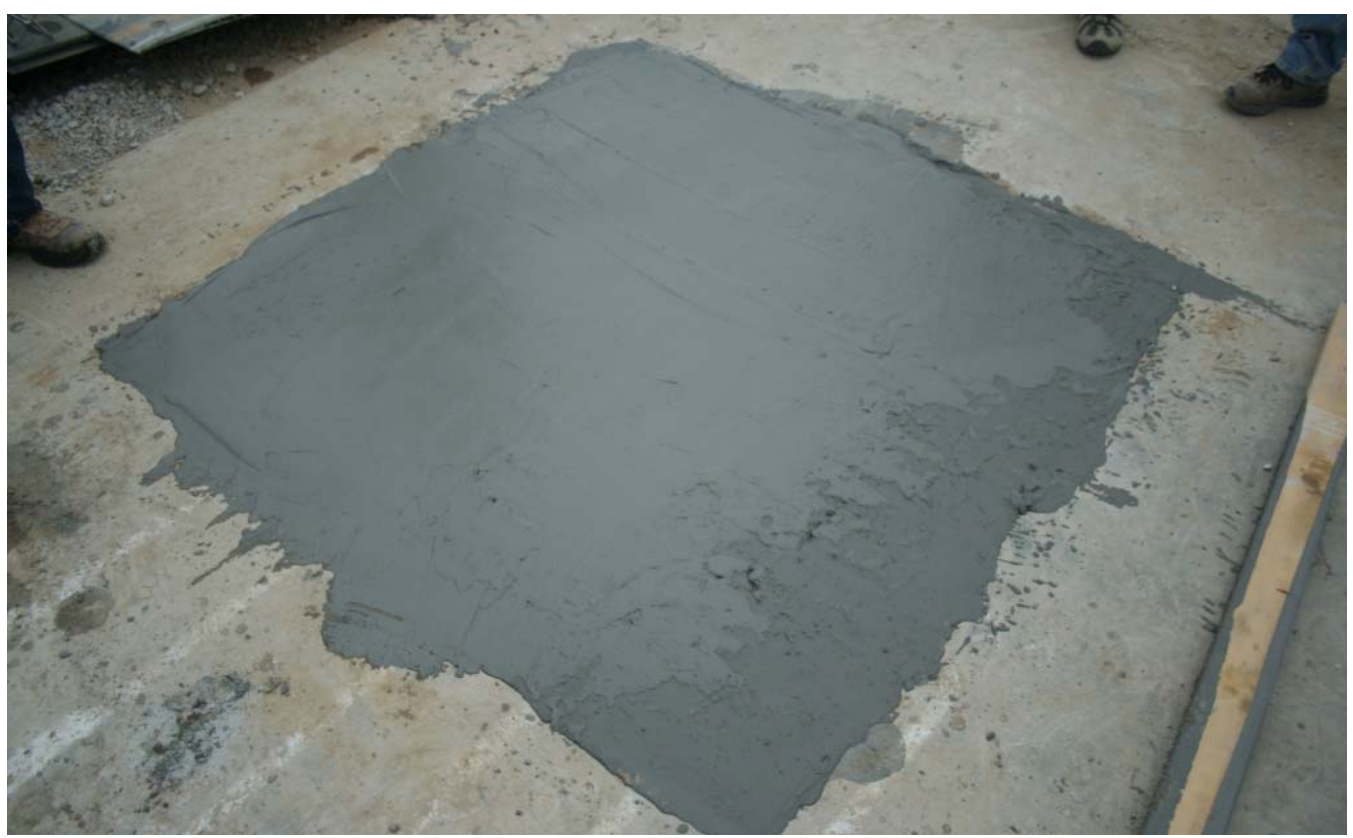

Figure 64. Crater H. Pavemend SLQTM repair after finishing.

\section{Crater G-2-TAMMS Express Repair}

Tamms Express Repair is a rapid-setting portland cement-based material used for rapid concrete patching and repair. In the absence of the vendor, the engineer briefed the six-person crew on proper mixing and placing of this material based on the technical data sheets provided on the product. The material was mixed in a $9 \mathrm{ft}^{3}$ portable drum mixer and emptied 
directly into the crater at the southeast corner. Each batch started by adding $2.25 \mathrm{gal}$ of water to the running mixer followed by three 50 -lb bags of concrete mix. Each batch was mixed for 2 to 4 min until lump-free and uniform in consistency. Material was placed in 1.5-in. lifts until repair was complete. By the last lift, the previously placed lift was set. A total of nine batches were required for the repair, and a total of $30 \mathrm{~min}$ was required to mix and place the repair material. The cap was struck level, hand troweled, and finished with a bull float. Figure 65 shows finishing the edges with a hand trowel.

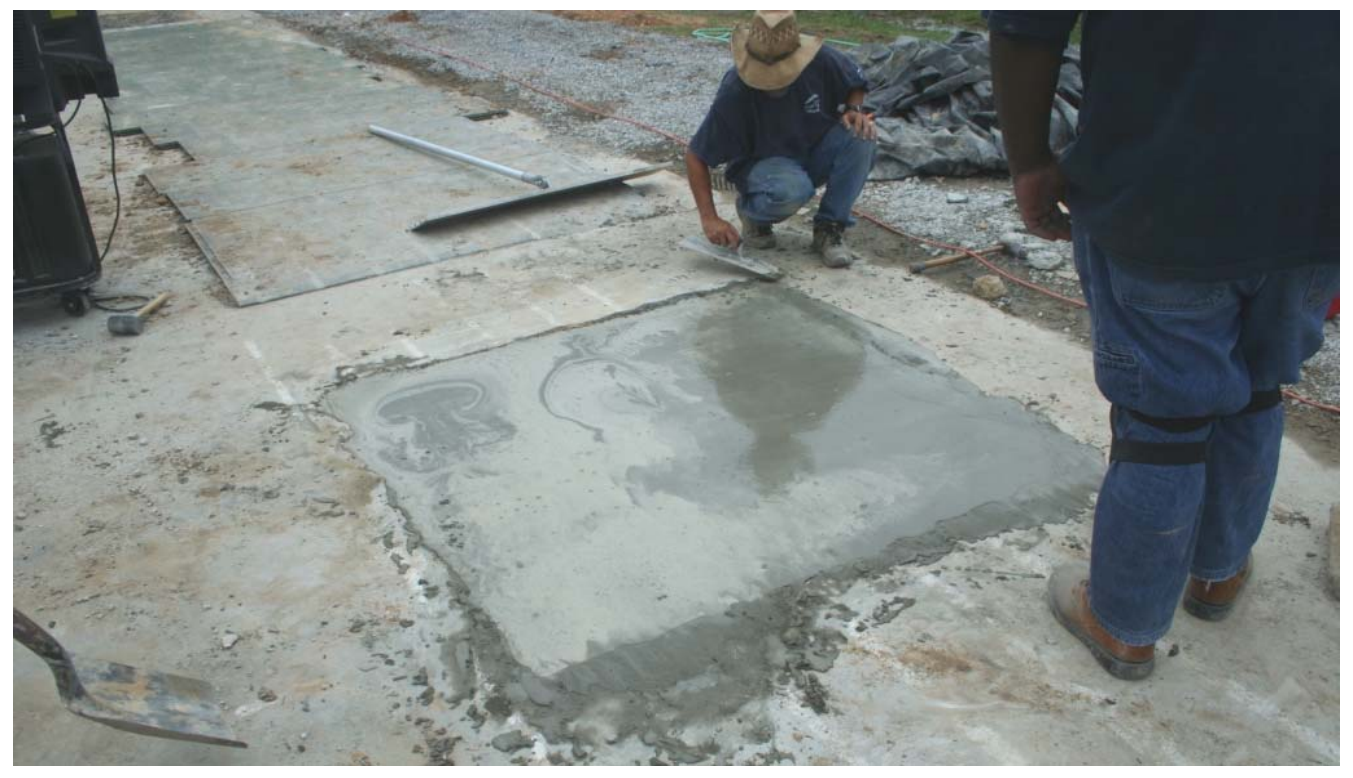

Figure 65. Crater G-2. Finishing Express Repair surface.

\section{Crater C-2-ThoRoc 10-60 Rapid Mortar}

ThoRoc 10-60 Rapid Mortar is a high-alumina content and portland cement-based material that is used for rapid concrete pavement repair. The vendor shipped ThoRoc 10-60, ThoRoc 10-61, and Set 45 HW for laboratory testing. In absence of the vendor, the engineer briefed the sixperson crew on proper mixing and placing of this material. A portable horizontal shaft mortar mixer was used to mix this material. The mixer was set up at the corner of the crater. Eighteen empty 5-gal buckets were filled with 50-lb each of the same 3/ 8-in. aggregate used in the ThoRoc 10-61 Rapid Mortar. To mix one batch, 2 gal of water is poured into a mixer followed by three buckets of aggregate and three 50-lb bags of material (Figure 66). The materials were mixed for $3 \mathrm{~min}$. An extra $0.25 \mathrm{gal}$ of water was added to each batch. When mixing was complete, the mixer was emptied directly into the crater. The material was spread with 
shovels and rakes from the south end to the north end of the crater as each batch was poured. The shovels were used to prevent formation of thin layers (Figure 67). Eighteen bags of material and buckets of aggregate were required to repair the crater. A total of $19 \mathrm{~min}$ was required to mix, place, and finish the material. The material was leveled with a straightedge (Figure 68) and finished with a bull float. Water was sprayed on the surface of the crater and allowed to cure.

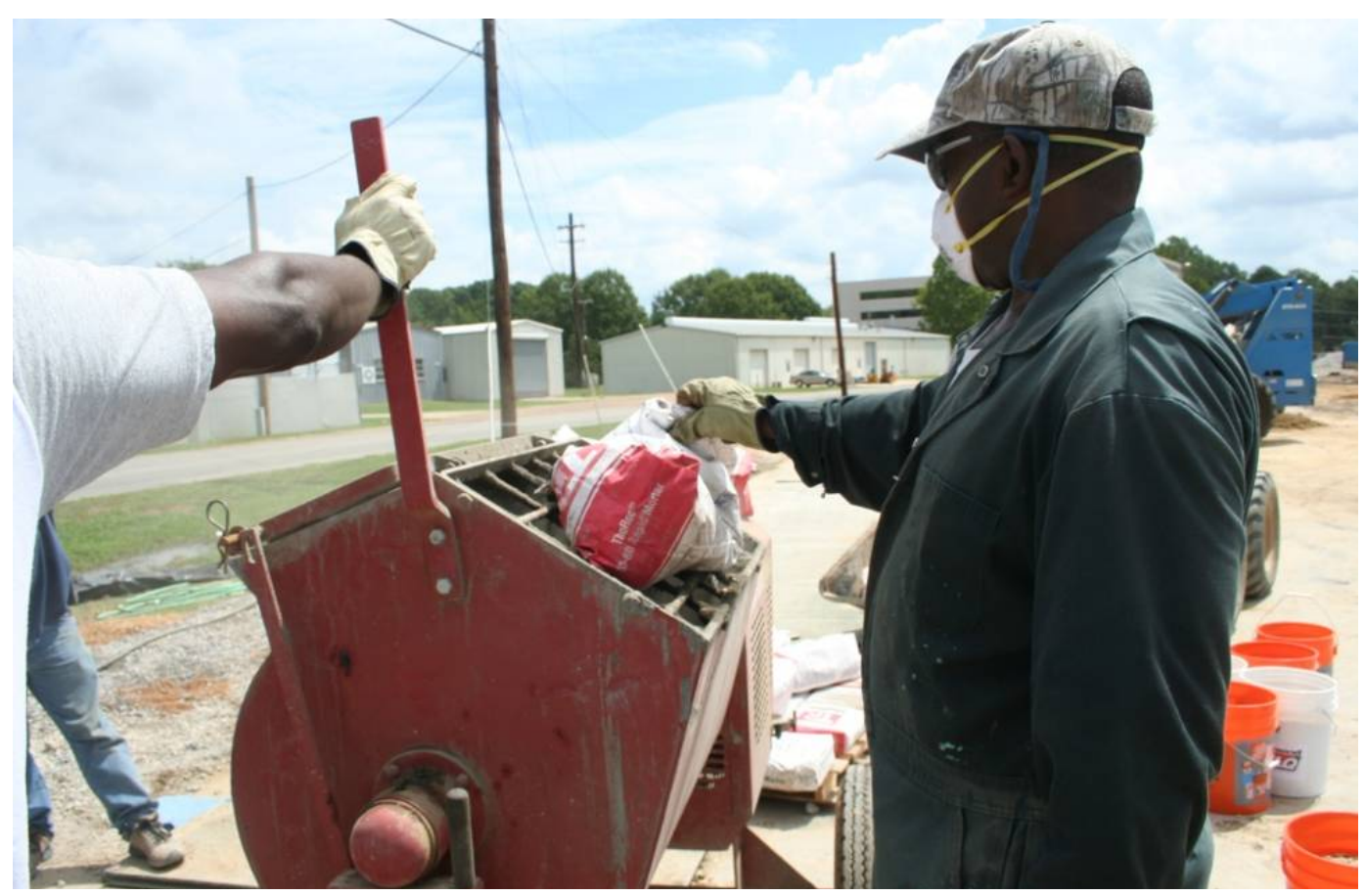

Figure 66. Crater C-2. ThoRoc 10-60 mixing. 


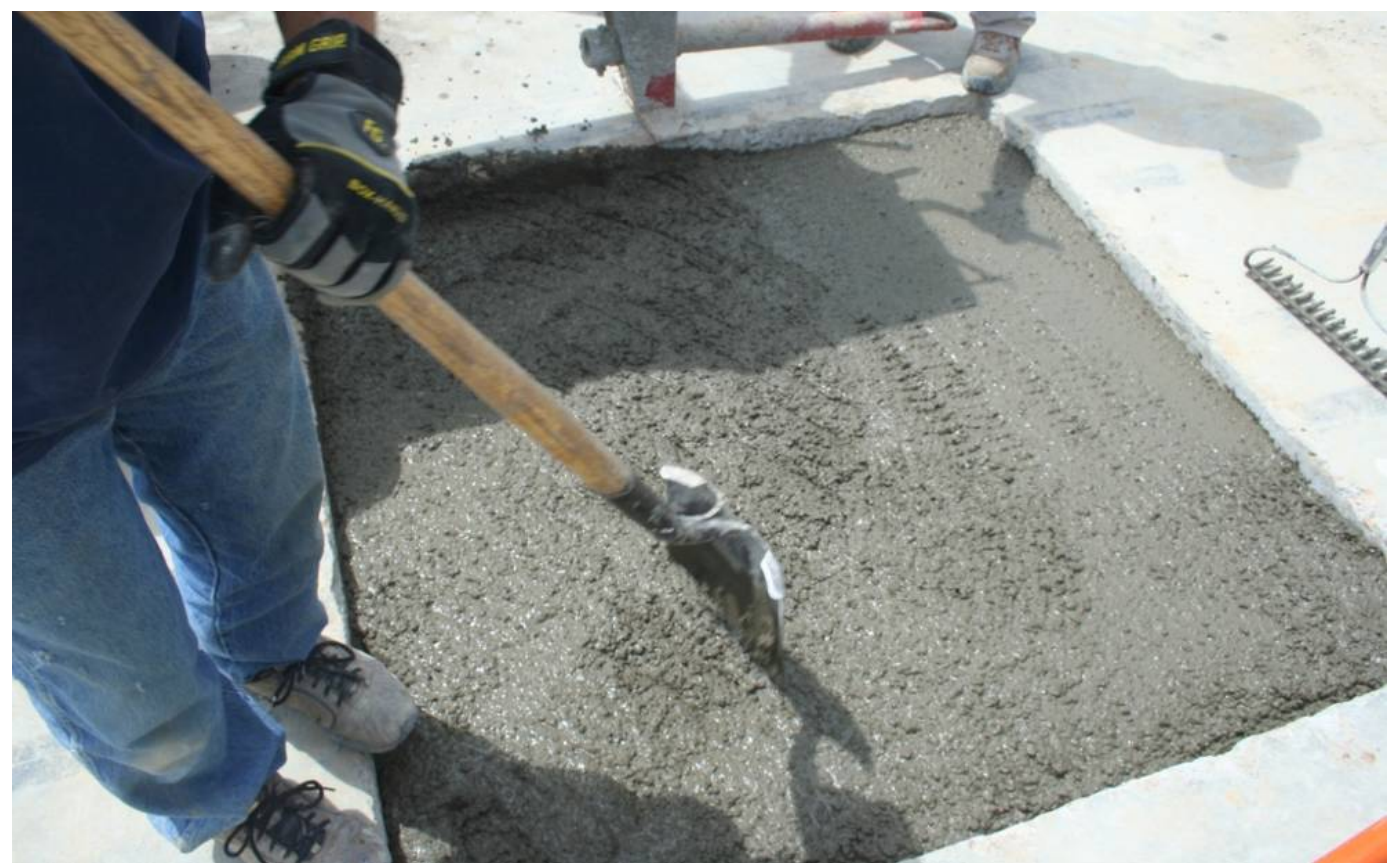

Figure 67. Crater C-2. Placing ThoRoc 10-60.

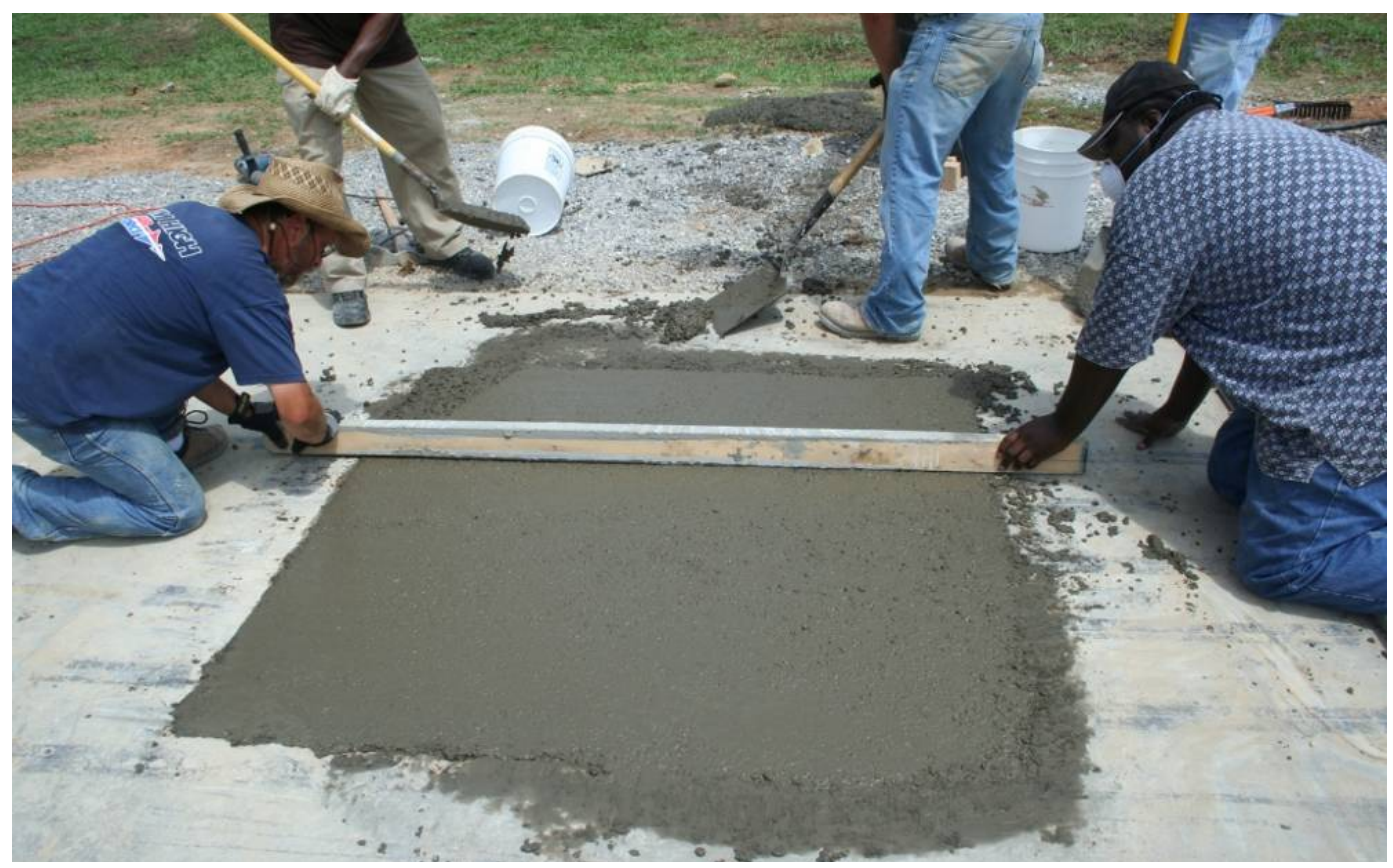

Figure 68. Crater C-2. Finishing ThoRoc 10-60.

\section{Series 2 crater repairs}

A team from ERDC conducted the Series 2 crater repairs in August 2006. Each repair had a total volume of 7.1 cu yards including a cap volume of $48.0 \mathrm{ft}^{3}$. Six repairs were conducted. Prior to each crater repair, the subgrade material was excavated to a depth of $3 \mathrm{ft}$ below the surface to 
locate the instrumentation conduit. As with Series 1 repairs, the instrumentation wires were pulled through the conduit in each crater and routed through a main trunk line adjacent to the north side of the section to the instrumentation pod. Three temperature thermocouples and one pressure cell were installed in each crater prior to cap placement; one pressure cell was placed at the center of the crater, and three thermocouples were placed near the edge of the repair, as shown in Figure 69.

Moisture, density, and elevations were measured for the existing subgrade material. A clay gravel base was then compacted in 6-in. lifts until the repair was within $12 \mathrm{in}$. of the surface of the test section with a 136-lb plate compactor with a 12- by 10-in. plate area (Figure 70). This material consisted of gravelly, clayey sand with a Unified Soil Classification system (ASTM D 2487) designation of SP-SC. This soil had the following percentages of gravel, sand, and fines: 15.5, 75.7, and 8.8 percent, respectively. Its liquid limit and plasticity index (ASTM D 4318) were 24 and 12 percent, respectively. The color of this soil was a reddish brown in color. With modified Proctor compaction (ASTM D 1557), this soil had an optimum moisture content and a laboratory maximum dry density of approximately 6.9 percent and $130.0 \mathrm{lb} / \mathrm{ft}^{3}$, respectively.

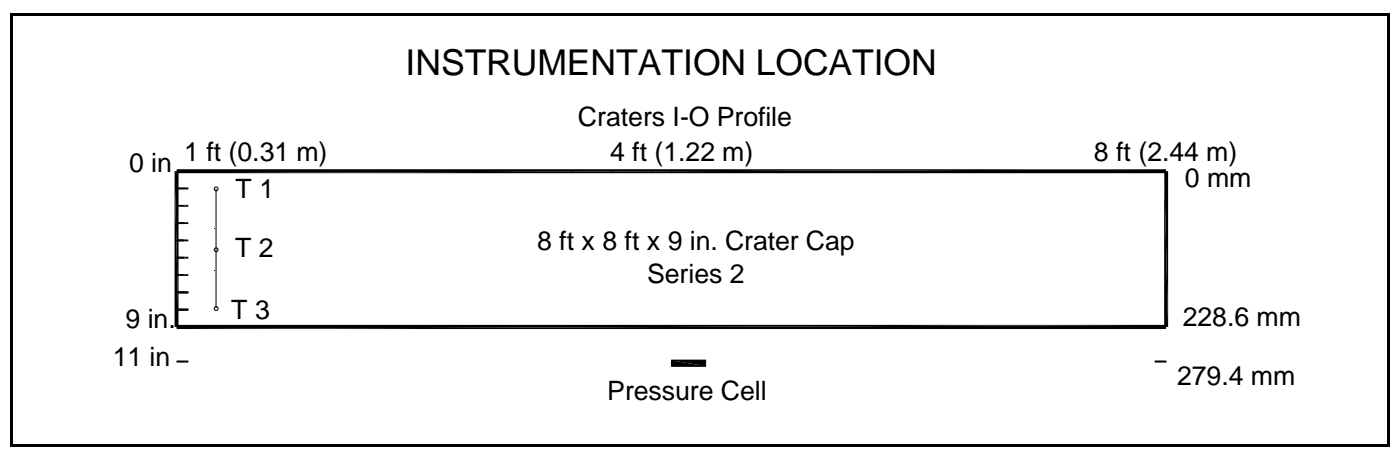

Figure 69. Instrumentation layout Series 2 craters. 


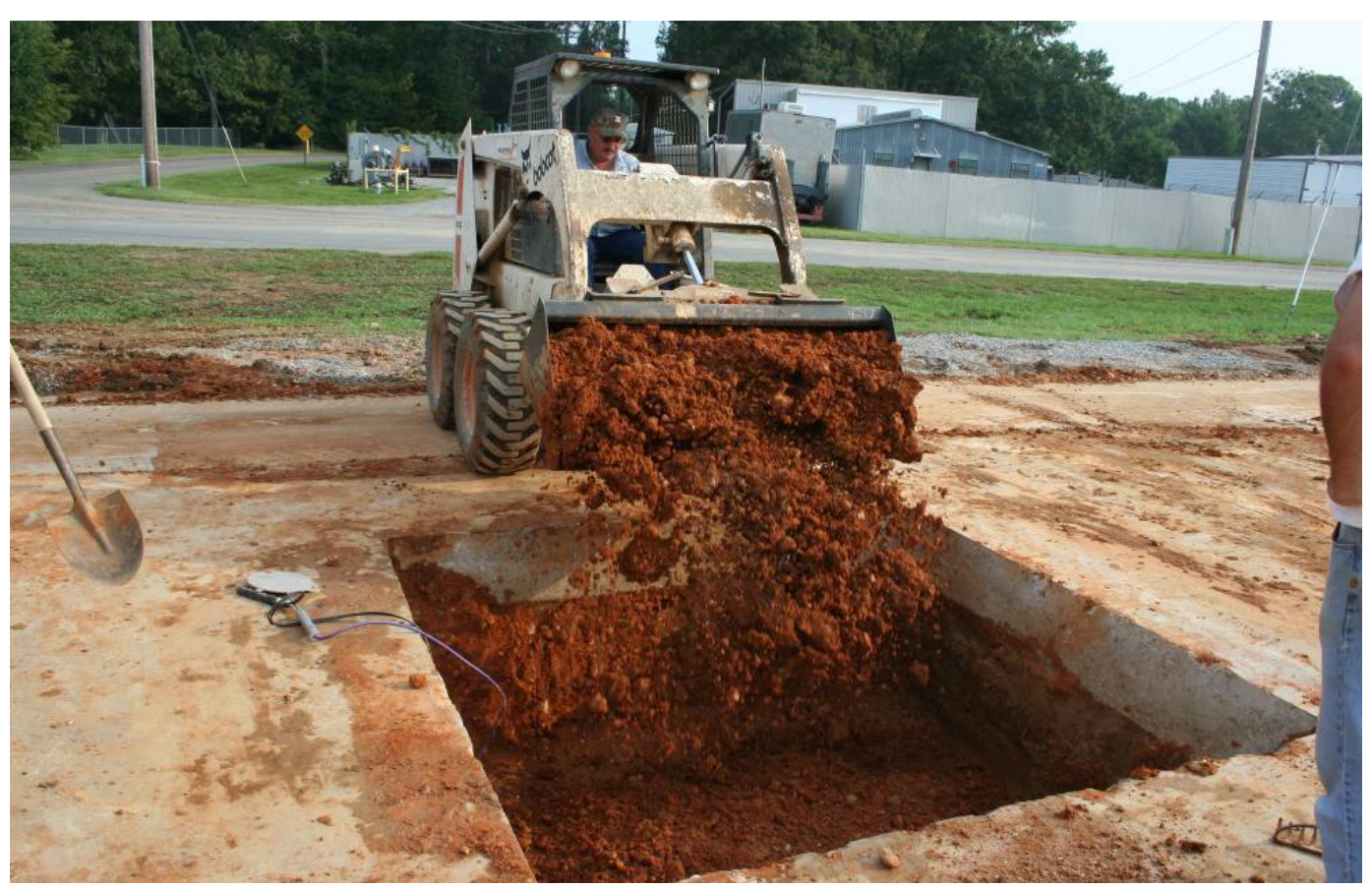

Figure 70. Placement of clay gravel base.

Pressure cells were installed at the 12-in. depth in the same manner as Series 1. Additional clay gravel was placed until the base was within 9 in. of the surface. Prior to placing the cap, DCP tests were performed to determine the strength of the underlying layers. Moisture and density measurements were performed with a nuclear gauge to ensure proper compaction. These measurements were performed in the same manner as Series 1 testing in the southwest, southeast, and northeast corners of the repair, approximately $1 \mathrm{ft}$ from each corner. The base surface was surveyed to ensure that proper cap thickness would be achieved. Density, moisture, and DCP data are presented in Tables 22 and 23. 
Table 22. Series 2 construction density and moisture content.

\begin{tabular}{|c|c|c|c|c|c|c|}
\hline \multirow[b]{2}{*}{ Feature } & \multirow[b]{2}{*}{ Location } & \multirow[b]{2}{*}{ Depth, in. } & \multirow[b]{2}{*}{ Material } & \multicolumn{3}{|c|}{ Nuclear Gauge Measurements } \\
\hline & & & & $\begin{array}{c}\text { Wet } \\
\text { Density } \\
\left(\mathbf{l b} / \mathbf{f t}^{3}\right)\end{array}$ & $\begin{array}{c}\text { Dry } \\
\text { Density } \\
\left(\mathbf{l b} / \mathbf{f t}^{3}\right)\end{array}$ & $\begin{array}{c}\text { Moisture } \\
\text { Content } \\
\text { (\%) }\end{array}$ \\
\hline \multirow[t]{8}{*}{ Crater J } & Southwest & 27 & Sandy Clay & 127.8 & 113.7 & 11.4 \\
\hline & Southeast & 27 & Sandy Clay & 135.0 & 122.4 & 10.2 \\
\hline & Northeast & 27 & Sandy Clay & 120.2 & 104.2 & 15.3 \\
\hline & \multicolumn{3}{|r|}{ Average } & 127.7 & 113.4 & 12.3 \\
\hline & Southwest & 9 & Clay Gravel & 134.2 & 124.1 & 8.2 \\
\hline & Southeast & 9 & Clay Gravel & 133.9 & 124.0 & 8.1 \\
\hline & Northeast & 9 & Clay Gravel & 132.8 & 120.8 & 9.9 \\
\hline & \multicolumn{3}{|r|}{ Average } & 133.6 & 123.0 & 8.7 \\
\hline \multirow[t]{8}{*}{ Crater K } & Southwest & 27 & Sandy Clay & 121.7 & 100.5 & 21.1 \\
\hline & Southeast & 27 & Sandy Clay & 121.5 & 102.5 & 18.1 \\
\hline & Northeast & 27 & Sandy Clay & 123.0 & 99.5 & 23.6 \\
\hline & \multicolumn{3}{|r|}{ Average } & 122.1 & 100.8 & 20.9 \\
\hline & Southwest & 9 & Clay Gravel & 127.7 & 119.1 & 7.2 \\
\hline & Southeast & 9 & Clay Gravel & 124.4 & 114.5 & 8.6 \\
\hline & Northeast & 9 & Clay Gravel & 123.0 & 80.6 & 6.1 \\
\hline & \multicolumn{3}{|r|}{ Average } & 125.0 & 80.7 & 7.3 \\
\hline \multirow[t]{8}{*}{ Crater L } & Southwest & 27 & Sandy Clay & 123.0 & 106.7 & 15.2 \\
\hline & Southeast & 27 & Sandy Clay & 121.6 & 100.3 & 21.3 \\
\hline & Northeast & 27 & Sandy Clay & 113.9 & 92.2 & 23.5 \\
\hline & \multicolumn{3}{|r|}{ Average } & 119.5 & 99.7 & 20.0 \\
\hline & Southwest & 9 & Clay Gravel & 119.0 & 112.4 & 6.0 \\
\hline & Southeast & 9 & Clay Gravel & 124.4 & 115.4 & 7.8 \\
\hline & Northeast & 9 & Clay Gravel & 122.1 & 114.3 & 6.9 \\
\hline & \multicolumn{3}{|r|}{ Average } & 121.8 & 114.0 & 6.9 \\
\hline \multirow[t]{7}{*}{ Crater N } & Southwest & 36 & Sandy Clay & 119.8 & 102.5 & 16.9 \\
\hline & Southeast & 36 & Sandy Clay & 119.7 & 104.1 & 15.0 \\
\hline & Northeast & 36 & Sandy Clay & 125.0 & 110.1 & 13.6 \\
\hline & \multicolumn{3}{|r|}{ Average } & 121.5 & 105.6 & 15.2 \\
\hline & Southwest & 9 & Concrete Debris & \multirow{3}{*}{\multicolumn{3}{|c|}{$-a$}} \\
\hline & Southeast & 9 & Concrete Debris & & & \\
\hline & Northeast & 9 & Concrete Debris & & & \\
\hline \multirow[t]{8}{*}{ Crater 0} & Southwest & 36 & Sandy Clay & 131.8 & 112.7 & 17.0 \\
\hline & Southeast & 36 & Sandy Clay & 134.0 & 113.7 & 17.8 \\
\hline & Northeast & 36 & Sandy Clay & 132.4 & 112.5 & 17.7 \\
\hline & \multicolumn{3}{|r|}{ Average } & 132.7 & 113.0 & 17.5 \\
\hline & Southwest & 15 & Clay Gravel & 133.2 & 123.8 & 7.7 \\
\hline & Southeast & 15 & Clay Gravel & 129.5 & 119.0 & 8.9 \\
\hline & Northeast & 15 & Clay Gravel & 126.6 & 116.3 & 8.9 \\
\hline & \multicolumn{3}{|r|}{ Average } & 129.8 & 119.7 & 8.5 \\
\hline
\end{tabular}

a Moisture and density values could not be determined for the rubble base used in Crater $\mathrm{N}$. 
Table 23. Series 2 average DCP estimated CBR values.

\begin{tabular}{|c|c|c|}
\hline \multirow{2}{*}{ Crater } & \multicolumn{2}{|c|}{ CBR, \% } \\
\cline { 2 - 3 } & Base & Subgrade \\
\hline J & 22 & 10 \\
\hline K & 28 & 8 \\
\hline L & 34 & 9 \\
\hline N & $-a$ & 5 \\
\hline O & 17 & 5 \\
\hline
\end{tabular}

Once the crater subgrade and base were prepared, a 9-in. cap repair was conducted by a team from ERDC.

\section{Crater J-Rapid Set ${ }^{\circledR}$ concrete mix}

The Rapid Set ${ }^{\circledR}$ material was mixed in a 2 -yd $\mathrm{d}^{3}$ portable concrete mixer and emptied directly into the crater. A forklift was used to raise the bags of material level with the top of the mixer. Two batches were mixed by adding 50 gal of water measured in 5-gal buckets to the running mixer followed by fifty 60 -lb bags of concrete mix and 150 packets of Rapid Set FLOW CONTROL plasticizing admixture to extend the working time. The batches were mixed for 1.5 min until lump-free and uniform in consistency. Each batch was installed in full depth sections and progressed horizontally from the north side of the crater to the south with the aid of rakes and shovels. Two batches were required for the repair. A total of 45 min was required to mix and place the repair material. The cap was struck level, hand troweled, and finished with a bull float. Figures 71 and 72 present the mixing, placing, and finishing of the crater. 


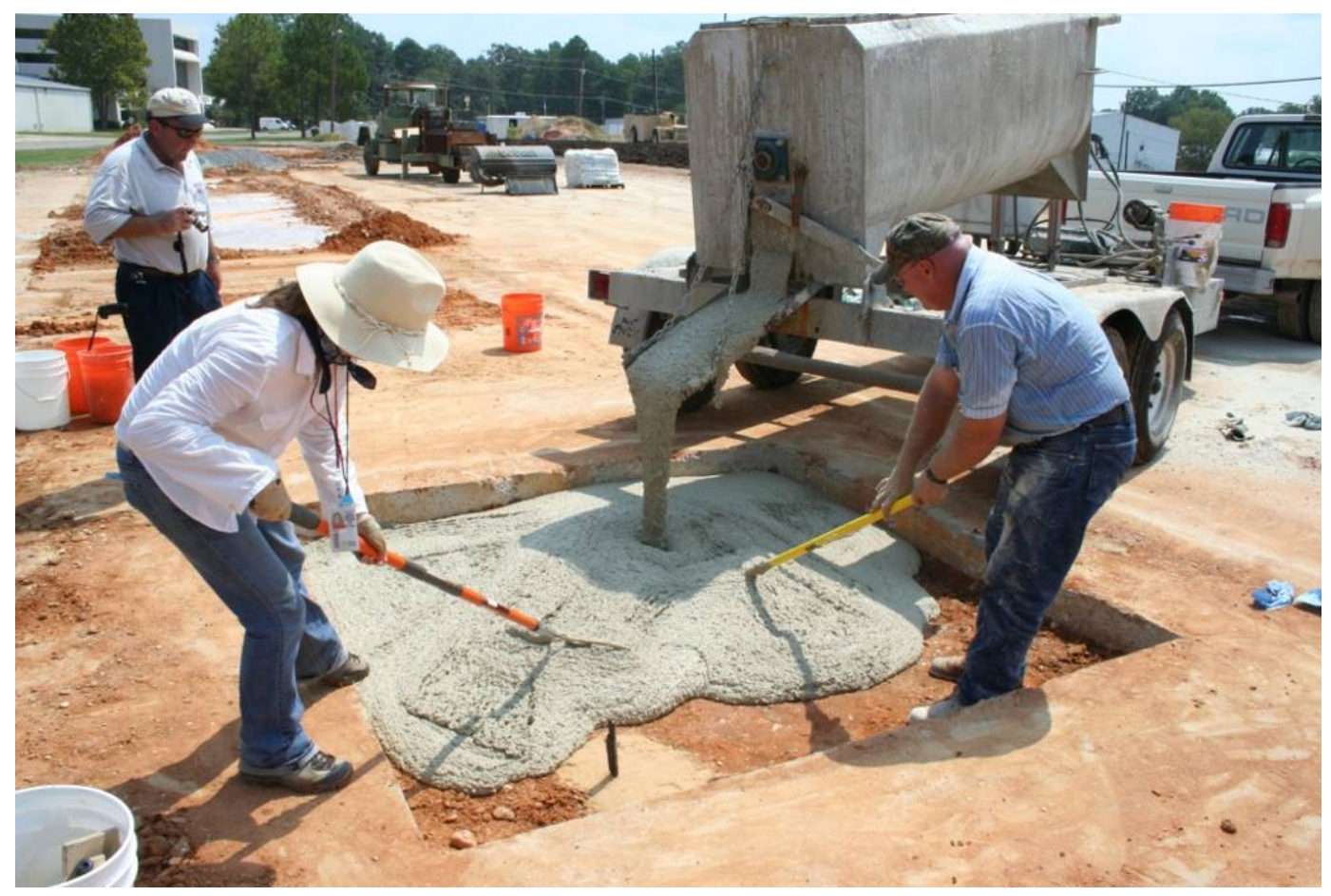

Figure 71. Crater J. Series 2 Rapid Set ${ }^{\circledR}$ placement.

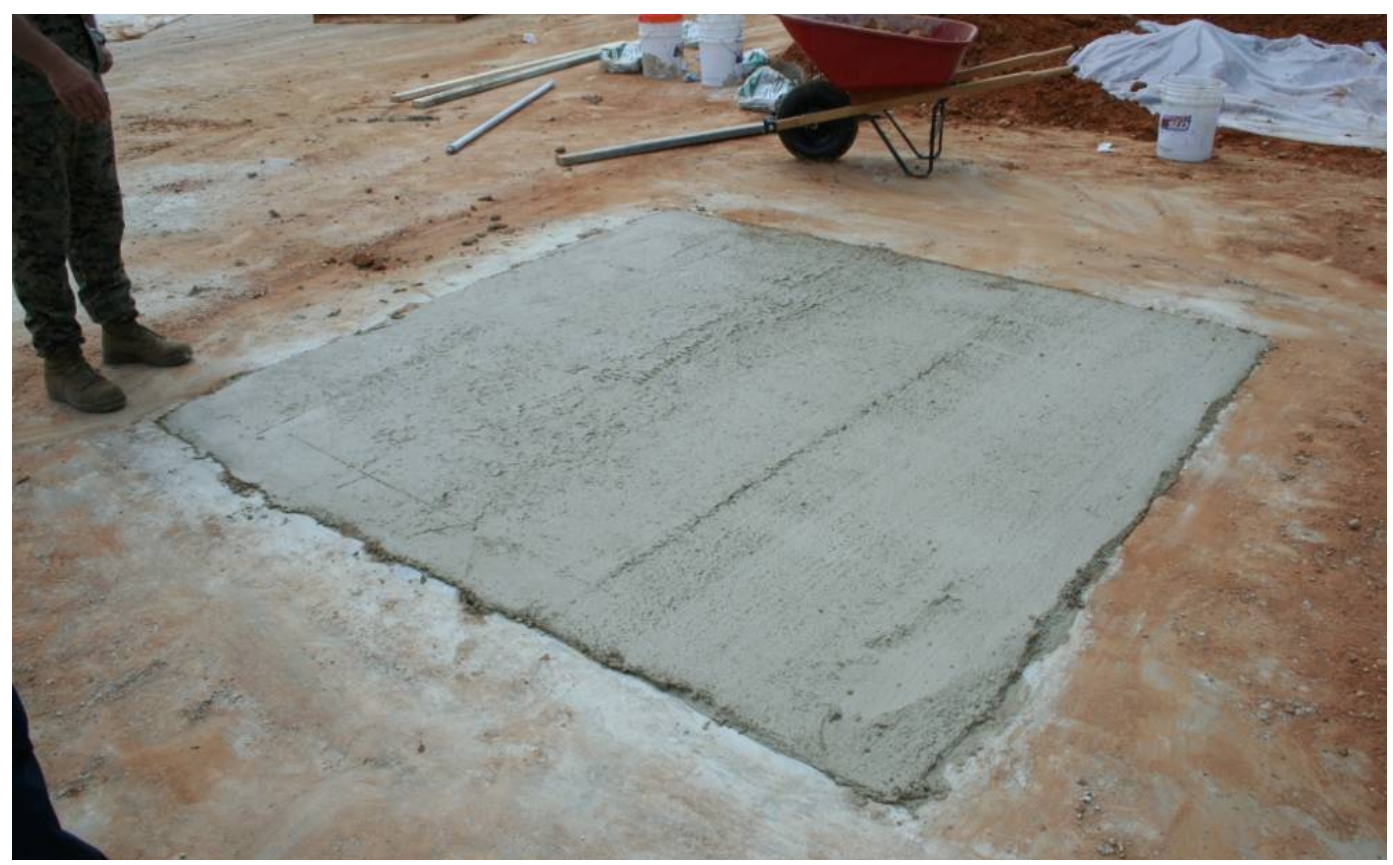

Figure 72. Crater J. Finished Rapid Set $\circledast$ surface.

\section{Crater K-Pavemend SLQ ${ }^{\mathrm{TM}}$}

The same mixing and placement used for Pavemend $\mathrm{SLQ}^{\mathrm{TM}}$ in Series 1 was followed. Approximately $1 \mathrm{hr}, 45 \mathrm{~min}$ was required to mix 93 buckets of 
repair material, place, and finish with hand trowels and a straightedge. Figures 73 and 74 present the placement and finished surface of the repair.

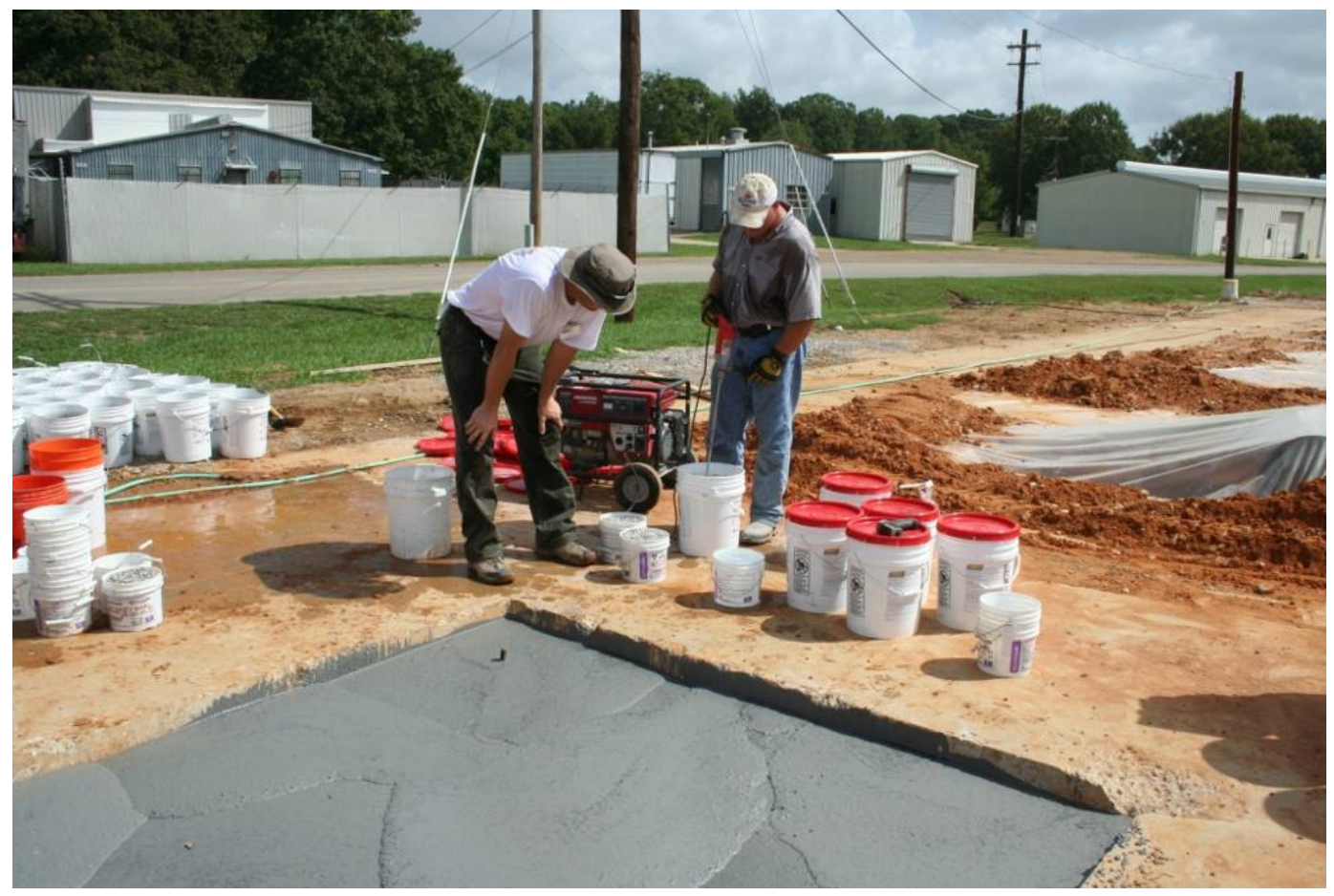

Figure 73. Crater K. Mixing Pavemend SLQ ${ }^{\mathrm{TM}}$ and crater placement.

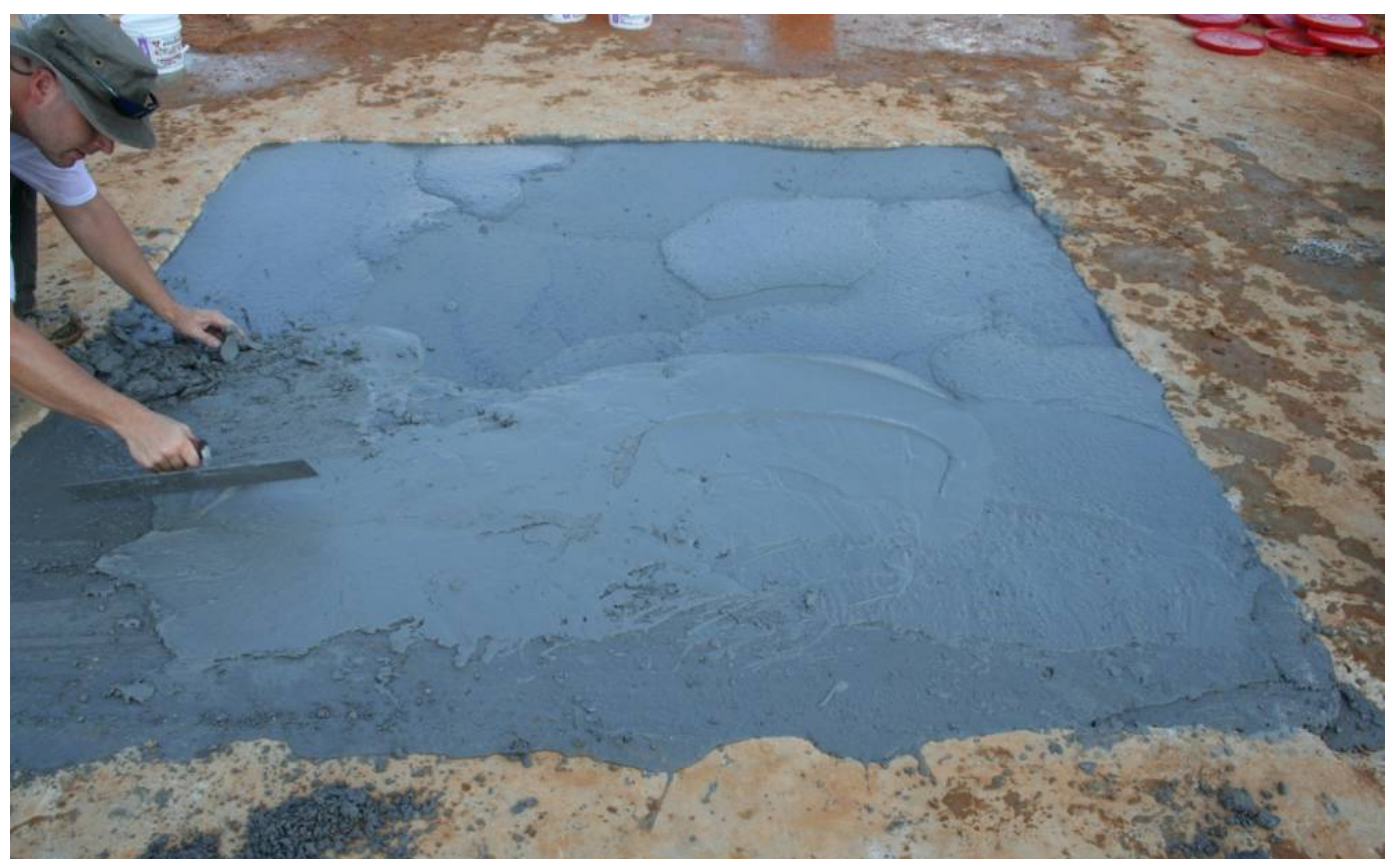

Figure 74. Crater K. Finishing Pavemend SLQ ${ }^{\mathrm{TM}}$ surface. 


\section{Crater L-ThoRoc 10-61 Rapid Mortar}

ThoRoc 10-61 Rapid Mortar was used as the cementitious cap for Crater L. The 2-yd ${ }^{3}$ mixer was set up on the north edge of the crater. Prior to mixing, empty 5-gal buckets were filled with $50 \mathrm{lb}$ each of 3/8-in. aggregate to supplement thirty 30 -lb bags of aggregate shipped by the manufacturer. Additionally, ThoRoc 10-60 was used to supplement the ThoRoc 10-61 due to inadequate on-hand quantities of ThoRoc 10-60 material using technical guidance from the vendor. Once all materials were prepared, mixing and placing began. Three batches were mixed. As with Crater J , a forklift was used to raise the material level with the top of the mixer to aid in breaking the bags. The first batch was mixed by loading the mixer with 22 gal of water measured in 5-gal buckets and thirty 50-lb bags of aggregate supplied by the manufacturer with three 5-gal buckets of supplemental aggregate. Those materials mixed while twenty-two 50-lb bags of 10-61 and eleven 50-lb bags of 10-60 were added. The second batch mixed 20 buckets of aggregate with 13 gal of water with 10 bags of 10-61 and 10 bags of 10-60. The final batch contained only 4 gal of water with six 5-gal buckets of aggregate and six 50-lb bags of 10-61 material. Each batch was allowed to mix for $3 \mathrm{~min}$; additional water was added by the $0.5 \mathrm{gal}$ as needed. When mixing was complete, the material was emptied directly into the crater and was spread with rakes from the north end to the south end. Fifty-nine 50 -lb bags of material were required to repair the crater. Approximately 30 min was required to mix, place, and finish the material. The material was struck level with a straightedge and finished with a bull float. Water was sprayed on the surface of the crater, and the repair was covered with plastic sheeting and allowed to cure. Figures 75 and 76 present the mixing, placing, and finished surface of the crater cap. 


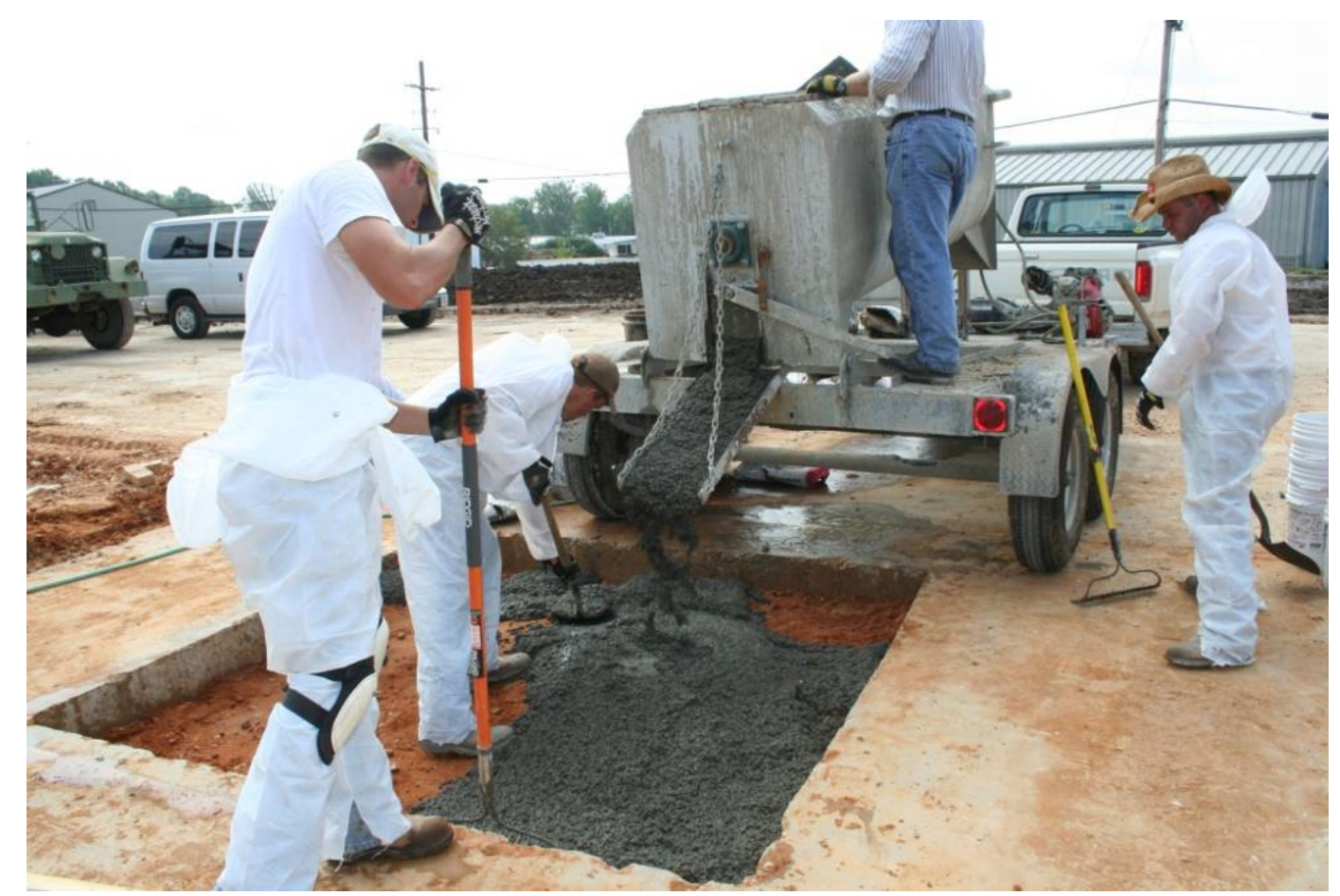

Figure 75. Crater L. Mixing and placement of ThoRoc 10-61.

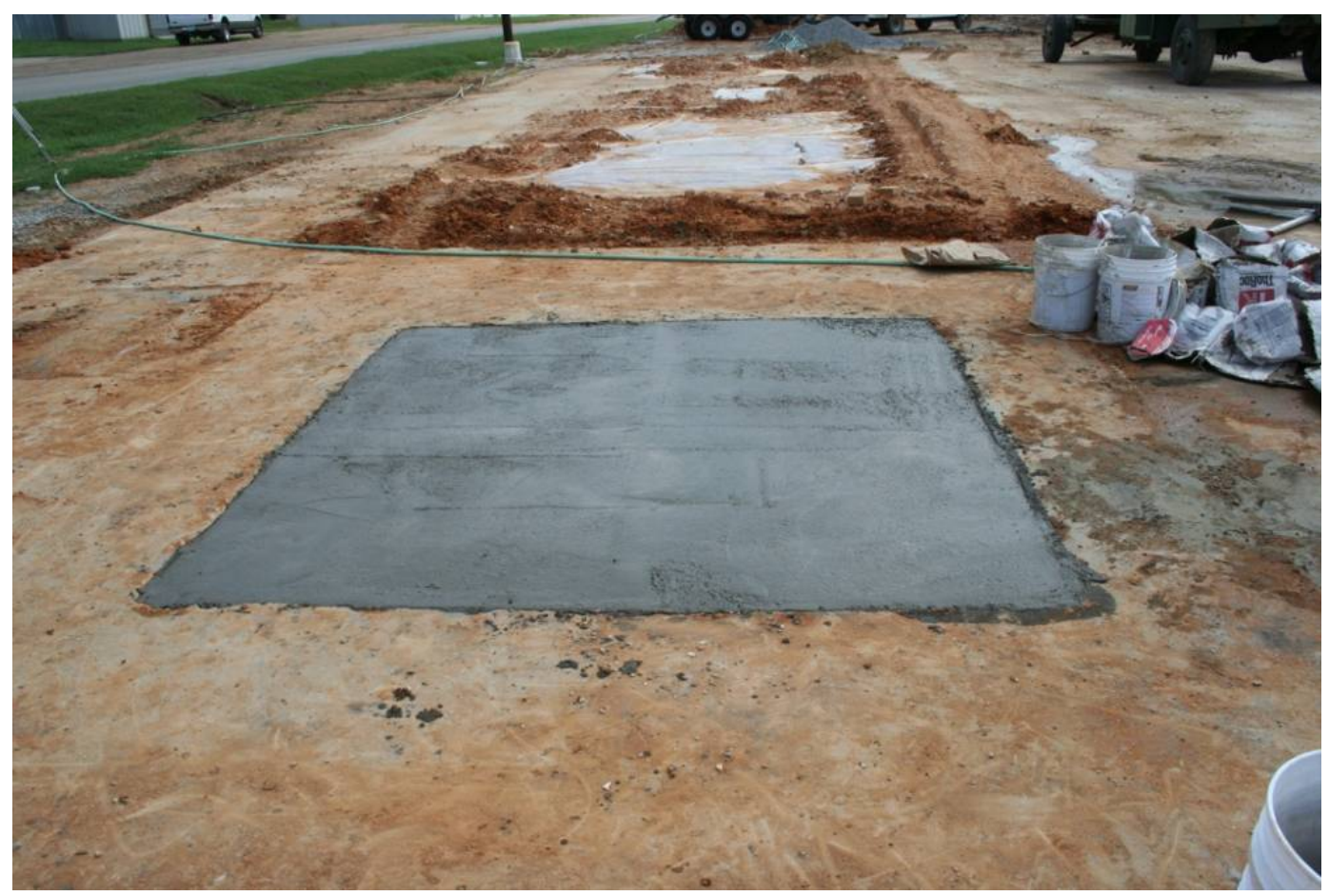

Figure 76. Crater L. Finished ThoRoc 10-61 surface. 


\section{Crater N-Foam Backfill Replacement Crater}

Unlike the other craters in Series 2, Crater $\mathrm{N}$ was reserved for foam backfill testing. After the subgrade preparation and measurements were completed, 1-ft maximum diameter concrete debris was placed in the crater until approximately 9 in. remained for a cap to be placed.

Foam-iT! 5 was mixed in a 1:1 ratio of components A and B in 5-gal buckets. Approximately $5 \mathrm{gal}$ of material was mixed at a time using high-speed drills with foam mixing attachments. Thirty gallons of foam was required to complete the debris stabilization. Each bucket was mixed according to manufacturers instructions until the foam had a consistency of glue and was light tan in color. The foam was immediately poured into the crater over the debris, flowing to the bottom of the crater, then rising to the surface of the debris. No visible voids were noticed. The material caused the debris to rise 1 to $2 \mathrm{in}$. despite the weight of each piece. As in the lab, small pieces of aggregate were pushed out of the system by the rising foam as it floated on the surface. The foam caused small swells in the surface resulting in an irregular profile. After the foam had settled for $30 \mathrm{~min}$, the excess foam mounds were removed by a pick ax and flat head shovel to create as level a surface as possible. The objective of Crater $\mathrm{N}$ was to evaluate foam backfill placement techniques. Thus, the crater remained uncapped and was not subjected to simulated aircraft traffic.

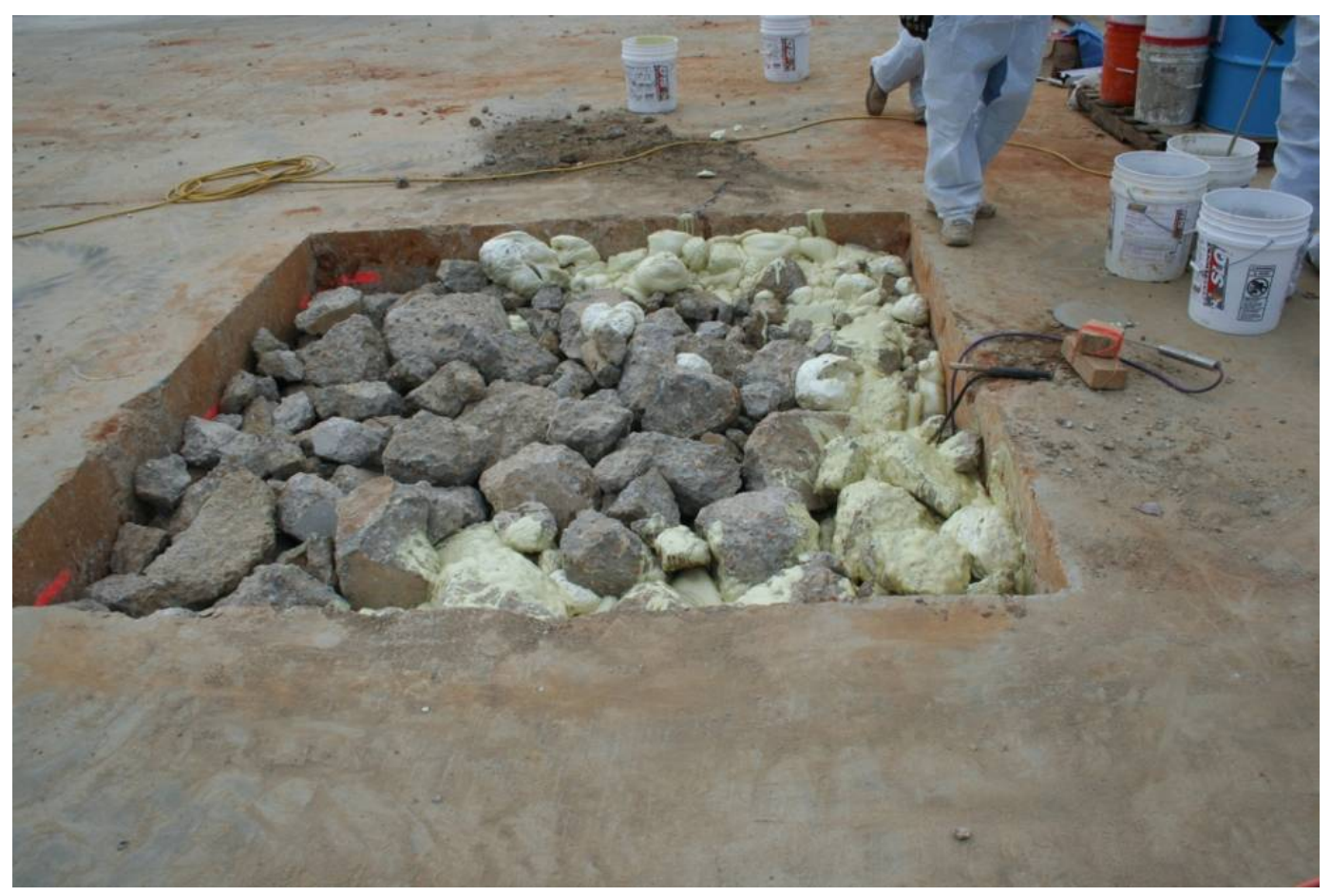

Figure 77. Crater N. Foam-iT! 5 application to debris. 


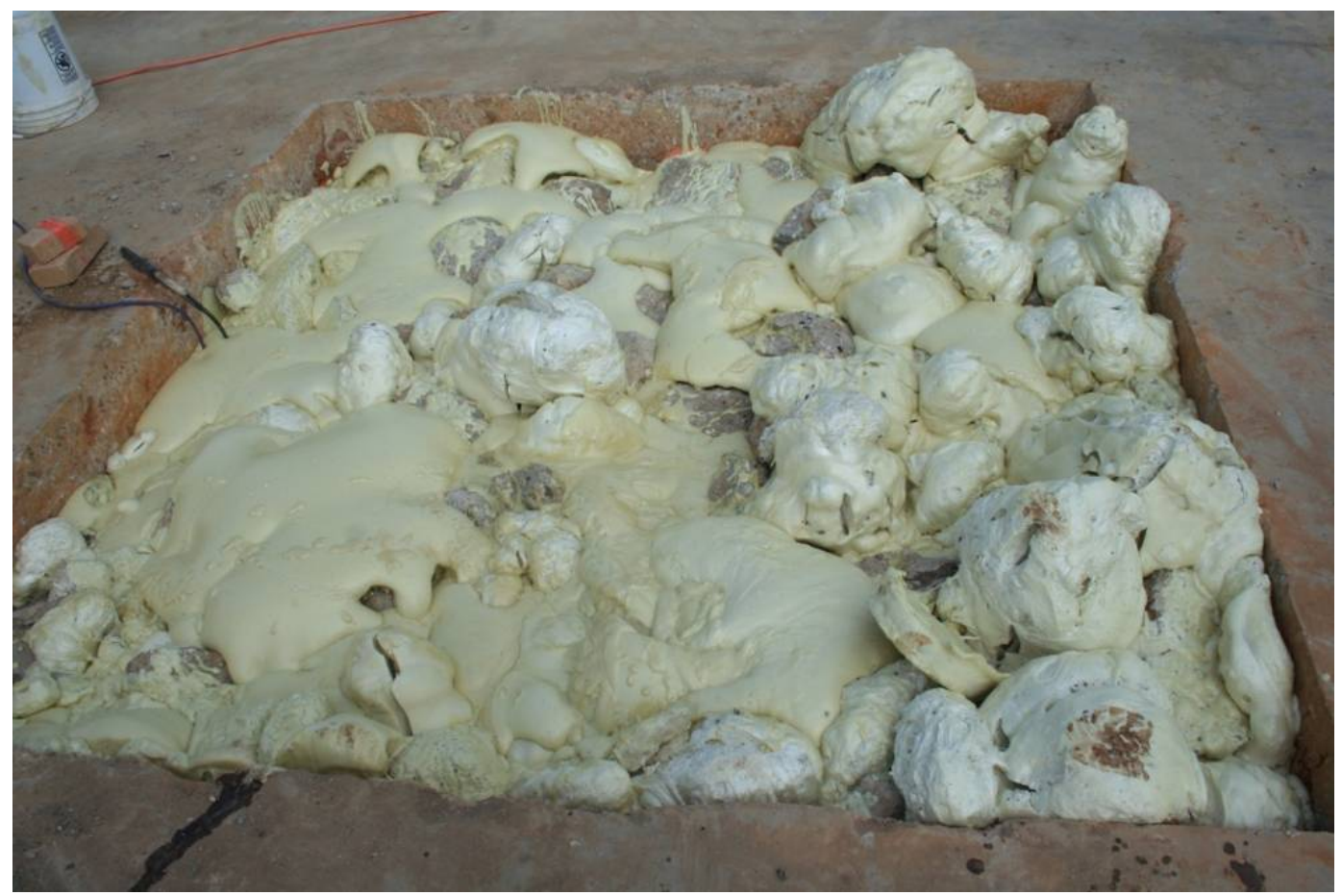

Figure 78. Crater N. Foam-iT! 5 application to debris after expansion.

\section{Crater 0-Foam base repair}

Like Crater N, Crater O was reserved for foam backfill testing. After the subgrade preparation was completed, clay gravel was compacted in 6-in. lifts leaving enough room for a 6-in. foam base and a 9-in. cap. Foam-iT! 15 was mixed in a 1:1 ratio of components A and B in 5-gal buckets. Approximately $5 \mathrm{gal}$ of material were mixed at a time using high-speed drills with foam mixing attachments as in the previous crater. Only $15 \mathrm{gal}$ of foam were available. This was estimated to be enough material to rise 2 to 4 in. in height based on expansion ratios measured at similar temperatures in the laboratory. Each bucket was mixed according to manufacturer instructions until the foam had a consistency of glue and was light tan in color. The foam was immediately poured into the crater and allowed to rise. The foam flowed across the bottom of the crater as it rose. No visible voids were noticed. The material rose 2 to 4 in. leaving a 2to 4-in. gap. The surface of the foam was relatively smooth without the "mounds" seen in the previous crater. As with Crater N, Crater O was used to evaluate foam backfill placement techniques. Thus, Crater $\mathrm{O}$ was not capped or trafficked. 


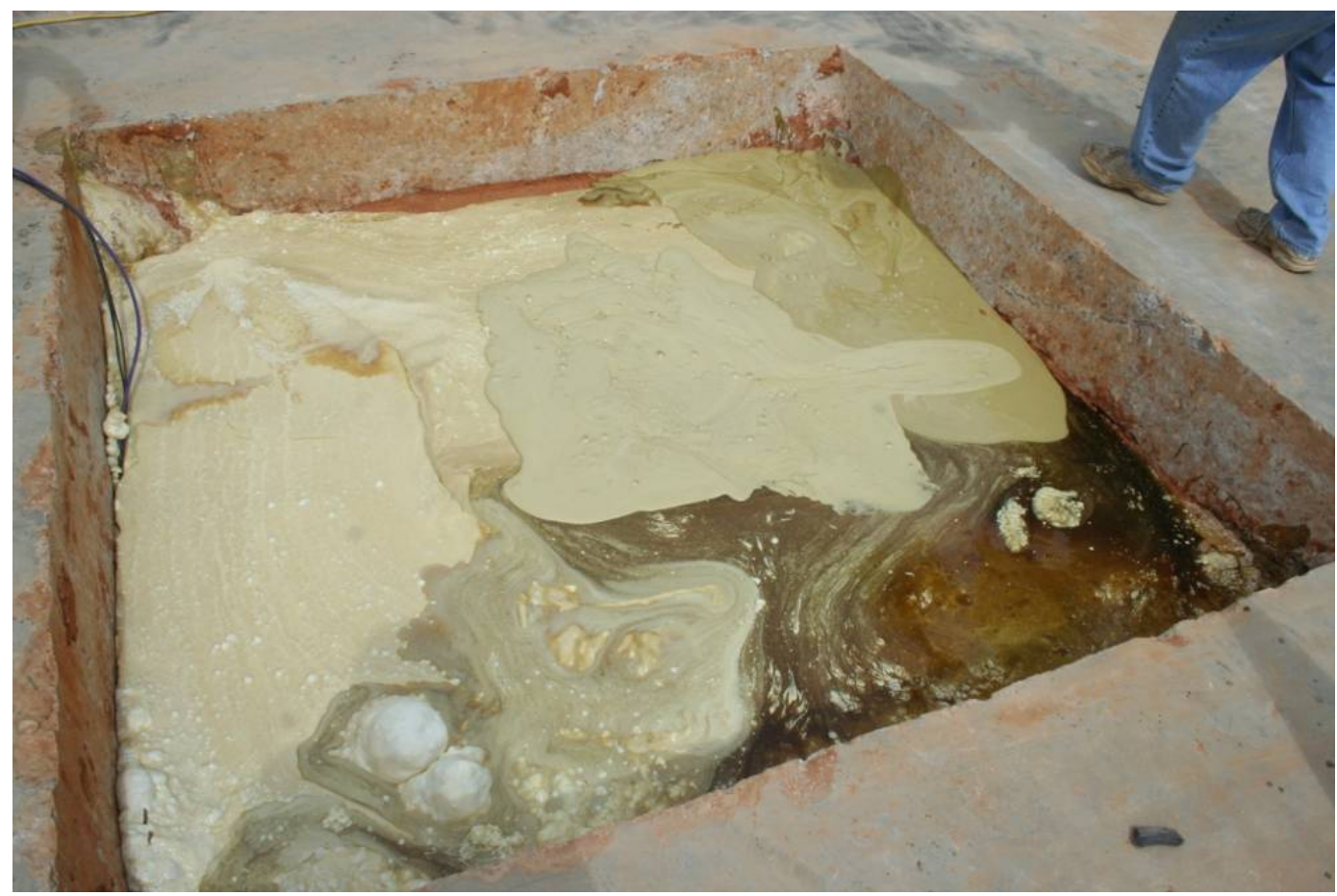

Figure 79. Crater 0. Foam-iT! 15 application as backfill.

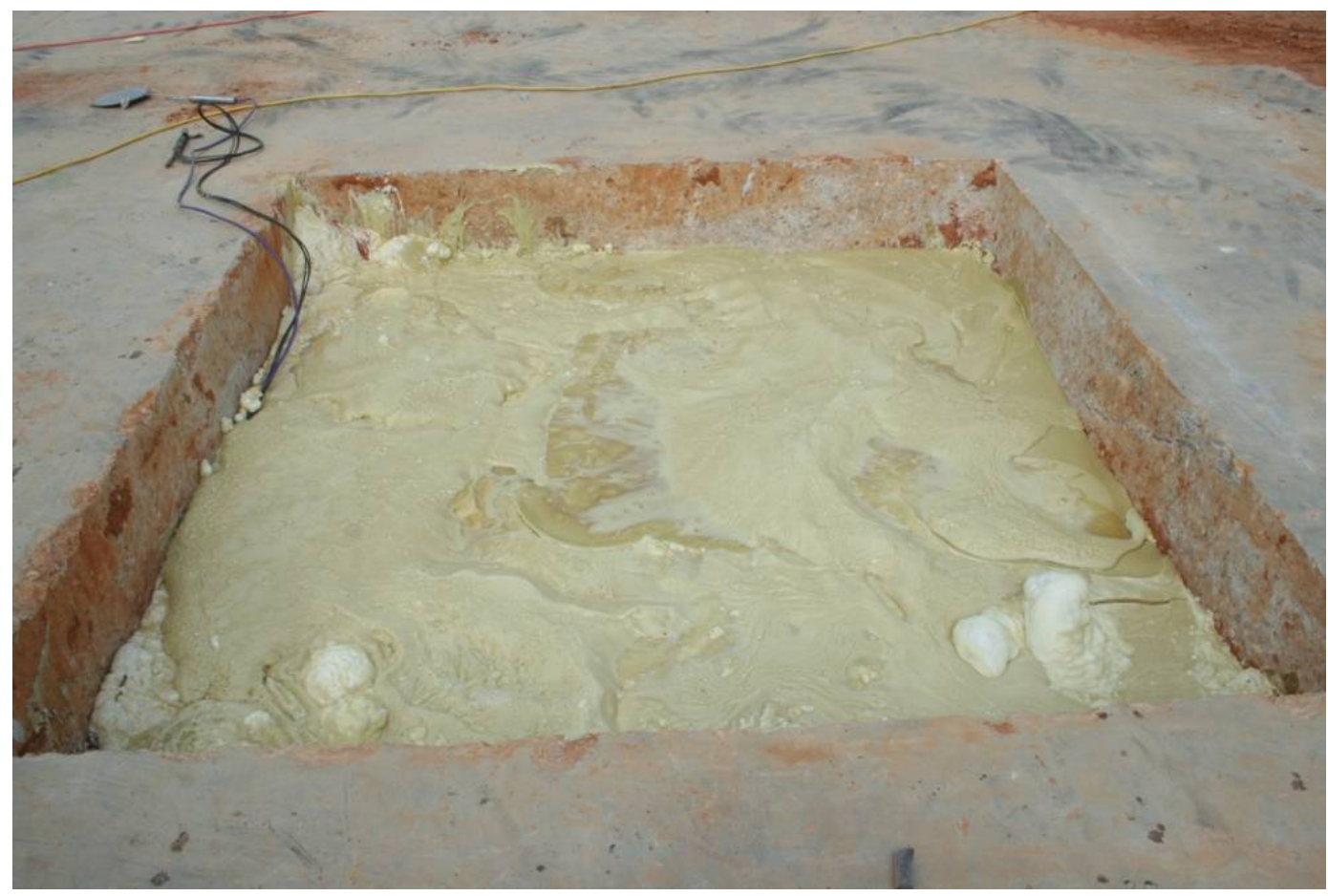

Figure 80. Crater 0. Foam-iT! 15 application as backfill after expansion. 


\section{Series 3 crater repairs}

Series 3 crater repairs were conducted by a team from ERDC. Each repair consisted of a total volume of $13.0 \mathrm{yd}^{3}$ and a cap volume of $83.3 \mathrm{ft}^{3}$.

Four repairs were conducted. Prior to each crater repair, the subgrade material was excavated to a depth of $3.5 \mathrm{ft}$ below the section surface to locate the instrumentation conduit. As with Series 1 and 2 repairs, the instrumentation wires were pulled through the conduit in each crater and routed through a main trunk line adjacent to the north side of the section to the instrumentation pod. Three temperature strings (thermocouples) and one pressure cell were installed in each crater prior to cap placement: one pressure cell at the center of the crater, and three thermocouples near the edge of the repair, as shown in Figure 81.

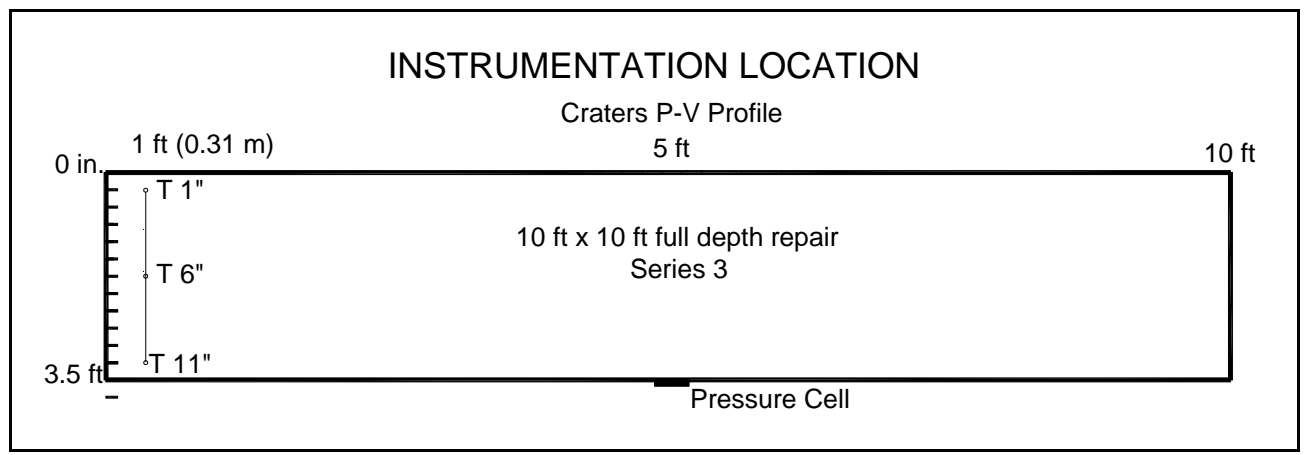

Figure 81. Instrumentation layout Series 3 craters.

Moisture, density, DCP, and elevation measurements were performed for the existing subgrade material. These measurements were performed in the same manner as the previous series. The pressure cells were installed in the subgrade using the same procedure used in previous series. Concrete debris was created by breaking up the excavated material from the crater with a breaker attachment on a skid steer (Figure 82). This debris was then placed within 10 to $12 \mathrm{in}$. of the surface using a front-end loader and skid steer with a bucket attachment (Figure 83). This material had a maximum diameter of $1 \mathrm{ft}$, and because of this size, no moisture, density, or DCP measurements could be measured for this material. Density, moisture, and DCP data for the subgrade are presented in Tables 24 and 25. 
Table 24. Series 3 construction density and moisture content.

\begin{tabular}{|c|c|c|c|c|c|c|}
\hline \multirow[b]{2}{*}{ Feature } & \multirow[b]{2}{*}{ Location } & \multirow[b]{2}{*}{$\begin{array}{l}\text { Depth, } \\
\text { in. }\end{array}$} & \multirow[b]{2}{*}{ Material } & \multicolumn{3}{|c|}{ Nuclear Gauge Measurements } \\
\hline & & & & $\begin{array}{c}\text { Wet } \\
\text { Density } \\
\left(\mathbf{l b} / \mathbf{f t}^{3}\right)\end{array}$ & $\begin{array}{c}\text { Dry } \\
\text { Density } \\
\left(\mathbf{l b} / \mathbf{f t}^{3}\right)\end{array}$ & Moisture Content (\%) \\
\hline \multirow{7}{*}{ Crater P } & Southwest & 32 & Silty Clay & 117.3 & 100.4 & 16.8 \\
\hline & Southeast & 32 & Silty Clay & 116.0 & 99.3 & 16.9 \\
\hline & Northeast & 32 & Silty Clay & 116.9 & 102.5 & 14.0 \\
\hline & & & Average & 116.7 & 100.7 & 15.9 \\
\hline & Southwest & 10 & Concrete Debris & \multirow{3}{*}{\multicolumn{3}{|c|}{$--a$}} \\
\hline & Southeast & 10 & Concrete Debris & & & \\
\hline & Northeast & 10 & Concrete Debris & & & \\
\hline \multirow{7}{*}{ Crater Q } & Southwest & 32 & Silty Clay & 121.4 & 102.4 & 18.5 \\
\hline & Southeast & 32 & Silty Clay & 117.7 & 95.8 & 22.9 \\
\hline & Northeast & 32 & Silty Clay & 115.7 & 99.4 & 16.4 \\
\hline & & & Average & 118.3 & 99.2 & 19.3 \\
\hline & Southwest & 10 & Concrete Debris & \multirow{3}{*}{\multicolumn{3}{|c|}{$--a$}} \\
\hline & Southeast & 10 & Concrete Debris & & & \\
\hline & Northeast & 10 & Concrete Debris & & & \\
\hline \multirow{7}{*}{ Crater R } & Southwest & 32 & Silty Clay & 111.3 & 94.1 & 18.3 \\
\hline & Southeast & 32 & Silty Clay & 122.9 & 102.7 & 19.7 \\
\hline & Northeast & 32 & Silty Clay & 121.6 & 103.2 & 17.8 \\
\hline & & & Average & 118.6 & 100.0 & 18.6 \\
\hline & Southwest & 10 & Concrete Debris & \multirow{3}{*}{\multicolumn{3}{|c|}{$--a$}} \\
\hline & Southeast & 10 & Concrete Debris & & & \\
\hline & Northeast & 10 & Concrete Debris & & & \\
\hline \multirow{7}{*}{ Crater S } & Southwest & 32 & Silty Clay & 119.3 & 100.1 & 19.1 \\
\hline & Southeast & 32 & Silty Clay & 121.3 & 100.7 & 20.5 \\
\hline & Northeast & 32 & Silty Clay & 116.4 & 97.9 & 18.9 \\
\hline & & & Average & 118.9 & 99.3 & 19.5 \\
\hline & Southwest & 10 & Concrete Debris & & & \multirow{3}{*}{- -a } \\
\hline & Southeast & 10 & Concrete Debris & & & \\
\hline & Northeast & 10 & Concrete Debris & & & \\
\hline
\end{tabular}

a Moisture and density values could not be determined for the rubble base.

Table 25. Series 2 average DCP estimated CBR values.

\begin{tabular}{|c|c|}
\hline Crater & $\begin{array}{c}\text { CBR, \% } \\
\text { Subgrade }\end{array}$ \\
\hline $\mathrm{Q}$ & 22 \\
\hline $\mathrm{R}$ & 24 \\
\hline $\mathrm{S}$ & 26 \\
\hline $\mathrm{T}$ & 24 \\
\hline
\end{tabular}




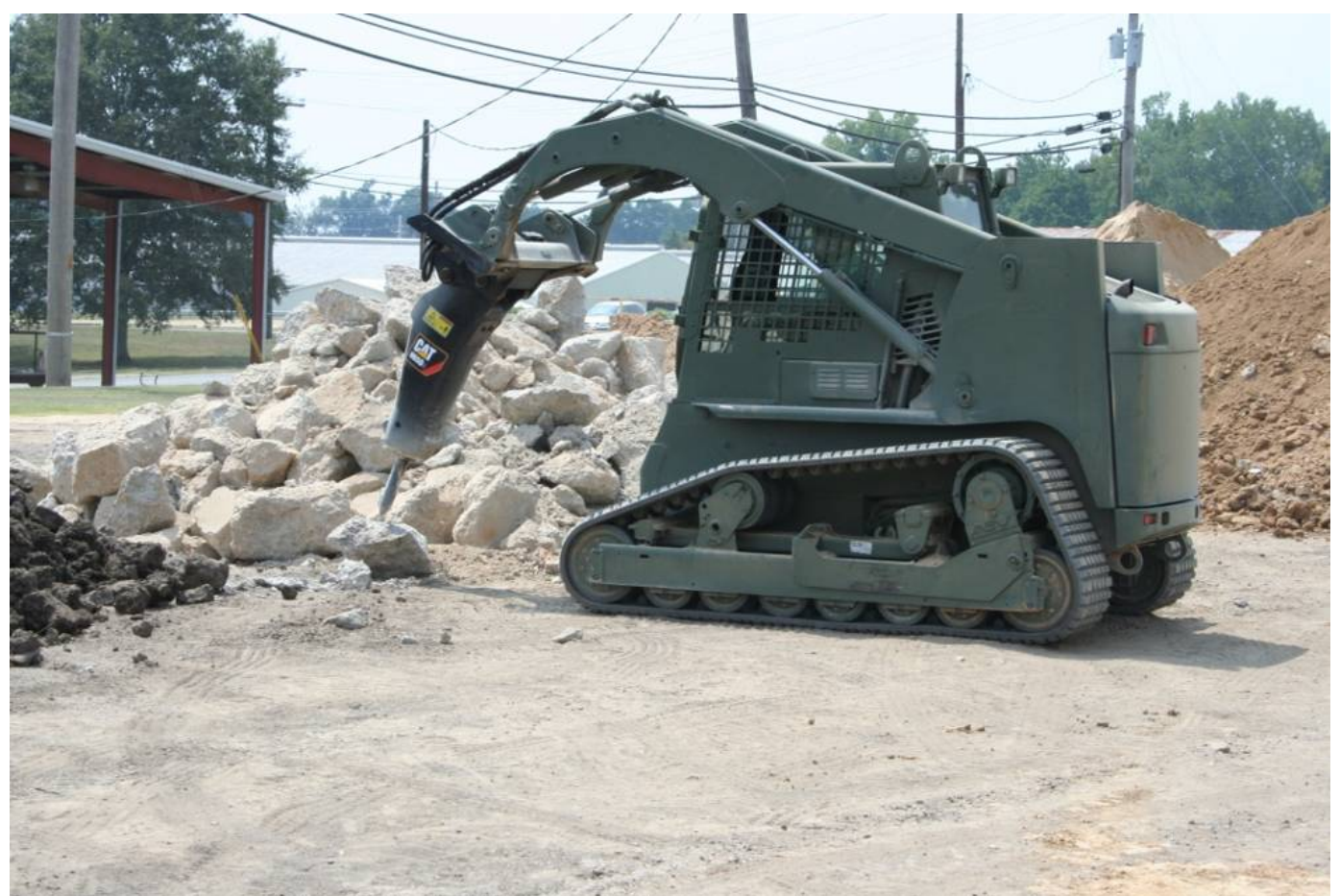

Figure 82. Skid steer with breaker attachment creating debris.

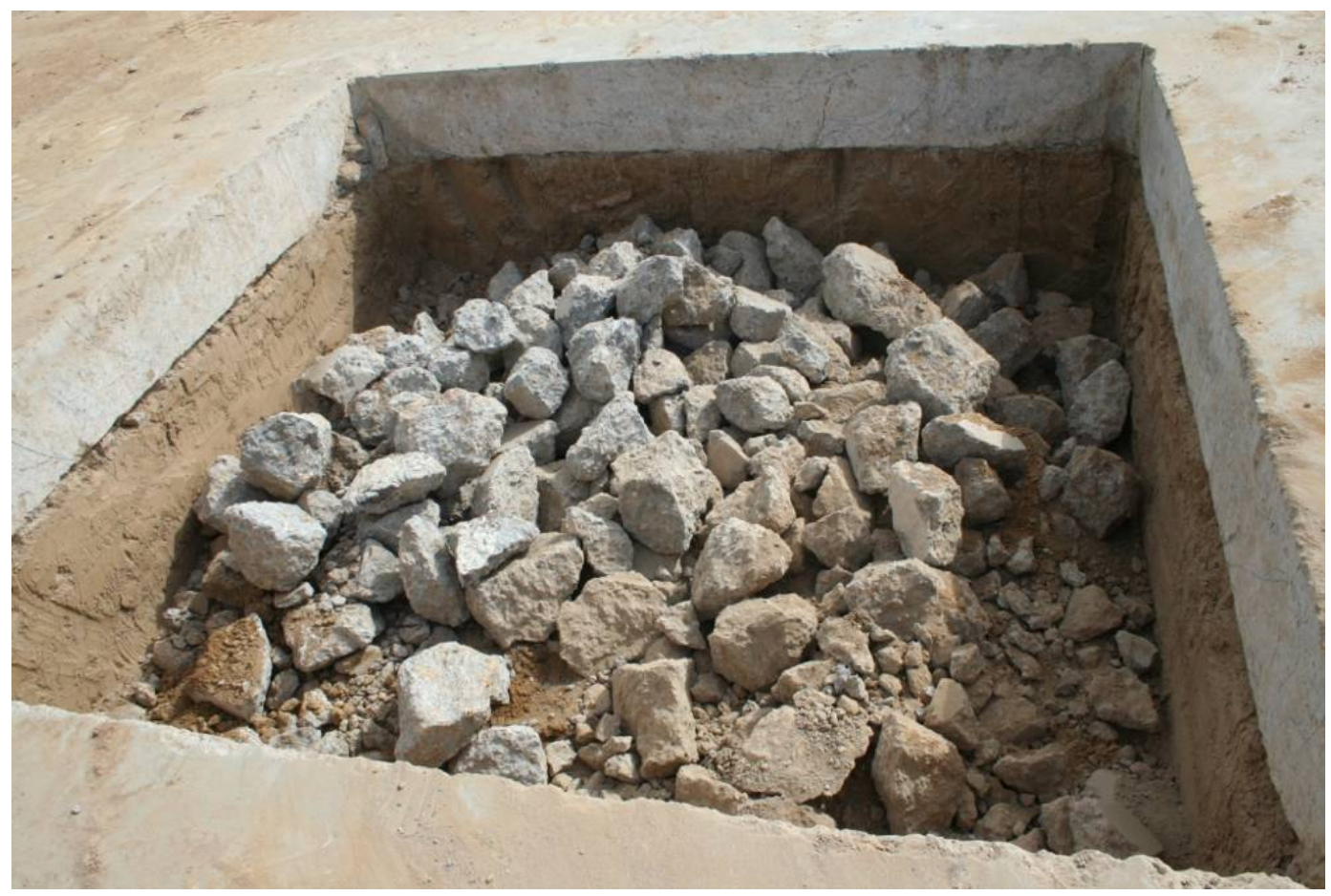

Figure 83. Concrete debris during placement in crater. 


\section{Crater P-Rapid Set ${ }^{\circledR}$ concrete mix}

The Rapid Set ${ }^{\circledR}$ repair was prepared by mixing the cementitious material in the same $2-\mathrm{yd}^{3}$ portable concrete mixer as Series 2 and emptied directly into the south edge of the crater. A forklift was used to raise the bags of material level with the top of the mixer. The first batch was mixed by adding 42 gal of water measured in 5-gal buckets to the running mixer, followed by forty-two 60-lb bags of concrete mix and 126 packets of Rapid Set FLOW CONTROL plasticizing admixture to extend the working time. The second batch consisted of forty 60 -lb bags of Rapid Set concrete mix and $40 \mathrm{gal}$ of water. No plasticizer was used for the remaining batches as the temperature was below $85^{\circ} \mathrm{F}$. The batches were mixed for $1.5 \mathrm{~min}$ until lump-free and uniform in consistency. After these batches were mixed and placed, it was apparent that the material was completely penetrating the debris to the bottom of the crater and that there was not enough material to fill the whole volume. The remaining 86 bags were mixed in two 43-bag batches and placed on the north side of the crater so that the entire traffic area would be level with the surrounding pavement. Approximately 5 in. of material were needed on the north side of the crater in the non-traffic area. Additional materials were moved to the site and were mixed and placed to fill the remaining volume. A total of $2.5 \mathrm{hr}$ was required to mix and place the repair materials; $1.5 \mathrm{hr}$ was required for the Rapid Set portion of the cap. The cap was struck level, hand troweled, and finished with a bull float. Figures 84- 86 present the mixing, placing, and finished surface of the crater. 


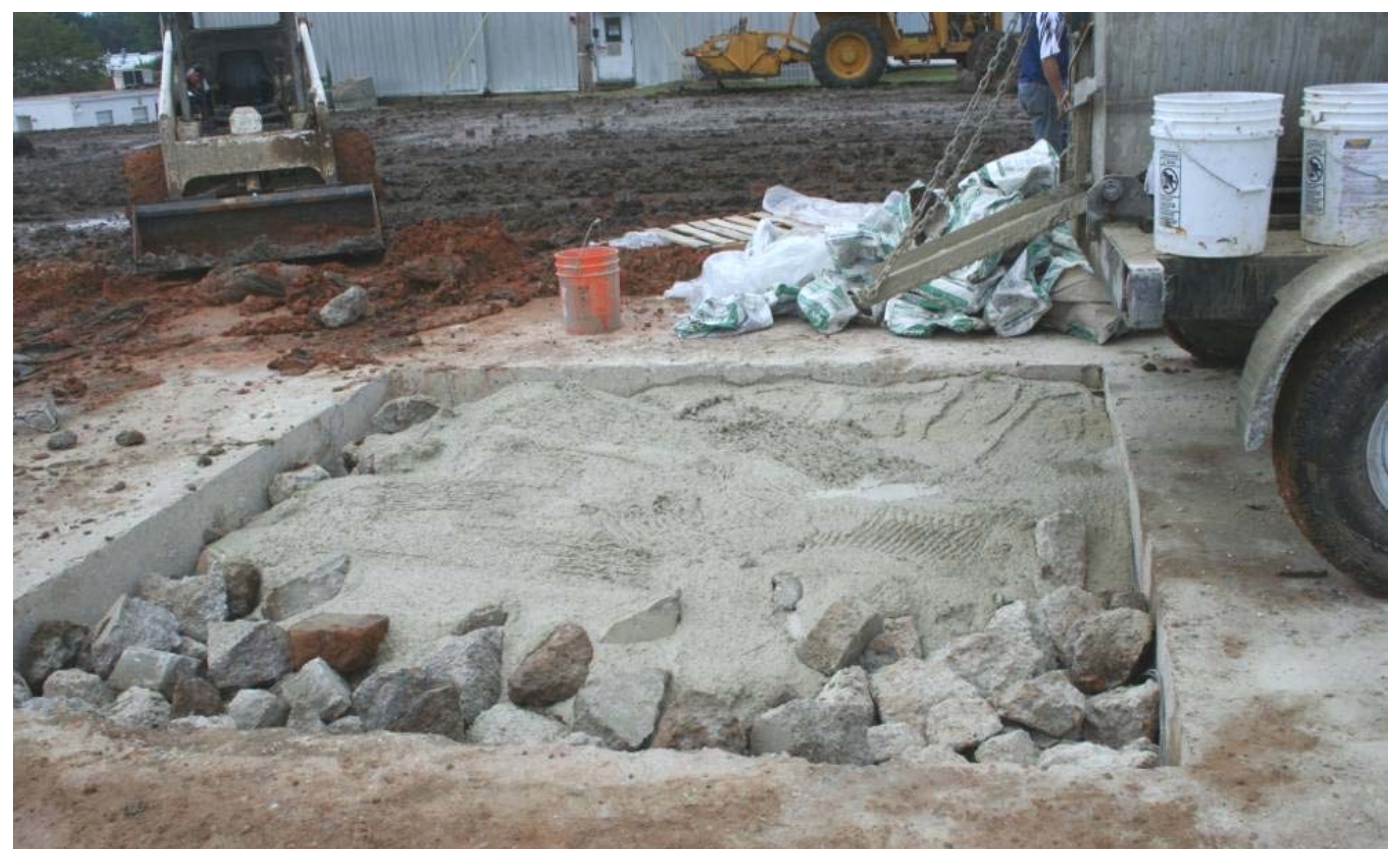

Figure 84. Crater P. Placement of Rapid Set over concrete debris.

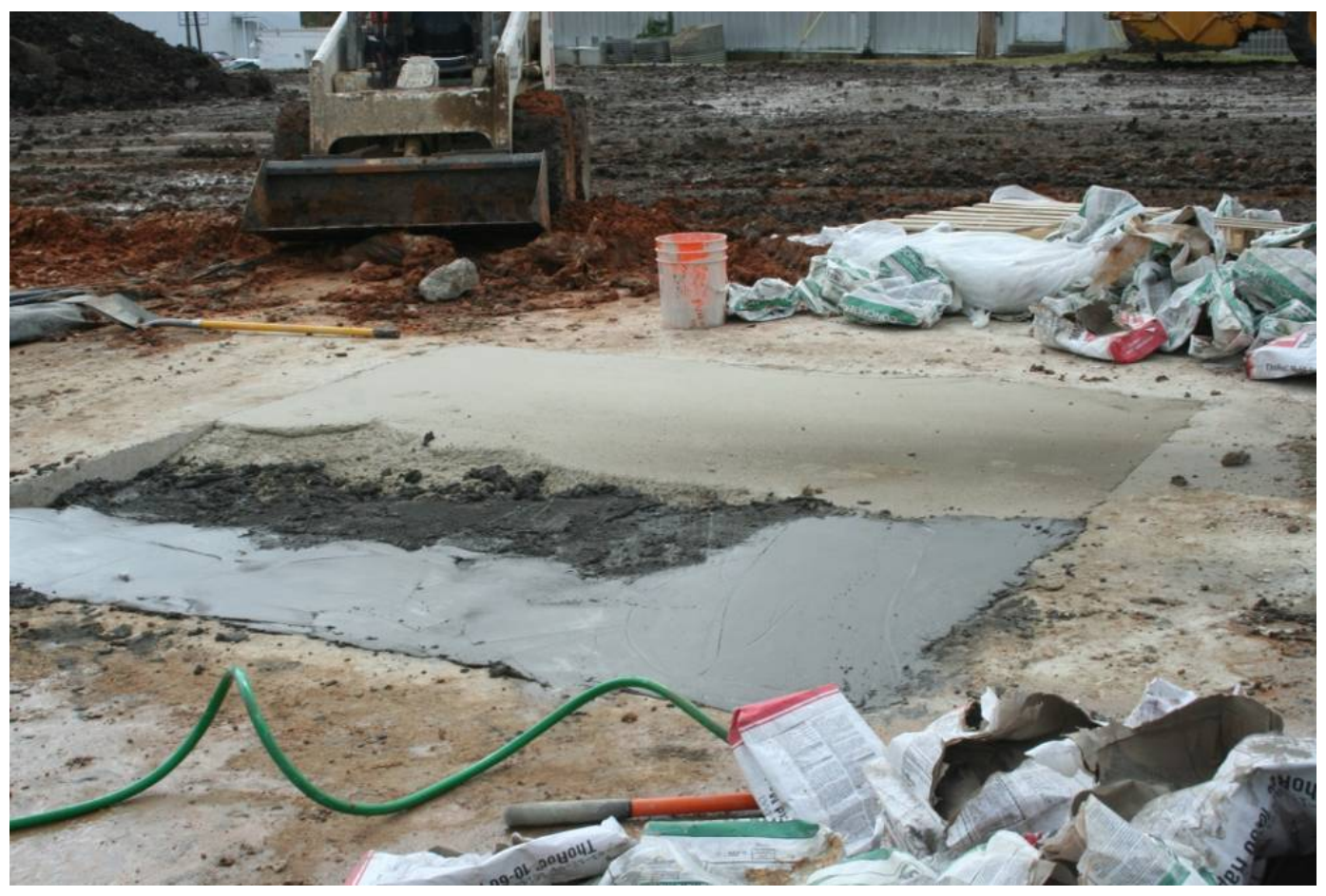

Figure 85. Crater P. Finishing Rapid Set repair with additional RS materials. 


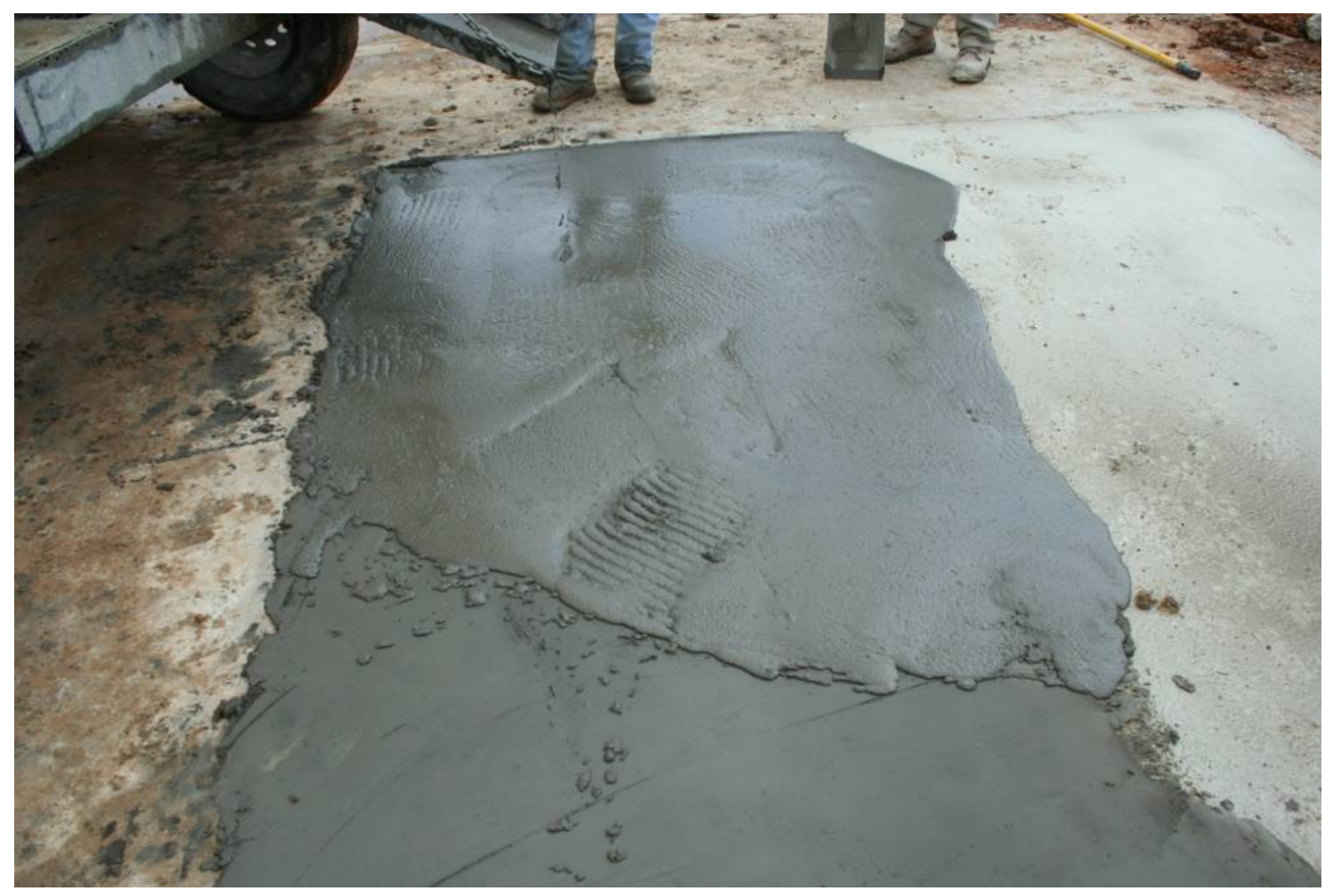

Figure 86. Crater P. Finished surface.

\section{Crater Q-Pavemend SLQ ${ }^{\mathrm{TM}}$}

Pavemend SLQ ${ }^{\mathrm{TM}}$ was selected for Crater Q. The same mixing and placement as used in Series 2 was followed with the addition of two drills. The material was quickly poured over the debris. The material easily penetrated to the bottom of the repair and flowed towards the center. Approximately $2 \mathrm{hr}, 54 \mathrm{~min}$ was required to mix 213 buckets of repair material. The material was placed and finished with hand trowels and a straightedge. The mixing was very labor intensive, but the addition of two extra drills reduced the time required to mix the large quantity of material with hand drills. Figure 87 presents the placement and finished surface of the repair. As with the other Pavemend repairs, it was difficult to achieve a smooth surface finish as can be seen in Figure 88. 


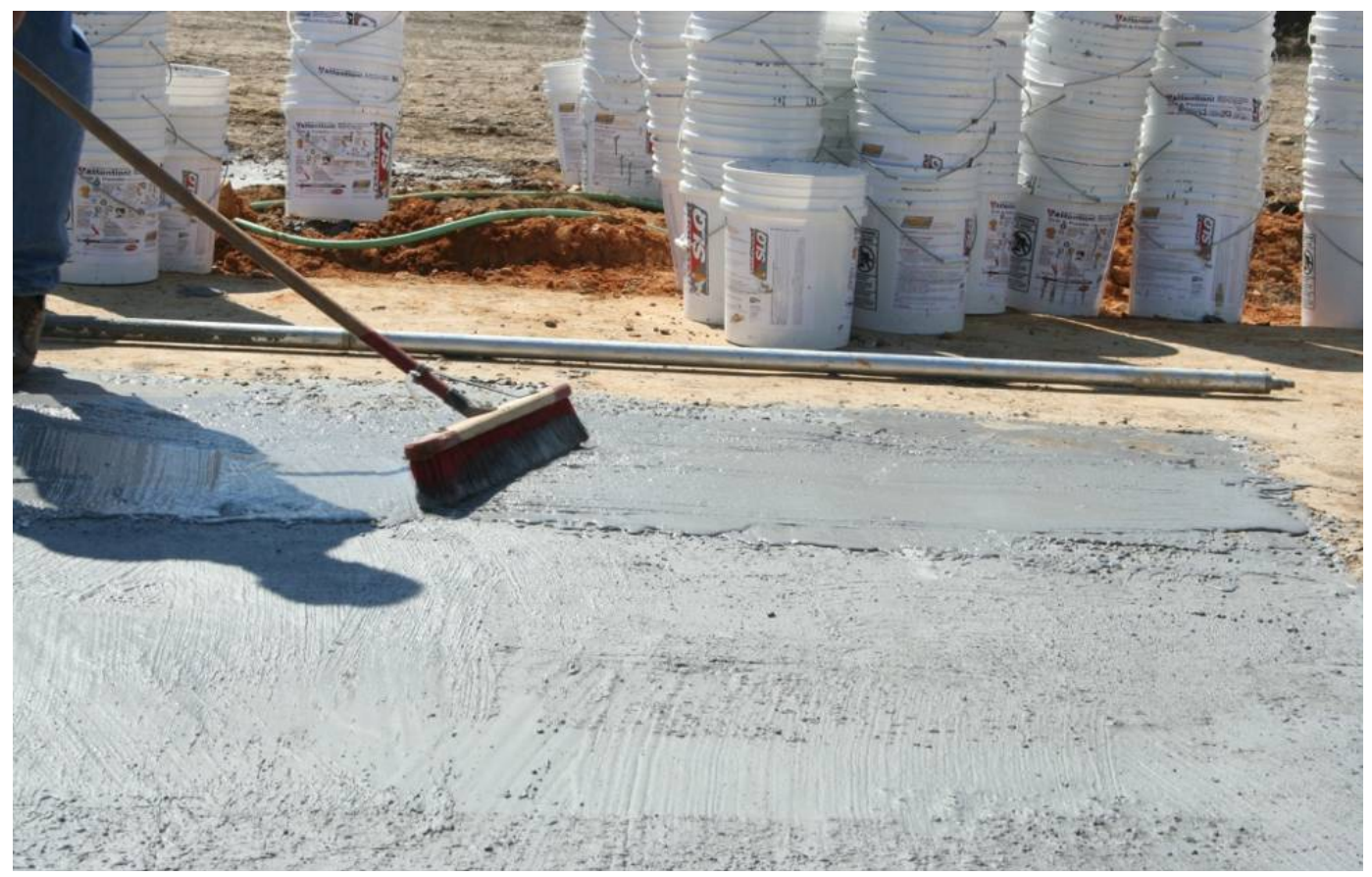

Figure 87. Crater Q. Placement of Pavemend SLQTM over debris.

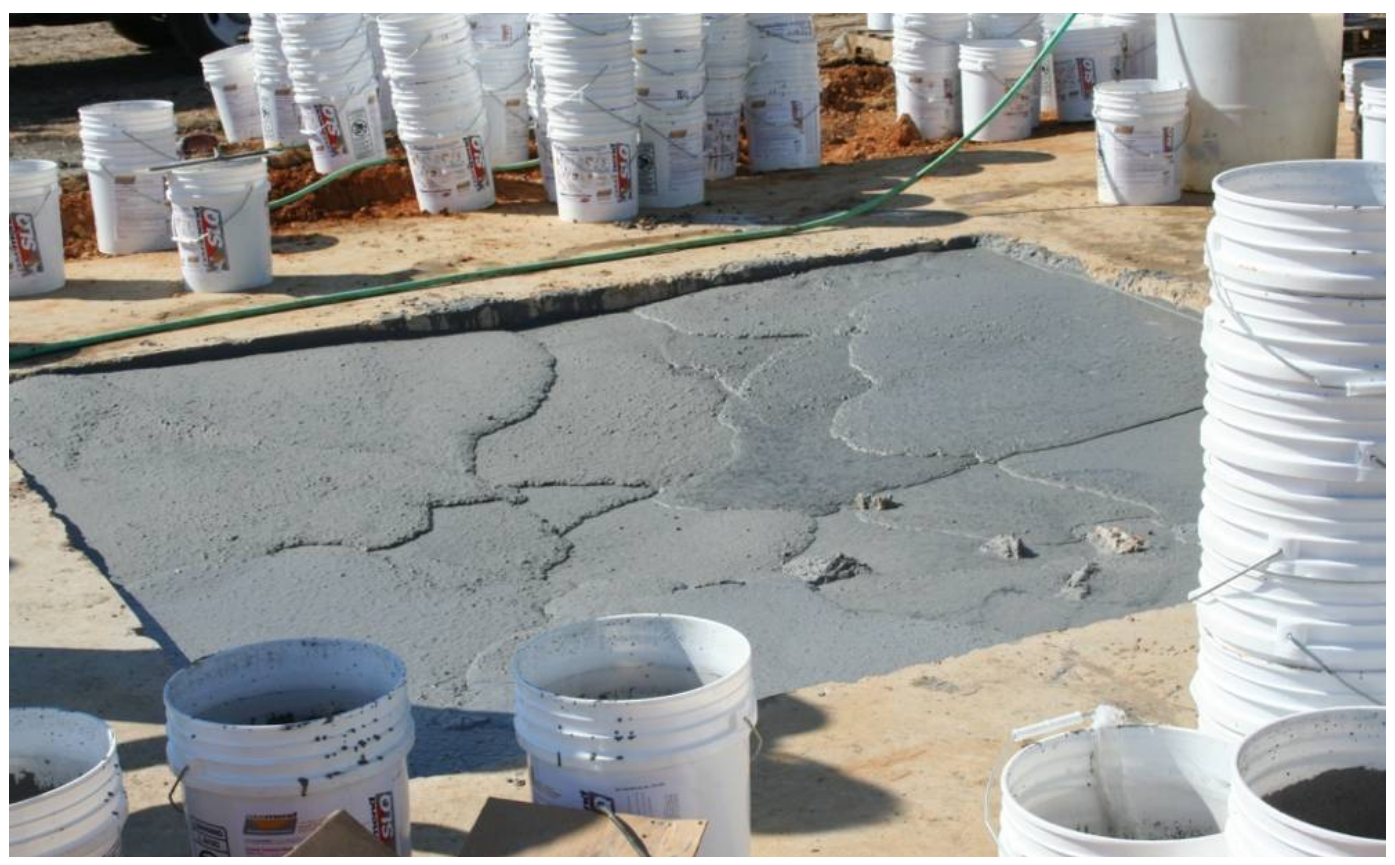

Figure 88. Crater Q. Surface of Pavemend SLQTM crater before finishing.

\section{Crater R-ThoRoc 10-61 Rapid Mortar}

ThoRoc 10-61 Rapid Mortar was selected for Crater R. The 2-yd ${ }^{3}$ mixer was positioned on the north edge of the crater to mix a flowable fill called RheoFill sent by the manufacturer to fill voids in the debris. Two batches each containing one 95-lb bag of Type III cement, 2,260 lb of concrete 
sand, $20.5 \mathrm{gal}$ of water, $1 \mathrm{lb}$ of calcium chloride $(\mathrm{CaCl})$, and one 3 - oz bag of RheoFill were mixed in the mixer for $5 \mathrm{~min}$. The $\mathrm{CaCl}$ amount was recommended by the vendor representative prior to mixing. The material was then emptied into the crater on top of the debris. The material did not readily penetrate the voids in the debris, and it settled on the surface as can be seen in Figure 89. A small vibratory plate compactor was used to aid the penetration as seen in Figure 90 . After $4 \mathrm{hr}$, the material had not fully cured and was very wet in some places. The cap was not placed until 4 days later. ThoRoc 10-61 was available for the placement of the cap. Once all materials were in place, mixing and placing began. The material was mixed in five batches in the 2-yd ${ }^{3}$ mixer ranging from 20 to 25 bags of ThoRoc 10-61. Each batch was allowed to mix for 3 min; additional water was added by the half-gallon as needed. When mixing was complete, the material was emptied directly into the crater and was spread with rakes from the north end to the south end. A total of 120 bags of material were required to repair the crater and were mixed using manufacturer instructions. Approximately $1 \mathrm{hr}, 13 \mathrm{~min}$ was required to mix, place, and finish the material. The material was struck level with a straightedge and finished with a bull float. Water was sprayed on the surface, and the crater was covered with plastic sheeting and allowed to cure. Figure 91 presents the placement of the material, and Figure 92 presents the finished cap.

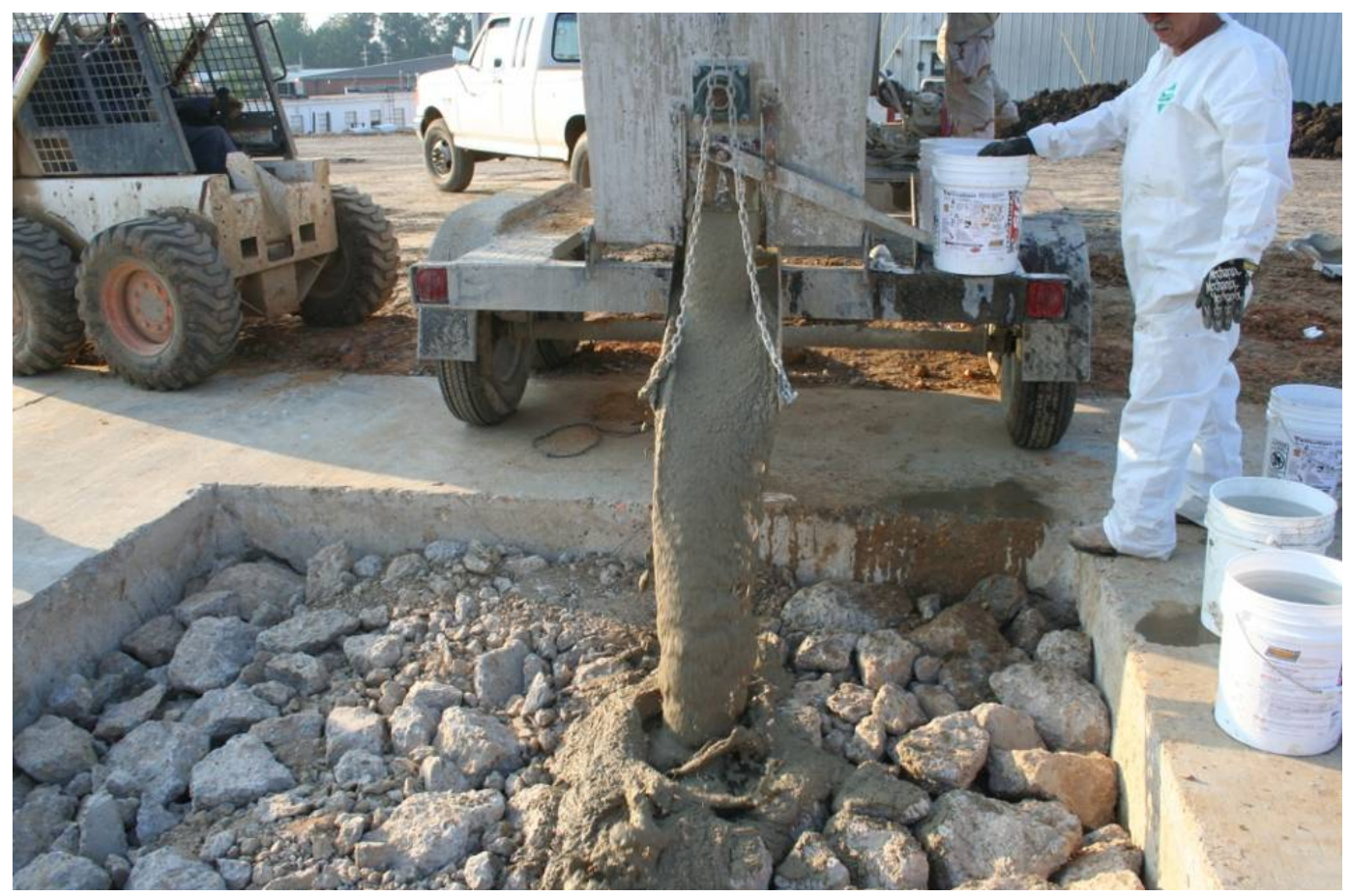

Figure 89. Crater R. RheoFill placement. 


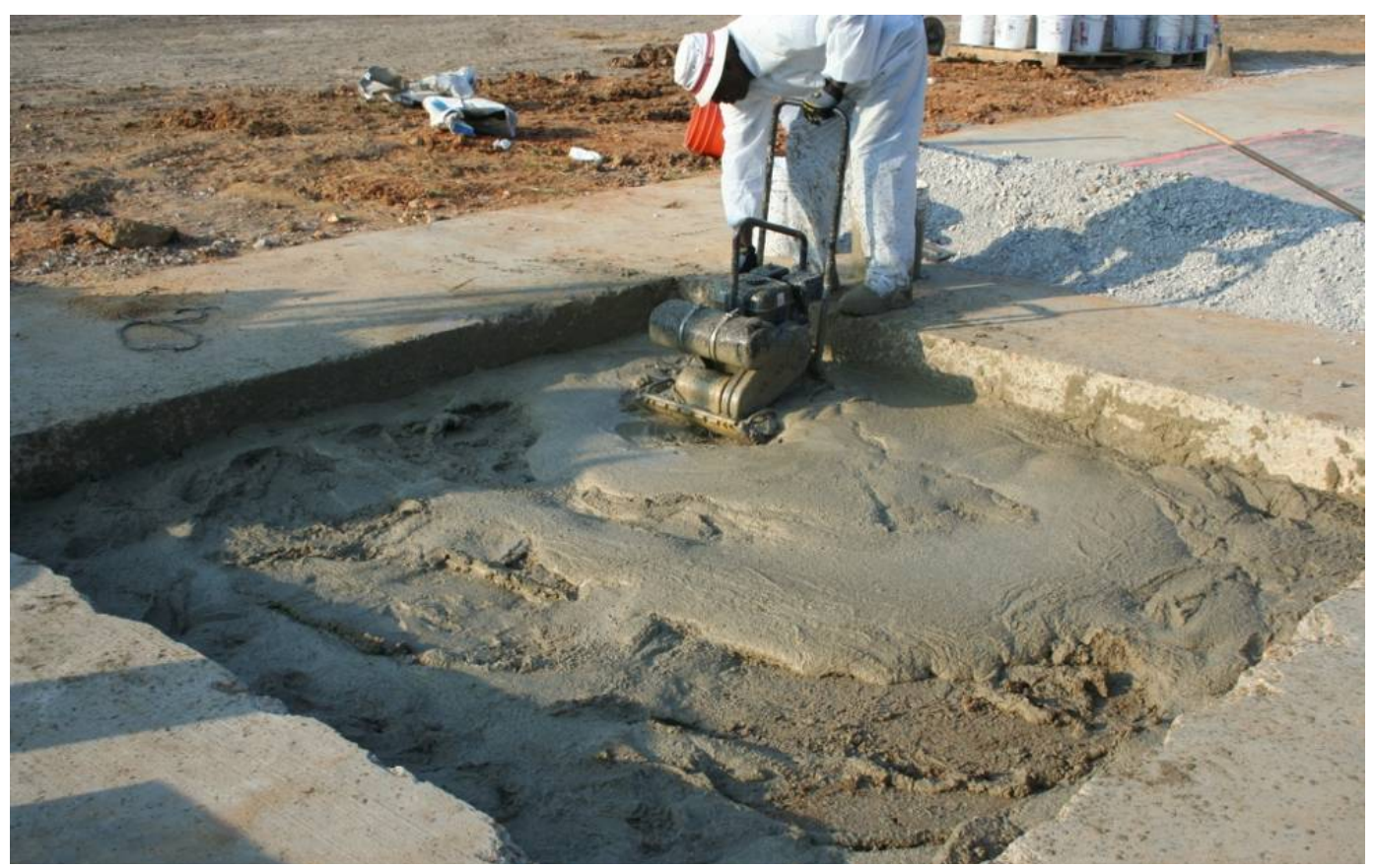

Figure 90. Crater R: Using plate compactor to aid in RheoFill flow.

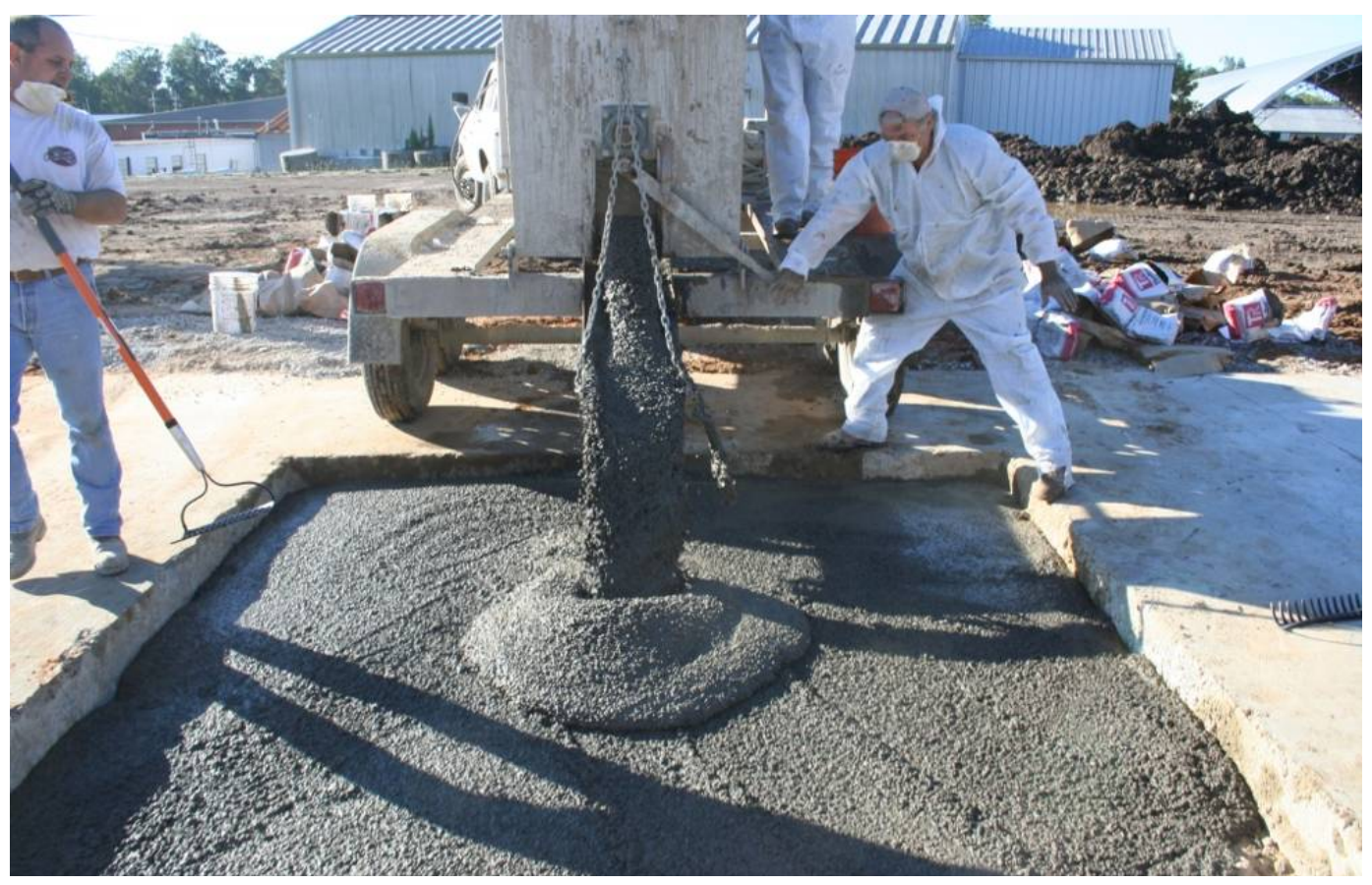

Figure 91. Crater R. Placement of ThoRoc 10-61 cap. 


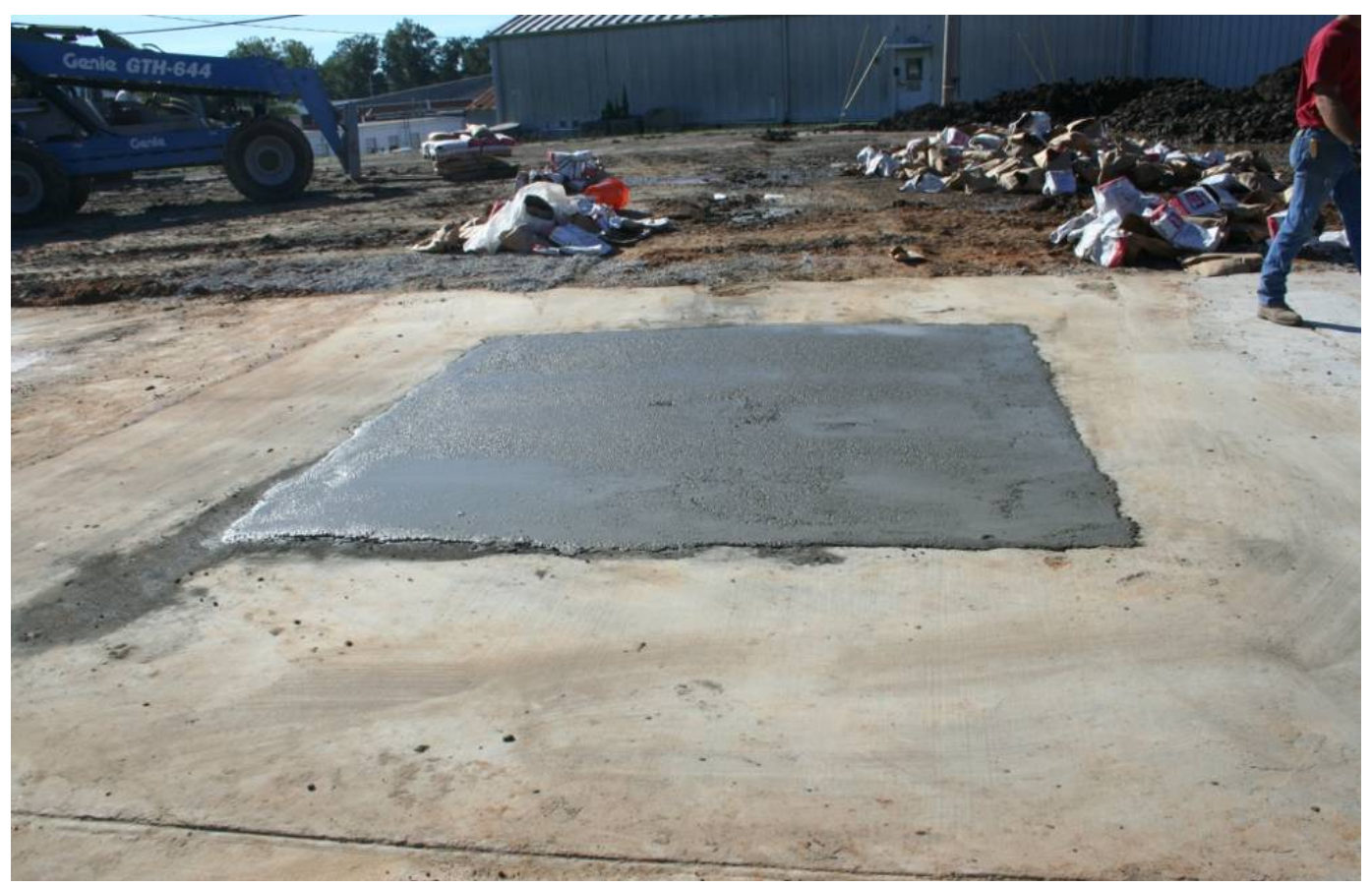

Figure 92. Crater R. Finished cap.

\section{Crater S-Ultimax Concrete}

Ultimax Concrete was selected for Crater S. The same 2-yd 3 mixer from Crater $\mathrm{S}$ was set up on the north edge of the crater. A material known as Aquacrete was used as a flowable fill material. This material had been used unsuccessfully in field trials for large crater repair as a capping material, but it showed promise as a flowable fill material. Three 25-bag batches (50 lb per bag) of this material and one eight-bag batch were required to stabilize the debris. Each 25-bag batch was mixed with 50 gal of water, and the eight-bag batch was mixed with $16 \mathrm{gal}$ of water. Each batch was allowed to mix until uniform in color and consistency, and once mixed, the material was allowed to flow over the debris. This material had the consistency of water and easily flowed through the debris voids (Figure 93). The material would have created a smooth surface, but not enough material had been sent for the repair. The top of the debris was not covered by this material (Figure 94). A total of 23 min was required to mix this material, and it was allowed to cure for $30 \mathrm{~min}$ while the Ultimax Concrete was readied. 


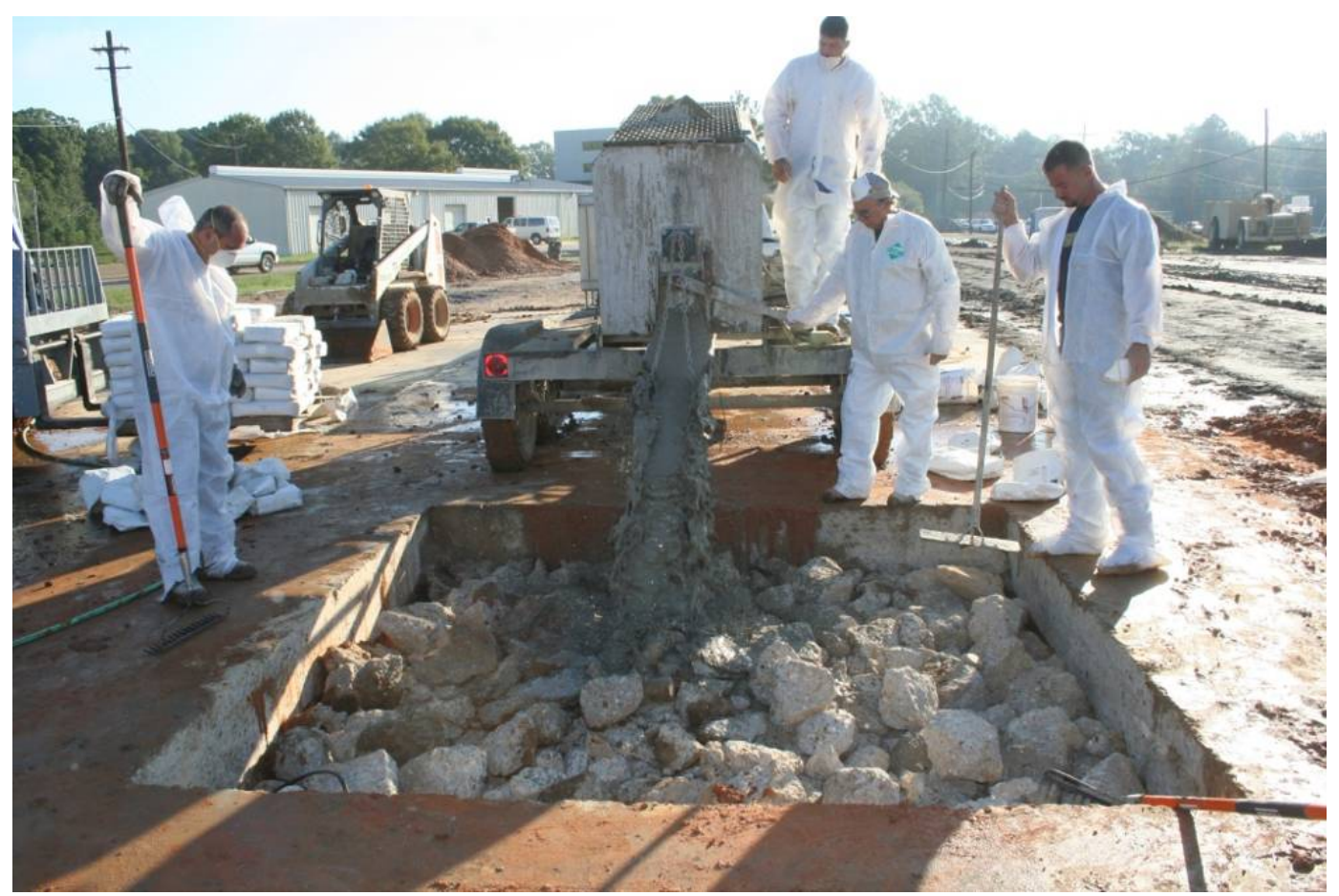

Figure 93. Crater S. Placing Aquacrete as flowable fill.

Once all materials were prepared, mixing and placing began following manufacturer instructions described in Series 1 repairs. When mixing was complete, the material was emptied directly into the crater and was spread with rakes. Approximately 200 bags of Ultimax concrete were required to produce the cementitious cap. Cap thickness varied due to debris geometry between 9 and $12 \mathrm{in.} \mathrm{Each} \mathrm{batch} \mathrm{contained} \mathrm{approximately} 2850$-lb bags of material and 20 gal of water. Additional water was added by the halfgallon as needed. A total of $2 \mathrm{hr}, 51 \mathrm{~min}$ was required to place the flowable fill and cap. Once complete, the capping material was struck level with a straightedge and finished with a bull float. See Figures 95 and 96 for the placement of the cap and finished surface. 


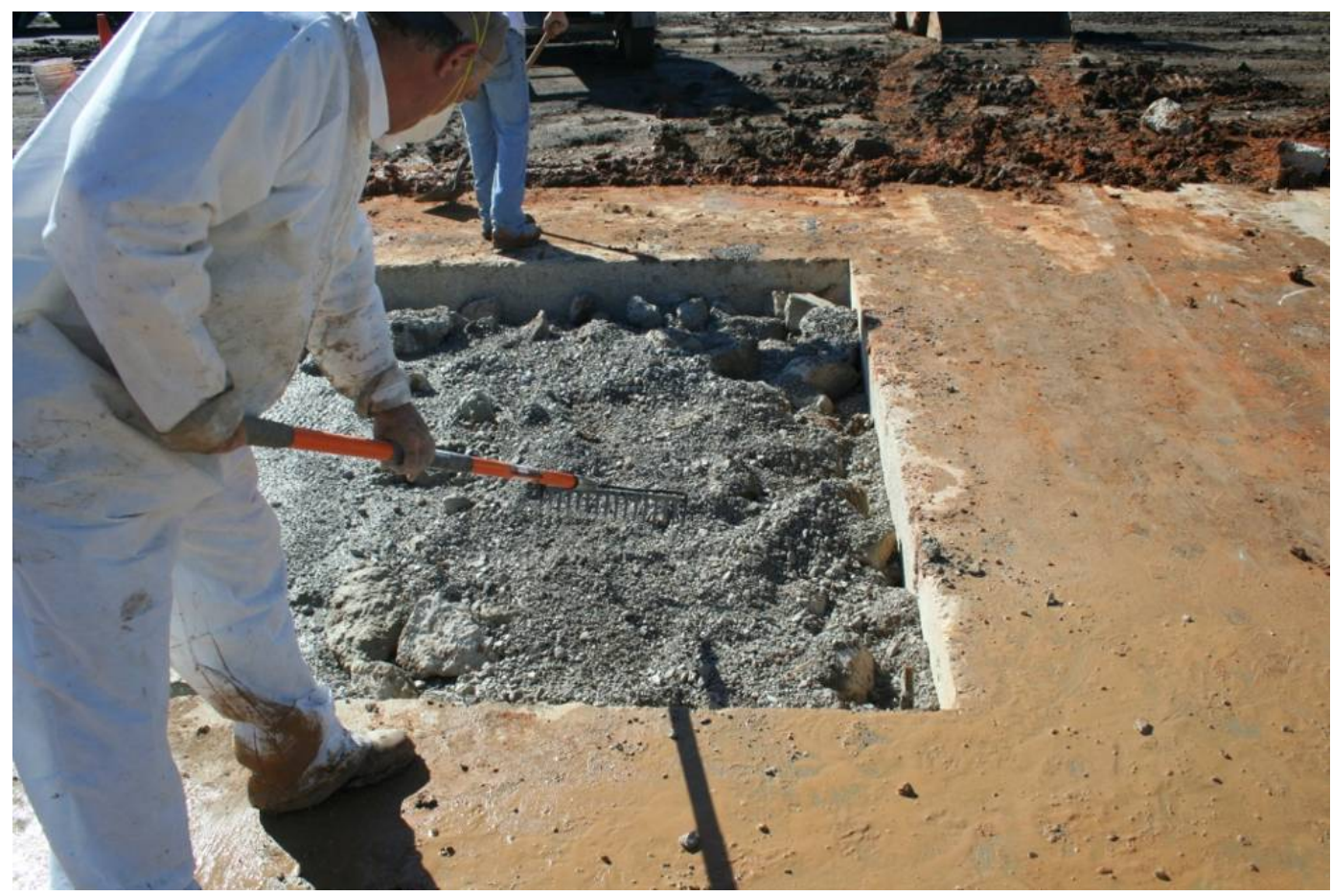

Figure 94. Crater S. Addition of limestone to Aquacrete surface.

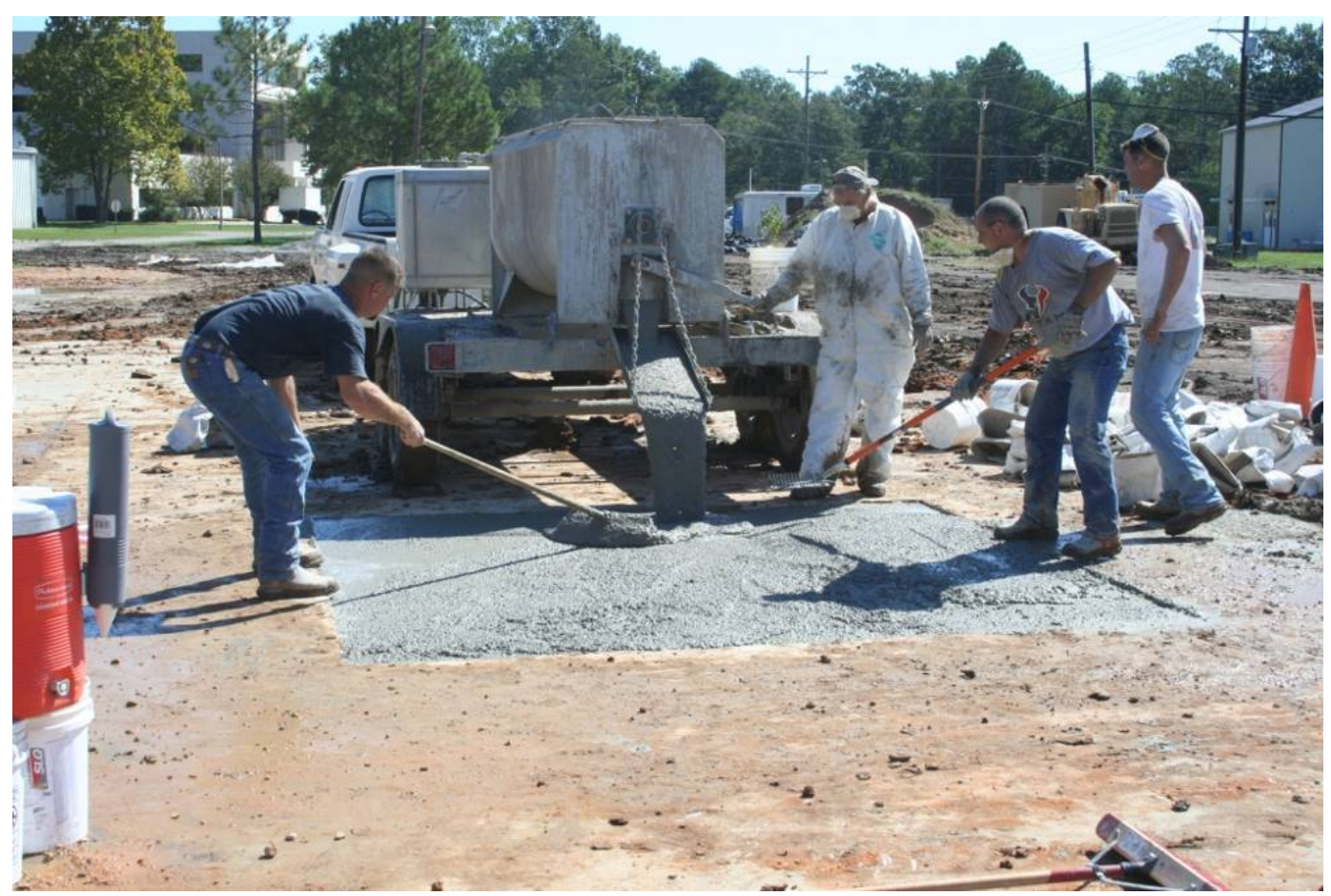

Figure 95. Crater S. Placing Ultimax Concrete cap. 


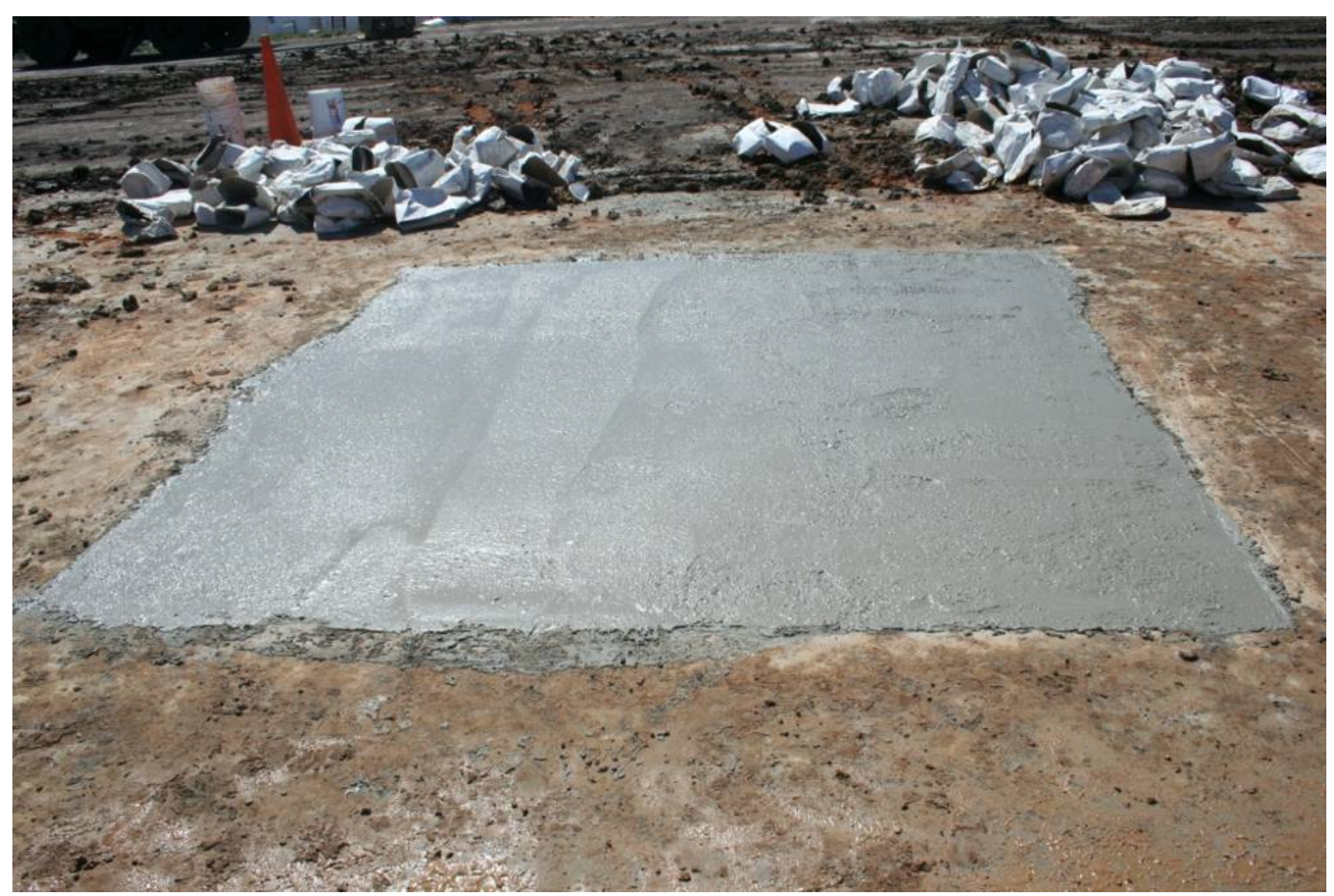

Figure 96. Crater S. Finished Ultimax Concrete cap.

\section{Summary}

In summary, the following were observed during the three series of crater repairs:

a. Excessive shrinkage cracking, initially a concern for the crater sizes and volumes of RS materials used, was not observed in any of the series of repairs.

b. Materials in buckets take approximately 30 to 50 percent longer to place, with the difference increasing with increasing crater size.

c. Use of large diameter (1-ft) concrete debris increases the volume of concrete needed and time required to cap the repair due to flow of material through voids in concrete debris.

d. Average cap placement times for each crater size were measured:

(1) 5 - $\mathrm{ft} \times 5$ - $\mathrm{ft} \times 6$-in. caps averaged $25 \mathrm{~min}$ to place using materials in bags.

(2) 5 - $\mathrm{ft} \times 5$ - $\mathrm{ft} \times 6$-in. caps averaged $35 \mathrm{~min}$ to place using materials in buckets.

(3) 8-ft $\times 8$-ft $\times 9$-in cap averaged $1.25 \mathrm{hr}$ to place using materials in bags.

(4) 8 - $\mathrm{ft} \times 8$ - $\mathrm{ft} \times 9$-in caps averaged $1.75 \mathrm{hr}$ to place using materials in buckets. 
(5) 10 - $\mathrm{ft} \times 10$ - $\mathrm{ft} \times 10$-in. caps averaged $1.5 \mathrm{hr}$ to place using materials in bags.

(6) $10-\mathrm{ft} \times 10$ - $\mathrm{ft} \times 32$-in. $\mathrm{RS}$ and concrete debris repairs averaged $1.6 \mathrm{hr}$ to place using materials in bags.

(7) 10 - $\mathrm{ft} \times 10$ - $\mathrm{ft} \times 32$-in. $\mathrm{RS}$ and concrete debris repairs averaged $2.9 \mathrm{hr}$ to place using materials in buckets 


\section{Rolling-Wheel Bearing Capacity Tests}

\section{Description of the load cart}

A specially designed single-wheel load cart was used to perform rollingwheel bearing capacity tests. This cart was used to simulate F-15E aircraft traffic and is equipped with a 36-in.-diam, 11-in.-wide, 18-ply tire inflated to $325 \mathrm{psi}$ and loaded so that the single test wheel supported 35,235 lb. The load cart is powered by the front half of a U.S. Army 2.5-ton transport truck with an outrigger wheel to prevent overturning. The truck portion of the cart was used only for steering. Figure 97 shows the load cart on the Small Crater Test Section.

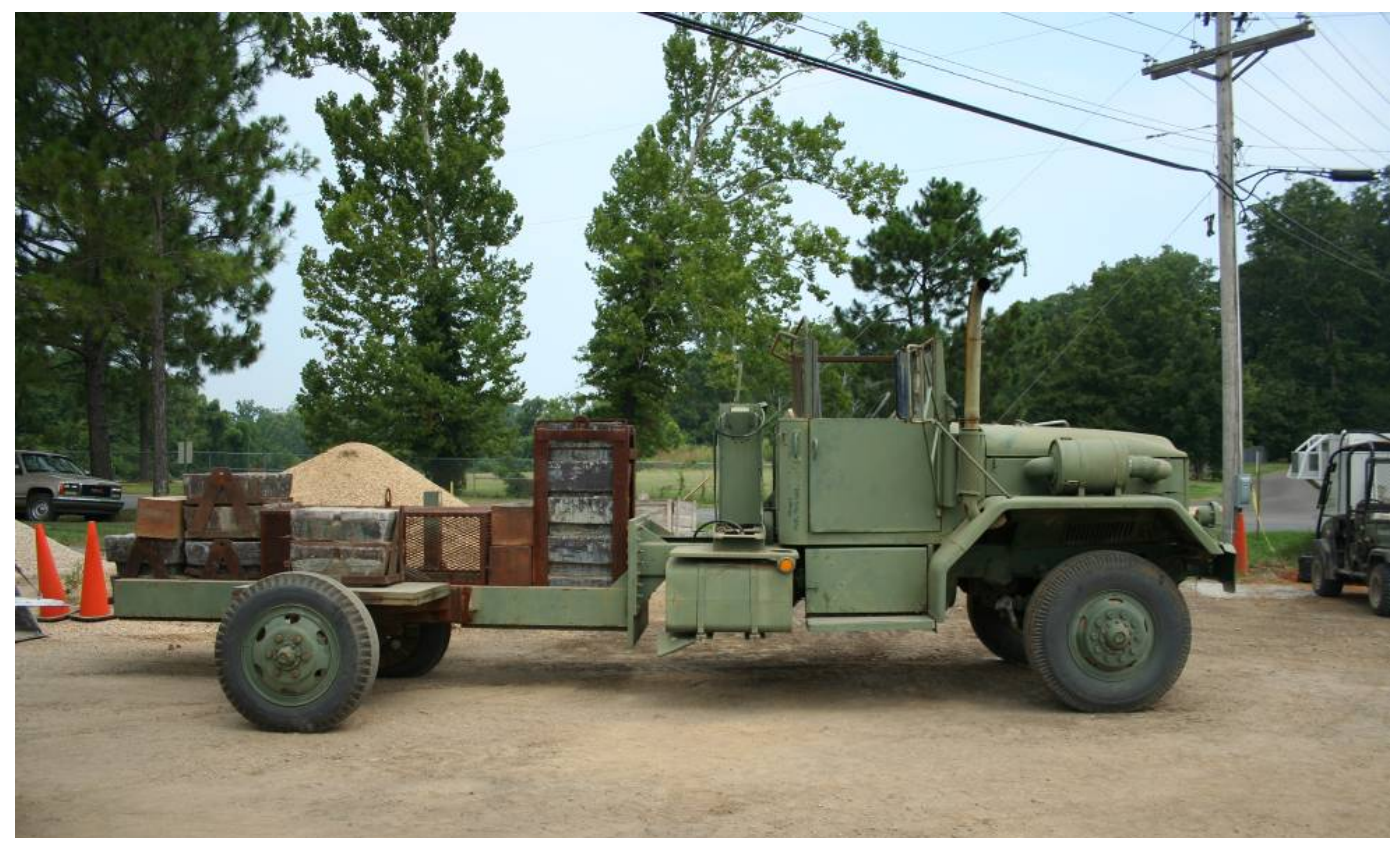

Figure 97. F-15E Load cart.

\section{Application of traffic}

Simulated modified normally distributed traffic was applied in a 3.75-ftwide traffic lane. These lanes were designed to simulate the traffic distribution pattern, or wander width, of the main landing gear wheel on the concrete surface when taxiing on an active runway. The normally distributed traffic pattern was simplified for ease of use by the load cart operator. Traffic was applied by driving the load cart forward and then backward over the length of the repair or test section, and then shifting the path of 
the load cart laterally approximately one tire width, 9 in., on each forward path. This procedure was continued until one pattern of traffic was completed consisting of 16 passes. The pass to coverage ratio for this traffic pattern was 4.0. For initial trafficking, each crater repair was trafficked off-center at the third point (Figure 98) a minimum of 112 passes (seven patterns and 28 coverages) $3 \mathrm{hr}$ after repair completion. The traffic lane was offset at the third point of the repair to evaluate each repair under the edge loading conditions. Traffic was continued on each repair until 112 passes were reached or failure occurred. Periodic interruptions were made during trafficking to collect performance data and inspect the repair surface for damage. Once all crater repairs were complete and received all 112 initial passes, the repairs were trafficked simultaneously in a straight line until failure or until 5,008 passes were reached. Figure 99 shows the location of the traffic lanes and sequence.

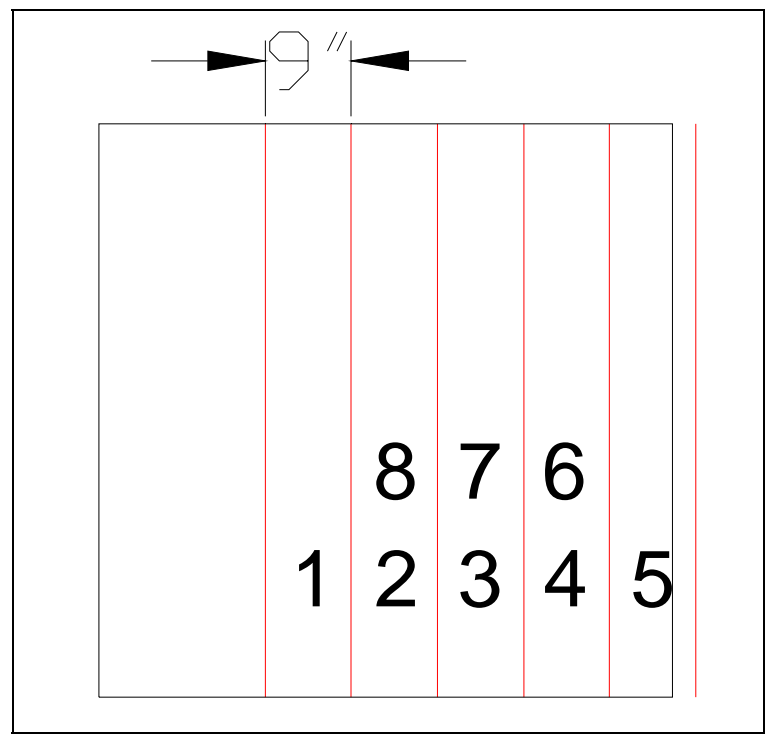

Figure 98. F-15E Traffic pattern. 


\section{Traffic Pattern}

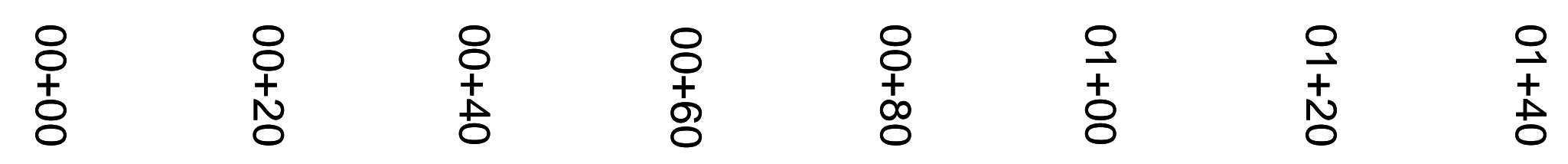

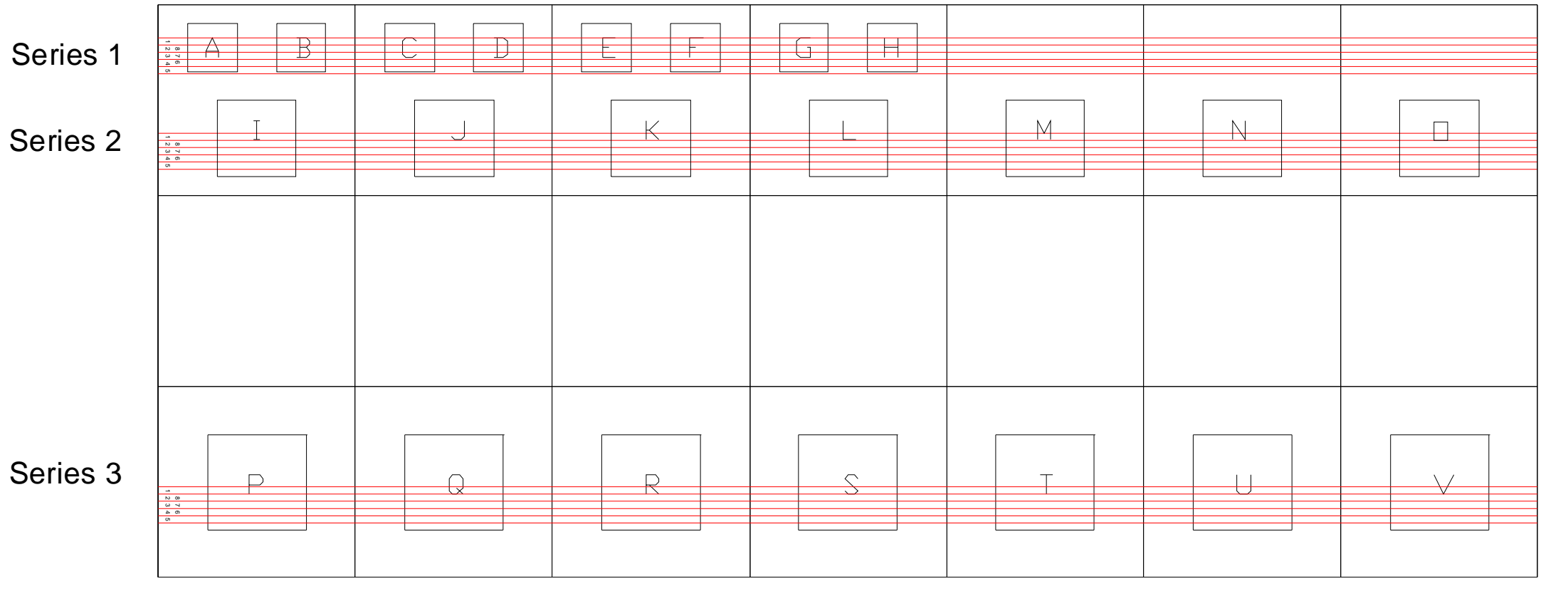

Figure 99. Traffic pattern. 


\section{Failure criteria}

\section{Description}

Crater repair failure was expected to occur as a result of surface deterioration or settling of the crater backfill under heavy vehicle traffic. Visual inspections were performed at selected traffic intervals to identify specific distresses associated with a high FOD potential such as cracking, spalling, corner breaks, map cracking or scaling, and shattered slabs. Cracking was considered minor unless development of associated spalls resulted in the accumulation of spalled material or in cracking with widths $1 \mathrm{in}$. or greater. Spalled materials have the potential to be sucked into jet engines or damage propellers and rotors of aircraft. Additionally, spalled concrete and wide cracks present a tire hazard due to the potential of the sharp edges or wide cracks to cut aircraft tires. When distresses posed high FOD potential or tire hazards were identified, the repair was considered failed. The repairs were also monitored for failure due to high roughness potential. High roughness potential is associated with permanent deformation of a repair due to settlement, loss of bond of the repair material to the surrounding pavement, or through the deterioration of the pavement surface resulting in abrupt elevation changes of $1.25 \mathrm{in}$. or more. Elevation changes in excess of 1.25 in. are unacceptable for F-15E aircraft due to the potential of damaging the landing gear. When elevation changes in excess of $1.25 \mathrm{in}$. or more occurred, the repair was considered failed due to high roughness potential.

\section{Data collection}

Surface roughness, permanent deformation, and elastic deformation were monitored periodically using rod and level measurements and visually with the aid of video and photography. All deterioration of the repair surface was recorded during trafficking to document both the amount of damage and the mode of failure. Additionally, pressure cells were installed beneath the structural cap to provide stress measurements for calculation of each repair's ability to distribute the load. Performance measurements were made at designated intervals consisting of the following tests:
a. Pavement condition assessment
b. Heavy weight deflectometer (HWD)
c. Roughness measurements taken along the profile, cross-section, and at spot locations.


Additional HWD testing was conducted after 112 passes were reached as shown in Table 26. These tests were conducted the next day both in the morning and afternoon as well as 7, 14, and 28 days after each repair was complete (if trafficking was conducted during that time) to monitor temperature shifts in repair strength.

Table 26. Frequency of testing - HWD, roughness, deterioration monitoring, and photos during traffic.

\begin{tabular}{|c|c|c|}
\hline Passes & Patterns & Coverages \\
\hline 0 & 0 & 0 \\
\hline 112 & 7 & 28 \\
\hline 512 & 32 & 128 \\
\hline 1,008 & 63 & 252 \\
\hline 2,000 & 125 & 500 \\
\hline 5,008 & 313 & 1,252 \\
\hline
\end{tabular}

Dynamic response data were collected with the earth pressure cells (EPC) at selected intervals. For the first 112 passes, data were collected with every pass. For straight-line trafficking, one pattern (16 passes) was collected at designated pass intervals. These intervals were increased if the repairs began deteriorating prior to the planned data collection interval. These intervals are presented in Table 27.

Table 27. Dynamic response data collection intervals.

\begin{tabular}{|c|}
\hline Pass Interval \\
\hline $1-112$ \\
\hline $225-240$ \\
\hline $337-352$ \\
\hline $497-512$ \\
\hline $609-624$ \\
\hline $720-736$ \\
\hline $993-1008$ \\
\hline $1,217-1,232$ \\
\hline $1,457-1,472$ \\
\hline $1,985-2,000$ \\
\hline $4,993-5,008$ \\
\hline
\end{tabular}

Change in elevations was calculated for each repair for different pass levels. Locations surveyed are presented in Figure 100. 


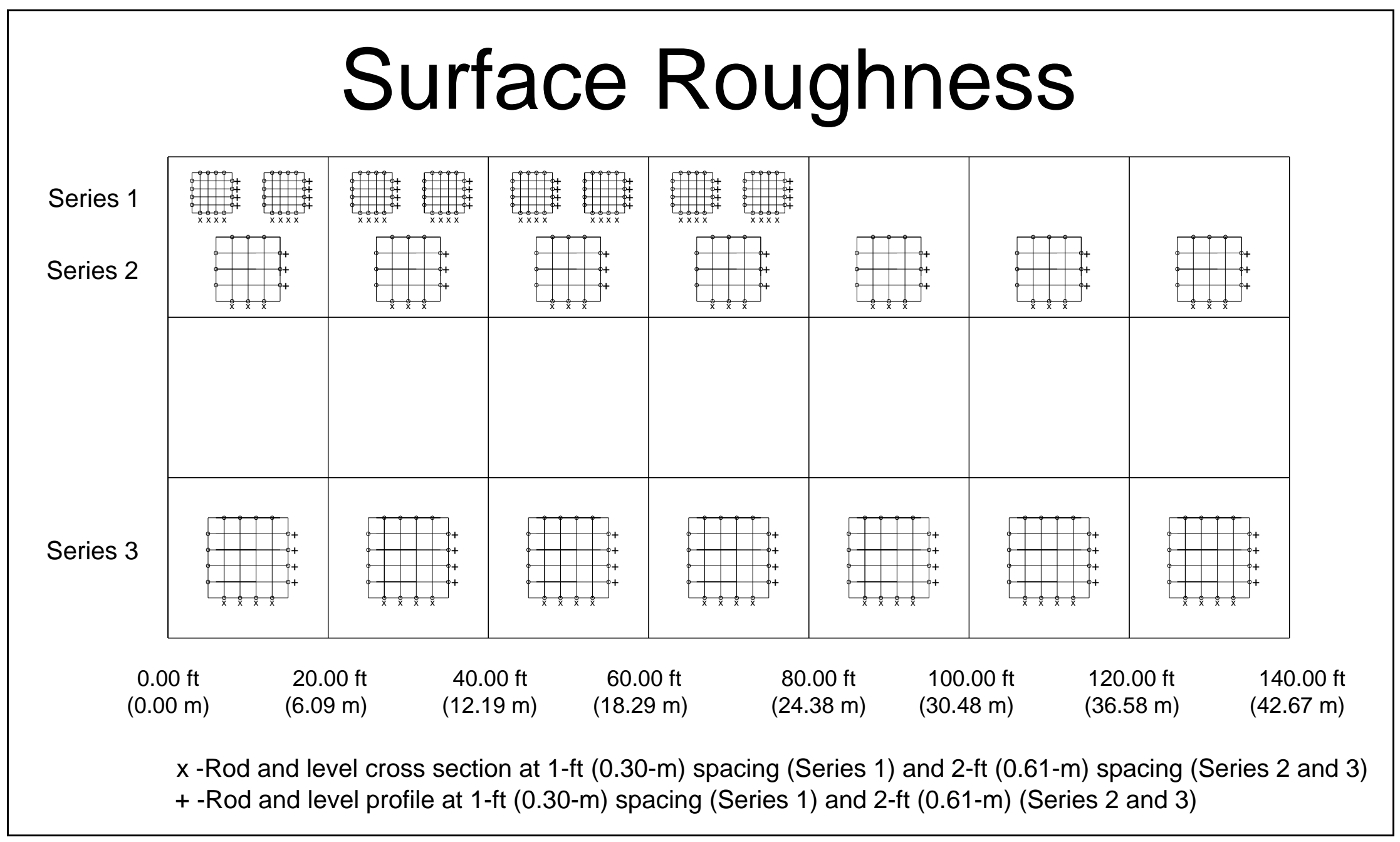

Figure 100. Locations of roughness measurements. 


\section{Behavior of crater repairs under traffic-Series 1}

\section{Crater A-Pavesaver}

Passes 0-62

HWD and roughness measurements were performed prior to traffic. Due to load cart problems, tests could not be performed until $3 \mathrm{hr}$ after the repair was completed. After the completion of one pass, the pressure cell measuring capacity was over ranged by the load cart. The patch deformed under the tire load but remained elastic until 10 passes. After this time, deformation became permanent, and after 30 passes, no more traffic could be applied to lane 5 due to complete loss of bond of the patch to the edge receiving loading (Figure 101). After 62 passes, the 1.25-in. roughness criteria were exceeded with maximum deformation on the repair edges reaching $1.56 \mathrm{in}$. The east edge experienced 3/ 16-in. separation. In addition, 1.5-ft and 5-ft low severity cracks were noticed near the northwest and southeast corners, respectively (Figure 102). Trafficking was discontinued on this repair, and the product was not recommended for Series 2 testing.

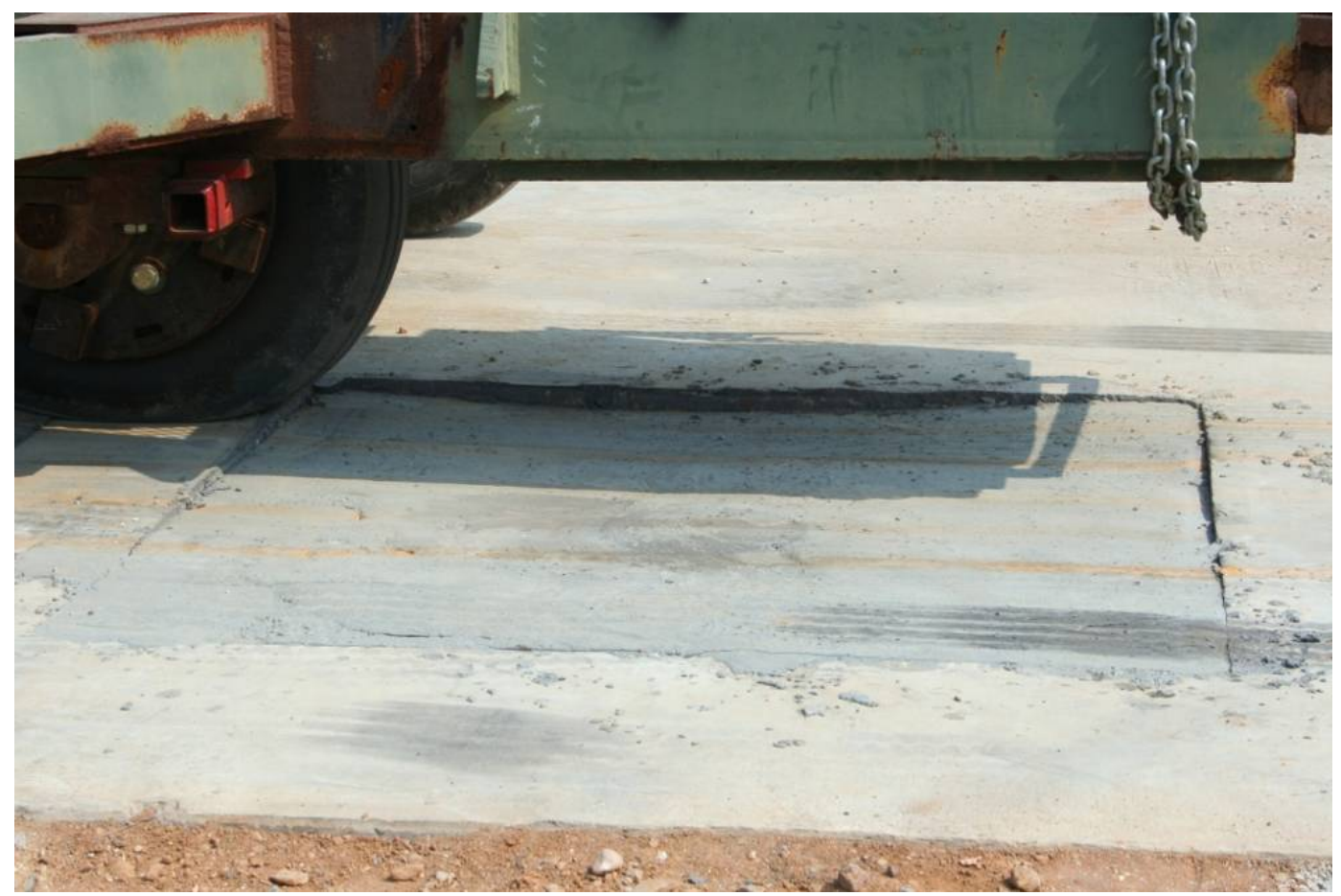

Figure 101. Crater A: Debonding of repair to slab on the south and west edges. 


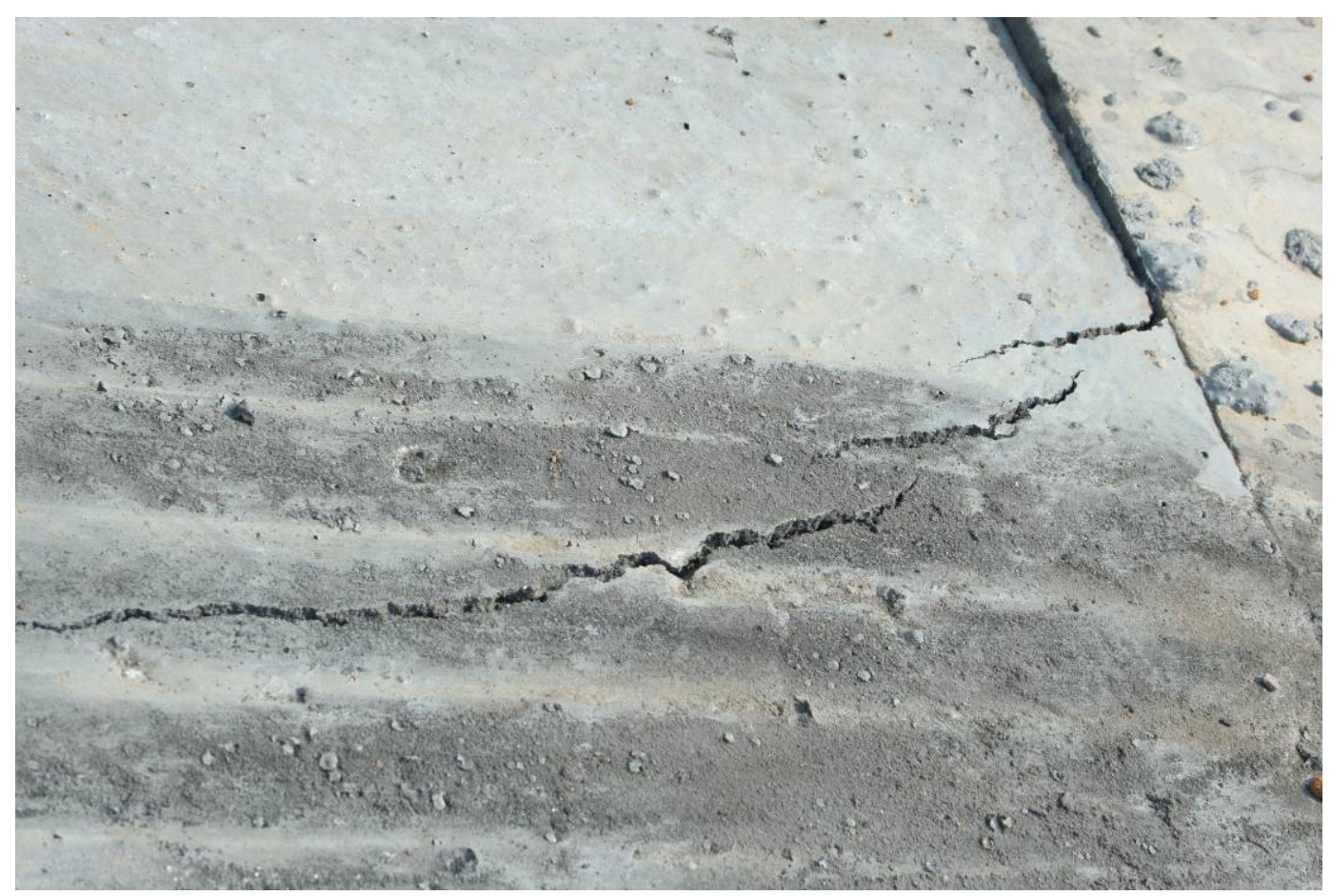

Figure 102. Crater A: Cracking and debonding of repair on west edge.

\section{Crater B-Rapid Set}

Passes 0-112

HWD and roughness measurements were performed prior to traffic. For consistency, load cart tests for this repair and the remaining craters in Series 1 would not be performed until $3 \mathrm{hr}$ after the repair completion. After 32 passes, minor spalling was noticed where the repair overlapped the existing concrete (Figure 103). The spalling did not progress significantly, and a total of 112 passes were completed by the load cart with no cracking, noticeable deformation, or additional FOD. HWD and survey data were collected after 112 passes. Expedient criteria were met with this repair. 


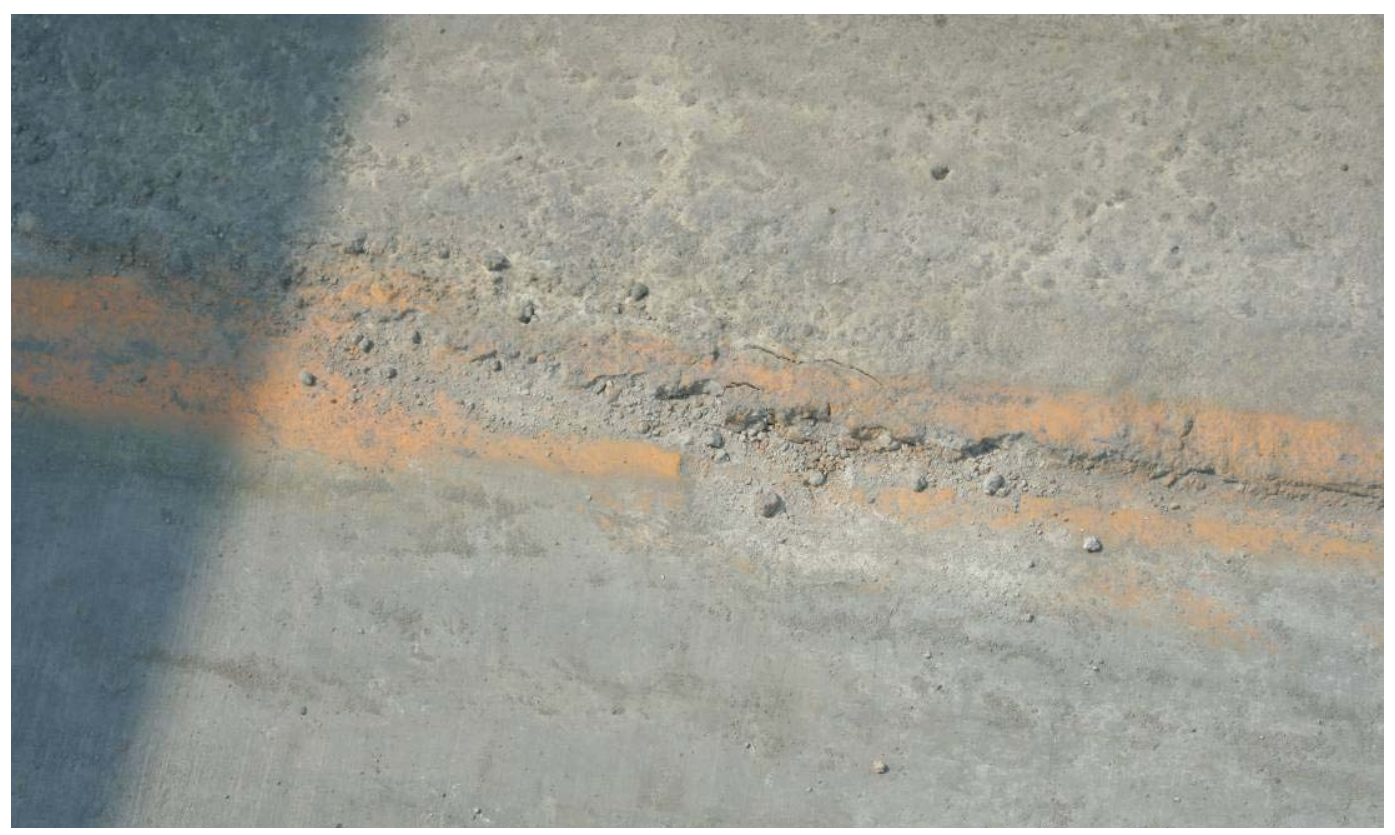

Figure 103. Crater B: Spalling after 32 passes.

Passes 113-688

Additional HWD measurements were performed prior to continuation of traffic. Craters B- $\mathrm{H}$ were simultaneously trafficked in a straight line until failure was reached. At 176 passes, a corner spall formed at the southeast corner, and at 182 passes, the crater began audibly popping. At 224 passes, cracks along the east and west edges began to appear (Figure 104), and at 256 passes, the corner spall and edge cracks continued to lose material. After pass 304, spalling was more noticeable on the northwest edge. Deterioration continued, and after 320 passes, a crack became noticeable along the south edge (Figure 105). After pass 336, a new crack was noticed along the east edge. At pass 480 , significant joint spalls were formed along the south, east, and west edges of the repair (Figure 106). At 512 passes, additional HWD and roughness measurements were performed. Trafficking was discontinued on this repair at 688 passes due to high FOD potential along the south, east, and west edges (Figure 107). This material met expedient criteria but produced significant FOD along the loaded edges prior to the desired 5,000 sustainment passes. The performance of this material in a larger repair may be better. Because of this, the product was recommended for Series 2 testing. 


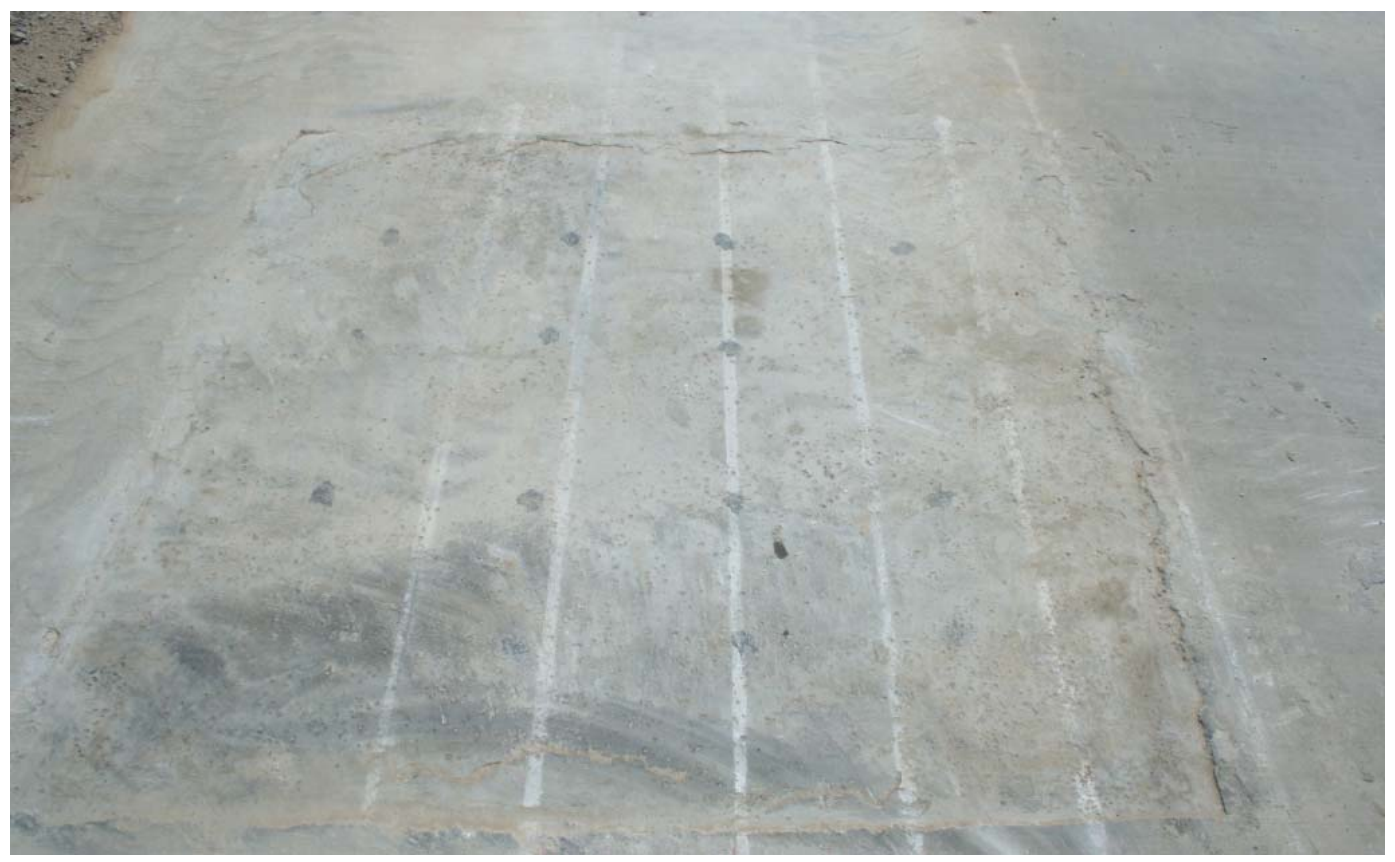

Figure 104. Crater B: Spalling and cracking- east and west edges after 224 passes.

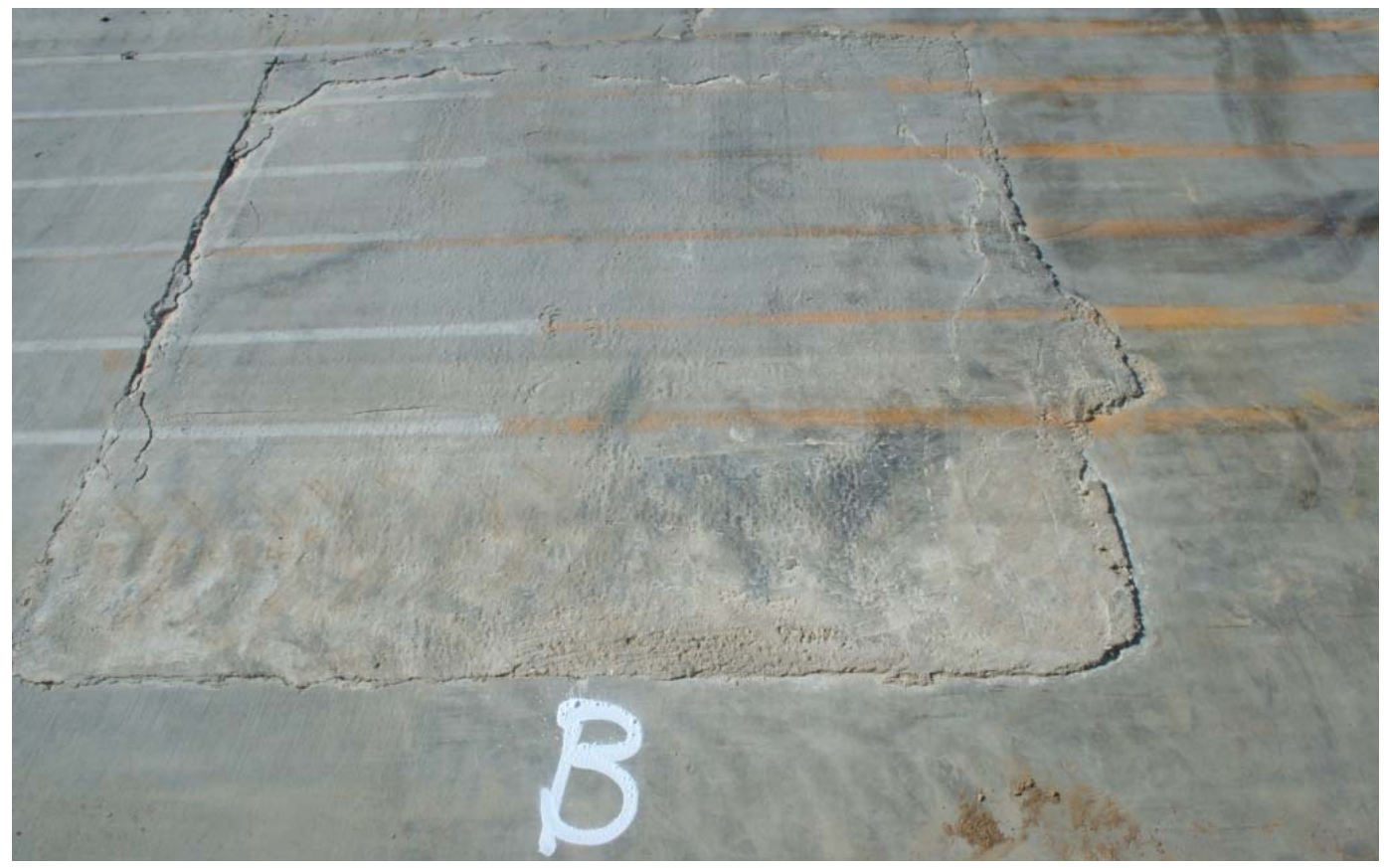

Figure 105. Crater B: Spalling and cracking- south, east, and west edges after 320 passes. 


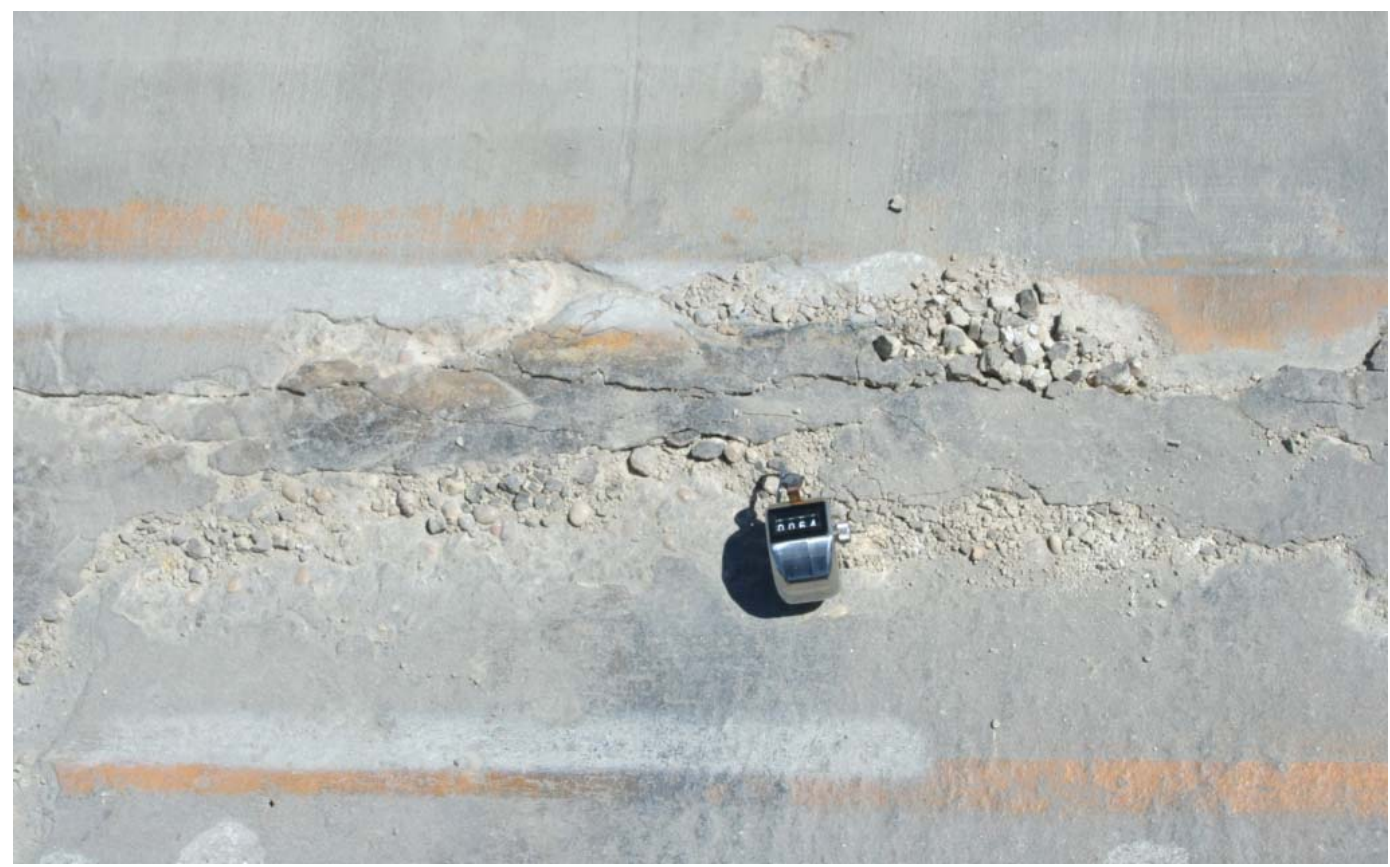

Figure 106. Crater B. Spalling and cracking along south edge after 480 passes.

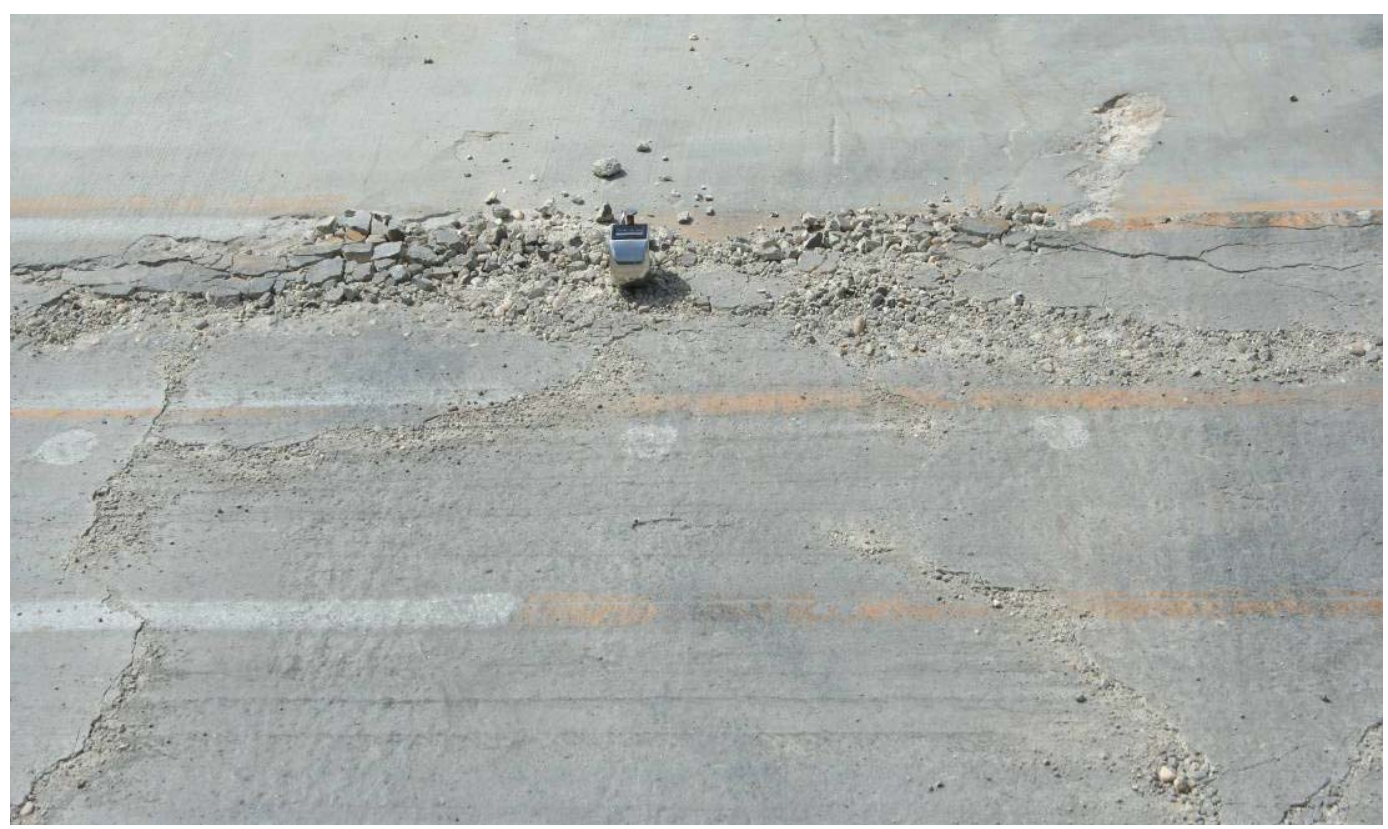

Figure 107. Crater B: Significant FOD and cracking along south edge after 688 passes. 


\section{Crater C-1-Pavemend SLQ}

Passes 0-96

HWD and roughness measurements were performed prior to traffic. High deflections were noted with the HWD, indicating that the subgrade was still weakened from the heavy rain the day prior. After 80 passes, settlement and cracking were noticed in lanes 1 and 2. After 96 passes, settlement increased, major cracking occurred, and the surface was pulverized in lane 4. A bowl shaped depression became evident, and subgrade failure was confirmed as shown in Figure 108. Trafficking was discontinued on this repair, and a repeat repair was scheduled for the following week.

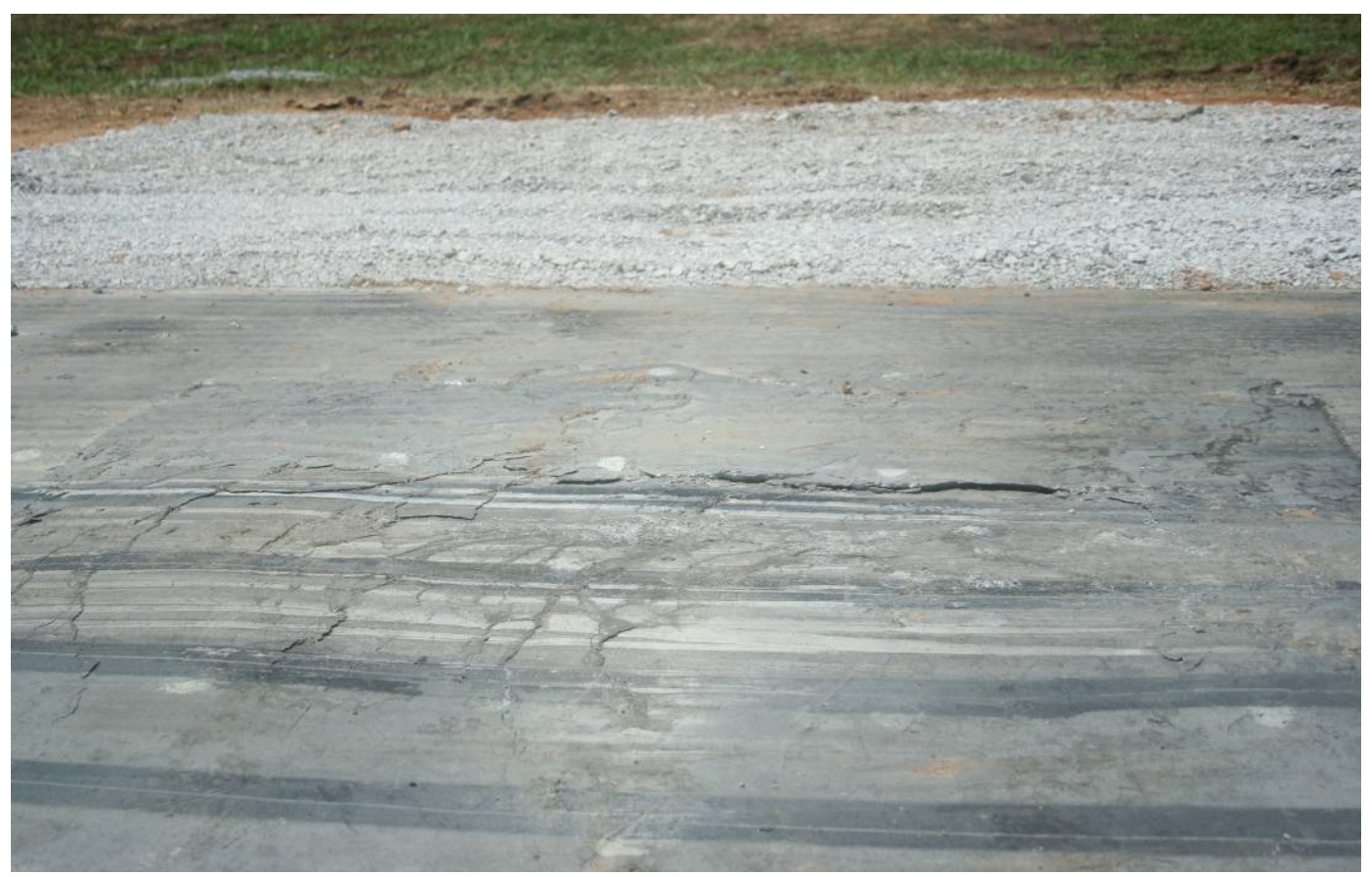

Figure 108. Crater C-1: Significant cracking and settlement after 96 passes.

\section{Crater C-2-ThoRoc 10-60}

Passes 0-112

HWD and roughness measurements were performed prior to traffic. After 80 passes, minor spalling was noticed on the northwest edge as shown in Figure 109. The spalling did not progress significantly and a total of 112 passes were applied with the load cart with no cracking, noticeable deformation, or additional FOD. Expedient criteria were met with this repair. Figure 110 shows the crater spalling on the northwest edge. 


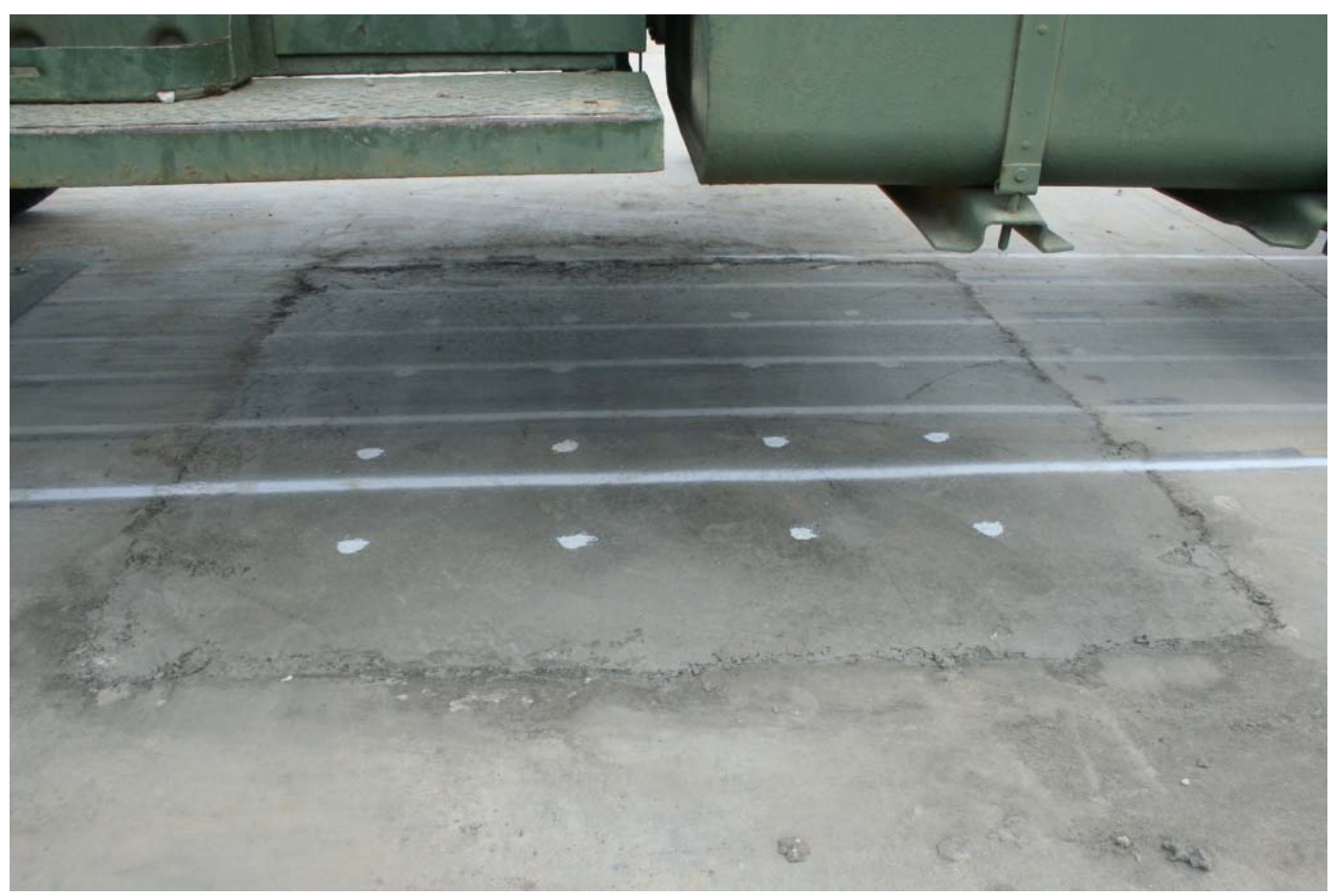

Figure 109. Crater C-2. Under traffic.

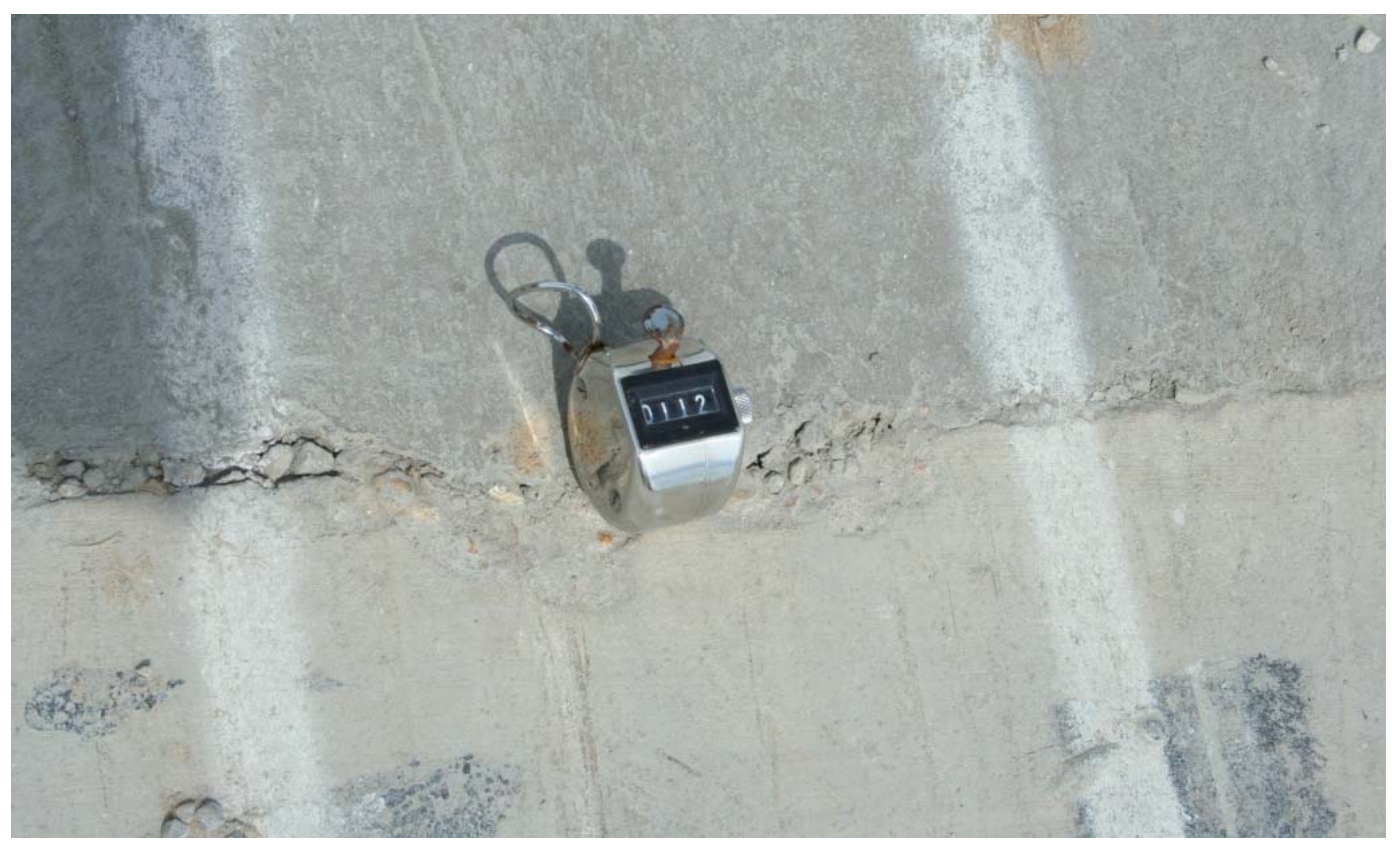

Figure 110. Crater C-2. Spalling - northwest edge after 112 passes. 
Passes 113-704

Additional HWD measurements were performed prior to continuation of traffic. Craters B- H were trafficked simultaneously in a straight line until failure was reached. At pass 157, popping noises occurred as the crater began moving under traffic. At pass 384, a minor spall became apparent in the center of the northwest edge. At 512 passes, additional HWD and roughness measurements were performed. After 688 passes, the south, east, and west joint spalls were widening and progressing rapidly to failure due to significant FOD. Crater C-2 was considered failed after 704 passes due to the crumbling of material on the south edge of the repair. The repair had high FOD potential. Despite meeting expedient pass criteria, this product did not perform as well as the 10-61 product by the same vendor. This product was not recommended for Series 2 testing.

\section{Crater D-ThoRoc 10-61}

\section{Passes 0-112}

HWD and roughness measurements were performed prior to traffic. After 32 passes, minor spalling was noticed. Popping noises were noted at pass 64 as the crater repair began to move under traffic. The spalling did not progress significantly and a total of 112 passes were completed by the load cart with no cracking, noticeable deformation, or additional FOD. Expedient pass criteria were met with this repair.

\section{Passes 113-720}

Additional HWD measurements were performed prior to continuation of traffic. Craters B- H were trafficked simultaneously in a straight line until failure was reached. Popping continued during trafficking. Light cracking along the south, east, and west joints began to become noticeable around pass 272 . After 320 passes, light cracking and spalling occurred along the south, east, and west edges as shown in Figure 111. At 512 passes, additional HWD and roughness measurements were performed. After 688 passes, the south, east, and west edge cracks and spalling were widening and progressing rapidly to failure due to significant FOD (Figure 112). Spalled edges were visibly deflecting under load. After 720 passes, the repair was considered failed due to FOD and excessive deflection (Figure 113). This product was the top performer from the BASF products tested with the least cracking and FOD, and it was recommended for Series 2 testing. 


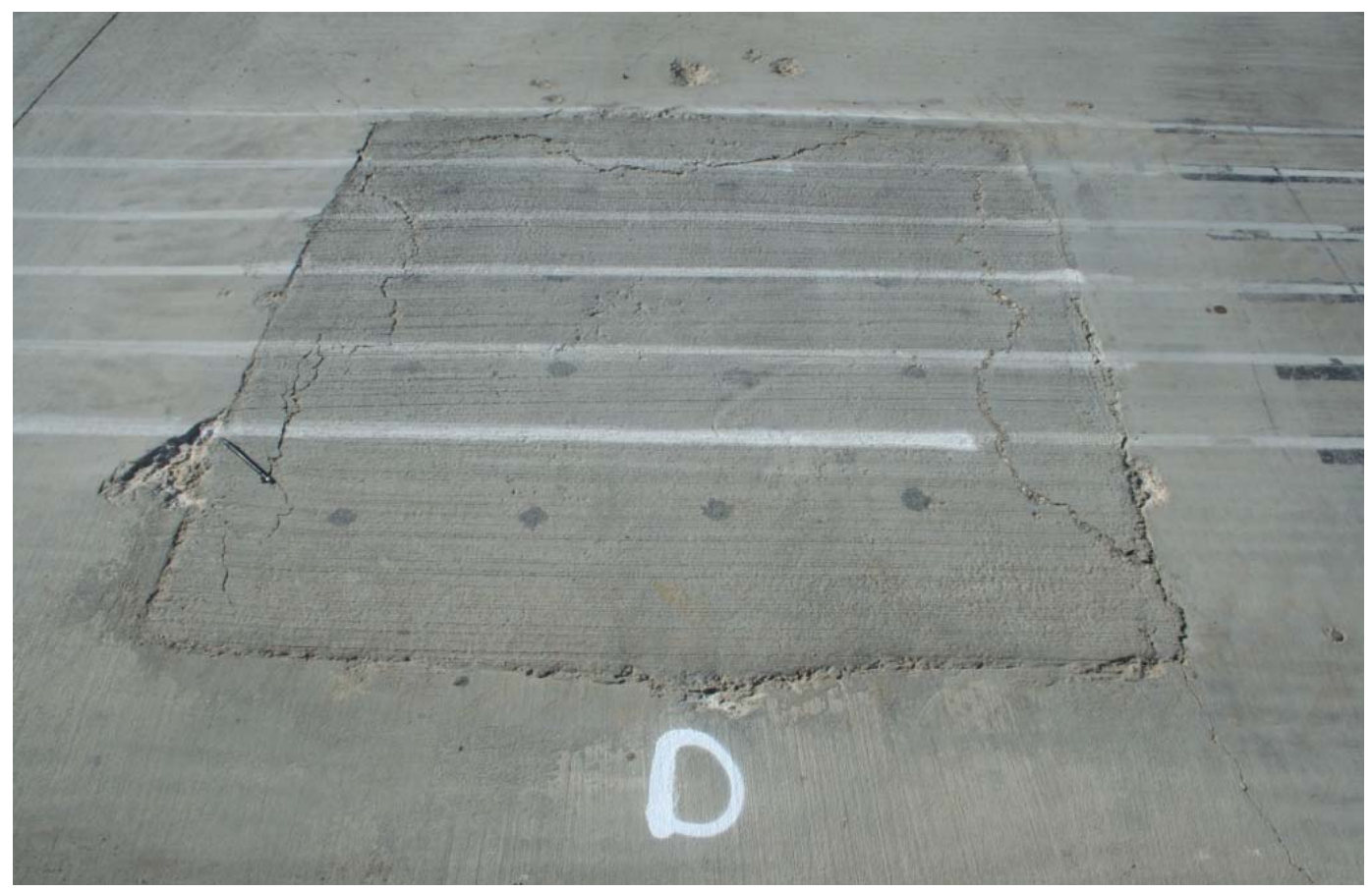

Figure 111. Crater D. Cracking and spalling of the south, east, and west edges after 320 passes.

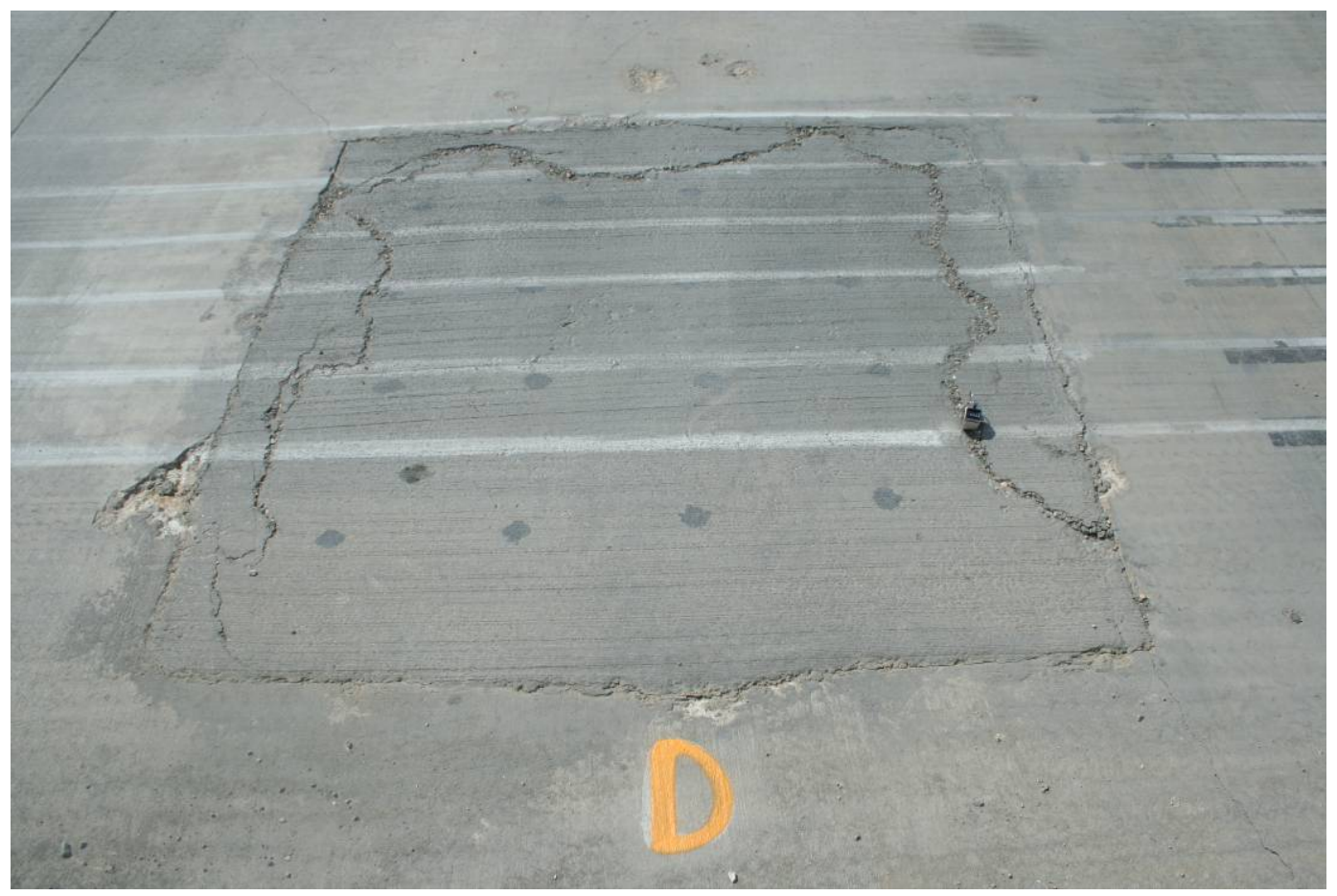

Figure 112. Crater D. Cracking and spalling of the south, east, and west edges after 688 passes. 


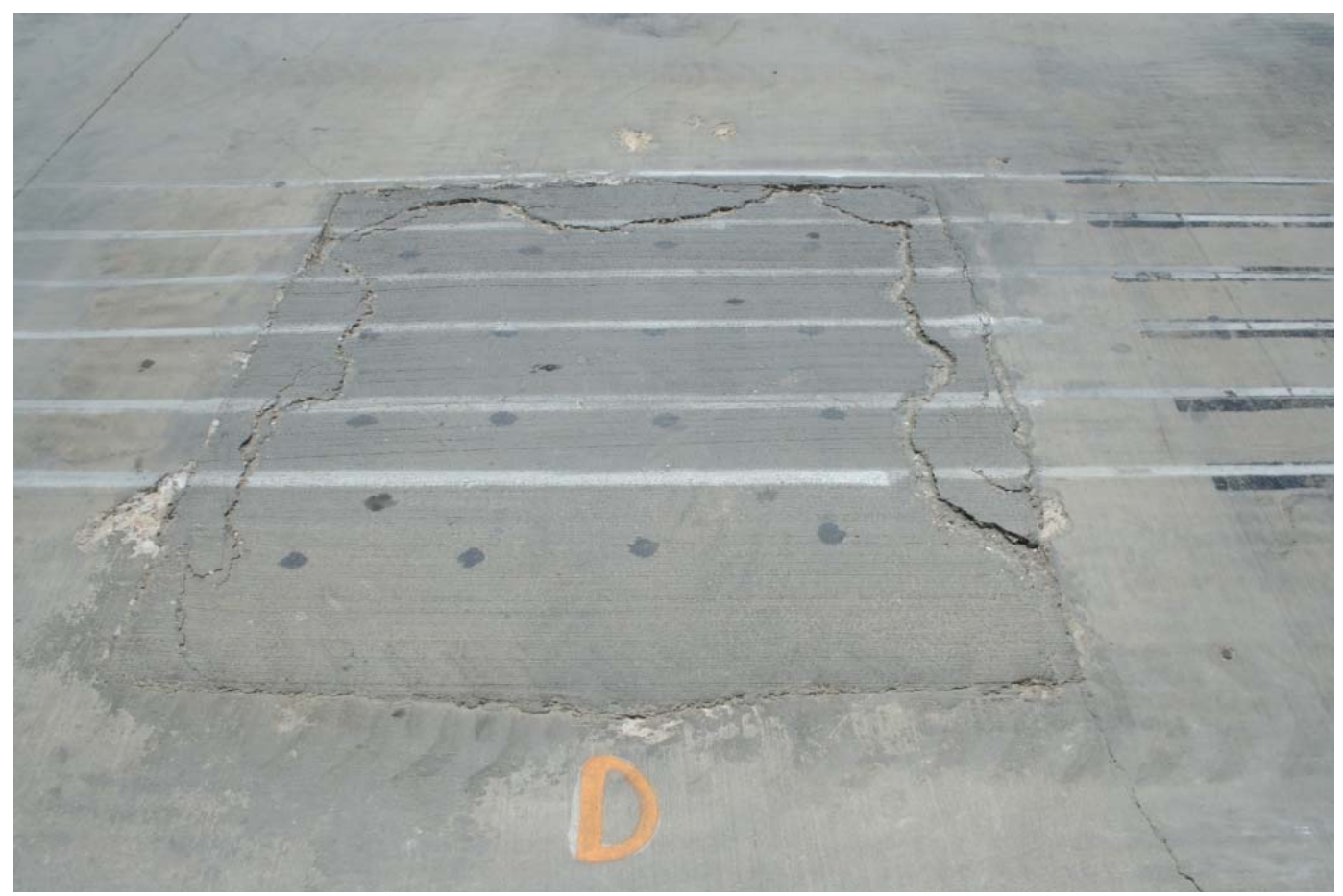

Figure 113. Crater D. Cracking and spalling - south, east, and west edges after 720 passes.

\section{Crater E-Set 45 HW}

Passes 0-112

HWD and roughness measurements were performed prior to traffic. After 32 passes, minor spalling was noticed along the south joint (Figure 114). Popping noises accompanied this spalling. The spalling did not progress significantly, and a total of 112 passes were completed by the load cart with no cracking, noticeable deformation, or additional FOD. Expedient criteria were met with this repair. 


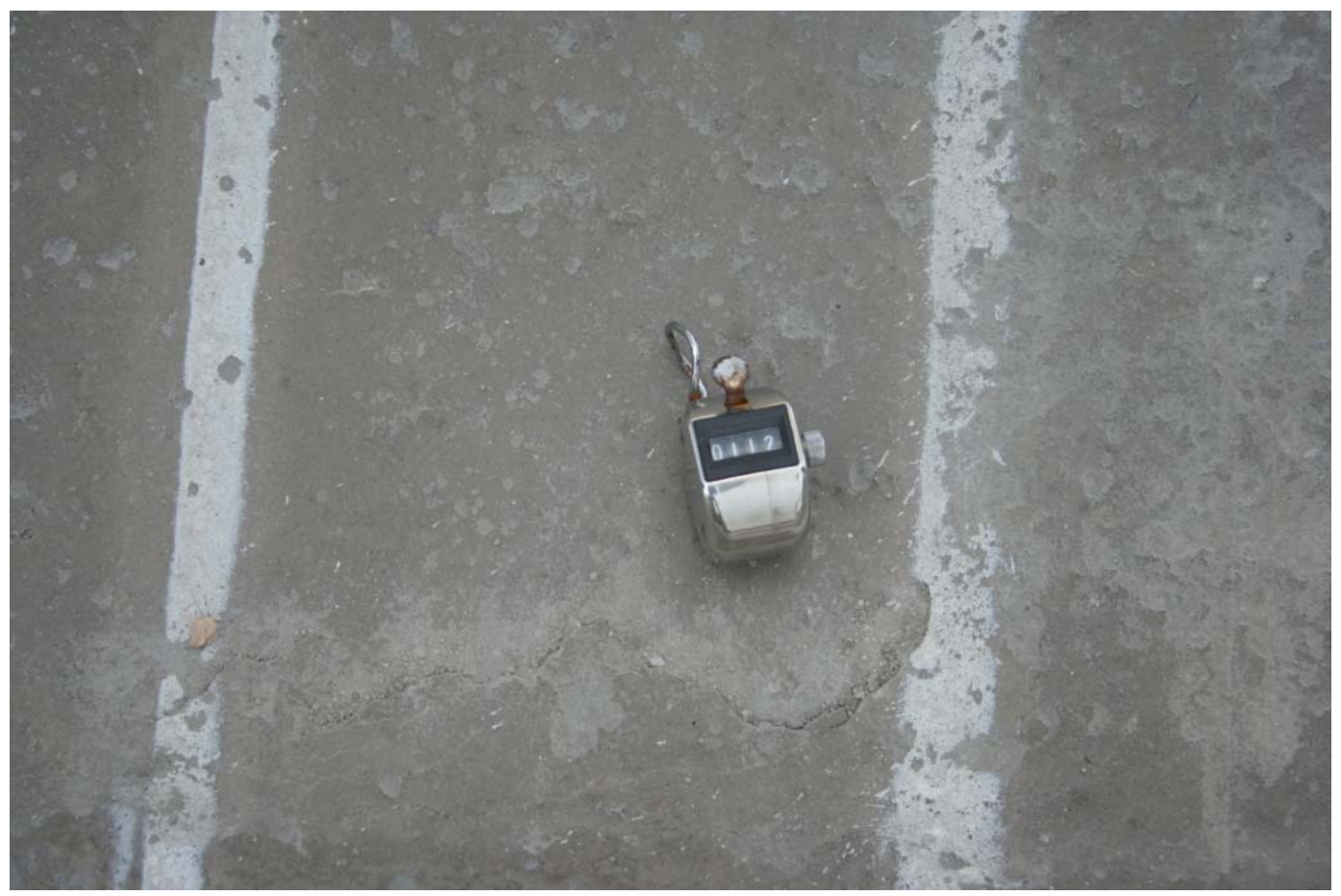

Figure 114. Crater E. Cracking along the south joint.

\section{Passes 113-704}

Additional HWD measurements were performed prior to continuation of traffic. Craters B- H were trafficked simultaneously in a straight line until failure was reached. Popping noises began at 157 passes. More spalling was noticed at 182 passes along the south, east, and west edges (Figure 115). Spalling had worsened by pass 384 . At pass 481, a new crack formed along the northwest edge of the repair. At 512 passes, additional HWD and roughness measurements were performed. After 688 passes, the south, east, and west joint spalls were widening and progressing rapidly to failure due to significant FOD removed during sweeping (Figure 116). The repair was deflecting under load. After pass 704, this repair was considered failed due to FOD and deflection. Although the repair met expedient pass requirements, the product did not perform as well as the ThoRoc 10-61 by the same vendor. Of the three BASF products, the 10-61 was recommended for Series 2 testing. 


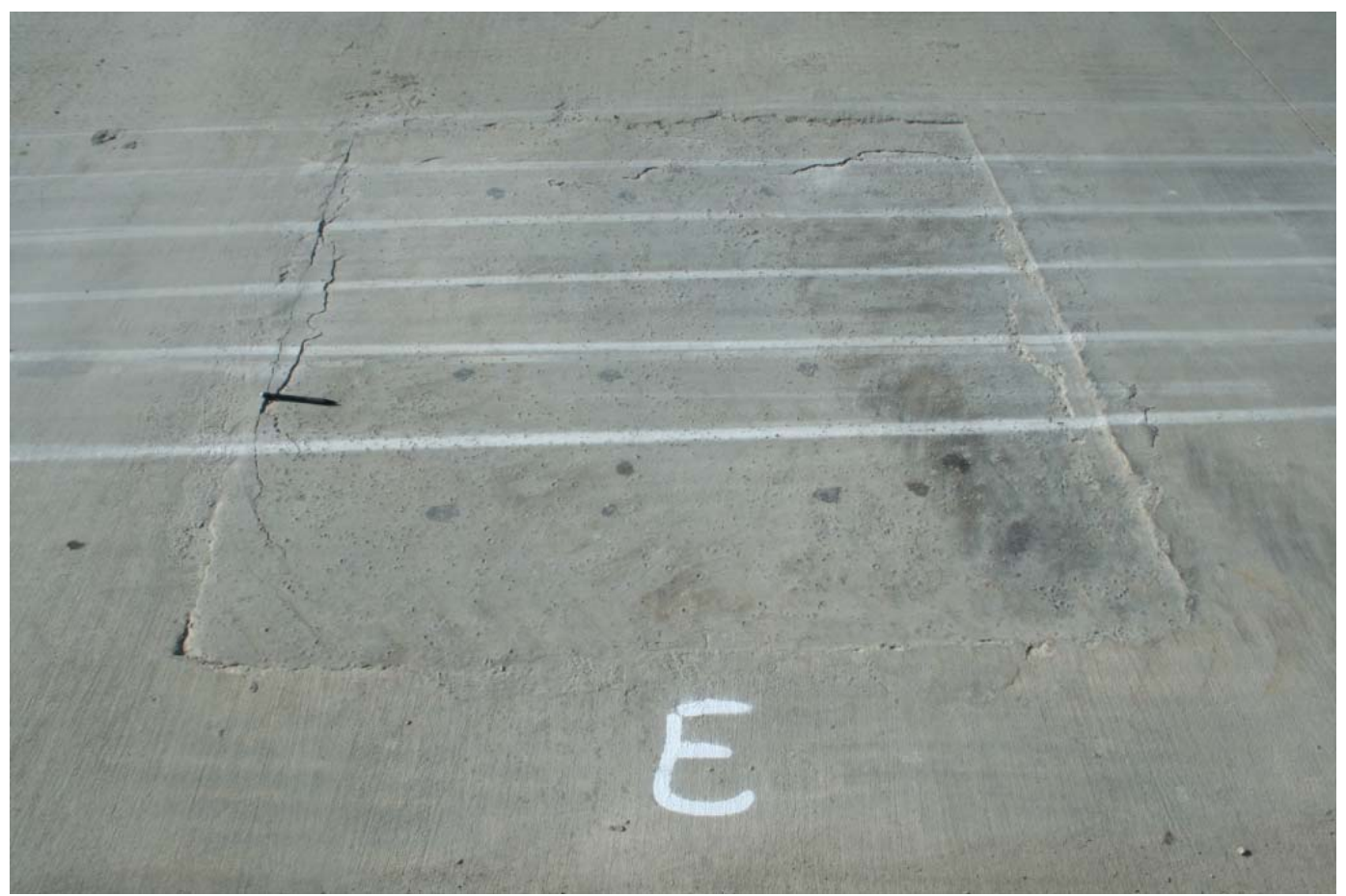

Figure 115. Crater E. Cracking and spalling along the south, east, and west edges after 182 passes.

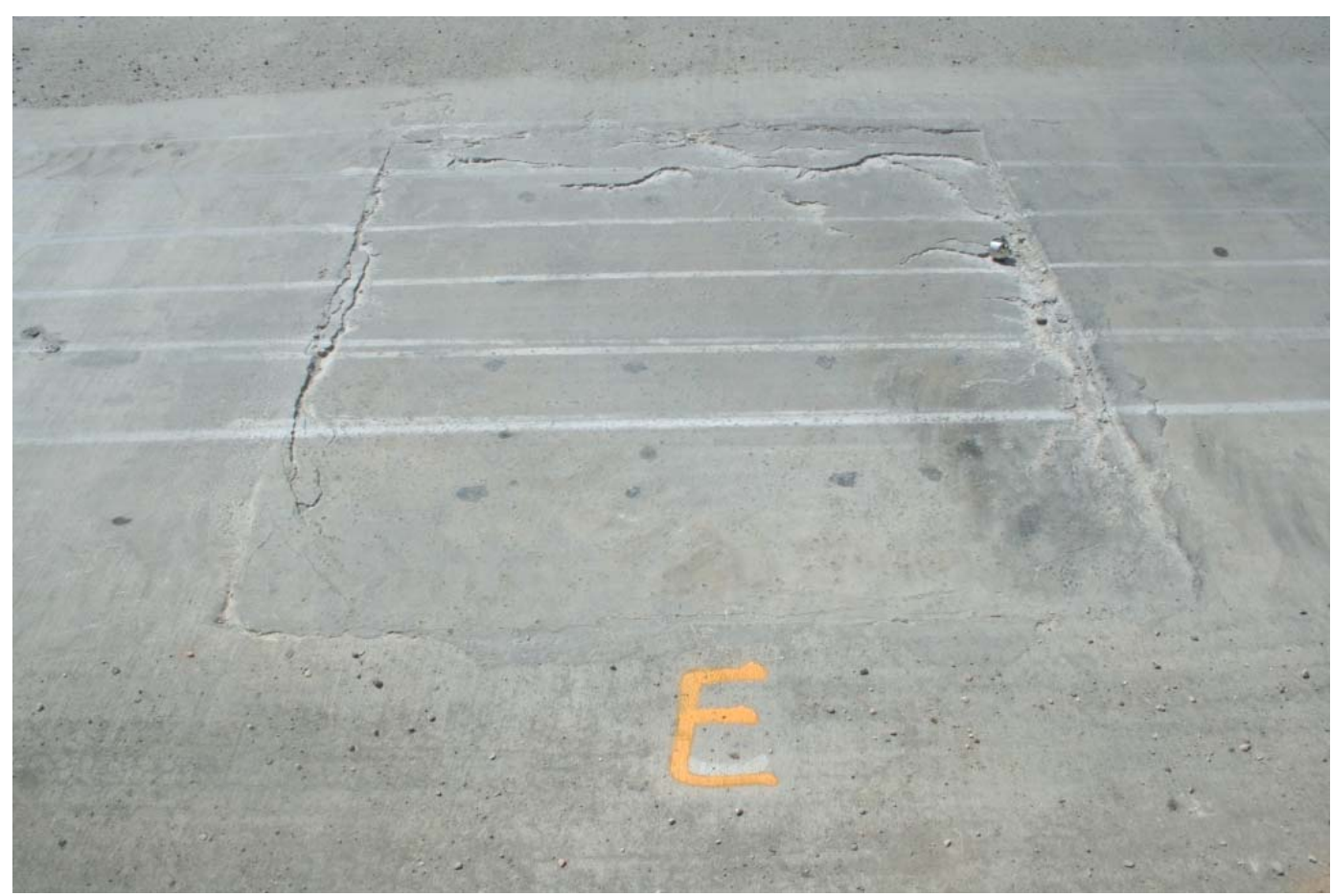

Figure 116. Crater E. Spalling along the south, east, and west edges after 688 passes. 


\section{Crater F-Ultimax Concrete}

Passes 0-112

HWD and roughness measurements were performed prior to traffic. After 64 passes, minor spalling was noticed at the northwest corner. After 80 passes, hairline cracks were noticed at the northeast corner. The spalling and cracking did not progress significantly and a total of 112 passes (Figure 117) were completed by the load cart with no significant cracking, deformation, or additional FOD. Expedient criteria were met with this repair.

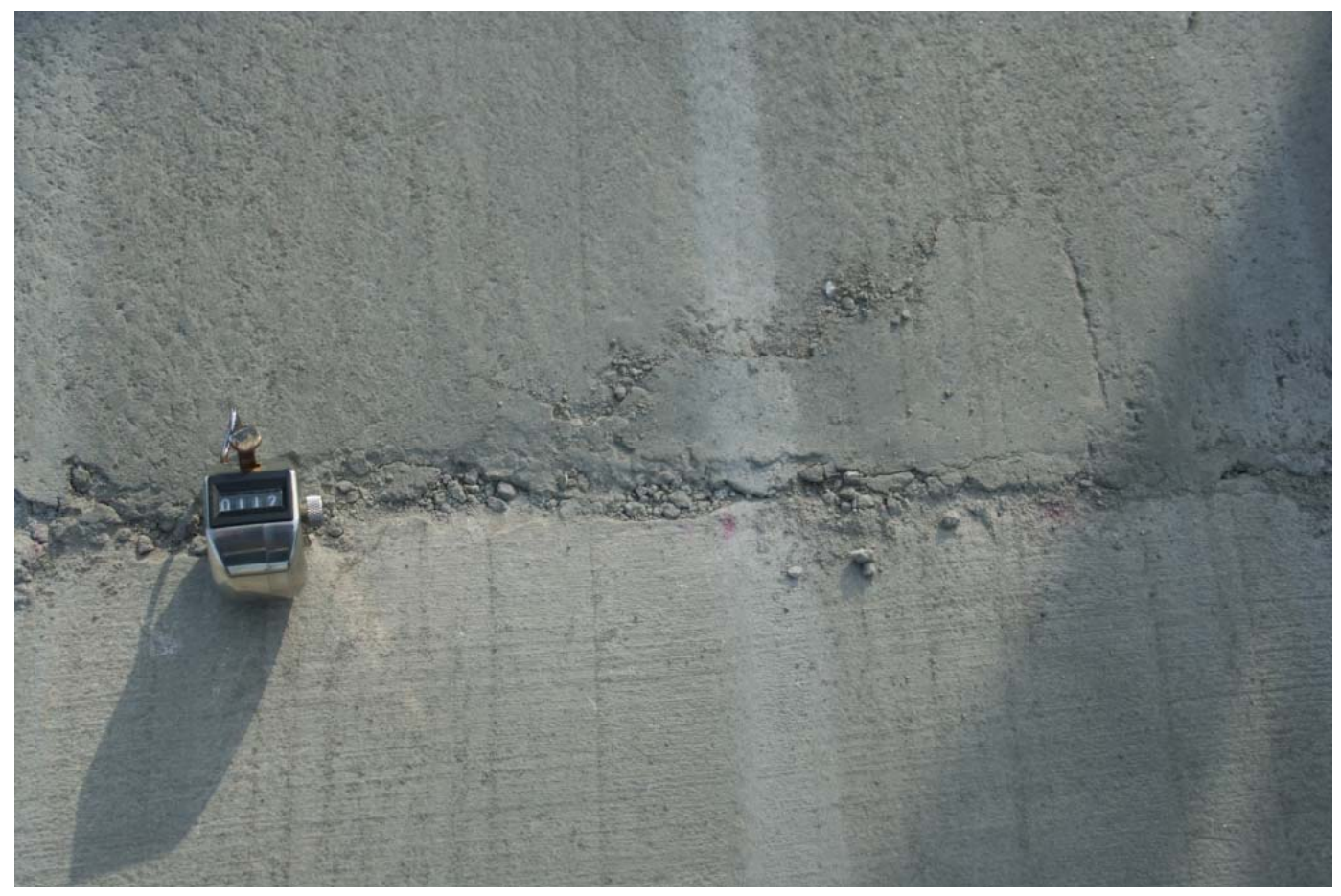

Figure 117. Crater F. Cracking on northeast corner after 112 passes.

\section{Passes 113-720}

Additional HWD measurements were performed prior to continuation of traffic. Craters B- H were trafficked simultaneously in a straight line until failure was reached. Light cracking along the south, east, and west joints occurred as well as light raveling along the south joint at 144 passes. At 176 passes, cracking continued to form along the joints noted previously. Light spalling continued along the south joint. This spalling continued at 182 passes. Popping became audible at 194 passes. At 288 passes, the light cracking along the joints mentioned previously began widening due to material loss. At 304 passes, the spall worsened in the northeast corner. 
Spalling continued along the joints at 384 passes as shown in Figure 118. At 512 passes, additional HWD and roughness measurements were performed. After 688 passes, the south, east, and west joint spalls were widening and progressing rapidly to failure due to significant FOD. Spalled edges were visibly deflecting under load. After 720 passes, the repair was considered failed due to high FOD potential and movement as shown in Figure 119. This product was recommended for Series 2 testing.

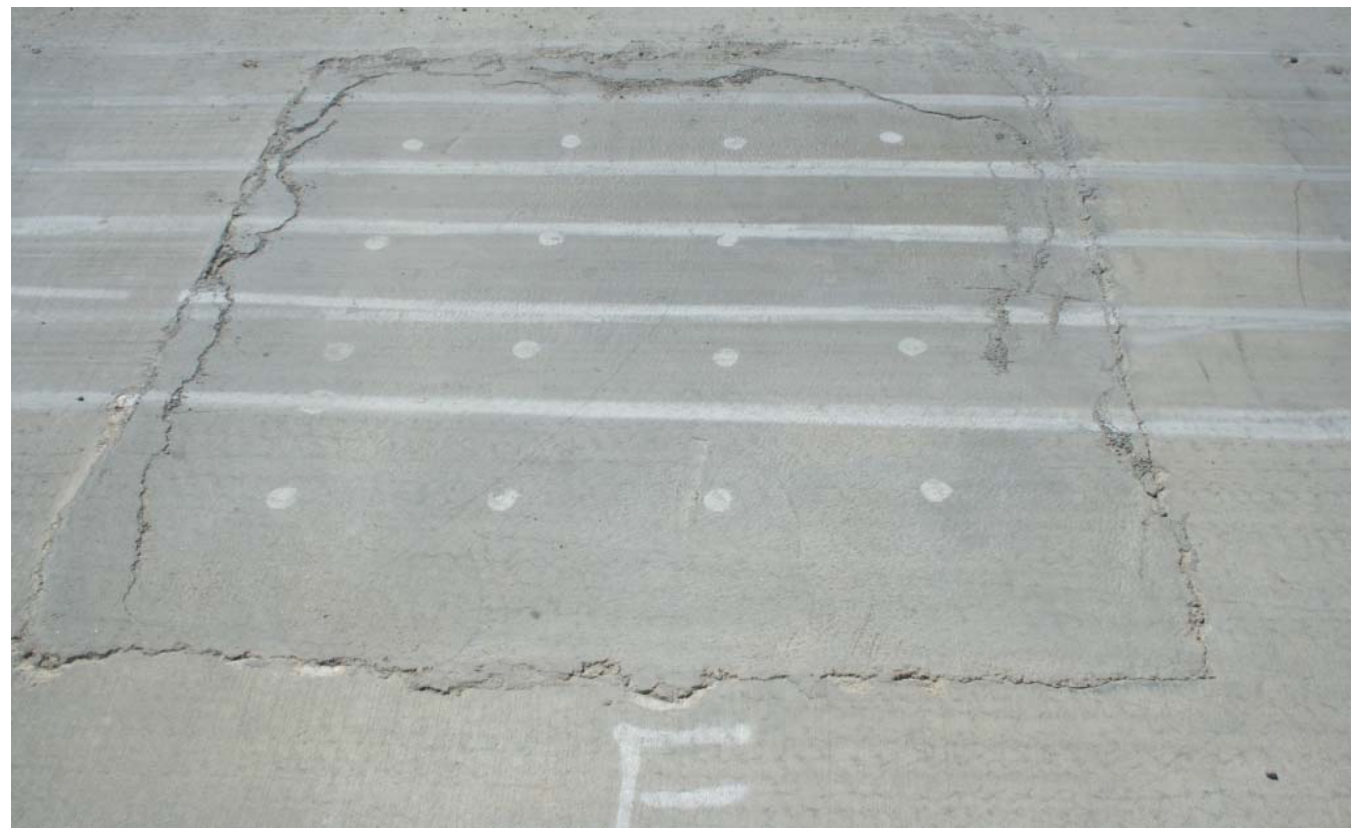

Figure 118. Crater F. Cracking along the east, south, and west edges after 384 passes.

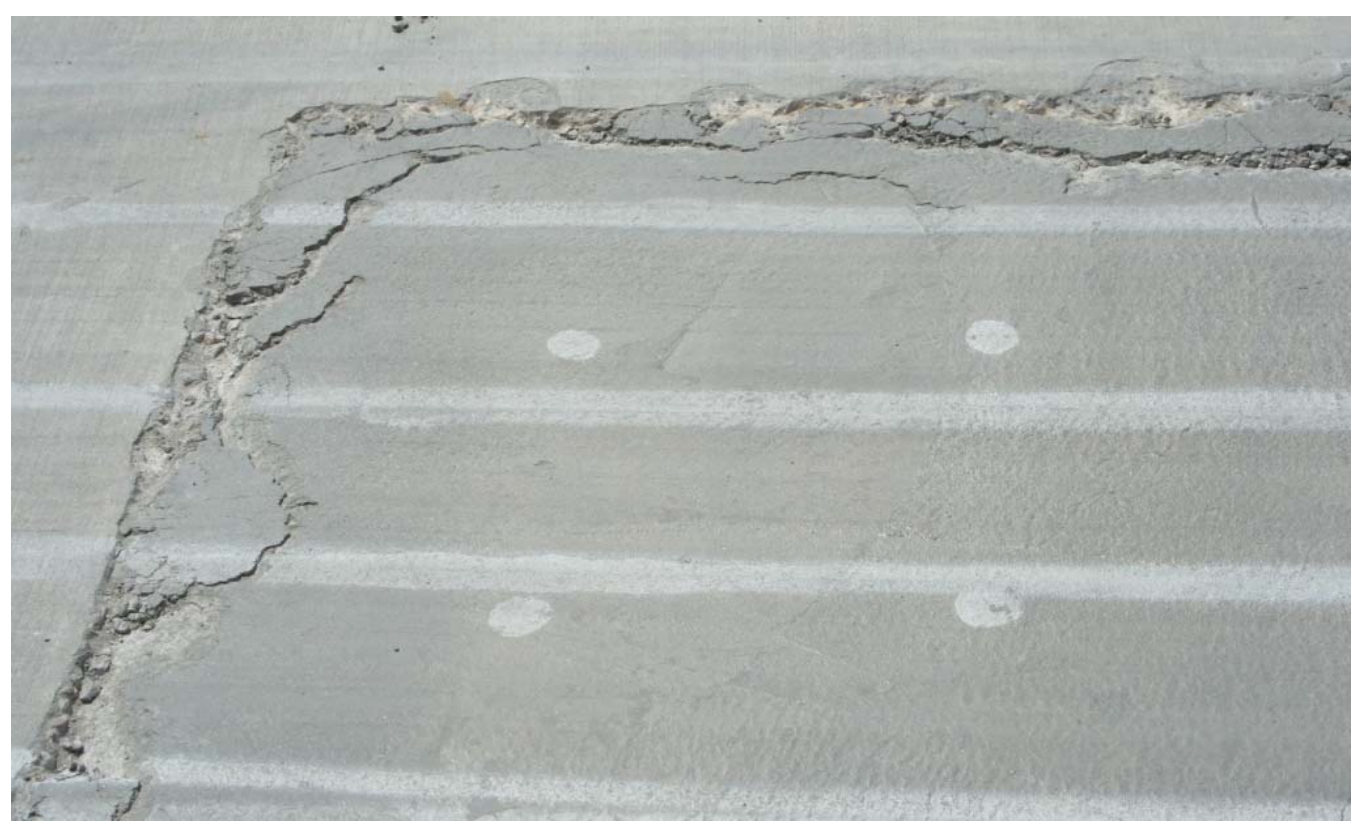

Figure 119. Crater F. FOD and cracking along the southeast corner after 720 passes. 


\section{Crater G-Pavemend SL}

Passes 0-16

HWD and roughness measurements were performed prior to traffic. High deflections were noticed with the HWD, and cracking occurred under the HWD load in the center of the crater as shown in Figure 120. Alow tire delayed trafficking nearly 45 min. After the completion of one pass, the surface began cracking. After 16 passes, traffic was discontinued due to a completely fractured surface (Figure 121). The surface was excavated by hand and picks to discover the top 4 in. of capping material was still curing. Below this level, the material was set. The surface material could be reanimated by rubbing loose material together to form a paste as seen in Figure 122. The vendor is investigating why the product did not cure as advertised. This product did not meet expedient pass criteria and was not recommended for Series 2 testing.

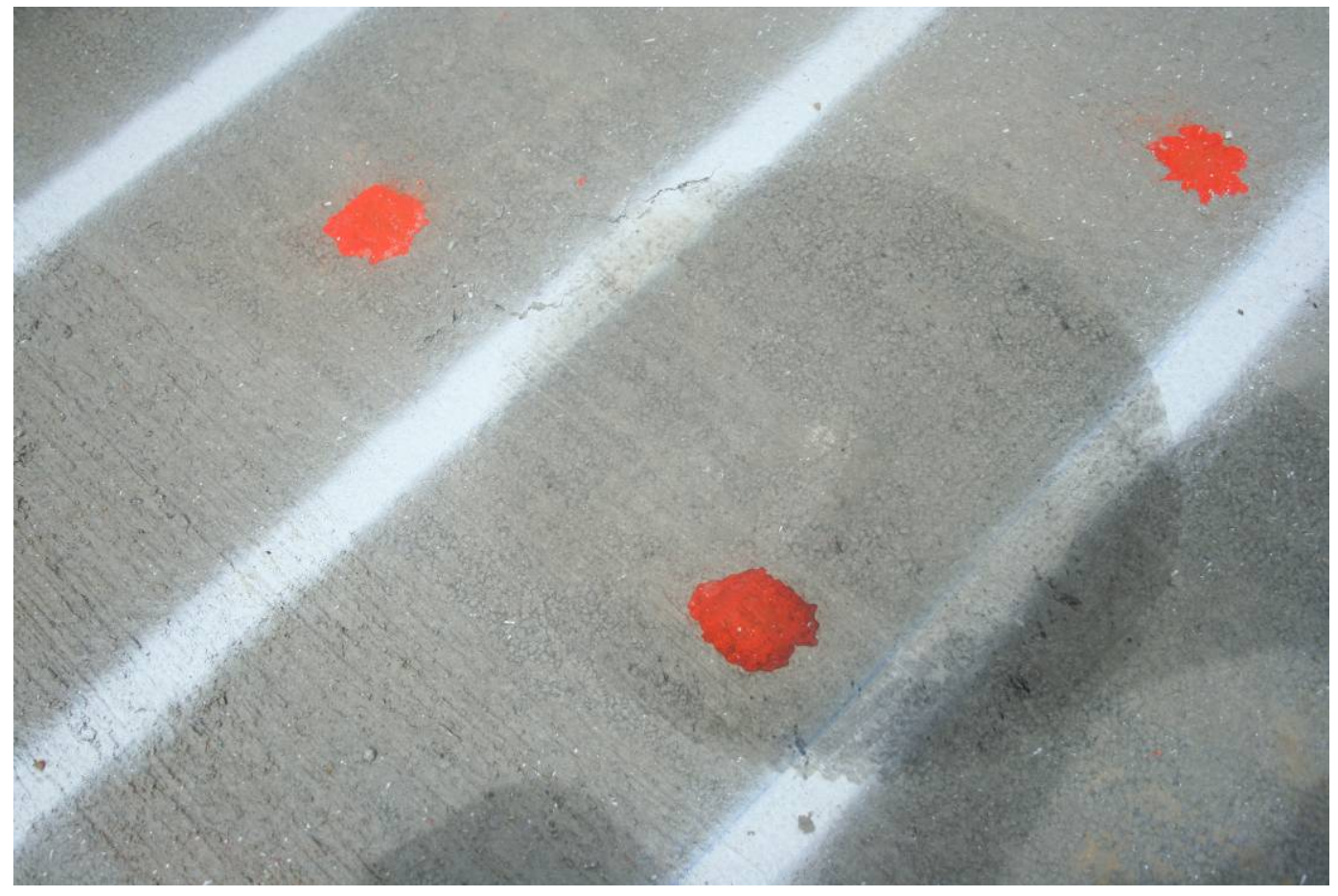

Figure 120. Crater G-1. Cracking caused by HWD testing. 


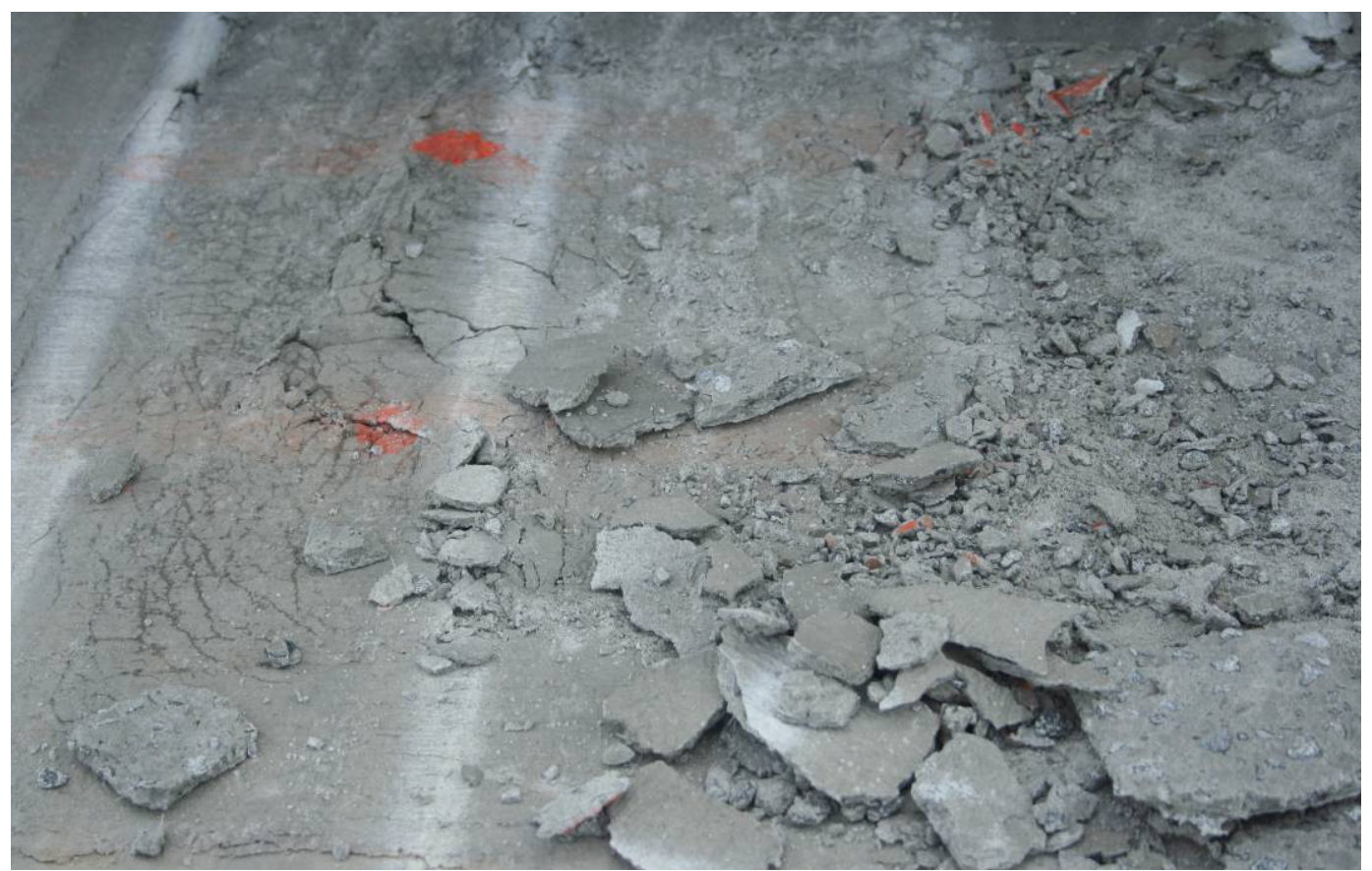

Figure 121. Crater G-1. Failure after 16 passes.

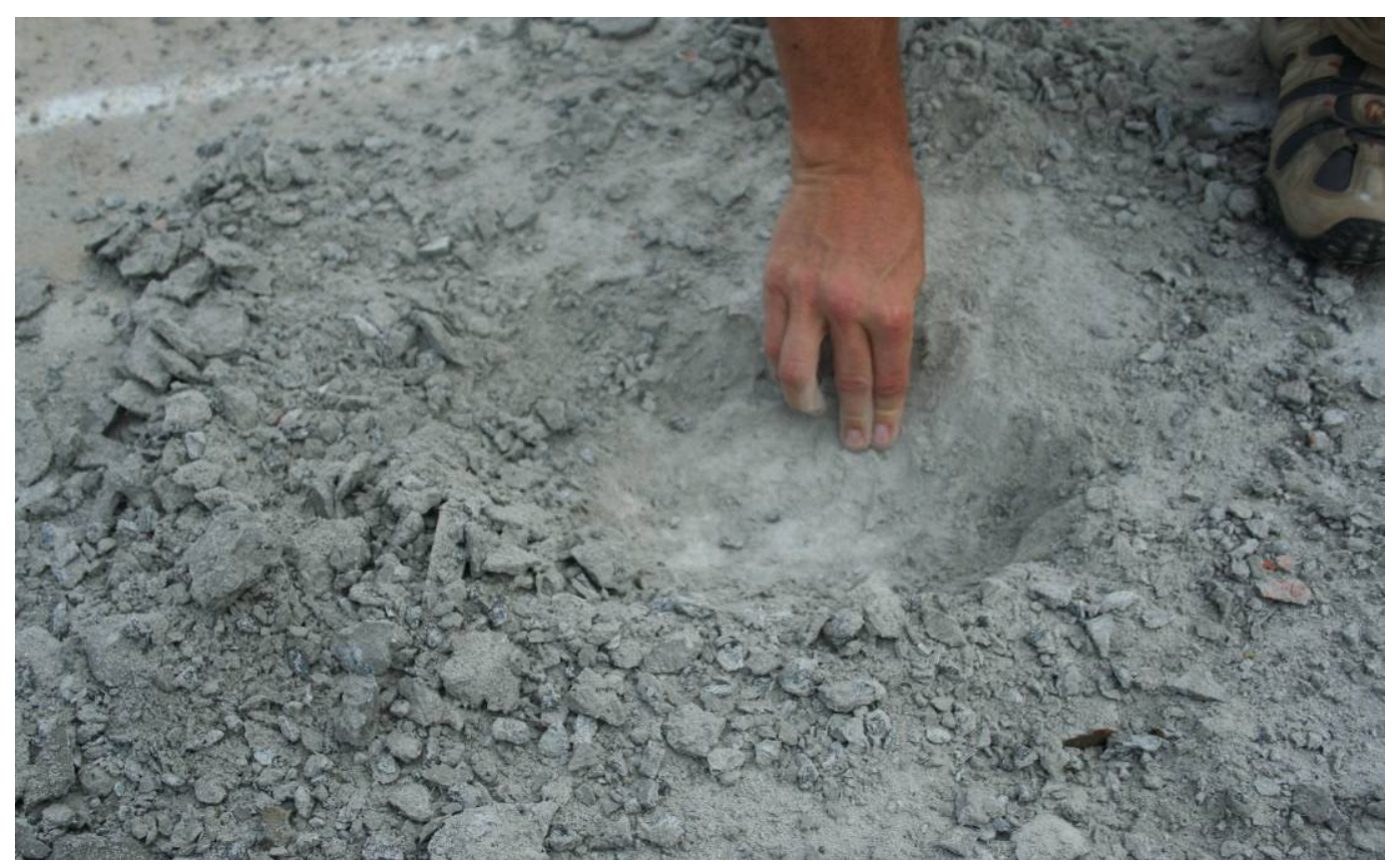

Figure 122. Crater G-1. Uncured material.

\section{Crater G-2 Tamms Express Repair}

Passes 0-112

HWD and roughness measurements were performed prior to traffic. Immediately after placement, the surface began to map crack. Cracks were 
monitored every 16 passes to see if map cracking progressed or significant FOD occurred. After 96 passes, more map cracking occurred under traffic. After 112 passes, no significant FOD occurred. The severity of the cracks did not increase, but additional cracking began to become visible (Figure 123). This repair met expedient pass criteria, but it was not recommended due to the surface cracking FOD potential.

\section{Passes 113-224}

Additional HWD measurements were performed prior to continuation of traffic. Craters B- $\mathrm{H}$ were trafficked in a straight line until failure was reached. The map cracking was monitored for additional crack progression or the loosening of surface material due to the cracking. At 144 passes, more raveling along these cracks occurred, and popping noises occurred along the south, east, and west joints. Cracks continued to spall, and at 182 passes, visible deflections under the tire became more noticeable. At 224 , roughness measurements were taken to determine if any settlement had occurred. A 0.25-in. difference in elevation from 0 passes occurred in traffic lanes 1- 3 . The surface cracks were widening, and large pieces of material were rocking under traffic. Figure 124 shows the repair after 224 passes. The repair was considered failed due to significant cracking and FOD potential. Trafficking was continued over the crater so that the other craters could still receive traffic. The crater continued to be monitored even after it had exceeded the failure criteria. At 304 passes, a new spall developed in the northeast corner, and cracking, popping, and spalling continued to progress. After 384 passes, spalling continued along corners and cracks. After pass 480, movement became more apparent in the repair under traffic. Spalls progressed along the east and west edges of the crater. At 512 passes, additional HWD and roughness measurements were performed. After 688 passes, no more traffic could be applied to this repair due to the high FOD potential. A photo after 688 passes is presented in Figure 125. Although this product met expedient pass criteria, the product was not recommended for Series 2 testing. 


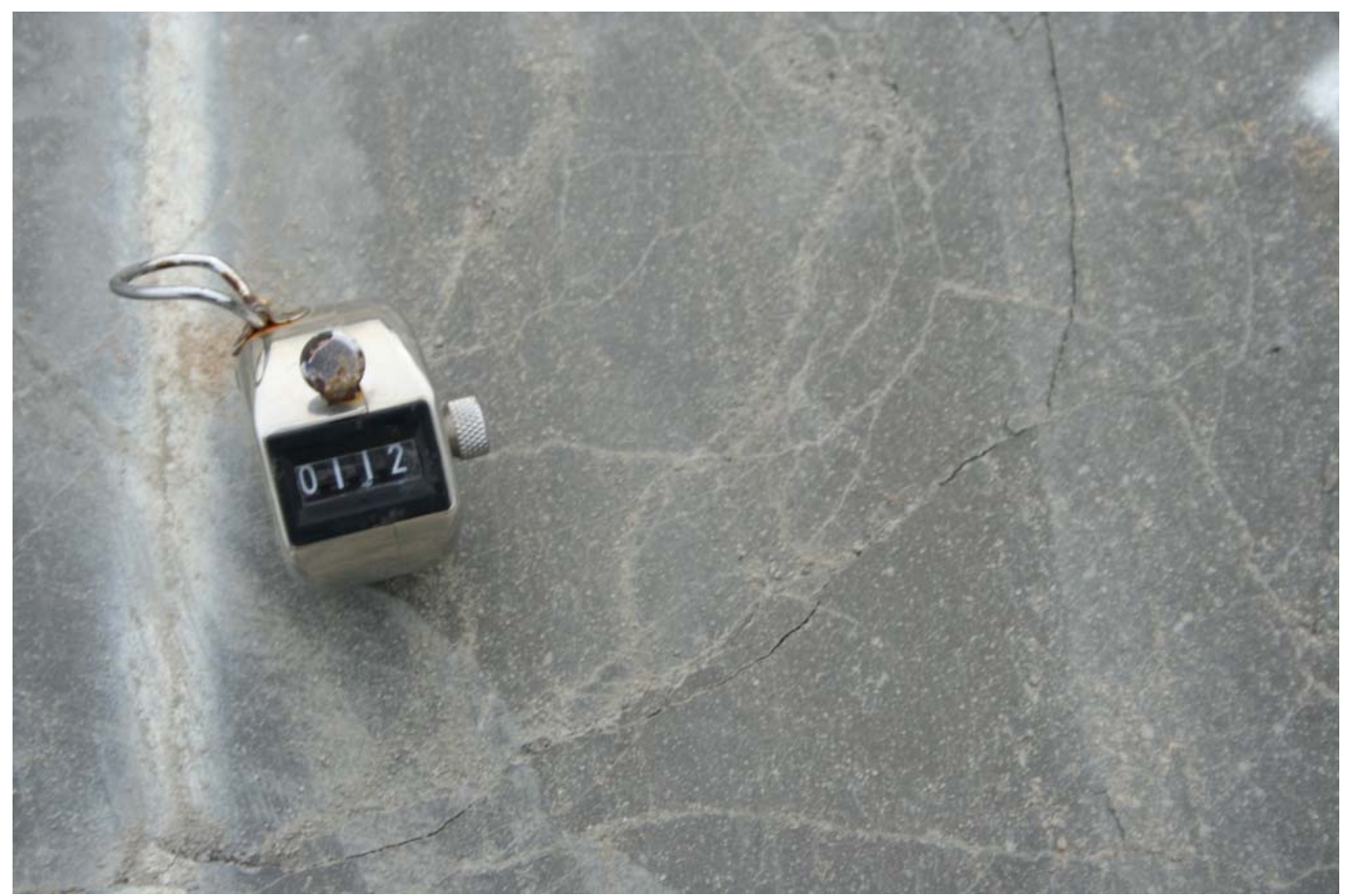

Figure 123. Crater G-2. Map cracking after 112 passes.

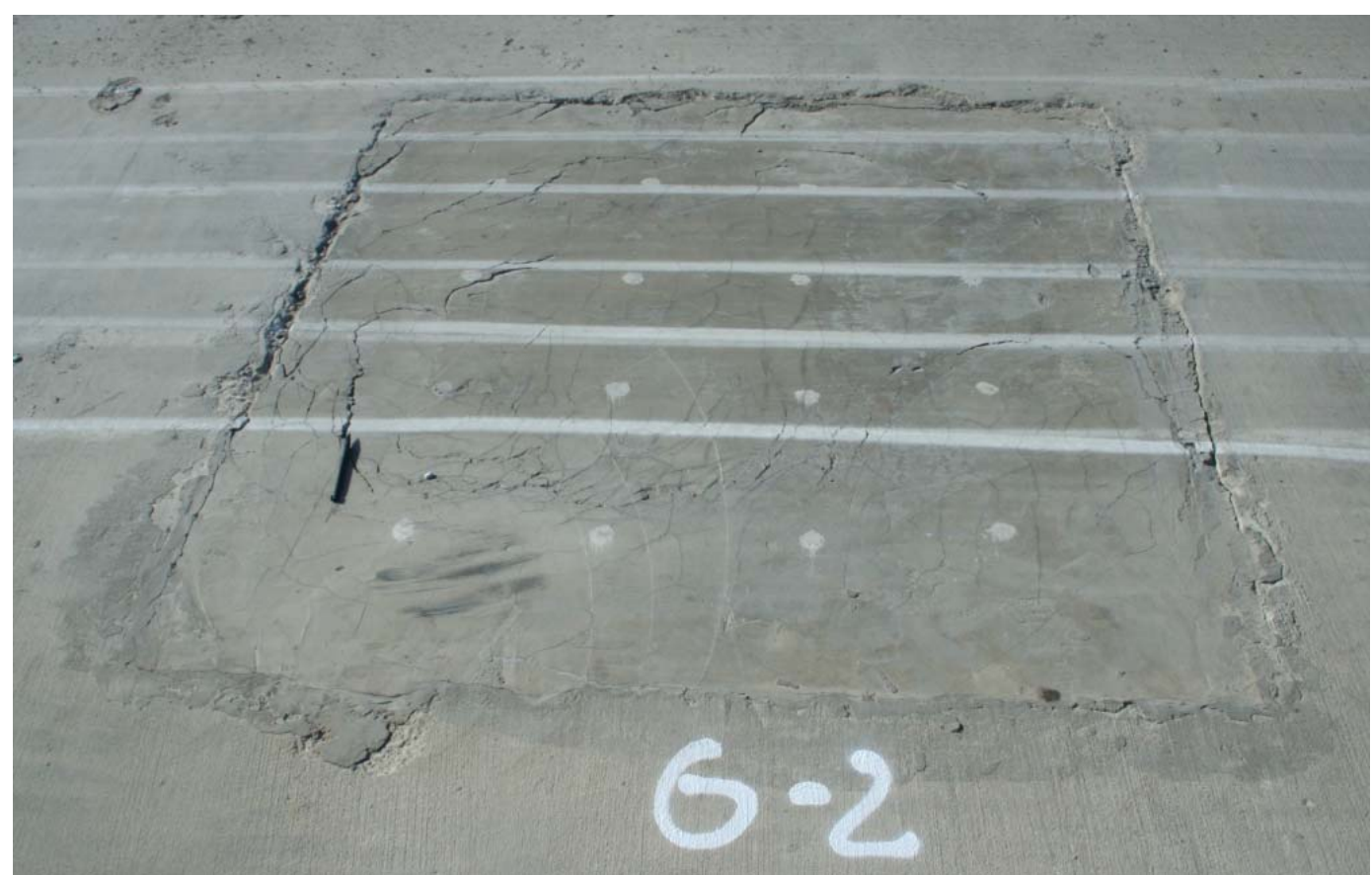

Figure 124. Crater G-2. After 224 passes. 


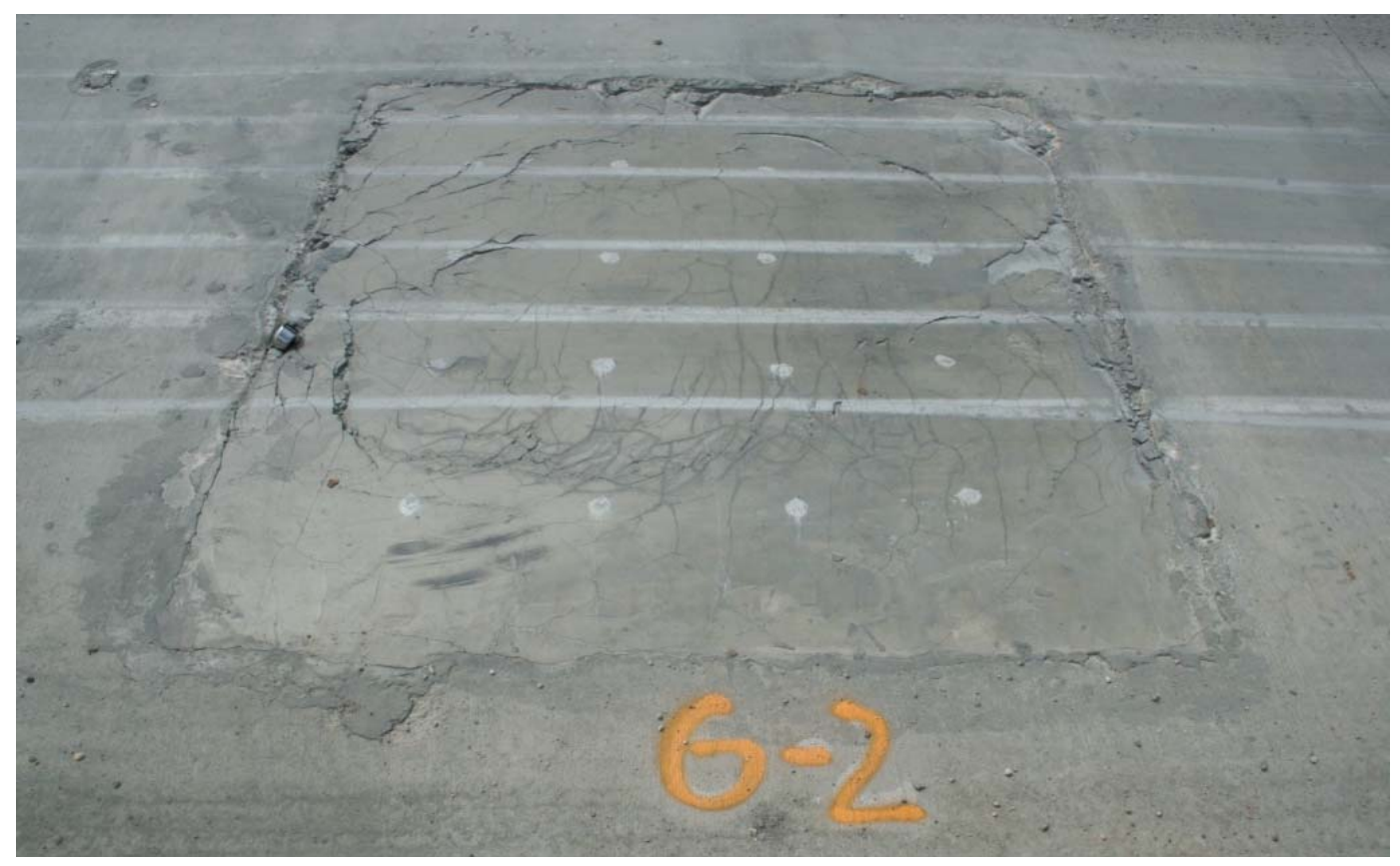

Figure 125. Crater G-2. After 688 passes.

\section{Crater H-Pavemend SLQ}

Passes 0-112

HWD and roughness measurements were performed prior to traffic. No FOD, cracking, or permanent deformation was noted during traffic. After 112 passes, a small hairline crack was noticed on the northwest joint. Figure 126 presents the repair after 112 passes. Expedient criteria were met with this repair. 


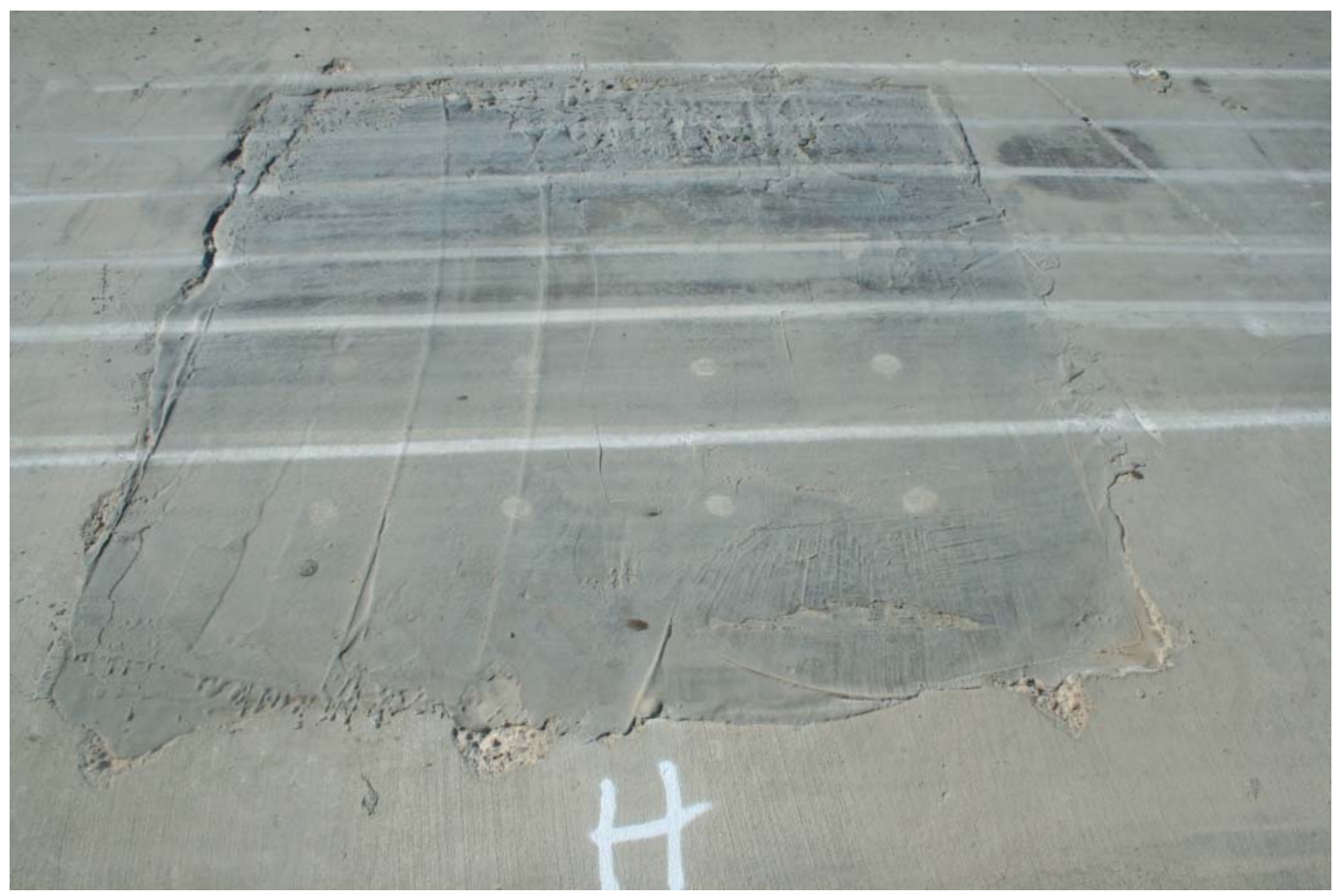

Figure 126. Crater H. After 112 passes.

Passes 113-1,344

Additional HWD measurements were performed prior to continuation of traffic. Craters B- $\mathrm{H}$ were trafficked simultaneously in a straight line until failure was reached. No cracking was noticed in the repair until pass 320 when a small crack developed in the center of the repair (Figure 127). At 512 and 1,008 passes, additional HWD and roughness measurements were performed. After 920 passes (Figure 128), cracking began to occur around the edges of the repair. At pass 1,104, the south and west edges began to ravel and spalling was occurring in the crack in the center of the repair. After 1,268 passes, more small cracks appeared along the edges and in the center. After pass 1,295, the material became spongy causing visible deformation under the loaded wheel. After 1,314 passes, more small cracks appeared in the center. After 1,330 passes, more FOD appeared with pieces up to $1.5 \mathrm{in}$. in length. Trafficking was continued over this repair until 1,344 passes when the repair began to ravel significantly along the south and west joints of the repair (Figures 129 and 130), and the center crack and deformation became noticeable under traffic. 


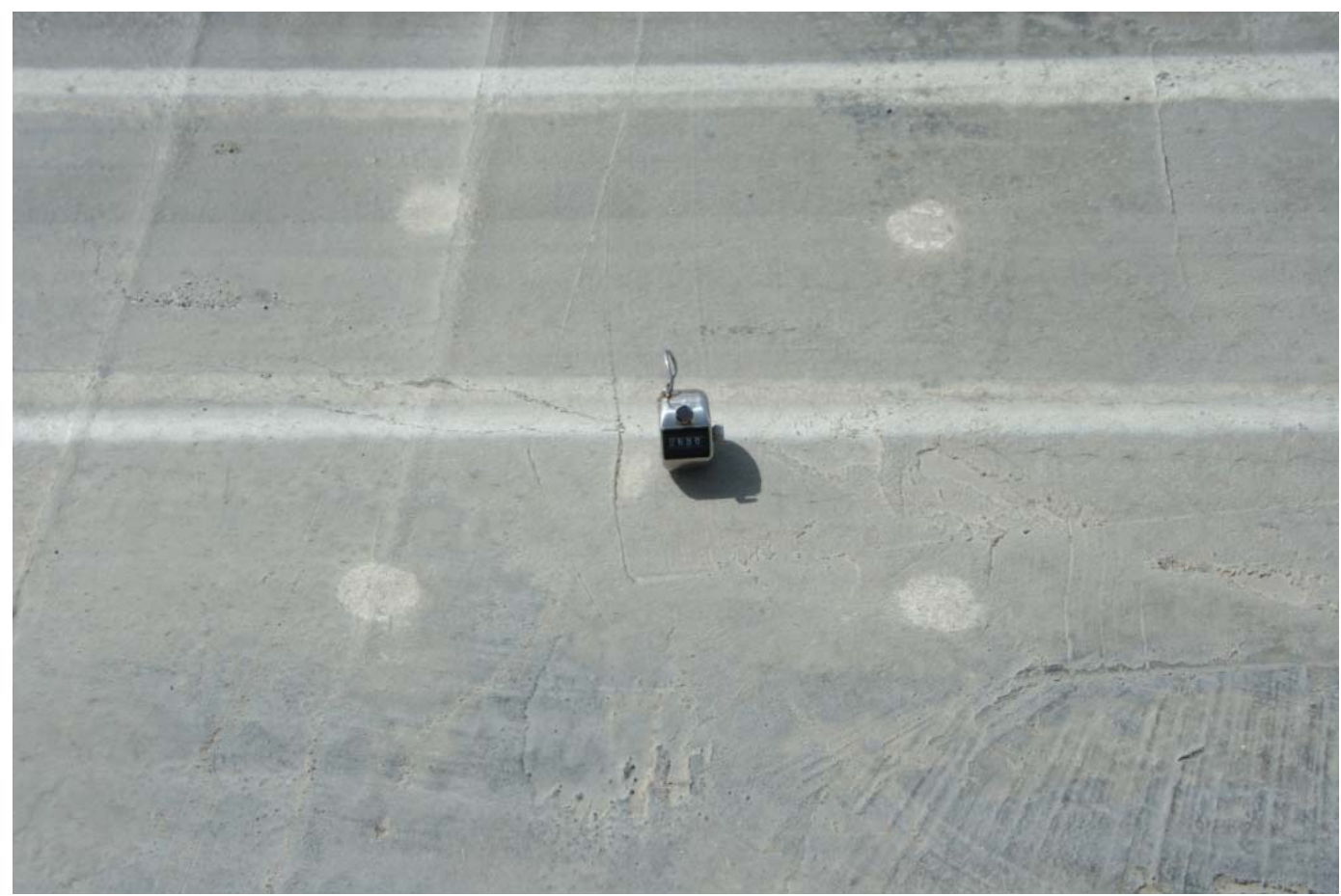

Figure 127. Crater H. Cracks in center of crater after 320 passes.

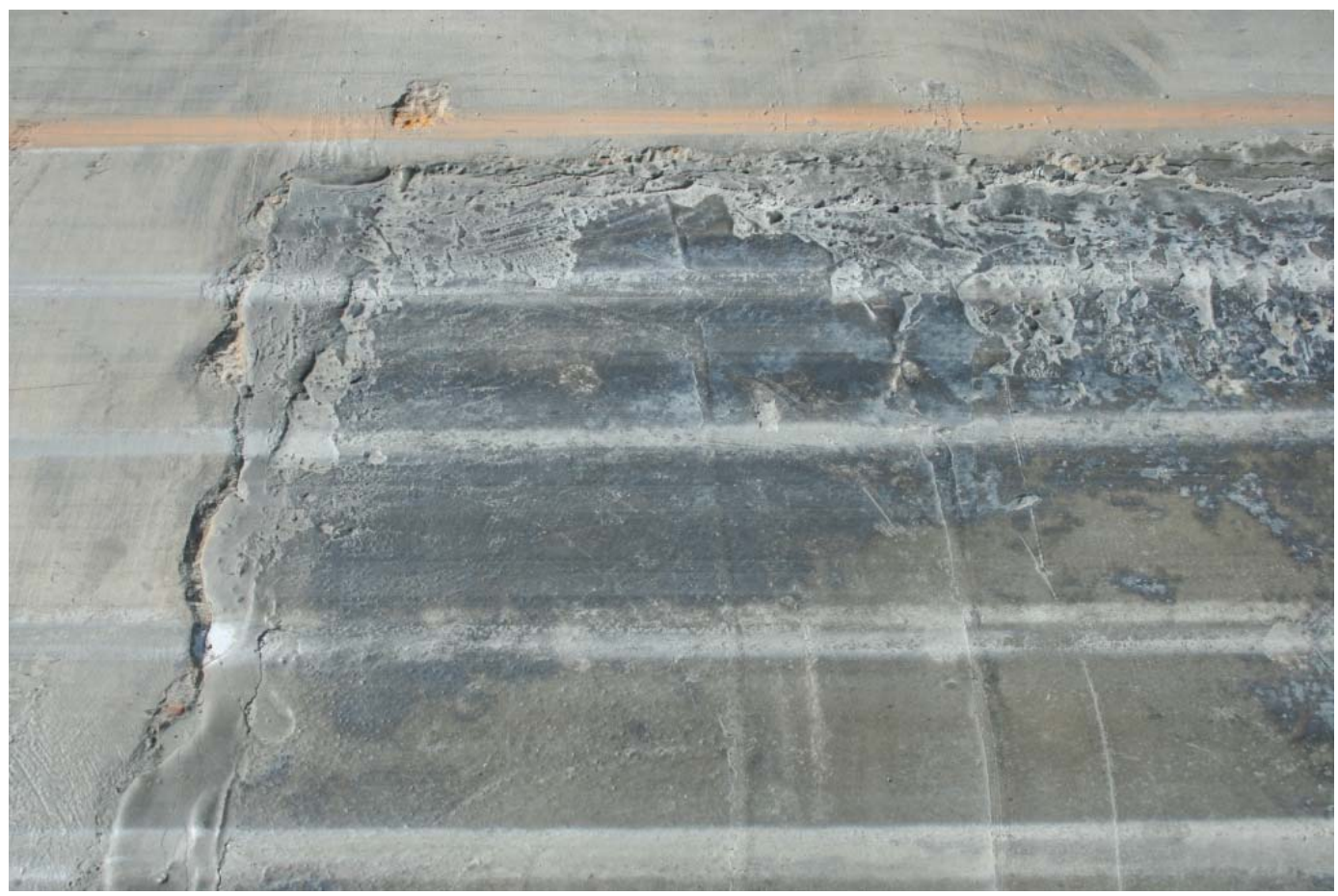

Figure 128. Crater H. Cracking along east and south edges after 920 passes. 


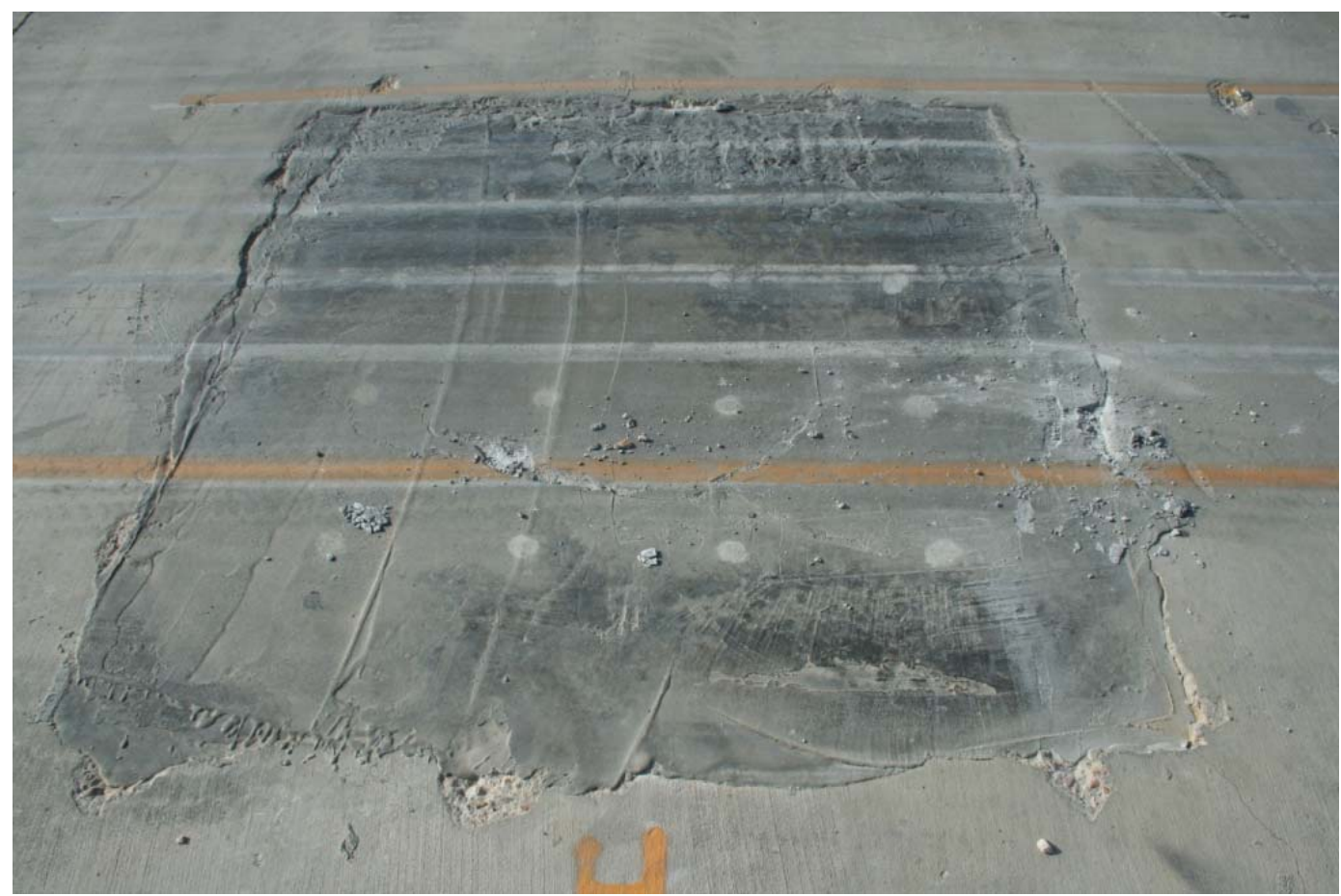

Figure 129. Crater H. Cracking after 1,344 passes.

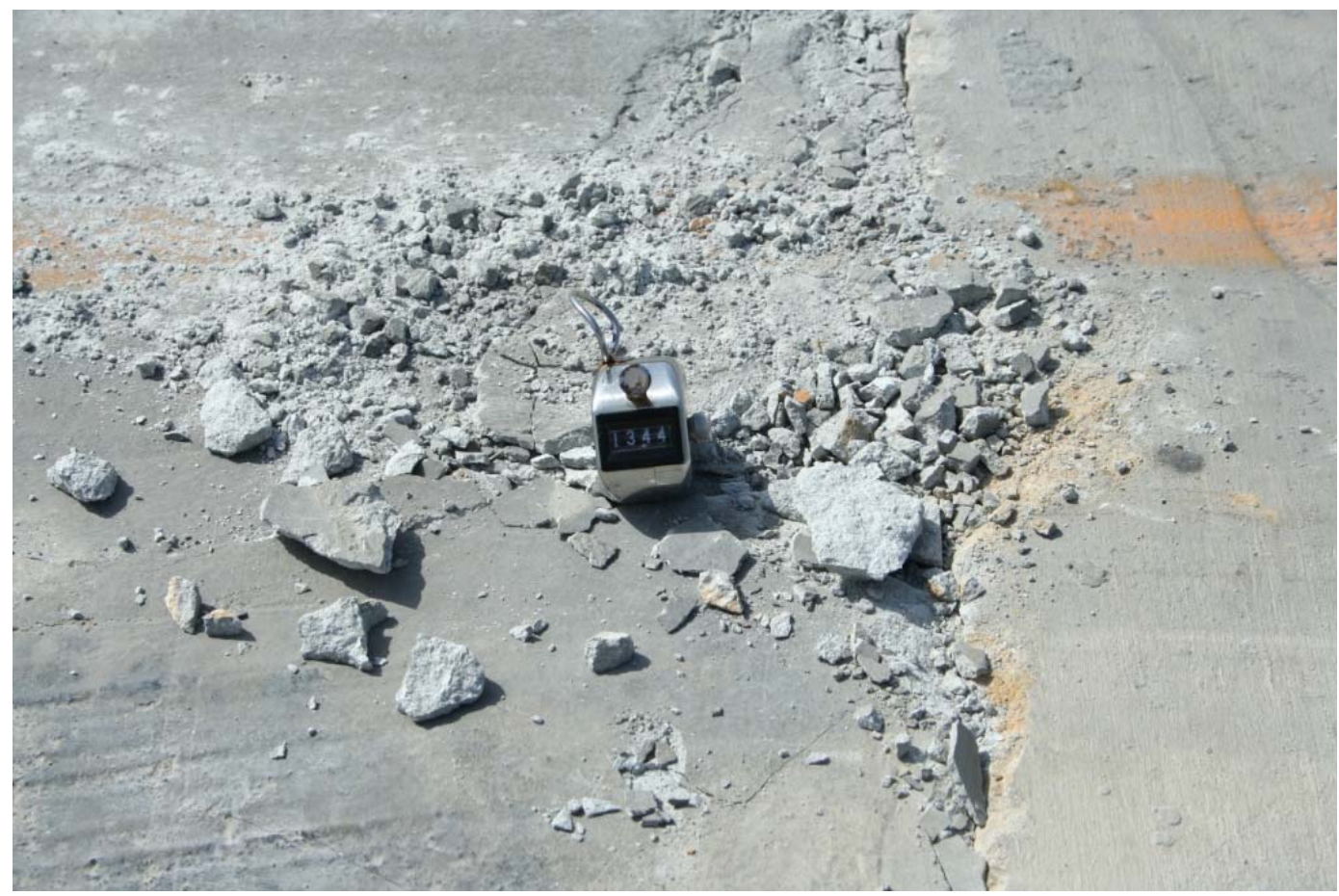

Figure 130. Crater H. High severity joint spall after 1,344 passes. 


\section{Behavior of crater repairs under traffic-Series 2}

\section{Crater J-Rapid Set}

Passes 0-112

HWD and roughness measurements were performed prior to traffic. Load cart trafficking was conducted $3 \mathrm{hr}$ after each repair was complete. After 112 passes, no spalling, cracking, or additional FOD were detected. HWD and survey data were collected after 112 passes. Expedient criteria were met with this repair.

\section{Passes 113-2,000}

Craters J - L were trafficked simultaneously in a straight line until failure was reached as shown in Figure 131. After 155 passes, a hairline crack developed on the south and east edges. After 224 passes, low severity corner spalls on the southwest corner of the repair and joint spalls with light raveling on the south and east edges were recorded. After 336 passes, the crack on the south edge extended the full length of the crater. Spalling continued on the south and west edges. Popping noises were noticed on the west edge at 328 passes. After 495 passes, spalling was recorded on the southwest corner. After 512 passes, spalling continued to progress on the south edge. After 1,008 passes, no significant increase in the severity of the recorded distresses was noticed. After 1,232 passes, spalling progressed on the west, east, and south joints. Trafficking was discontinued on this repair after 2,000 passes due to significant FOD along the south, east, and west edges. This material met expedient criteria but produced significant FOD along the loaded edges prior to reaching 5,000 passes. The product was recommended for Series 3 testing. Figures 132-135 illustrate the deterioration of the crater under traffic. 


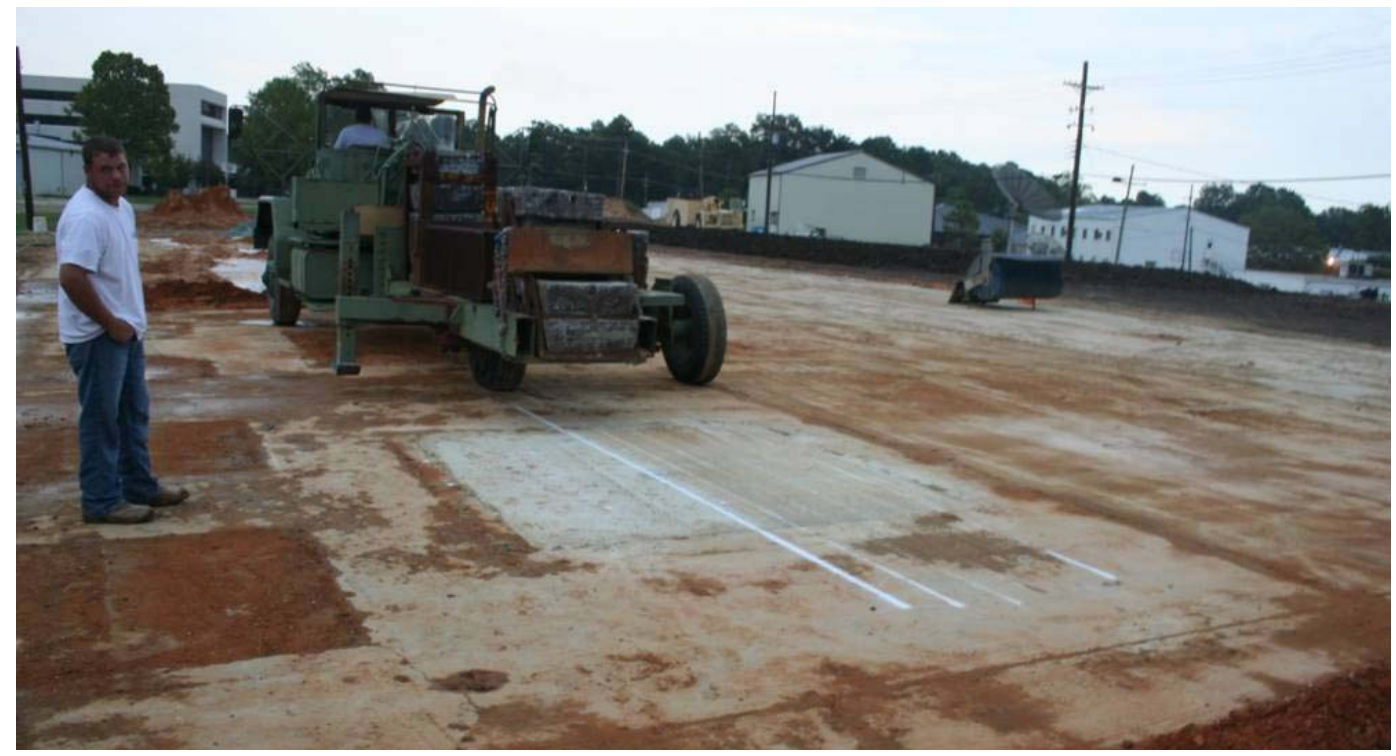

Figure 131. Crater J. Trafficking.

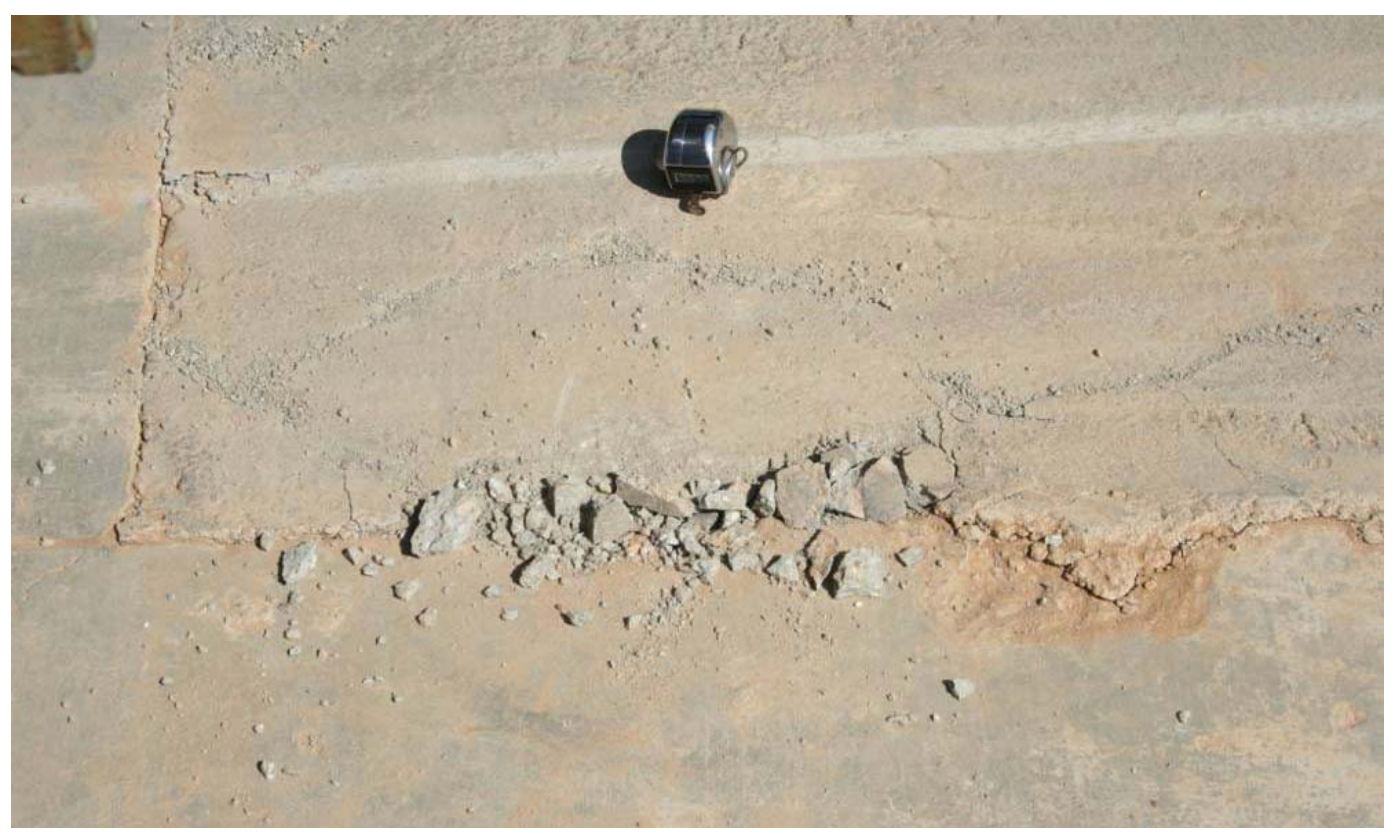

Figure 132. Crater J. Spalling on the south edge after 336 passes. 


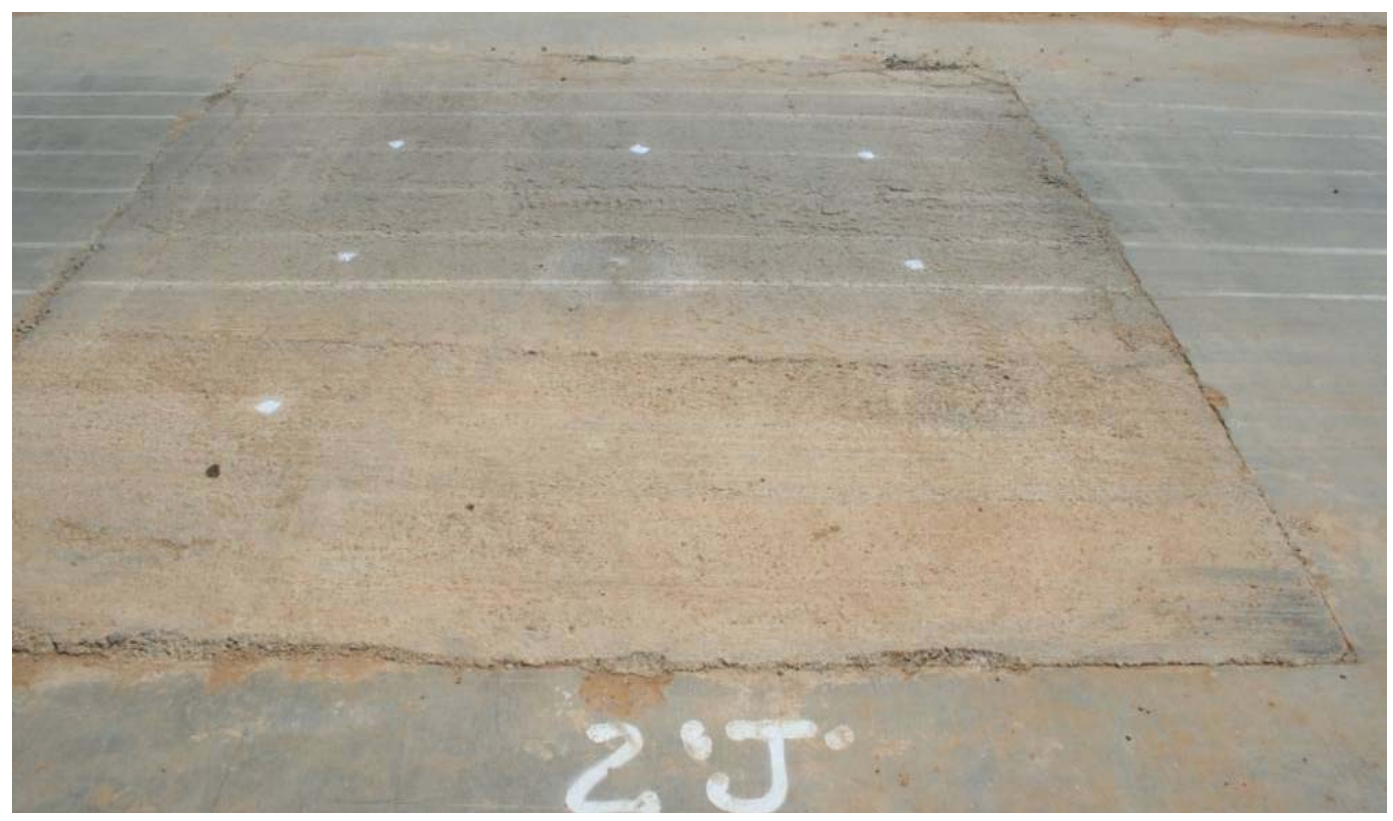

Figure 133. Crater J. After 512 passes.

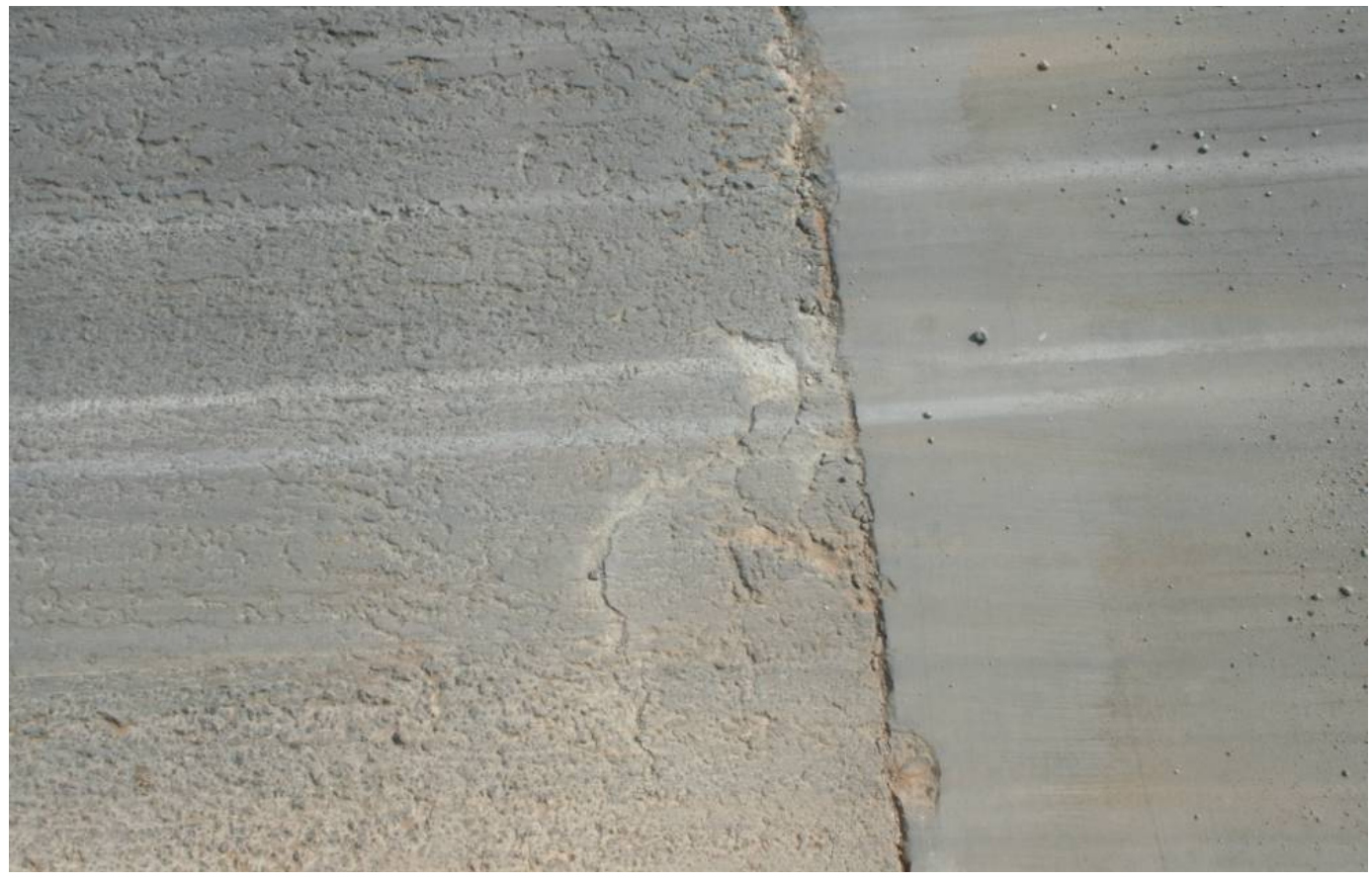

Figure 134. Crater J. Spalling on the south edge after 1,008 passes. 


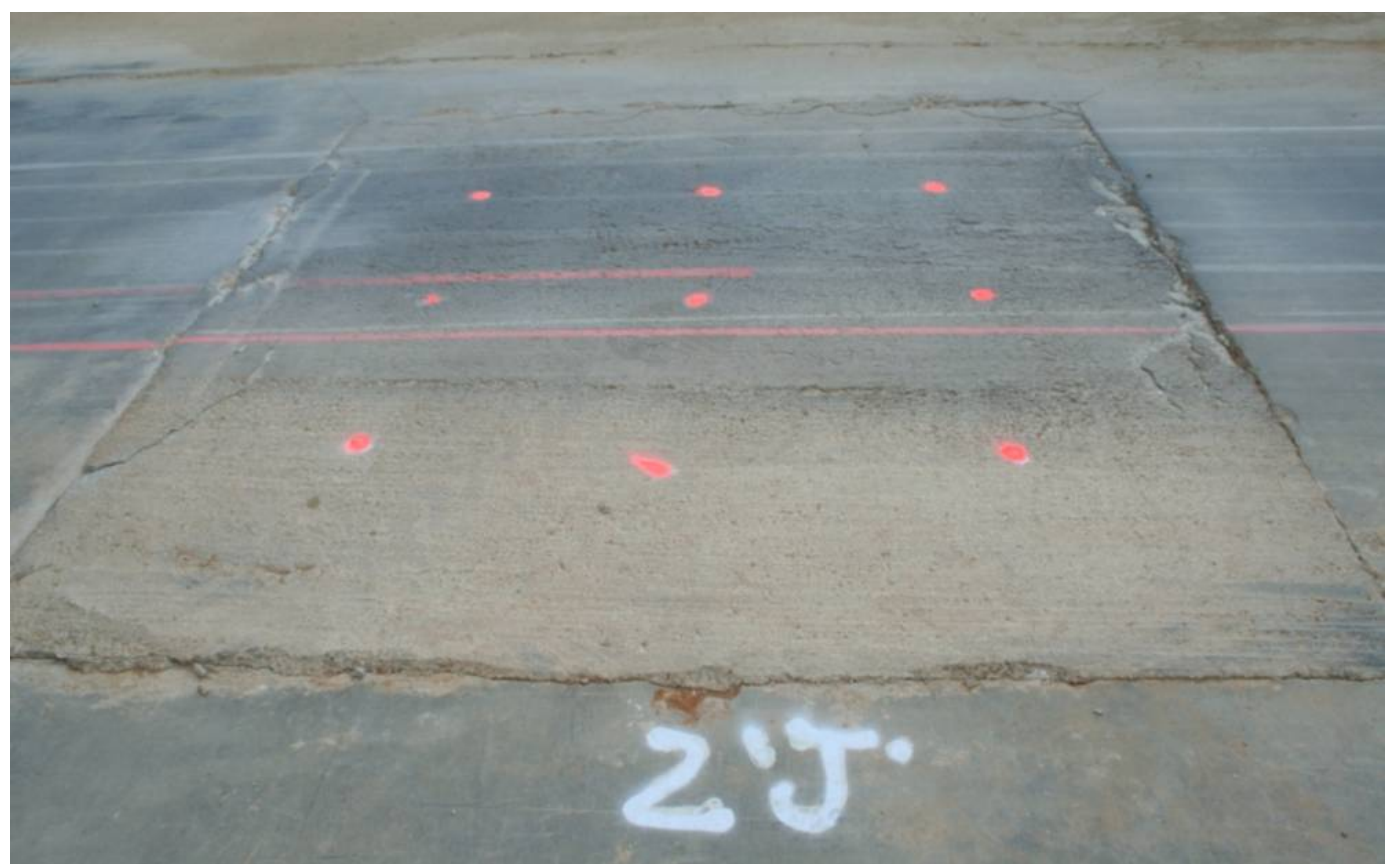

Figure 135. Crater J. Spalling on trafficked edge after 2,000 passes.

\section{Crater K-Pavemend SLQ}

Passes 0-112

HWD and roughness measurements were performed prior to traffic. Load cart trafficking was conducted $3 \mathrm{hr}$ after the repair was complete. After 112 passes, no spalling, cracking, or additional FOD were detected. HWD and survey data were collected after 112 passes. Expedient criteria were met with this repair.

\section{Passes 113-5,008}

Craters J - L were trafficked simultaneously in a straight line until failure was reached. No distresses were recorded on this repair until 570 passes with the east edge beginning to make popping noises under traffic. After 1,232 passes, a 1-ft long hairline crack developed on the east edge. Trafficking was discontinued on this repair after 5,008 passes. Figures 136 and 137 detail the deterioration of the crater under traffic. 


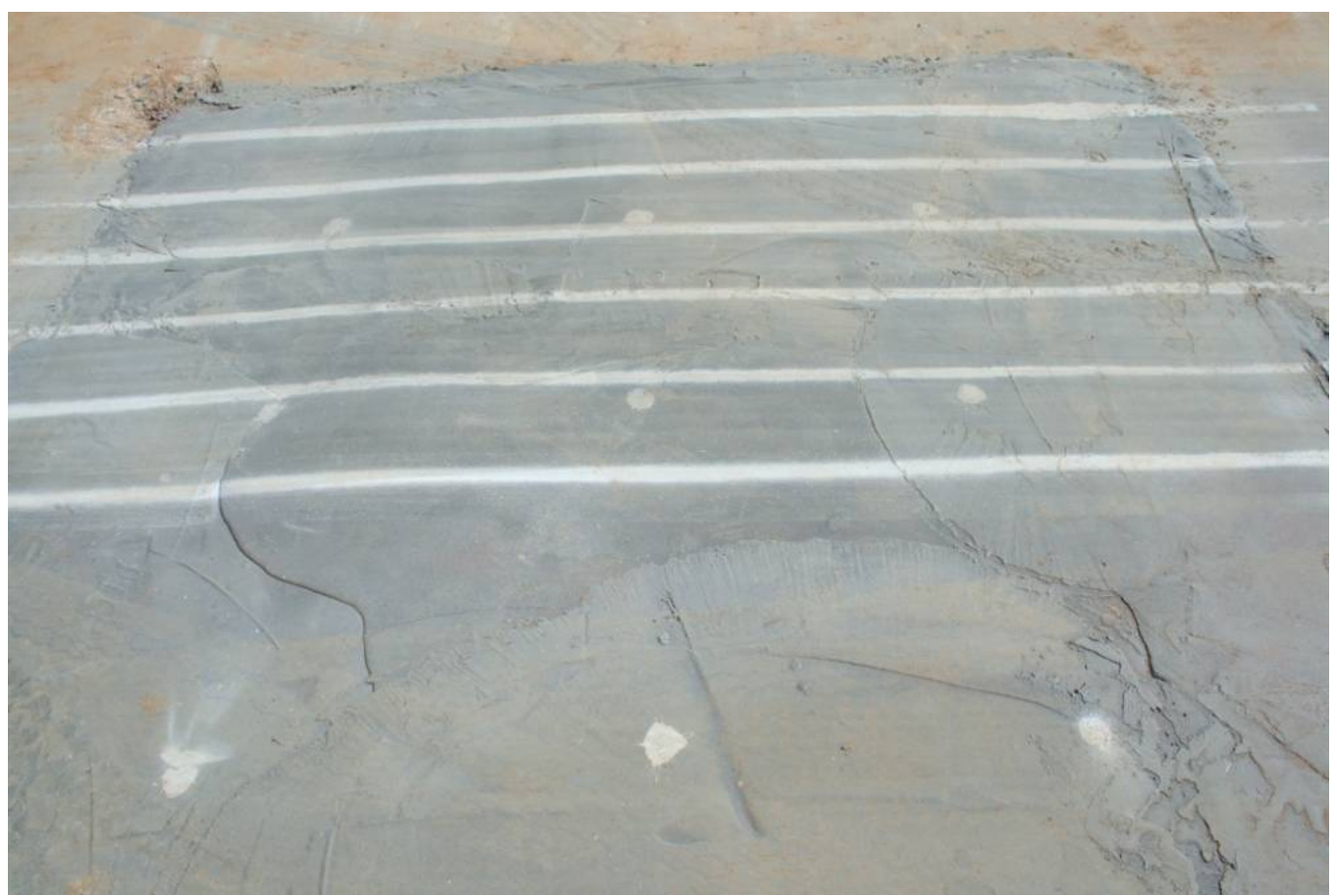

Figure 136. Crater K. After 112 passes.

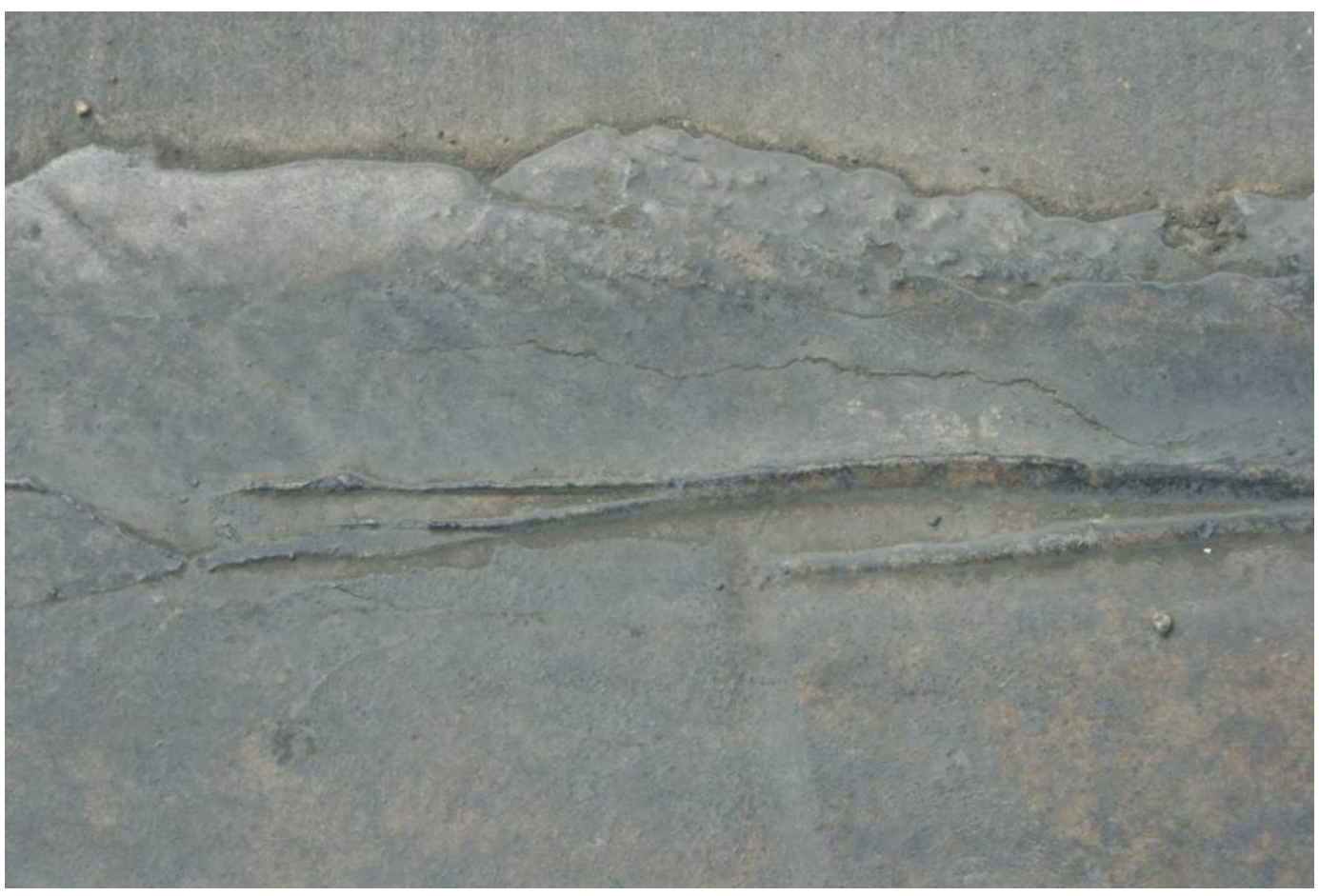

Figure 137. Crater K. Hairline crack after 5,000 passes. 


\section{Crater L-ThoRoc 10-61}

Passes 0-112

HWD and roughness measurements were performed prior to traffic. Load cart trafficking was conducted $3 \mathrm{hr}$ after the repair was complete. After 112 passes, no spalling, cracking, or additional FOD were detected. HWD and survey data were collected after 112 passes. Expedient criteria were met with this repair.

Passes 113-2,000

Craters J - L were trafficked simultaneously in a straight line until failure was reached. After 182 passes, popping noises were noticed when the tire crossed the west edge. After 224 passes, a hairline crack $2 \mathrm{ft}$ long was recorded on the south edge. Light raveling also had developed on the west and south joints. After 336 passes, a hairline crack developed on the east edge (Figure 138). Popping noises were heard after 380 passes on the west and south edges of the repair. After 495 passes, more spalling was recorded on the west edge and another hairline crack developed on the east edge. After 512 passes, raveling continued on the east and west joints, and the crack on the south edge continued to spall. After 1,008 passes, no significant increase in the severity of the recorded distresses was noticed (Figure 139). After 1,232 passes, the south, east, and west joints began raveling at an increased rate. A longitudinal crack also developed from the north to the south edge. FOD was becoming more evident. Trafficking was discontinued on this repair after 2,000 passes due to high FOD potential along the south, east, and west edges (Figure 140). This material met expedient criteria but produced significant FOD along the loaded edges prior to reaching 5,000 sustainment passes. The product was recommended for Series 3 testing. 


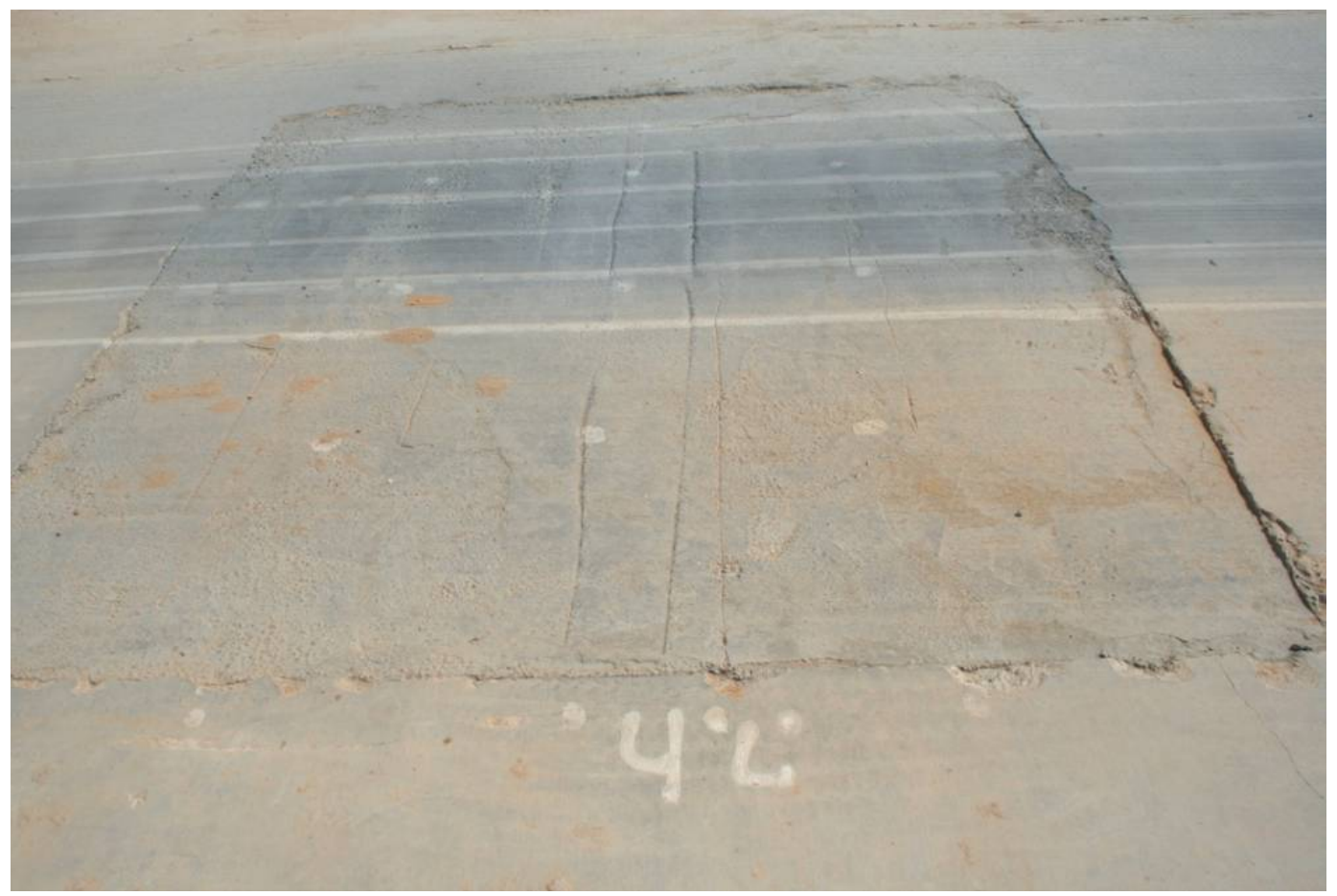

Figure 138. Crater L. Spalling and edge cracking on loaded edges after 336 passes.

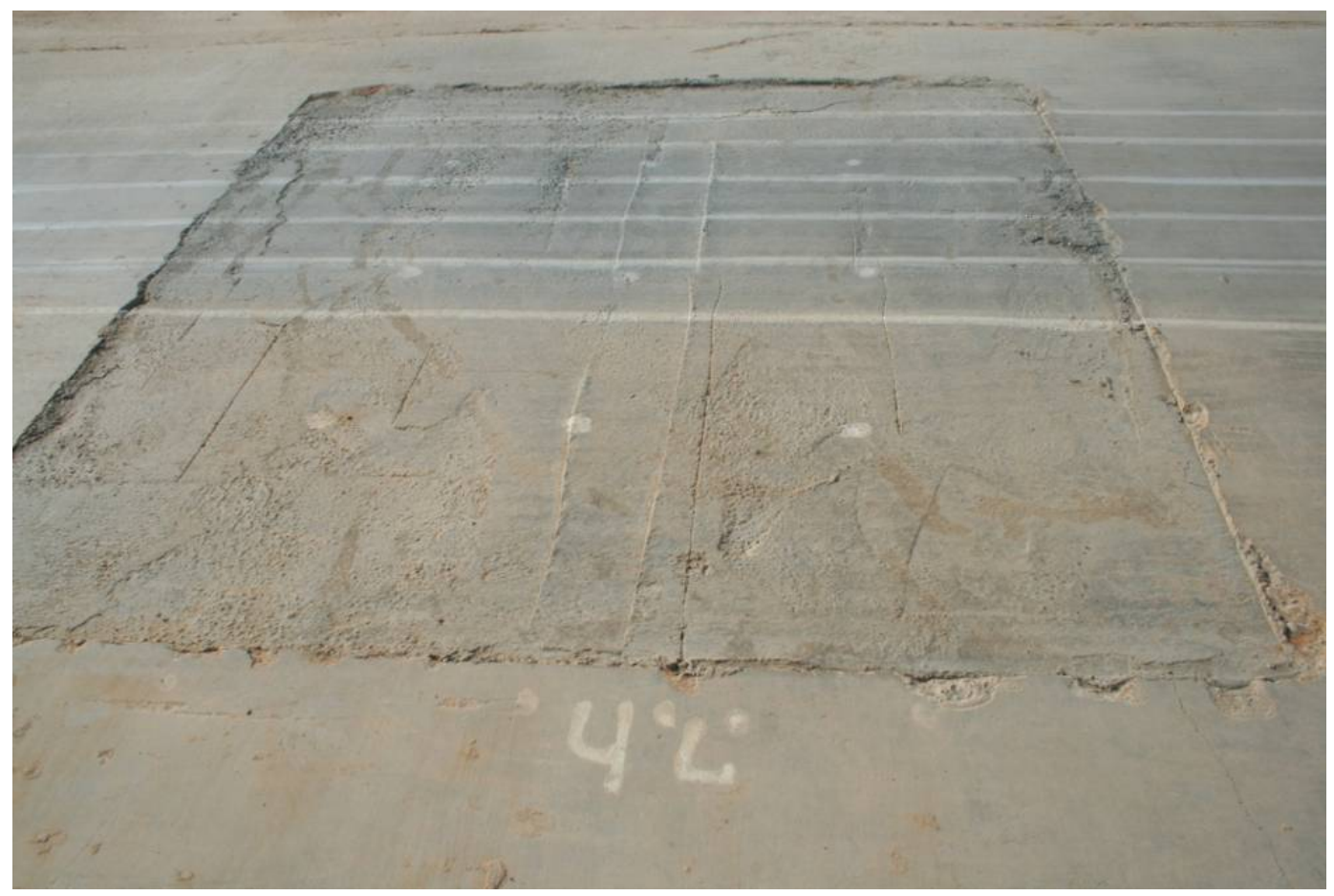

Figure 139. Crater L. Spalling and edge cracking on loaded edges after 1,008 passes. 


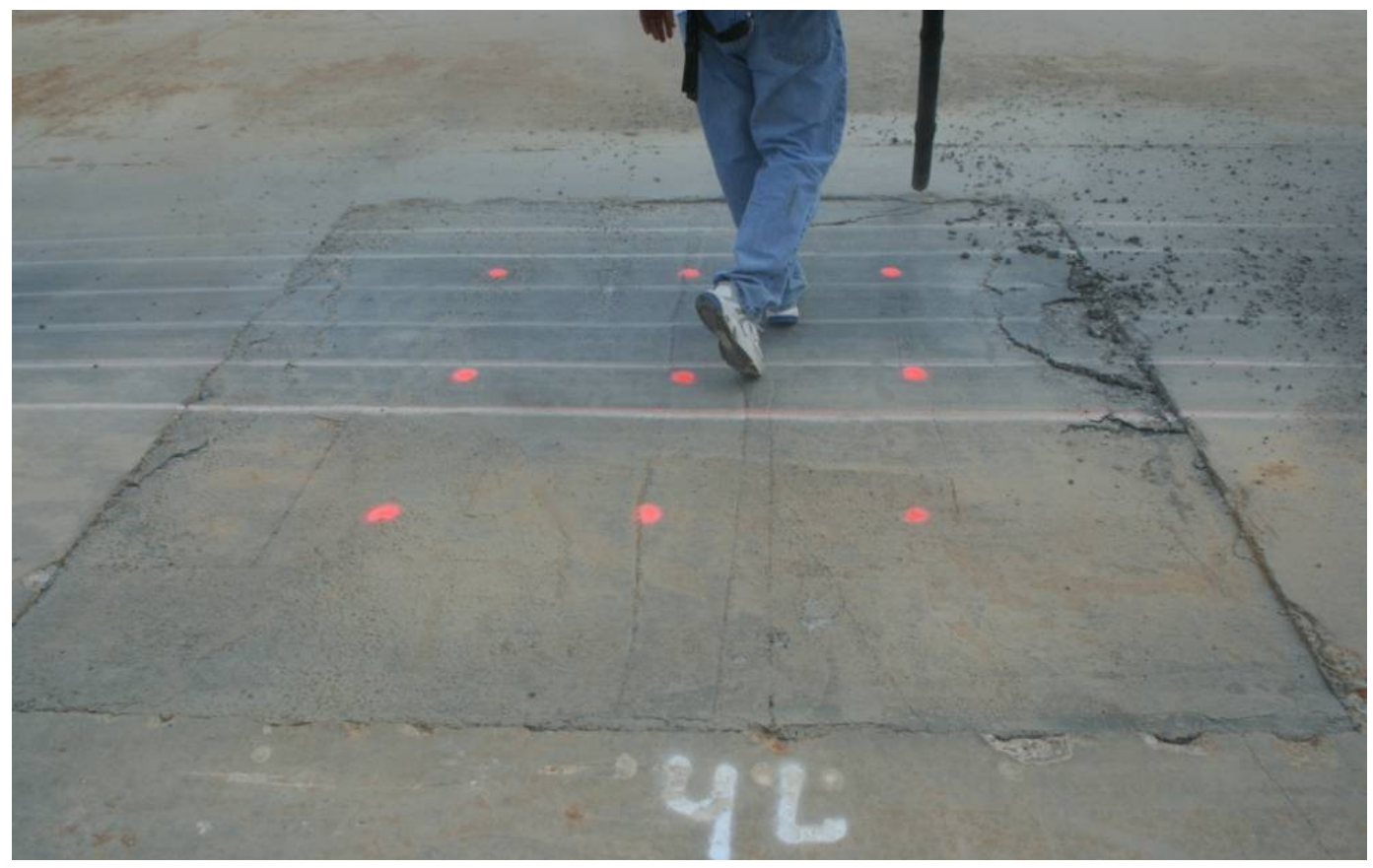

Figure 140. Crater L. Spalling and edge cracking on loaded edges after 2,000 passes.

\section{Behavior of crater repairs under traffic-Series 3}

\section{Crater Q-Rapid Set}

Passes 0-112

HWD and roughness measurements were performed prior to traffic. Load cart trafficking was conducted $3 \mathrm{hr}$ after the repair was complete. Immediately after installation, the repair capping material was cracked; small cracks appeared where pieces of debris were pointed towards the surface. These did not progress under traffic. Figure 141 shows the cracking noticed. After 112 passes, no spalling, cracking, or additional FOD were detected from trafficking. HWD and survey data were collected after 112 passes. Expedient criteria were met with this repair.

\section{Passes 113-5,008}

Craters Q- $\mathrm{T}$ were trafficked simultaneously in a straight line until 5,008 passes or failure was reached. After 512 passes, light cracking was noticed on the southern edge of the repair. No settlement of the debris was noticed. This cracking became more noticeable after 2,000 passes (Figure 142), and after 5,008 passes had not progressed significantly. This repair met expedient and sustainment criteria reaching greater than 5,000 passes without failing. 


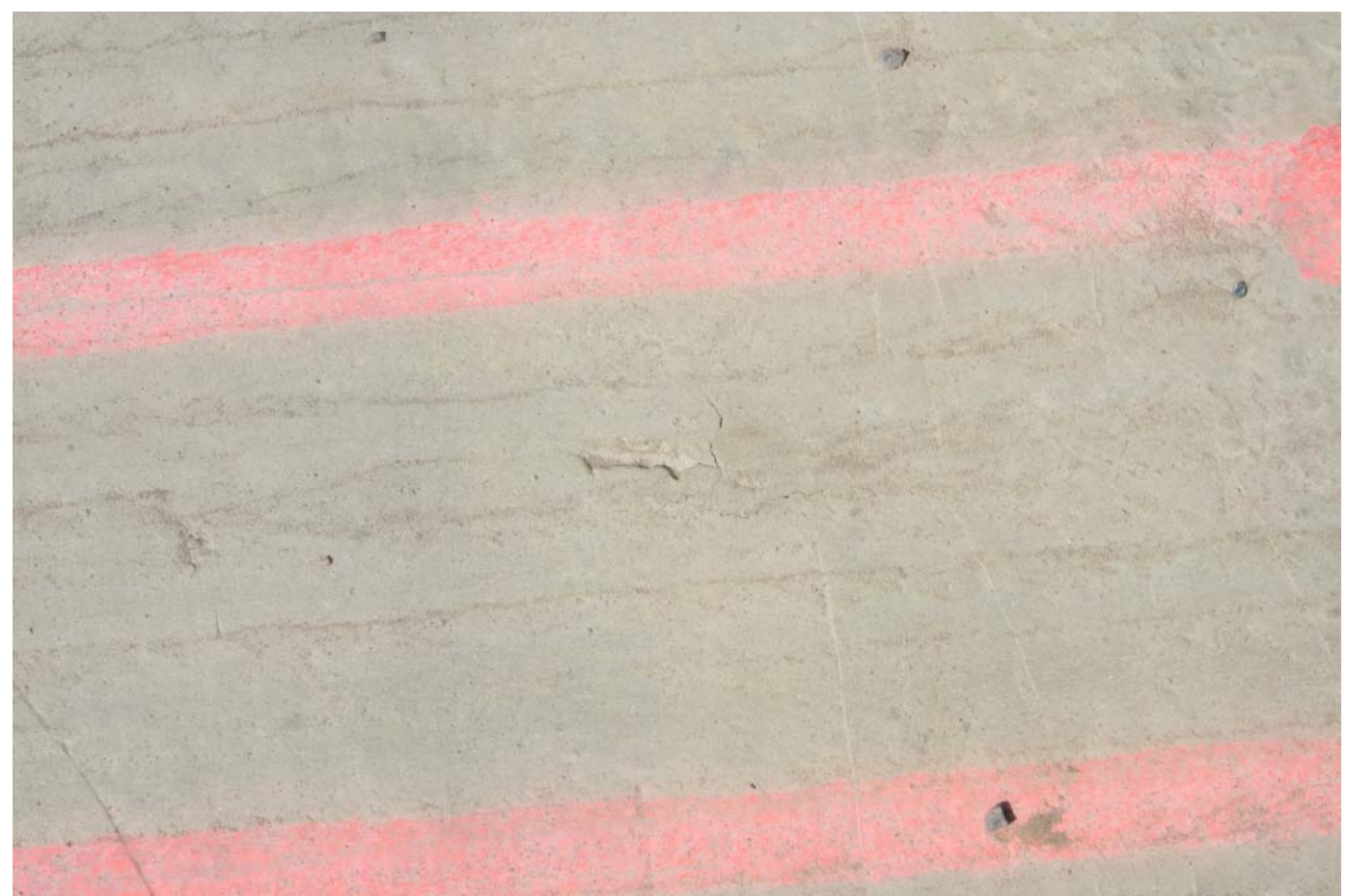

Figure 141. Crater Q. Rapid Set shrinkage cracking pre-traffic.

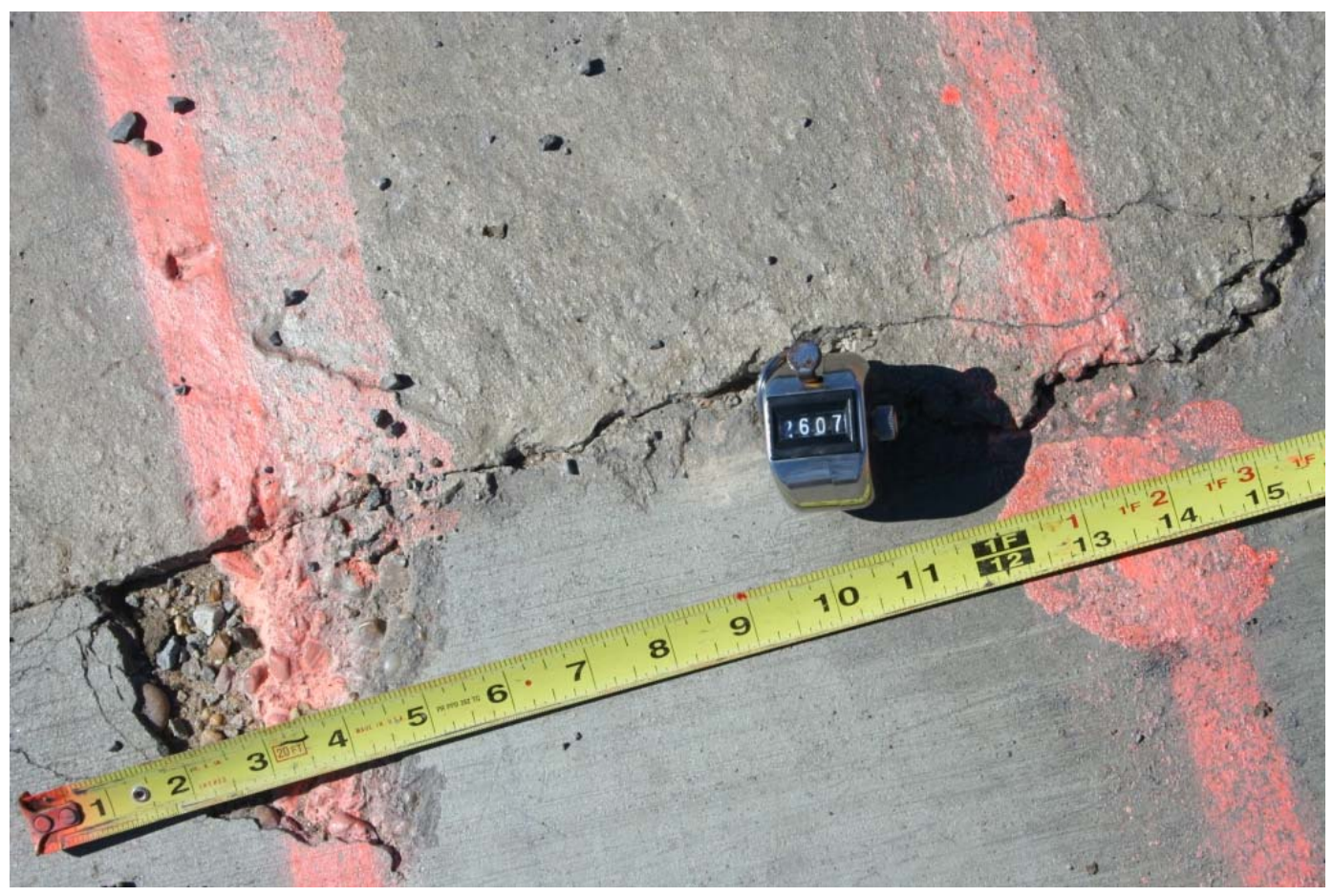

Figure 142. Crater Q. Rapid Set cracking on the south edge after 2,000 passes. 


\section{Crater R-Pavemend SLQ}

Passes 0-112

HWD and roughness measurements were performed prior to traffic. The surface was very uneven prior to traffic due to the surface finish of the material. Load cart trafficking was conducted $3 \mathrm{hr}$ after the repair was complete. After 112 passes, no spalling, cracking, or additional FOD were detected. HWD and survey data were collected after 112 passes. Expedient criteria were met with this repair.

Passes 113-5,008

Craters Q- T were trafficked simultaneously in a straight line until 5,008 passes or failure was reached. No settling of the debris was noticed. After 2,000 passes, light cracking resembling map cracking became noticeable but did not progress or spall. After 3,500 passes, two hairline cracks formed on the southern edge, and light spalling on the southwest edge was noticed. These cracks and spalls did not progress. This repair met expedient and sustainment criteria reaching greater than 5,000 passes without failing (Figure 143).

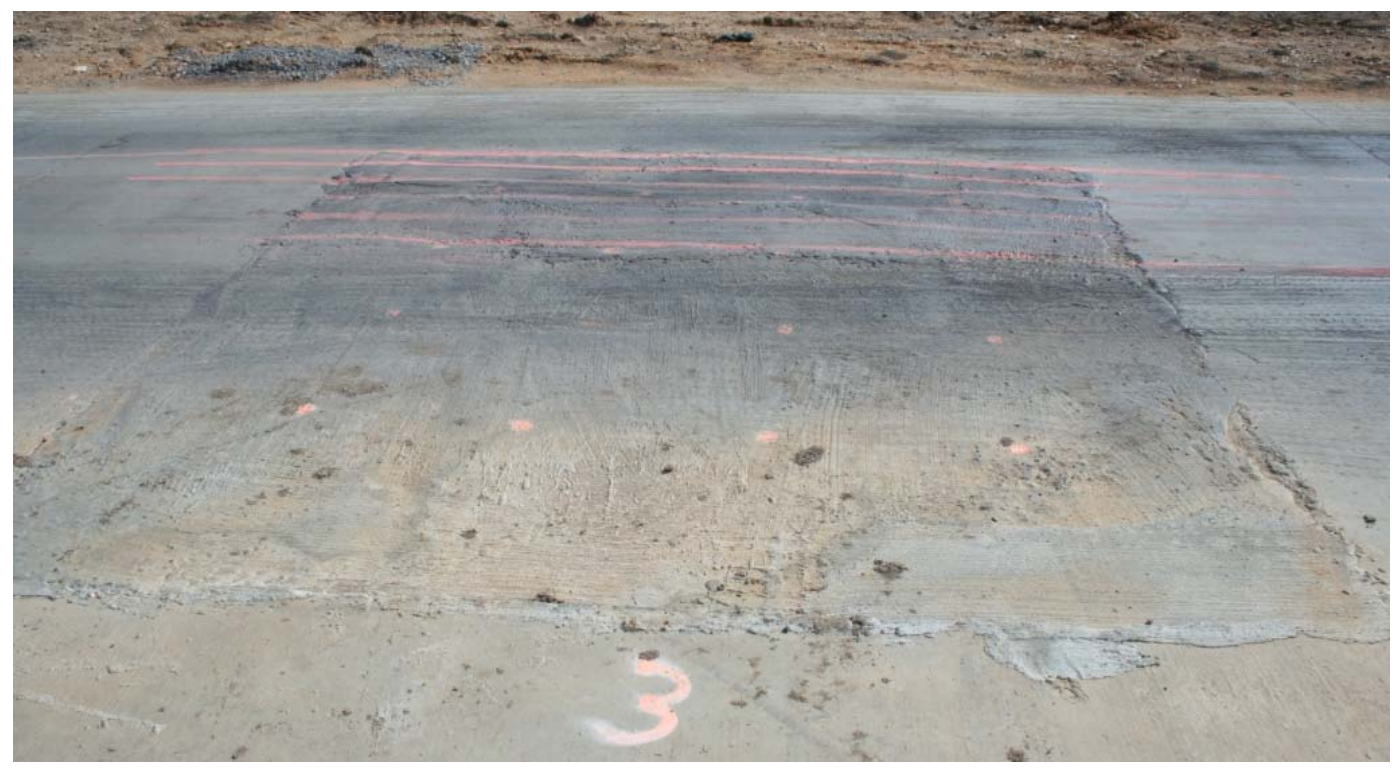

Figure 143. Crater R. Pavemend SLQ repair after 5,000 passes. 


\section{Crater S-ThoRoc 10-61}

Passes 0-112

HWD and roughness measurements were performed prior to traffic. Load cart trafficking was conducted $3 \mathrm{hr}$ after the repair was complete. Shrinkage cracks were noticed on the southern edge of the crater during this cure period. After 112 passes, no spalling, additional cracking, or additional FOD were detected. HWD and survey data were collected after 112 passes. The shrinkage cracks did not seem to progress under trafficking. Expedient criteria were met with this repair.

\section{Passes 113-5,008}

Craters Q- T were trafficked simultaneously in a straight line until failure or 5,008 passes were reached. After 281 passes, the hairline cracks on the south edge began to progress to a joint spall after 603 passes. These cracks began to have noticeable spalling after 1,150 passes. After 3,000 passes, the spall began to ravel more as seen in Figure 144. After 4,000 passes, more spalling and FOD was noticeable on the loaded edges. This repair material met expedient and sustainment criteria reaching greater than 5,000 passes without failing.

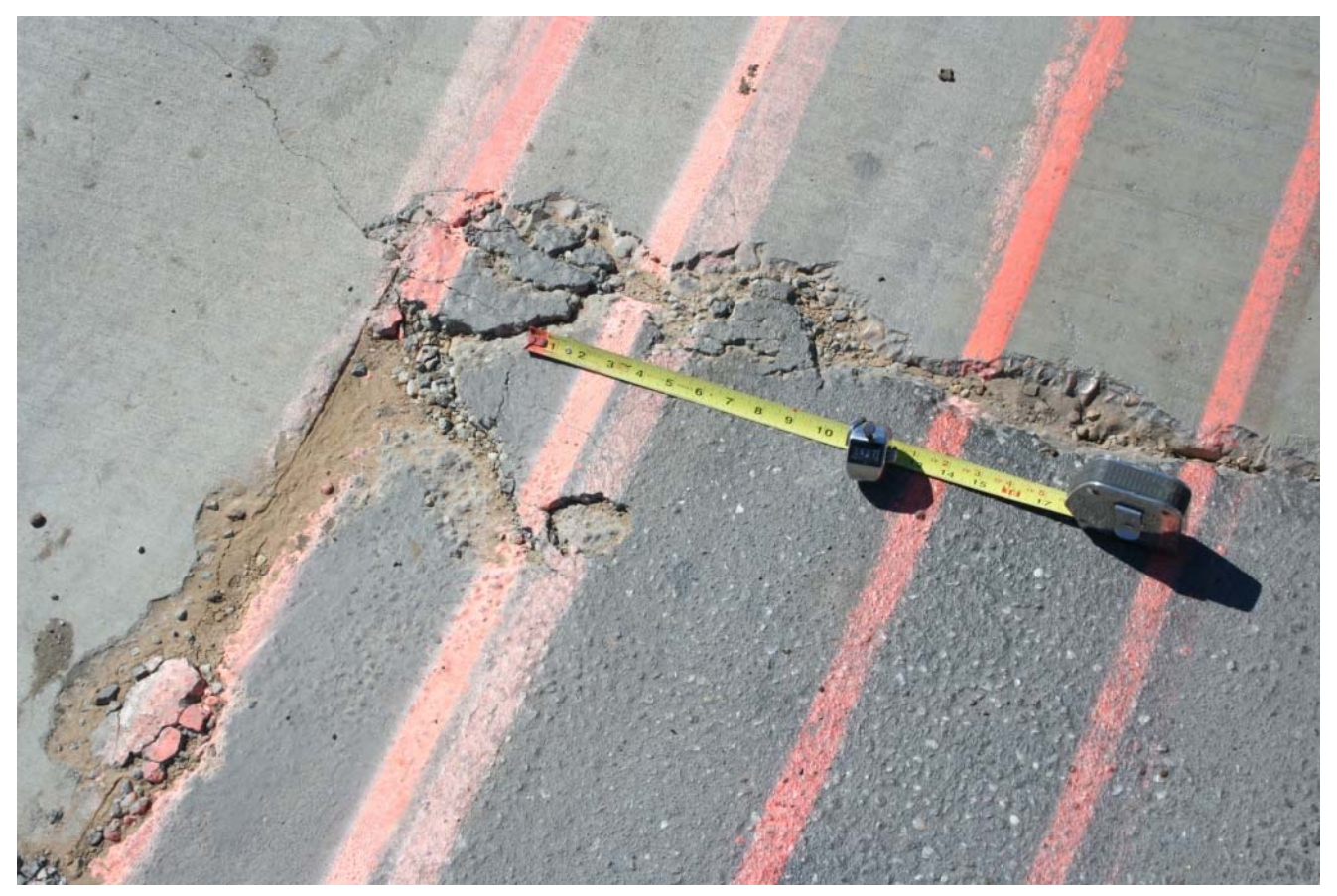

Figure 144. Crater S. ThoRoc 10-61 joint spall after 3,000 passes. 


\section{Crater T-Ultimax Concrete}

Passes 0-112

HWD and roughness measurements were performed prior to traffic. Load cart trafficking was conducted $3 \mathrm{hr}$ after the repair was complete. After 112 passes, no spalling, cracking, or additional FOD were detected. HWD and survey data were collected after 112 passes. Expedient criteria were met with this repair.

\section{Passes 113-5,008}

Craters Q- T were trafficked simultaneously in a straight line until 5,008 passes or failure was reached. Very light cracking was noticed progressing from the southern edge of the repair to the northern edge after 512 passes. After 3,000 passes, this crack did not ravel as can be seen in Figure 145, and after 5,008 passes, the crack extended across the entire repair. A 2.5-ft crack was also noticed after 5,008 passes extending from the northern edge. This repair material met expedient and sustainment criteria reaching greater than 5,000 passes without failing.

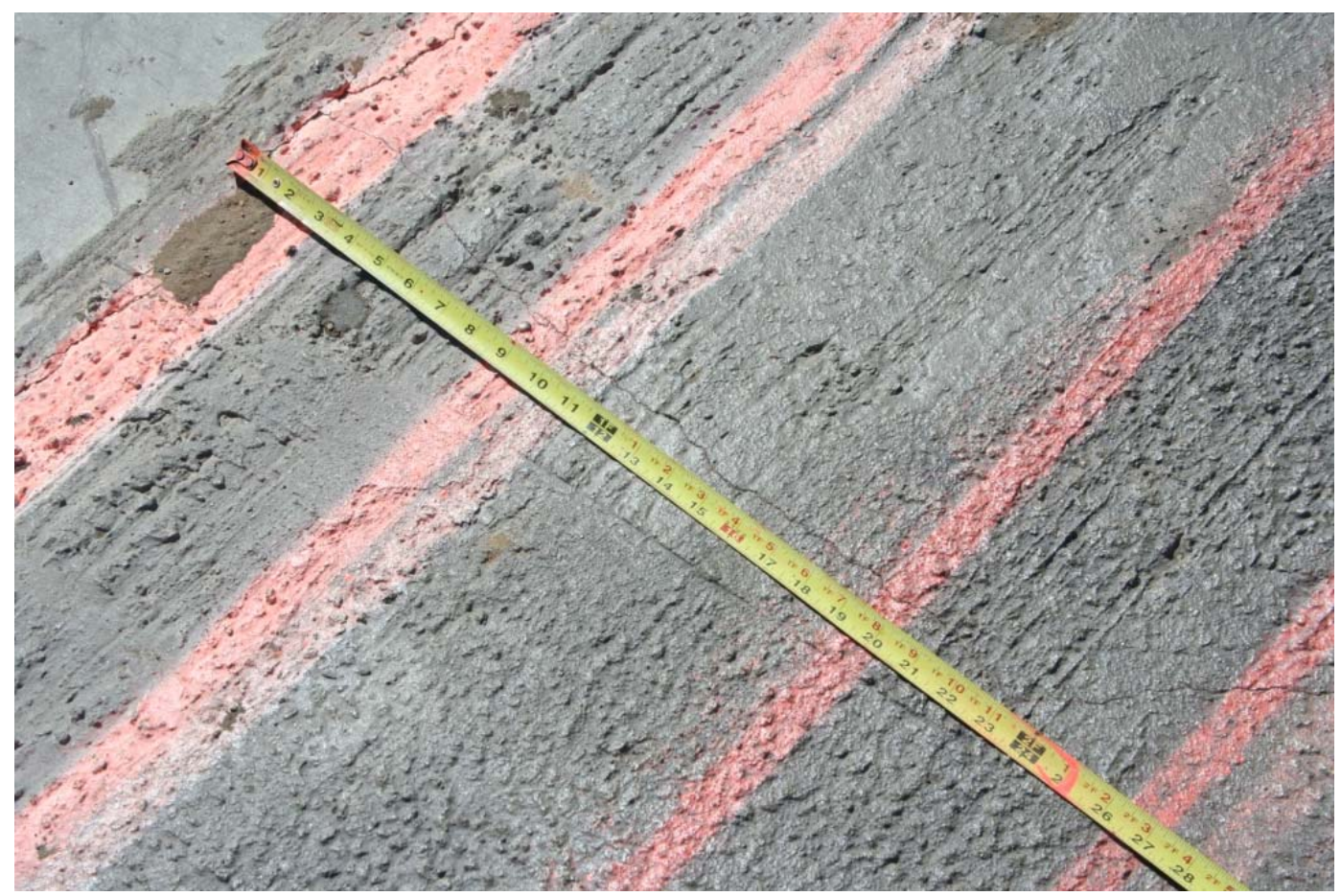

Figure 145. Crater T. Ultimax repair crack after 3,000 passes. 


\section{Permanent deformation}

Cross sections and profiles were performed along the repair surfaces at selected pass intervals during trafficking. The locations chosen for Series 1 craters were every $1 \mathrm{ft}$ for both the profiles and cross sections. For Series 2 and 3 craters, the locations were chosen every $2 \mathrm{ft}$. Changes in elevation at selected pass intervals were calculated and recorded to ensure that roughness criteria were not exceeded by permanent deformation or settling of the repairs under traffic. These values are presented in Tables 28- 30 . Negative values indicate downward changes.

Table 28. Change in elevation Series 1 craters at selected pass intervals (continued).

\begin{tabular}{|c|c|c|c|c|c|}
\hline \multicolumn{6}{|c|}{ Crater A } \\
\hline \multicolumn{6}{|c|}{ Change in Elevation, in. } \\
\hline Location & 0 Passes & 30 Passes & 46 Passes & \multicolumn{2}{|c|}{62 Passes } \\
\hline 1 & 0.00 & -0.36 & -0.36 & \multicolumn{2}{|c|}{-0.6} \\
\hline 2 & 0.00 & -0.96 & -1.08 & \multicolumn{2}{|c|}{-1.44} \\
\hline 3 & 0.00 & -0.72 & -1.08 & \multicolumn{2}{|c|}{-1.2} \\
\hline 4 & 0.00 & -0.24 & -0.24 & \multicolumn{2}{|c|}{-0.72} \\
\hline 5 & 0.00 & -0.96 & -1.2 & \multicolumn{2}{|c|}{-1.44} \\
\hline 6 & 0.00 & -1.2 & -1.44 & \multicolumn{2}{|c|}{-1.56} \\
\hline 7 & 0.00 & -0.12 & -0.12 & \multicolumn{2}{|c|}{-0.48} \\
\hline 8 & 0.00 & -0.6 & -0.72 & \multicolumn{2}{|c|}{-0.96} \\
\hline 9 & 0.00 & -0.96 & -1.08 & \multicolumn{2}{|c|}{-1.2} \\
\hline \multicolumn{6}{|c|}{ Crater B } \\
\hline \multicolumn{6}{|c|}{ Change in Elevation, in. } \\
\hline Location & 0 Passes & 112 Passes & 512 Passes & 800 Passes & 895 Passes \\
\hline 1 & 0.00 & 0.00 & -0.12 & -0.12 & 0.00 \\
\hline 2 & 0.00 & 0.00 & -0.24 & -0.12 & 0.00 \\
\hline 3 & 0.00 & 0.00 & 0.00 & 0.24 & 0.48 \\
\hline 4 & 0.00 & 0.00 & -0.24 & -0.24 & 0.12 \\
\hline 5 & 0.00 & 0.00 & -0.24 & -0.24 & -0.12 \\
\hline 6 & 0.00 & 0.00 & 0.00 & 0.12 & 0.36 \\
\hline 7 & 0.00 & -0.12 & -0.12 & -0.12 & 0.36 \\
\hline 8 & 0.00 & -0.12 & -0.36 & -0.12 & 0.12 \\
\hline 9 & 0.00 & 0.00 & 0.12 & 0.00 & 0.24 \\
\hline 10 & 0.00 & 0.00 & -0.12 & -0.24 & 0.00 \\
\hline 11 & 0.00 & 0.00 & -0.12 & -0.12 & 0.12 \\
\hline 12 & 0.00 & 0.00 & -0.36 & -0.12 & 0.12 \\
\hline 13 & 0.00 & 0.00 & 0.00 & -0.12 & 0.12 \\
\hline
\end{tabular}


Table 28. (Continued).

\begin{tabular}{|c|c|c|c|c|c|}
\hline \multicolumn{6}{|c|}{ Crater B (cont.) } \\
\hline \multicolumn{6}{|c|}{ Change in Elevation, in. } \\
\hline Location & 0 Passes & 112 Passes & 512 Passes & 800 Passes & 895 Passes \\
\hline 14 & 0.00 & 0.00 & 0.00 & 0.00 & 0.12 \\
\hline 15 & 0.00 & 0.00 & 0.00 & 0.00 & 0.24 \\
\hline 16 & 0.00 & 0.00 & -0.12 & 0.12 & 0.24 \\
\hline \multicolumn{6}{|c|}{ Crater C-1 } \\
\hline \multicolumn{6}{|c|}{ Change in Elevation, in. } \\
\hline Location & 0 Passes & 80 Passes & \multicolumn{3}{|c|}{96 Passes } \\
\hline 1 & 0.00 & 0.00 & \multicolumn{3}{|c|}{-0.24} \\
\hline 2 & 0.00 & 0.36 & \multicolumn{3}{|c|}{1.32} \\
\hline 3 & 0.00 & 0.12 & \multicolumn{3}{|c|}{0.84} \\
\hline 4 & 0.00 & 0.00 & \multicolumn{3}{|c|}{0.36} \\
\hline 5 & 0.00 & -0.12 & \multicolumn{3}{|c|}{-0.24} \\
\hline 6 & 0.00 & 0.36 & \multicolumn{3}{|c|}{1.32} \\
\hline 7 & 0.00 & 0.12 & \multicolumn{3}{|c|}{1.08} \\
\hline 8 & 0.00 & 0.00 & \multicolumn{3}{|c|}{0.36} \\
\hline 9 & 0.00 & 0.00 & \multicolumn{3}{|c|}{-0.12} \\
\hline 10 & 0.00 & 0.36 & \multicolumn{3}{|c|}{0.24} \\
\hline 11 & 0.00 & 0.12 & \multicolumn{3}{|c|}{0.84} \\
\hline 12 & 0.00 & 0.00 & \multicolumn{3}{|c|}{0.60} \\
\hline 13 & 0.00 & -0.12 & \multicolumn{3}{|c|}{-0.12} \\
\hline 14 & 0.00 & 0.36 & \multicolumn{3}{|c|}{1.20} \\
\hline 15 & 0.00 & 0.00 & \multicolumn{3}{|c|}{0.60} \\
\hline 16 & 0.00 & -0.24 & \multicolumn{3}{|c|}{0.12} \\
\hline \multicolumn{6}{|c|}{ Crater C-2 } \\
\hline \multicolumn{6}{|c|}{ Change in Elevation, in. } \\
\hline Location & 0 Passes & 112 Passes & 512 Passes & 800 Passes & 895 Passes \\
\hline 1 & 0.00 & 0.00 & 0.12 & 0.12 & 0.24 \\
\hline 2 & 0.00 & 0.00 & 0.12 & 0.24 & 0.36 \\
\hline 3 & 0.00 & 0.00 & 0.24 & 0.36 & 0.60 \\
\hline 4 & 0.00 & 0.00 & 0.24 & 0.48 & 0.96 \\
\hline 5 & 0.00 & 0.00 & 0.12 & 0.00 & 0.12 \\
\hline 6 & 0.00 & 0.00 & 0.12 & 0.12 & 0.36 \\
\hline 7 & 0.00 & 0.00 & 0.00 & 0.12 & 0.36 \\
\hline 8 & 0.00 & 0.00 & 0.12 & 0.24 & 0.60 \\
\hline 9 & 0.00 & 0.00 & 0.00 & 0.12 & 0.12 \\
\hline 10 & 0.00 & 0.00 & 0.12 & 0.24 & 0.36 \\
\hline 11 & 0.00 & -0.12 & 0.12 & 0.24 & 0.48 \\
\hline
\end{tabular}


Table 28. (Continued).

\begin{tabular}{|c|c|c|c|c|c|}
\hline \multicolumn{6}{|c|}{ Crater C-2 (cont.) } \\
\hline \multicolumn{6}{|c|}{ Change in Elevation, in. } \\
\hline Location & 0 Passes & 112 Passes & 512 Passes & 800 Passes & 895 Passes \\
\hline 12 & 0.00 & 0.12 & 0.12 & 0.24 & 0.48 \\
\hline 13 & 0.00 & 0.12 & 0.12 & 0.12 & 0.36 \\
\hline 14 & 0.00 & 0.00 & 0.12 & 0.12 & 0.36 \\
\hline 15 & 0.00 & 0.00 & 0.12 & 0.12 & 0.36 \\
\hline 16 & 0.00 & 0.00 & 0.12 & 0.24 & 0.48 \\
\hline \multicolumn{6}{|c|}{ Crater D } \\
\hline \multicolumn{6}{|c|}{ Change in Elevation, in. } \\
\hline Location & 0 Passes & 112 Passes & 512 Passes & 800 Passes & 895 Passes \\
\hline 1 & 0.00 & -0.72 & -0.60 & -0.60 & -0.36 \\
\hline 2 & 0.00 & -0.60 & -0.48 & -0.48 & -0.24 \\
\hline 3 & 0.00 & -0.60 & -0.36 & -0.36 & -0.24 \\
\hline 4 & 0.00 & -0.60 & -0.36 & -0.36 & -0.12 \\
\hline 5 & 0.00 & -0.48 & -0.36 & -0.48 & -0.24 \\
\hline 6 & 0.00 & -0.60 & -0.48 & -0.48 & -0.36 \\
\hline 7 & 0.00 & -0.60 & -0.48 & -0.48 & -0.24 \\
\hline 8 & 0.00 & -0.48 & -0.36 & -0.36 & -0.12 \\
\hline 9 & 0.00 & -0.72 & -0.48 & -0.48 & -0.36 \\
\hline 10 & 0.00 & -0.72 & -0.60 & -0.60 & -0.36 \\
\hline 11 & 0.00 & -0.60 & -0.36 & -0.36 & -0.24 \\
\hline 12 & 0.00 & -0.60 & -0.36 & -0.36 & -0.12 \\
\hline 13 & 0.00 & -0.48 & -0.60 & -0.60 & -0.36 \\
\hline 14 & 0.00 & -0.48 & -0.36 & -0.48 & -0.24 \\
\hline 15 & 0.00 & -0.48 & -0.36 & -0.36 & 0.00 \\
\hline 16 & 0.00 & -0.36 & -0.36 & -0.36 & 0.00 \\
\hline \multicolumn{6}{|c|}{ Crater $\mathrm{E}$} \\
\hline \multicolumn{6}{|c|}{ Change in Elevation, in. } \\
\hline Location & 0 Passes & 112 Passes & 512 Passes & 800 Passes & 895 Passes \\
\hline 1 & 0.00 & -0.48 & -0.36 & -0.48 & -0.12 \\
\hline 2 & 0.00 & -0.60 & -0.36 & -0.36 & 0.12 \\
\hline 3 & 0.00 & -0.60 & -0.48 & -0.36 & 0.60 \\
\hline 4 & 0.00 & -0.48 & -0.36 & -0.24 & 0.36 \\
\hline 5 & 0.00 & -0.48 & -0.36 & -0.48 & -0.12 \\
\hline 6 & 0.00 & -0.60 & -0.48 & -0.48 & 0.12 \\
\hline 7 & 0.00 & -0.48 & -0.36 & -0.36 & 0.24 \\
\hline 8 & 0.00 & -0.60 & -0.48 & -0.48 & 0.12 \\
\hline 9 & 0.00 & -0.48 & -0.48 & -0.36 & -0.24 \\
\hline
\end{tabular}


Table 28. (Continued).

\begin{tabular}{|c|c|c|c|c|c|}
\hline \multicolumn{6}{|c|}{ Crater E (cont.) } \\
\hline \multicolumn{6}{|c|}{ Change in Elevation, in. } \\
\hline Location & 0 Passes & 112 Passes & 512 Passes & 800 Passes & 895 Passes \\
\hline 10 & 0.00 & -0.60 & -0.60 & -0.48 & -0.24 \\
\hline 11 & 0.00 & -0.48 & -0.36 & -0.24 & 0.00 \\
\hline 12 & 0.00 & -0.60 & -0.48 & -0.36 & 0.00 \\
\hline 13 & 0.00 & -0.60 & -0.48 & -0.48 & -0.24 \\
\hline 14 & 0.00 & -0.60 & -0.48 & -0.36 & -0.12 \\
\hline 15 & 0.00 & -0.60 & -0.36 & -0.36 & -0.12 \\
\hline 16 & 0.00 & -0.48 & -0.36 & -0.36 & -0.12 \\
\hline \multicolumn{6}{|c|}{ Crater F } \\
\hline \multicolumn{6}{|c|}{ Change in Elevation, in. } \\
\hline Location & 0 Passes & 112 Passes & 512 Passes & 800 Passes & 895 Passes \\
\hline 1 & 0.00 & 0.12 & -0.12 & -0.12 & 0.12 \\
\hline 2 & 0.00 & 0.24 & 0.00 & 0.00 & 0.12 \\
\hline 3 & 0.00 & 0.24 & 0.00 & 0.00 & 0.12 \\
\hline 4 & 0.00 & 0.36 & 0.12 & 0.12 & 0.12 \\
\hline 5 & 0.00 & 0.00 & -0.12 & -0.12 & 0.00 \\
\hline 6 & 0.00 & 0.24 & 0.00 & 0.00 & 0.12 \\
\hline 7 & 0.00 & 0.12 & 0.00 & -0.12 & 0.12 \\
\hline 8 & 0.00 & 0.36 & 0.00 & 0.12 & 0.24 \\
\hline 9 & 0.00 & 0.00 & -0.12 & -0.12 & 0.00 \\
\hline 10 & 0.00 & 0.12 & 0.00 & 0.00 & 0.12 \\
\hline 11 & 0.00 & 0.12 & 0.00 & 0.00 & 0.24 \\
\hline 12 & 0.00 & 0.36 & 0.00 & 0.12 & 0.24 \\
\hline 13 & 0.00 & 0.12 & 0.00 & 0.00 & 0.24 \\
\hline 14 & 0.00 & 0.00 & -0.12 & -0.12 & 0.12 \\
\hline 15 & 0.00 & 0.24 & 0.00 & 0.00 & 0.24 \\
\hline 16 & 0.00 & 0.36 & 0.12 & 0.12 & 0.24 \\
\hline \multicolumn{6}{|c|}{ Crater G-2 } \\
\hline \multicolumn{6}{|c|}{ Change in Elevation, in. } \\
\hline Location & 0 Passes & 112 Passes & 512 Passes & 800 Passes & 895 Passes \\
\hline 1 & 0.00 & 0.12 & -0.12 & 0.00 & 0.12 \\
\hline 2 & 0.00 & 0.12 & 0.12 & 0.00 & 0.24 \\
\hline 3 & 0.00 & 0.12 & 0.12 & 0.12 & 0.24 \\
\hline 4 & 0.00 & 0.12 & 0.12 & 0.12 & 0.24 \\
\hline 5 & 0.00 & 0.12 & 0.00 & 0.00 & 0.24 \\
\hline 6 & 0.00 & 0.24 & 0.12 & 0.12 & 0.24 \\
\hline 7 & 0.00 & 0.24 & 0.36 & 0.12 & 0.36 \\
\hline
\end{tabular}


Table 28. (Concluded).

\begin{tabular}{|c|c|c|c|c|c|c|}
\hline \multicolumn{7}{|c|}{ Crater G-2 (cont.) } \\
\hline \multicolumn{7}{|c|}{ Change in Elevation, in. } \\
\hline Location & 0 Passes & 112 Passes & \multicolumn{2}{|c|}{512 Passes } & 800 Passes & 895 Passes \\
\hline 8 & 0.00 & 0.12 & \multicolumn{2}{|c|}{0.12} & 0.00 & 0.24 \\
\hline 9 & 0.00 & 0.12 & \multicolumn{2}{|c|}{0.12} & 0.00 & 0.24 \\
\hline 10 & 0.00 & 0.24 & \multicolumn{2}{|c|}{0.12} & 0.12 & 0.36 \\
\hline 11 & 0.00 & 0.24 & \multicolumn{2}{|c|}{0.24} & 0.12 & 0.36 \\
\hline 12 & 0.00 & 0.12 & \multicolumn{2}{|c|}{0.12} & 0.00 & 0.24 \\
\hline 13 & 0.00 & 0.12 & \multicolumn{2}{|c|}{0.24} & 0.00 & 0.24 \\
\hline 14 & 0.00 & 0.24 & \multicolumn{2}{|c|}{0.12} & 0.24 & 0.36 \\
\hline 15 & 0.00 & 0.24 & \multicolumn{2}{|c|}{0.24} & 0.24 & 0.36 \\
\hline 16 & 0.00 & 0.12 & \multicolumn{2}{|c|}{0.00} & 0.00 & 0.24 \\
\hline \multicolumn{7}{|c|}{ Crater $\mathrm{H}$} \\
\hline \multicolumn{7}{|c|}{ Change in Elevation, in. } \\
\hline Location & 0 Passes & 112 Passes & 512 Passes & 800 Passes & 895 Passes & 1,344 Passes \\
\hline 1 & 0.00 & -0.36 & -0.36 & -0.48 & 0.00 & -0.24 \\
\hline 2 & 0.00 & -0.48 & -0.48 & -0.48 & -0.24 & -0.36 \\
\hline 3 & 0.00 & 0.00 & 0.00 & 0.00 & 0.36 & 0.24 \\
\hline 4 & 0.00 & 0.00 & 0.12 & 0.00 & 0.24 & 0.12 \\
\hline 5 & 0.00 & -0.12 & -0.12 & -0.24 & 0.00 & -0.12 \\
\hline 6 & 0.00 & 0.00 & 0.00 & 0.00 & 0.24 & 0.12 \\
\hline 7 & 0.00 & 0.12 & 0.00 & 0.00 & 0.24 & 0.24 \\
\hline 8 & 0.00 & 0.12 & 0.12 & 0.12 & 0.24 & 0.12 \\
\hline 9 & 0.00 & 0.12 & 0.12 & 0.00 & 0.24 & 0.12 \\
\hline 10 & 0.00 & 0.12 & 0.12 & 0.12 & 0.36 & 0.36 \\
\hline 11 & 0.00 & 0.12 & 0.12 & 0.12 & 0.36 & 0.24 \\
\hline 12 & 0.00 & 0.12 & 0.12 & 0.12 & 0.36 & 0.12 \\
\hline 13 & 0.00 & 0.12 & 0.00 & 0.00 & 0.12 & 0.00 \\
\hline 14 & 0.00 & -0.12 & -0.12 & -0.12 & 0.12 & 0.12 \\
\hline 15 & 0.00 & 0.00 & 0.00 & 0.12 & 0.24 & 0.24 \\
\hline 16 & 0.00 & 0.12 & 0.00 & 0.00 & 0.24 & 0.12 \\
\hline
\end{tabular}


Table 29. Change in elevation Series 2 craters at selected pass intervals.

\begin{tabular}{|c|c|c|c|c|c|c|}
\hline \multicolumn{7}{|c|}{ Crater J } \\
\hline \multicolumn{7}{|c|}{ Change in Elevation, in. } \\
\hline Location & 0 Passes & 112 Passes & 512 Passes & 1,008 Passes & 2,000 Passes & 5,008 Passes \\
\hline 1 & 0.00 & 0.00 & -0.12 & 0.00 & 0.12 & \\
\hline 2 & 0.00 & 0.00 & 0.00 & 0.24 & 0.36 & \\
\hline 3 & 0.00 & 0.00 & -0.12 & 0.12 & 0.24 & \\
\hline 4 & 0.00 & 0.00 & -0.12 & 0.00 & 0.24 & \\
\hline 5 & 0.00 & 0.00 & -0.12 & 0.12 & 0.24 & \\
\hline 6 & 0.00 & 0.00 & -0.24 & 0.60 & 0.24 & \\
\hline 7 & 0.00 & 0.00 & 0.00 & 0.36 & 0.24 & \\
\hline 8 & 0.00 & 0.00 & -0.12 & 0.12 & 0.24 & \\
\hline 9 & 0.00 & 0.00 & -0.12 & 0.12 & 0.36 & \\
\hline \multicolumn{7}{|c|}{ Crater K } \\
\hline \multicolumn{7}{|c|}{ Change in Elevation, in. } \\
\hline Location & 0 Passes & 112 Passes & 512 Passes & 1,008 Passes & 2,000 Passes & 5,008 Passes \\
\hline 1 & 0.00 & 0.12 & 0.00 & 0.36 & 0.48 & 0.36 \\
\hline 2 & 0.00 & -0.12 & 0.36 & 0.36 & 0.48 & 0.60 \\
\hline 3 & 0.00 & 0.12 & -0.12 & 0.24 & 0.36 & 0.48 \\
\hline 4 & 0.00 & 0.00 & 0.00 & 0.36 & 0.48 & -0.24 \\
\hline 5 & 0.00 & 0.00 & -0.48 & -0.24 & -0.24 & -0.12 \\
\hline 6 & 0.00 & 0.00 & -0.36 & -0.12 & 0.00 & 0.00 \\
\hline 7 & 0.00 & 0.00 & 0.00 & 0.24 & 0.24 & -0.36 \\
\hline 8 & 0.00 & 0.00 & -0.12 & 0.12 & 0.12 & -0.24 \\
\hline 9 & 0.00 & -0.12 & 0.12 & 0.12 & 0.36 & 0.36 \\
\hline \multicolumn{7}{|c|}{ Crater L } \\
\hline \multicolumn{7}{|c|}{ Change in Elevation, in. } \\
\hline Location & 0 Passes & 112 Passes & 512 Passes & 1,008 Passes & 2,000 Passes & 5,000 Passes \\
\hline 1 & 0.00 & -0.12 & 0.00 & 0.12 & 0.12 & \\
\hline 2 & 0.00 & 0.00 & -0.24 & 0.12 & 0.12 & \\
\hline 3 & 0.00 & -0.12 & 0.00 & 0.24 & 0.36 & \\
\hline 4 & 0.00 & -0.24 & 0.00 & 0.12 & 0.12 & \\
\hline 5 & 0.00 & 0.00 & 0.84 & 0.84 & 0.84 & \\
\hline 6 & 0.00 & -0.12 & 0.48 & 0.60 & 0.72 & \\
\hline 7 & 0.00 & -0.12 & 0.24 & 0.36 & 0.48 & \\
\hline 8 & 0.00 & 0.00 & 0.24 & 0.60 & 0.48 & \\
\hline 9 & 0.00 & 0.00 & 0.12 & 0.36 & 0.48 & \\
\hline
\end{tabular}


Table 30. Change in elevation Series 3 craters at selected pass intervals (continued).

\begin{tabular}{|c|c|c|c|c|c|c|}
\hline \multicolumn{7}{|c|}{ Crater Q } \\
\hline \multicolumn{7}{|c|}{ Change in Elevation, in. } \\
\hline Location & 0 Passes & 112 Passes & 512 Passes & 1,008 Passes & 2,000 Passes & 5,008 Passes \\
\hline 1 & 0.00 & 0.00 & -0.02 & -0.02 & -0.02 & -0.01 \\
\hline 2 & 0.00 & 0.00 & -0.01 & -0.02 & -0.01 & -0.01 \\
\hline 3 & 0.00 & 0.00 & 0.00 & -0.01 & 0.00 & 0.00 \\
\hline 4 & 0.00 & 0.00 & 0.00 & -0.01 & -0.01 & -0.01 \\
\hline 5 & 0.00 & 0.01 & 0.00 & -0.01 & 0.00 & -0.01 \\
\hline 6 & 0.00 & 0.00 & -0.01 & -0.02 & -0.02 & -0.02 \\
\hline 7 & 0.00 & -0.09 & -0.10 & -0.11 & -0.10 & -0.01 \\
\hline 8 & 0.00 & -0.10 & -0.10 & -0.10 & -0.10 & 0.00 \\
\hline 9 & 0.00 & 0.00 & 0.00 & -0.01 & 0.00 & -0.01 \\
\hline 10 & 0.00 & 0.00 & 0.00 & -0.01 & 0.00 & -0.01 \\
\hline 11 & 0.00 & 0.00 & 0.00 & 0.00 & -0.01 & -0.01 \\
\hline 12 & 0.00 & 0.00 & -0.01 & -0.02 & 0.00 & -0.01 \\
\hline 13 & 0.00 & -0.08 & 0.01 & 0.00 & 0.02 & 0.09 \\
\hline 14 & 0.00 & 0.01 & 0.00 & 0.00 & 0.00 & -0.01 \\
\hline 15 & 0.00 & -0.01 & -0.01 & -0.01 & -0.01 & 0.00 \\
\hline 16 & 0.00 & 0.01 & 0.01 & 0.00 & 0.00 & -0.01 \\
\hline \multicolumn{7}{|c|}{ Crater R } \\
\hline \multicolumn{7}{|c|}{ Change in Elevation, in. } \\
\hline Location & 0 Passes & 112 Passes & 512 Passes & 1,008 Passes & 2,000 Passes & 5,008 Passes \\
\hline 1 & 0.00 & 0.01 & 0.01 & -0.01 & 0.00 & -0.02 \\
\hline 2 & 0.00 & 0.00 & 0.00 & -0.01 & -0.01 & -0.01 \\
\hline 3 & 0.00 & 0.00 & 0.00 & -0.01 & 0.00 & -0.02 \\
\hline 4 & 0.00 & 0.07 & 0.07 & 0.07 & 0.06 & -0.02 \\
\hline 5 & 0.00 & 0.00 & 0.00 & -0.01 & -0.01 & -0.02 \\
\hline 6 & 0.00 & 0.00 & 0.01 & 0.00 & -0.01 & -0.01 \\
\hline 7 & 0.00 & -0.01 & -0.01 & -0.01 & -0.01 & -0.01 \\
\hline 8 & 0.00 & 0.00 & -0.02 & -0.02 & -0.01 & -0.02 \\
\hline 9 & 0.00 & 0.00 & 0.00 & -0.01 & -0.01 & -0.01 \\
\hline 10 & 0.00 & 0.00 & 0.00 & 0.00 & -0.01 & -0.02 \\
\hline 11 & 0.00 & 0.00 & 0.01 & 0.00 & 0.01 & 0.00 \\
\hline 12 & 0.00 & 0.01 & 0.01 & -0.01 & 0.01 & -0.01 \\
\hline 13 & 0.00 & 0.01 & 0.01 & -0.01 & 0.00 & -0.02 \\
\hline 14 & 0.00 & 0.00 & 0.01 & -0.01 & -0.01 & -0.01 \\
\hline 15 & 0.00 & 0.00 & -0.02 & -0.03 & -0.03 & -0.02 \\
\hline 16 & 0.00 & 0.00 & -0.01 & -0.01 & 0.01 & -0.01 \\
\hline
\end{tabular}


Table 30. (Concluded).

\begin{tabular}{|c|c|c|c|c|c|c|}
\hline \multicolumn{7}{|c|}{ Crater S } \\
\hline \multicolumn{7}{|c|}{ Change in Elevation, in. } \\
\hline Location & 0 Passes & 112 Passes & 512 Passes & 1,008 Passes & 2,000 Passes & 5,008 Passes \\
\hline 1 & 0.00 & 0.00 & -0.02 & -0.03 & -0.01 & -0.01 \\
\hline 2 & 0.00 & 0.00 & -0.02 & -0.03 & -0.01 & -0.02 \\
\hline 3 & 0.00 & 0.00 & 0.00 & -0.01 & 0.02 & 0.00 \\
\hline 4 & 0.00 & 0.00 & -0.01 & -0.02 & -0.01 & 0.00 \\
\hline 5 & 0.00 & 0.00 & -0.01 & -0.02 & -0.01 & -0.01 \\
\hline 6 & 0.00 & 0.00 & -0.01 & -0.02 & -0.01 & -0.02 \\
\hline 7 & 0.00 & -0.01 & -0.01 & -0.02 & -0.02 & 0.00 \\
\hline 8 & 0.00 & 0.00 & 0.00 & -0.02 & -0.01 & 0.00 \\
\hline 9 & 0.00 & 0.00 & 0.00 & -0.03 & -0.01 & 0.00 \\
\hline 10 & 0.00 & 0.00 & -0.01 & -0.03 & -0.01 & -0.01 \\
\hline 11 & 0.00 & 0.00 & 0.00 & -0.01 & -0.01 & 0.00 \\
\hline 12 & 0.00 & 0.00 & 0.00 & -0.02 & -0.01 & 0.00 \\
\hline 13 & 0.00 & 0.00 & -0.01 & -0.02 & -0.01 & -0.01 \\
\hline 14 & 0.00 & 0.00 & 0.00 & -0.01 & -0.01 & 0.01 \\
\hline 15 & 0.00 & 0.00 & -0.01 & -0.03 & -0.01 & -0.01 \\
\hline 16 & 0.00 & 0.00 & 0.00 & -0.01 & 0.00 & 0.00 \\
\hline \multicolumn{7}{|c|}{ Crater $\mathrm{T}$} \\
\hline \multicolumn{7}{|c|}{ Change in Elevation, in. } \\
\hline Location & 0 Passes & 112 Passes & 512 Passes & 1,008 Passes & 2,000 Passes & 5,008 Passes \\
\hline 1 & 0.00 & -0.02 & -0.02 & -0.04 & -0.03 & 0.00 \\
\hline 2 & 0.00 & -0.01 & -0.01 & -0.03 & -0.02 & -0.01 \\
\hline 3 & 0.00 & 0.00 & 0.00 & -0.02 & -0.01 & -0.01 \\
\hline 4 & 0.00 & 0.00 & -0.01 & -0.02 & -0.01 & -0.02 \\
\hline 5 & 0.00 & 0.00 & 0.00 & -0.02 & -0.01 & -0.01 \\
\hline 6 & 0.00 & 0.00 & -0.01 & -0.01 & -0.02 & -0.01 \\
\hline 7 & 0.00 & 0.00 & -0.01 & -0.02 & -0.01 & -0.01 \\
\hline 8 & 0.00 & 0.01 & 0.00 & -0.02 & 0.01 & -0.02 \\
\hline 9 & 0.00 & -0.01 & 0.00 & -0.04 & -0.02 & -0.01 \\
\hline 10 & 0.00 & 0.00 & -0.01 & -0.03 & -0.02 & -0.02 \\
\hline 11 & 0.00 & -0.01 & -0.02 & -0.04 & -0.02 & 0.03 \\
\hline 12 & 0.00 & 0.00 & -0.01 & -0.02 & -0.01 & -0.01 \\
\hline 13 & 0.00 & -0.01 & -0.01 & -0.03 & -0.01 & 0.00 \\
\hline 14 & 0.00 & 0.00 & -0.01 & -0.02 & 0.00 & -0.01 \\
\hline 15 & 0.00 & -0.01 & -0.01 & -0.03 & -0.01 & -0.01 \\
\hline 16 & 0.00 & 0.00 & -0.01 & -0.02 & -0.01 & -0.02 \\
\hline
\end{tabular}


The only craters that exceeded the roughness criteria in Series 1 were Craters A and C-1. Measurements taken from Series 2 craters did not show more than $0.85 \mathrm{in}$. of deformation in any one location with a maximum change in elevation of 0.36 in. for Crater J , 0.48 in. for Crater K, and 0.84 in. for Crater L. Series 3 craters showed the least amount of deformation of all the craters with only 0.01 to 0.03 in. measured. The debris did not show any settlement during the 5,008 passes. This is due to the extension of the debris with the RS material or flowable fill. Permanent deformation of the caps was not expected as they were cementitious materials, but settlement of the backfill materials could lead to an uneven surface and surface distresses as load is applied. In addition, the materials were trafficked in short time frames, so deformation of the surface due to inadequate curing could have occurred. With the exception of the Series 1 craters, for Pavesaver and Pavemend SLQ, this did not occur. Elevation change was not measured along the edges. The majority of the repairs failed due to high-severity joint spalls. When FOD was removed, the roughness criteria were exceeded in many cases along the loaded edges. The depth of the cracks was monitored throughout trafficking. It is recommended that elevations be conducted along the loaded edges for future FOD repairs.

\section{Heavy weight deflectometer data}

Nondestructive tests (NDT) were performed on the pavements with the Dynatest model 8081 (HWD). The HWD is an impact load device that applies a single-impulse transient load of approximately 25- to 30-msec duration. With this trailer-mounted device, a dynamic force is applied to the pavement surface by dropping a weight onto a set of rubber cushions that results in an impulse loading on an underlying circular plate $300 \mathrm{~mm}$ (11.8 in.) in diameter in contact with the pavement. The applied force and the pavement deflections, respectively, are measured with load cells and velocity transducers. The drop height of the weights can be varied from 0 to $15.7 \mathrm{in}$. to produce a force from 0 to approximately 50,000 lb. The system is controlled with a laptop computer that also records the output data. For this project, velocities were measured and deflections computed at the center of the load plate only.

For the test section, one test was conducted in the center of each crater repair at intervals described previously. Deflection measurements were 
made in these locations and recorded at force levels of approximately $15,000,25,000,35,000$, or 50,000 lb. Deflections were normalized to a force level of 50,000 lb to compare the increase in deflection for each repair as traffic was applied. As cementitious materials deteriorate, the deflections typically increase. This tended to be the case for Series 1- 3. The normalized deflection data for each crater is presented graphically in Figures 146- 148.

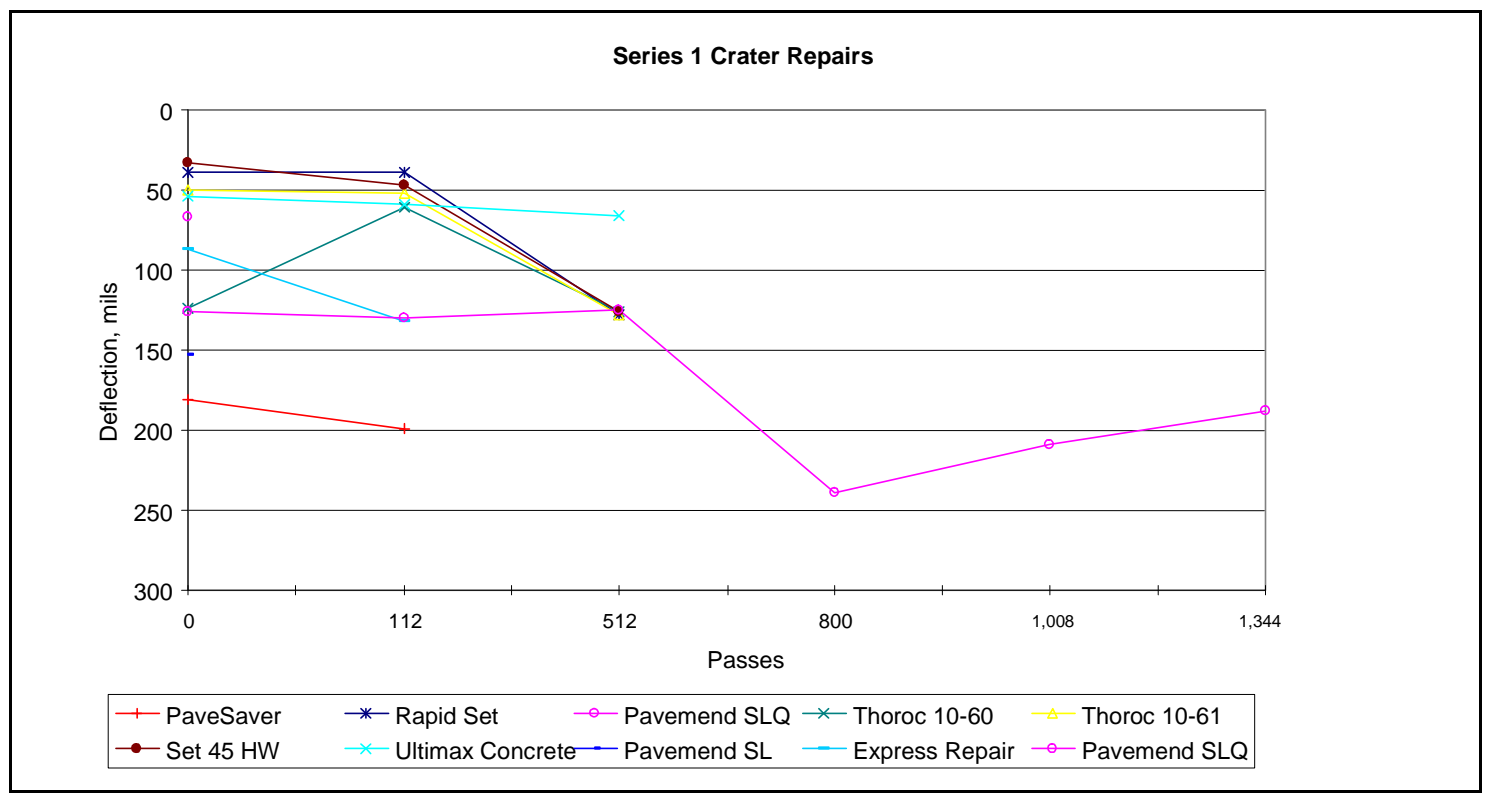

Figure 146 . Series 1 crater repair deflection with traffic.

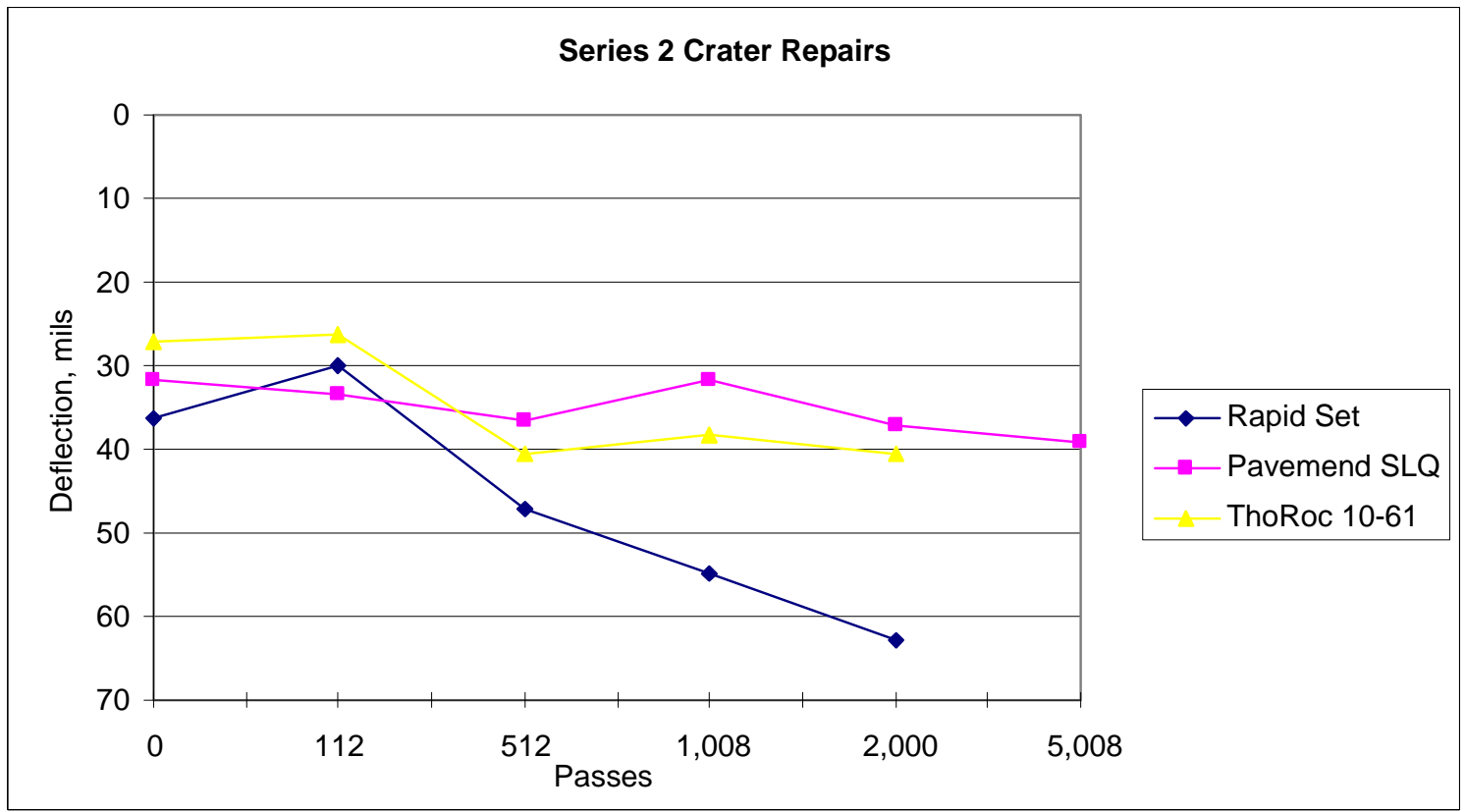

Figure 147 . Series 2 crater repair deflection with traffic. 


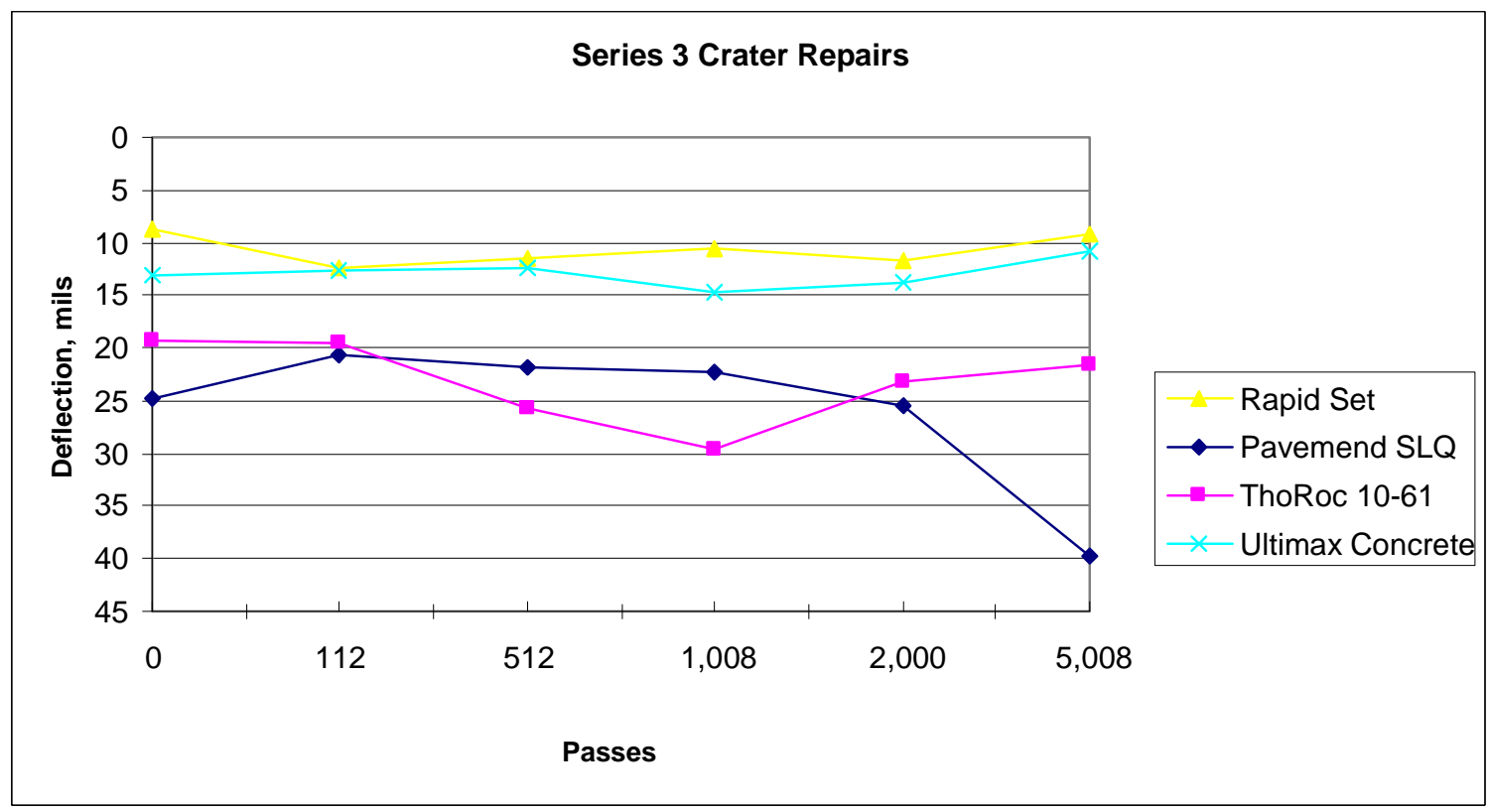

Figure 148. Series 3 crater repair deflection with traffic.

\section{EPC data}

EPCs were installed in the base or subgrade of the crater repairs below the cap material, and data were collected at regular intervals detailed previously. Data points were collected at a rate of 250 points per second by a data logger system operated by an experienced instrumentation technician. An example of the data collected can be seen in Figure 149. This example represents approximately 70,000 data points collected during passes 1- 16 at an 11-in. depth from the surface of Crater $\mathrm{J}$ in Series 2. For this example, each large peak represents one of the passes of the load cart. The wander pattern used during trafficking is also evident as the peaks increase as the load cart moves toward the gage, located under the center of the repair cap (indicated as 0 in the graph), and decrease as the load cart moves away from the gage. Because of the large amount of data collected during trafficking, the data was reduced to peak values for selected pass intervals and presented in graphical form to show the change in stress distribution as the repair deteriorates with traffic. This summarized data has been baselined, or normalized, to show only the influence of the load cart. A similar distribution was achieved for Series 1 and 3 crater repairs. 


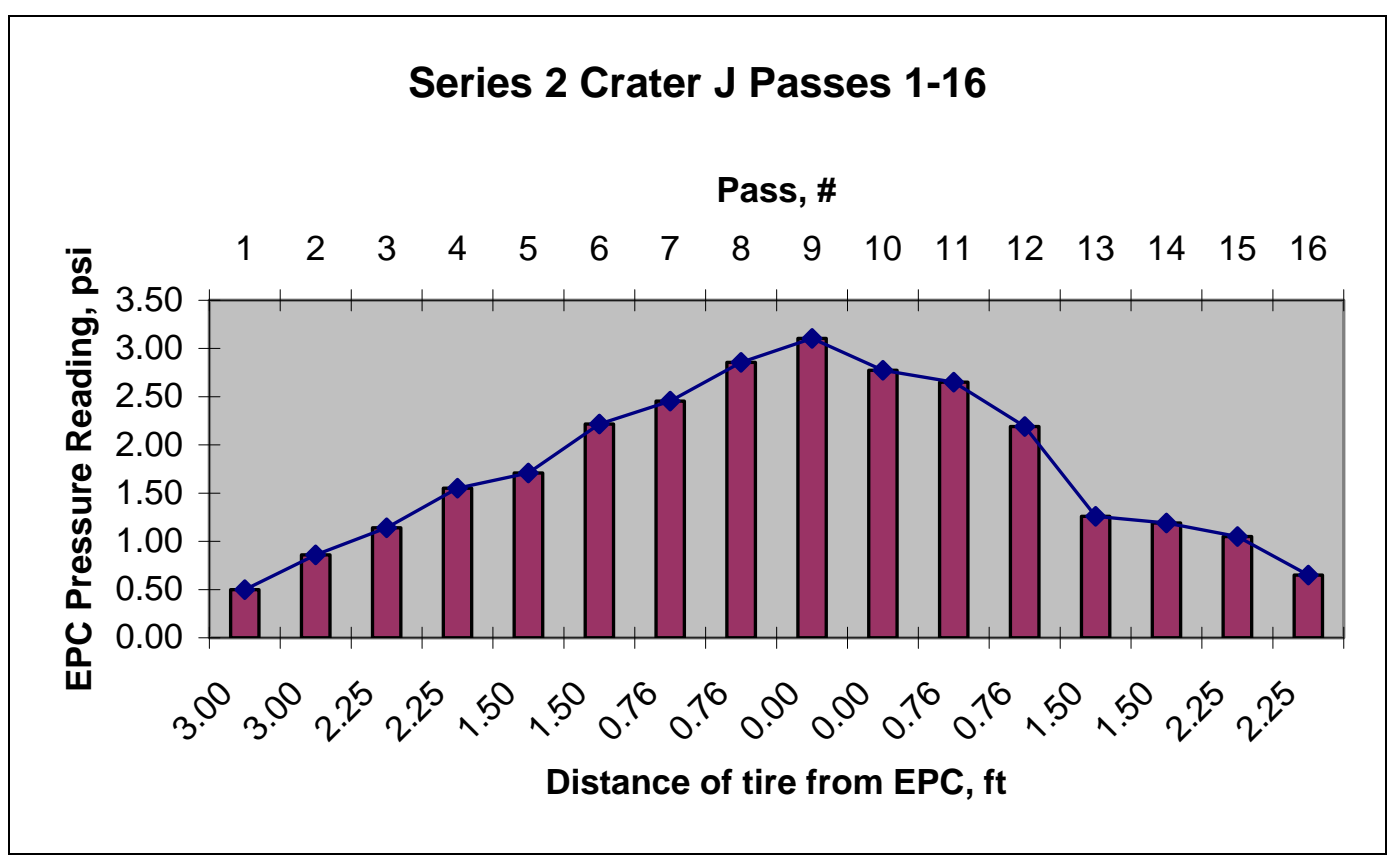

Figure 149. Example of pressure distribution under Series 2 Crater J.

Figure 150 presents the peak pressures measured by the EPC at selected pass intervals for Series 1. For Pavesaver, Express Repair, Pavemend SL, and Pavemend SLQ (first repair) caps, the pressure measured under the cap was greater than $60 \mathrm{psi}$. The greatest pressure was recorded under these repairs within the first 112 passes. Pressure measured under the Ultimax Concrete repair increased from 35 psi to nearly 60 psi within 240 passes. After 240 passes, the measured pressure stayed the same. ThoRoc 10-60, 10-61, and Rapid Set pressure cell readings increased 20 to 30 psi within the first 624 passes. Set 45 showed the least increase in pressure from approximately 12 psi to 26 psi. Pavemend SLQ (second repair) showed similar increases in pressure to 624 passes. The highest pressures recorded for this repair were 60 psi at 736 and 1344 passes.

Figure 151 presents the peak pressure at selected pass intervals for Series 2 data. It can be seen that between 497 and 512 passes and 993 and 1,008 passes that the peak pressure decreases. This may either be attributed to the aging material curing as traffic is applied, temperature changes during EPC measurements, or that a tire did not stay within the wander pattern and did not approach the EPC during that trafficking. As the traffic was applied over several days, craters were continuing to gain strength. At the time of application of 497 to 512 passes, the Rapid Set crater was the oldest at 8 days, Pavemend SLQ at 3 days, and ThoRoc 10-61 at 2 days. The Rapid Set had reached its 7-day strength and the material was trafficked 
in the afternoon at a cooler temperature. Passes 513-1,008 were applied the following day with the interval of 993 to 1,008 recorded at the same time in the afternoon as with passes 497 to 512 . Similar dates were associated with the 1,457 to 1,472 reduction in recorded pressure. Although time and age could be influencing the measurements, it is possible that the wander pattern could not be maintained as easily for small repairs, and the tire was in the correct lane during the datalogging. These factors could all attribute to the apparent healing of the repairs at these intervals.

For Series 3 craters, the EPCs were located approximately $3 \mathrm{ft}$ from the surface, thus the measured pressure was significantly less than the first two series (Figure 152). However, similar decreases in pressure were noticed in the same intervals noticed in Series 2. Ultimax Concrete repair recorded the highest pressure of all the repairs.

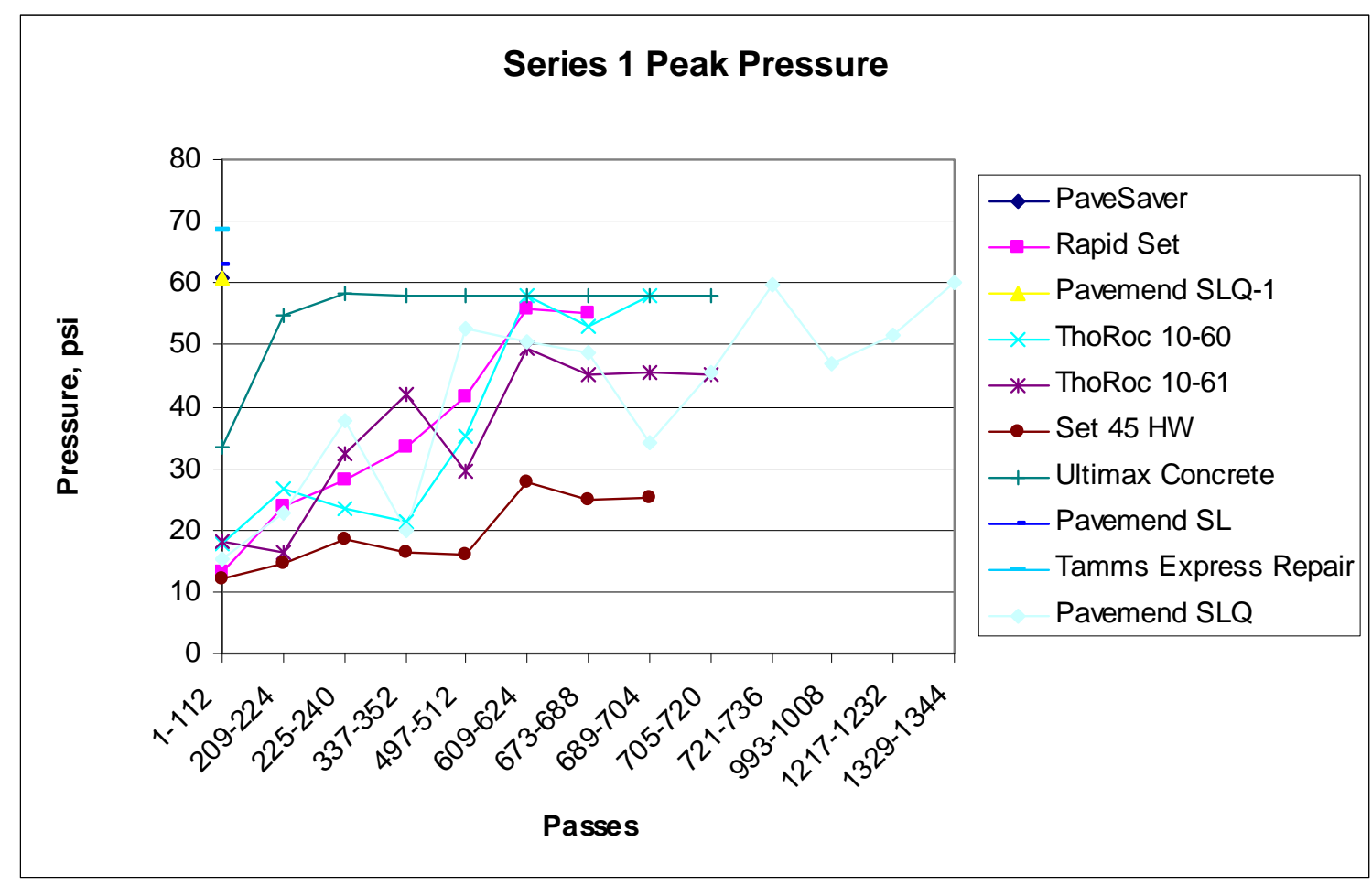

Figure 150. Series 1 peak pressure at selected pass intervals. 


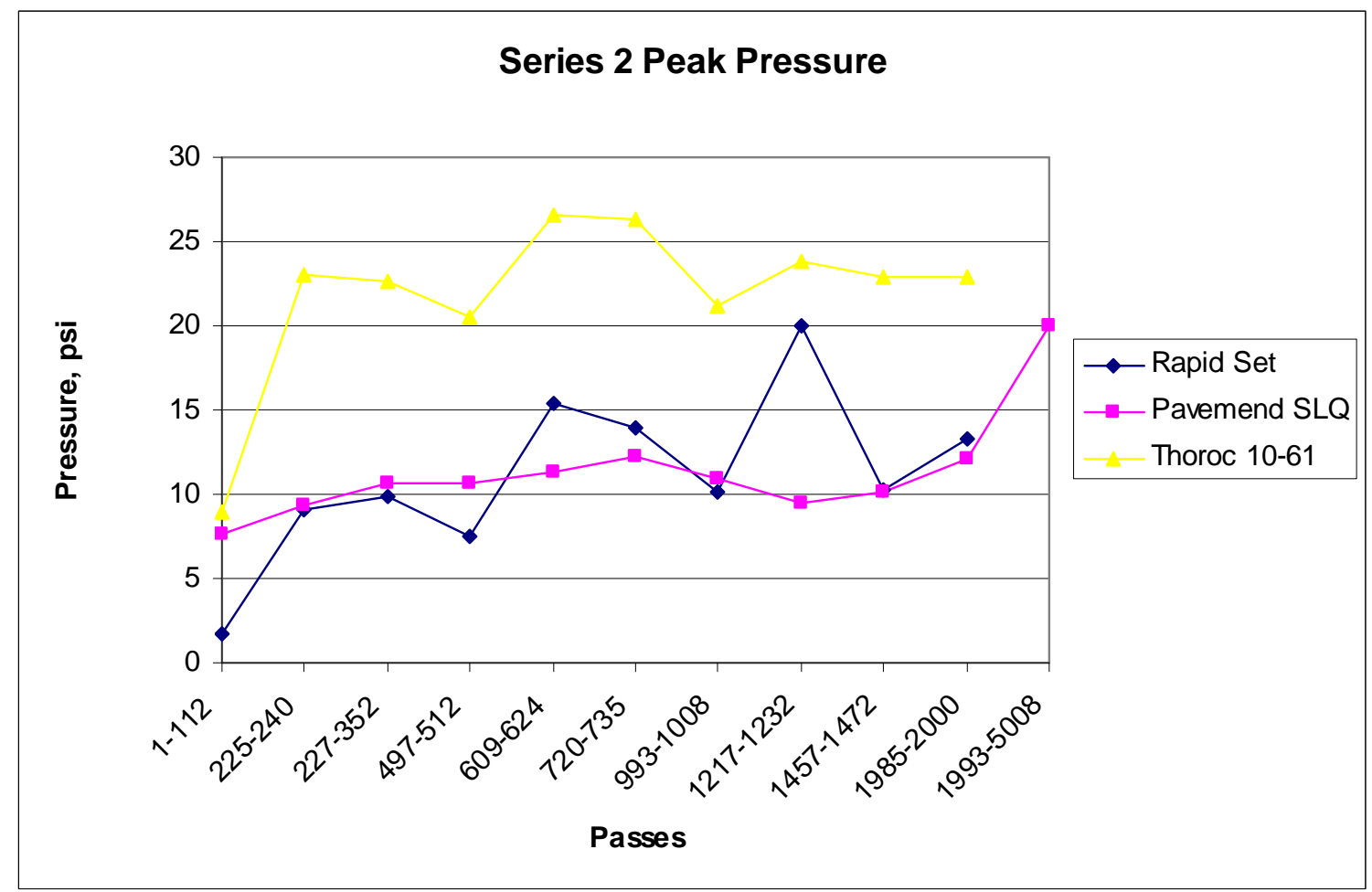

Figure 151. Series 2 peak pressure at selected pass intervals.

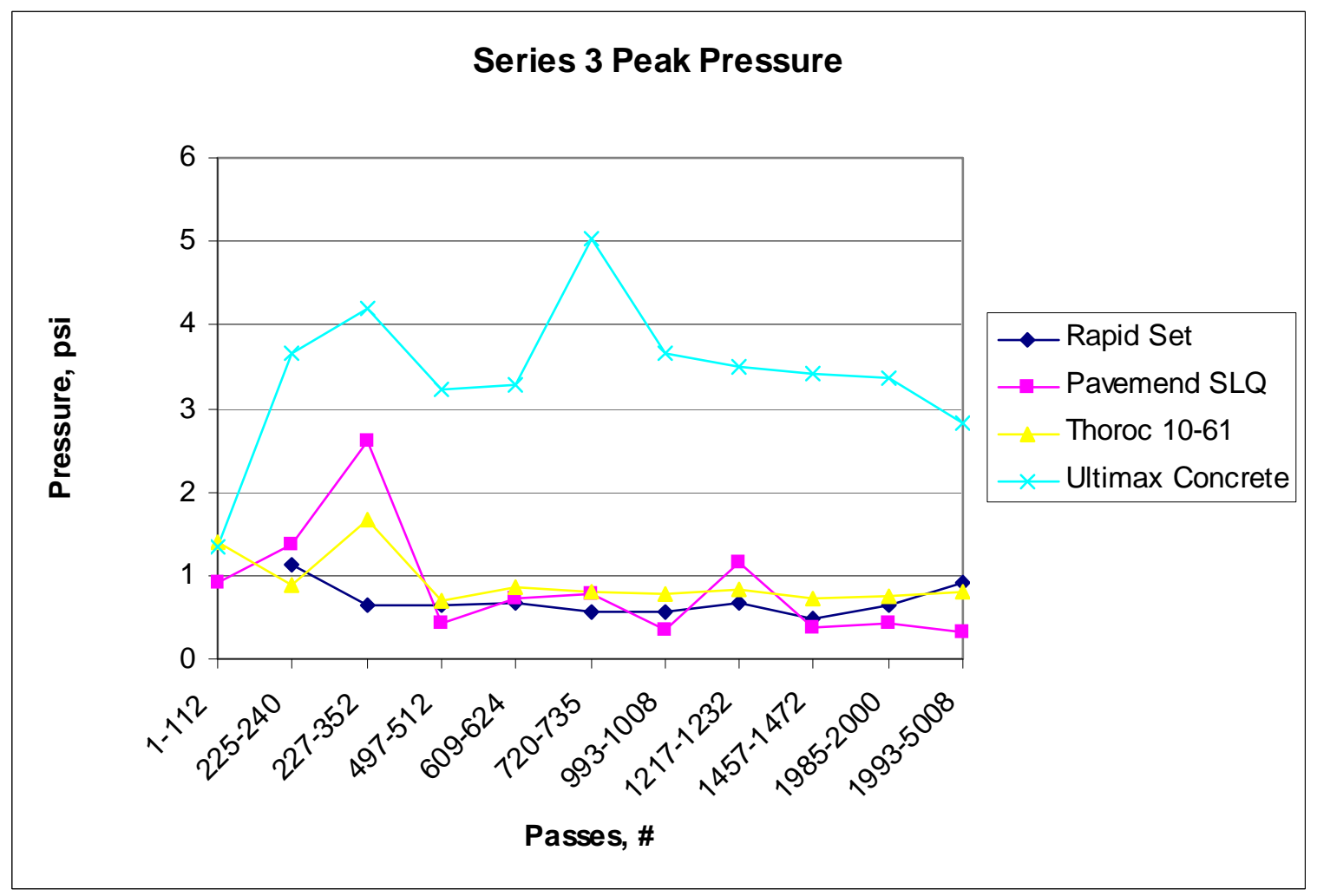

Figure 152. Series 3 peak pressure at selected pass intervals. 


\section{Temperature sensor data}

Temperature sensors were installed in each crater cap to monitor temperature development in the craters during curing. Fast rates of temperature gain can result in cracking of the repair; however, none of the materials generated enough heat fast enough to cause thermal cracking.

\section{Series 1 repairs}

A comparison of the average temperatures generated in each cap for Series 1 craters is presented in Figures 153 and 154. The time is the duration of the cap completion. Figure 253 presents all 10 repairs conducted. From this figure it can be seen that Pavemend SLQ (1) generated the most heat overall. The top four products recommended for Series 2 testing are presented in Figure 154. The rise in temperature was slower for Rapid Set than the other materials. A comparison of the temperature rise with depth for these craters is presented in Figures 155158. From these figures, ThoRoc 10-61, Pavemend SLQ, and Ultimax Concrete all reached maximum temperatures after $2 \mathrm{hr}$ of cure. Rapid Set took approximately $4 \mathrm{hr}$ to reach maximum temperature. The highest temperatures were measured near the surface of the repair. The maximum average temperature measured for Series 1 craters was $171.5^{\circ} \mathrm{F}$ for Pavemend SLQ (1). From these figures, it can be seen that although the materials were trafficable within $3 \mathrm{hr}$ of repair, the optimum time for traffic would have been when the temperatures returned to pre-cure conditions. Because hydration of cement compounds releases energy, this results in a large rise in temperature. Hydration is necessary for strength increase. If the temperature rise is too fast (steep gradient on the timetemp curves), cracking could occur. In addition, when the temperature returns to prehydration temperatures, the strength gain is almost complete. For the top four materials from Series 1, Rapid Set would be at ideal strength conditions when the temperature returned to approximately $95^{\circ} \mathrm{F}$. This would have taken $40 \mathrm{hr}$ to achieve. For ThoRoc 10-61, Pavemend SLQ, and Ultimax Concrete, 10, 18, and $12 \mathrm{hr}$, respectively, would have been ideal. 


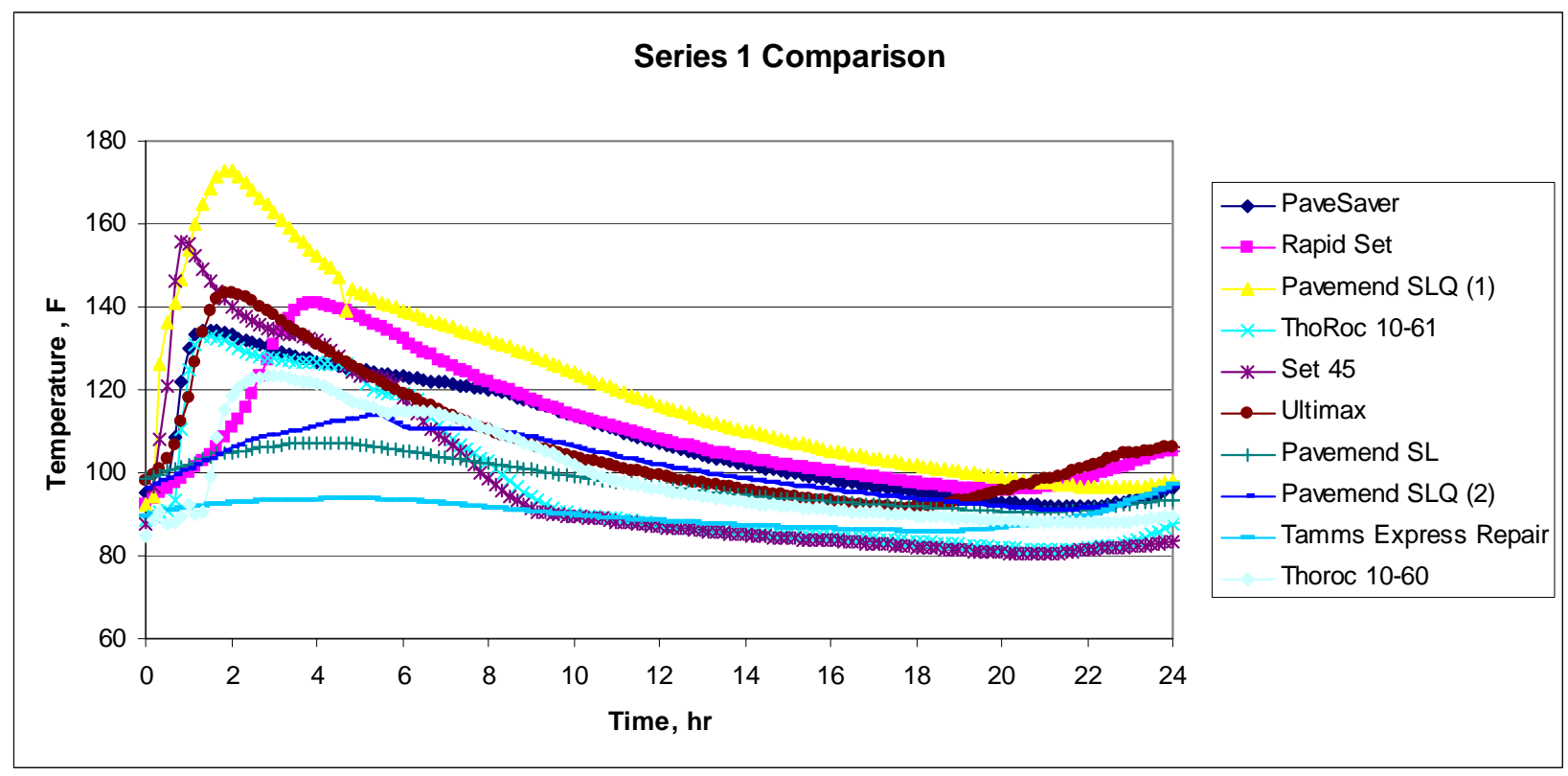

Figure 153. Rise in average temperature comparison for Series 1 craters.

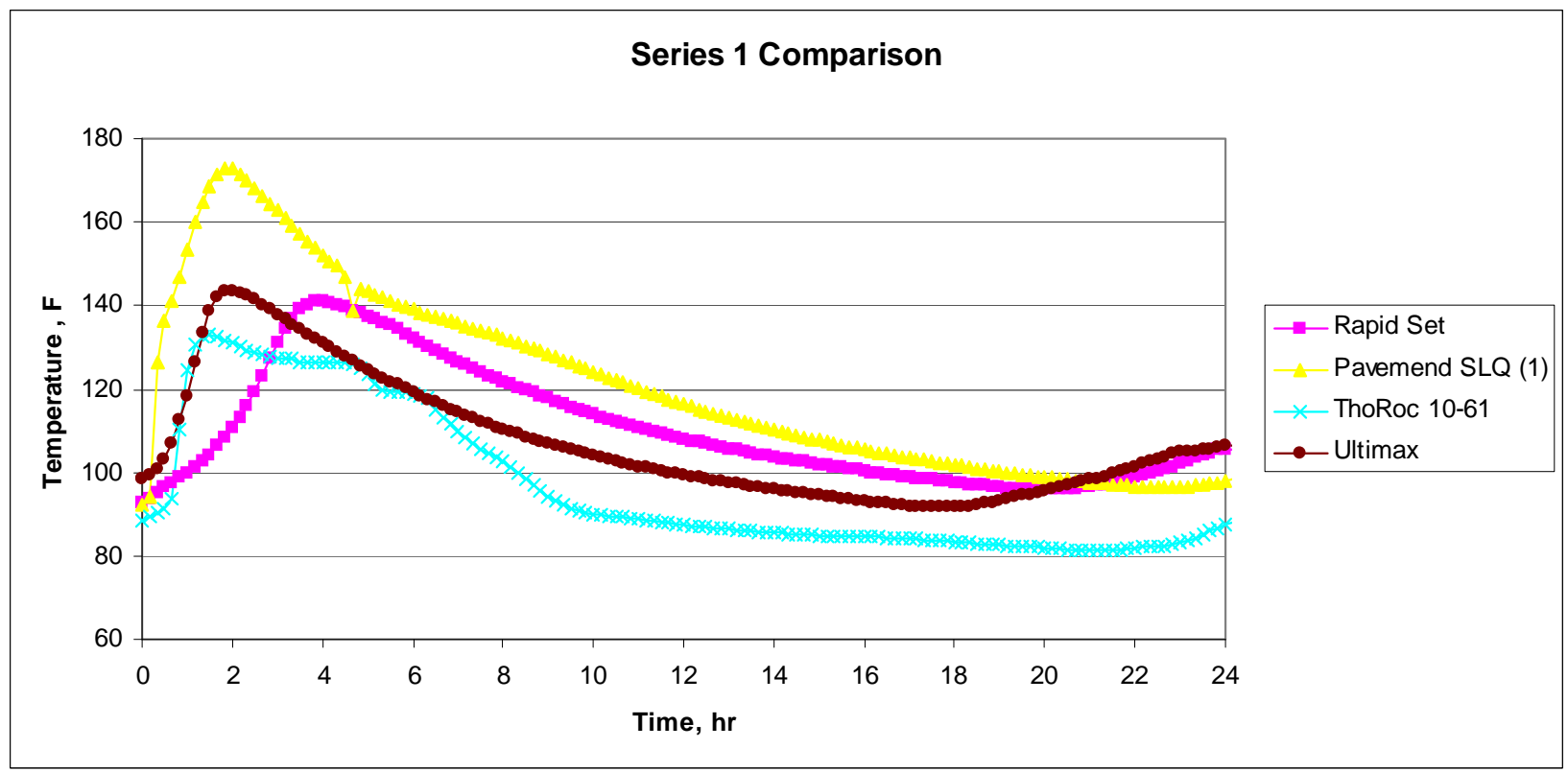

Figure 154. Rise in average temperature comparison selected Series 1 craters. 


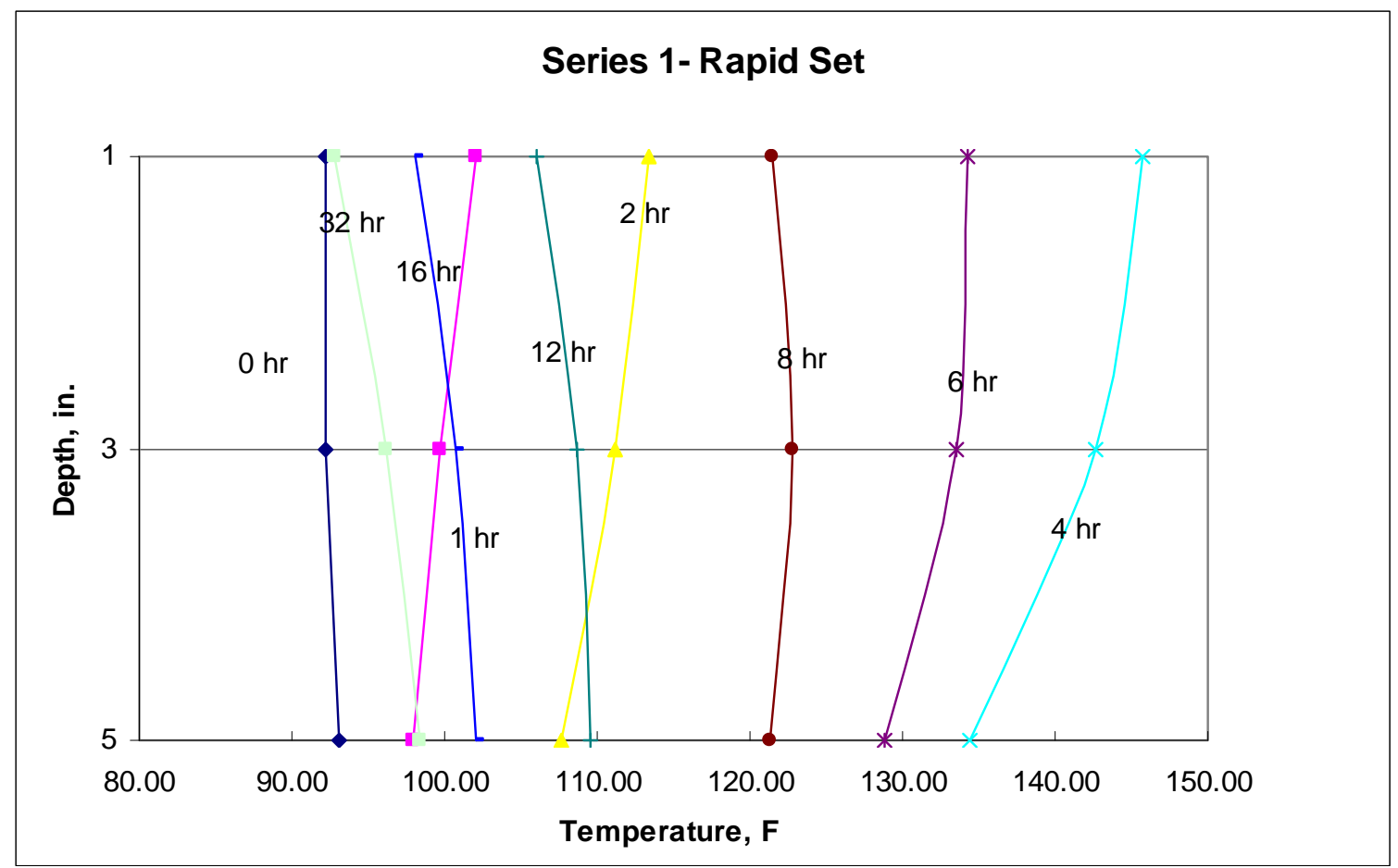

Figure 155. Series 1. Rapid Set-temperature with depth.

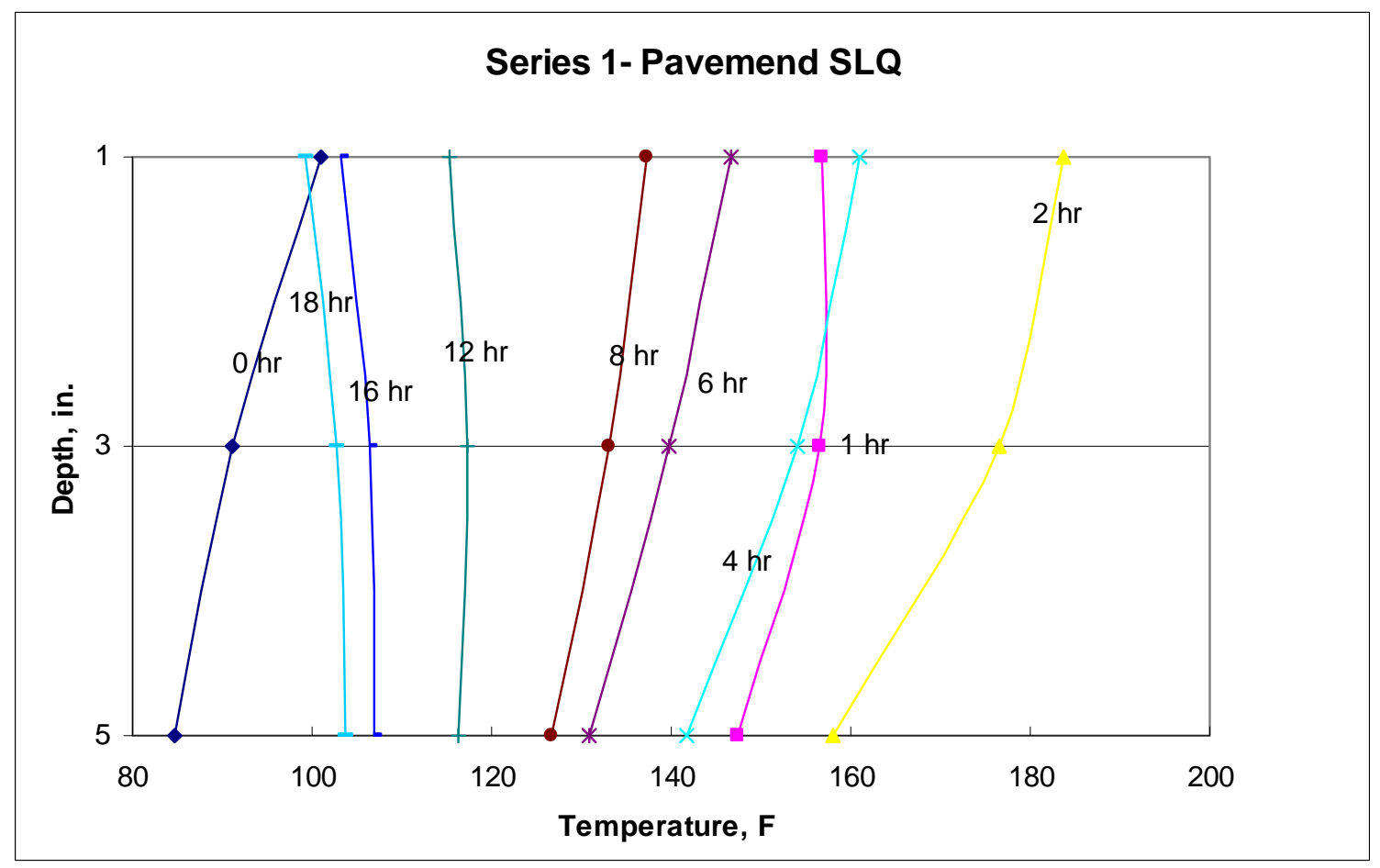

Figure 156. Series 1. Pavemend SLQ-temperature with depth. 


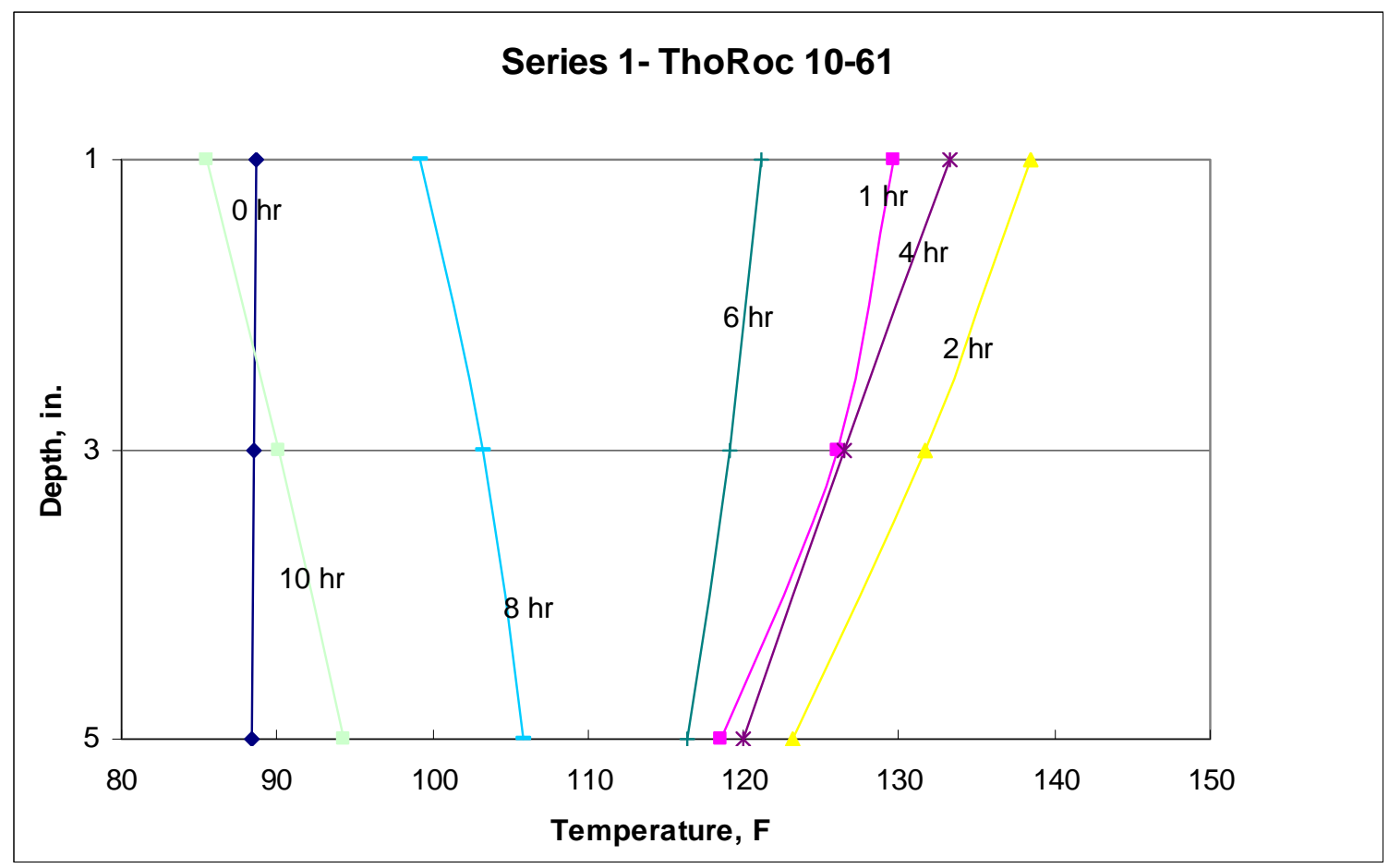

Figure 157. Series 1: ThoRoc 10-61-temperature with depth.

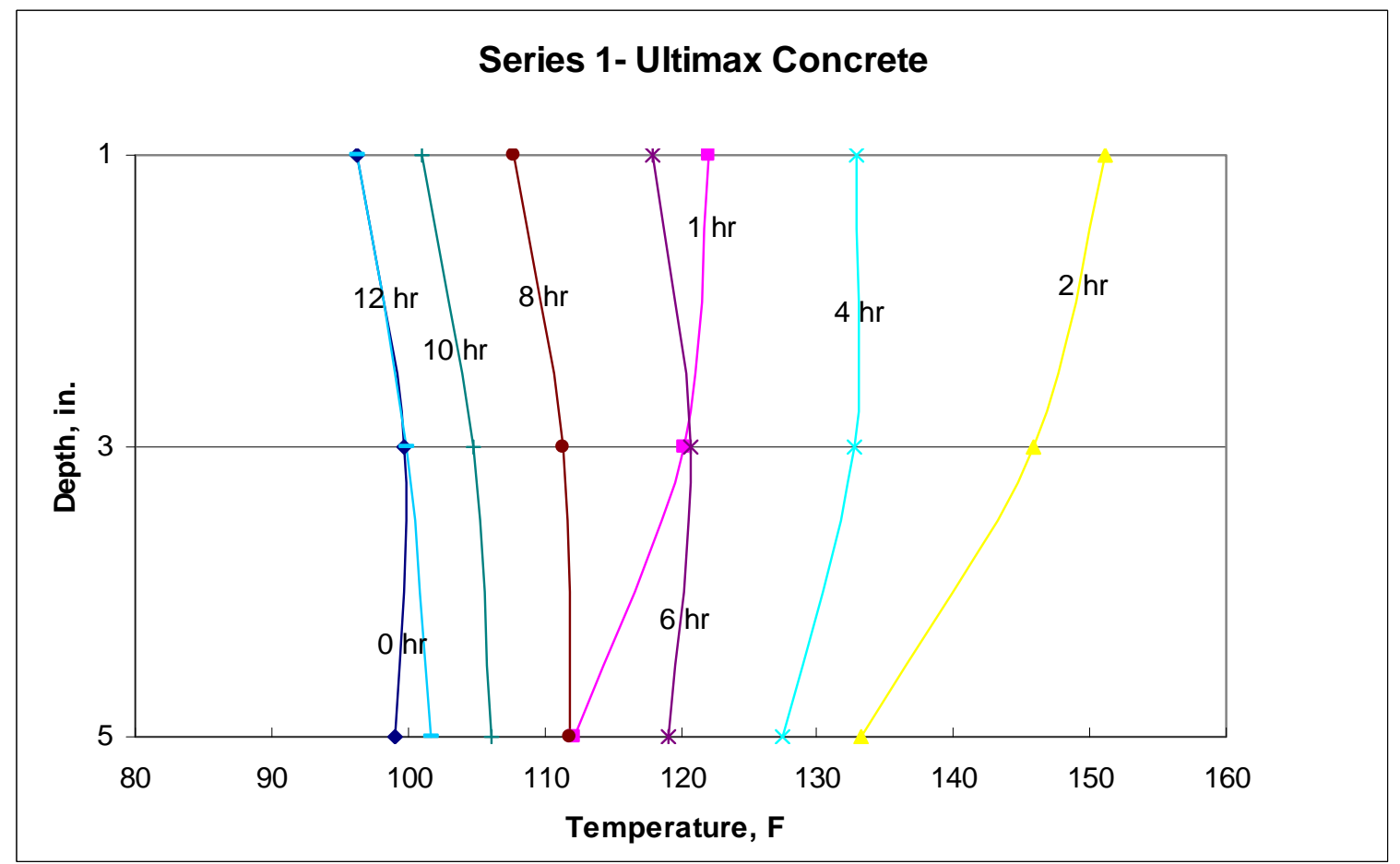

Figure 158. Series 1. Ultimax Concrete-temperature with depth. 


\section{Series 2 repairs}

A comparison of the average temperatures generated in each cap for Series 2 craters is presented in Figure 159. From this figure it can be seen that Pavemend SLQ generated the most heat overall as in Series 1 with a maximum average temperature of $162^{\circ} \mathrm{F}$. Ultimax Concrete was not used in Series 2 as described previously and is not shown. A comparison of the temperature rise with depth for these craters is presented in Figures 160162. From these figures, all materials reached maximum temperatures at approximately $2 \mathrm{hr}$ of cure. In addition, from the figures it can be seen that although the materials were trafficable within $3 \mathrm{hr}$ of repair, the optimum time for traffic would have been when the temperatures returned to precure conditions. For these materials, Rapid Set, Pavemend SLQ, and ThoRoc 10-61, 8, 16, and $12 \mathrm{hr}$, respectively, would have been ideal.

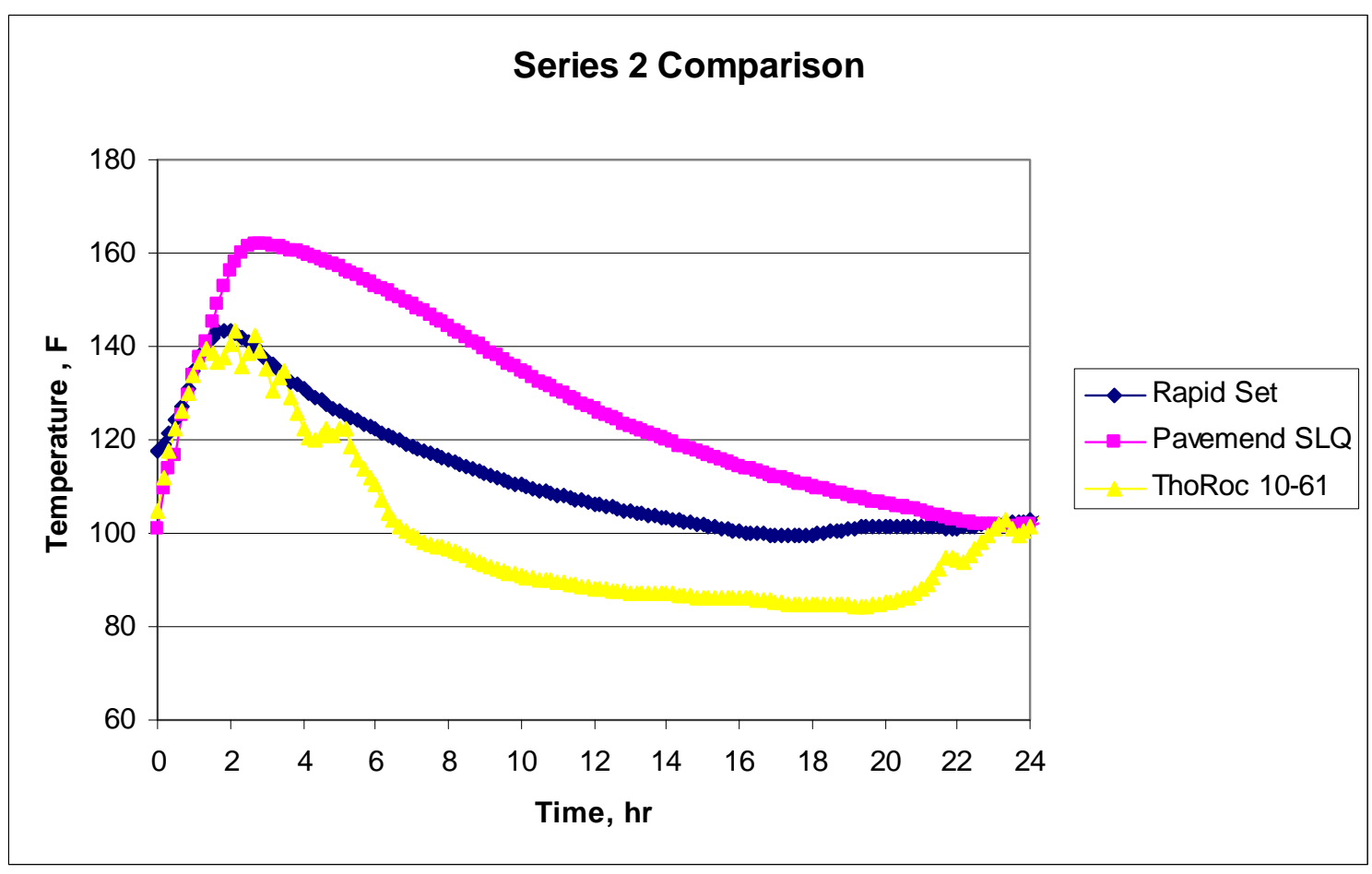

Figure 159. Temperature rise comparison for Series 2 craters. 


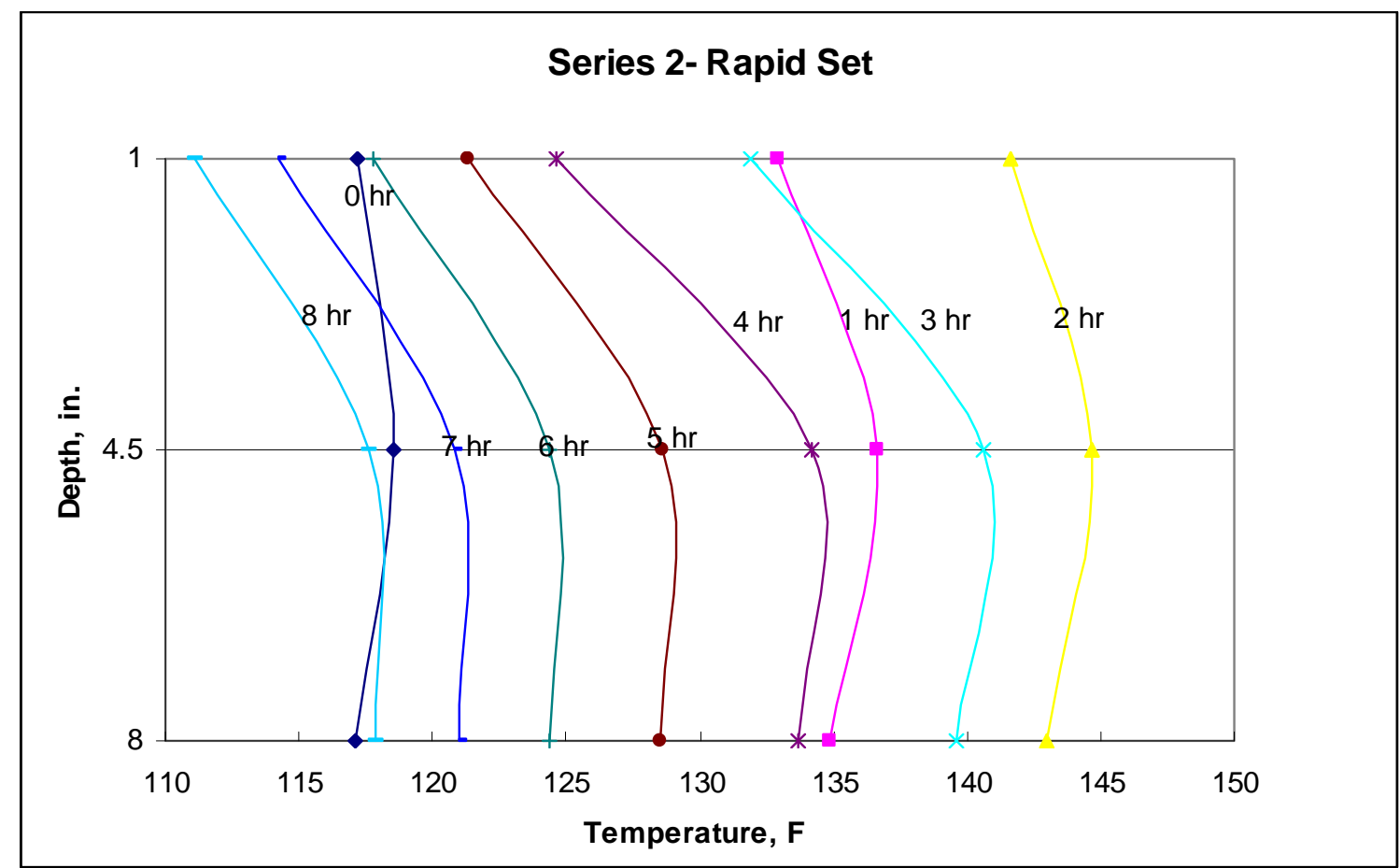

Figure 160. Series 2. Rapid Set Concrete-temperature with depth.

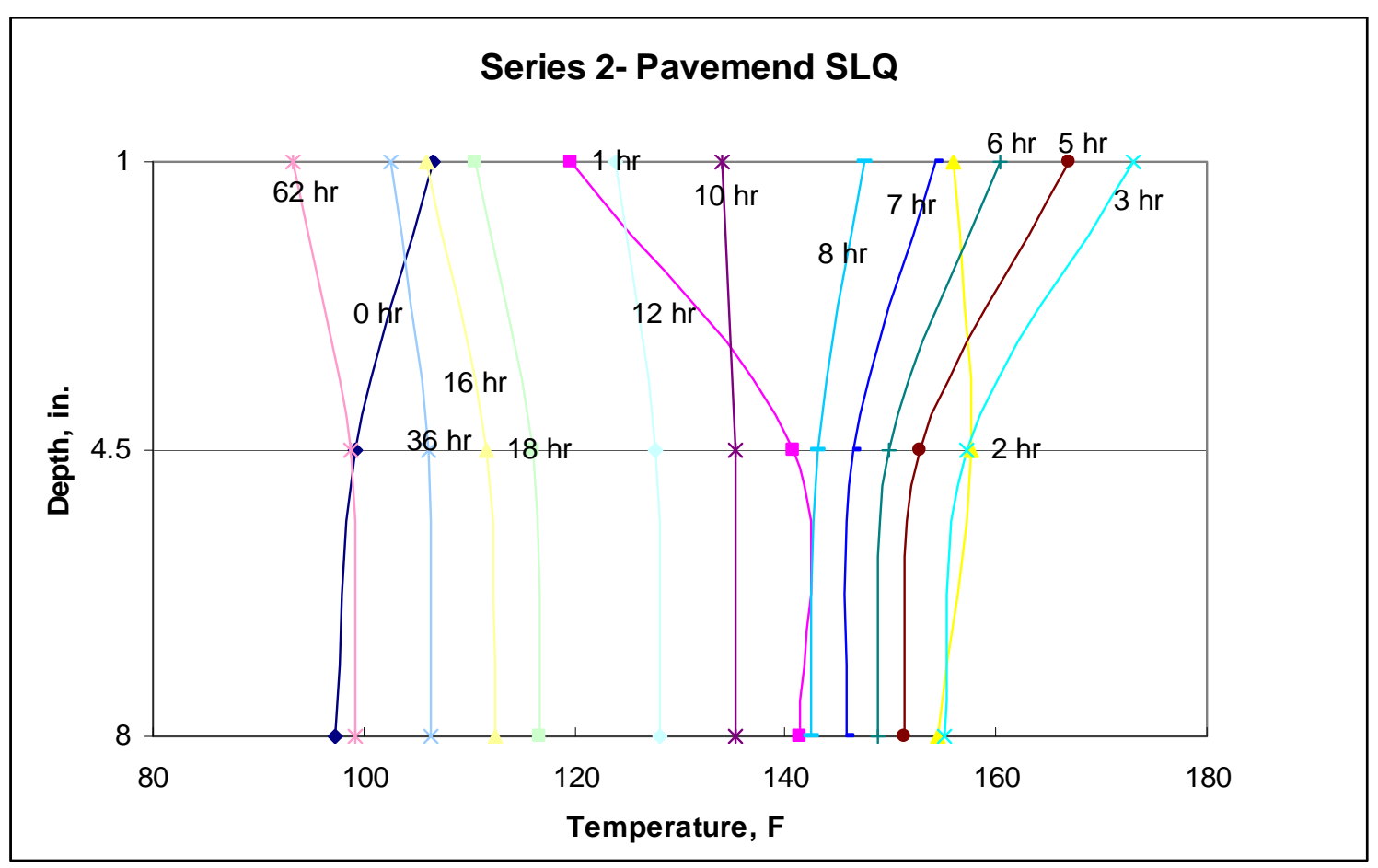

Figure 161. Series 2. Pavemend SLQ-temperature with depth. 


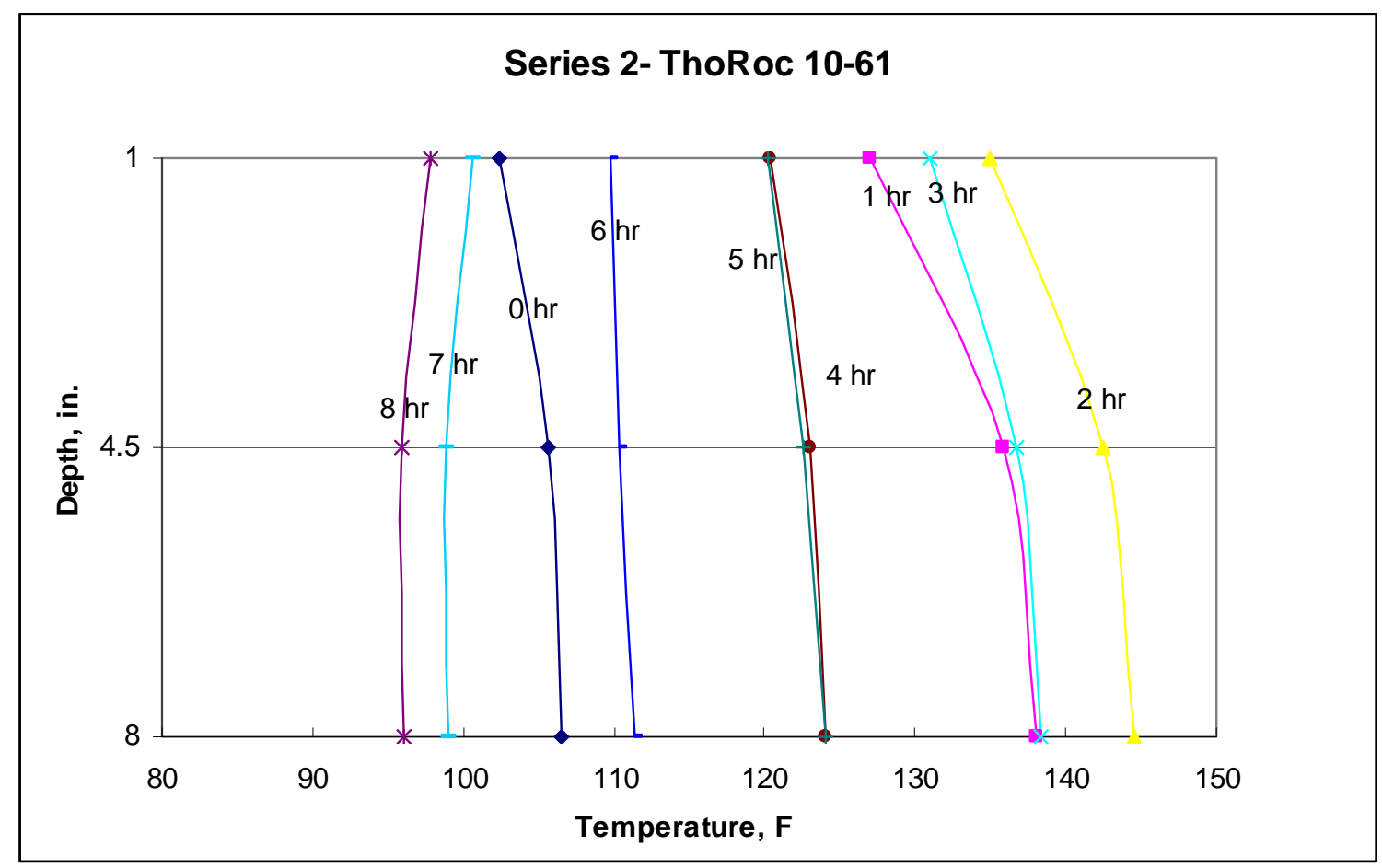

Figure 162. Series 2. Rapid Set Concrete-temperature with depth.

\section{Series 3 repairs}

A comparison of the average temperatures generated in each cap for Series 3 craters is presented in Figure 163. As with Series 1 and 2, Pavemend SLQ generated the most heat overall as in Series 1 with a maximum average temperature of $166^{\circ} \mathrm{F}$. Due to a broken cable, no data is presented for the Ultimax Concrete repair. A comparison of the temperature rise with depth for these craters is presented in Figures 164-166. From these figures, Rapid Set and ThoRoc 10-61 reached maximum temperatures at approximately $1 \mathrm{hr}$ of cure. Pavemend reached its maximum temperature after approximately $2 \mathrm{hr}$. From these figures, it can be seen that although the materials were trafficable within $3 \mathrm{hr}$ of repair, the optimum time for traffic would have been when the temperatures returned to pre-cure conditions. For these materials, Rapid Set, Pavemend SLQ, and ThoRoc 10-61, 40, 18, and $12 \mathrm{hr}$, respectively, would have been ideal. These are similar to those needed in Series 1 and 2 with the exception of Rapid Set in Series 2 with only $8 \mathrm{hr}$ needed.

In comparing the maximum temperatures for Rapid Set for the three series, the temperature did not vary significantly, but the cure time decreased as the cap thickness increased. This would be expected as the volume of material increased which would result in achieving hydration in 
shorter times due to the volume involved. This was not the same for Pavemend SLQ whose value did not vary significantly for maximum temperature, but the cure time at maximum temperatures increased for Series 2 and 3. The set times for the Rapid Set were very short, and the material had to be placed in smaller volumes in multiple batches.

ThoRoc 10-61 had the greatest drop in cure time at maximum temperature. Because the material was placed in a few batches at a greater volume in Series 3, the heat was generated at a faster rate. A summary of the maximum temperatures reached in each cap, location of the sensor, and cure time are included in Table 31.

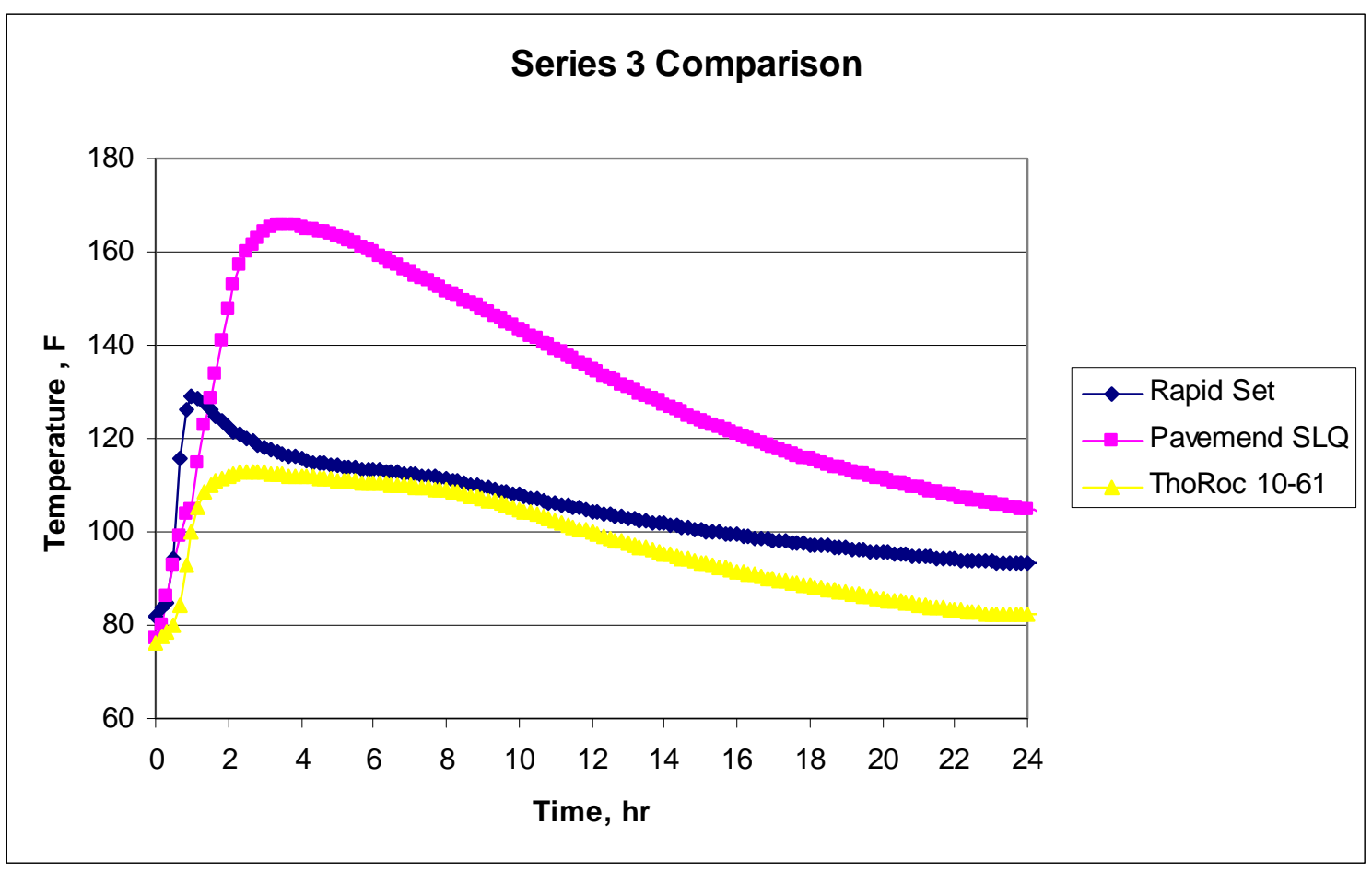

Figure 163. Temperature rise comparison for Series 3 craters. 


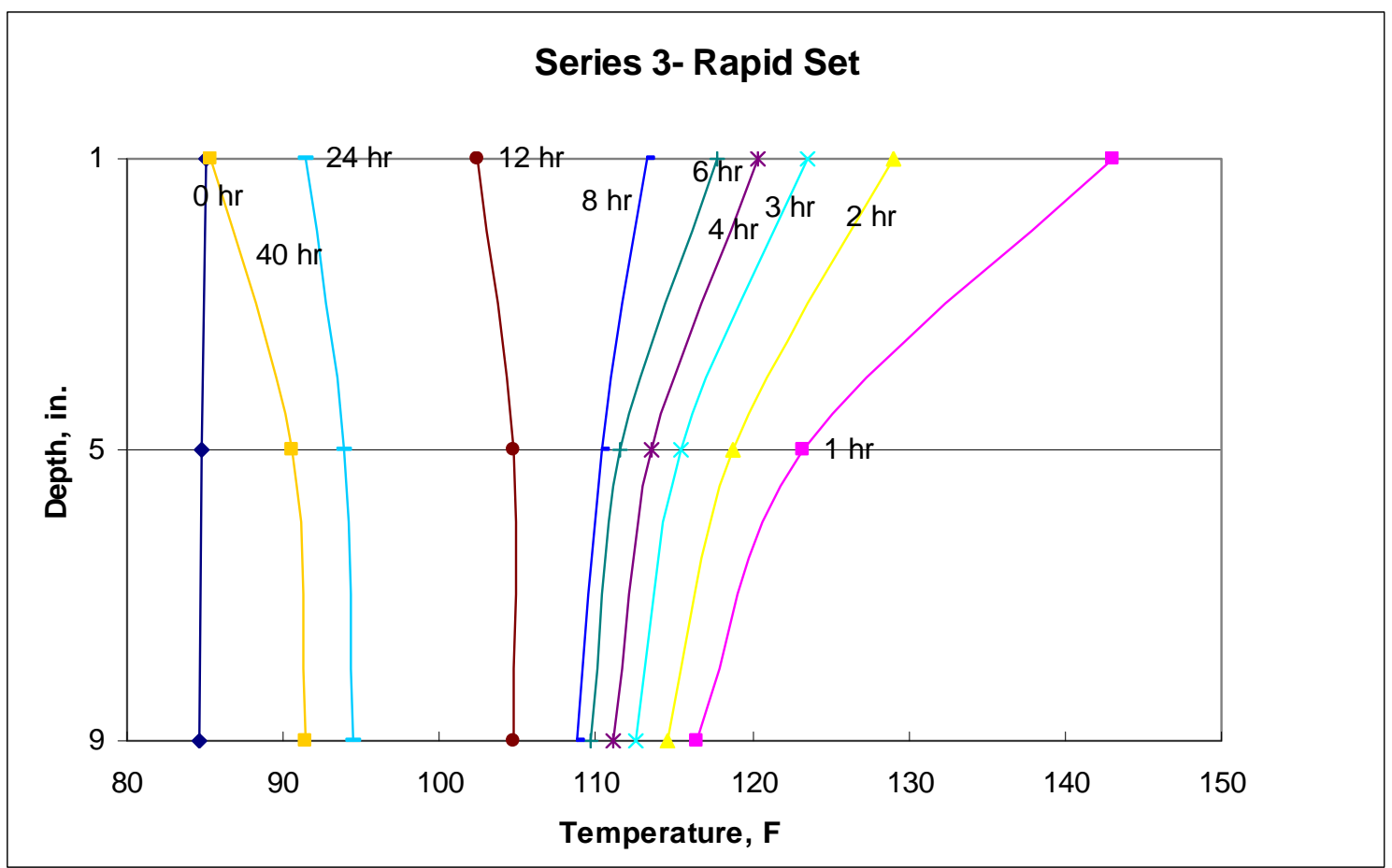

Figure 164. Series 3. Rapid Set-temperature with depth.

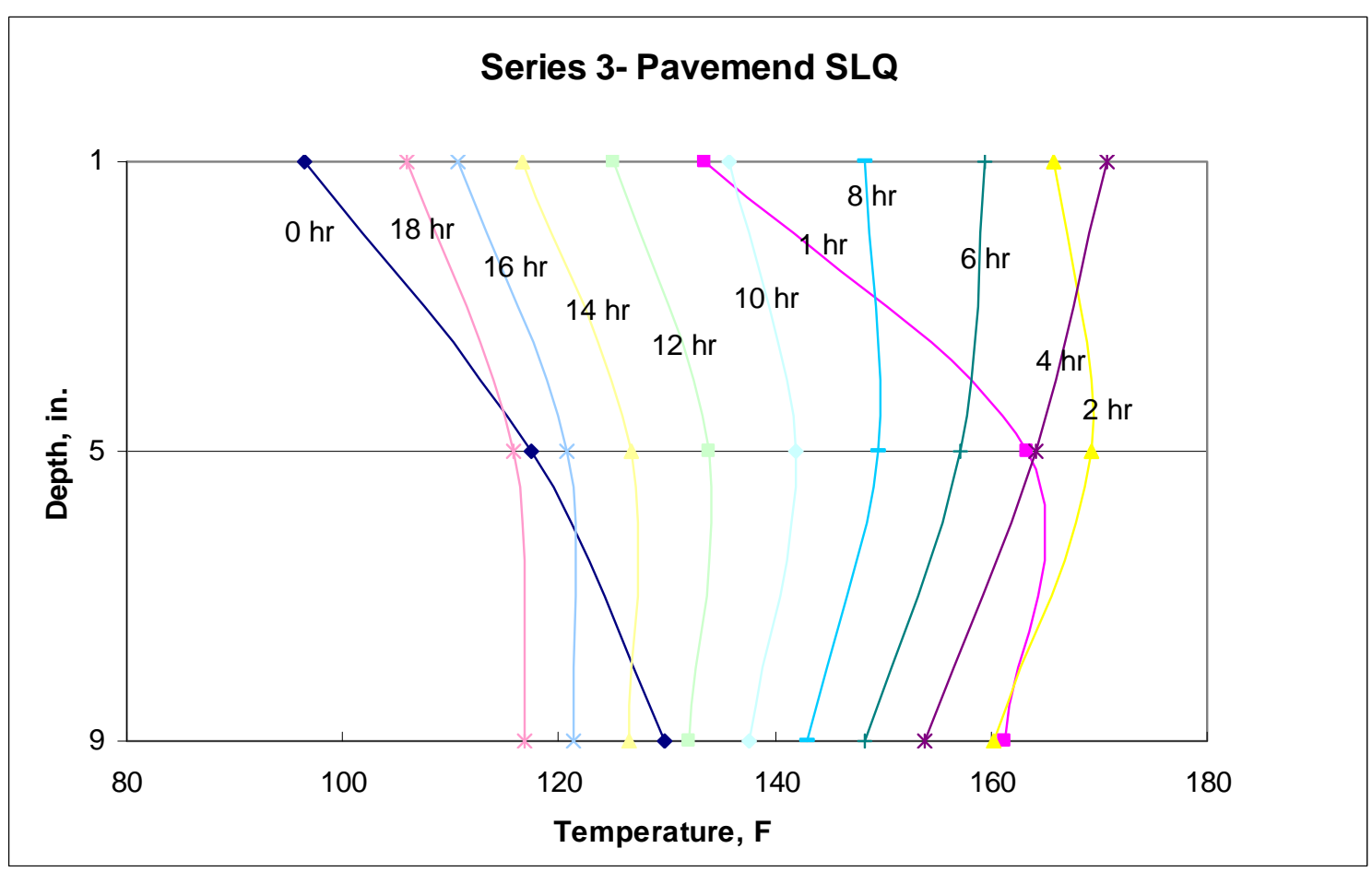

Figure 165. Series 3. Pavemend SLQ-temperature with depth. 


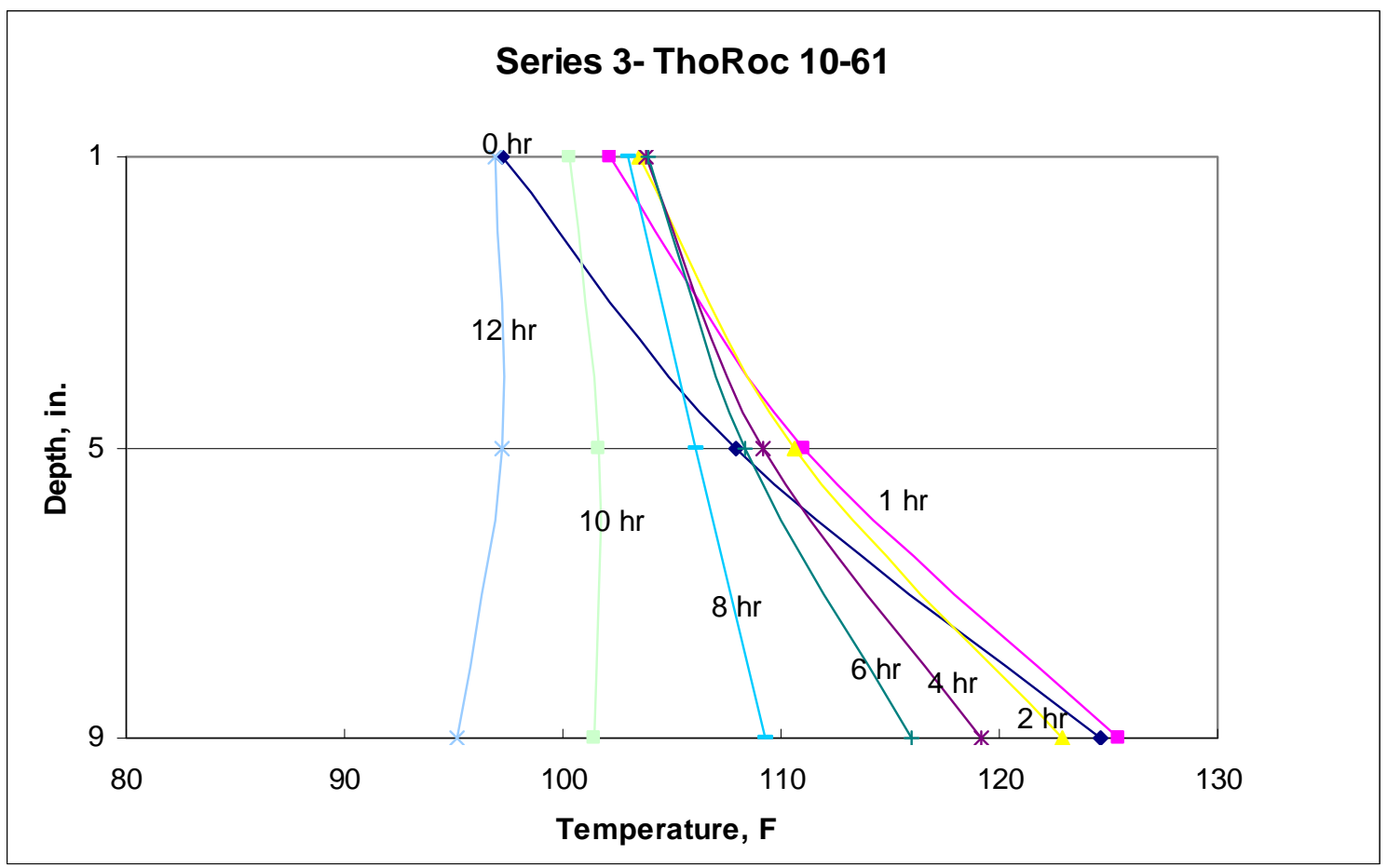

Figure 166. Series 3: ThoRoc 10-61-temperature with depth

Table 31. Summary of maximum temperatures for each series of crater repairs.

\begin{tabular}{|c|c|c|c|c|c|}
\hline Series & Crater & Material & $\begin{array}{c}\text { Max } \\
\text { Temp, }{ }^{\circ} \mathrm{F}\end{array}$ & $\begin{array}{l}\text { Sensor } \\
\text { Location }\end{array}$ & $\begin{array}{c}\text { Cure } \\
\text { Time, } \\
\text { hr:min }\end{array}$ \\
\hline \multirow{10}{*}{ Series 1} & A & Pavesaver & 149.3 & Top & $1: 20$ \\
\hline & $B$ & Rapid Set & 146.0 & Top & $3: 50$ \\
\hline & C-1 & Pavemend SLQ & 183.7 & Top & $2: 00$ \\
\hline & $\mathrm{C}-2$ & ThoRoc 10-60 & 134.9 & Top & $2: 30$ \\
\hline & D & ThoRoc 10-61 & 140.2 & Top & $1: 50$ \\
\hline & $\mathrm{E}$ & Set $45 \mathrm{HW}$ & 164.4 & Top & $0: 50$ \\
\hline & $\mathrm{F}$ & Ultimax Concrete & 151.4 & Top & $1: 50$ \\
\hline & G-1 & Pavemend SL & \multirow{3}{*}{\multicolumn{3}{|c|}{ Not Available }} \\
\hline & G-2 & Tamms Express Repair & & & \\
\hline & $\mathrm{H}$ & Pavemend SLQ & & & \\
\hline \multirow{3}{*}{ Series 2} & $\mathrm{~J}$ & Rapid Set & 144.7 & Middle & $2: 00$ \\
\hline & $K$ & Pavemend SLQ & 173.1 & Top & $3: 00$ \\
\hline & $\mathrm{L}$ & ThoRoc 10-61 & 147.1 & Bottom & $2: 10$ \\
\hline \multirow{4}{*}{ Series 3} & Q & Rapid Set & 149.4 & Top & $1: 20$ \\
\hline & $\mathrm{R}$ & Pavemend SLQ & 171.5 & Top & $2: 30$ \\
\hline & $\mathrm{S}$ & ThoRoc 10-61 & 126.3 & Bottom & $0: 30$ \\
\hline & $T$ & Ultimax Concrete & \multicolumn{3}{|c|}{ Not Available } \\
\hline
\end{tabular}




\section{Analyses of Results}

\section{Series 1 craters}

\section{Crater A-Pavesaver}

The Pavesaver crater repair sustained 62 passes of traffic before failure. Failure occurred when the roughness criterion was exceeded with maximum deformation on the repair edges reaching 1.56 in. Results from laboratory tests indicated that at the time of the repair testing ( $3 \mathrm{hr}$ ), the compressive strength and bond strength did not meet previous criteria for RS repair materials for smaller repairs. As indicated in Chapter 2, elevated compressive testing had not been completed on this material prior to field testing. With outside temperatures exceeding $90^{\circ} \mathrm{F}$, elevated conditions were present. At elevated conditions, the material's 2-hr compressive strength was $457 \mathrm{psi}$, which is far less than the 3,000 psi criteria, set forth for RS cementitious materials. Results of elevated slant shear strength also showed a reduction in strength for the bond of the repair material to concrete pavement. At 1 day under elevated conditions, the bond strength was $290 \mathrm{psi}$, which does not meet the 500 psi minimum for this type material. The loss of bond to the surrounding pavement after 30 passes implies that the bond did not improve in field placement.

The EPC data collected during trafficking shows how well the cap is distributing stress to the subgrade. HWD testing prior to traffic application exceeded the measuring range of the EPC instrumentation 60 psi being measured. The peak EPC value exceeded the measuring range of the instrumentation after seven passes. This peak was achieved when the tire was directly over the EPC. As more traffic was applied, the maximum stress of 60 psi was recorded when the tire approached the center of the repair where the EPC was located.

Based on the results of the field and laboratory testing, Pavesaver was not recommended for further Series 2 repairs or for small crater repairs during contingency operations. 


\section{Crater B-Rapid Set}

The Rapid Set crater repair sustained a total of 688 passes before failing due to high FOD potential as the result of high-severity joint spalls on the loaded repair edges. Loose FOD was removed by sweeping after traffic intervals. After 688 passes, the repair edges also exceeded the roughness criterion. Laboratory criteria were met for compressive strength and bond strength at elevated and ambient criteria.

The EPC data collected during trafficking showed a peak measurement of 56 psi after 621 passes. This peak was achieved when the tire was directly over the EPC. This value was recorded several more times in the last 100 passes before failure occurred. As expected, these additional peak values were recorded when the tire approached the location of the EPC. As the repair deteriorated, increasing stress was measured by the datalogger.

Based on the results of laboratory and field testing, Rapid Set was recommended for Series 2 testing.

\section{Crater C-1-Pavemend SLQ}

The first Pavemend SLQ repair failed after 96 passes due to high FOD potential as the result of a shattered slab. This failure was the result of a weakened subgrade. The second repair will be described in this section. EPC data collected during the first 96 passes measured a peak value of 60 psi.

\section{Crater C-2-ThoRoc 10-60}

The ThoRoc 10-60 repair failed after 704 passes due to high-severity joint spalls on the south edge of the repair resulting in the repair having a high FOD potential. Additionally, when FOD was swept from the crater, the 1.25-in. roughness criterion was exceeded. Laboratory criteria were met for this product for both compressive strength and bond strength at ambient temperatures. However, at elevated conditions, the product did not meet the 3,000 psi requirement at 2 or $6 \mathrm{hr}$ after cure for compressive strength.

The EPC data collected during trafficking reported a peak measurement of 58 psi after 617 passes. As expected, this peak was achieved when the tire was directly over the EPC and was recorded more frequently as the tire 
approached the EPC for the last 100 passes. As with the Rapid Set repair, as the repair deteriorated, increasing stress was measured by the datalogger.

Although the product withstood more passes than the Rapid Set repair, the results of the laboratory testing did not meet the compressive strength criteria for elevated conditions. Additionally, the ThoRoc 10-61 of similar formulation had less FOD than the 10-60 repair at the same level of passes. Therefore, ThoRoc 10-60 was not recommended for Series 2 testing.

\section{Crater D-ThoRoc 10-61}

The ThoRoc 10-61 repair failed after 720 passes due to high-severity joint spalls along the loaded edges resulting in a high FOD potential for the repair. As with the other craters, when this FOD was swept away, the roughness criterion was exceeded. Additionally, this product met previous laboratory compressive strength and bond strength criteria.

The EPC data collected during trafficking reported a peak measurement of 50 psi after 619 passes. EPC behavior was similar to the other craters with increasing stress with repair deterioration.

Based on laboratory and field testing, ThoRoc 10-61 was recommended for Series 2 testing.

\section{Crater E-Set 45 HW}

The Set 45 HW repair failed after 704 passes in the same manner as the previous repairs due to high FOD potential and exceeding the roughness criterion when FOD was removed from the loaded edges. Under elevated conditions, this product met laboratory testing criteria.

The EPC data collected during trafficking reported a peak measurement of 28 psi after 622 passes. EPC behavior was similar to the other craters with increasing stress with repair deterioration.

Because of reduced number of passes to failure and field testing results, Set $45 \mathrm{HW}$ was not recommended for Series 2 testing. 


\section{Crater F-Ultimax Concrete}

The Ultimax Concrete repair failed after 720 passes due to high FOD potential. Laboratory criteria were met with this product. Because of these results, this product was recommended for Series 2 testing.

The EPC data collected during trafficking reported a peak measurement of 55 psi after 218 passes. After 224 passes, the average pressure for each interval measured was similar to this value. This EPC behavior was not similar to the other craters with increasing stress measured before significant cracking and FOD was noticed.

\section{Crater G-Pavemend SL}

The Pavemend SL repair failed after 16 passes due to material problems. Uncured material after $3 \mathrm{hr}$ of setting crumbled under traffic as it was not strong enough to support the aircraft tire. Prior to trafficking, very high deflections were noticed under HWD loading, and cracking occurred during this testing. The material was excavated by hand to expose uncured material in the top 4 in. of the surface. Similar experiences were noted in laboratory testing for elevated conditions as experienced in the field. At elevated conditions, this product did not set as fast as at ambient conditions. Only after $24 \mathrm{hr}$ of cure at elevated conditions did this product meet the 3,000 psi minimum compressive strength.

The EPC data collected during trafficking exceeded the measuring range of the EPC instrumentation after nine passes. After 16 passes, the repair was considered failed. These high EPC measurements indicate that the repair was cracking after minimal traffic had been applied due to the material not being fully cured.

Because of laboratory and field testing results, Pavemend SL was not recommended for Series 2 testing.

\section{Crater G-2 Tamms Express Repair}

The repair with Express Repair failed after 224 passes due to high FOD potential associated with a high-severity shattered slab. As with the previous repair, the EPC data collected during trafficking exceeded the 60psi measuring range of the EPC instrumentation after nine passes. These high EPC measurements indicate that cracking was occurring below the 
surface as well as the cracks visible on the surface after minimal traffic had been applied.

Based on field testing, Express Repair was not recommended for Series 2 testing.

\section{Crater H-Pavemend SLQ}

Because of subgrade failure on a previous Pavemend SLQ repair, the material was tested again. The material failed after 1,344 passes due to high FOD potential associated with high-severity joint spalls along the south and west edges of the repair and linear cracking in the center of the crater. Laboratory testing revealed that the strength criteria for compressive and bond strength were met with this product.

The EPC data collected during trafficking resulted in a peak EPC value of 60 psi after 736 passes. EPC behavior was similar to the other craters with increasing stress with repair deterioration.

Based on results from laboratory and field testing, Pavemend SLQ was recommended for Series 2 testing.

\section{Series 2 craters}

\section{Crater J-Rapid Set}

The Series 2 Rapid Set repair failed after 2,000 passes due to high FOD potential associated with high-severity joint spalls similar to those that occurred in the crater repair of Series 1.

EPC data collected during trafficking resulted in a peak EPC value measured at 20 psi after 1,231 passes. As expected, additional peak values similar to this peak were recorded when the tire approached the location of the EPC. Additionally, as the repair deteriorated, increasing stress values were measured by the datalogger.

It is predicted that the thicker cap thickness led to the higher number of passes-to-failure and better load distribution across the thicker, wider repair cap. Based on Series 2 repair performance, Rapid Set was recommended for Series 3 testing. 


\section{Crater K-Pavemend SLQ}

The Series 2 Pavemend SLQ repair did not fail after 5,000 passes. Only minor cracking was noticed during traffic.

EPC data collected during trafficking resulted in a peak EPC value of $12 \mathrm{psi}$ after 5,000 passes. This peak value was measured as final traffic was applied. It is expected that as the repair deteriorated, increasing stress values measured by the datalogger would be expected.

As with the Rapid Set repair, it is predicted that the thicker cap thickness led to the higher number of passes-to-failure and better load distribution across the thicker, wider repair cap. Based on Series 2 repair performance, Pavemend SLQ was recommended for Series 3 testing.

\section{Crater L-ThoRoc 10-61}

The Series 2 ThoRoc 10-61 repair failed after 2,000 passes due to the same mode of failure (high FOD potential) that occurred in the crater repair of Series 1. It is predicted that the thicker cap thickness led to the higher number of passes-to-failure. The repair material was recommended for Series 3 testing.

EPC data collected during trafficking resulted in a peak EPC value measurement of $27 \mathrm{psi}$ after 735 passes. This repair showed a higher amount of deterioration sooner than the other repairs in this series. A higher peak value measured sooner would be expected.

Based on Series 2 repair performance, the material was recommended for Series 3 testing.

\section{Series 3 craters}

\section{Crater Q-Rapid Set}

The Series 3 Rapid Set repair did not fail or show any significant settlement or distresses after 5,008 passes were applied. The thick pavement consisting of RS material and concrete debris met sustainment criteria for exceeding the minimum 5,000 passes-to-failure.

EPC data collected during trafficking resulted in EPC values less than 2 psi. 


\section{Crater R-Pavemend SLQ}

The Series 3 Pavemend SLQ repair did not fail or show any significant settlement or distresses after 5,008 passes were applied. The thick pavement consisting of RS material and concrete debris met sustainment criteria for exceeding the minimum 5,000 passes-to-failure.

EPC data collected during trafficking resulted in EPC values less than 3 psi.

\section{Crater S-ThoRoc 10-61}

The Series 3 ThoRoc 10-61 repair did not fail or show significant settlement after 5,008 passes were applied. The thick pavement consisting of RS material and concrete debris met sustainment criteria for exceeding the minimum 5,000 passes-to-failure.

EPC data collected during trafficking resulted in EPC values less than 2 psi. ThoRoc 10-61 showed the highest amount of deterioration with FOD and cracking along the loaded edges. This repair was dissimilar to the other repairs due to the flowable fill used to fill voids in the concrete debris backfill. Set time required for the flowable fill did not meet sustainment repair requirements for time. However, based on the ThoRoc cap performance, it is predicted that a 10-in. cap over a high-quality base material or debris containing fines would have met sustainment requirements.

\section{Crater T-Ultimax Concrete}

The Series 3 Ultimax Concrete repair did not fail or show any significant settlement or distresses after 5,008 passes were applied. The thick pavement consisting of RS material and concrete debris met sustainment criteria for exceeding the minimum 5,000 passes-to-failure.

EPC data collected during trafficking resulted in EPC values less than $5 \mathrm{psi}$. This repair was dissimilar to the other repairs due to the Aquacrete RS product used to fill voids in the concrete debris backfill.

\section{Summary}

A summary of crater repair results is presented in Table 32. 
Table 32. Summary of crater repair failures.

\begin{tabular}{|c|c|c|c|c|c|c|c|c|}
\hline Crater & $\begin{array}{l}\text { Capping } \\
\text { Material }\end{array}$ & $\begin{array}{c}\text { Cap } \\
\begin{array}{c}\text { Thickness, } \\
\text { in. }\end{array} \\
\end{array}$ & $\begin{array}{l}\text { Failure } \\
\text { Mode }\end{array}$ & Failure Detail & $\begin{array}{c}\text { Passes } \\
\text { to } \\
\text { Failure, } \\
\#\end{array}$ & $\begin{array}{c}\text { Peak } \\
\begin{array}{c}\text { Temperature, } \\
{ }^{\circ} \mathrm{F}\end{array} \\
\end{array}$ & $\begin{array}{c}\text { Peak } \\
\text { Stress, } \\
\text { psi }\end{array}$ & $\begin{array}{c}\text { Passes } \\
\text { at } \\
\text { Peak } \\
\text { Stress, } \\
\#\end{array}$ \\
\hline A & Pavesaver & 6 & Roughness & $\begin{array}{c}\text { Loss of } \\
\text { bond/deformation }\end{array}$ & 62 & 149.3 & 60 & 7 \\
\hline $\mathrm{B}$ & Rapid Set & 6 & FOD & $\begin{array}{l}\text { High-severity } \\
\text { joint spalls }\end{array}$ & 688 & 146.0 & 56 & 621 \\
\hline C-1 & $\begin{array}{l}\text { Pavemend } \\
\text { SLQ }\end{array}$ & 6 & FOD & Subgrade failure & 96 & 183.7 & 60 & 96 \\
\hline $\mathrm{C}-2$ & $\begin{array}{c}\text { ThoRoc } \\
10-60 \\
\end{array}$ & 6 & FOD & $\begin{array}{l}\text { High-severity } \\
\text { joint spalls }\end{array}$ & 704 & 134.9 & 58 & 617 \\
\hline $\mathrm{D}$ & $\begin{array}{c}\text { ThoRoc } \\
10-61\end{array}$ & 6 & FOD & $\begin{array}{l}\text { High-severity } \\
\text { joint spalls }\end{array}$ & 720 & 140.2 & 50 & 619 \\
\hline$E$ & $\begin{array}{c}\text { Set } 45 \\
\text { HW }\end{array}$ & 6 & FOD & $\begin{array}{l}\text { High-severity } \\
\text { joint spalls }\end{array}$ & 704 & 164.4 & 28 & 622 \\
\hline $\mathrm{F}$ & $\begin{array}{c}\text { Ultimax } \\
\text { Concrete }\end{array}$ & 6 & FOD & $\begin{array}{l}\text { High-severity } \\
\text { joint spalls }\end{array}$ & 720 & 151.4 & 55 & 218 \\
\hline G-1 & $\begin{array}{c}\text { Pavemend } \\
\text { SL }\end{array}$ & 6 & FOD & $\begin{array}{l}\text { High-severity } \\
\text { shattered } \\
\text { slab/uncured } \\
\text { material }\end{array}$ & 16 & See ${ }^{b}$ & 60 & 9 \\
\hline G-2 & $\begin{array}{c}\text { Tamms } \\
\text { Express } \\
\text { Repair }\end{array}$ & 6 & FOD & $\begin{array}{l}\text { High-severity } \\
\text { shattered slab }\end{array}$ & 224 & See $^{b}$ & 60 & 9 \\
\hline $\mathrm{H}$ & $\begin{array}{c}\text { Pavemend } \\
\text { SLQ }\end{array}$ & 6 & FOD & $\begin{array}{l}\text { High-severity } \\
\text { joint spalls }\end{array}$ & 1,344 & See $^{b}$ & 60 & 736 \\
\hline $\mathrm{J}$ & Rapid Set & 9 & FOD & $\begin{array}{l}\text { High-severity } \\
\text { joint spalls }\end{array}$ & 2,000 & 144.7 & 20 & 1,231 \\
\hline $\mathrm{K}$ & $\begin{array}{l}\text { Pavemend } \\
\text { SLQ }\end{array}$ & 9 & No Failure & N/A & $5,008+$ & 173.1 & 12 & 5,008 \\
\hline $\mathrm{L}$ & $\begin{array}{c}\text { ThoRoc } \\
10-61 \\
\end{array}$ & 9 & FOD & $\begin{array}{l}\text { High-severity } \\
\text { joint spalls }\end{array}$ & 2,000 & 147.1 & 27 & 735 \\
\hline $\mathrm{Q}$ & Rapid Set & $10^{a}$ & No Failure & $\mathrm{N} / \mathrm{A}$ & $5,008+$ & 149.4 & 2 & 5,008 \\
\hline $\mathrm{R}$ & $\begin{array}{l}\text { Pavemend } \\
\text { SLQ }\end{array}$ & $10^{\mathrm{a}}$ & No Failure & $\mathrm{N} / \mathrm{A}$ & $5,008+$ & 171.5 & 3 & 5,008 \\
\hline $\mathrm{S}$ & $\begin{array}{c}\text { ThoRoc } \\
10-61 \\
\end{array}$ & 10 & No Failure & N/A & $5,008+$ & 126.3 & 2 & 5,008 \\
\hline $\mathrm{T}$ & $\begin{array}{l}\text { Ultimax } \\
\text { Concrete }\end{array}$ & 10 & No Failure & N/A & $5,008+$ & See ${ }^{b}$ & 5 & 5,008 \\
\hline
\end{tabular}

a Cap thickness not including 32 in. of RS stabilized concrete debris.

b Temperature sensor data unavailable due to instrumentation failure. 


\section{Conclusions and Recommendations}

ERDC was tasked to develop new concepts for repairing small craters for hardened airfield pavements. Laboratory testing on materials and field testing of selected products were conducted to develop recommendations for new materials, equipment, and procedures for crater repair during contingency and sustainment operations.

Laboratory investigations were conducted February- September 2006 by personnel at the ERDC laboratories in Vicksburg, MS. Laboratory results were used to identify materials for field testing.

The full-scale field testing in this investigation was performed on a controlled test section at ERDC, Vicksburg, MS, during May- November 2006. The test section was used to evaluate various materials selected from laboratory testing for conducting small crater repairs under short time frames (less than $4 \mathrm{hr}$ ), with minimal equipment, labor, and materials. These repairs were trafficked within $3 \mathrm{hr}$ of repair completion using an F-15E load cart with a single-wheel main gear assembly load of 35,235 lb and a 36-in.-diam by 11-in.-wide, 18-ply tire inflated to $325 \mathrm{psi}$. The performance of the repairs was based on deterioration, surface roughness, and permanent deformation of the surface during trafficking.

A summary of the performance of these repairs and the repair materials tested in the laboratory is included in this report. Relevant conclusions from the laboratory and field testing are noted below. Recommendations for the selection and placement of RS materials for small crater repairs are also provided below.

\section{Conclusions}

The following conclusions were derived from the Small Crater Repair project for bomb-damaged pavements during investigations conducted February- November 2006:

a. Because of the extreme time restrictions for rapid runway repair, a minimum of 3,000 psi unconfined compressive strength (UCS) is required at $2 \mathrm{hr}$ of cure for RS materials for crater repairs. Materials must meet this 
minimum strength under temperature conditions similar to those expected during field placement.

b. A minimum of 800 psi bond strength of RS materials to ordinary OPC and 1,000 psi of RS materials to RS materials is required after 1 day of curing. These materials must be tested under temperature conditions similar to those expected during field placement.

c. Based upon the laboratory testing described in this report, high-density polyurethane foams result in higher UCS than lower density foams. UCSs between 300 and 1,000 psi are achievable with expandable polyurethane foams with densities between 8 and $15 \mathrm{lb} / \mathrm{ft}^{3}$. With $300 \mathrm{psi}$ UCS reasonably achievable at low strain levels ( 2 percent), these high-density polyurethane foams appear to possess adequate strength to serve as backfill in bomb craters by providing UCSs similar to well-compacted soil or aggregate without the need for aggregate extension.

d. High-density polyurethane foams ( 8 to $15 \mathrm{lb} / \mathrm{ft}^{3}$ ) provide a tack-free surface within $15 \mathrm{~min}$ when placed at temperatures between 32 and $110 \stackrel{\circ}{\circ}$. Higher temperatures result in shorter tack-free times. Thus, the rapid tack-free time indicates suitability of their use in rapid repair scenarios.

e. The optimal temperature for obtaining maximum compressive strength for foam is $70 \stackrel{\circ}{\circ}$. Higher and lower temperatures result in a reduction in strength and density. Higher temperatures result in a higher rate of reaction reducing the set time (working time) of the material. At lower temperatures, lower rates of reaction take place resulting in a decrease in compressive strength. Thus, foam should be placed slightly deeper in the crater repairs during elevated and lower temperatures due to the slight strength reduction.

f. The average expansion ratio of the high-density foams is inversely proportional to foam density and ranges from 4.1 to 9.8 . This indicates that the foam material could be used to replace a minimum of four times its volume as backfill in a bomb crater, resulting in a savings of at least 75 percent material.

g. High-density foams can be strengthened by packing the foams with the addition of aggregate; however, extension of the foam with aggregate sizes less than $0.5 \mathrm{in}$. will result in the expulsion of material from the composite system and a reduction in the overall strength.

h. Laboratory investigations indicate that twice as much high-density foam will be needed in the field if extended with aggregates or debris.

i. Based upon the full-scale traffic tests described in this report, most of the RS materials evaluated demonstrated an ability to sustain aircraft traffic within $3 \mathrm{hr}$ of repair completion and are suitable for rapidly repairing 
small bomb craters provided minimum material specifications are met. Table 33 presents a summary of these materials.

j. Excessive shrinkage cracking, initially a concern for the crater sizes and volumes of RS materials used, was not observed in any of the series of repairs. Although the RS materials did produce high temperatures (maximum measured temperature was $183^{\circ} \mathrm{F}$ ) during curing, this heat generation was not fast enough to cause thermal cracking.

$\mathrm{k}$. Use of large diameter (1ft) concrete debris increases the volume of concrete needed and time required to cap the repair due to flow of material through voids in concrete debris.

1. Materials such as Pavemend SLQ that are shipped in buckets take approximately 30 to 50 percent as long to place, with the difference increasing with increasing crater size. Average cap placement times for bagged materials ranged from $25 \mathrm{~min}$ to $96 \mathrm{~min}$ depending on crater size and cap thickness. For buckets of materials, the placement time ranged from $35 \mathrm{~min}$ to $174 \mathrm{~min}$.

m. For expedient repairs, a 6-in. cementitious cap of RS materials meeting minimum material requirements is capable of withstanding greater than 100 passes of F-15E traffic when placed over 8 in. of well-graded, highquality base material having a CBR of 50 or greater and a compacted subgrade having a CBR of 4 or greater.

n. A 9-in. cementitious cap of Rapid Set, Ultimax Concrete, or ThoRoc 10-61 is capable of sustaining at least 2,000 passes of F-15E traffic when placed over 18 in. of low-quality base material having a CBR of 25 or greater and a compacted subgrade having a CBR of 4 or greater after $3 \mathrm{hr}$ of curing.

o. A 9-in. cementitious cap of Pavemend SLQ is capable of withstanding at least 5,000 passes of F-15E traffic when placed over 18-in. of low-quality base material having a CBR of 25 or greater and a compacted subgrade having a CBR of 4 or greater after $3 \mathrm{hr}$ of curing.

p. A crater repair consisting of Pavemend SLQ or Rapid Set extended with $2.5 \mathrm{ft}$ of high-quality concrete debris with a maximum diameter of $1 \mathrm{ft}$ and capped with $10 \mathrm{in}$. of the same RS material is capable of withstanding at least 5,000 passes of F-15E traffic after $3 \mathrm{hr}$ of curing.

q. A 10-in. cementitious cap of Ultimax Concrete is capable of withstanding at least 5,000 passes of F-15E traffic when placed over Aquacrete Concrete extended with $2.5 \mathrm{ft}$ of high-quality concrete debris after $3 \mathrm{hr}$ of curing.

r. A repair consisting of $10 \mathrm{in}$. of ThoRoc 10-61 over Rheocell extended with $2.5 \mathrm{ft}$ of high-quality concrete debris is not recommended for expedient operations due to long curing times, but will withstand greater than 5,000 passes of an F-15E load after approximately $24 \mathrm{hr}$ of curing. 
s. The majority of the repairs failed due to FOD potential caused by highseverity joint spalls on the loaded repair edges.

\section{Recommendations}

Based on laboratory and field testing completed by ERDC personnel, the following recommendations are provided:

a. Mixing and dispensing devices need to be developed for placement of foam backfill to aid in cleanup and proper application of material.

b. Field testing is recommended to verify that field construction procedures can reasonably obtain similar engineering properties to the lab specimens and to verify that foam materials would generate sufficient strength to resist consolidation and prevent structural failure under traffic loads when placed at various depths beneath cementitious caps.

c. Additional testing needs to be conducted to improve the foam-aggregate composite. By reducing separation of aggregate, the stone-on-stone contact will increase and generate higher strength composite materials. Once this separation is reduced, it is predicted that lower strength foams could be used as a binding material for aggregate stabilization where high expansion ratios that these foams exhibit would reduce the amount of foam necessary to complete the repair.

d. Additives such as a retarding agent for Pavemend SLQ need to be explored to improve the surface appearance and roughness associated with Pavemend SLQ by extending the working time of the material.

e. Rapid Set, Pavemend SLQ, Ultimax Concrete, and ThoRoc 10-61 have desired properties for small crater capping materials under expedient conditions. These materials are recommended for capping small crater repairs.

f. Rapid Set is recommended as the user's choice for small crater repairs due to its ease of use, controllable set time, performance, and fast cure time.

g. Future exercises should be conducted to determine if the recommended repairs could be completed in the 4-hr time frame using manpower and equipment similar to that available during expedient and sustainment operations.

h. The required cap thickness as a function of backfill strength and expected aircraft loading should be explored through additional field testing and/ or the use of finite element models. Until this testing is complete, Table 34 provides a matrix of layer thicknesses for standard pavement sections for typical design aircraft, traffic levels, conservative material properties, and relevant environmental conditions for expedient and sustainment repair 
missions. This matrix was developed based upon experimental testing and proven analytical techniques developed to simplify selection of pavement repair layer thicknesses.

i. Should the available backfill materials fail to meet the minimum strength requirements indicated in Table 34, an additional 1 in. of RS cap material is recommended to be added to the RS cap thickness noted in Table 34 for every 10 percent CBR less than the minimum strength of 50 percent CBR.

Table 33. Summary of recommended capping products.

\begin{tabular}{|c|c|c|c|}
\hline Manufacturer & Product Name & Small Craters & Aggregate Extension \\
\hline CeraTech, Inc. & Pavemend SLQ & $\mathrm{X}$ & Extendable \\
\hline $\begin{array}{c}\text { CTS Cement } \\
\text { Manufacturing Corp. }\end{array}$ & Rapid Set Concrete Mix & $\mathrm{X}$ & Aggregate included \\
\hline \multirow{3}{*}{ BASF Building Solutions } & ThoRoc 10-60 Repair Mortar & $\mathrm{X}$ & Extendable \\
\cline { 2 - 4 } & ThoRoc 10-61 Repair Mortar & $\mathrm{X}$ & Extendable \\
\cline { 2 - 4 } & Set 45 HW & $\mathrm{X}$ & Extendable \\
\hline Ultimax Corp. & Ultimax Concrete Mix & $\mathrm{X}$ & Aggregate included \\
\hline
\end{tabular}

Table 34. Summary of recommended pavement repair thicknesses.

\begin{tabular}{|c|c|c|c|c|c|c|}
\hline $\begin{array}{c}\text { Mission } \\
\text { Aircrafta }\end{array}$ & $\begin{array}{c}\text { RS Cap } \\
\text { Material }\end{array}$ & $\begin{array}{c}\text { RS Cap } \\
\text { Thickness, } \\
\text { in. }\end{array}$ & $\begin{array}{c}\text { Base Material } \\
\text { Type }\end{array}$ & $\begin{array}{c}\text { Base } \\
\text { Strength, } \\
\text { CBR }\end{array}$ & $\begin{array}{c}\text { Subbase } \\
\text { Thickness, } \\
\text { in. }\end{array}$ & $\begin{array}{c}\text { Subgrade } \\
\text { Strength, } \\
\text { CBR }\end{array}$ \\
\hline \multicolumn{7}{|c|}{ Expedient Repairs (Minimum 100 Passes) } \\
\hline F-15E & See Table 33 & 6.0 & High Quality & $80-100 \%$ & 8.0 & 4.0 \\
\hline F-15E & See Table 33 & 9.0 & Marginal Quality & $50-75 \%$ & 24.0 & 4.0 \\
\hline C-130 & See Table 33 & 6.0 & High Quality & $80-100 \%$ & 8.0 & 4.0 \\
\hline C-130 & See Table 33 & 7.0 & Marginal Quality & $50-75 \%$ & 24.0 & 4.0 \\
\hline C-17 & See Table 33 & 7.5 & High Quality & $80-100 \%$ & 8.0 & 4.0 \\
\hline C-17 & See Table 33 & 10.0 & Marginal Quality & $50-75 \%$ & 24.0 & 4.0 \\
\hline & Sustainment Repairs (Minimum 5,000 passes) & \\
\hline F-15E & See Table 33 & 10.5 & Marginal Quality & $50-75 \%$ & 24.0 & 4.0 \\
\hline C-130 & See Table 33 & 8.0 & Marginal Quality & $50-75 \%$ & 24.0 & 4.0 \\
\hline C-17 & See Table 33 & 11.0 & Marginal Quality & $50-75 \%$ & 24.0 & 4.0 \\
\hline
\end{tabular}

a The mission requirement suggested appropriate design aircraft (F-15, C-130, or C-17).

b Use guidance in UFC 3-270-07 to determine quality of locally available materials. 


\section{References}

Ahlberg, H. L., and E. J . Barenberg. 1965. Pozzolanic pavements. Bulletin 473. Urbana, IL: University of Illinois Engineering Experiment Station.

Air Force Civil Engineering Support Agency (AFCESA). 2006. Testing protocol for rigid spall repair materials. Engineering Technical Letter (in publication). Tyndall AFB, FL.

American Society for Testing and Materials (ASTM). 1994. Standard test method for flexural strength of concrete (using simple beam with third-point loading). Designation: C 78-94 (reapproved 1998). West Conshohocken, PA.

. 2000. Standard test method for liquid limit, plastic limit, and plasticity index of soils. Designation: D 4318-00. West Conshohocken, PA.

. 2002. Standard test methods for laboratory compaction characteristics of soil using modified effort. Designation: D 1557-02. West Conshohocken, PA.

. 2003. Standard test method for tensile and tensile adhesion properties of rigid cellular plastics. Designation: D 1623-03. West Conshohocken, PA.

. 2004. Standard test method for compressive properties of rigid cellular plastics. Designation: D 1621-04a. West Conshohocken, PA.

. 2004. Standard test methods for density of soil and soil-aggregate in place by nuclear methods (shallow depth). Designation: D 2922-04. West Conshohocken, PA.

. 2004. Standard test method for water content of soil and rock in place by nuclear methods (shallow depth). Designation: D 3017-04. West Conshohocken, PA.

. 2004. Standard test method for the use of the dynamic cone penetrometer in shallow pavement applications. Designation: D 6951-03. West Conshohocken, PA.

. 2005. Standard test method for bond strength of epoxy-resin systems used with concrete by slant shear. Designation: C 882-05. West Conshohocken, PA.

. 2005. Standard test method for compressive strength of cylindrical concrete specimens. Designation: C 39-05. West Conshohocken, PA.

. 2006. Standard practice for classification of soils for engineering purposes (Unified Soil Classification System). Designation: D 2487-06. West Conshohocken, PA.

. 2006. Standard test method for use of unbonded caps in determination of compressive strength of hardened concrete cylinders. Designation: C 1231-06. West Conshohocken, PA. 
Headquarters, Departments of the Army, Navy, and Air Force. 2003. Airfield damage repair. Unified Facilities Criteria UFC 3-270-07. Washington, DC.

Mann, T. A. 2006. Grout impregnation of pre-placed recycled concrete pavement (RCP) for rapid repair of deteriorated portland cement concrete airfield pavements. MS thesis, Mississippi State University.

Shoenberger, J . E., W. D. Hodo, C. A. Weiss, P. G. Malone, and T. S. Poole. 2005. Expedient repair materials for roadway pavements. ERDC/GSL TR-05-7. Vicksburg, MS: U.S. Army Engineer Research and Development Center.

Vaysburd, A.M., P. H. Emmons, J. E. McDonald, R. W. Poston, and K. E. Kesner. 1999. Performance criteria for concrete repair materials, Phase II summary report. Technical Report REMR-CS-62. Vicksburg, MS: U.S. Army Engineer Waterways Experiment Station. 


\section{Bibliography}

Alford, S. J ., and G. M. Hammitt II. 1981. Bomb crater repair techniques for permanent airfields; Report 2, Series 2 and 3 tests. Technical Report GL-81-12, Vicksburg, MS: U.S. Army Engineer Waterways Experiment Station.

Alford, S. J ., and G. M. Hammitt II. 1981. Bomb crater repair techniques for permanent airfields; Report 3, Series 4 tests. Technical Report GL-81-12, Vicksburg, MS: U.S. Army Engineer Waterways Experiment Station.

Baker, E. J ., J r., and E. P. Bergmann. 1979. New concept study for repair of bomb damaged runways; Vol I: Concept identification. Technical Report ESL-TR-7927. Tyndall Air Force Base, FL: Engineering and Services Laboratory, Air Force Engineering and Services Center.

Baker, E. J ., J r., et al. 1979. New concept study for repair of bomb damaged runways; Vol II: Detailed evaluation of promising concepts. Technical Report ESL-TR-7927. Tyndall Air Force Base, FL: Engineering and Services Laboratory, Air Force Engineering and Services Center.

Barber, V. C., H. L. Green, and G. M. Hammitt II. 1979. Airfield damage repair. Field Reference Document. Washington, DC: Office, Chief of Engineers, U.S. Army.

Beyer, G. T., and T. E. Bretz. 1981. Flush bomb damage repair field testing. Technical Report ESL-TR-81-48. Tyndall Air Force Base, FL: Engineering and Services Laboratory, Air Force Engineering and Services Center.

Boeckman, G. O., T. J . Dent, and B. A. Walton. 1987. Rapid runway repair, area group multiple-crater repair test report. Technical Report ESL-TR-85-69. Tyndall Air Force Base, FL: Engineering and Services Laboratory, Air Force Engineering and Services Center.

Bolduc, D. J., J r., et al. 1984. Surface for crushed stone-Phase III; Vol I. Technical Report ESL TR-83-38. Tyndall Air Force Base, FL: Engineering and Services Laboratory, Air Force Engineering and Services Center.

Bolduc, D. J ., J r., et al. 1984. Surface for crushed stone-Phase III; Vol II. Technical Report ESL TR-83-38. Tyndall Air Force Base, FL: Engineering and Services Laboratory, Air Force Engineering and Services Center.

Boyer, J . P., et al. 1982. Advanced materials development for repair of bomb damaged runways. Technical Report ESL-TR-82-14. Tyndall Air Force Base, FL: Engineering and Services Laboratory, Air Force Engineering and Services Center.

Brabston, W. N. 1984. Bomb damage repair precast slab design. Technical Report ESLTR-84-21. Tyndall Air Force Base, FL: Engineering and Services Laboratory, Air Force Engineering and Services Center. 
Campbell, M. S. 1983. Multiple-crater repair test report and analysis. Technical Report ESL-TR-83-22. Tyndall Air Force Base, FL: Engineering and Services Laboratory, Air Force Engineering and Services Center.

Cooksey, D. L. 1981. Bomb crater repair techniques for permanent airfields; Report 1, Series I tests. Technical Report GL-81-12, Vicksburg, MS: U.S. Army Engineer Waterways Experiment Station.

Forrest, J . B., and T. A. Shugar. 1974. A structural evaluation of rapid methods of backfilling for bomb damage repair. Technical Report AFWL-TR-73-29. Kirtland Air Force Base, NM: Air Force Systems Command.

Fowler, D. W., et al. 1982. Methyl methacrylate polymer-concrete for bomb camage repair. Technical Report ESL-TR-82-04. Tyndall Air Force Base, FL: Engineering and Services Laboratory, Air Force Engineering and Services Center.

Hammitt, G. M., II, and L. D. McCallister. 1985. Airfield damage repair exercise in Europe, 1982; Progressive crater repair. Miscellaneous Paper GL-85-31. Vicksburg, MS: U.S. Army Engineer Waterways Experiment Station.

Hammitt, G. M., II , J . W. P. Patin, and R. Devens. 1986. Technical evaluation reports of airfield damage repair solution. Technical Report GL-86-17. Vicksburg, MS: U.S. Army Engineer Waterways Experiment Station.

Hammitt, G. M., II, and R. S. Rollings. 1987. Expedient landing strips and airfield damage repair for C-130 aircraft in support of airborne/ air assault missions. Miscellaneous Paper GL-87-31. Vicksburg, MS: U.S. Army Engineer Waterways Experiment Station.

Haworth, D. S., III, R. S. Fleming, W. S. Anthony, and G. L. Geiger. 1981. Airfield damage repair techniques. Monograph. 412th Engineer Command, Vicksburg, MS.

Hokanson, L. D. 1975. Tyndall AFB bomb damage repair field test, documentation and analysis. Technical Report AFWL-TR-75-148. Kirtland Air Force Base, NM: Air Force Systems Command.

Hokanson, L. D., and R. S. Rollings. 1975. Field test of standard bomb damage repair techniques for pavements. Technical Report AFWL-TR-74-226. Kirtland Air Force Base, NM: Air Force Systems Command.

Kistler, C., A. S. Kubo, and D. L. Read. 1985. Engineering development and testing of advanced materials and methods for bomb damage repair; Part I. Technical Report ESL-TR-84-01. Tyndall Air Force Base, FL: Engineering and Services Laboratory, Air Force Engineering and Services Center.

Kistler, C., A. S. Kubo, and D. L. Read. 1985. Engineering development and testing of advanced materials and methods for bomb damage repair; Part II. Technical Report ESL-TR-84-01. Tyndall Air Force Base, FL: Engineering and Services Laboratory, Air Force Engineering and Services Center.

Kubo, A. S., et al. 1984. Advanced bomb damage repair system; Phase II, Prototype design. Technical Report ESL-TR-84-38. Tyndall Air Force Base, FL: Engineering and Services Laboratory, Air Force Engineering and Services Center. 
McNerney, M. T. 1979. Interim field procedure for bomb damage repair using crushed stone for crater repairs and Silikal ${ }^{\circledR}$ for spall repairs. Interim Report ESL-TR79-01. Tyndall Air Force Base, FL: Engineering and Services Laboratory, Air Force Engineering and Services Center.

Patin, J . W. P., and G. M. Hammitt II. 1985. Airfield damage repair (ADR) training and evaluation outlines. Miscellaneous Report GL-85-33. Vicksburg, MS: U.S. Army Engineer Waterways Experiment Station.

Pfau, J . P., et al. 1982. Heat-initiated Furan Resin for rapid runway repair. Technical Report ESL-TR-82-37. Tyndall Air Force Base, FL: Engineering and Services Laboratory, Air Force Engineering and Services Center.

Pfau, J. P, et al. 1982. Ultraviolet curable resin system for rapid runway repair. Technical Report ESL-TR-82-51. Tyndall Air Force Base, FL: Engineering and Services Laboratory, Air Force Engineering and Services Center.

Semple, A. W., and J. W. Horne. 1985. Airfield damage repair exercise in Europe, 1983. Miscellaneous Paper GL-85-32. Vicksburg, MS: U.S. Army Engineer Waterways Experiment Station.

Semple, A. W., and J . W. Horne. 1985. Airfield damage repair exercise in Europe, 1984. Miscellaneous Paper GL-85-34. Vicksburg, MS: U.S. Army Engineer Waterways Experiment Station.

Springston, P. 1982. Crows Landing bomb damage repair rest-FRP membrane repair methods. Technical Report AFESC ESL-TR-82-36. Tyndall Air Force Base, FL: Engineering and Services Laboratory, Air Force Engineering and Services Center.

Stroup, T., D. Reed, and G. M. Hammitt II. 1986. Airfield damage repair techniques of 18th Engineer Brigade in Europe. Miscellaneous Paper GL-86-01. Vicksburg, MS: U.S. Army Engineer Waterways Experiment Station.

Sugama, L. E., et al. 1982. Water-compatible polymer concrete materials for use in rapid repair systems for airport runways. Interim Report ESL-TR-82-35. Tyndall Air Force Base, FL: Engineering and Services Laboratory, Air Force Engineering and Services Center.

Sugama, T., et al. 1984. Advanced water-compatible materials for bomb damage repair. Technical Report ESL-TR-84-03. Tyndall Air Force Base, FL: Engineering and Services Laboratory, Air Force Engineering and Services Center.

Tucker, S. G. 1962. Bomb-crater repair study, Fort Bragg, N.C., 23J une- 3J uly 1962. Miscellaneous Paper No. 4-526. Vicksburg, MS: U.S. Army Engineer Waterways Experiment Station.

Tyndall Air Force Base. 1977. Resin concrete for bomb damage repair of airfield pavements. Technical Report CEEDO-TR-77-53. Tyndall AFB, FL: Engineering and Services Laboratory, Air Force Engineering and Services Center.

Vedros, P. J., and Hammitt, G. M. II. 1985. Airfield bomb damage repair methods. Miscellaneous Paper GL-85-30. Vicksburg, MS: U.S. Army Engineer Waterways Experiment Station. 
Williams, T. P. 1989. Light Engineer Force crater-repair demonstration, Fort Bragg, N.C. Miscellaneous Paper GL-89-4. Vicksburg, MS: U.S. Army Engineer Waterways Experiment Station.

Wilson, M. J., and T. J . Dent. 1985. Multiple-crater and spall-repair test report. Test Report ESL-TR-85-1. Tyndall Air Force Base, FL: Engineering and Services Laboratory, Air Force Engineering and Services Center. 


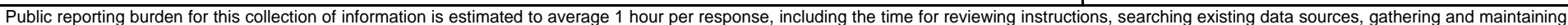

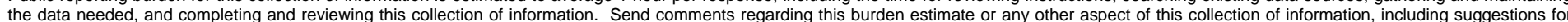

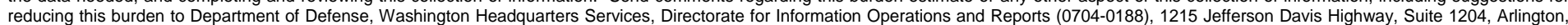

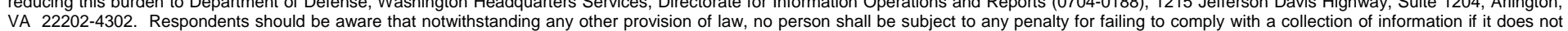
VA 22202-4302. Respondents should be aware that notwithstanding any other provision of law, no person shall be sube
display a currently valid OMB control number. PLEASE DO NOT RETURN YOUR FORM TO THE ABOVE ADDRESS.

\begin{tabular}{l|c}
$\begin{array}{l}\text { 1. REPORT DATE }(D D-M M-Y Y Y Y) \\
\text { September } 2007\end{array}$ & $\begin{array}{c}\text { 2. REPORT TYPE } \\
\text { Final report }\end{array}$ \\
\hline
\end{tabular}

4. TITLE AND SUBTITLE

Laboratory and Field Investigations of Small Crater Repair Technologies

3. DATES COVERED (From - To)

5a. CONTRACT NUMBER

Laboratory and Field Investigations of Small Crater Repair Technologies

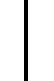

\section{AUTHOR(S)}

Lucy P. Priddy, Jeb S. Tingle, Timothy J. McCaffrey, and Ray S. Rollings

5b. GRANT NUMBER

5c. PROGRAM ELEMENT NUMBER

5d. PROJECT NUMBER

5e. TASK NUMBER

5f. WORK UNIT NUMBER

7. PERFORMING ORGANIZATION NAME(S) AND ADDRESS(ES)

8. PERFORMING ORGANIZATION REPORT NUMBER

U.S. Army Engineer Research and Development Center,

Geotechnical and Structures Laboratory,

ERDC/GSL TR-07-27

3909 Halls Ferry Road, Vicksburg, MS 39180-6199;

Rollings Engineering, 27 Park Square North,

Beaufort, SC 29907

9. SPONSORING I MONITORING AGENCY NAME(S) AND ADDRESS(ES)

10. SPONSOR/MONITOR'S ACRONYM(S)

Headquarters, Air Combat Command,

Langley Air Force Base, VA 23665

11. SPONSOR/MONITOR'S REPORT NUMBER(S)

\section{DISTRIBUTION I AVAILABILITY STATEMENT}

Approved for public release; distribution is unlimited.

\section{SUPPLEMENTARY NOTES}

\section{ABSTRACT}

In support of the U.S. Air Force Air Combat Command, the U.S. Army Engineer Research and Development Center (ERDC) was tasked to develop and test innovative techniques, materials, and equipment for expedient and sustainment repairs of small bomb craters in airfield pavements. This airfield damage repair (ADR) investigation consisted of laboratory testing of selected crater fill and capping materials, as well as full-scale field testing of small crater repairs to evaluate field mixing methods, installation procedures, and repair performance. After $3 \mathrm{hr}$ of cure, each crater was trafficked under controlled traffic conditions to determine the ability of the repairs to support the gross load of an F-15E aircraft. Results of the traffic tests identified multiple repair materials that can be used for expedient and sustainment repairs of concrete airfield pavements. Both the laboratory and full-scale traffic tests were conducted at the ERDC in Vicksburg, MS from February to November 2006. Experimental results were used to develop ADR criteria for rapidly repairing small craters.

\section{SUBJECT TERMS}

Airfield damage repair

F-15E

16. SECURITY CLASSIFICATION OF:

a. REPORT

UNCLASSIFIED

b. ABSTRACT
UNCLASSIFIED

Polyurethane foam

Rapid setting

(17.

c. THIS PAGE

UNCLASSIFIED
17. LIMITATION OF ABSTRACT

Small crater

18. NUMBER OF PAGES

215 19a. NAME OF RESPONSIBLE PERSON

19b. TELEPHONE NUMBER (include area code) 